Dr. J. E. ZUeiss

\title{
Lebrbuch) der
}

\section{Krankheiten und beschädigungen}

\section{unserer kulturgewächse}

$\ldots \rightarrow$ Mit 134 Hbbildungen. $\approx+$.

Eugen Ulmer, StuttGart. 
Verlag von Eugen Ulmer in Stuttgart.

Allgemeine Landwiptschaft Martin-Zeeb, Handbuch der Landwirt-

Grossh. bad. Ökonomierat. Mit 385 Abbild. Preis 16.70 , in Leinw. geb. th. 7.70. In Partien th. 6.-. In Leinw. geb. Mk. 7.-

Das Jahr des Landwirts in den Vorgängen der Natur und in den Verrichtungen der gesamten Landwirtschaft. Ein Handbuch für den praktischen Landwirt, dargestellt von Fritz Möhrlin. 2. Auflage von Victor Weitzel. Mit 122 Abbildungen. Gebunden Mk. 4.-.

Die Landwirtschaft in den Verein. Staaten von Nordamerika. Von Prnf $T_{n}$ E! Romm Mit oA A hildunman InTafaln und $1 \mathrm{~K}$ arte der Mk. 6.70.

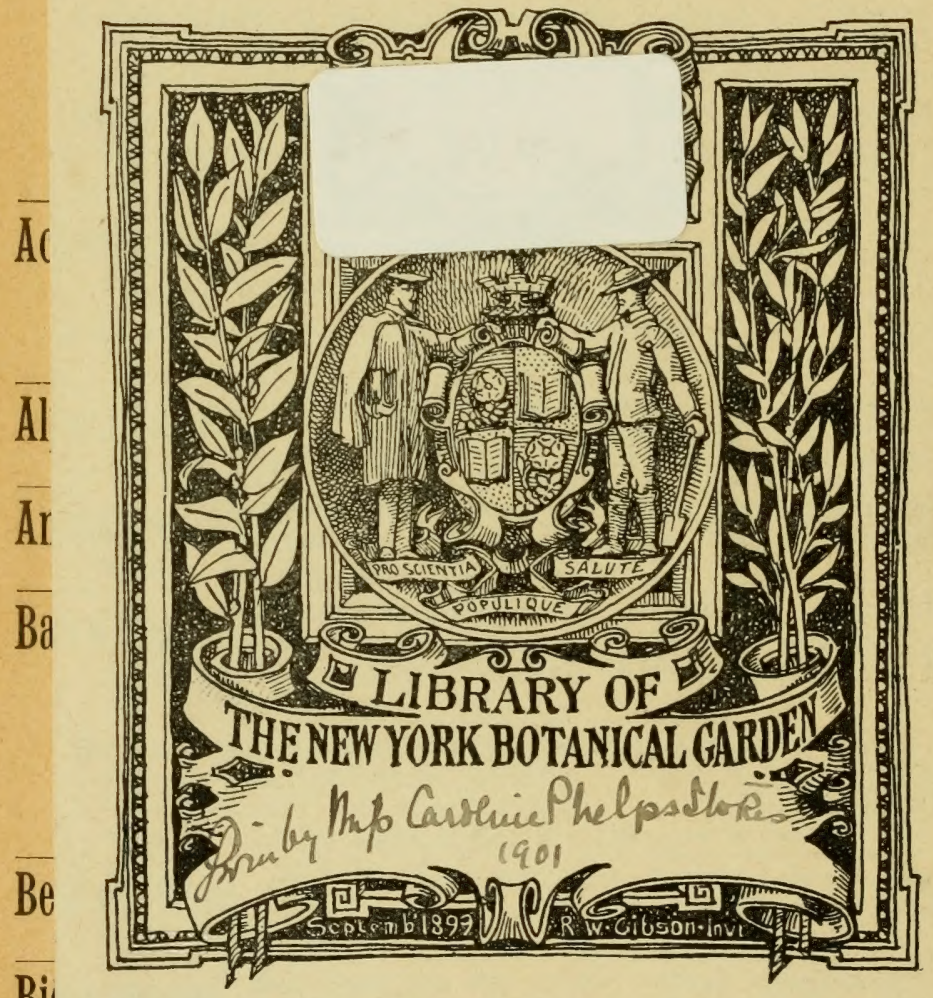

Schrift: n UnterMk. 3.80. rtschaft. ichaft an Mk. 3.-. a UnterMïller, Mk. 2.60. schulen.

n. Für Fiü $\mathrm{f}$ Mk. 550 . ıe, nebst $102 \mathrm{Abb}$.

ichtung, rbauten $22 \mathrm{Ta}-$

t. Zum i u. S. W. - (Kann

eitfaden n. Von

Lehrer tor Dr. nrancher una Lanawirt wust herausgegeben von J. W itzgall. Mit 295 Abbild. Eleg. geb. Mk. 6.50.

Der Bienenhaushalt. Von Fr. Pfäfflin, Oberinspektor des K. Waisenhauses in Stuttgart. Dritte Auflage. Mit 28 Abb. Geb. Mk. 1.-.

Wandtafel für Bienenwirtschaft. Von Pfarrer Gmelin. Mk. 2.50. Rrennepeihetpieh Kurzgefasste Anleitung zum praktischen BrennereiBrennereloetrien, betrieb. Von Prof. Dr. P. B ehrend. 2. Aufl. Mit Abb. Preis ca. Mk.3.-. (Erscheintim August 1900.)

Buchfïhplıng Einfache landwirtsehaftl. Buchfïhrung. Ein Lehrbuch Bllchluhplung, für landw. Schulen, wie für den Selbstunterricht. Von Ludwig Lemke. Gebd. Mk. 1.20.

Chemia Iandw Leitfaden für den Unterricht in der landw. Chemio

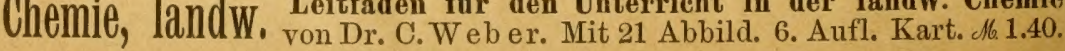




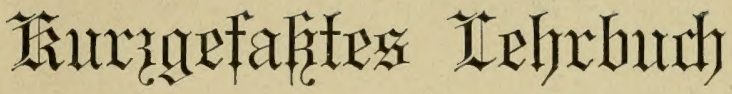

Dex

\section{Rrankheiten und Beschädigungen}

\author{
unferex \\ Rulturgewächse.
}

CFin Triffaden

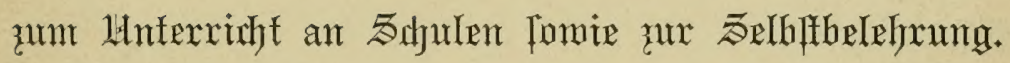

Bon

Brofelfor Dr. I. (E. MA) Det.

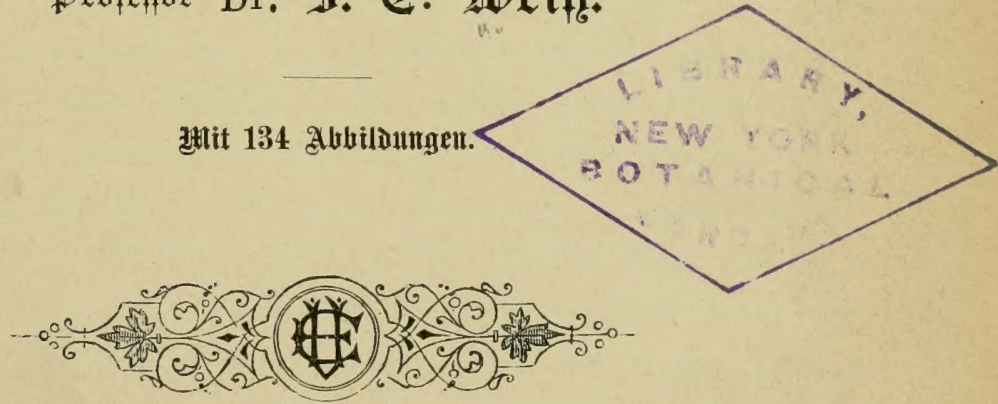

Słutfgart 1901.

LA ExI

Derlag für famomirt「djaft, (1)bf- nno Gartenbau. 
SB 601

.W4

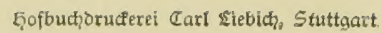




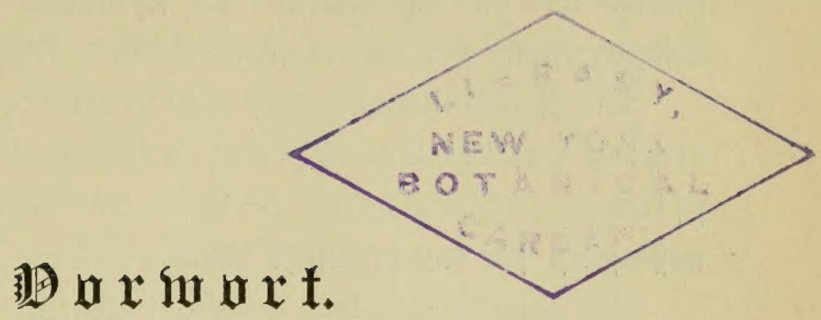

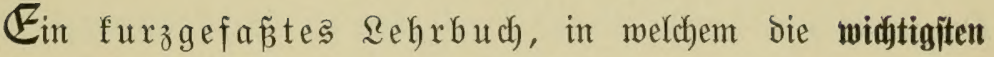

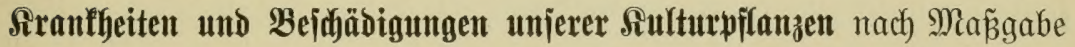
Der vorfiegenden Beobachtungen bejprochen und bie zmectmäp̃igiten $\mathfrak{B}_{e}=$

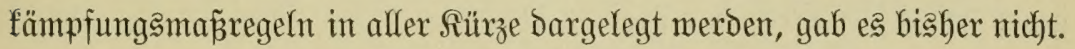

Bei Der hohen Bedeutung, welche Dem in unjerem Rebrbuche behandelten Gregenftande fowohl won Seite der Stantsregierungen alś audh von Seite ber Wirifenichaft, ipeziell aber audh won Seite Der beteifigten Sreije im eigenen wohlverftandenen Snterefie beigemeffen wiro, ift mit alfer ßeftimmtheit anzunehmen, Daß̧ der naturmifjen= fchaftliche Unterricht an allen mittleren und höheren Rehranitalten naturgemä̃ nach biejer hocbmichtigen praftijchen Seite hin ergänzt werben múp.

Itus diejem Grombe hat es der Berfafier gerne übernommen, Durch) IVfafijung eines furzgefap̃ten uno zugleich billigen Refrbuches

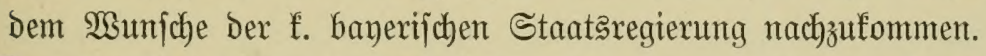

5 Die Behandlung des Stoffes muß̃te naturgemä -Berbältniffen jich anjchltepenen. Die Durch parajitäre ßitze hervor= - gerufenen Franfheiten, Die bisher Dem Rehrgegenitande an mittleren und höheren Rehranjtalten mit Stusnahme der landmirtichaftlichen Schulen volffommen fremo marem, muñten augfübrlicher nach ihrer Urfache, Errfenmung, Wirfung und Befämpfung erörtert werben; da= gegen fonnten jïh Die Darlegungen über bie burch I Iere verurjachten Schäbigungen, auth bie Rebensmeife ber Schäbiger, wie bie $\mathfrak{A} x t$ Der befdäbigung und bie aflenfalls anzumendenden $\mathfrak{B} e=$

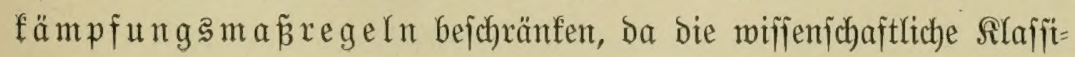


fifation und bie (Sharafteriftif ber jhäblichen Iiere aud bisher f(c)on Rehrgegenitand des naturmifienjachaftlichen Unterrichts war.

Die $\mathfrak{A}$ usbehnug bes naturwiffenfdaftichen unter= ridtes auf bie אranfheiten und Sdäbigungen Der אultur=

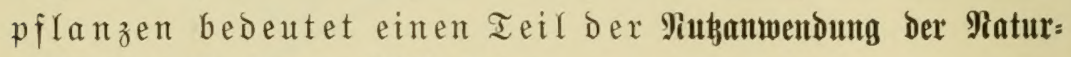

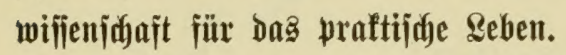

Die einfache und Doch möglidyjt genaue Darjtellungsmeife fowie bie zahlreichen, Dem Ierte beigejügten 2 (tbbiloungen, welche z. T. nach) Driginalbildoen Des $\mathfrak{A t t a s ~ D e r ~ R r a n f h e i t e n ~ u n d ~ B e f c h a ̈ b i g u n g e n ~ u n j e r e r ~}$

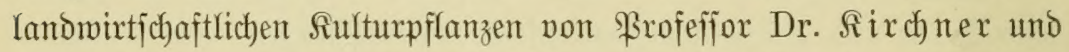
5. Boltshaufer gejertigt, 子. I. Dem Siserfe "Schub der Dbjtbäume gegen feindliche Tiere und gegen Sranffeiten" von Prof. Dr. Iafden= berg und Brof. Dr. Baul Sorauer entnommen wurden, exteichtern Die fithere (Erfenmung Der Schädinge uno machen Das Buch auch für Den praftijchen Ranomirt, Dbjtbaumzüchter und Gsärtner zum Selbjt= ftubium in hohem Grade geeignet.

Mäge das Büchlein zu গuth und Frommen Der Rambmirtichaft, Des Sbjt= uno Gartenbautes im Gropenen und Sileinen recht gute Früchte bringen.

3um Schluije füble idh mich) verpflichtet, Dem Seern $\mathfrak{B}$ erleger für Die vorz̈̈̈liche $\mathfrak{A}$ (usjtattung meines Rebrbuches bet Dem auperordentlict)

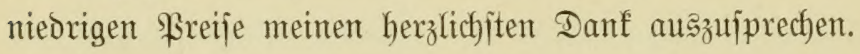

Freifing, im atpril 1901.

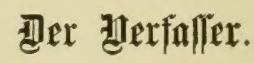




\section{खึำ}

Sinleitung

I. 2 b

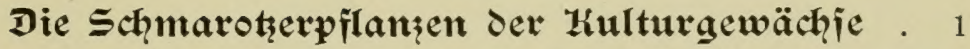

1. Rapitel: Die idjmarołenden Blïtenpflanjen ober phanerogamen $\mathfrak{P a r a j i t e n ~} 3$

I. Die blattgrünlojen phanerogamen Schmarober . . . . 3

II. Die blattgrünf̈̈brenden phanerogamen Schmaroser . . 6

2. Rapitel: Die Sdumaroberpilse . . . . . . . . . . . . . . . . . 8

I. Bau und Fortpflanzung Der Pilze . . . . . . . . 8

II. Die Ernährung Der Schmaroberpilze . . . . . . . . . . 9

III. Эermebrung und Fortpflanzung Der ßilze . . . . . 10

IV. Die ßerbreitung Dex Sporen . . . . . . . . . . 11

V. Die 凡eimung Der Sporen. . . . . . . . . . . . 11

VI. Befämpfung Dex Durch) Schmarnberpilze veruxjachten Pflanzenfranfbeiten . . . . . . . . . . . 13

VII. Die für die Betämpfung der Pilzparafiten geeigneten Sprizen. . . . . . . . . . . . . . 20

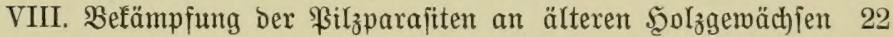

IX. Befämpfung ber Schmaroberpilze an Wurzeln . . . . 23

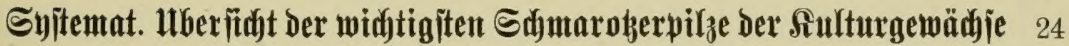

1. Dromun: Die Schleimpirze (Myxomyceten) . . . . . . . 24

2. " Die Spaltpilze (Schizomyceten) . . . . . . . 25

3. " Die falfiben Mehltauarten (Peronosporaceen) . . 27

Einteilung Der Dronung . . . . . . . . . . . . . . . . 30

1. Familie: Reimlingstöter (Pythieen) . . . . . . . . . 30

2. " Ẇeiß̄rojtpilze (Albugineen) . . . . . . . . . 30

3. " Falfche Mehlthauarten (Peronosporeen) . . . . . 32

1. Gattung: Phytophthora . . . . . . . . . . . . 32

2. " Plasmopara . . . . . . . . . . . . 34

3. " Peronospora . . . . . . . . . . 36

4. " Bremia............ . . . 38

4. Sronung: Die $\mathfrak{B} a$ \{ioiomnceten . . . . . . . . . 38

1. Familie: Die Branopilž (Ustilagineen) . . . . . . . . 38 
1. Sattung: Dex Steinbrand (Tilletia) . . . . . . . . 40

2. " Dex Flug= ober Staubbrano (Ustilago) . . . . 41

3. " Der Stengelbrano (Urocystis) . . . . . . . . 43

2. Familie: Die Rojtpilze (Uredineen) . . . . . . . . . . 43

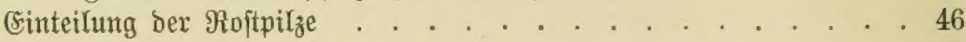

1. Sattung: Uromyces . . . . . . . . . . . . . 47

2. " Puccinia . . . . . . . . . . . . 48

3. " Phragmidium . . . . . . . . . 50

4. " Gymnosporangium . . . . . . . . . 51

5. " Cronartium . . . . . . . . . . 53

6. „ Chrysomyxa . . . . . . . . . . . 53

7. " Coleosporium . . . . . . . . . . . 54

8. " Melampsora . . . . . . . . . . . 54

9. " Calyptospora . . . . . . . . . . . . 54

3. Familie: Die Saut= ober Şutpilze (Hymenomyceten) . . . . 55

1. Battung: Exobasidium . . . . . . . . . 56

2. " Trametes . . . . . . . . . . . 56

3. " Polyporus . . . . . . . . . . . . 56

4. " Hydnum . . . . . . . . . . . . 58

5. " Agaricus . . . . . . . . . . . 58

6. " Merulius . . . . . . . . . . 58

5. Dromung: Die Schlauchpilze (Ascomyceten) . . . . . . . 59

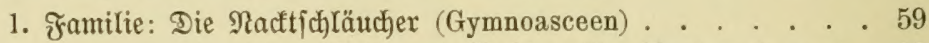

2. " Die ect)ten Mehl= und Rǘtaupilze (Perisporiaceen) . 62

1. Interfamilie: Die eçten Mebltaupilze (Erysipheen) . . . . 62

1. Sattung: Sphaerotheca . . . . . . . . . . 63

2. " Podosphaera . . . . . . . . . . 64

3. " Phyllactinia . . . . . . . . . . 64

4. " Uncinula . . . . . . . . . . . . 64

5. " Microsphaera . . . . . . . . . . 64

6. " Erysiphe . . . . . . . . . . . 64

7. " Oidium . . . . . . . . . . . . 65

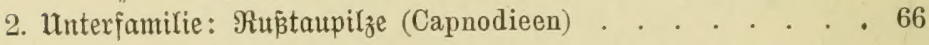

3. Familie: Rernpilze (Pyrenomyceten) . . . . . . . . . 67

Einteilung dex Rernpilze . . . . . . . . . . . . 67

1. Unterfamilie: Hypocreaceen . . . . . . . . . . . . 68

1. Sattung: Nectria . . . . . . . . . . . . 68

2. " Polystigma . . . . . . . . . . . . 69

3. " Epichloë . . . . . . . . . . . . . 69

4. " Claviceps . . . . . . . . . . . 70

2. Unterfamilie: Dothideaceen . . . . . . . . . . 70

1. (Sattung: Diachora . . . . . . . . . . . . 70

2. " Plowrightia . . . . . . . . . . . 71

3. " Phyllachora . . . . . . . . . . . 71

4. " Dothidella . . . . . . . . . . . 71 
3. Unterfamilie: Sphaeriaceen . . . . . . . . 71

1. S̋attung: Trichosphaeria . . . . . . . . . . 71

2. " Herpotrichia . . . . . . . . 72

3. Rosellinia . . . . . . . . . . . 72

4. " Cucurbitaria . . . . . . . . . . 72

5. " Stigmatea . . . . . . . . . . . . . 73

6. " Sphaerella . . . . . . . . . . . . 73

7. " Leptosphaeria . . . . . . . . . . 73

8. " Ophiobolus . . . . . . . . . . . . . . 74

9. " Pleospora. . . . . . . . . . . . . 74

10. "Gnomonia . . . . . . . . 75

4. Familie: Die Scheibenpilze (Discomyceten) . . . . . . . 75

1. (5attung: Lophodermium. . . . . . . . . . . . . 76

2. " Rhytisma. . . . . . . . . . . . . . . 76

3. " Pseudopeziza . . . . . . . . . . . . . 77

4. " Dasiscypha . . . . . . . . . . . . 78

5. " Sclerotinia . . . . . . . . . 78

5. Familie: Unvollitändige $\mathfrak{P i l z e ~ ( F u n g i ~ i m p e r f e c t i ) ~ . ~ . ~ . ~ . ~ . ~} 80$

1. Unterfamilie: Sphaeropsideen . . . . . . . . . 80

1. Sattung: Phyllosticta . . . . . . . . . . . 80

2. " Phoma . . . . . . . . . . . . . . . 82

3. " Ascochyta . . . . . . . . . . . . . . 83

4. " Actinonema . . . . . . . . . . . . . . 83

5. " Septoria . . . . . . . . . . 84

6. Pestalozzia . . . . . . . . . . 86

2. Unterfamilie: Melanconieen . . . . . . . 87

1. Siattung: Gloeosporium . . . . . . . . . . 87

2. "Marsonia. . . . . . . . . . . . . 88

3. Unterfamilie: Hyphomyceten . . . . . . . . . . . 88

1. Şattung: Monilia . . . . . . . . . . . . 88

2. " Fusicladium . . . . . . . . . . . . . . 90

3. "Clasterosporium . . . . . . . . . . 92

4. " Ceratophorum . . . . . . . . . . . . 92

5. " Helminthosporium . . . . . . . . . . . 92

6. " Cercospora . . . . . . . . . . . . . . 93

7. " Heterosporium . . . . . . . . . . . 94

\section{2abf̧̨itt.}

Die tiexijchen Schäolinge . . . . . . 96

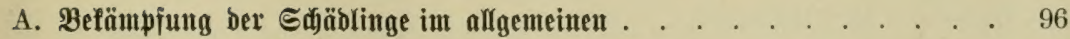

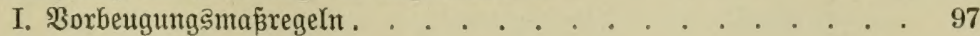

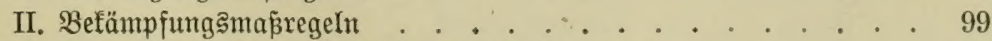

B. Spezielle Beipredjung Der widjtigiten tierijanen Edjäblinge . . . . . 108

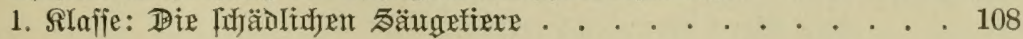


a) Miederfäuer

b) Nagetiere . . . . . . . . . . . . . . . . 109

2. Rlafie: Die fuädliffrn Dögel . . . . . . . . . . . . 110

3. Rlafie: Die Infekfen . . . . . . . . . . . . . . . 111

a) Injelten mit vollfommenex \$ermanolung . . . . . . . . 111

1. ̊äfex; 2. Schmettexlinge; 3. Sartflüglex; 4. Bmeiflüglex . . 111

b) Эnfeften mit unvolffommener Bermanolung . . . . . . . . 112

5. Resflüglex; 6. Beradf́lïglex; 7. Schnabelferfe . . . . . . 112

1. Dromung: Die Räfer. . . . . . . . . . . . . . . 112

2. Sromung: Die Sdymetteringe . . . . . . . . . . . 122

1. Familie: Die Iagfalter . . . . . . . . . . . . . . 122

2. " Die \$̧olzbohrer. . . . . . . . . . . . . . 123

3. " Die Spinner . . . . . . . . . . . 126

4. " Die Eulen . . . . . . . . . . . . 130

5. " Die Spanner . . . . . . . . . . . 130

6. " Die Büzlex. . . . . . . . . . . . . 132

7. " Die Widfler . . . . . . . . . . . . 133

8. " Die Bejpinitmotten . . . . . . . . . 135

9. " Die Motten . . . . . . . . . . . . . 137

3. Sronung: Die Şautflüglex . . . . . . . . . . . 139

4. " Die 3roeiflügler oder Jliegen.... . . 143

5. ". Die Ręflüglex ........ . . 147

6. " Die (Sexabflügler . . . . . . . . . . . 147

7. " Die Shnabelferfe . . . . . . . . . . . 149

1. Familie: Die Bifaben . . . . . . . . . . . . . . 150

2. "Die Wanzen . . . . . . . . . . . . . 150

3. " Die Blattflöhe . . . . . . . . . . . . 151

4. " Die Blattläule . . . . . . . . . . . . 151

5. " Die Shiloläuje . . . . . . . . . . . . 156

1. Unterfamilie: Die Diaspinen . . . . . . . . . . . . 157

1. Battung: Aspidiotus . . . . . . . . . . . . . . 157

2. " Diaspis . . . . . . . . . . 158

3. " Mytilaspis . . . . . . . . . . 158

2. Unterfamilie: Lecaniinen . . . . . . . . . . . 158

1. Sattung: Lecanium . . . . . . . . . . . 159

2. " Pulvinaria . . . . . . . . . . 159

4. Slaffe: Die Spimmentiere . . . . . . . . . . . . 159

1. Familie: Die \&aufmilben . . . . . . . . . . . 160

2. . Die S3allmilben . . . . . . . . . 161

5. Rlaffe: Bie đaufendfüfel . . . . . . . . . . . 163

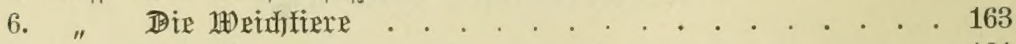

7. " Die l一ïmtex . . . . . . . . . . 164

1. Familie: Die Fabenwürmer . . . . . . . . . . 164

2. " Die Boxptenwürmer . . . . . . . . . . . 167

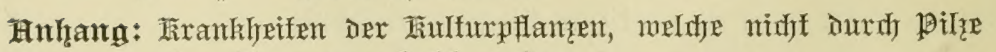
noer Tiexe vexuxtauff merden . . . . . . . . . 168 


\section{Einleitung.}

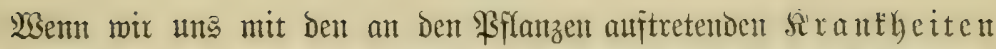

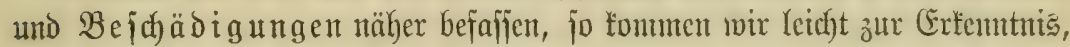

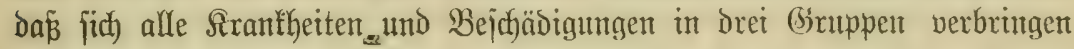
Iaffen, , nämlidid:

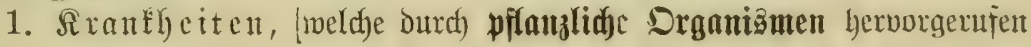
merdent,

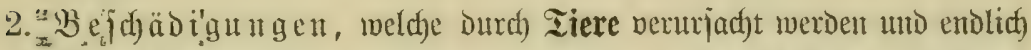

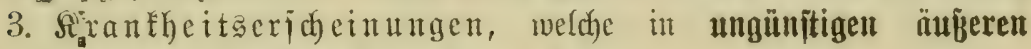

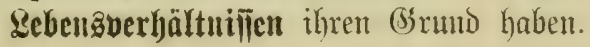

\section{I. $\mathfrak{A b} \not{d} \boldsymbol{n}$ itt.}

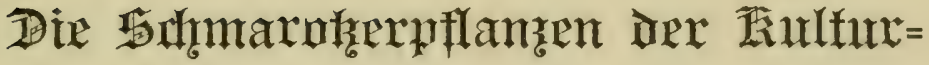

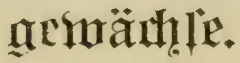

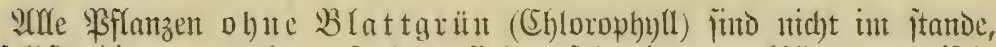

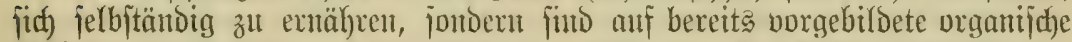

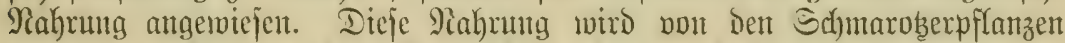
entweder nod) lebendent (bewäd) jent (ober aud) Tieren) entzogen, Doer fie ftamm von den liberefen bereits toter Fifaltzen ober Tiere.

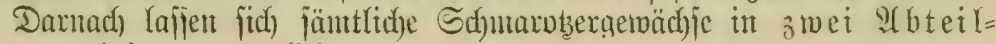
unge เ verbritgen, näntlid):

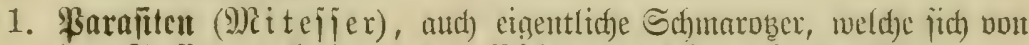
Den Stoffen nod) lebender $\$$ ffflazen (oder Tiere) unt

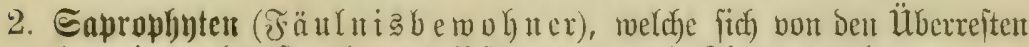
bereits abgeftorbener Biflanzen (und Tiere) emähren.

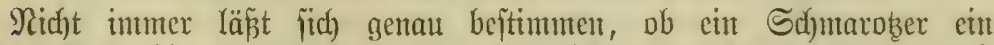
reiner $\mathfrak{F a r a j i t}$ oder Saprophut ift; nidjt jelten fommt

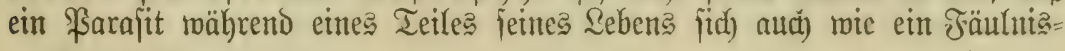

$\mathfrak{W}$ e í. Pflanzenfruntheiten. 


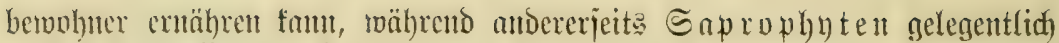

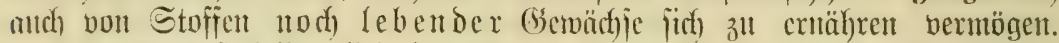

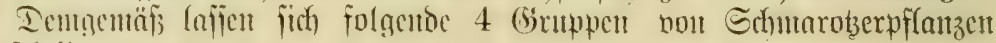
unterjodyeiben:

1. (Sd)te Eaprophyten; fic ernäbren fich) ftets mu von Don liberreften

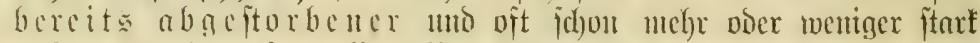

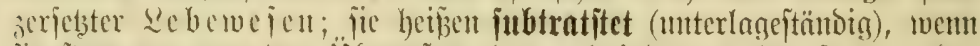

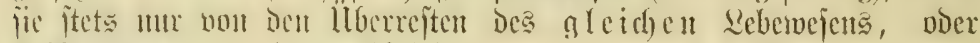

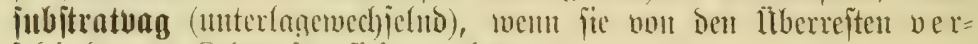
idficbener Qeberwejen fich errähren.

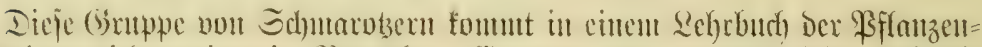

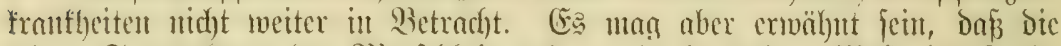

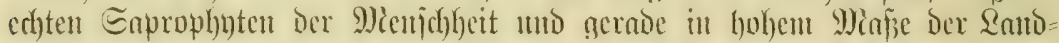

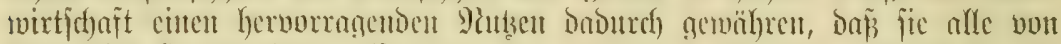

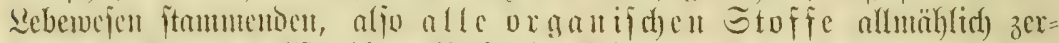

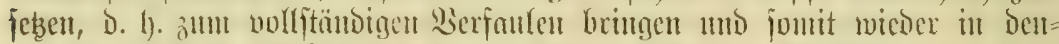

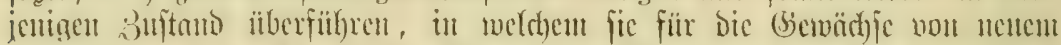
aufuchnbar finto. Duth dic edhten Eaprophnten meroen Dic vrnaniidjen

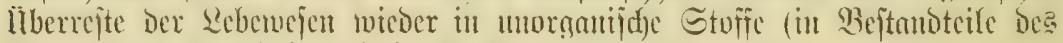

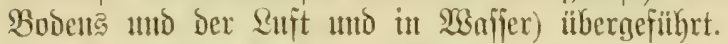

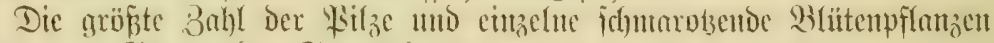
nefören zur Grutupe ber Saprophyten.

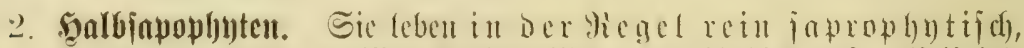

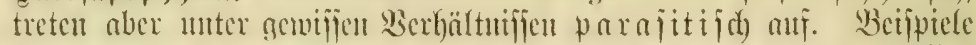
finto mandye Sobinmelarten, be meift bon toten organiijd)en Stoffen

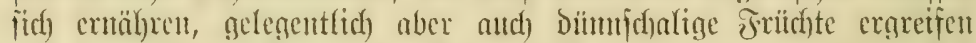

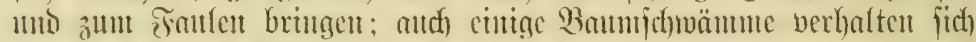
jo, 3. B. Der SHallimajdy.

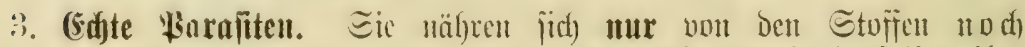

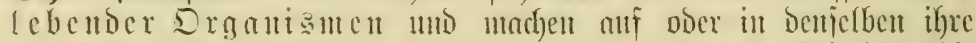

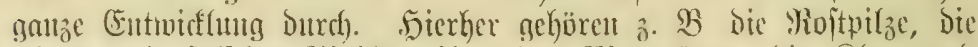

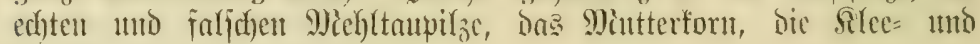

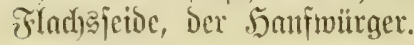

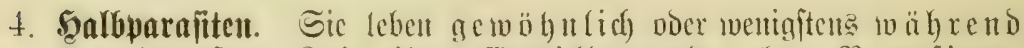
ber längiten 3eit ihrer Entruidfung ale edhte Barajiten,

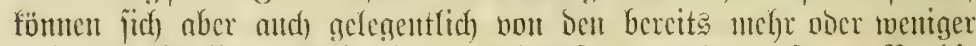
ierjebten Stoffen abgejtorbener Lebemejen crnähren, jo 3. B. bic Branopitze, welche ftets cinent Teif ibres Scbens als \$arnfiten zu

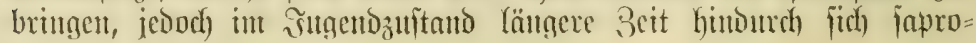
phytifid ernäbren.

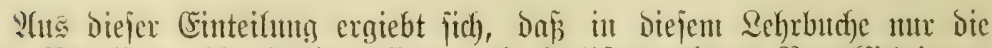
edften Parajiten, die Salbparafiten und Salbjaprophnten Beriidfichtiguma finsen fömtent. 


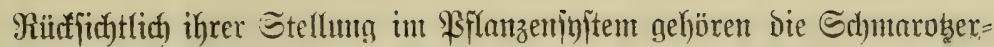
gerwäd)fic

1. entwebex Den Blïtenpflanzen (Shanterogament) alt mid inerbent datut phanerogame \&arafitelt genamit,

2. voder ben blütenlojen Pilamjen und zwar mtr der Rlajic der

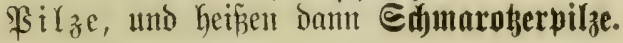

\section{Fiapifel.}

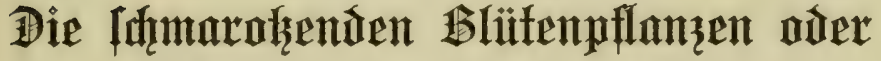 phaneragamen jomrnliten.}

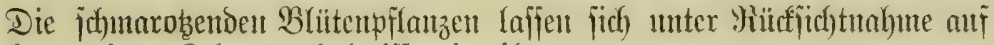
ihre eigenartigen Rebenz̧berhältniffe einteilen:

1. in blattgrïnloje $\mathfrak{B a r a f i t e n , ~ そ . ~} \mathfrak{B}$. die Sanfwiirgerarten, Silcęeide, Sdyuppentumz;

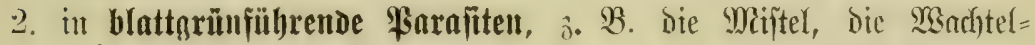
weizentarten.

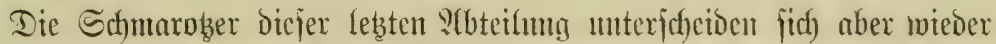

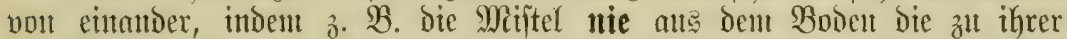

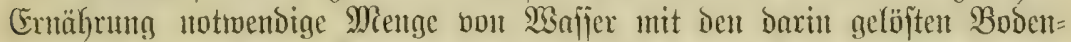

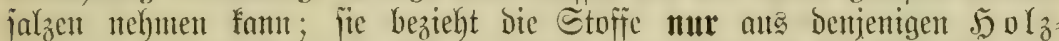

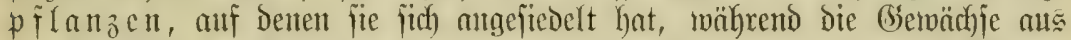
Der Familie der Rhinanthacecn mit ifren WSurzeln Warfier unt Boden=

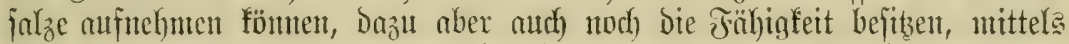

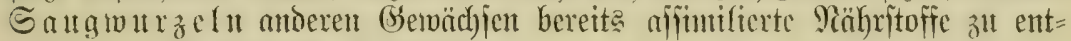

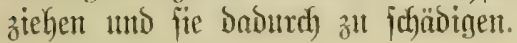

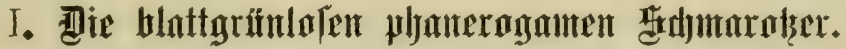

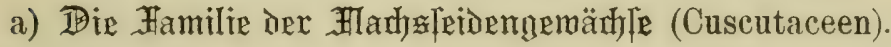

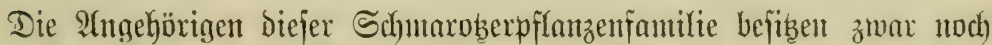

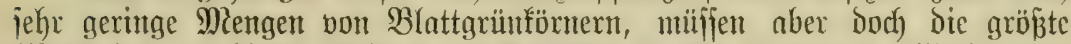

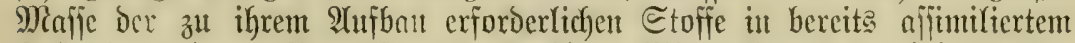

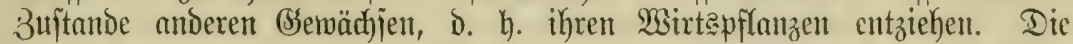

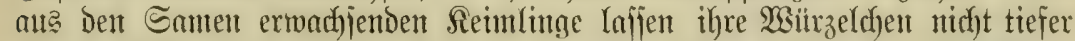

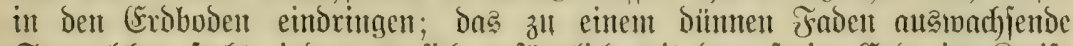

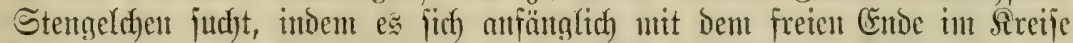

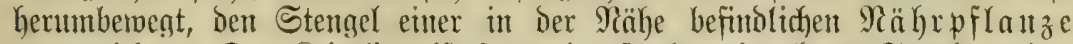
zut erreichent. Der Reinting ift jogar int ftande, cinte furze Streffe weiter

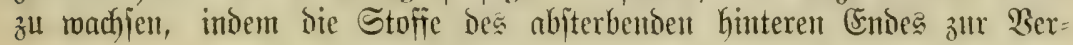


längerung Deś (Sipfeltriebes Dienen. S⿹ Jat Die junge Seidenpflanze eine ihr zujagende Wirtapflanze erreicht, fo umjultingt fie biejelbe; an Den Stellen,

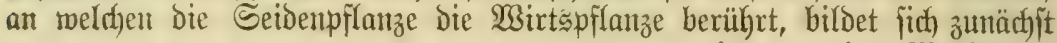

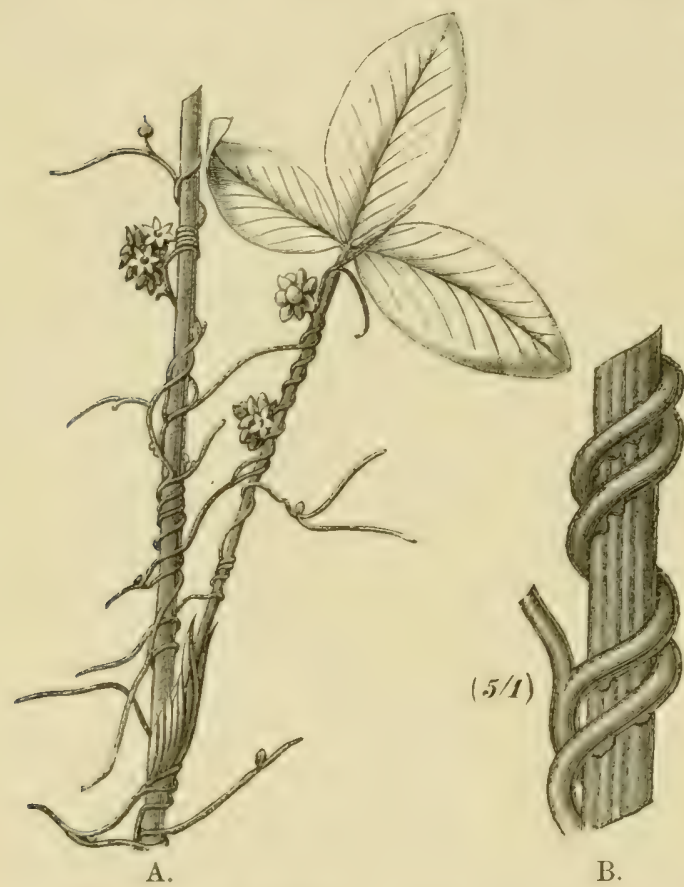

Jig. 1. Die Alecieibe (Cuscuta 'T'rifolii).

A. Etengel und slatt ber Rleepflanze bon bluhbenber Rleejeibe umrounber.

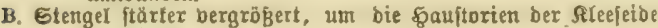
zu zeigen.

Dic Werbreitung Der Cuscutaceen erjolgt burdh Samen, die jede

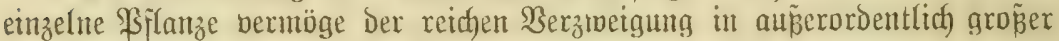
Bahl erzengt.

\section{Befämpfung der Seidenpflanzen.}

1. Man verwende ftets nur jeidenfreies Saatgut.

2. Tritt irgento eine Seidenart an einer Rulturpilanze auj, jo $\mathfrak{b} \mathfrak{c}=$ nidfte man fie nod) bor bem Blïhen over ventgitens bor Der Samenreife, indem man bie jämtlichen bejallenen Bilanzen $a b=$

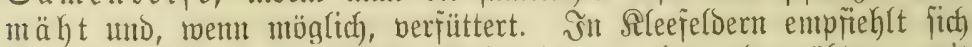
jpeziell nod) eine grünoliche $B$ efpribung Der abgemäbten, mit Sileejetide behafteten Gtellen mit eimer 15-20prozentigen (Fifen= 
witriollöjung, wodurch bie zarten Stengel ber an den Sllee= itoppeln befindlid)en Seidenpflanzen vernichtet merden.

Das gleiche $\mathfrak{B} e r f a h r e n$ ift anzumenden, menn Wiejen

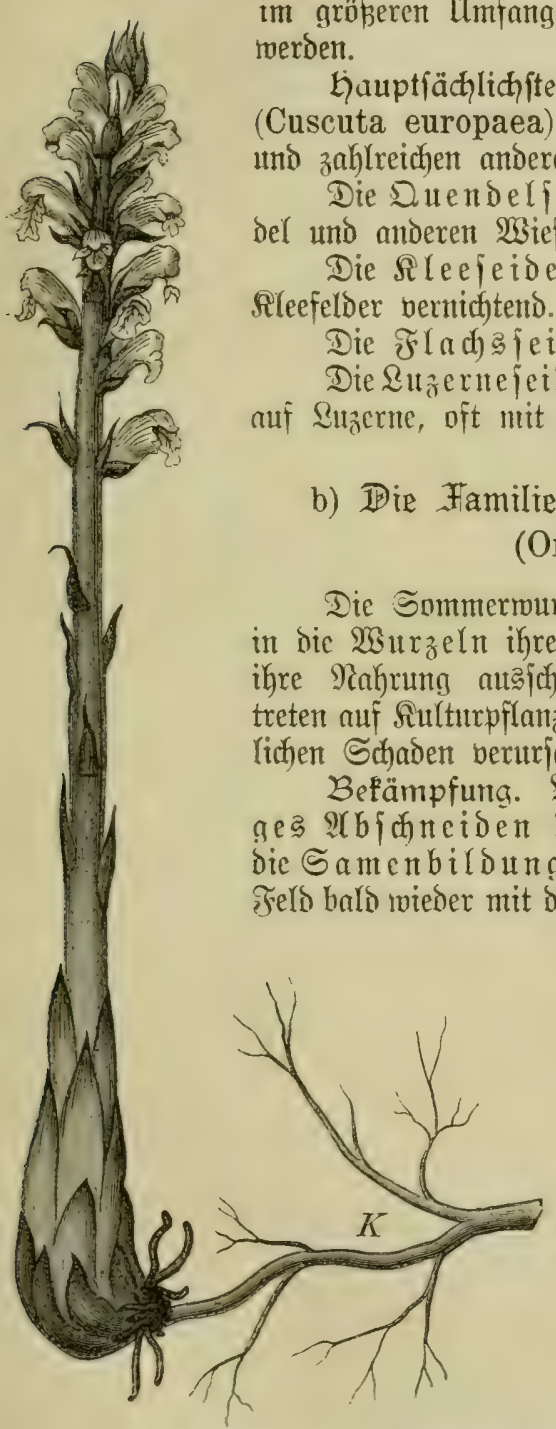

‡ig. 2. Der Alectenifel (Orobanche minor). lichen Schadent berturjachent.

C. Trifolii) aní Sllee, oft ganze (F⿱⺈. 1.)

(C. Epilinum) auf శład) (C. racemosa var. suaveolens) auf $\Omega_{3}$ crme, oft mit fremben \&uzernejamen eingejchleppt.

\section{(Orobanchaceen). \\ b) Die Familie dex Bnmmexmurzุgemäx} in die $\mathfrak{W} u r z e l n$ ifrer $\mathfrak{W}$ irtapflanzen cin und beziehen

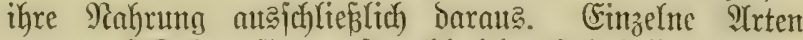
treten auf fulturpflamzen jo zahlreich) aurf, bon fie beträcht=

Befämpfung. Man verhindere burch redizeiti=

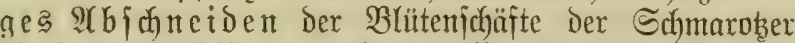
bie Samenbildung und vermeide $e^{3}$, das durchjeuthte Fels bals wieder mit der gleichen Wirtapflanze zu bejtellen.

Die jdäblidfiten Som= mexwurzgeroäd fe find:

Die rötlidue Sommer= $\mathfrak{w} \mathfrak{u} \mathfrak{r}_{z}$ (Orobanche rubens) alf Rlzerne;

ber Sleeteufer (O. minor) auf Wiejentlee (Fitg. 2 ; ber 5 an f mil rger (O. ramosa) mit äjtigem Sten= gel auf STee, Inbat umo Meerrettic).

Rake bermandt nit den Som= mermurzarten ift bie Sduppen= wurz, weldye mit ihren Saun= murzeln auf den Murzeln de?

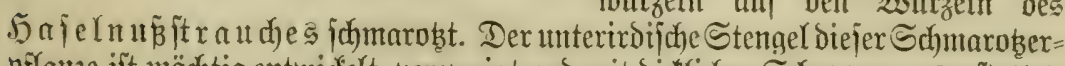

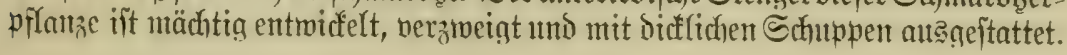




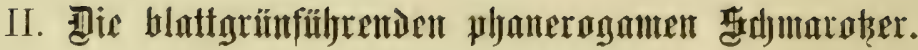

c) Die Riemtenbhmengemärf) le (Loranthaceen).

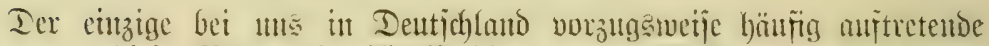
Schmarober biejer Piflanzenjamilic ijt bie gemeine Miftel (Viscum album

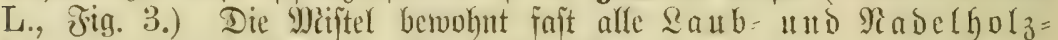

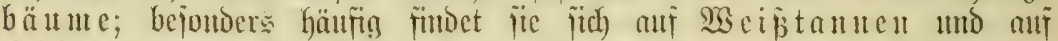

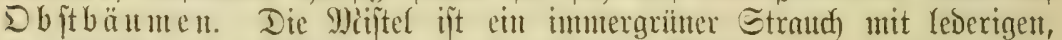

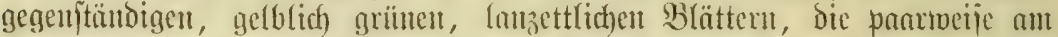

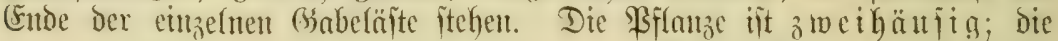

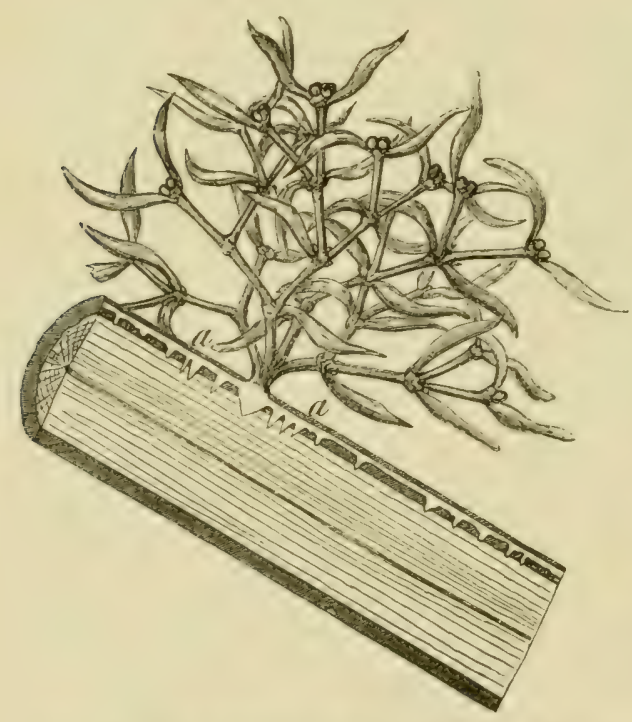

Fig. 3. Dic gencine Mlittel (Viscum album). Beeren fint toeif́r $(\mathrm{i} d)$, ihr Frud)tf(ciid) idyleimtig. Die lïbertragutg Der Snmen wiro D ttr f) Bägel, bejonders Durd) Die Myijtelorofiel, be= iverfitelligt. Der feimende Same biloet zunäddjt eine Urt Saugidseibe, aแs Derent Mitte dic Sauptmurzel Gerborbridyt, dic jobant die

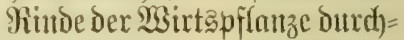
Gohet und bi tärper berjelben vorbringt; in Denfolz zörper jelbit vermag ïtid) Die Mintelwumzel nidft curubohren; jedes Jahr aber

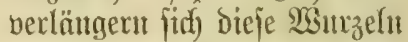
Giuter iffrer Sptze $14 m$ eit Dem 3unadje Des . Jol $z=$ แnd

S3ajtringes entĩpredjentes

Stïf. Dadurdy fam die Dititelwumel jedes Jaho vou Dem jud bildentoen 5olzaring

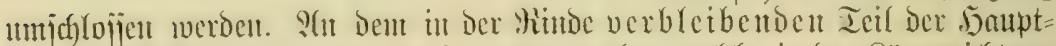

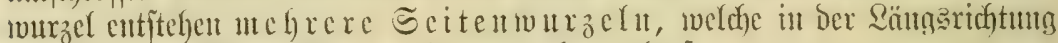

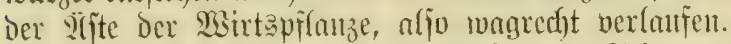

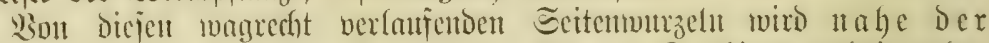

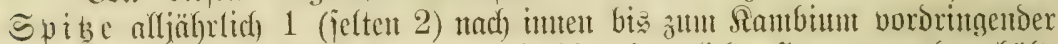
Senter gebildet, ber fich genau wie bie eigentliche Şauptwurzel verfält.

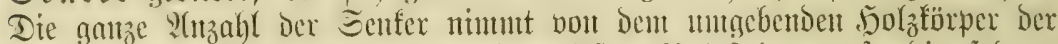

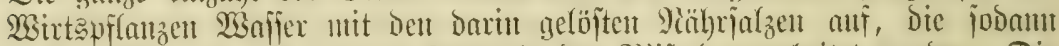
in den Blättern unto gritment Stengelı Der Miijtel verarbeitet 1verbent. Dic Stellen, an denten J)iijtelpffanzen fich angejiedelt haben, berdiffen fich. Die

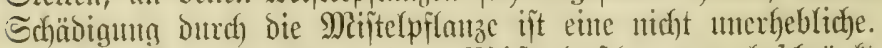

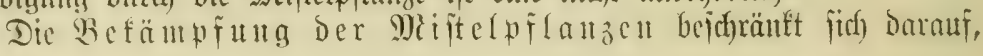




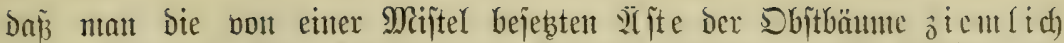
weit hinter ber fnolligen âf

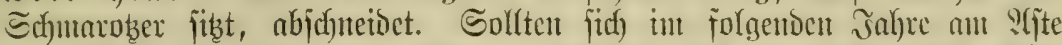

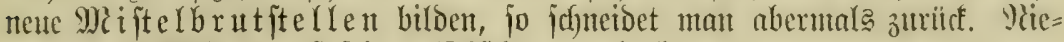
mand joll Mifiteln auf jeiten Dbjtbäumtent buldent.

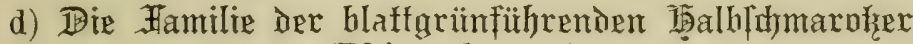 (Rhinanthaceen).}

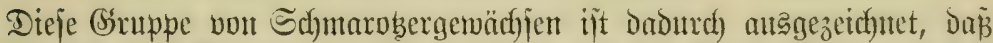

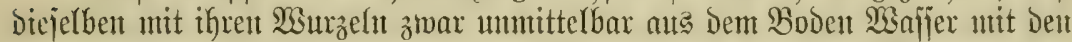

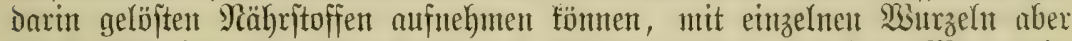
bermittels citte Saugapparate (Haustorien) a

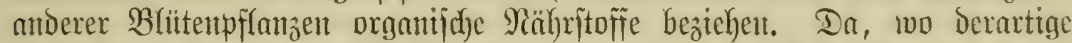

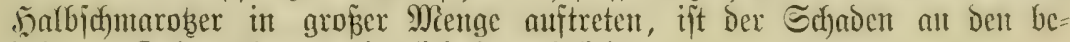
fallenen Sulturpflanzen ziemlid) beträd)tlid).

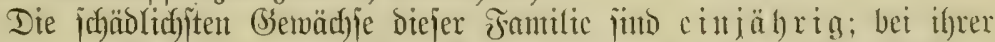

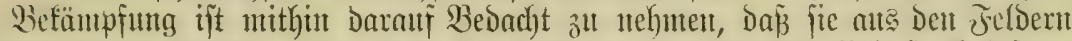

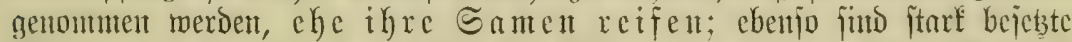

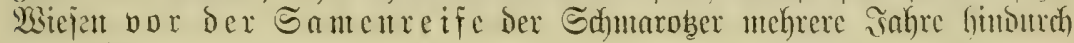
żt mähent.

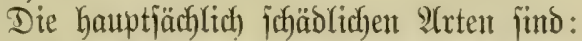

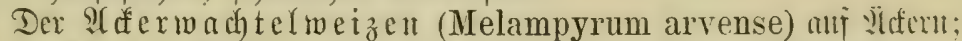
die fleine $\mathfrak{B}$ iejenflapper (Alectorolophus minor) und

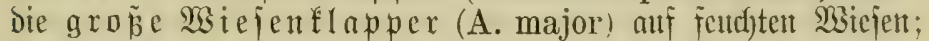
Die befaartc $\Re$ lapper (A. hirsutus) unter Getreide;

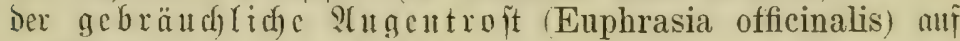
Wiejen;

Der rotblütige $\mathfrak{A}$ ugentroit (E. Odontites) unter Getretie.

3u biejer S(bteilung ber Schmarober gebörent and nodh bie Berg

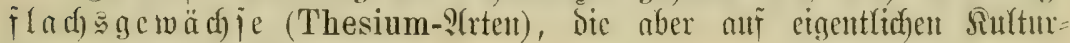
pflanzent uid)t vortommen.

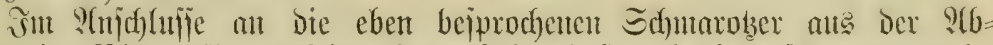

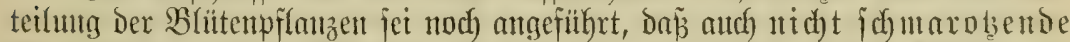

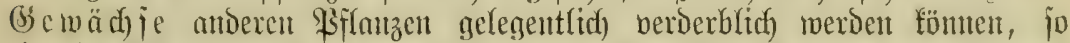

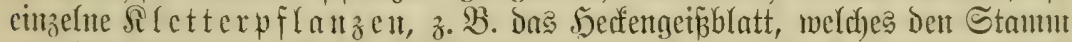

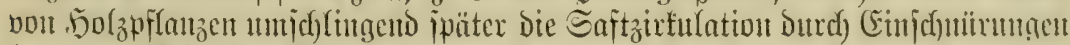
henunt. P(efultide Bejd)äbigutgen faum auth ber (Ephen herborrufen.

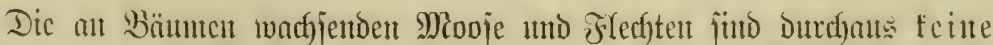

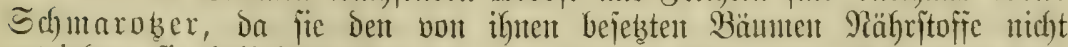

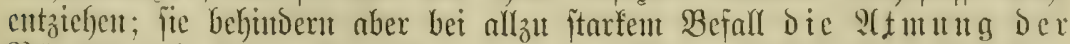

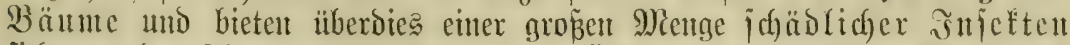

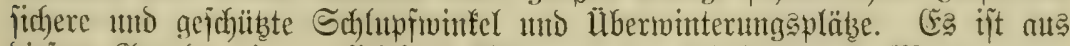

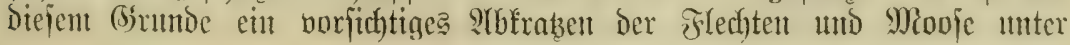




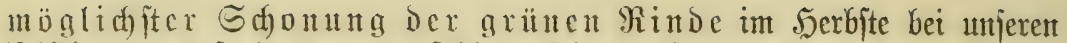
Dhjtbämmen bejonders zut empfeblen. Die abgejcharrte Borte (ältere Rintoe) mit ben baran befintolichen Flechtent unto Miovjen ift jorgfältig zu fammeln und zat verbrement.

Durch bafbiges Beftreiden ber fo gejäuberten Sbitbäınte mit

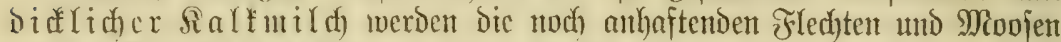

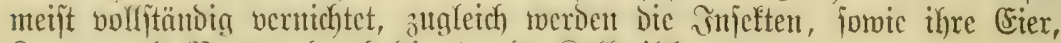
Sarben uno \$itpen burch die äbende Salfmil(ch getötet.

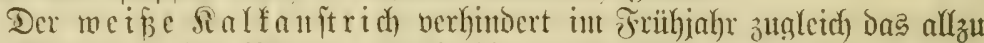

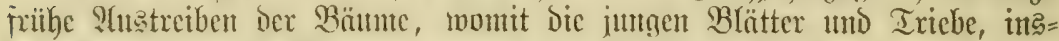
bejondere aber bic Bäten mentạer ber ichäblichen Mirtututg der Spät= fröpte atbaciebt weroen.

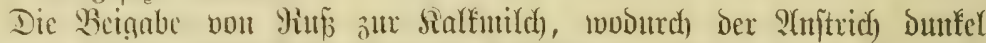

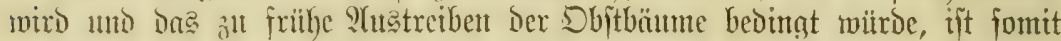

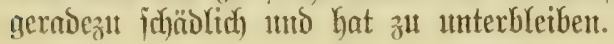

\section{Kapifel.}

\section{Die Strmmarofzerpilże.}

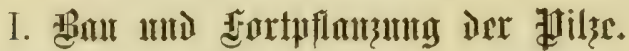

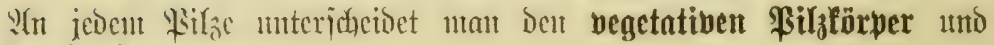
ìn Irửjtträger.

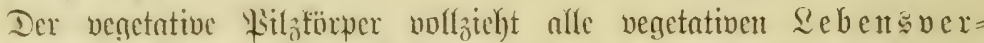

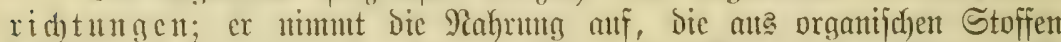

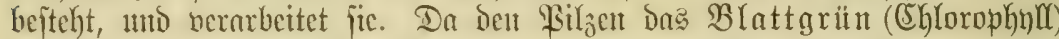

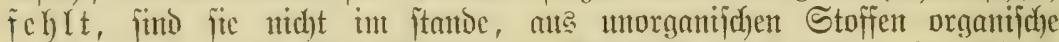

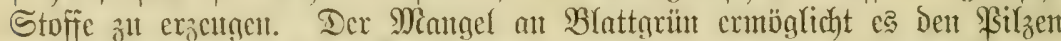

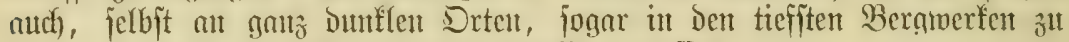
Yeben, ment fic Dajelbjt organifiche Stoffe antreffen.

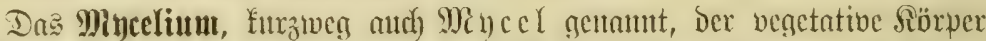

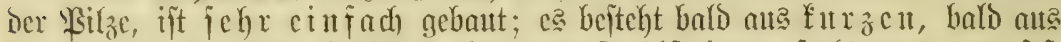
fängeren eitzeluen Belfen ober aus 3elffäden, feltener ats feft

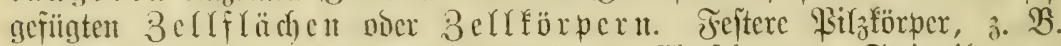
bet belt groß̧ent 5utpilzen, wie Champignon, Sicrid)wamm, Steinpila, ent=

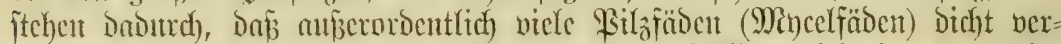

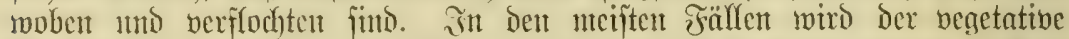

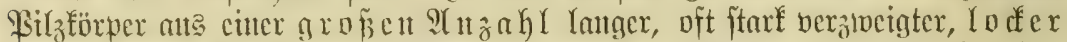

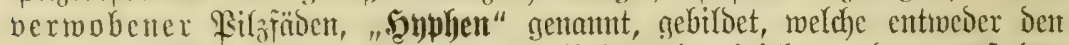
mit organijhen Etoffen Durdjetsten Boden Durchzieben oder auf ber Atubenjeite, me ift aber im Sunern bon lebenden Drgantemen mutdern.

Dic ale Irtanffyeitserreger an mijeren Sulturgetwächjen in Betracht

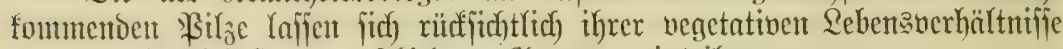

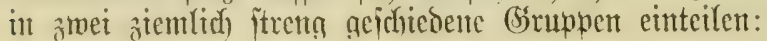




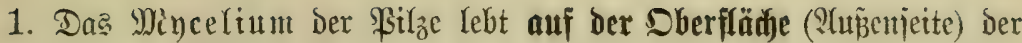

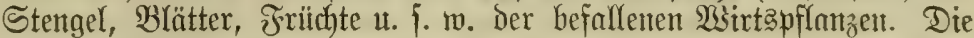
befallenen Pflanzenteile twerdent jomit pout bell weiblid en oder violetten ober idrärzlichen Mincelfäben übergogen uno erhalten baburdh ein meiplid)graues (bei ben echten Miehltmuilzen)

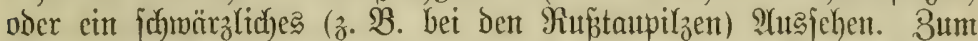
Bwecfe der Cruährung entftehen an Den Mincelfäben fleine Eaug: fäben, melche fich in bie Dberhantzellen einbohren und barate bie গähritoffe entnehnten. Die ertern wadjienden oder erophnten Sdjmarotgerpilze.

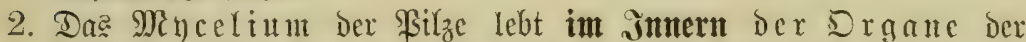

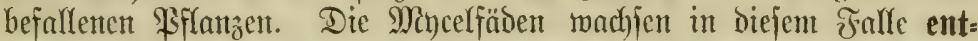
weder in ben 3 wijd)enzell äumen der Bfflanzentgetwebe meiter tmo cinżelnc Saugfüben Durchbohren bie Wandungen Der Beflen unto intnebmen nus bem Belfinhalte bie zu ibrer (Ernäbrumg erforderlichen organifichen Stoffe, ober bie Mincelfäben jelbit burdb bhren bie Bellmandungen und Durchyuthern jo bie Belfen. Die Billoung von eigentlichen Saugfäben (Syautorien genaunt) ift in lebteren Falle überflüfïg. Die intern wadjenden ober enoophyten Sdjmarober: pilze, 3. B. bie Shrano= uno Miojtpilze, die faljchen Miehltautarten, iiberhanpt die alfermeiften Srantheitspilze der Pflanzen.

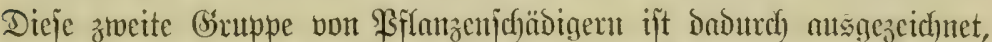

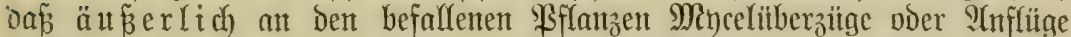
nicht wahrzumehmen itnd; erit went ifyre Früdte gebildet merden, melche meitenteile direft unter ber D berhant entitehen ober hä ufig jogar liber die Dberhant heroorfommen, merden die Frucht= förper ober die bie Sporen erzugenden Fruththyphen fidytbar.

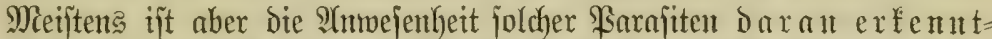
Yich, Daf bie innerlich) bon Dem Mincelium Durchjebten Gemebepartien ber befallenen Bfflanzenorgane infolge der Sdyäbigung abfterben uns fidh

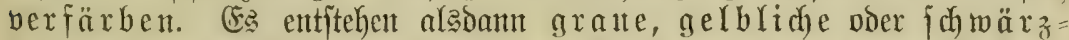
lidbe, oft bon berfdicbenfarbigen $\Re$ ämbern ungebenc Gleffe.

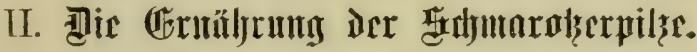

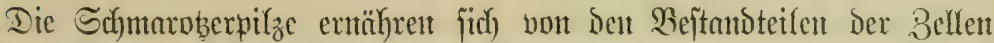

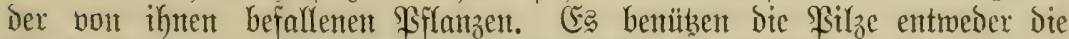
Stoffe ber Berlmand oder fie entuehment meiftens dem Berringalte

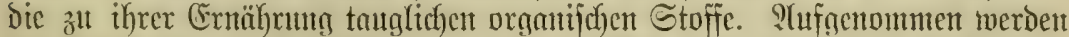

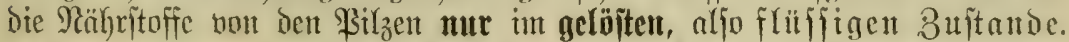

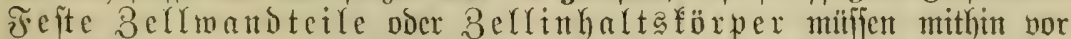

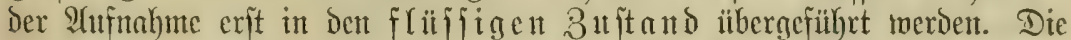

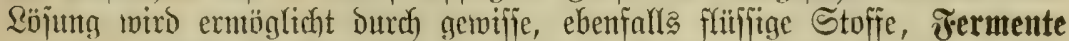

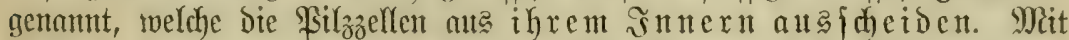

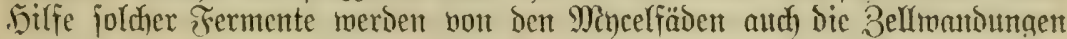




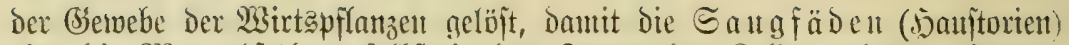
ober die Mincelfäben felbit in das Jumere der Bellent gelangen föment.

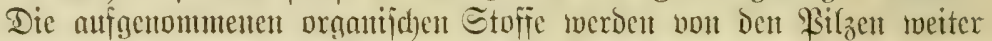

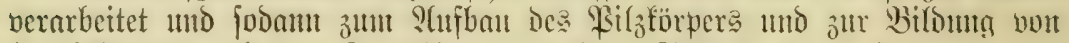

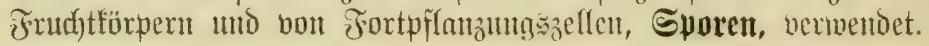

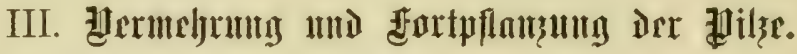

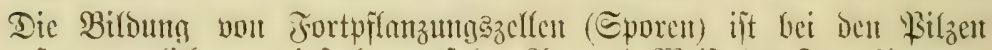

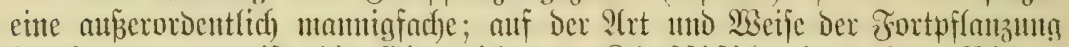

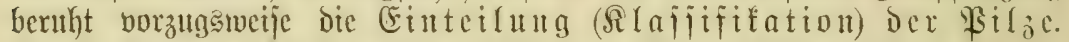

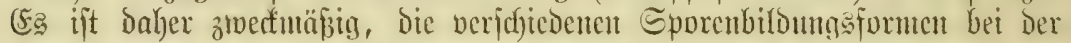

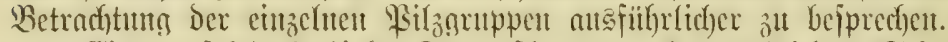

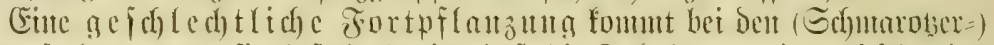

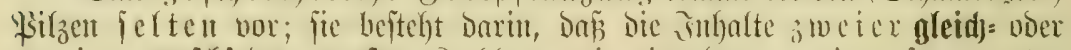

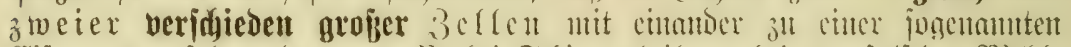

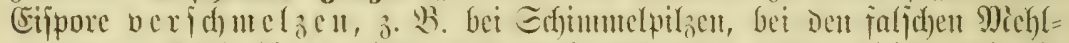

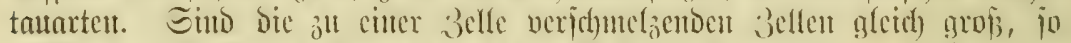

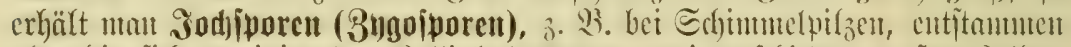

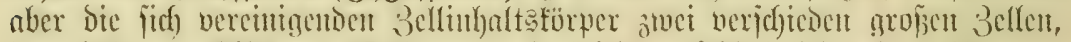

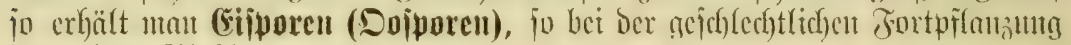
Der ed)ten Miefitnutarten.

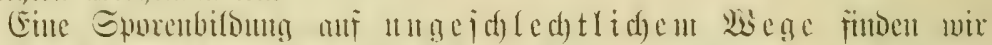
bei allen Edjumatgerpilisen. Es Inffen fich folgende Formen ber Exuren=

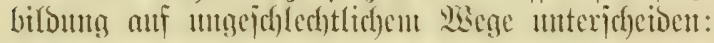

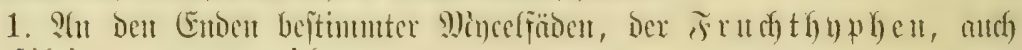
Bajidien genamt, twiro:

a) cutweder mu cine cimzige, fungelige voer ciförmige voer jtäbchent=

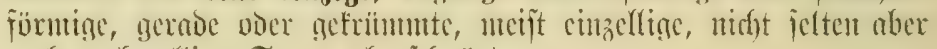
audf) utebrzellige Spore abgejchnitrt,

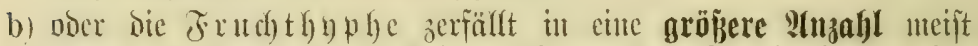
furzer, futgeliget ober vielieitiger Sporen, ż. 23. Die Sporen Der

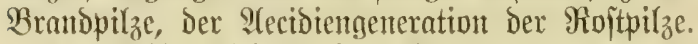

Dic Pilze dicjer eriten Gruppe nemt man Bapibiounuceten.

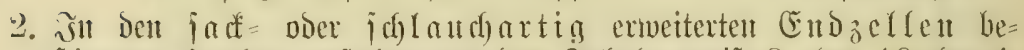
itimuter Б口ywhen entítehen ants dem Inthalte meift 8 ober 16 oder 4 ,

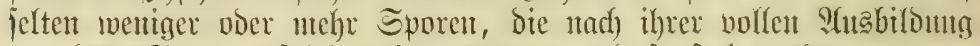
aus dent Sporenjchlaudbe austreten mo fo frei merden.

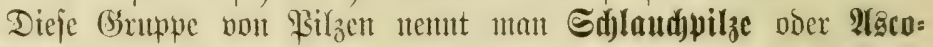
mycetell.

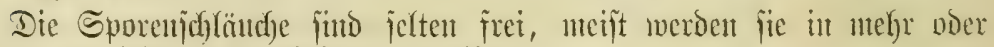
meniger entwidfelten Frudfffórpern gebildot.

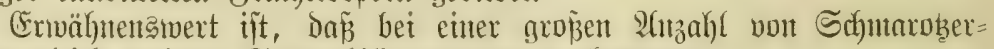
pilzen gleid) mebrere Sporenbildunganaten vortonmen.

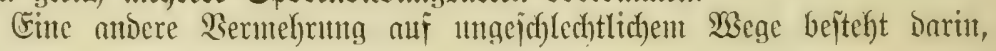




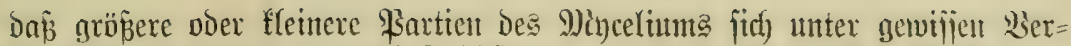

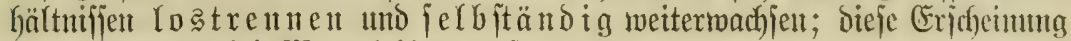
tritt befonders bei Murzelpilzen auf.

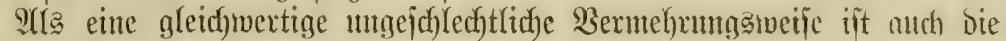
Tcilung ber einzelligen Spaltpilž aufzufaffen.

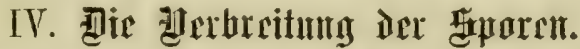

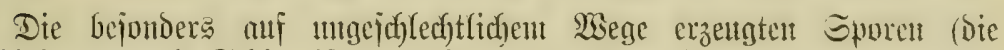

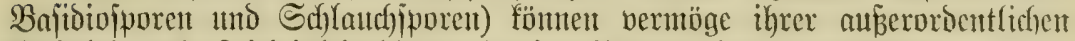

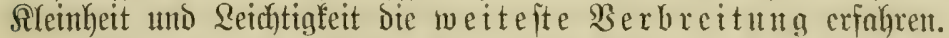

Die geeignetiten $\mathfrak{B}$ erbreitungämittel find:

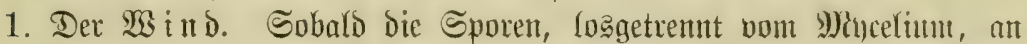
Dic Ruft gelangen, fömten fic bont leijeftent Minsouge fichon fort=

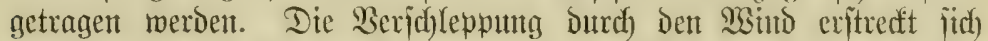

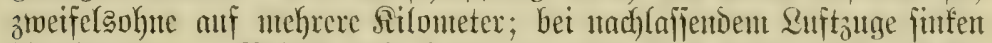
Die Sporen zll Boden uno fallen jo zum Teil wonigitens anf bie

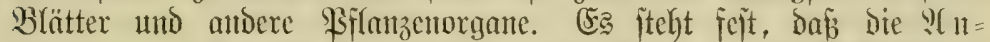

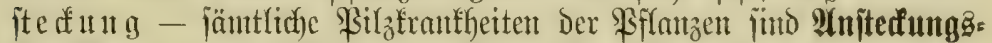
fraufheiten - Der Blätter meift non der B lattoberiette aus ge=

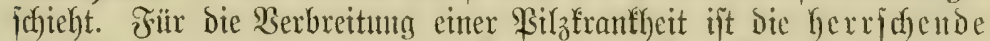

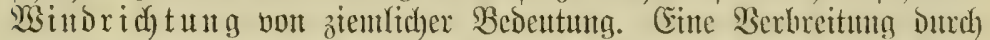

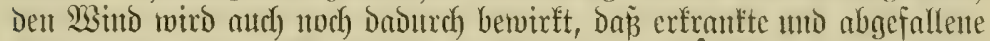

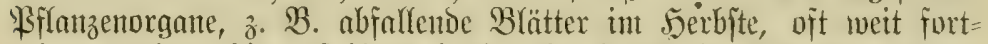
gejagt merben; die auf ibnen frither oder jpäter jitd biloenden Sporen fömten andere, näher oder ferner itehende Pfflamzen amiterten.

2. Die Tiere uto ber Menjid.

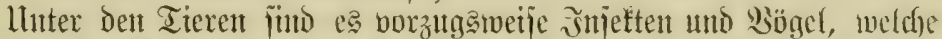

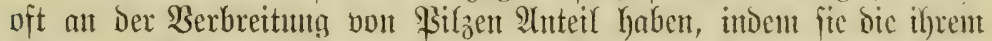

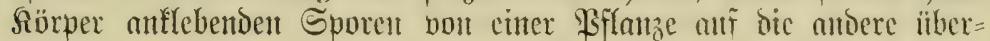
tragen.

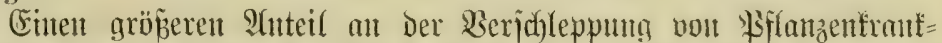
heiten hat Der Mienjch. Durch (Einfauf fporenbehafteten Saatgutes

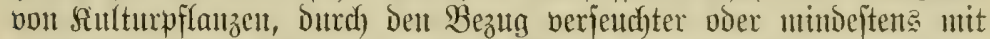
Sporen bejebter Bffanzent werocn Siranfheiten äıserît bequen iiber ganze \&änder, jogar bon cintem Sroteil zum anderen berbreitet. Fine

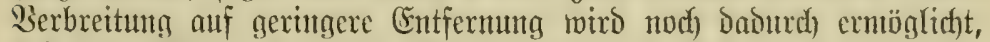

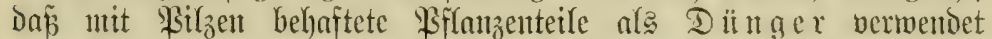
werben oder unbead) tet liegen breiben, obrobl je nejanmelt uno

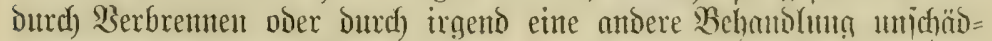
(id) gemacht werden folltent.

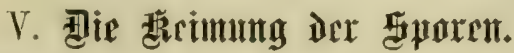

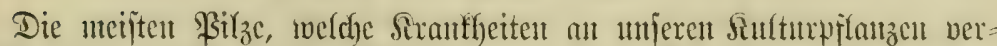

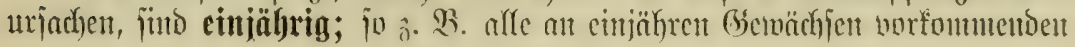




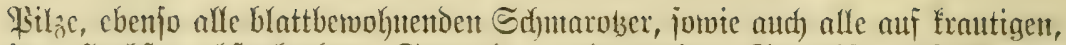

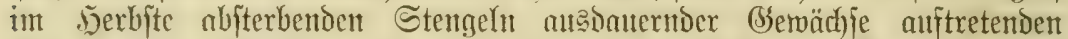

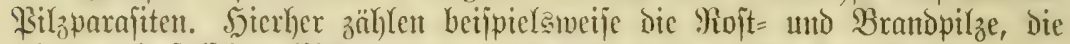

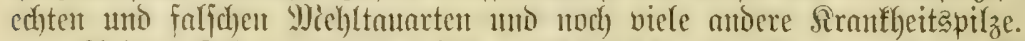

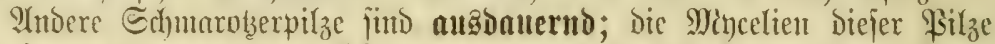

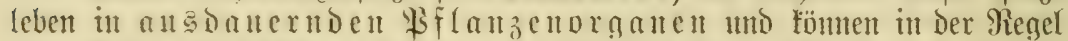

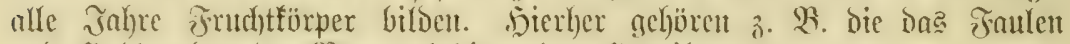
unto .5ohltwerden ber Bäıme bedintgenten . Dutpilze.

Wern die Sdymaroberpilze mefrere Formen Der Eporentitsung be=

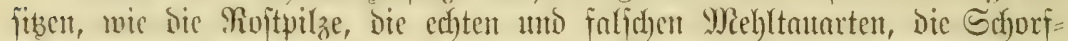
filac uno nod) bicle antore, io laffen bie Eporen fich als Sommeriporen mo ala Winter D Dex Daueriporen untericheiden.

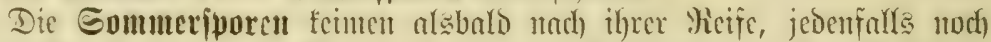

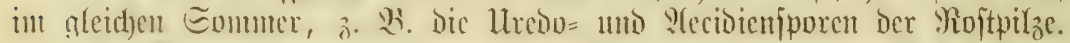

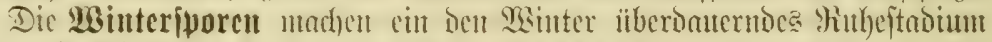

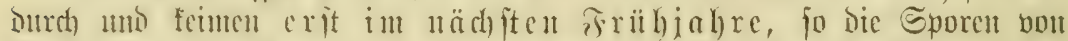
Branbpilzen, Die Danter: oder Ieleutopporen Der Yuptpilze, Die Eiporen Der

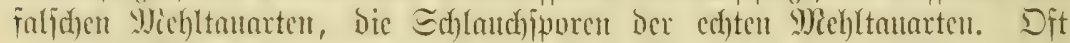
reifen die winterjporen erjt wälrend De 2 Winters oder im folgendent

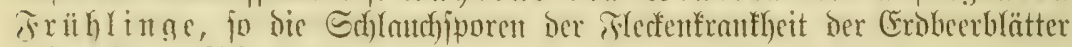
IIII) amberer Sdjmarober.

Dic ficmunta Der Eporen faum ftet a mur bei Gegenmart bou Whafier erfolncn, b. h. Die Sporen funt mur im befendieten Bujtande

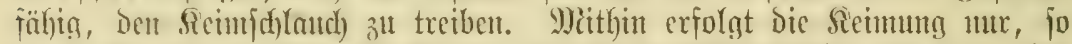
Iantạe bic mit nangeflongenen Sporen behafteten Wfflanzenteile bon Imat ober

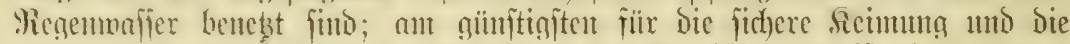

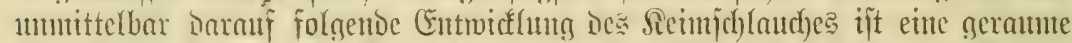

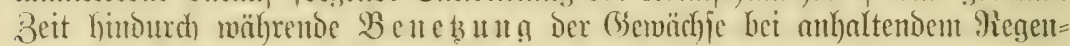

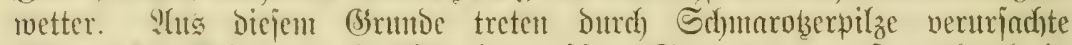

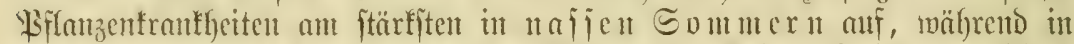

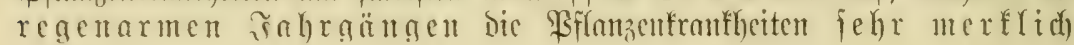
abnebmen.

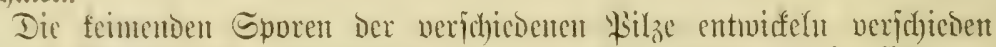

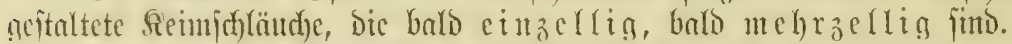

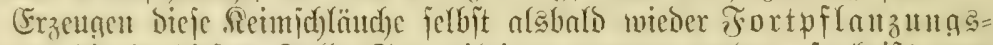

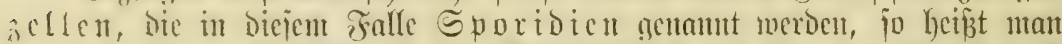
cimen Derartigen ficmidyland) cin Promucelium, fo bei ben Brand = 1mo

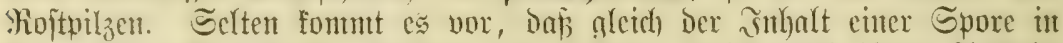

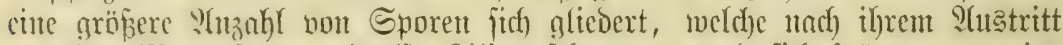

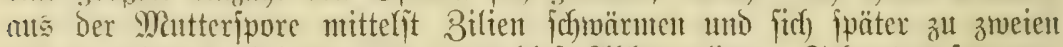

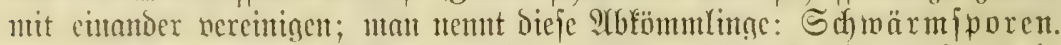

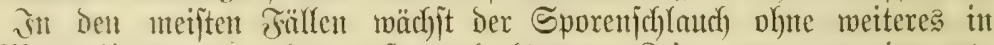
eit Mencelinm anz, das erit nad) längerer Beit, went es cine ent=

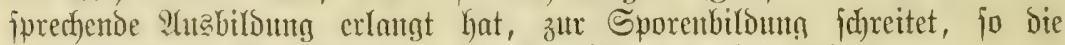
Ertorfpilze Der fiernobjtbäume, bie Sutpilze umb vicle andere.

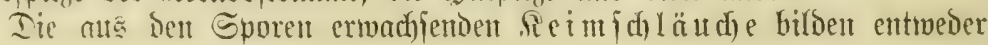


ein, auץ Dex Dberbant Der

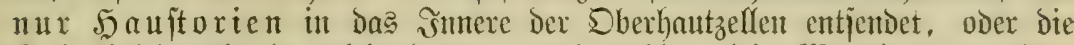

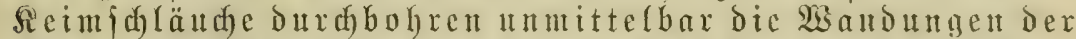
Dberbautzellen und gelangen jo in bas znnexc ber befallenen Drgante, ober jie madjen oberflädhlid jolange fort, bis jie zu

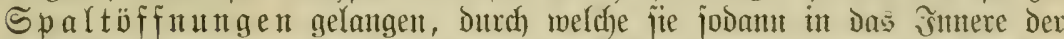

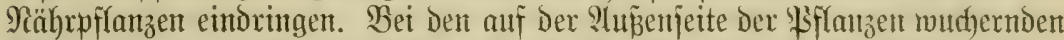
Sdmmarobern merden uatürlich auch Dic Sporen und Die Frudbttörper ftet? anterbalb des Bffanzentürpers gebildet. Bei ben intern mucherndent Schmarobern aber merben bie Sporen meijt ebenfalls an ber :Yupenjeite

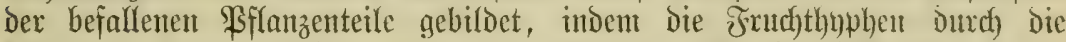

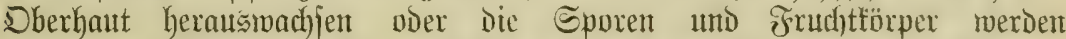
unter Dex Dberhaut gebildet. Jinjolge Der gropenen Menge der bajelbjt ent= itehenden Sporen voer infolge der verbältnismäßigen Giröpe Der erzeugten Frudhtförper wird jollieblich Die Dberbaut gejprengt, und die Sporen ge= langen jo untuttelbar in bie Ruft. Nux in feltenen Fällen bleiben bie

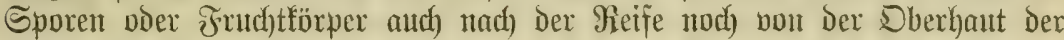
Wirtipflanze bederft uns merden erjt bei Der Berwejung Der betreffenden Pflanzenorgane frei.

Die eme Grappe von Sduntaroberpilzen befällt jtets nux eine

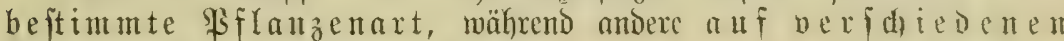
Bflanzenarten vorfommen fömen.

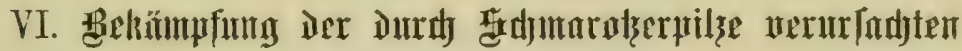

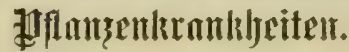

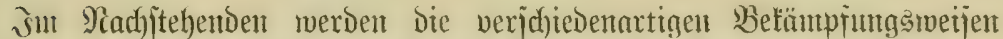

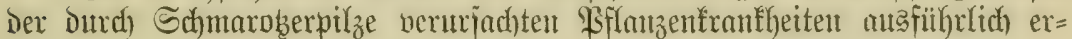
örtert.

Fine auf ciner genaucu Seuntnis der einzelnen Sirautbeitspilac bc= ruhende l̈berlegung erleichtert Die Wah) der anzuwendenden Mittel ungemein,

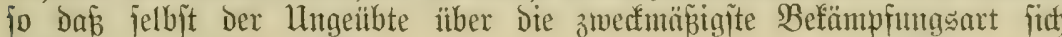
bolffommen auffärent fant

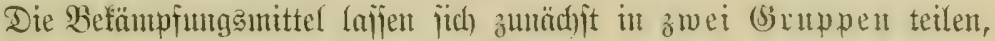
nämlich:

1. Bernidtung Dex Hilziporen, che fie anf die Julturptanzen

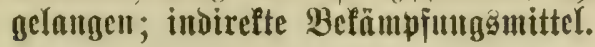

2. Bernidutung Dex Sporen, madbem ïe mif bie Drtuane Dex Sulturgemächje gelangt find; Direfte Bcfümpfungąnttel.

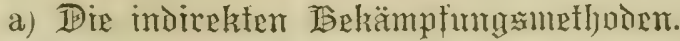

Man veriteht Darunter alle jene Mañregefn, Durch weldhe Den Sdymarober= pilzen bie Miöglid)feit entzogen wird, Sullturvflanzen zu befallen.

Die hauptjädylichiten hierher gehörigen Măfreneln fino: 
1. Dic 岁ernidutug franter Bflanzentgane ourd) Ber= rennen.

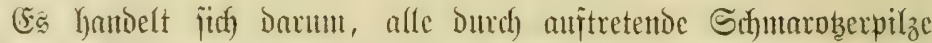

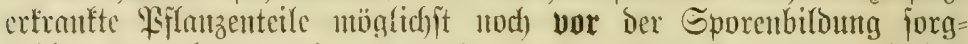

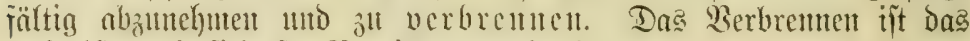
cinfachite und fidjerjte Bernidytumgantittel.

So joll bas Ratb exfraufter Sfflanzen, iusbejonoere ber Dbjt=

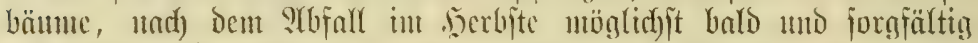
gefammelt mis verbramt werben; cbenfo follen Stengel mo Zweige,

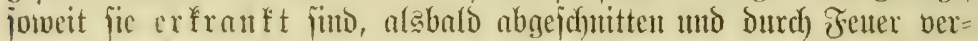

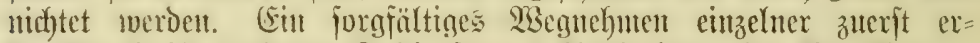

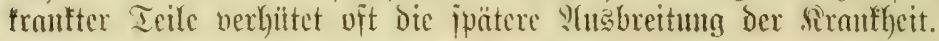

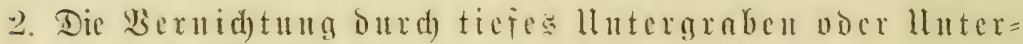
pfrti gen erfrantter Bflanzenteile.

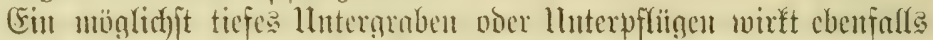

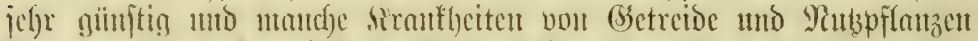
fömen erfolgreid) anf bieje Werije befämpft meroen. Dahin gehört bas alsbaldige Sergraben des Raube franter Sbitbämune und Forit =

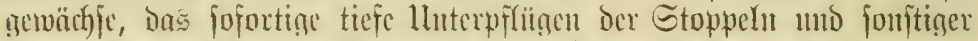
Hleberrefte non franfen Wiflamsen, Dic anf bent Felde verbleiben.

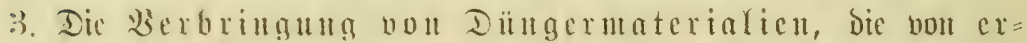
frunfen Bflamsen itanmen, anf Dic Felder ift zu vermeiden.

(E) fïmten Dic Interiporen (Ielentopporen) berichiedener firant=

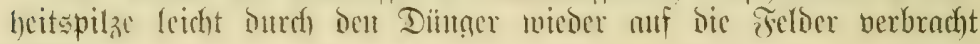
merien.

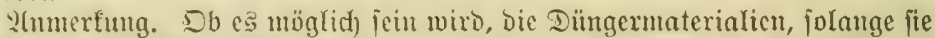
noch auf ber Düngeritätte liegen, vollftäntoig pif iterilifieren), bleibt ber 3utunft überlaffen.

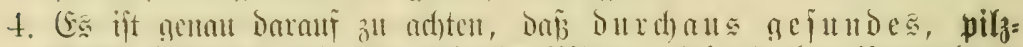

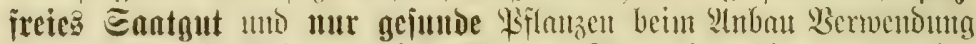
finton; dies gilt bejontorre für alle jene Sämereien, die bermöge ber

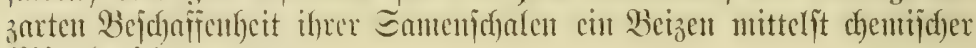
Mittel nidgt bertragent.

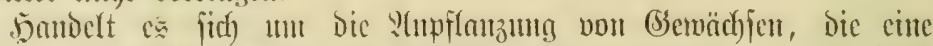
Reintgung (Desinfettion) non Schntarobern extragen, fo iit bieje

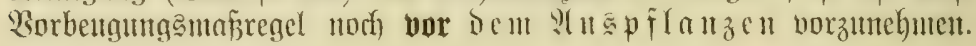

5. Wou hervorragendem Serte ift $c$, mur jold) (Setreidearten, Dbftorten mo jouftige sulturgewäd) fe anzubanen, bie fid

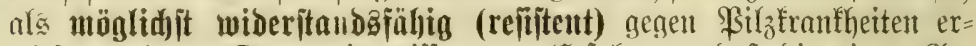

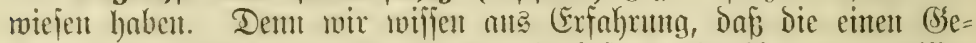

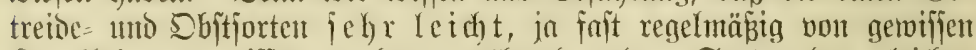
Sirmffyeiten exgriffen merden, wähyreno moere Sorten bex gleichent

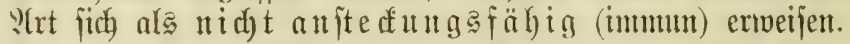

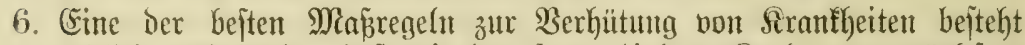

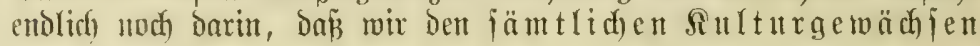




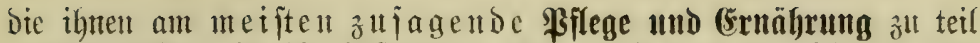

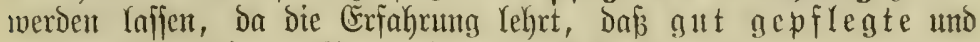

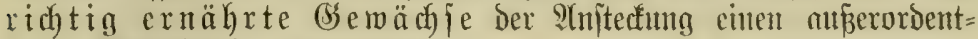
richen $\mathfrak{B i d e r j t a n d}$ entgegenjeben.

\section{b) Dik direkfen Bekämpfungamitfel.}

Die Dirctten Befämpfunganttel wirfen ent tweder heifend, wem die Siranfheit bercit mehr oder weniger bedenflich jtarf aufgetreten ift, oder fie verbindern bas ?luftreten Der Rranfheit, inbem bie $\Re$ eime (Sporen)

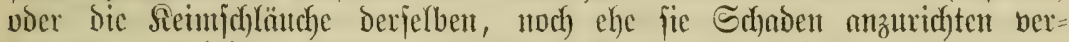

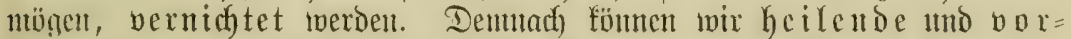
beuneube (prophylaftijd)e) Befämpfungamittel untericheioen.

3ur $\mathfrak{B e r w e n d u n g ~ f o ̈ m e n ~ m u r ~ j o l d y e ~ d ) e m i j i c h e ~ M i t t e l ~ g e l a n g e n , ~ s u e l d a e ~}$

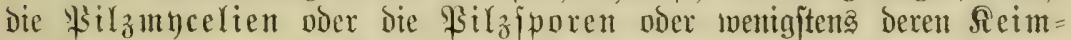
jd)läud)e töten, die befallenen Sitlturgetwäd) ue und Deren Drgane aber jelbjt nidjt ium geringiten bejchäbigen.

arfe jene diemijden Mittel aljo, weldye bic zarteren Mffanzen= Drgante, wie bie Blätter, die grinten zarten Stengel, Die Frildyte berleben,

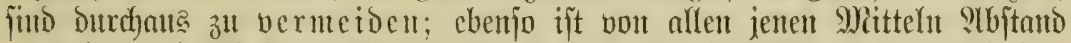

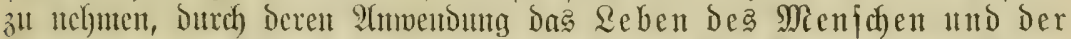

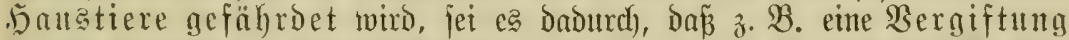

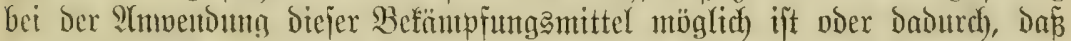

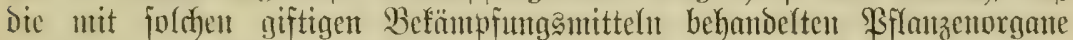

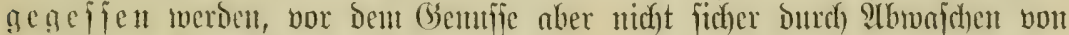
Dent Gifiten befreit merden fönuten.

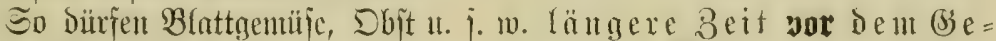

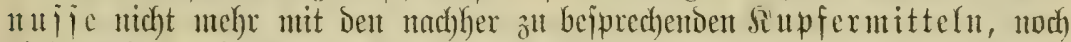
viel weniger mit $\mathfrak{A}$ rfentfpräparaten behandelt werben, währens z. $\mathfrak{B}$. Das Sartoffelffraut, went es nötig wärc, nod) unmittelfbar nor ber fintollen= crute mit den bezeichneten Biffen behandelt werden biirf̌te.

Die Befämpfung Der Scfmaroberpilze hat fich in jebem Falle nach Der Rebensmeije Derjelben zu ridjten.

Wir unterjuetion folgende Fälle:

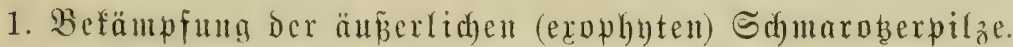

Ins Mencelium ber cxophyten ober äuñer(idy mudjernoen Schmarober=

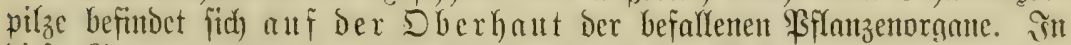

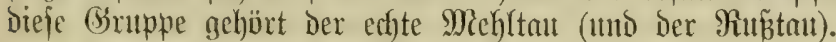

Dic anzuventenden Mittel fömten foubhl heilend, als aud borbeugend wirfen.

9(re mirffamites Mittel gilt dic Bebandunng mit Sdjwejel.

Der Sdyefel wird in jeinitgepulvertem 3uitande - Sdy wejel=

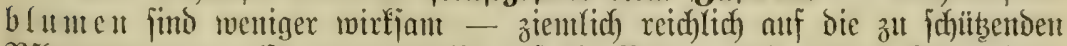

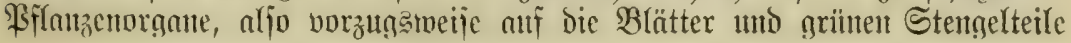




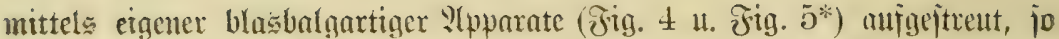

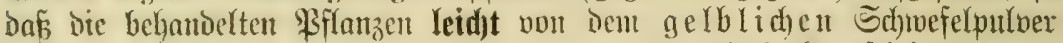

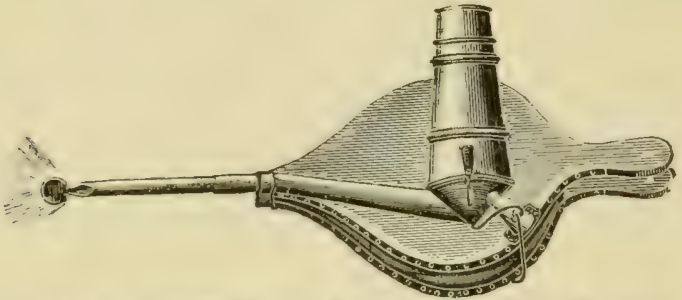

Fig. 4. (5itober Blajebalg mit zerlegbarem Bled)rohr à 16. 7. -

it ande der Blätter aufgejtreut wiro.

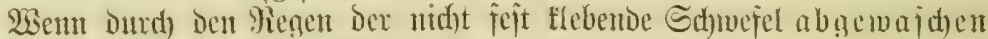
ift, mús vou neuen cine Beptäubung vorgenomuten werden.

Dex Erfyefel mirtt einzig Durd) bie bildung vou idjucfliger

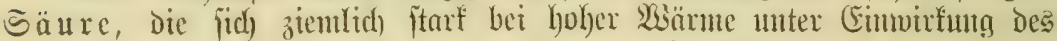

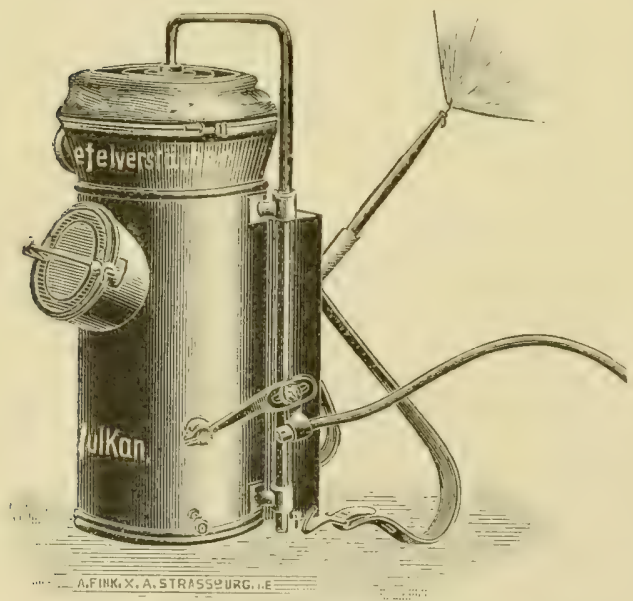

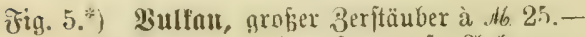
auf Dem Hü̈fen tragbar, für: grof̧e Inlagen. Saueritoffes der Ruft bilbet. Die jo entitehende fodrueflige Säure tötet bie Mincelfäben Dex Sdmaroberpilze, ohne Den viel Derberen 3ellen Der Bllatt= and Stengeloberbant zu juaden.

Da bic editell Miehl= taupilze mux bejonder's bet trodener, warmer Witterung zur Entwidflung gelangen, föment fie an zocdunäbingtent burd) bie jabreflige Säure bernidistet toerden. Sitpfer = berbindungen find วur $\mathfrak{B e}=$ fämtpfung diejer \$ilzgruppe utidy geeiguet, da fie mux im flüfingen Buitande tötento anf Die Spuren und mif Die Siemijobläutche Derjel= ben eimwirten.

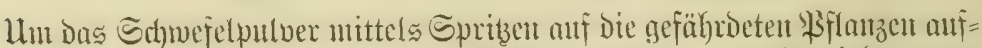

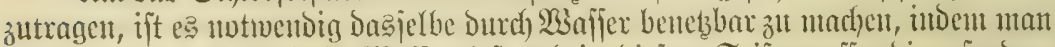

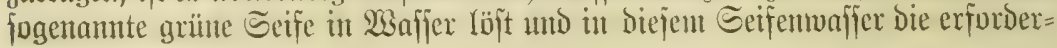

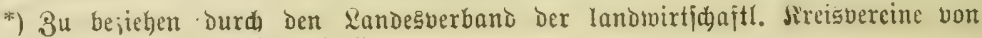
Eljab-Lotbringen in Strafburg i. (E. 


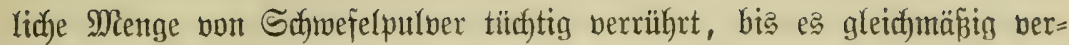
ipribt werden fann.

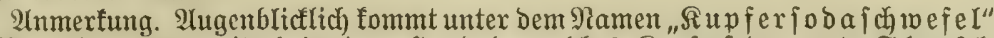

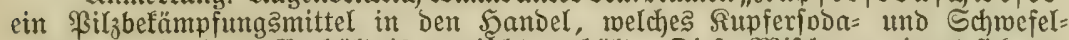

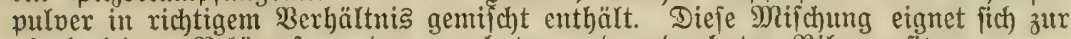
gleich)eitigen $\mathfrak{B}$ efämpfung Der exophnten und enopphnten Pirzparafitent.

2. Befämpfung Der intrerlichen (endophnten) Schnaroberpilze.

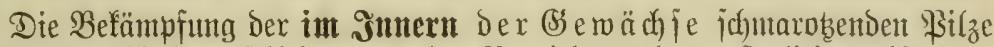

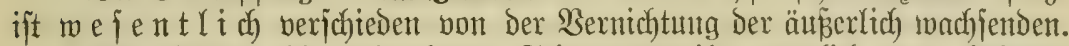

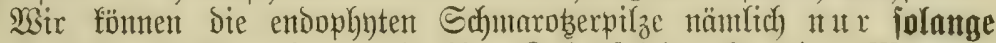

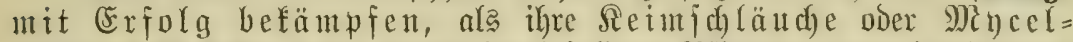

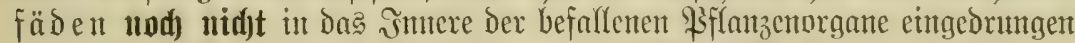
find. Die Befämpfung ift jonit eine veit vorbengenbe (prophylaftijche).

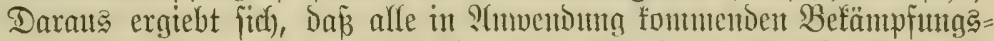

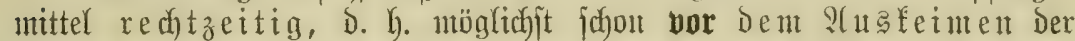

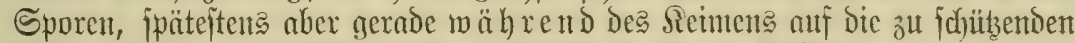

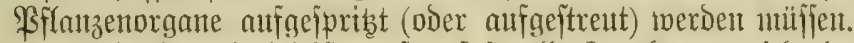

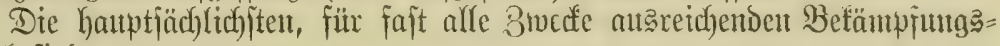
mittel find:
aa) Rutervitriol,
bb) Лupfervitriol= Sodabrühe,

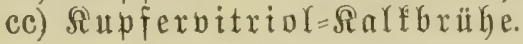

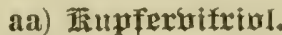

Supfervitriol oocs Brautein= jdwefeliaures Supfer, fann mu it jehr verditnuten 3 uftande segen ber fdyarfäbenden (Eigenidnaften angemendet werden. Man benüzt ihn zun Beizen de?

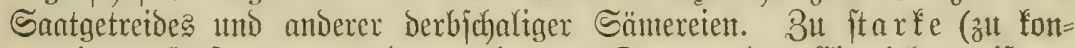

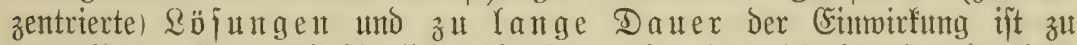
vermeiben. (Es empfiehlt jidc), bie Sämereien 12-16 Stunden in einer $1 / 2$ prozentigen Supfervitriollöjung zu beizent.

Anmerfung. Dą Beizen wiro in Der Meije vorgentummen, dá̉ nan in einem hölzernen Bottich) (3uber, ₹ẩ) Die $1 / 2$ prozentige fupferlölung bringt

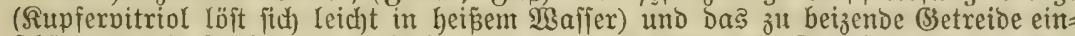

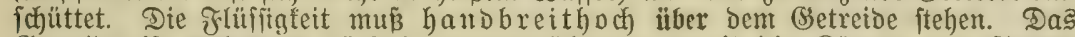
(setreide ijt meljmals tüd)tig umzurühren, Damit bie Rörner und Samen

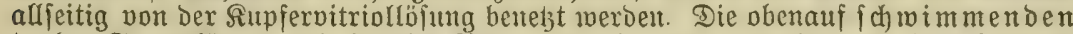
tauben Samentöner und fonftige Serunreinigungen merben por bem Seraus= nehmen Des Saatgutę forgfältig abgefw) b̈pft.

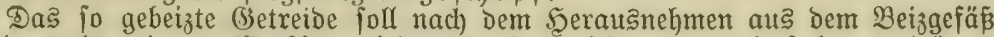
entweder mit reinem $\mathfrak{B}$ affer wicberlolt abgewajden oder mit fehr verditun= tem Sialfwaffer übergofien merben. Ralfwaffer erhält man ourch söfchen gebramnten Ralfes in viel $\mathfrak{B a f i j e r}$

Uuß̧er zum सeizen Der Sämereien fan Supfervitriol in einter $1 / 2-1$ pro= zentigen \&öfung hö hiten 3 nod) zum Hefpriben von wäumen im unbelaubten 3uftand vermendet merben, Doch ift ftets (Sefahr vorhanden, daß bie Rnoipen und bie äußeriten Triebipiben angegriffen merben.

Krautartige Pffanzen und «aume bürfen im belaubten Zuftande

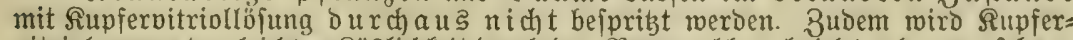

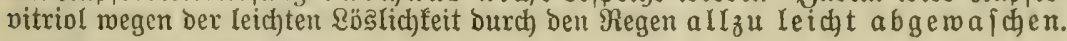




\section{bb) Tiupfexbitxiol-5udaturithe.}

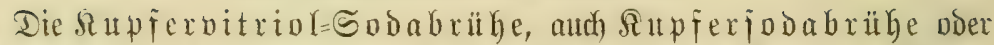

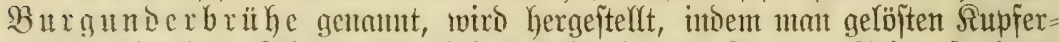

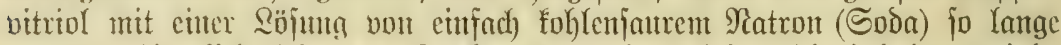

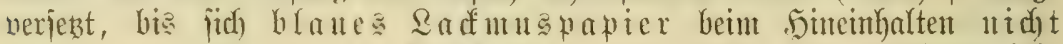
mebr rot und gelbes Rurfumapapier nifft oder hödyjtens fehre jolywach brau fürbt, bis aljo bic Brübe meutral ift.

Doppelttohlenfaures Ratron verurfacht cin ftarfes 2 luforaufu, ift teuer uno eignet fich Daber nicht fo gut jur Seriftellutg Der supferjodabrübe.

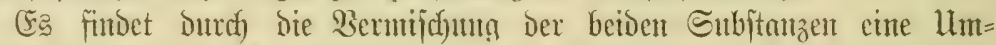

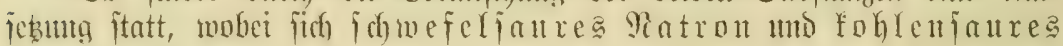
Sitpier bildet.

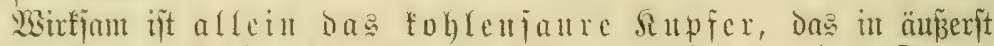
iciufloffigem 3 utitaube, aljo ale fejter, jehr fein verteilter fiörper,

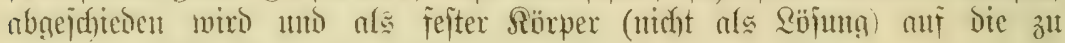
ichuibenden \$flamzenorgane anfgeipribt miro.

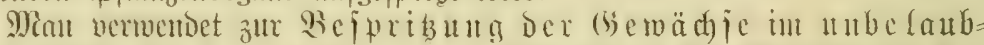

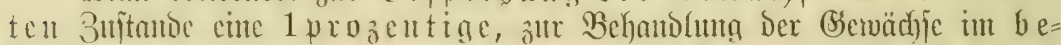
bläterten 3 uftande ene $1 / 2$ prosentige Supferjodabrithe, b. h. anf 100 Siter Wanjer verwentot man 1 Rifo beziehnungescic fïr belaubte Bff́nzen mux $1 / 2$ Rilo Simpferbitriol.

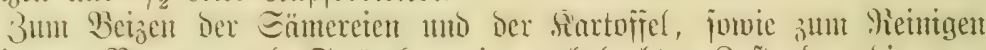

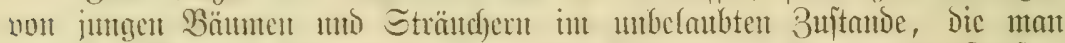

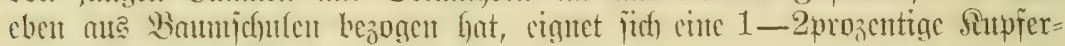
jodabrühe ebenfalle antsgezeidynet.

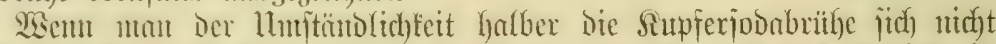

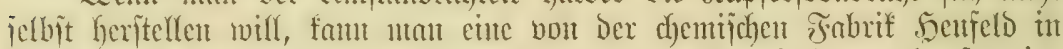
Dherbanern Dutrd)aus im richtinen Berhältnie hergefteflte pulnerförmige

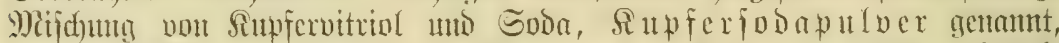

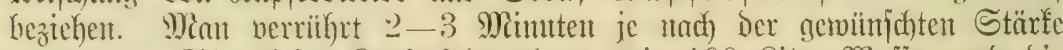

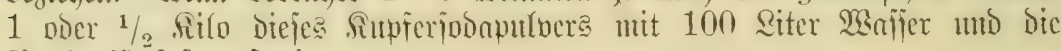
Britilye ift jofort jertig.

Die neteften Berfuche hahen crgeben, Dẩ vou aflen bisher angemendeten fupferhaltigen befämpfugamitteln bie situferfodabrübe ant beften anf Den bejpribten 'Bflanzenorganen haften bleibt. 3ugleich) benötigt man 3ur Serjtellung einer Durd)as wirffamen Brübe bebeutend weniger von bem inmerbin ichon etwas foftipiefigen Rupfervitriol als bei ber nachber ju be= iprechenden §upferłaltfbrühe.

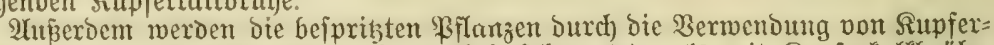

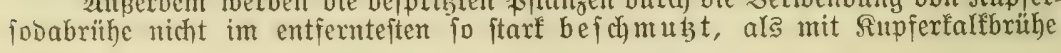

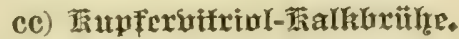

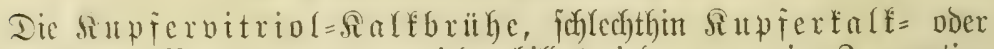
Borbela ifer Bräbe gentamt, wiro gebiloct, intom man eite 2prozentige Siupfervitriollöjung mit ciner 2prozentigen Salfmild) nentralifiert. Man

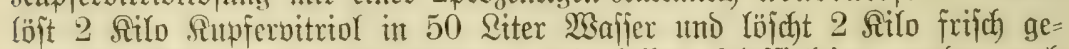

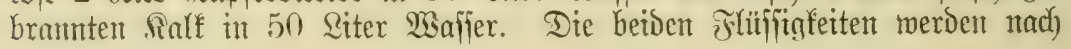


Dem vollitändigen Erfalten langian unter Umrïhren bermijat. Es billoet (id) Dabei unlöslicher (s)

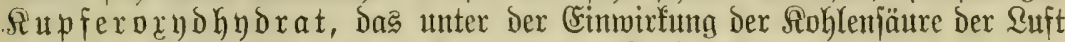
nack Dent Suffipriben bals in fohlemjaures Supfer iibergebt.

Die nach diejer Boridnrift hergeitellte Brïhe enthält Salf im Über=

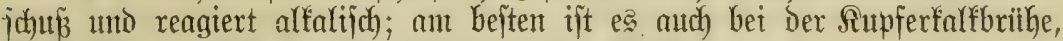
Raltmilch mur bis zur Neutralijation beizufügent.

Die Siupferfalfbrithe weift gegenibber ber fitpferionnbriilye einige wejent=

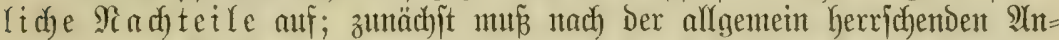
idfaumg bie Brilhe 2 prozentig jein, modurdy fich bie fioften bedentend

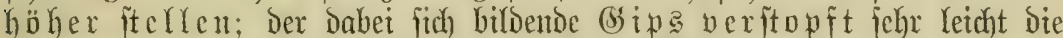
Sprtken; Die mit fitpferfalfbriihe bejpribten 'Sflanzen werden fehr ftart verunreinigt mo infolgedefjen wird Die Ifätigfeit der Blätter, da bie

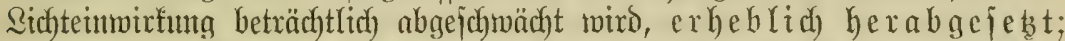

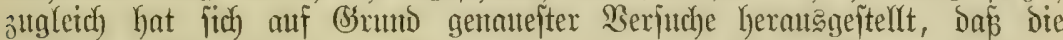
wirfianten Beftandeile der Brithe uricht io gut auf Den Bffanzen haften als bei Sutprerjodabrübe.

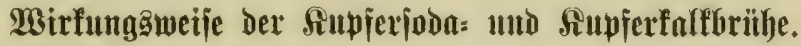

Die Wirfungameije der beioen genannten Brïhen berultit auf der

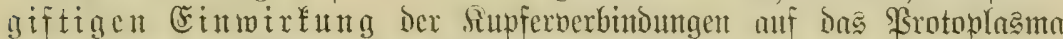

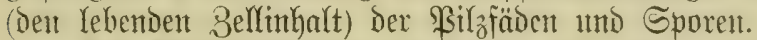

Die Supferberbintungen wirfen mur im gelöiten 3urtanto. Sine

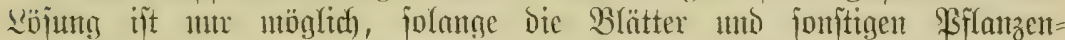

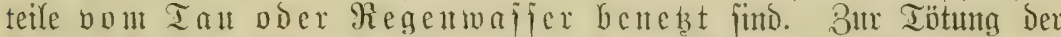

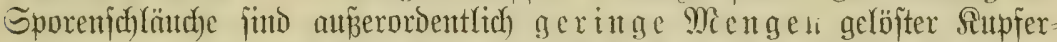

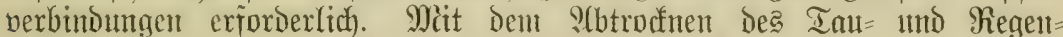
wajfers merion bie gelöfen Rutpferberbindungen fonzentriertex uno wirfen energiticler.

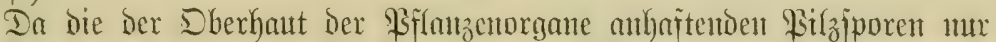
bei Gegentwart bou $\mathfrak{B a j j e r ~ f e i m e n ~ f o ̈ m e n , ~ f o ~ i j t ~ b e i ~ z m e d e ~}$

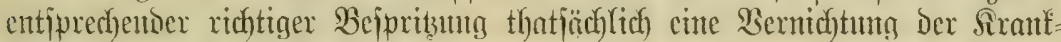

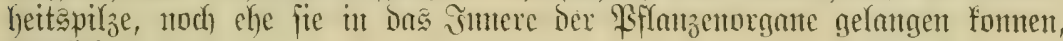
inöglich).

Beipribugen mit hod)prozentigen Supferbriben fümen den zarten

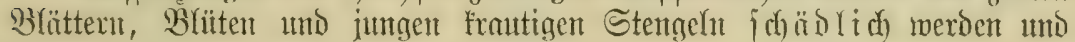
finto mithin zu vermeiden.

Dic Beigabe non 3uder, Eruth, Melajie zu Det finprer= brïhen ift wertlos, meil nad) Den neuten Unterjudjungen fich ergeben hat, Daj burch bieje Stoffe bie Jaftfähtgfeit ber Brinken nidat exhäht

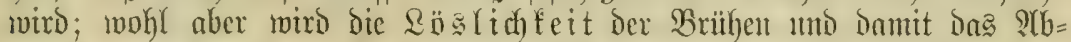
wajchen Derjelbent Durch Reaen wejentlid) exleidhtert.

Das Eintringen von Kinreichenden Mengen Der Beftanoteife Der Sutpfer=

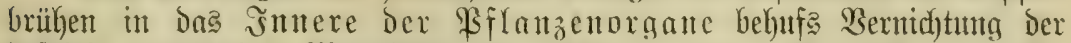

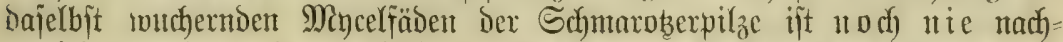

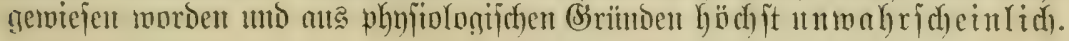




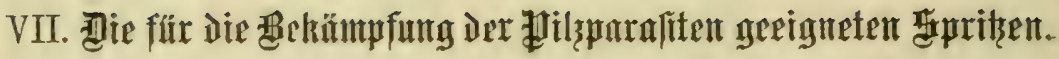

Die zur Bernidutung Der Sdymaroberpilze geeianeten Bejpribungä=

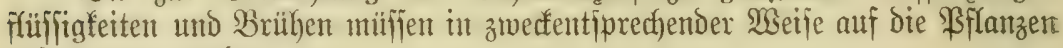
aufgetragen weroen.

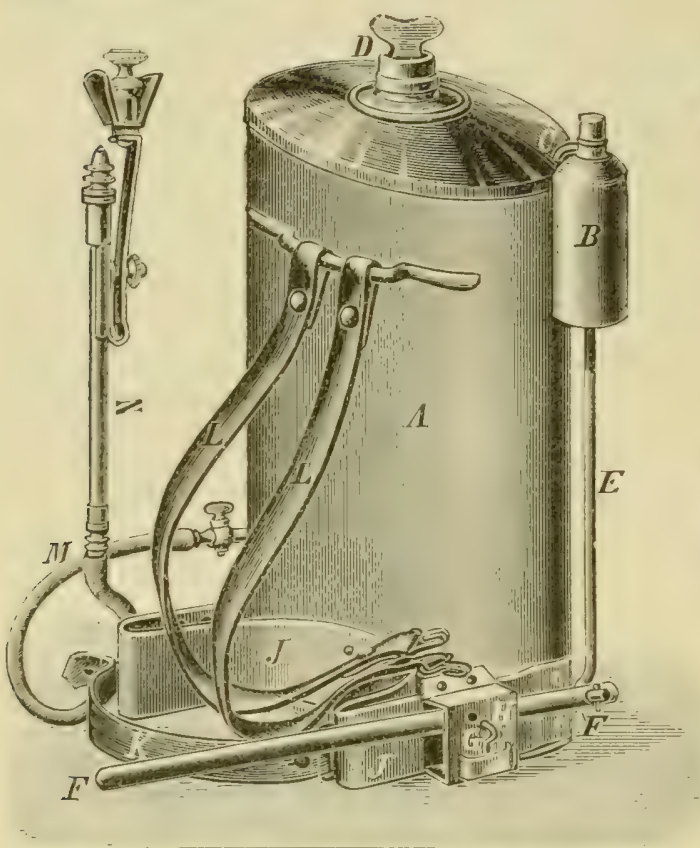

ĩig. 6. Itmiverjalipribe Sardinia von Drejajer in salle.

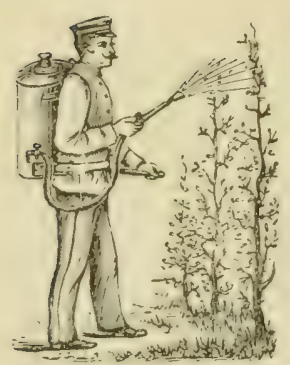

Sprizen in (sebrauche.
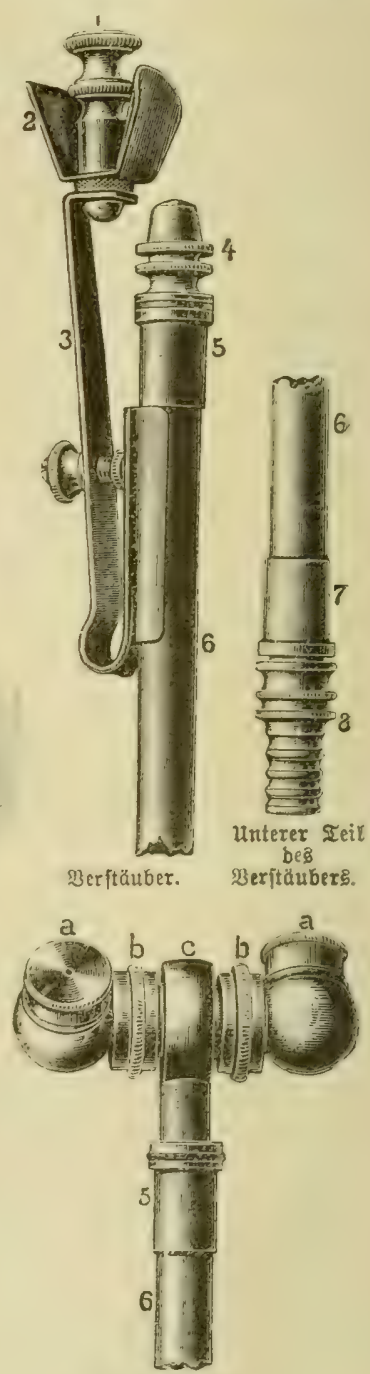

Belentberteirer.

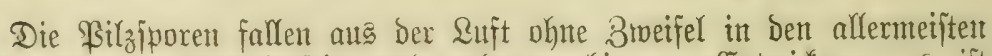

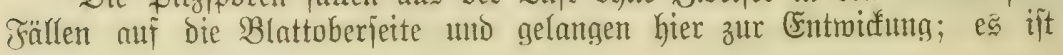


jomit in Der Regel nux bie Blattoberjeite zu bejpriben. Nur bei Kerabfängenden ober nach Der Dberjeite eingerollten $\mathfrak{B l a ̈ t t e r n ~ i j t ~ e i n ~} \mathfrak{A}$ uf = fliegent ber Sporen audh auf Der Blattunterfeite leirht möglidh; ebenjo ift bei

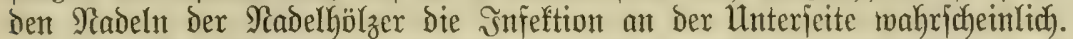

In all biejen Fällen gelangent aber auth) bie Bejpribungabrïhen burd) das AUfipriben von jelbj̃t auf die gefährdeten Stelfen der Blätter und der Brweige.

Da die Miöglichfeit bejteht, dẩ die Sporen auf jeder Sterfe der Blattoberjeite oder Der jonjtigen $\mathfrak{B f f}$ (anzenorgane auffallen unto unter giuntigen

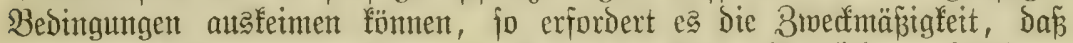
Die ganze Dberjeite Der Blätter und Dic Dberfläche jämtlidjer gefäl)roeter

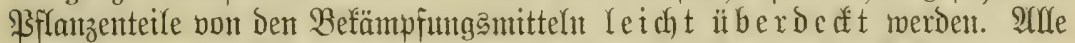

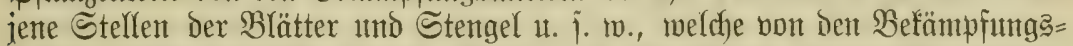
unttefn uticht betroffen wurben, fömmen von Den \$ilzen angegriffen merben.

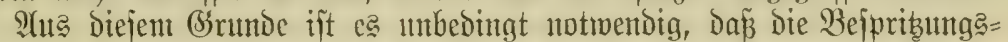
mittel in äuferft fein verteilten $3 u$ tande gleidnmäbig auf bie Sberflädhe Der $\mathfrak{B f l a n t z e n o r g a n e}$ anfgetragen werden. Da bie genanntent $\mathfrak{B e}=$ fämpfunganttel mtr folange wirfen tömen, ale fie vorbanden fino, fo

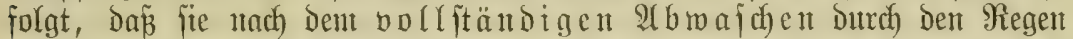

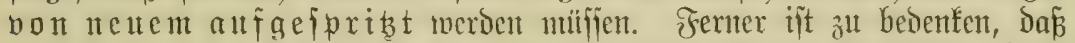
alle nad) einer B̉ejoribung nen entitandenen Blätter mo Stengelteile

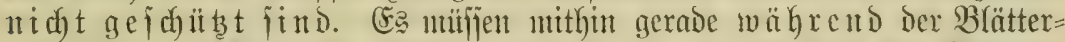
utto Iriebentwidfung bie Beipribungen $h \ddot{a} u f i g e r$ ala bor ber Sitoppen=

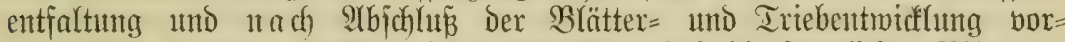

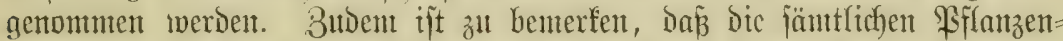
organte gerabe im jugcnorichen Buftande jefre leidyt infiziert (angeftecft) merden fömen.

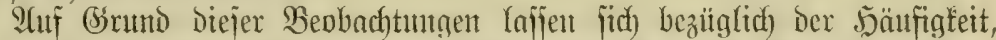

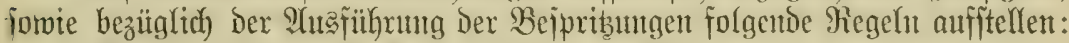

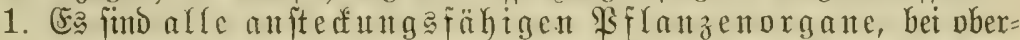
irbijchen Getwädjen aljo insbejontoere dic grinen Ieile Durchans

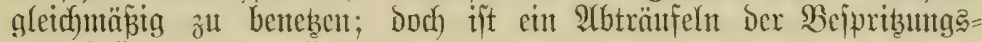
interialien zil verntetben.

2. Die 3ahl Der in cinem Sommer vorzmehntenou Beipribungen richtet

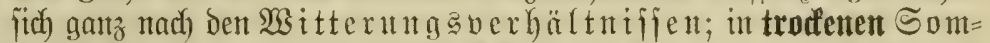
mern find toenige, it regnerijdjen mehr Bejpributugen erforderlich.

3. Die erite Sbejpribut ift int eritent Frithahr unmittelbar vor Dem $\mathfrak{A}$ ufbredhen der finvipen vorzunebmen; die zmeite bet Dbjt=

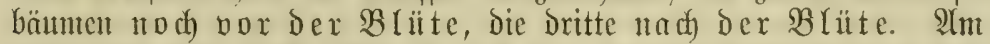
midytigften und mirfijamiten ift nady den neufeften Beobadhtungen einc

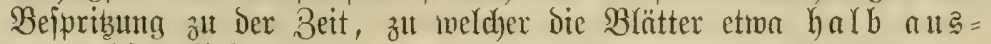
geroadjen fino.

4. Єelbjt in troffenen Jahrgängen nuijīen die Beppribungen mährend Der Sinoipent = unt Iriebentfaltuty mintoettents alle 14 Tage bor= genommen werben. Sind bie Blätter uno Triebe außgerwadjen, fo ift in trodenen Sommern jedeamal erit mieber nadh einigent 


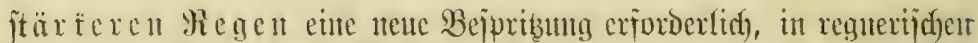
Somment aber alfe 3 W3odjen. Das Samptgemicht ift unter allent

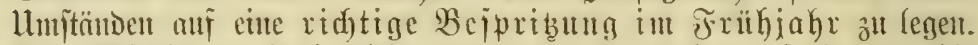

5. Die Sejpributug Dari utht vorgenummen werdent, folange bic Bffamenteile vom Ian obex Regen benetst jind, weil bie

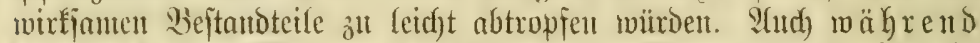
ber beipeften Mittagezeit bei vollem Somnenidyein barf nidht gejpribet verben, Da (eid)t Bejd)äbigungen der zarten Pflanzenteile Durdh die Bejpribungmittel entitehen fömnen, bejonders menn bie

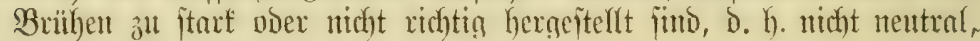
jondern äbend reagierent.

6. Dic in f́

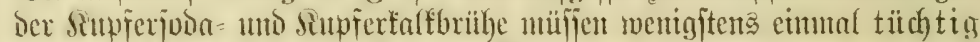

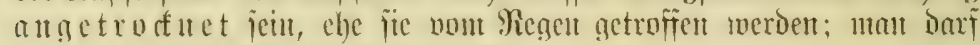

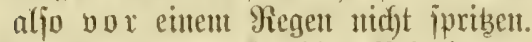

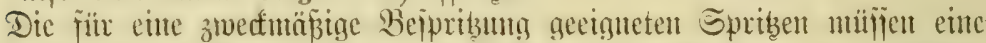

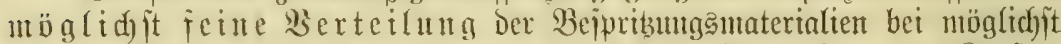

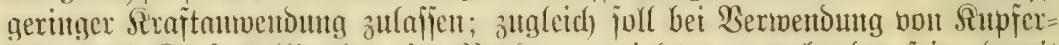

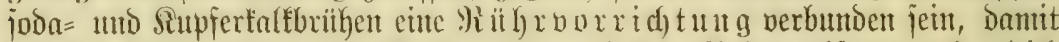

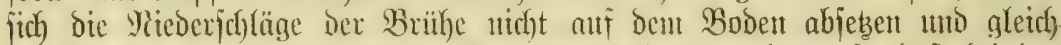

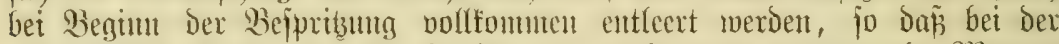
affmähfirf)en (Entfeerung Der Spribe mu melyr ganz ungentigento Mengen von futpferverbindungen voer gar reites 3 affer aufgetragen merben.

Es aicbt bereits zahlreiche Snjteme von jogentanten Peronoipora=

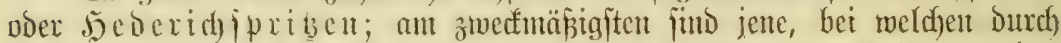

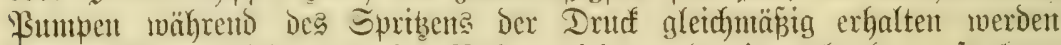

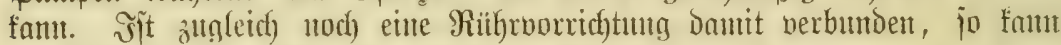
die Spribe als muitergiltig bezeidjuet werden.

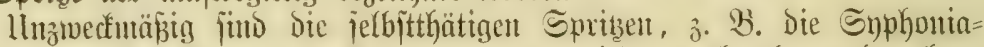

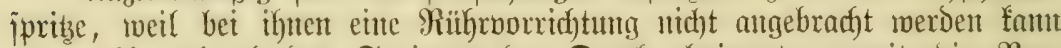

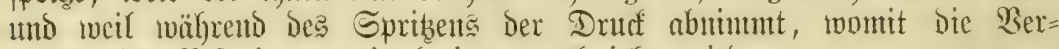
teilung ber Bepributganttel cinte ung (eid)e miro.

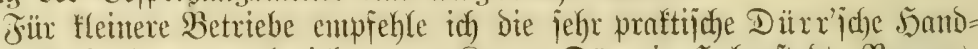

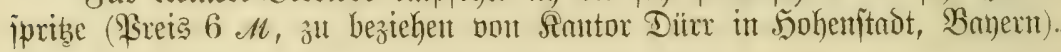

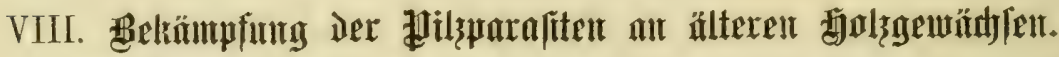

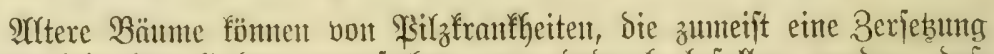

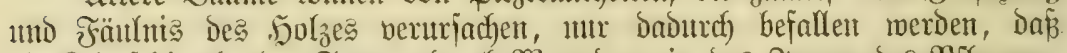

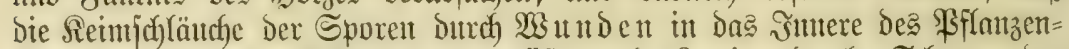

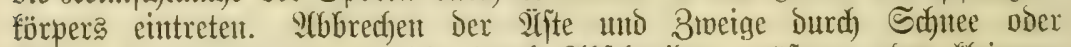

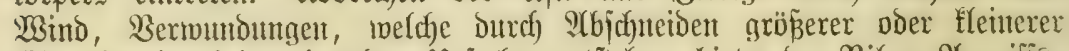

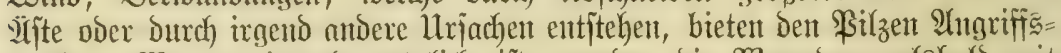

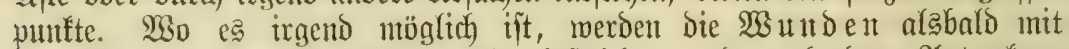

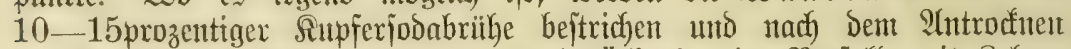
mit faltfliififigem Baumwadbs, over mit Slfarbe, im Notfalle mit Refyu= 


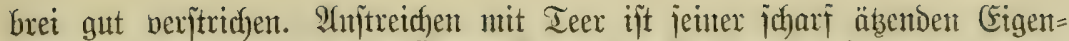
jufaften harber, wodurch bie überwallung jehr itart verlangjamt twiro, nidjt

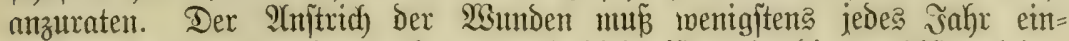
mal nadjgejehen werden, ob ex nod) birht ift, bis bie volrfitändige Bernarbung Der Wunden eingetreten ift.

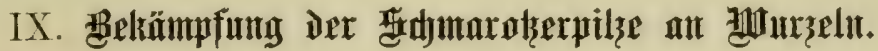

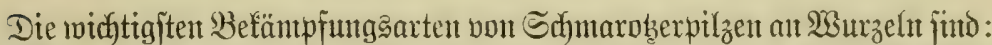

1. Man zieht genügend tiefe $\mathfrak{j}$ oliergräben um die erfranften

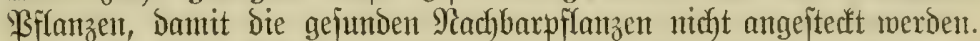

2. Die extranften \$fflantzen werden möglidyjt mit ifrem gejantent

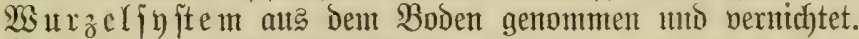

3. Man bepflanzt die betreffenden Qändereicn crit nach längerer 3eit mieder mit ben gefähroeten Bflanzen.

4. Man juche ben Boven Durdh Beigabe von gebrantent Siatt oder

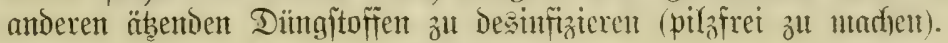

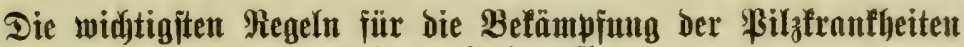 an unjeren Siulturpflanjen.}

1. Mian jorge Durd) gecignete Bfflege und Eruährung fïr eine

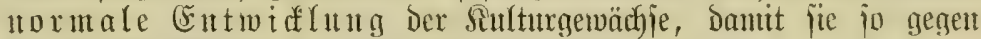

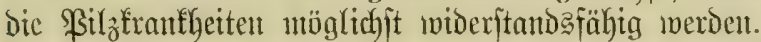

2. Man wähle mu fold c Formcu und Spielarten vou fultur= gewächfen, bie fich crfahrungagentän als wiberitandefähig (im mun) gegen Pilgtrantheiten erwiejen haben.

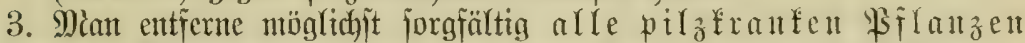
und $B f C a n z e n t c i l e, ~ i n v e n$ man jie berbrent oder ticf unter= gräbt ober interpflügt.

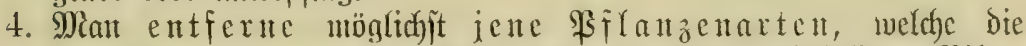

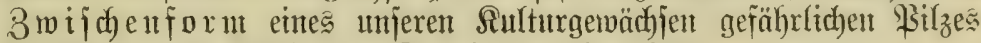
beherbergen, fo Serberibe, Srenzont uno andere.

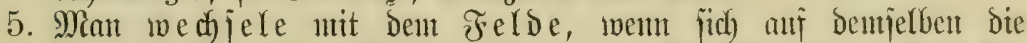
Daueriporen ober bie Danctmucelien eines Siranfycitaptges enter be= itimmten Pflamzenart angejanmtelt haben.

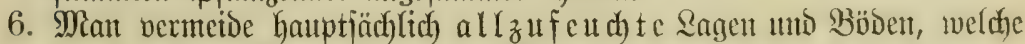
für die Entwidflung bejtinmter ßilze bejonder gecignet find.

7. Man vermetse nöglidfjt alle $\mathfrak{B}$ erwundu gen, weldye Bilztrant= Geiten beranlajien; entiftandene $\mathfrak{B u n v e n}$ verjehe utan jofort mit cintent pilzmibrigent (antijeptijhent) Beridhluffe.

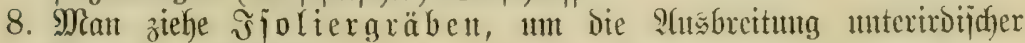
$\mathrm{Bil}_{z}$ zu verfindern.

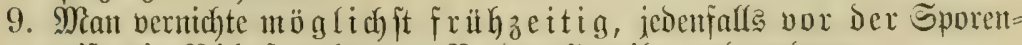

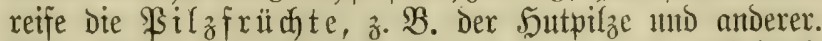

10. Man befreie (fiterififiere) Das Saatgut von den ankaftenden Eporen von Sranflyeitspilzen burd $\mathfrak{B} e i z e n$. 
11. Mian bejpritbe redutzeitig und voridriftamäbig bie gegen

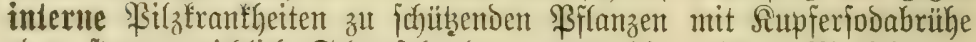

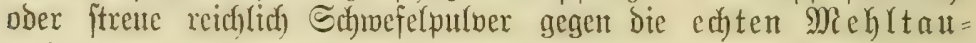
arten.

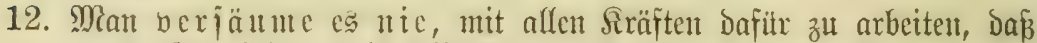
ganze Gentinden und Dijtrifte gleidyntäßjig mo jorgfältig Dic er= forberlidfen Befämpf̃unģarbeiten vornehmen.

\section{Spftematifhe z̈lberficht der wichtigiten Schmarokser= pilje der Kulturgewächie.}

\section{Brommat Die Fdı̨leimprilge (Myxomyceten)}

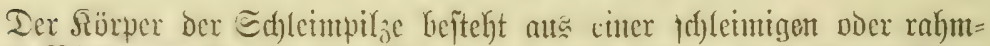

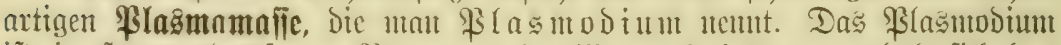

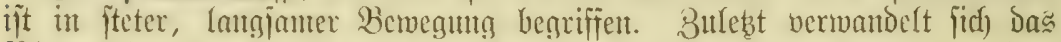

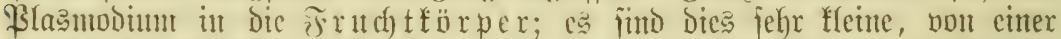

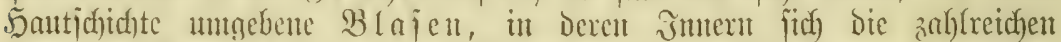
Sporen bilden. Iic feimenden Sporen erzcungen Sthroürmzellen, Die

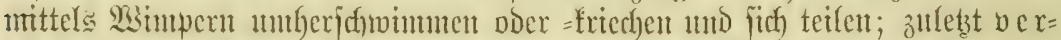

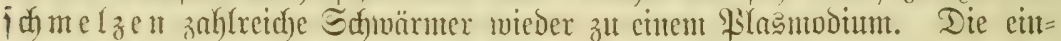
zige fdymarotzente $\mathfrak{A}$ rt biejer \$ilzgruppe ift:

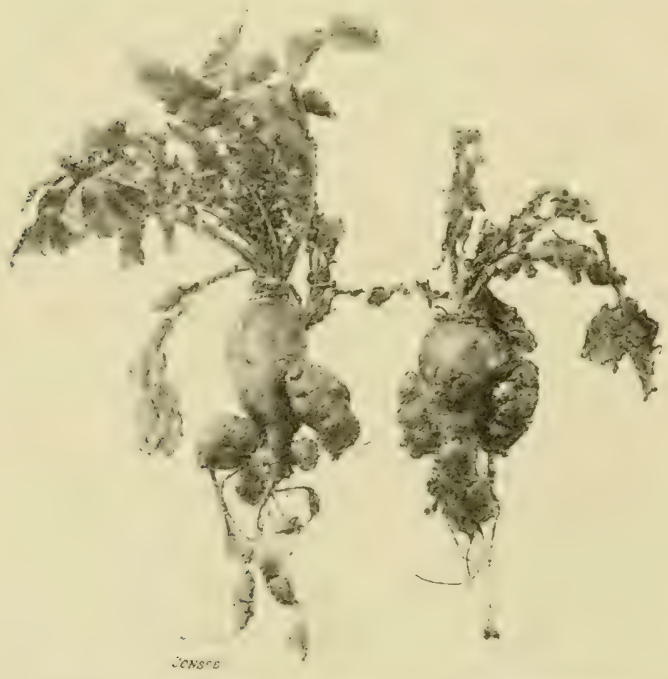

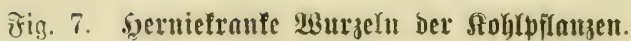

Die Sernie ndex firopffrattheit ber fioflitilanzen (Plasmodiophora Brassicae). Dą $\mathfrak{B}$ lasmodium diejes \$itzzes lebt in gröperen Bellen der Wurzeln uno zerfällt zule bst in eine jebr groß̧e 2 (nzahl bon Sporen, melche die be= treffenden Bellent erfitllen. Die Siranfheit ift erfennt= (idi) an erbjen = bis

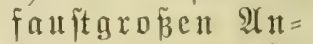
fかwellungen der Wurzeln ber verjdjie= denen Rohl=, Rübent= und Ritbjenarten, ebenjo an Den Murzeln Der Seotojen und jelbit der

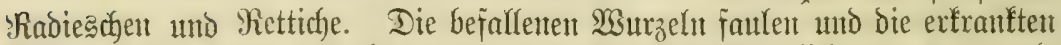
Pffamzen fterben cutweder ganz ab oder entwidfeln fidc) wur mangel= 
haft. Beim Berfaulen werben bie Sporen frei; aus ifnen jülüpfen im nädjten Jahre amöbenartige Schwärmer aus, weldye in bie $\mathfrak{B u r z e l n ~ b e r ~}$

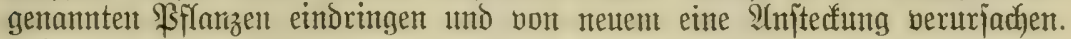
(Fig. 7.)

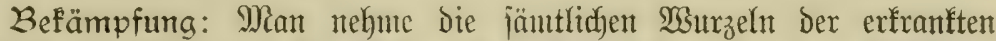
\$Sflamzen jorgfältig aus der Frob und verbrente fie ober man verbringe

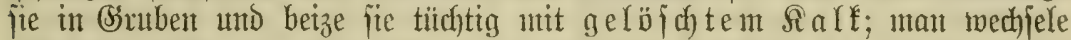
nit dent Ranoc und unterlafie es, einige Sahre bindurd) mit Den genannten Rulturpflanzen die verjeudftent F̌elder zu bebauten. Die Saatbeete, in welchen bie Seblinge von Sioblartent $2 x$. Kerantgezogen werben, Dürfen nie ver=

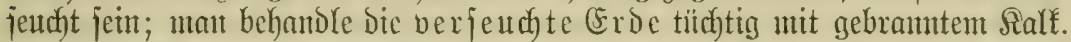

Alnmerfung. Die Rohlhernie barf nicht mit Dem Relch, welcher burch eine Räfertarne hervorgebracht wirb, verwechjelt werben.

\section{Drimmu: Die Gpaltpiltye (Schizomyceten).:}

Die ভsaltpilze, häuffig audd Bafterient genamt, find cinzellige,

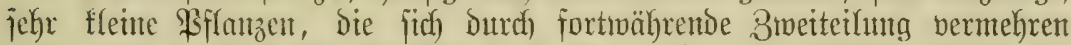

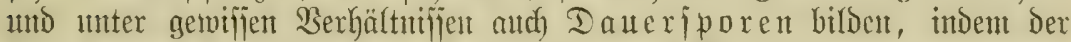

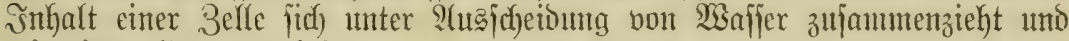
mit einer Şaut imtgiebt.

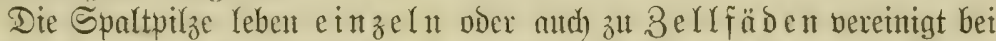
Gregenwart bon viel Frlüfifigfeit in lebenoent ober toten Drganizmen, in

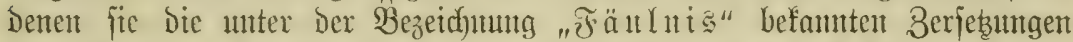

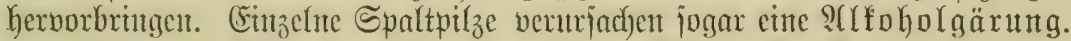

Dic bout Epaltpilzent herborgerufenen Biflanzenfrautfeiten find bon untergeorbueter Bedeutung, währent die Spaltpilzfranfheiten ber

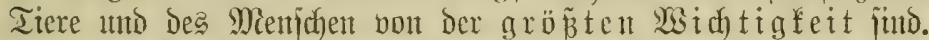

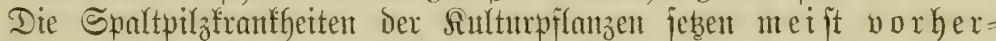

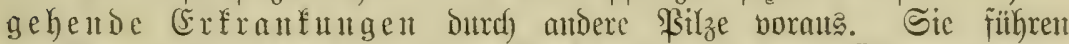

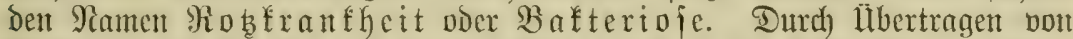
Bafterien bon frantent auf gejunbe Bfflanzen fanm die Erffrantung gejunder GSemädjie herbeigefiufyrt merden.

Folgende Bafterientrantfheitent jeien erwähnt:

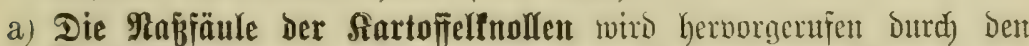
Butteriäurepiry (Clostridium butyricum), meldyer ïberafl, bejonbers aud) int Boden, japrophytifd lebt. Durd) Den Rartofffelpilz (Phytophthora infestans) erfrantfte Sinollen werben häulfig von bem

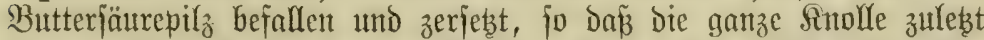

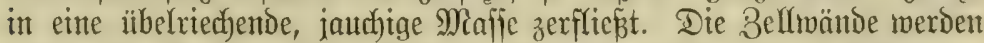

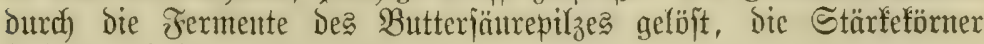
bleiben erfhalten.

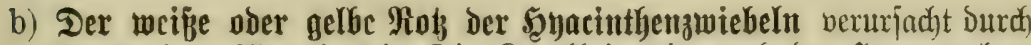
Bacterium Hyacinthi. Die Rranffeit tritt nad) Der Seraustahme

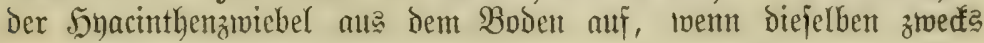




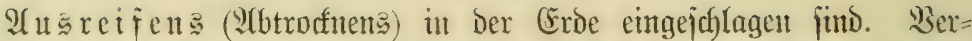

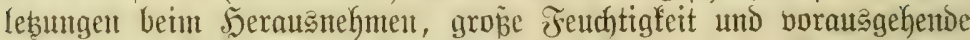

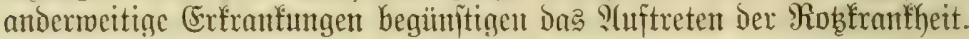

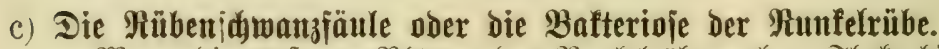

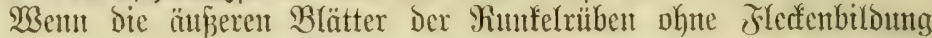
gelb meroen utno abtrodtuen, währeno die Serzblätter noch gejund

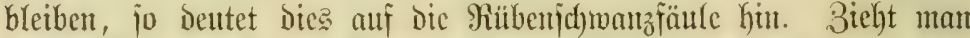
joldye Shiiben aus dem Boben, jo crmeijt fith bie 5auptwarzel

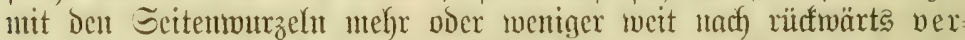

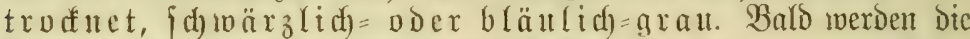
Wurzeln nod) junger, bafd älterer \$fflanzen befallen, oft verfault bie

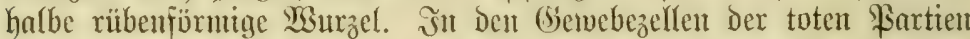

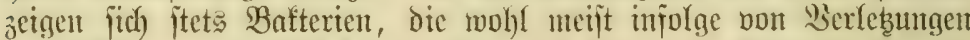

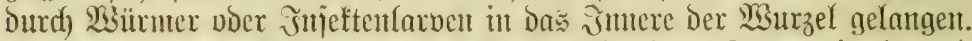

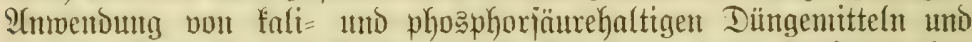

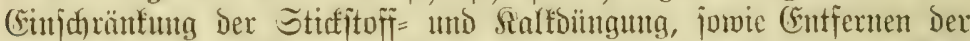

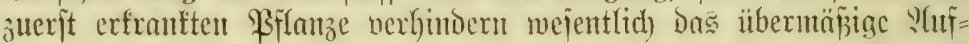
treten biejer Sirmifheit.

d) Der Sifnrĩ ber Siartofifelfnollen.

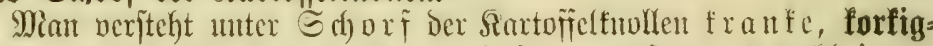
fruitige, Gald flache, bald verticfte, größzere oder fleinere Stellen der Rartoficlidalc. Die cinzehte Snolle fam eine

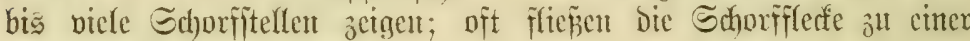
gröperen Rutute zu[ammen.

Mant unterïcheidet folgende Forment:

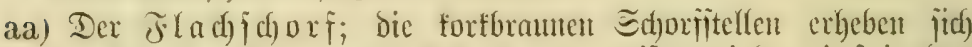

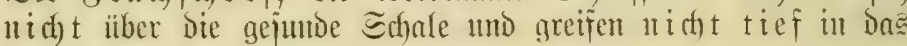
Fleijd) Der Fntlle ein.

bb) Der Iiefid) orf. Das (jemebe fitrbt oft melyr noer wentiger ticf (in das siartoffelflerijh) limein ab utto es entitehen lod)= förmige Bertiejutgen.

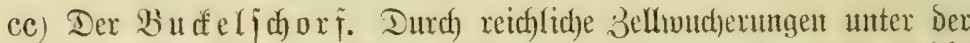
crfrantten Siartie entitehen beträd)tliche (Getwebemucherungen, iveldae etroas bu defelartig über bie Sortjuldale emporragen.

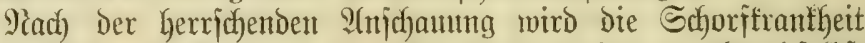
Dutch Bo Denbafterien bewirft. Dod merben mandmal jelbjt ein Fabenpilz, "Oospora scabies" uno eit Shleimpit?, "Spongospora Solani" als Edjorjerreger angejehen.

Éegenmittel jind: Wedjel mit Dem Adterland, Bermetoung ge= mergelter Böben unt joldher ïlfer, it denen jchorffrante fiartoffelt erzielt murben. Düngung mit gebrauntem fialf und mit Thomasjach)lacte (4 Bentner

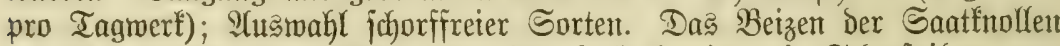
vor bem Setzen hilft nichta, ment doa Feld bereits mit Schoripilzen ver=

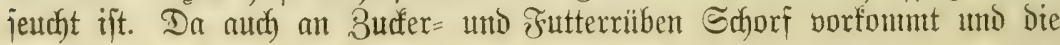




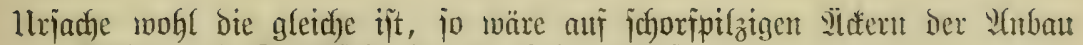

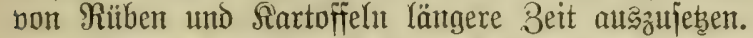

Meniger michtige $\mathfrak{B}$ afterientrantheiten find mahrichein(id):

1. Der Roj Der Speijezwiebeln;

2. Die rojenroten Meizenföruer; regelmäp̃ig ausgebíloete aber rojent=

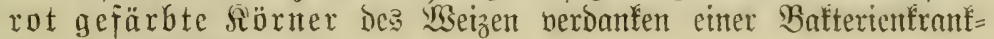
heit ihre Entitehung;

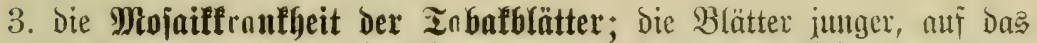
Jero verpflanzter Tabafpflanzen finto belf= und Sunfelgriin gerärbt.

Die Befämpfung Der Bafterientranffeiten berutht int mejentlictent darauj,

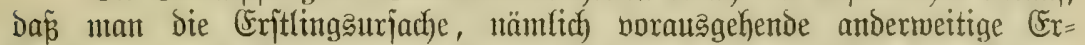

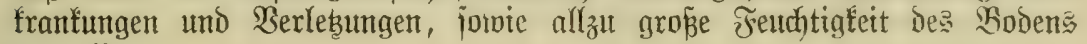
vermeidot.

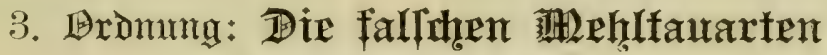 (Peronosporaceen),}

Die Hexpupiporacen oder falfden Miebltauaten jüb

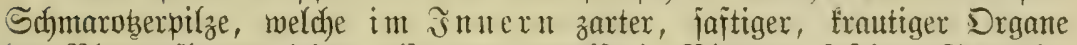
Der Błütempflanzen leben, aljo vorzutgeneije in Blättern, jaftigen Stengeln, Früd)ten; Dodh befallen jie atth Rnollent.

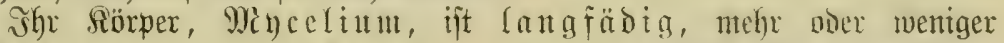
reidyerzweigt, aber ofue Sllerwände, mitfin aljo einzelfig;

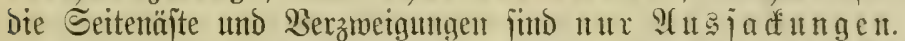

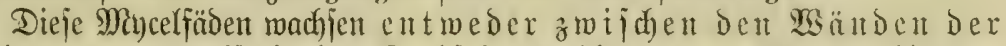

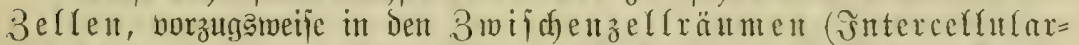

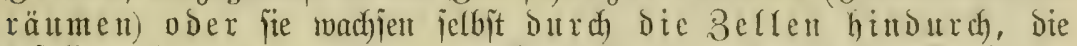

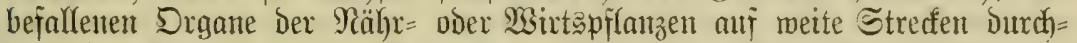

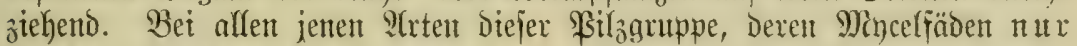

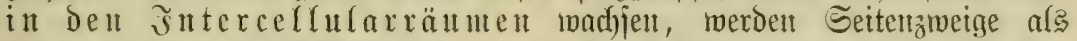
Saugfäben, Sgautorien gentant, Durch Die MSandungen ber Beflen hin=

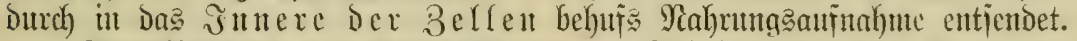

Jortpflanzung Der Beronoiporacen. Bei Dent meiften 2 itent at?

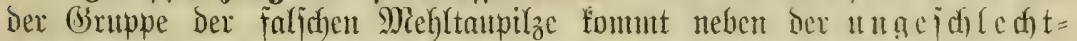
lichen aud nodh eine gefolded)triche Fortpflansung vor.

1. Die ungejdededtlidje Bermelyrung ber Beronoiporaceen bejteft in Der Billoung bon Sporen - wegen ihrer eigenartigen Siemung fonidien genannt - an bent Enden won beitimmten Mincelfädent. (J̌ig. 8.) Die reifen fonioien fund jogleidh teimfähig; dic fiontioten temen aur âteierlei Weije, nämlich: cntweber bie Spore treibt umittelbar

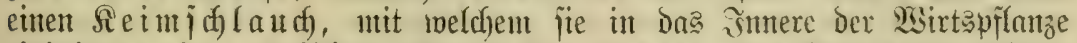

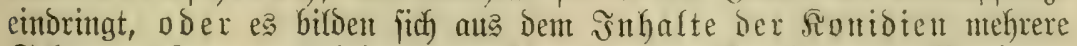

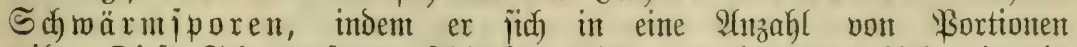

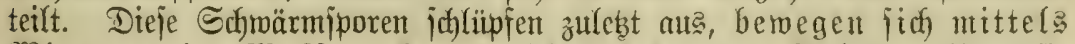
Wimpern im $\mathfrak{B a f i e r , ~ f o m m e n ~ j e o n d ~ j p a ̈ t e r ~ z u m ~ F u t h e , ~ m a d b e n t ~ f i e ~}$ 


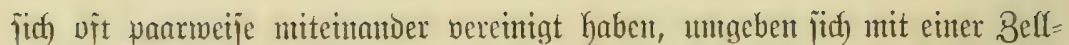
mand und treiben ntadher die in bas snntere ber Pflanzen eindringendent Reimjớläud)e.

Die Sonidien meroen an nteijt verzweigten Mincelfäben, tweldhe meiĩt büjdelseife aus ben Spaltöffungen ber Blattunterjeite oder an Den Stengeln herborbredben, einzelu, ober jeltener reibenweije

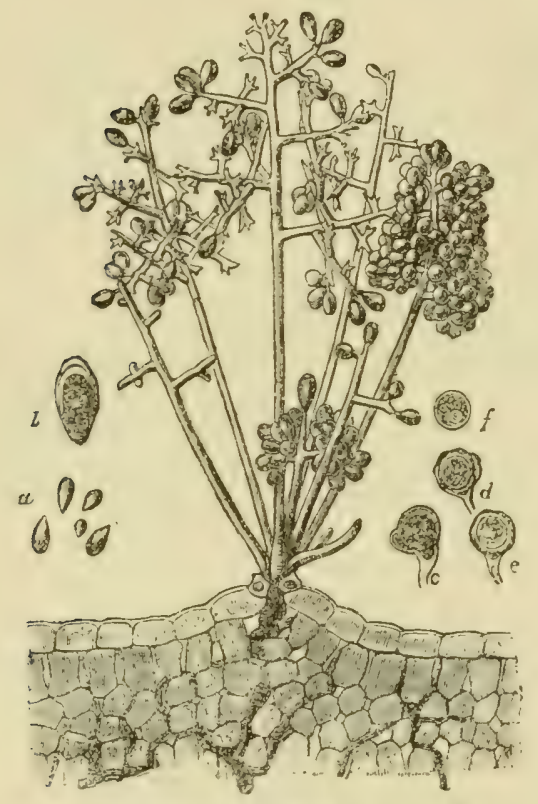

Fig. 8. fontoienbilbung an den Fruditt= hophen Der Peronojporaceen.

$a$ abgefallene fonibien, $b$ eine stonibie bergrößzert, $c$ u. $d$ Dogonien mit anlegenden Prtheribien, eir reifes Sogonien mit + Eifpore. abgeidniirt. Die fontibientragenden Mincelfäben itellen einen weifien bis grauen, jeltener jobady= biolett oder jomutiggran gefärbten, bals roderen, bald bid)ten Shim me lüberzug bar.

2. Die geidjledjtlidje Frort= pilanzung, tweldhe fait bei allent Qrten vortommut, wollziebt fich in Der Weife, dapj fing im Jntueru ber Nähroffanzen an Mincel die weiblidbent uto männlichen (S) foldedtaorgane bilden.

Die weiblidgen Drgane, Dogonien genannt, fint futgelig angeid)wollene, infaltareidye uno burdy eime Sdjeidemand abgegrenzte 3rueigenton bes Mincels und ent= halten int snttern eine groß̉e Eizelle. Die männlidjen $D r=$ gaue, $\mathfrak{A}$ ntheribien genant, find ebentialle Dutrd) cinc Duerwamo abgeid)nürte, etrwas feultig ber= bicfte Mincelfabenentoen, weld)e iid) ftets itt Der $\mathfrak{R}$ ähe der $\mathrm{D}_{\mathrm{D}}=$ gontien bilon, an bicjelben $i \mathrm{i}$ d) anle gen, nit citem idsuabelartigen Fortjab Die Mand Des Dogonium?

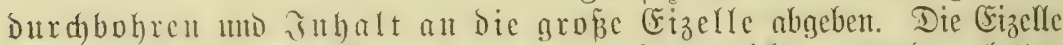
umgiebt fich alsoam erît nit einer zarten, jpäter Didfen, entweder glatten

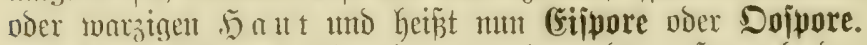

Dicje Criporen überwintert und werben erjt nad) Der Bjerwejum

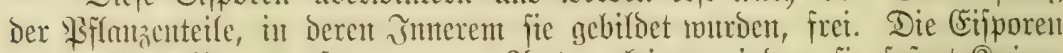
Der meiften Yicronofporaceen=\{

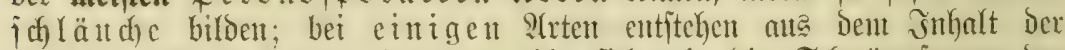

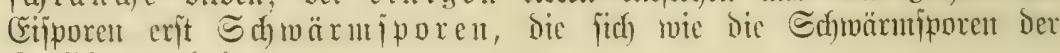
Ronitien berhalten.

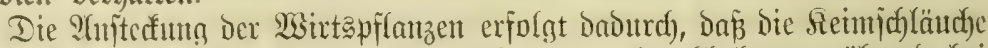

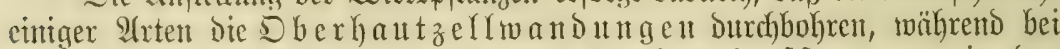

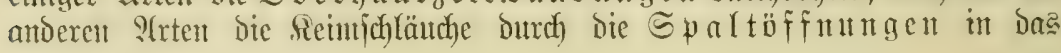




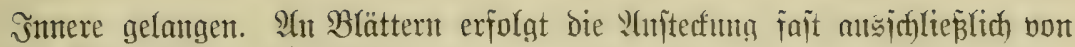
Der $\mathfrak{B}$ lattoberieite aus.

Bei jenen Slrten, bei weldhen teine Gijporen gefildet werben, iiberwintert das Mincel.

(Erfenmung und Sdjaden Der faljdjen Mefjltauarten. Esinge Irten

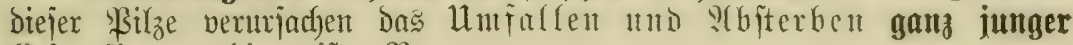
fieimpflanzen; bie meijten łerond= iporaceen geben fich dem unbemaffi=

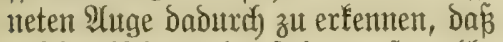
auf der $\mathfrak{B l a t t o b e r j e i t e ~ e x i t ~ g e l b = ~}$ liche, blajfe olederen entitehen; an biejen Stellen beobachtet man auf Der Blattunterieite oder an Stengeln etwas exhabene, $a b=$ wijabbare, meift ziemlidy bidnt=

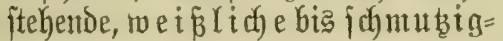
graue oder fdradiolette Sdimmelrajen, weldje bon Den aน马 Den Spaltoffnungen heroorgetvadje= nen, fontoien tragenden MincelfäDent, ich) (echtweg fonidienträger genannt, gebildet werden. Die erfrantten Stelfen werben ipäter braun, trofftent ab, ober faulen bei naffem Wetter; meift gehen bie Blätter uno bäufig die ganzen Bflanzenzu Sírunde. Bein ,weif̧en $\Re$ o ft", Cystopus, fino die glänzend tweipen, bidyten fonidient = lager anfänglich bon ber $D$ ber $=$ haut der Wirtspflanzen bede det.

Der Sdjaben, Den bie ber= idjedenen \$eronojporaceen an unje= ren Rutturpflanzen, bejonders in nafjen, regentreichen Sommern ber= uriad)en, ift oft ein a úperorbent= (id) grofer.

Befämpfungs: und $\mathfrak{D o r}=$ beugunasmittel: গiäfie und Feud $t i g$ fe it begüntigen in jebr hokem Sirabe das 2 uftreten Des jarifuen Meryltaues, baher tritt er in regenreidyen כahrgängen

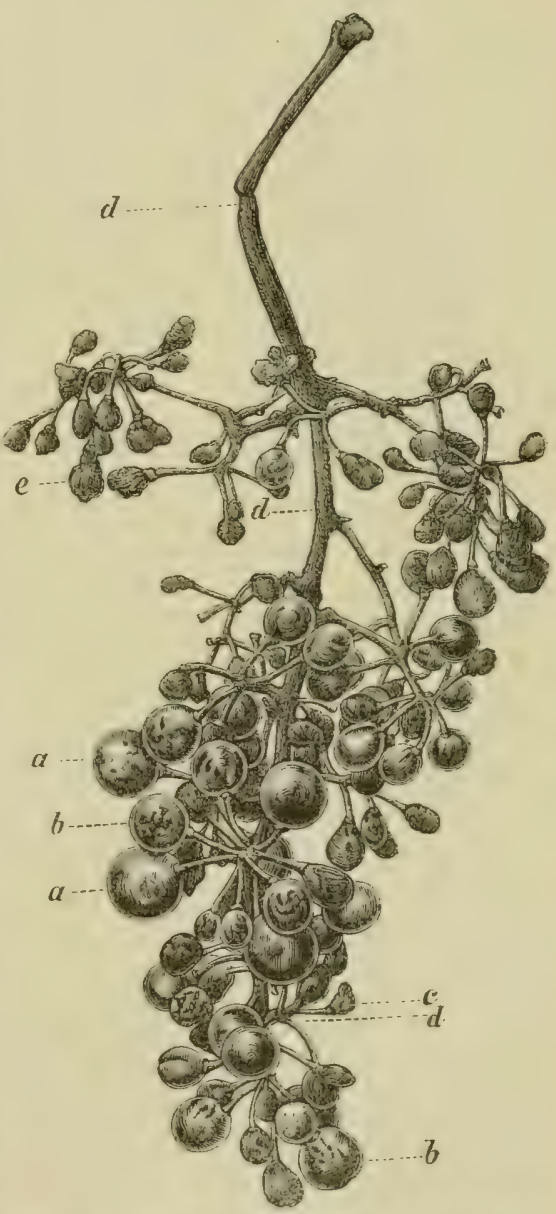

Fig. 9. \$om falidien ग)(ehlltau vernidytete Iraube. am berberblichiten auf. Mian ber=

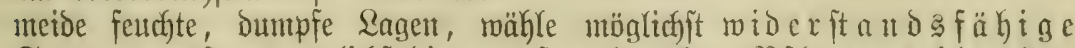
Sorten, entferne möglichit die zuerit erfranten Bffanzenteile oder 


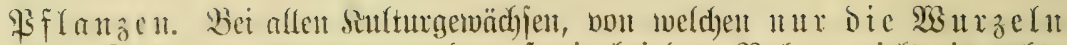

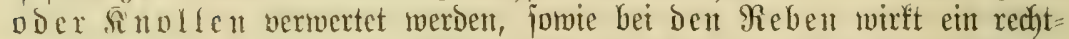
zeitige unt wieberholtes, jorgfältiges $\mathfrak{B}$ ejpriben mit cinten ber frither ant= gegebenen supferpräparate. Die fïr bic cinzelnen firtturpflanzen ge=

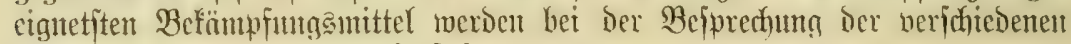
Beronoporaceen eigens anfgefülyrt.

\section{Einteilung Dejr Dromung.}

A. Dic Sintibient bilben fich im Innern Der Mirts= pfla abgejtorbenen \&fflanzenteile frei. Sicimliuggtöter, Pythieen.

B. Dic Stontidien bitsen fich reilgenseife (fettenförmig)

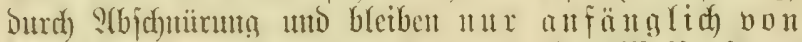
De 2 berkaut Der Mirtapflanta bedeft. Beiproit, Albugineen.

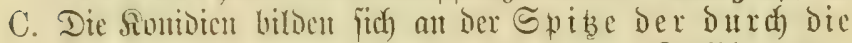

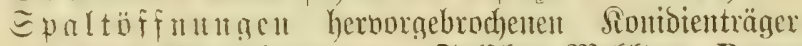

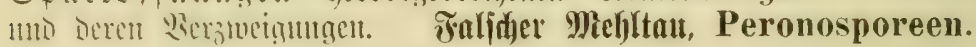

\section{Familix. \\ Div dicimlingstîter Pythieen.}

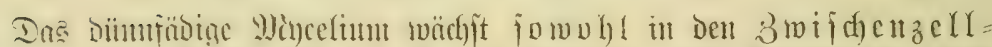

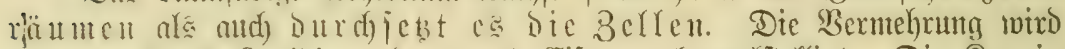

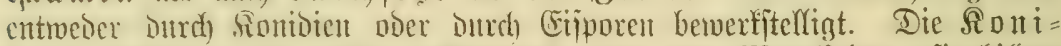

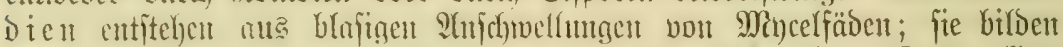

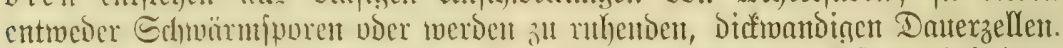

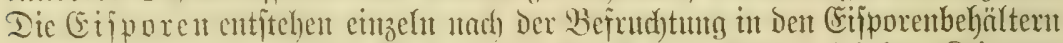

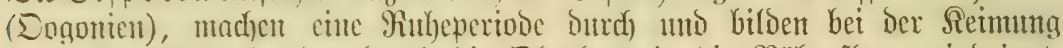

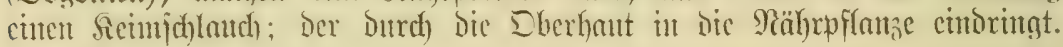

Wicktig ift:

Ier gemeiue fieimliugatöter (Pythium de Baryanum).

Diejer Barafit befällt bic erft wentige Tage alten Sicimpflänzd)ent

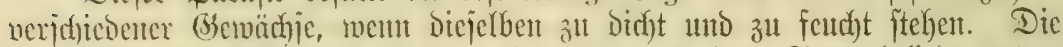
Seimpflänzonen betommen weid)e Eterlen an Dent Stengelgliedo unter= hatb ber lieimblätter, neigen jich, fallen um unto gehen zul Grumbe. Bon Pythium merden zahlreich) Sulturpflanzen, bejonders Srenzblütler befallen.

Befämpfung. Da Der Schäbling aud faprophytijd) (eben fann, iit eine unmittelbare Befümpfunt? nicht möglich; es handelt fid dabei um

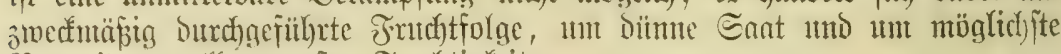
Bermeioung allz̆ groferer Feudtigfeit.

\section{Tamilix.}

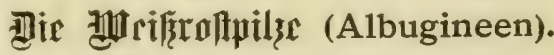

Das Mincelum Der Weifaroitarten wäd)fit zwijhen den Beffen und ent=

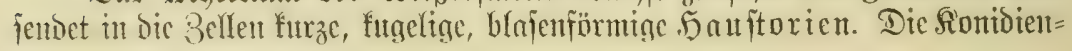




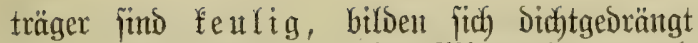
unter Der Dberhaut Der Wirtapflanzen und fdyüren die einzelnten fugeligen oder eiförmigen fonibien (Sporen) in fettenförmigen Reiben ab; in ifnen bitben fidh bei Der Reimung

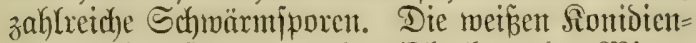
lagex find anfanga von ber Dberhaut ber $\mathfrak{W}$ irta $=$ pflanze besecft, fpäter reifft bie Dberbaut auf uno Die einzelnen, weipen fionibien werden entlaffen. Die marzigen, im Innern Dex $\mathfrak{W i r t a p f l a n z e ~ a m ~}$ Mincelium fid bildenden Dojporen überwintern

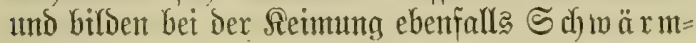
iporen.

Erfennung. Der Weiproft ît jebr reicht ant ben weípen oder gelblichmeifen, etwas her=

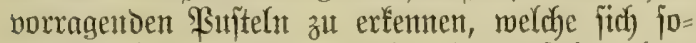
wohl auf ber Dber = twic Unterjeite ber Blättex, offt autch an ben frautigen Stengeln bilben, bie Dant Käufig anjobrwellen und fỉd frümmen. Starf befallente PFflanzen Keiden jebr erkeblidy.

B̉etämpfungànittel. Da die Dauer= fporen (Giex find es bie Eifporent) in Den Stengcln und Blättern überwintern, fo mur man Dieje forgfältig fammeln unto verbrennen; ebenjo

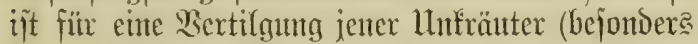

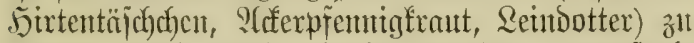
forgen, burch weldhe Dic Sulturpflanzen angejtedf twerden. B̉et WGurzelgetwächjen (Meerrettidch, Sdhwarzmurzel) fömten vorbeltgend jogar $\mathfrak{B} e=$ ipribungen mit Supferjodabrithe berwentoet mer= Den, nicht aber bei jolchen Gemädffen, deren oberirdifone Ieile gegeffen ober berfittert werden.

Dic midftigiten $\mathfrak{2}$ rten find:

\section{Der Meibroit ber freublïtler (Cystopus candidus).}

Befallen werden ber Meerrettid), Die

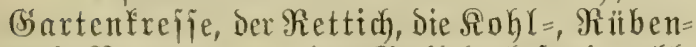

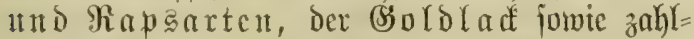
reich) Unfränter aus Der Fantilis Der Sireuzblütter.

\section{Der Meižroit ber Rompoîten (Cystopus Tragopogonis).}

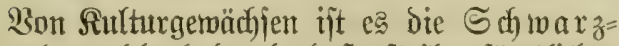

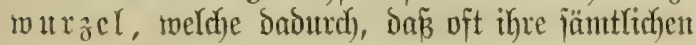

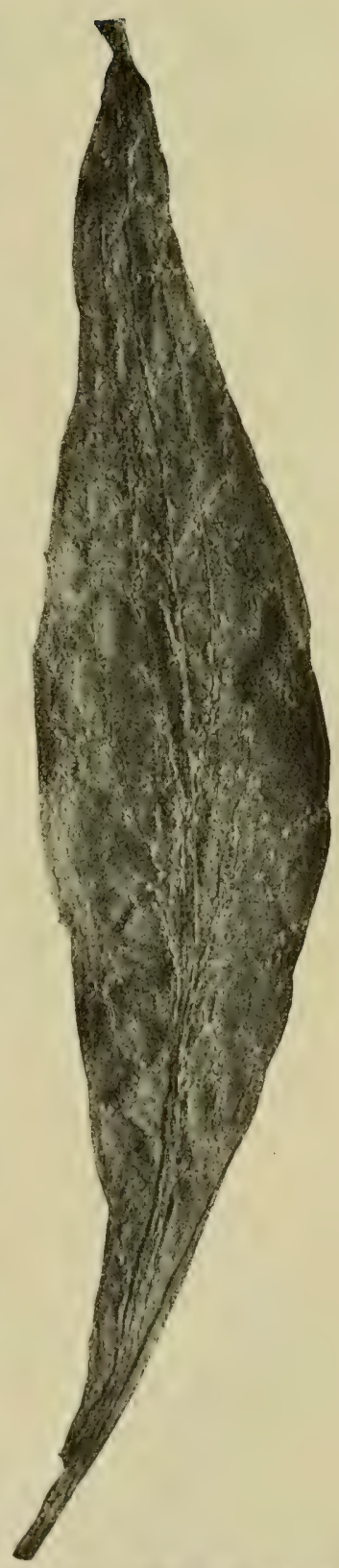

Fig. 10. Wheifruft all bell Blättern der Edjwarżmurzel. 


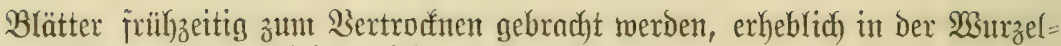
augbildoung beeinträchtigt miro. (J̧ig. 10).

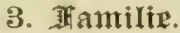

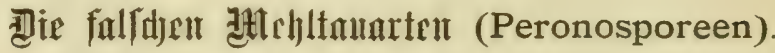

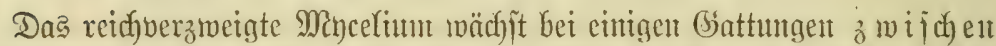

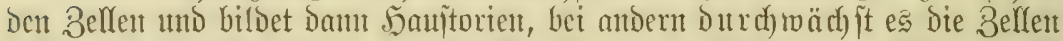
jelbit ohne Sauftorienbildoung. Iie Sionibienträger (Bafitoien).wad)jen zumeift

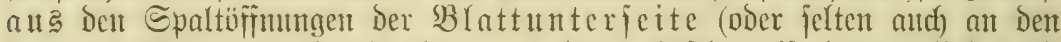

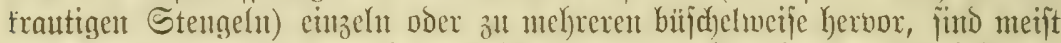

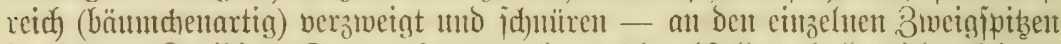
je eine - Sionibien (Eommeriporent) ab, weldye abfallen, bald wieder feimen

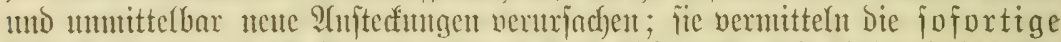

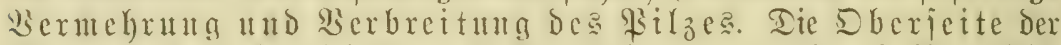

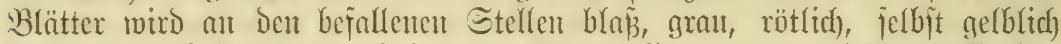
bis weif, auf Der lluterjeite Der Blätter jieht man an Den betreffenden

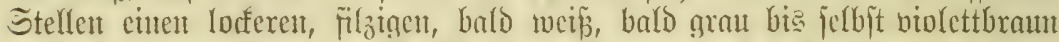
nefärbten abwijeb baren Ŝf

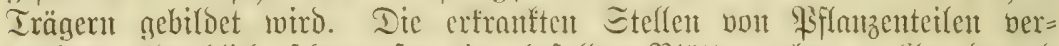

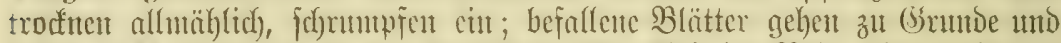
Fallen nidyt felten $a b$, jo bei Der Blattfalltrantheit Der Pebe, oder berdorrent mit jant den Stengelut (bei Sintoffelpflanzen) und verfaulen jogar bei

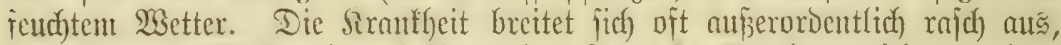
jo Daf3 ganze Flächen interhalf wentger Tage frant min vernichtet merden.

\section{überitd)t ber bsattungen.}

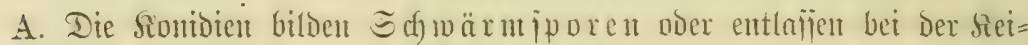
mung dent sththalt als (s)anzes.

1. Die fionidicuträger find bis zur Bitloum der erjten Sontobie einfad), fpäter meiter madbjeno uno fid berżveigento.

2. Die Rontotenträger fint vor Bifoung Der fiontioten

Phytophthora. jertiggebildet, berzmeigt, nidjt tweiterwadjjend, bie

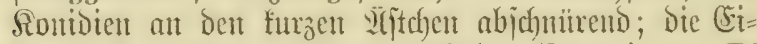
iporen liegen frei im Eifporentbehälter (Dogonium). Plasmopara.

B. Die Sontibien feimen mit einem $\Omega$ eim $j \mathfrak{d})(a$ ud .

1. Ronibien obne Reimnarze (Papille), an Der Seite ausfeimend.

2. Sionibien mit Retmuarze (Papille) an Der Spibe und burd dieje aủfeimend.

Peronospora.

Bremia.

\section{Sattung: Phytophthora.}

Dą reidjuerzmeigte Mnceliun wädyit jowoht zwijud en ben Belfen

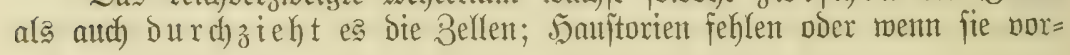




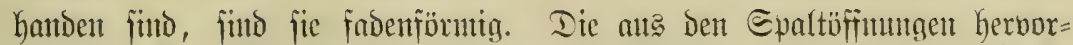
tretenden fiontoienträger find bis oult Silbung Der erjten Spore einfach, jpäter meiterwardjend und jparjan veržmeigt. Die zuerjt gebildoten Sontbien

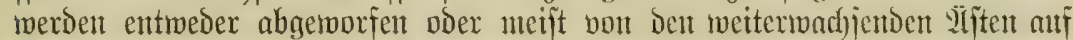

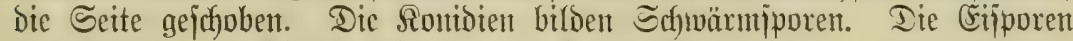

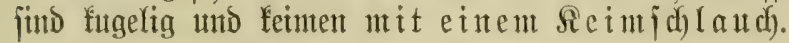

\section{a) Die Siartoffelfranflyeit (Phytophthora infestans).}

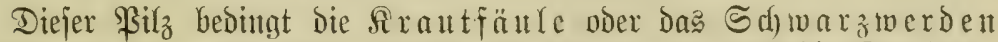

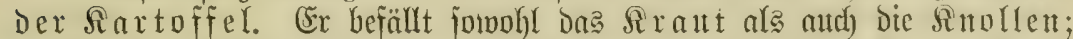
or tritt jebr hertig und weit verbreitet beiondere in uafjen Sommern anf. Bon Mitte Juni ab bereit? zeigen fitch an einzelnen Blätt= d)ent bes Rartoffelfrautes brautte bis jobroärzlidye Fllectfden; die gebrätiltten Stelfen welfent und iterben alsubalo ab. 2Am Rambe der franfen Stellen beobachtet man bie Ronibienträger in Form eines graumeifinen Sdjimels. Bei regne= rijobem Wetter bejonder: nimmt bie $\mathfrak{A}(n z a \mathfrak{h})$ Der fronfen Stellent rajch) zit, autd) Blatt= fitiele ind Stengel merden befallen; das Siraut miro Dann inmerbalb mentiger Iage jofwarz; natürlich fönnen bie Sinollen ifre normale $\mathfrak{A} u$ s: bildung nid)t exlangen. (J̧ig. 11.)

Meift tritt auf Den श्âfern mit firautfäulle altर́t)

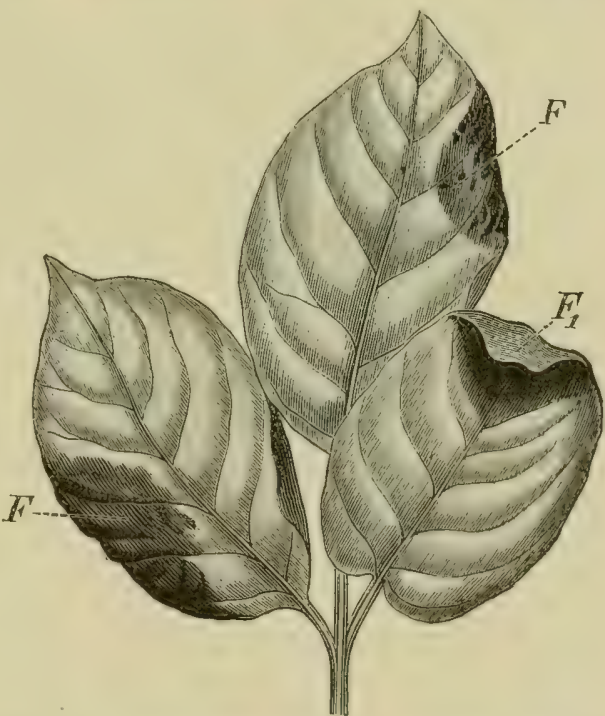

テ̛ig. 11. Sartoffielblatt utit tratfen Flerlen. $F^{\prime}$ u. $F_{1}$.

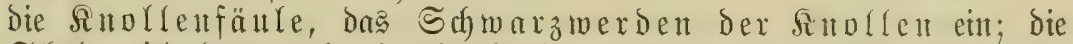
Sdyale wird braun und zeigt eingepunfene Stellen; das ficherite Beichen finto bie gebräunten bis $j$ d) wärzlichen Stellent un geringer Tiefe innerbalb Der Schale. Dieje "jd) warzen" Sartoffeln fömten längere Beit feit blciben, oft aber fauten fie fofon in ber Erise nod bor bom Scrats:

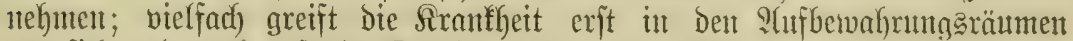
Int fich) und nod) gefunde Snollen merden angeitedt.

Das Minceltum zeritört bie in Bellen enthaltene Stärfe nicht; jubarze Siartoffelu lömten nod) in Der Bremterei (jelbit nod) als \$iehfutter) $\mathfrak{B e r}=$

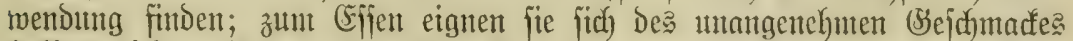

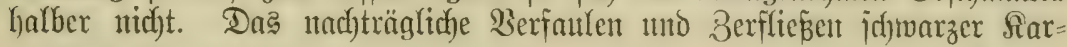




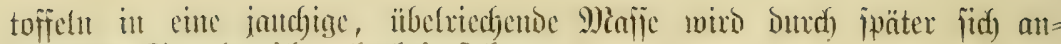
fiedelnde spaltpilze herbeigeführt.

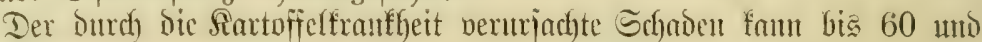
mehr ßrozent der ganzen finollenerute umfajfen.

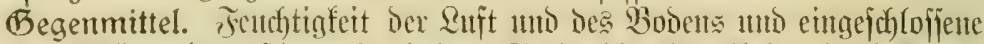
Rage Der Felder begüntigen in hobent Grobe bie siranffeit; in rodferem,

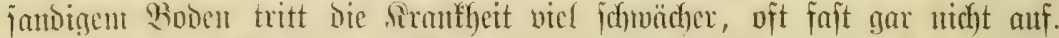

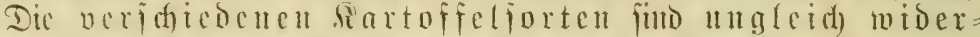

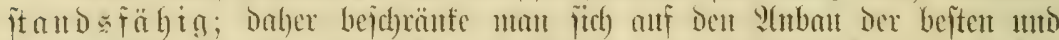
eraiebigiten w iderftandefähigen Sorten; man verwende feille franten

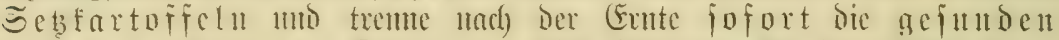

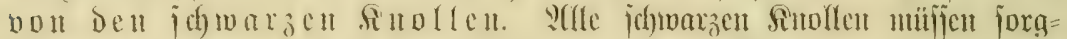

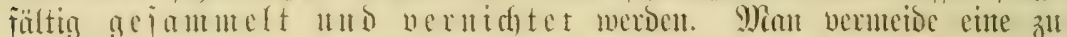

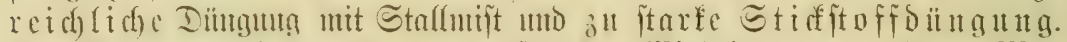

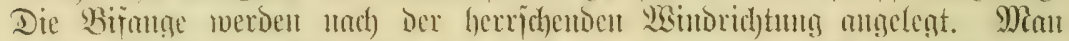

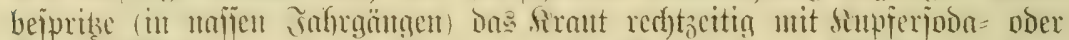

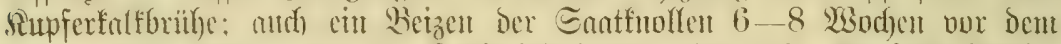

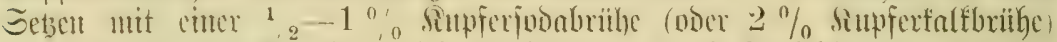

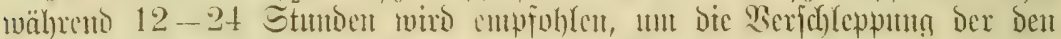

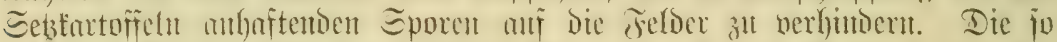

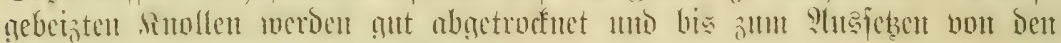
nicht gebeizten getrenut aufberwahes.

b) Der Sieiuliugatöter Der \$golzgewädje (Phytophthora omnivora).

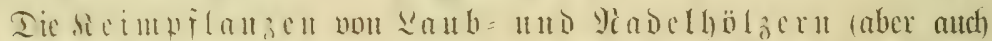

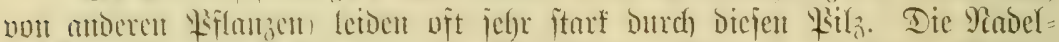

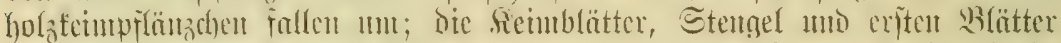

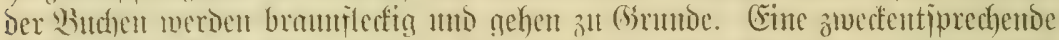

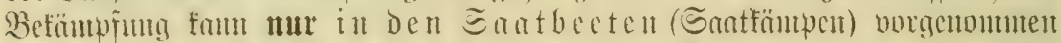

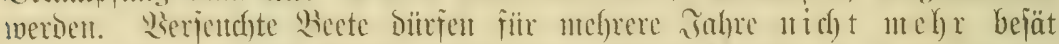

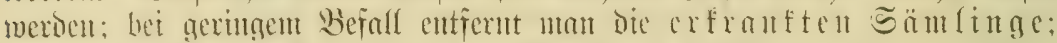

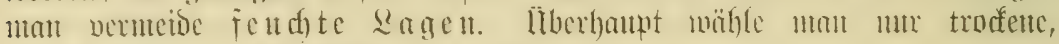

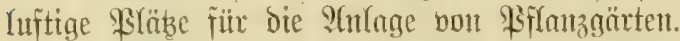

\section{Battutg: Plasmopara.}

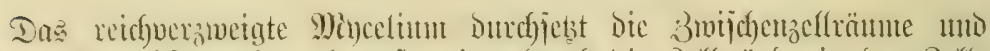

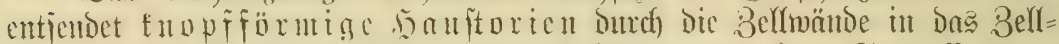

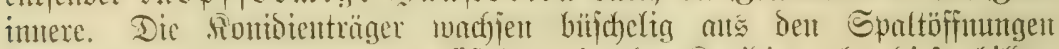

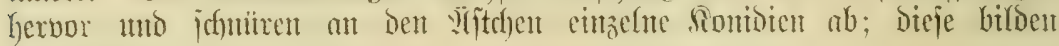
Sđjwärmiporen.

Die midftigiten ?trten jind:

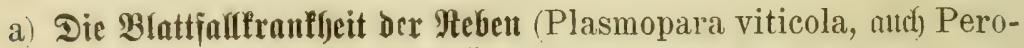
nospora viticola genaunt).

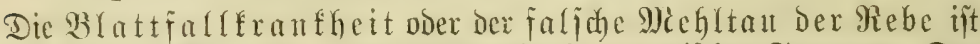

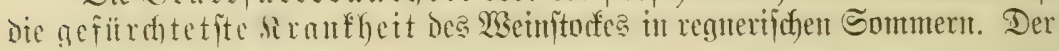


Płilz, weldher bereita im Jumi nuftreten faun, befällt nidjt nur bie Blätter, weldhe oberjeits erit gelbliche, jpäter bräunliche, bald bertrodfnende Flecten bilden, auf Denen fich an ber $\mathfrak{B}$ rattunterjeite bald fleme, bald fait bie

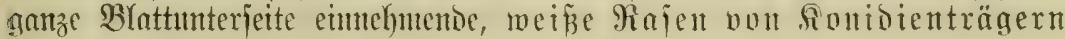

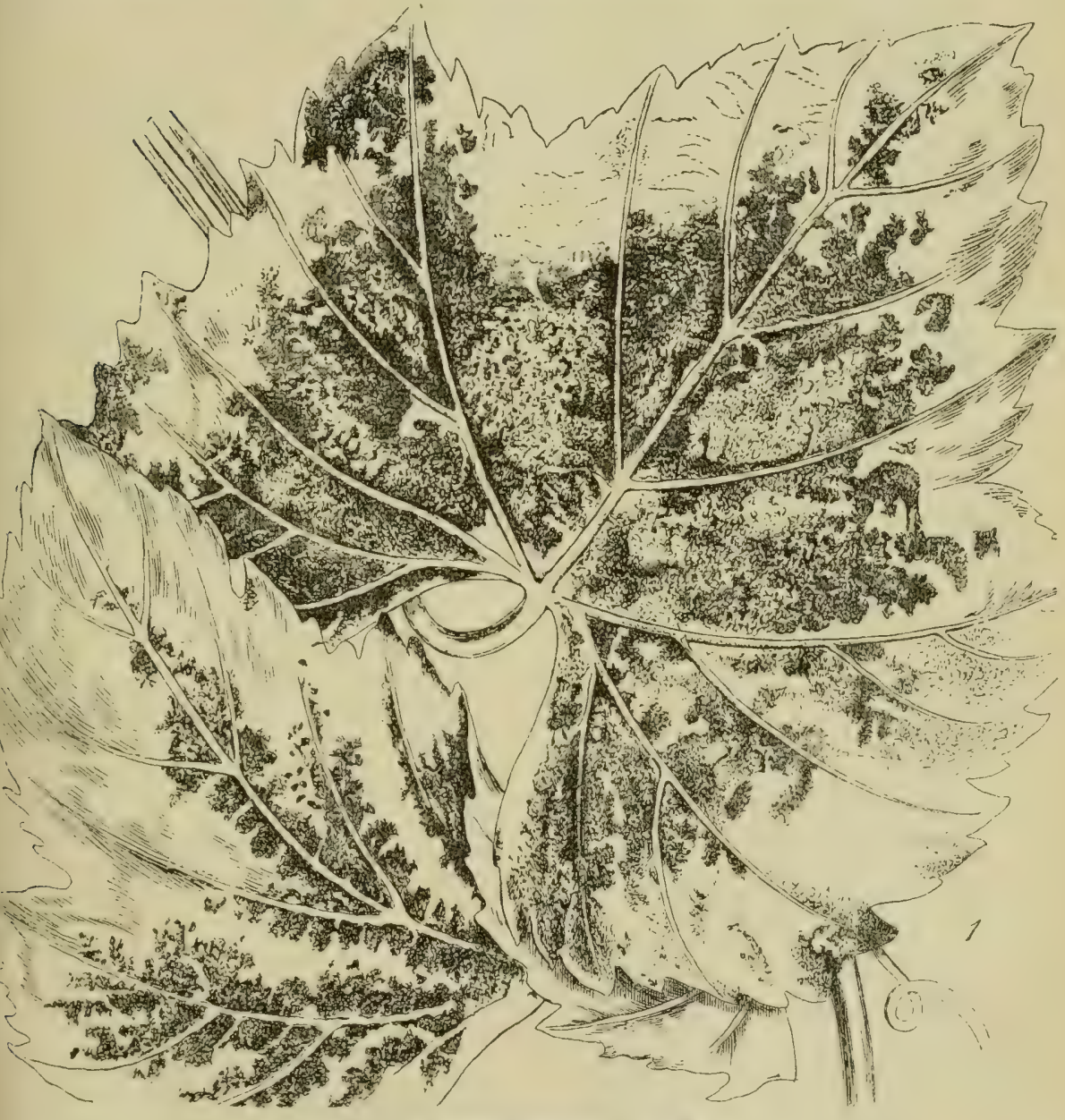

Fig. 12. BInttiallfrnntheit ber :tebe.

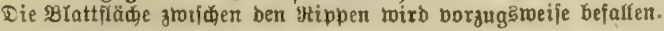

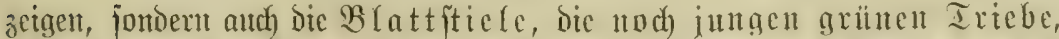
jelbjt dic Kanfen, Iraubenticle, Blüten uno Beeren. Die

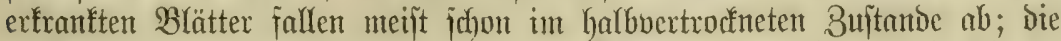

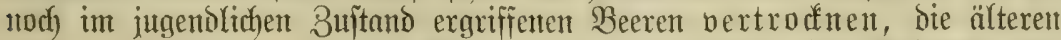

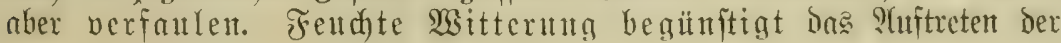


Srantheit, währeno Irocfenheit biejelbe fait gänglid) verhindert; junge

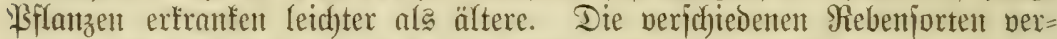
halten jidf verid)ieden, D. h. die eitten fint mehr, altoere menig oder gar nidht twideritandsfähig. (Jig. 12.)

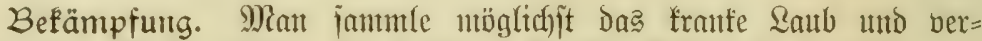

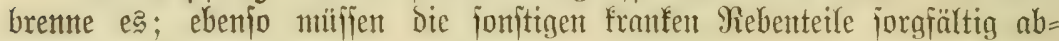
gefochnitten und berbrant werden.

2(le beftes Befämpfungamittel hat jitch ein red)tzcitiges unt jorg=

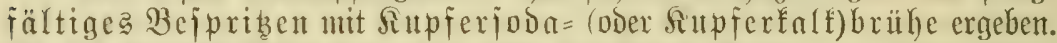

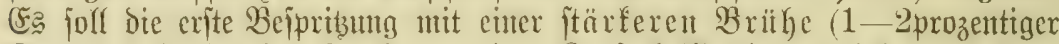
Supferjobabrithe oder 3-4prozentiger Supferfalfbriibe) gleidh tiad) be m Sd) titt borgenommen werden; mit einer $1 / 2$ prozentigen Supferjoda= briifye bejpribt mant bic jungen Blätter und Iriebe jodan bor Der Blïten=

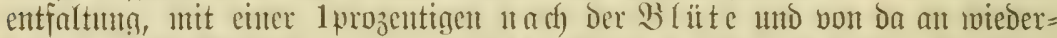

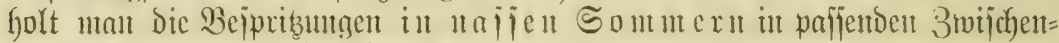
räunten bis etiva Ende Sarguit.

b) Der falidje Mellyltau ber Doldenblütler (Pl. vivea).

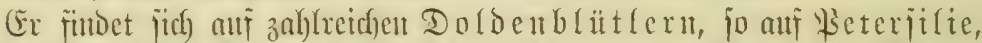

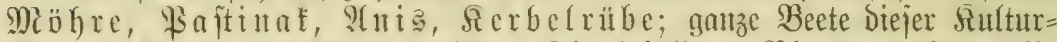
pfilanzen föment bernichtet merben. Die bejallenen Blätter werden gelb=

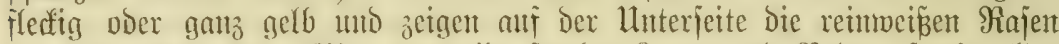
won Sporenträgent. Mant vernteioe fentd)te Ragen unt Böbent, jomie allzut

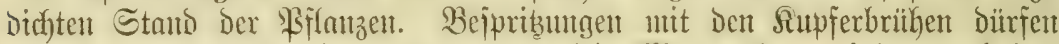

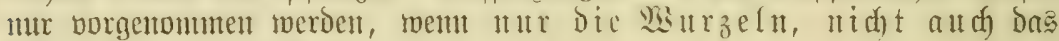
Sraut $\mathfrak{B}$ ermentumg finden.

\section{Grattung: Peronospora.}

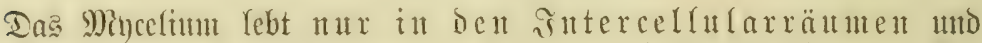
jendet funpfförmige bis reidfwerzmeigte Sauftorien in bas Belfintere. Die

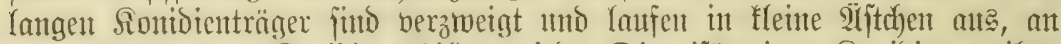
Deren Spiłe ie 1 Sinnibie gebilDet wiro. Die eiförmigen Sontoient treibent

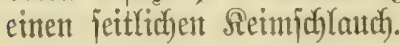

Die svidytigiten 2 rten biejer Gattung fund:

a) Der falidje Mieflytau Der Sreuzblütler (P. parasitica) auĩ Delt allermeiften Siretzblittlent; twird bejonders ichäblich, went ex at

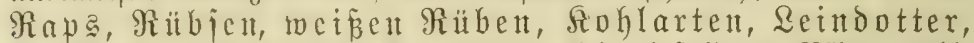
Levtojen uno Brold la df auftritt. Die befallenent Bffanzenteile

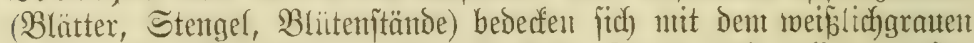

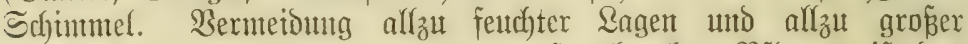
jeudjtigfeit, jowie Entfermuttg Der zuerjt erfranften Pflanzen ijt Das bejte Mittel zun Befämpfung.

b) Der Bwiebelidiunmel (P. Schleidenii), an dent Blättern unt Stengelı Der Speijezmiebelı (Allium Cepa und All. fistulosum und anderer Intdjarten); ganze Beete merben befallen und fterbent rajd ab. 
Sd)inntel überzieht fic. Das bejte Borbengungamittel bejteht in der Wak)l eines recht luftigen, fonnigen Stanoortes; ein Bep̧täuben mit Sabmefel joll gute Dienjte geleijtet haben; ein Bejpriben mit Supfer= jobabriibe ift mu angezeigt, wem einzig bie 3 wiebel mo nicht audid B̧ätter und Stengel berwertet twerden.

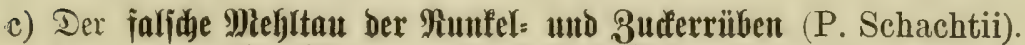

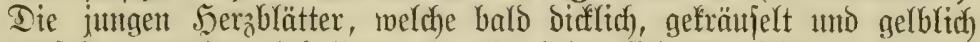
ausfeben, toerden befallen uno ïberziehen fich unterjeits mit einem

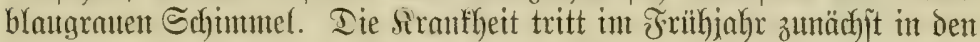
Santuriiben auf, Daher möge man bieje einer bejonderen $\mathfrak{B} e=$

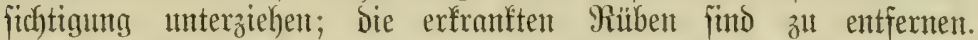

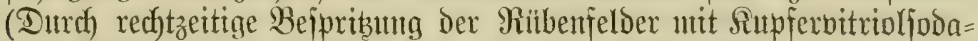

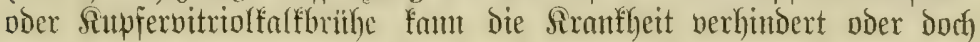
gehemut werden.)

d) Der Spinatidjumel (P. effusa). S3on Siutturpflanzen ift in reg= nerijchen Beiten Der Spint Der Siratfheit auggejest; bic erfranften Stellen des Blattes jund oberjeits gelblid), unterjeits mit einem graublaten Sdymmel bededt, jterbent bald ab und berfaulen. Ber=

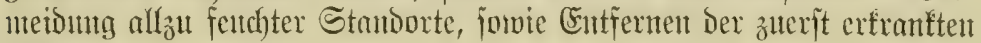
BSflanzen ifit anzuraten.

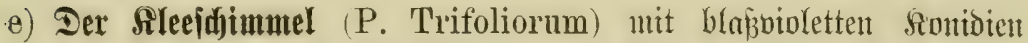
anf der llnterieite der Blätter von $\mathfrak{i} l e e=$, Steintlee = und Quzeruearten; Die befallenten Brlätter zeigen anf der Dberfeite

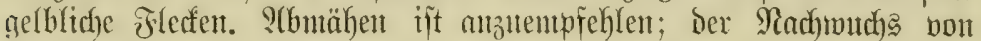
flee sviro bant frei bleiben.

f) Der Sarbenidjumel (P. Dipsaci) anf aflent grïnett Ietlent Dex Weberf ard e und anderer Dipjactsarten, bemirft cine Berfïnmerumg Der Pflanze. Die lïberwinterung exfolgt nuf den żur litberwinterumg

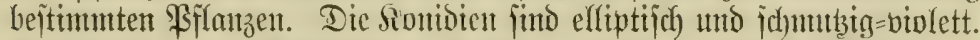
(5) fömen ganze Simidenfelder befallen weroen, wobei die fioppe ver= Derben. Borbengent joll mit Supfernitrioljodabrïhe bejprizet soerden.

g) Der Mtofuidimmel (P. arborescens) anf Miohnarten, jo be= jonder an den jungen Bflanzen bes Bartennohnes (Papaver somniferum), mit fugeligen, faft farblofen fionibient.

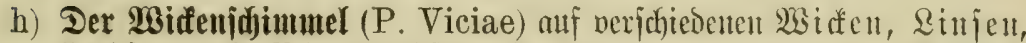
Erbjen uno Blatterbien, jo Lathyrus silvestrer. Rontoien

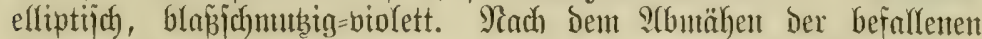

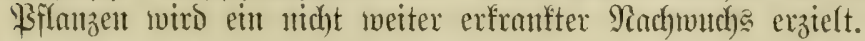

i) Der Rojenidjimmel (P. sparsa) auf Den Blätten ber fłtltioierten Rojen, braute Fledfen auf Der Dberjeite unt einen zarten grauen

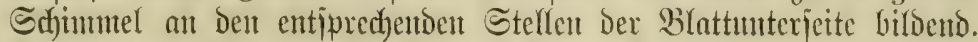

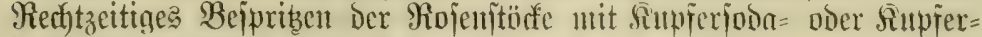
falfbriilye verfindert do âs aftreten. 


\section{Gattung: Bremia.}

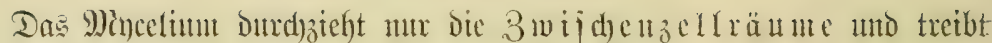
von Da Samitorien in bas Bellimtere. Die Sinntotenträger füto an ber

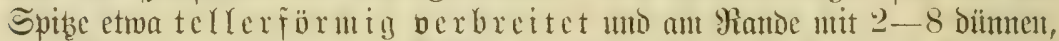

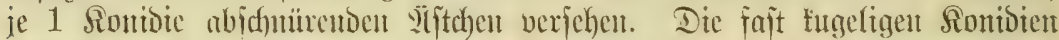

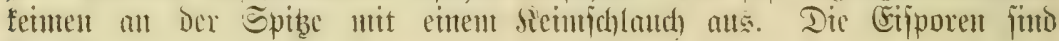
fugelig.

Der fulfide Mieljtau Deß Salatę (Bremia Lactucae). Whgejehen

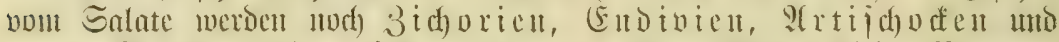

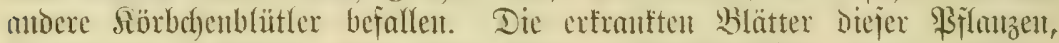

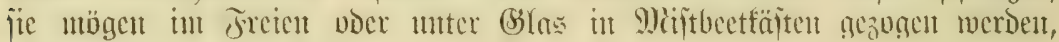
merden fidwarz unt faulent.

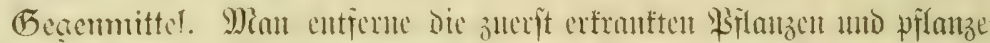

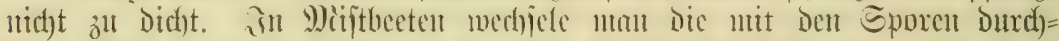

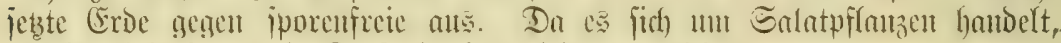
ift éu $\mathfrak{B}$ ejprizen mit Sunferbrihben nicht ambendbar.

\section{Brommg: Die Galisiunturefen.}

\section{Familit.}

\section{Difir Bramipilze (Ustilagineen).}

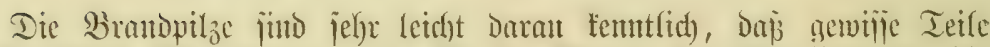

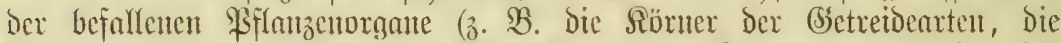

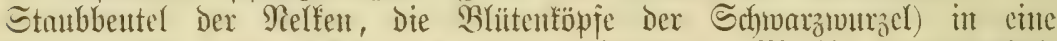

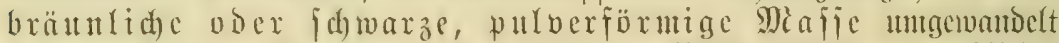

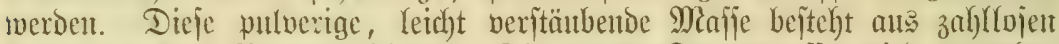
Sporent des Brandpirzes. Dic ganze Sporenmaffe miro entimeder

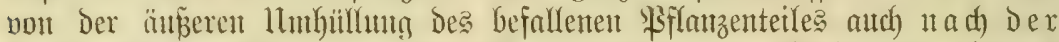

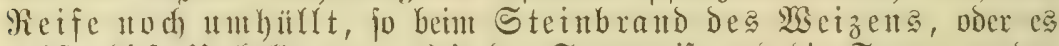

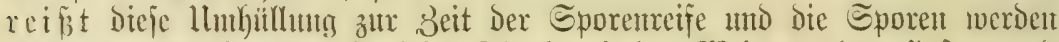

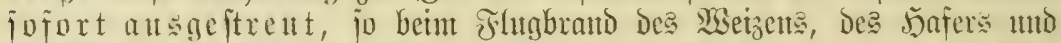

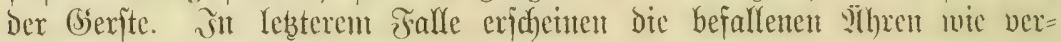
fofit noer verbrannt.

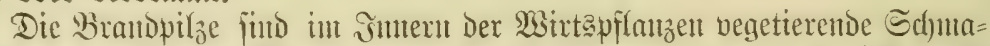

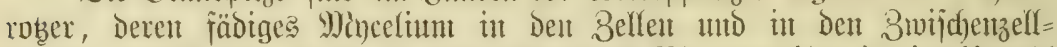

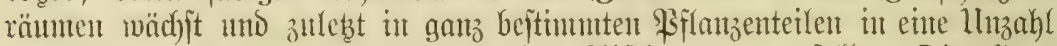

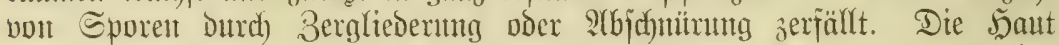
Bejer Dauteripore ut ift bei Den einen Strten glatt, bei underen twarzig.

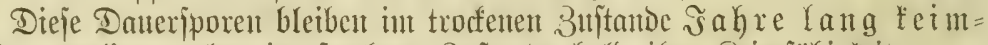

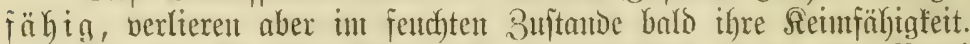

Bei ber Reimung bildot fidf) bei einzelnen $\mathfrak{A}$ rten non Brantopilzen

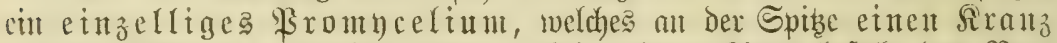
non länglident Sporibient erzengt, bei anderent Artent befteht das $\mathfrak{P r o}=$ uncelium me cinem furzen, geglederten Belfiaden, defien GSticber 
entweder in Sporibien jerfallent oder joldhe burch Sprofjung alt bent Seitent erzeugen.

Dieje Sporioten fömen fofort wiebcr feimen mo ihr dietut=

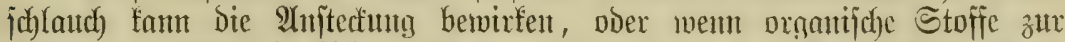

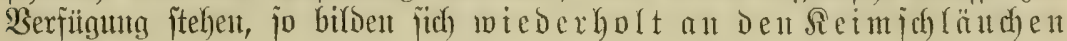
Der Sporidien tene Sporibien ourdy Sproffutg.

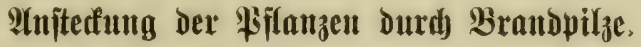

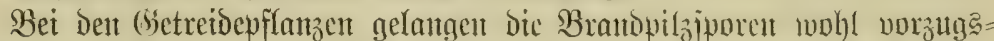
meije beim Dreichen an bie Getreibeföner und weriben jo ntit Dem Getretio

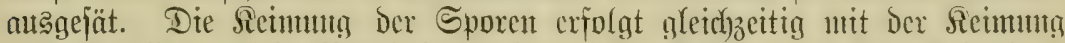

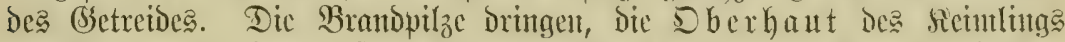

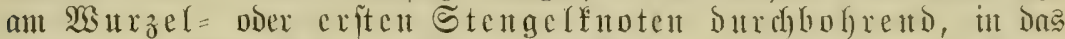

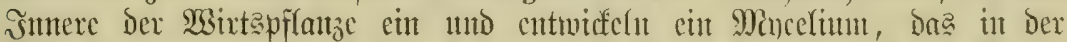
Pffanze meiter madjents fidh zulebt in bejtimuten Teilen s. B̉. bei

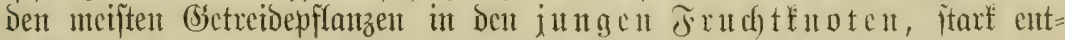

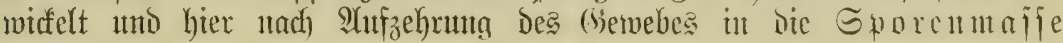
zerfällt.

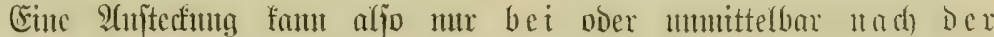
Sietung dor Mirtapflanzen exforgent.

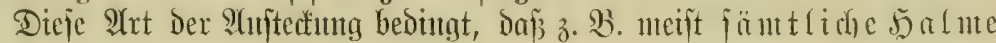
eilles Stodes bratidig merben.

\section{Befäutuiung Der Branopilze.}

Die Befämpfung bejteht Darin, daj mant bas Saatgut jpoucu= frei madht.

Die Sporen hatten bent Gsetrciótöntem mu loje ant, fömten aljo

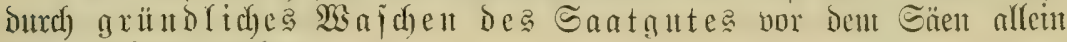
idjon entfernt werdent.

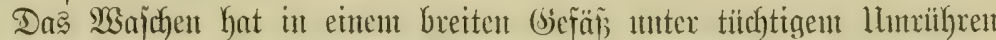

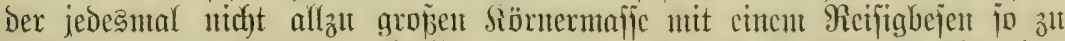

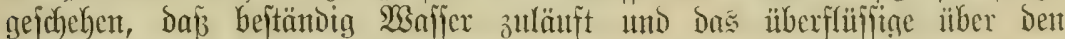

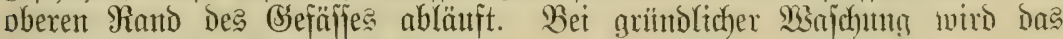
Saatgetretbe fret von Branojporent.

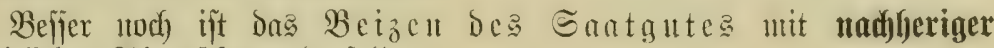

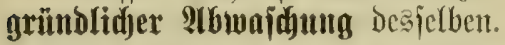

Eupfehleuswerte Beizutitel find:

1. $1 / 2$ sito Supfexutriol in 100 Siter Manjer gelöit. Dater Dex B̉eizung 12 Stmmoen.

2. 1 Sitlo Rupferbitriol in 100 Siter Barficr gelojt. Dater Dex Beizutg 5 Minuter.

3. 2 Sito Soba in 100 Siter Maffer. Dauter 12 Stumben.

4. 1 Sillo mentrale sapjervitrioljobabräbe in 100 Siter $23 a f j e r$. Dautex 12-24 Stumben.

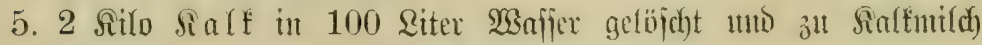
berrilibrt. Daucr 12-24 Stundett. 


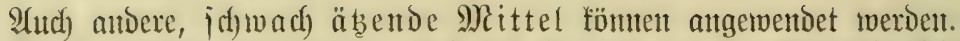

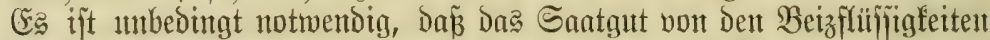

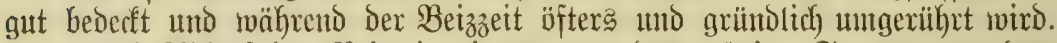

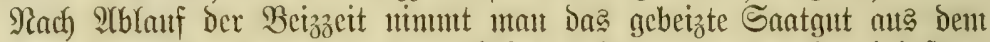

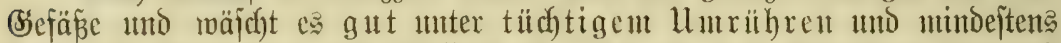

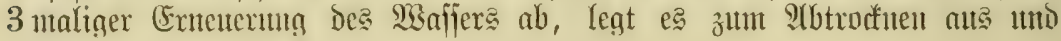
jüt jobantt.

\section{Die Seintuajerbeizutg.}

Sic beitefyt barin, dâj man das Saatgut 5 Mimuten lanı in

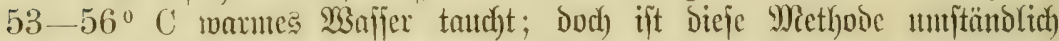

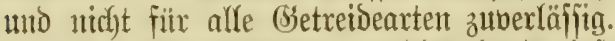

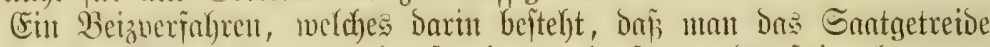

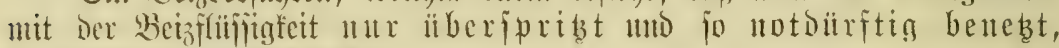

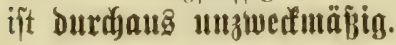

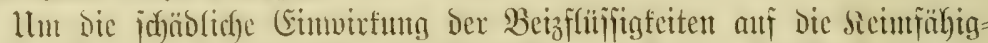

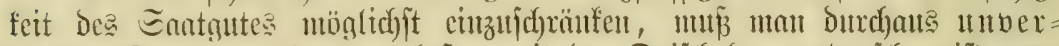

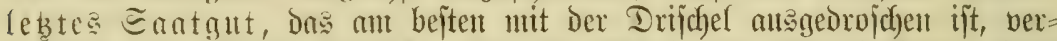

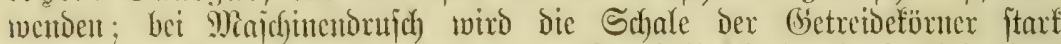

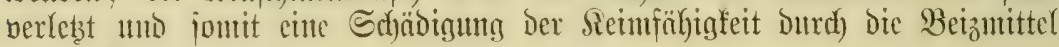
ermöglidert.

\section{überjicht ber battunen.}

1. Sporen einzellig.

a. Prommectum cinfad), Die Eporibien an Der Eptize

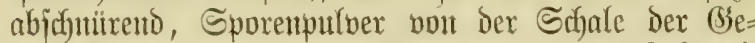
treideförner unichlofien bleibents.

Steinbrand (Tilletia).

b. Bromucelium gegliebert, die Sporibient an Dent Seiten ber Belfen des Pronmechum Kervorjprofient,

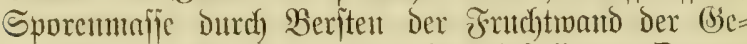
treidefönter voer Der Sant ber befallenen Drgatte fret merdeno utto veritäubeno.

J̆Lghrand (Ustilago).

2. Sporen mehrzellig, mobei eine bis mentige gröpere

Mittelzelfen bont mehreren flemteren umgeben finto.

Roggenitengelfrand (Urocystis).

\section{Gattum?. Dex Stentuxantor, Tilletia.}

Die cinzelligen, fugeligen Dauter=Sporen billoen bet Der Siemmung ein

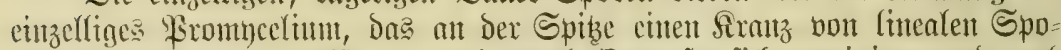

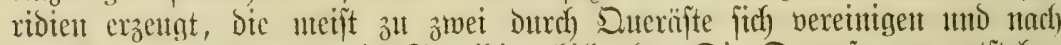
Der Siemung oft nod)mals Sporibien bifbent. Die Dauterjporen entitehen

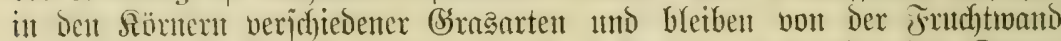

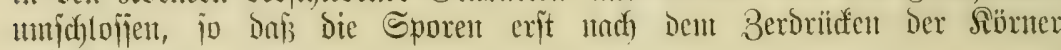
fret werdett.

Die wichtigiten ?Yrten fins: 


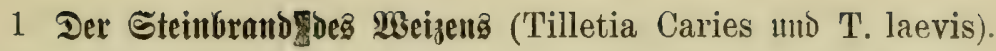

Der Stcinbrand Des Meizens, attd Stintbrand, Sdumier= brand, Jaulbrand, gejalojīener Brand genant, befällt den $\mathfrak{B e i z e n , ~}$ Spelt und Das Einforn. Db ein Befall borliegt, fam erit gegent bie

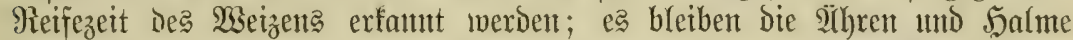
gritnlidy, Die Spelzen jtehen iparrigab. Die brandigen Weizentöner

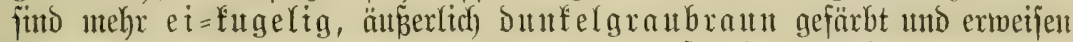

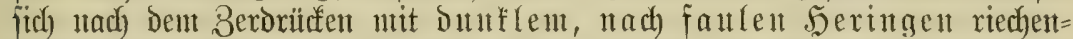
Dem Sporenpulber erfïllt. Sicht felten bleiben bie Salme ber brandigen Bffanzen ziemlich futrz. Durdy Das Drejd)en werdent Die Brandföner zer= fablagen tno die Sporen gelangen an die Saatfönter. Der Stembranto nimmt immerntehr überhand und ein Befall von 20-30, ja bie $50 \%$ Der fäntlidyen Siffouzen cines Feldes ift nicht mefyr felten.

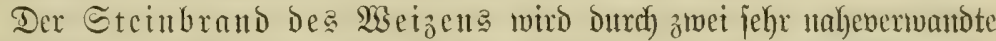
Ytrten bedingt. Bei T. Caries ift bie Sporenbaut nebig gezeid)net, bei T. laevis glatt, afjo ohne boriprintgende Reijten. Beibe ?rten fomment

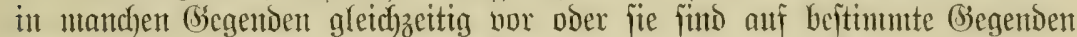
berteilt. 'T. Caries ift die an bäuffigiten vorfonmenoc SYrt.

\section{Dex Steinbrand Deß Roggenz (Tilletia secalis).}

Der Stentbrand Des Koggents ift bis jebet erjt bon ganz wentigent Drten Dentidilands befaunt. Die Rönter des Roggens werden in Der gleitchen Weije verumtaltet, wie bie iteinbrandigen Weizentönner. Daz Sporentulber ijt braın, riedyt gleidgfalle nach faulen Seringen, uno die ?tujentmano ber Sporen ift itarf nebig gezeidnet.

Dic Befümnfuntg ift fül alle 3 STrten bie gleidhe uno oben fichout angegebent.

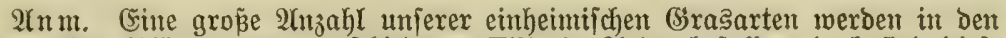

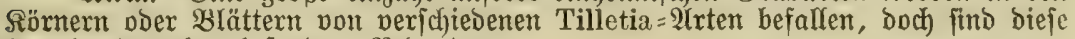
Brandarten ofne bejondere Bedeutung.

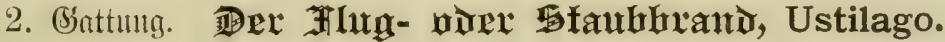

Dic Datterporen find telu, cinzellig; fite bilben bei ber ficimung

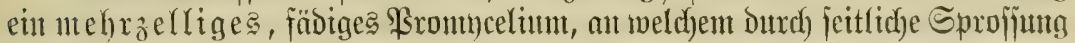

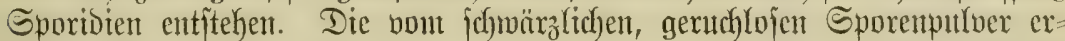

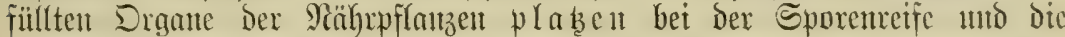

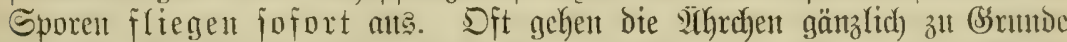
unto bie 2thrempindel alleit bleibt iibrig, nad)dem bie Spotent wout Regent ober Binto fortgetrieben finto.

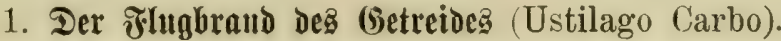

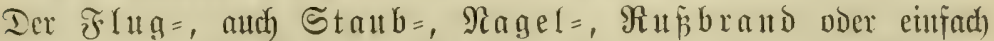

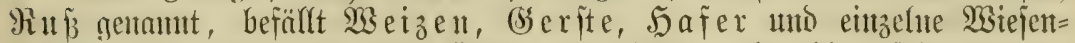

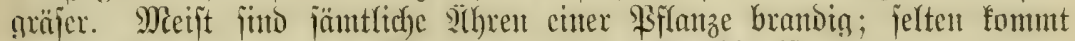

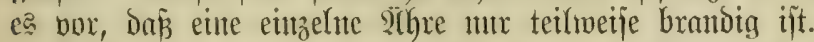

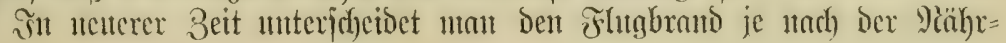




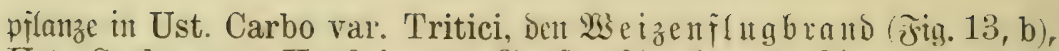
Ust. Carbo var. Hordei, Den (beritenflugbrand (Fig. 13, a) uno
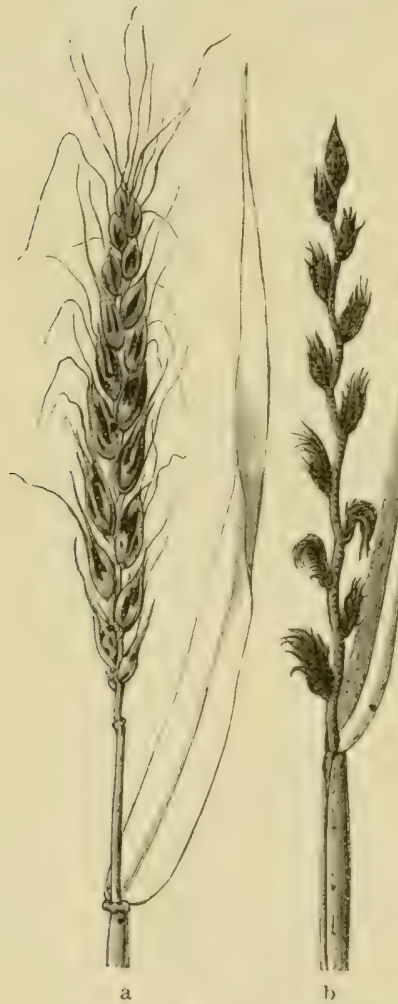

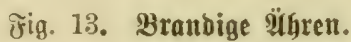

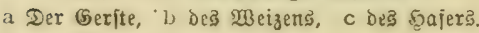

Ust. Carbo var. Avenae, dent Faferilug= bratto (Jig. 13, c). $5 \mathrm{~b}$ dieje Iremung beredhtigt ît, mag Dahingeîtellt jein.

\section{Der Şirjebrano} (Ustilago destruens).

(Ev bcrällt die $\Re i j=$ pen der நirie (Panicum miliaceum), jo Dẩ dex gauze Blittenitand in cine mit idfwarzem Sporenitanb exriillite Branbblaje ungemantolt miro, melaje àtvijchent dent oberent B̉lättern jiben blcibt. Die runtrict edfigen Sporen find undeutlid) neţïrmig gezeidnet.

\section{Der Mtaighrant} voer Beulenbrand (Ustilago Mayidis). Afn Dent Seitentriebent Der MRais= pflanze, auj melchent jida) Die Rolben entroicfeln, bildent jidf) unförmige Beulent, weldye Б̆ajel=

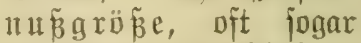
సau t= oder jelbit $\Omega$ inder= fopfgxöве erreidfen, z $\mathfrak{u}=$

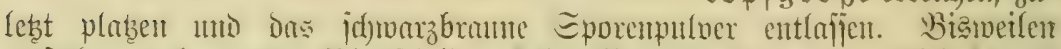

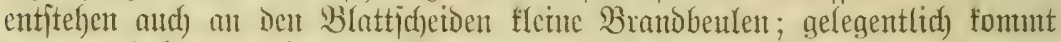
es vor, Daj mux einzelte Sï̈nex eines Solbens in Brandbenten umge=

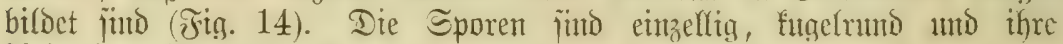
Aupenthaut tit feinftadjelig.

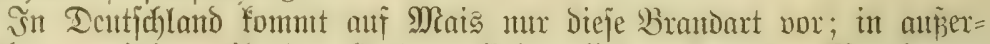

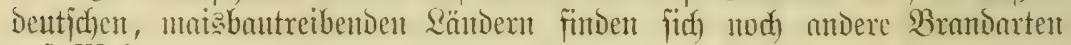
ali Mais.

Indere, weniger bedentungänolle Brandarten find:

Der Gorghumbrand (Ustilago Tulasnei) auf Der Miohrific Sorghum vulgare; Ust. Crameri auj ber Si olbcnhixie Setaria italica.

Berjchiedent andere Brrïjer, Riedgräjer, Eiltaceen und andere Pffanzen= 
famtiten juto von Branbpilzen heingejudt. Ustilago Antherarum ver= nidjtet die Staubbeutel bon Selfen= bliitlern uno Ust. receptaculorum

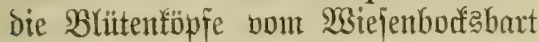
und ber Sifwarzmurzel.

\section{Sattung. Bex 马fengelluxanto Urocystis.}

Der Stengelbrand berällt die Stengel oder ïhren won wer=

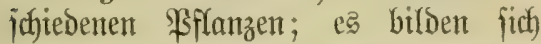
lange, a tfang gasue, etwas id)twielenförmige Streifen, die bei

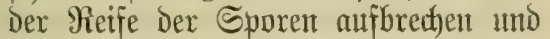
Das jidntwärzlidide Sporenpulber ent= Iajen. Die Salme merden daourd)

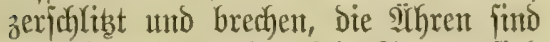
zu allermeift taub. Die Sporen futto $\hat{z}$ ulanmengelebt; cine oder eintige größere dunfelgefärbte Bellen find von

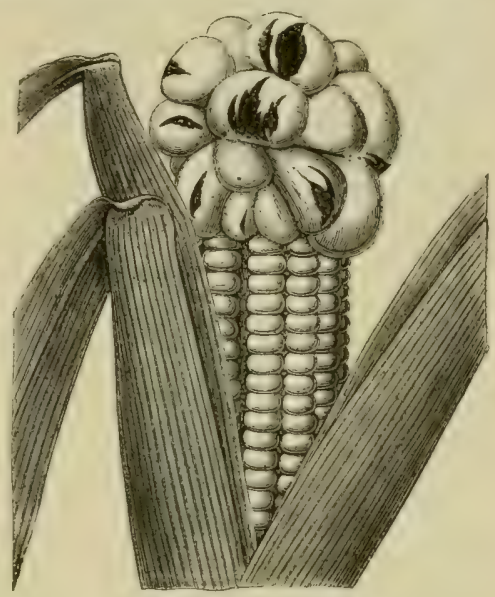

Fig. 14. Mlais̄brand.

Die oberen fiörne jinto bejallen. mehreren Heineren ungefärbten oder hel= leren umid) lojien. Nar bie mittleren, gropent Bellen bilden ent einzellige Fromeelum, Daß an Der Spibc Sporibient erzeugt.

1. Der Roggenitengelfranto (Urocystis occulta). Dex ?loggenitengel=, autch Moggenitiel= brand findet jich in ben oberiten Salmtgliedern

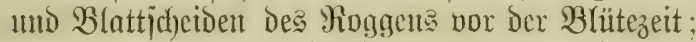

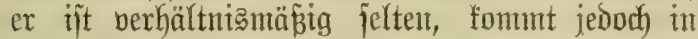
Deutjulatand bor. (Fig. 15).

2. Der 3wiebelbrand (Urocystis Colchici). Er findet fich auf beridjedenen Liliaceen, jo aui Scilla, Muscari, auf der Einbeere unt Derbitzeitloje, fommt aber autd auf Der Sperie= z'wiebel (Allium Cepa) vor; er ergreift jugn

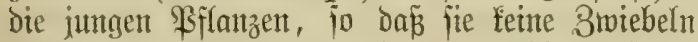
befommen. 2Anfangs merben mur die äuf̧eren Bmiebelichalen befalfen, ipäter aber auch) bic Błätter, 3miebeln uno Wurzeln.

\section{Mamilite.}

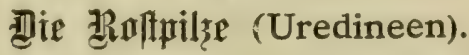

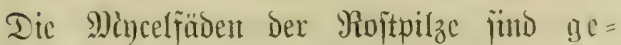
gliebert (mehrzellig) mto wadjen im șneren

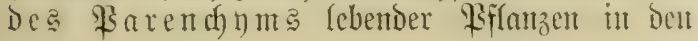

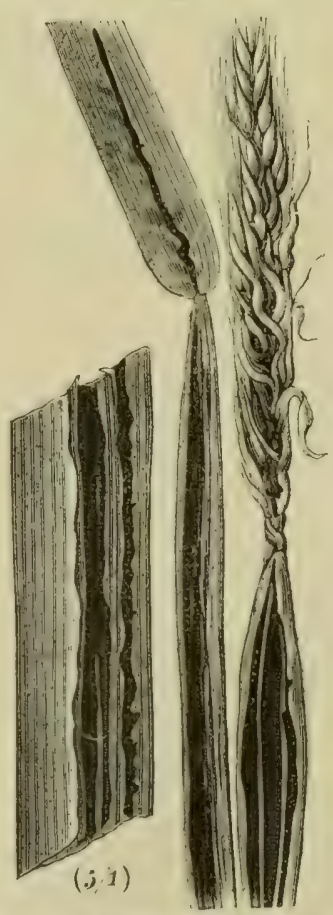

ช̃ig. 15 . Noggenitengelbrano. 


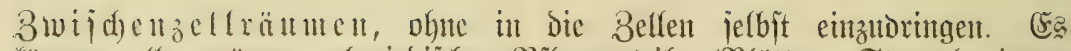
fömten alte grïnen, oberirbifichen $\mathfrak{B f l a n z e n t e i l e ~ ( B R l a ̈ t t e r , ~ S t e n g e l , ~ j u n g e ~}$

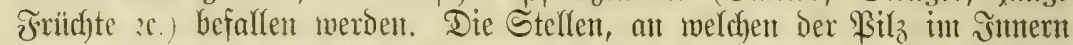

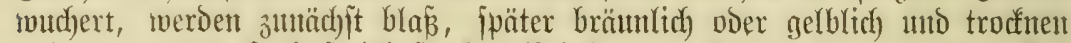

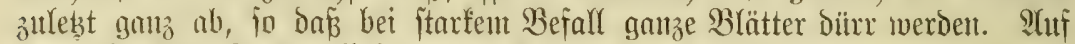

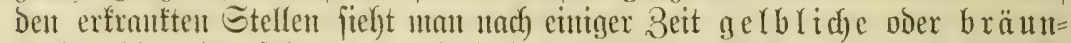

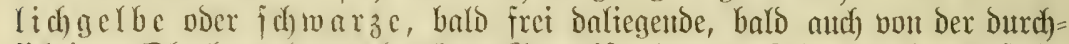
jid)tigen Dberbant Der crfrantiten (Gewärd) längere Beit bederfte \$ulfteln, bie nus antllojen Eporen des Moitpilzes beitelyen.

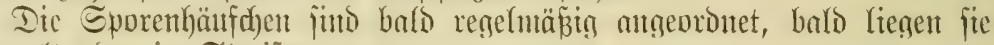
veremizelt oder in Streifent.

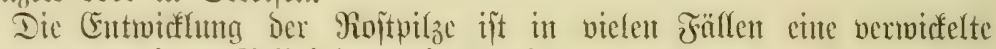
ınt) utöge an eincm Beippiele gezeigt werden.

Die (meift) in Jerbite gebifocten Eporen, Dic diffwandigen unb braun!cfärbteu Daucriporen, Zelentoiporen, ̈̈berwintern uno teimen

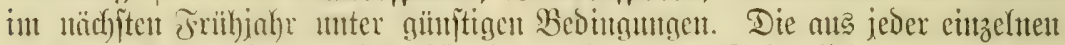

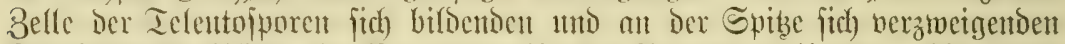

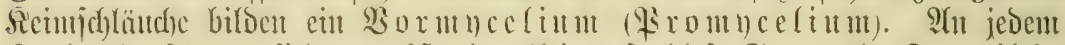

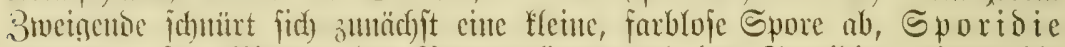

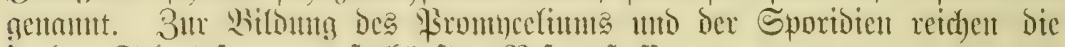
in Den Ielentofporen auffgehäuften Referveftoffe.

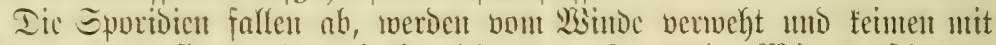

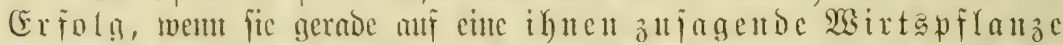

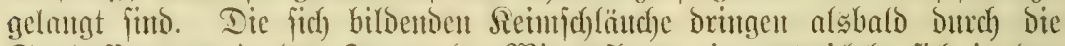

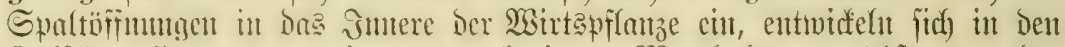

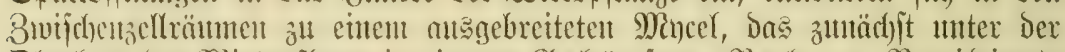

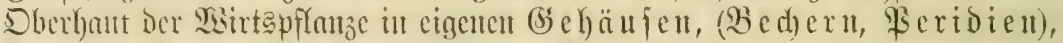
Sc c id ium gennunt, an enditündincu Mincelföben reifenweife Sporen, Dic Hecibienjporen, abjontiirt. Die 2lecibien ftelfen in ber Yiegel gelbe,

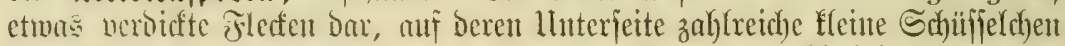

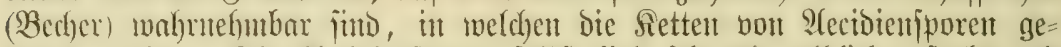

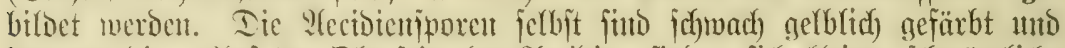

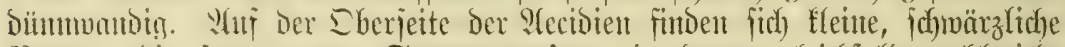

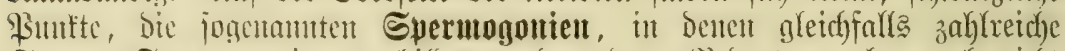
Spuren (Speruntien) gebilibet merben, Deren Bedentung aber nod) nidht allfgeflärt iit.

Die Sfectotenporen fömen meiterbin ent Doppeltes Werhalten zeigen, jc nach Den Yojtpilzarten, zu denen fic gehören; nänlich:

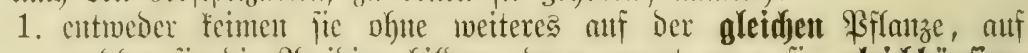
seelcher jie bic ?lecisien bilden, bann nent man fie gleidhbäultge,

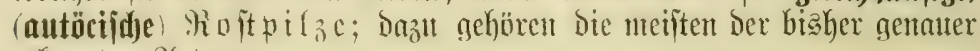
erfanutent 2 (rtent;

2. ober fite feiment criplareidh erft, went fie ani cinte andere Pfflanzentart

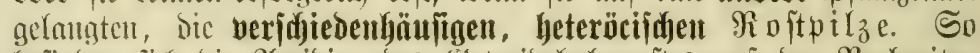

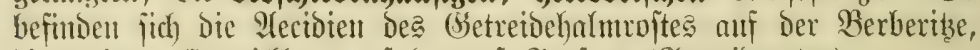
bic meitere Entwidflung cripolgt anf Bräjern (Getreibearten). 
Die feimende Aecibienipore bildet ein nettes Mincel, vont Dent aberntale j(y)wach) gelblid) gefärbte, Dünmwandige, einzellige Sporent ciłzel aũ dïnnen Stielen abgejdnürt merbent. Win nennen fie Hredoiporett und bie

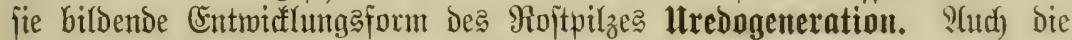
Ureboiporen bringen bon neutent Injtedungen Gernor, Dod) fömtent intmer mur bie gleichen oder nahe berwando Pflamzenarten won ihmen befallent mer= Dent. Bsegent Den Serbit entitelyen aut Dent Minceliunt Der llredogenteration Bafibien, meldye roejentlidh anders geftaltete Sporen, cintzeln auf Dünnen, balo längeren, bals fürzeren Stielen (Bajibien), erzengen, bie jo= gettanten Daueriporen ober Teleutojporen. Die Dauteriporen funt je nach Den berichtedenen Bsattuntgent Der Rojtarten einzellig ober mehrzellig,

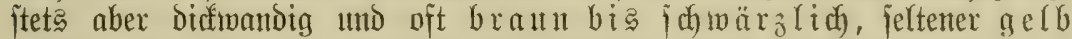

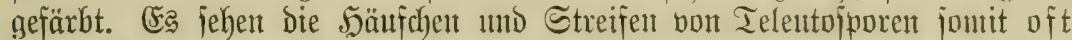

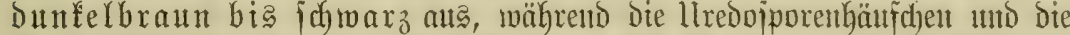

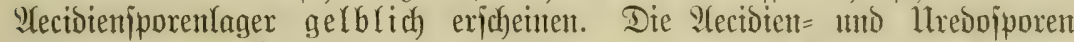

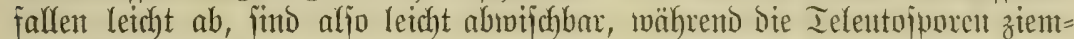
(ich) feft fiben.

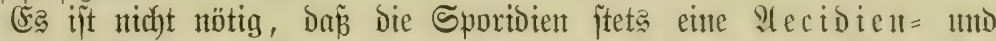
uredo = und Teleutogeneration erzengen. Bei eitrigen ?frtent won Roitpilzen fent man nut die Telentogeneration, bei anderen bie Qecibien = mo Ieleutogeneration und bet anderen bie Uredo= uno Ieleutogeneratiou. Sätfig hat man zu Secibien= mo llredo= genterationen bie bazu gehörige Ielentogenteration nod) utcht gefundent.

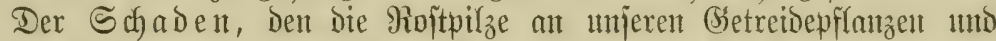

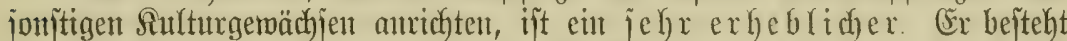

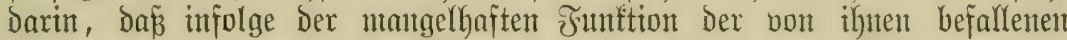
Bflanzenteile, bejonders der Blätter แno ihres frühzeitigen ?Gojterbens, die

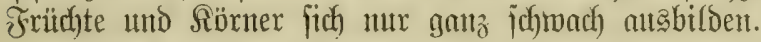

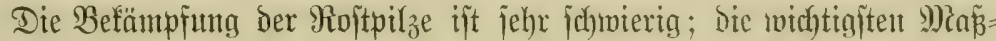
regeltn fint:

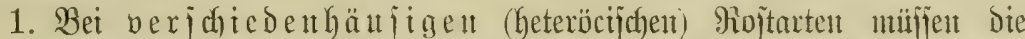

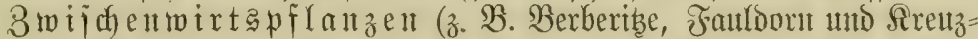
born, Sebenbaunt u. a.) auggerottet werden, mindeftens auf cine (Ent= fermung von einem fillometer vom Sulturlande.

2. Man bejeitige möglichjt alfe rojtigen, o. h. mit den Iefeutopporen bejebten Pflanzenteile; bejontoers joll ber Dünger nicht allăl frijd), jondent gut berrottet auf bie Jelder gebracht merben. Das Saub roft tranfer Pffanzen wird entweder berbrant ober ctwas tief untergegraben.

3. Nan wende red)tzeitig Bejpritungen mit Supferioda= ober

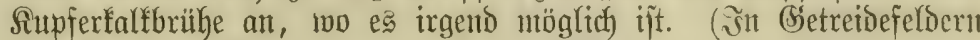
find Derartige Bejpribungen nicht Dutrchfiibrbar).

4. Mant wechale bejonders mit Den Feldern (Frutchtmedjel), Diutge regelrecht uno bejdaffe fich Saatgut bon wiberftand Sorten ber betreffenden fulturpflanzen. 
Winteilung Der Roftpilze.

A. Dic Ictentoiporen (Dateriporen) gettelt, eitudu bleibent.

Pucciniaceen.

1. Telentopporen nidht in eine bsallertmajie ein= gebettet, nidit auf Rabclbölzern.

a. Ieleutopporen cinzellig, llrebojporen ftachelig ober rbarzig.

Uromyces.

b. Teleutopporent zweizellig (jelten $2=$ uno $1=z e l l i g e$ gemijadt.)

Puccinia.

2. Telentoporen in cine biallertmajie eingebettet, langgeftielt, zroeizellig, auf Rabelbölzerut.

\section{Giymuosporangium.}

3. Telentopporen 3 oder melhrzellig (jelten $2=3$ ellig).

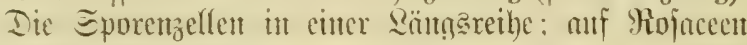
lebende Barafiten.

Phragmydium.

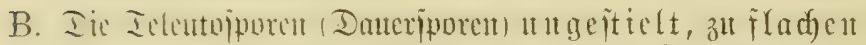
Docr politerförmigen angern ober fäulen= förmigen $\Re$ ï rpern feit bercungt oder fo fe in bae

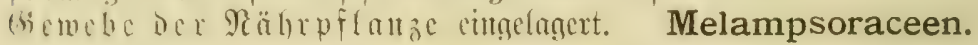

1. Ielentoporen in \&ängsveifen angeoronet (in= folge wiederlyolter Bildung an Denjelben Styphen); ina Sporentager die Dberbatt Der Rährpflanze Dit $x$ chbrediend.

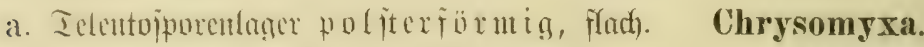

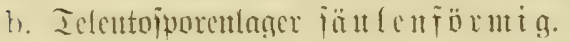

Cronartium.

2. Iclentojpoten uicht in \&ängareiben angeoromet, Sporenlager von der Dberbant der Mähroflanze bededt.

a. Dic Ielentojporen bilden fein $\mathfrak{B r o m} y \in \mathbb{L}$, das = ielbe ift Durch eine Biterteifung Des Sporeninhaltes nutr angebeutet.

Coleosporium.

b. Die Telentoporen bildont bei ber Retnumg ein irei herbortretendes $\mathfrak{P}$ romncelium.

x. Ieleutojporent eit zellig (oder 2zzellig, Dann die Bellen itbereinander fteheno.

Melampsora.

今. Telentoporent ate $2-4$ nebeneituander riegenden Bellen gebildet, Ieleutopprenlager fruitenfömiạ gan Stengel itberzieheno. Calyptospora. 
Die widftigiten Gattungen uno Yrten ber Kojtpifze fint:

\section{Softuntu: Uromyces.}

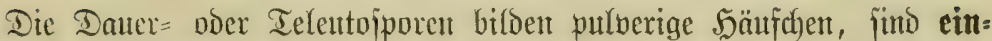
zellig uno entïtehen einzeln an Der Spibe eines fadenförmigen Trägers.

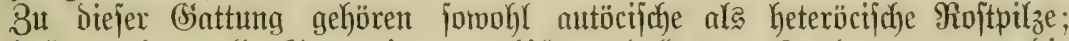
baldo merben alle Géenerntionen gebildoet, bafd mur 2 noer gar nut bic Teletttogeneration.

Die uvidytigften $\mathfrak{A}$ rten fins:

1. Hrombcesarten, bon dencu nur $\mathfrak{A}$ redo= und Teleuto= iporen gebildet werdent.

(5oldoregenroit, Uromyces Cytisi, bejonders auf Bonloregent.

Bupinenroit, U. Lupini, auf Der meiß̌en uno gelben Rupine.

2. Hromucesarten, bon denen Aecidien $=$, Uredo= und Telentoporen gebiloet werden.

\section{a) Zutöcijche צrten.}

Dic orei Sporenartent bildsen fich auf ber gleichen \$Sflanze.

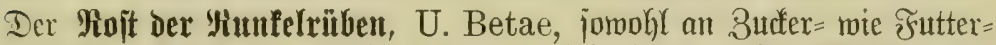

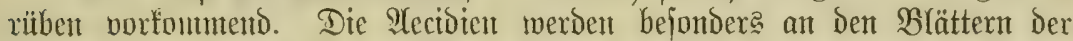
Samentüben entridüelt; man fant Daher Den $\mathfrak{S i l}_{z}$ befümpfen, wenn mant Die befallenen Blätter Der Samentübent frübzeitig, D. h. fofort beim 9 Uuf=

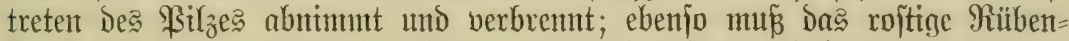

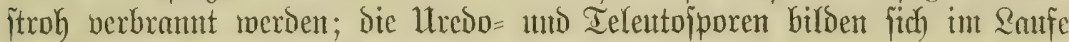
Des Sommers anf Dent heranmadfientent Saatribben.

Der filecroit (U. apiculatus) alf ßifecartent und auf Eqparjette. Dic

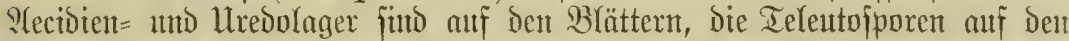

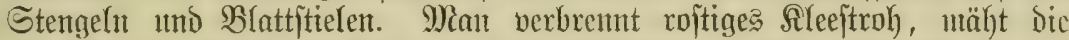

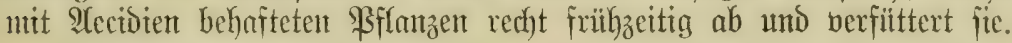

Der Midfenroît (U. Viciae Fabae) auf der Ŷtéterbohnte, dent wer=

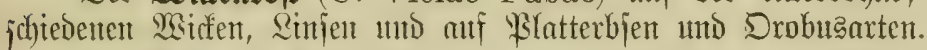

Der Bofnenroit (U. Phaseolorum) auf Der gemeinen Bohne (Stantgen=

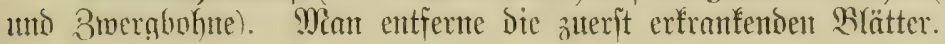

\section{b) Geteröcijche $\mathfrak{U}$ rtert.}

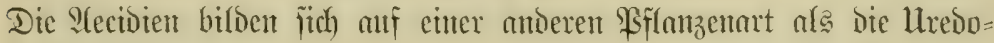
unto Ieleutoporen.

Der Crbjentoit (U. Pisi) auf Dent Erbjen, auf WBiffentarten แmb aû́

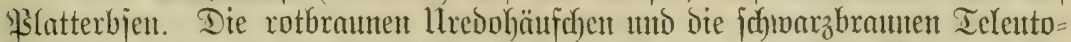

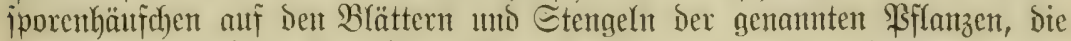

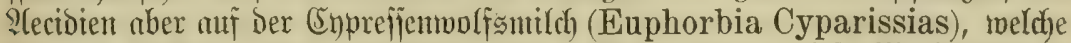

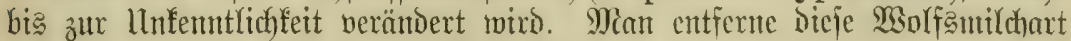

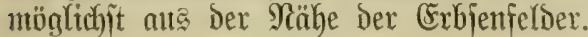




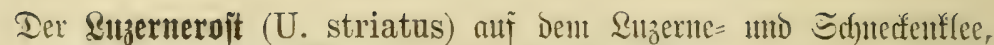

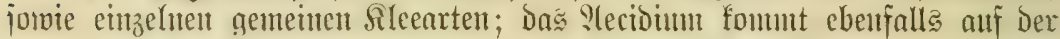

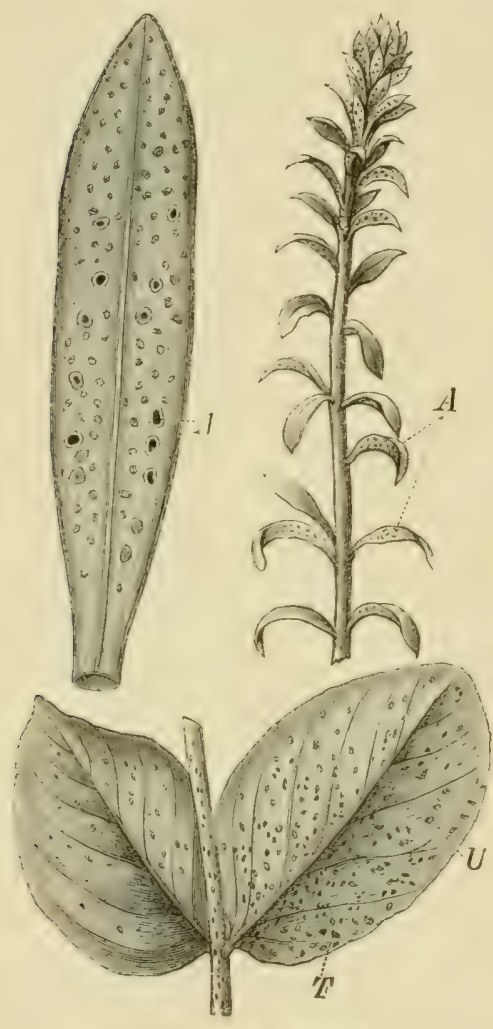

テ̌ig. 14. Erbjenroft.

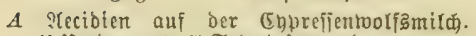
1. Itrebo= unto ' 2 ' Teleutoporenlagerung.

(Enprefiennolfsmild bor. Die $\mathfrak{B e}=$ fämpfung ift beshalb diejelbe wie beim Erbjenrojt.

\section{Gattutg: Puccinia.}

Die Ieleutojporen jimo geitielt, biftwantig, braunichwarz gefärbt uno ziveizellig; beide Sporenzellen bil= Den bein Seimen ein Prontncelum. Die Telentopporen entitehen unter ber Dberbant ber befallenten Piflanzenteile unt durdybrechent biejelbe entweder bei Der Яeife oder fie bleiben, weil furz= geftielt, bou ber Dberhaut bedecft.

1. Puccintarten, vondenen ut $x$ Teleutoporen be= faunt jind.

Der Mialvenroit (P. Malvacearum) auf verjchicdenten Mialven Into bejonders auf Der Stodtroje (Althaea rosea) oft fo ftarf, Daf it mandjen (śegenden dieje Bierpflanze gar nicht mebr angepflamst iverdent fant. Red)tzeitige Befpribung mit Supferiodabriibe erjobeint angezeigt.

Der Moit beg Burbaunte (P. Buxi) auf den Blättern Des Burres; man entferne und berbrente bie be= fallenen \$flanzent oder bejprike fie mit Siupferjodabriilye.

Ier Melfenrojt (P. Caryophyllearum), von Sulturpflanzen bejonder? anf Der Bart= mo jebentelfe. Dic żuerit befaflenen Bffanzen werden id) Jennigit entfernt.

2. Mur Uredo= und Ieleutojporen werden gebildet.

Der Miaiarnoit (P. Mayidis) auf Den Blättern des Mais mit branten Uredo = und jobrwarzen Teleutojporenthäuffchen. bliittern.

Der Gellerieroit (P. bullata) anf Sellerie mo moeren Dorbent=

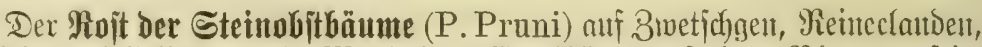

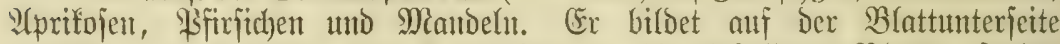
Dumfelbraune J̧äufoben von Telentojporen; bie befallenen Blätter färben 


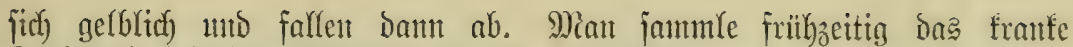
Satb uttro beipribe redstzeitig mit Sitpferjodabrühe.

Ier Riridjenroft (P. Cerasi) alf Den Blätternt Der Sitrid)en.

3. Fecidien und Iefentofporen werden gebirdet, lledo= iporen fehlen.

Dex Jofamis: und Stadjelbeerenroit (P. Grossulariae) auf Dent

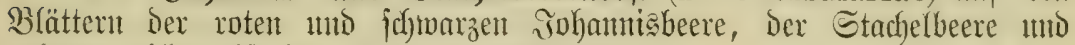

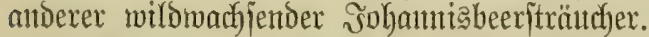

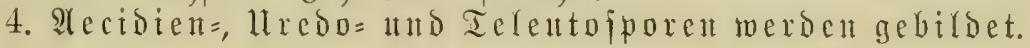

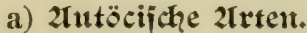

Der 3wiebel: poer \&audroit (P. Porri) auf alfen grïnen Teiten

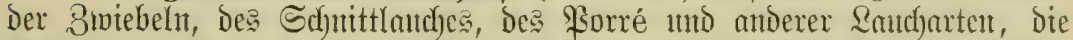

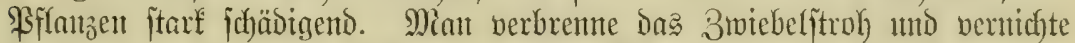
Die äcistentragenben Teife Der genamten Bftanzen.

Der Spargeliroit (P. Asparagi), häutfig auf Epargelpfflanzent. Mian werbremte Das abgetrodfnete Spargelftroh im herbite.

Der Beildjenroit (P. Violae) anf beriffiedenen Beilchenarten; bie er=

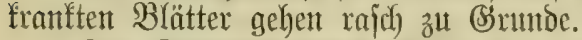

Der Somnenbluntenroit (P. Helianthi) auf den Blättem mo Suillen

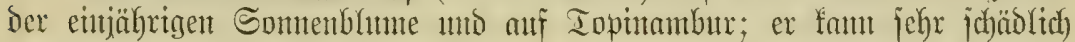
werben. Das Stroh ift jorgfältig zall werbrentent uno mit bent Felbern ift zut toechjeltn.

\section{b) Ģeteröcijche Irten.}

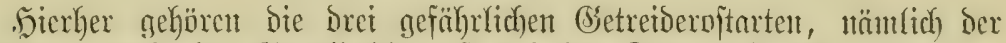

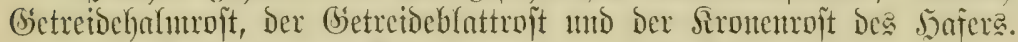

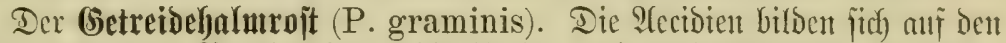

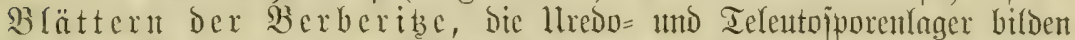

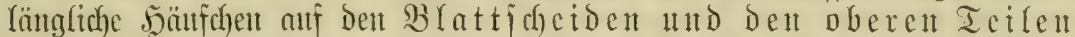

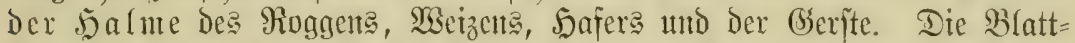

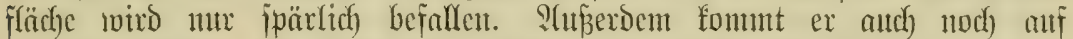

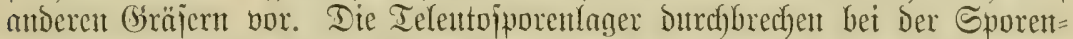

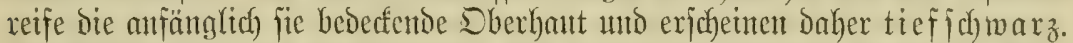

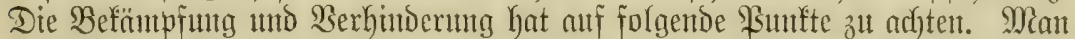

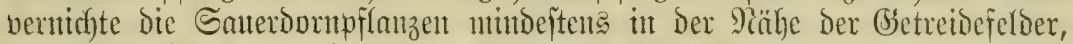
vernidgte roîtiges Stroh, pfflige Die Stoppefln gut unter, entferne bont Dent

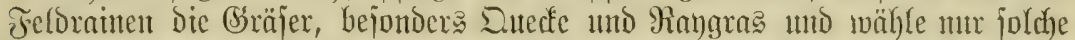

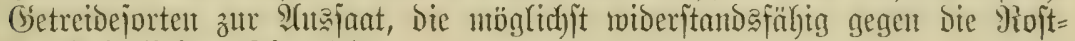
frantfheit fino. (ร̌tg. 15.)

Der Getreibeblattroit (P. Rubigo-vera) auf Den Spreiten Der

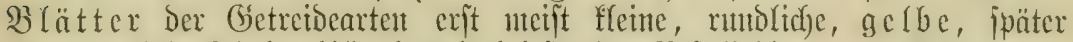

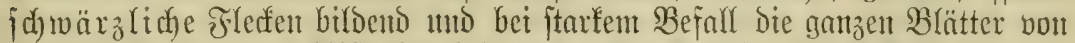

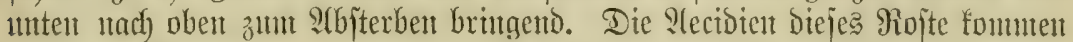

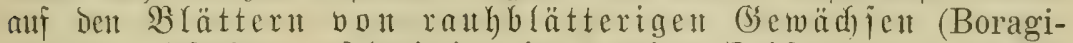

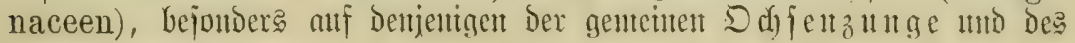




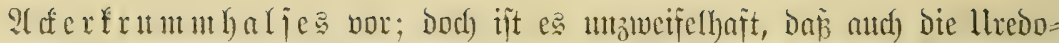

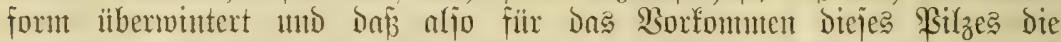

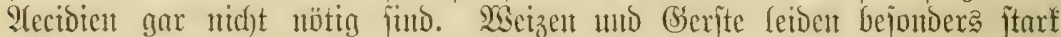

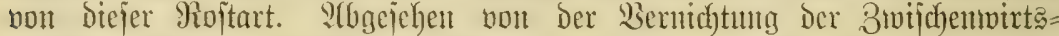

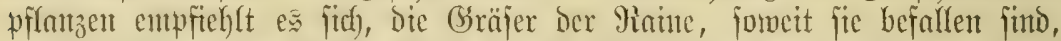

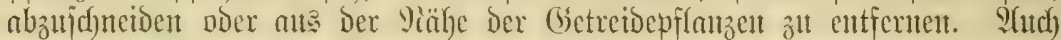
eit jpätes ?(utbanten de jebre erbeblich.

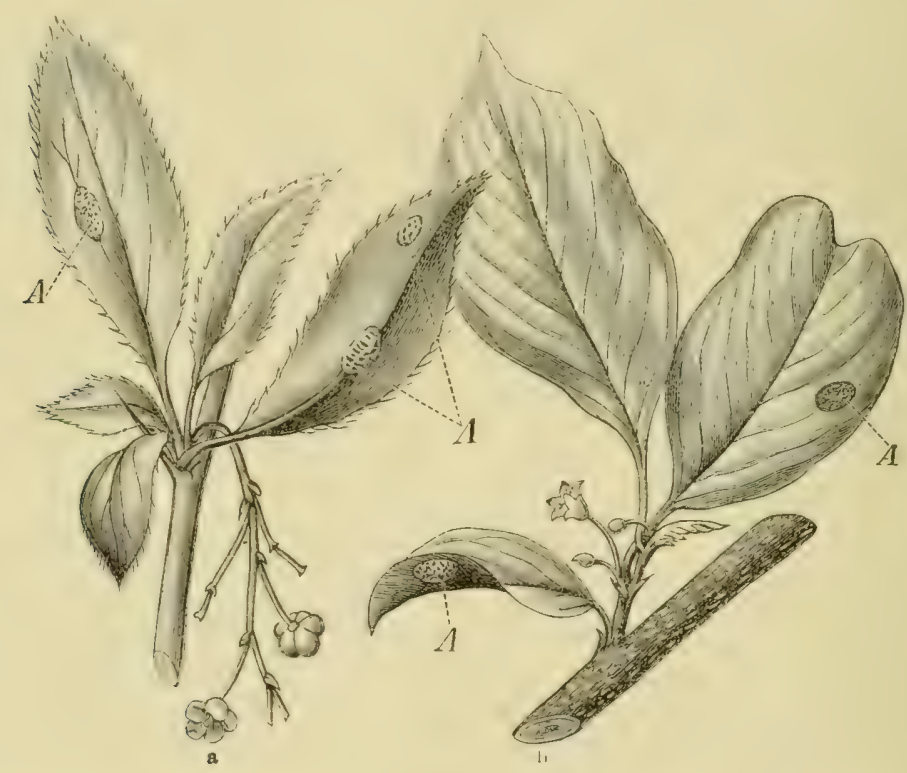

ìig. 15.

A शecioien auf ben Brätlern ber Berberibs.

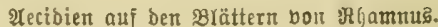

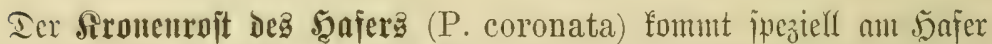

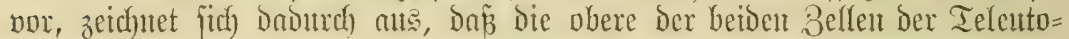

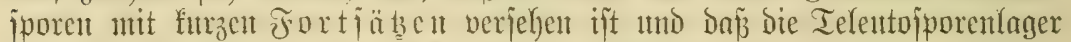

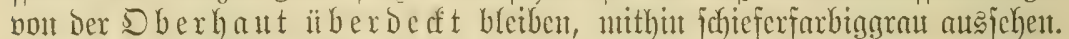

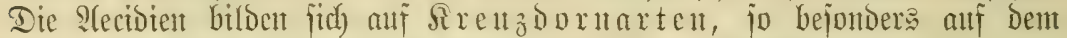
Bitrgierftenzonn (Rhamnus cathartica), Dem Bwergtrenzoorn (R. pu-

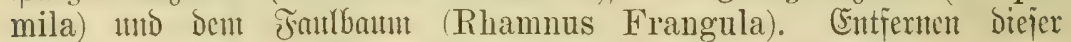

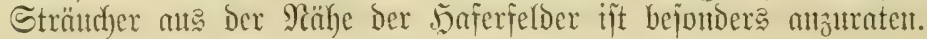

\section{Gattung: Phragmidium.}

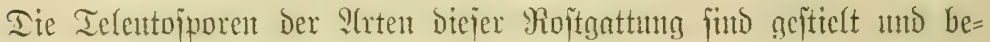

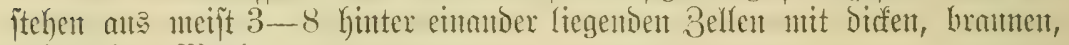
getörnelten Mantungent. 


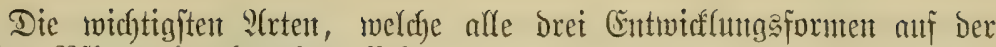
gleid)ent \$flanze Dutrdimadhent, find:

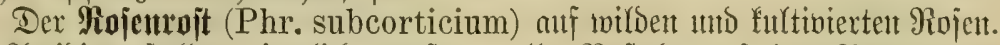

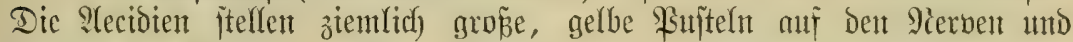

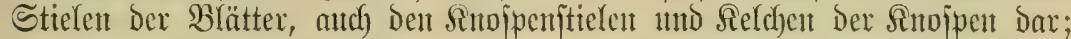

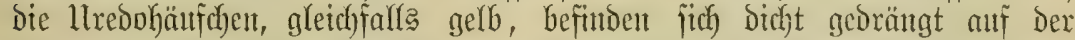

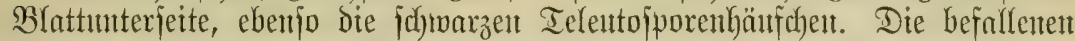

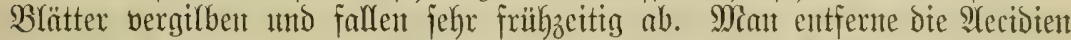

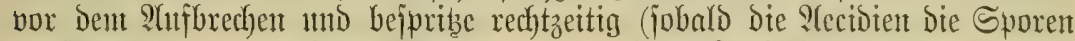

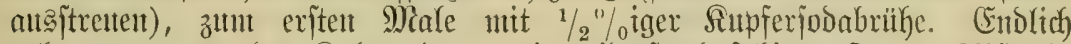

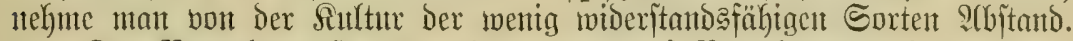

Der Brombeerroit (Ph. violaceum) auf Brombeeren unt ähnllide.

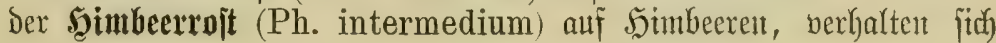

\section{Battung: Gymnosporangium.}

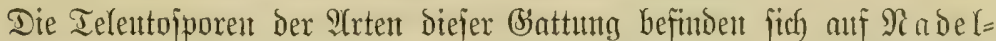

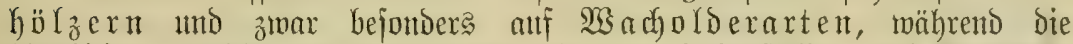

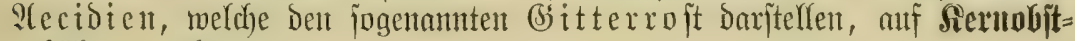
gebülzen vorfommen.

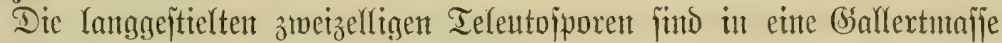
eingebettet.

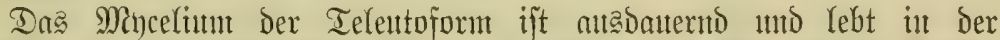

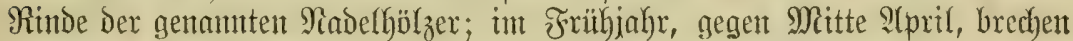

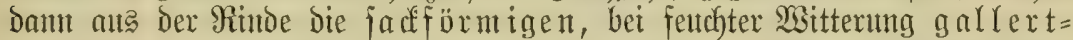
artigen, bräunlichen Eporenlager herbor, weldhe alts zmeeżelfigen,

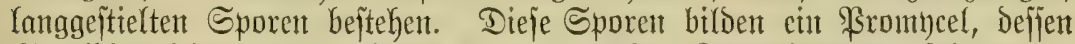

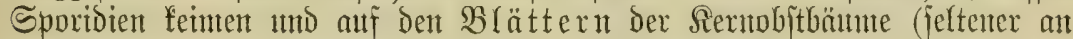

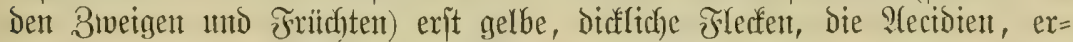
zettgen, auf Detten fith) auf Der Dberfeite bie Spermogonien, auf ber

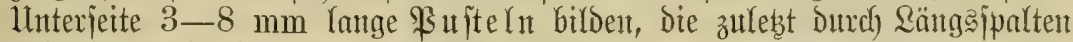
aufreipent und bie Sporent entlaffent. Hrebojporent fonmment nicht bor. Cine

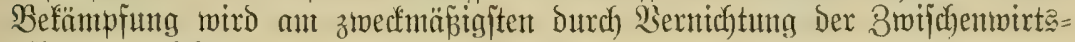
pflanze erreicht.

Der Gitterroit Dez Birnbaume (Gymnosporangium Sabinae, G. fuscum). Das Tlecibium fonmut auf Binnbätntent, bie Ielentogenerationt an Den Btweiget Des Sebent= doer Sadebatmles (Juniperus Sabina) vor.

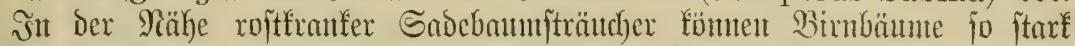

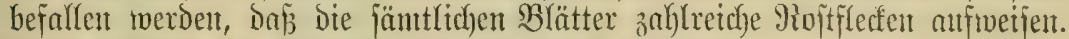
Matr entferne Die Seventbärme nuts den Dbj̈tgärtert.

Der (Gitterroit Der Duttte und De: Sanerourue (G. confusum).

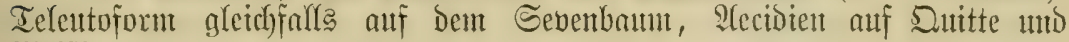

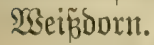

Der Meipoormroit (G. clavariaeforme); Telcutoform auf dem $g c=$

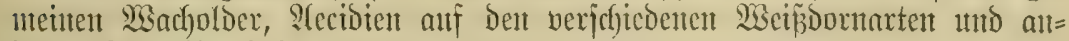
Deren Siernobitgehölzent. 


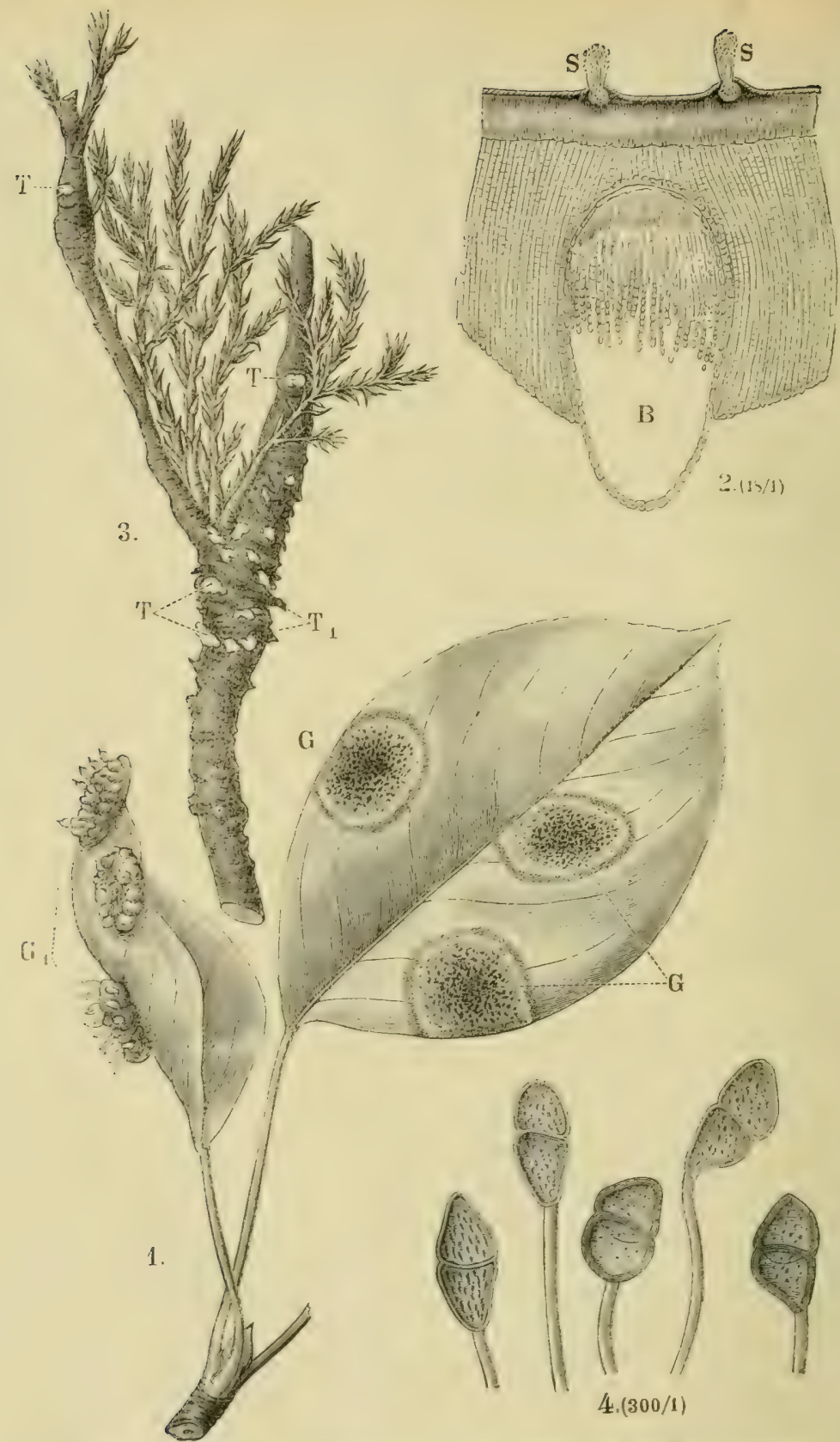

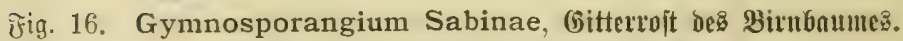

1. Blätter Dę Birnbaumes mit ben 2lecidien. $G$ 2 Uuf Der 3 rattoberfeite, $G, 3$ rattunterfeite.

2. Hecioienbed)er. 3. Teleutojporenlager ant Eevenbaum. 4. Einzelne Teleutojporen. 
Der (Bitterroit Deß 21pfelbnumes (G. tremelloides); bie Telento=

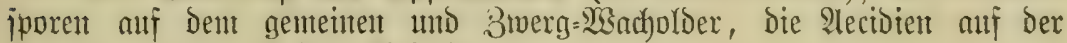
Bogelbeere und auf Dem $\mathfrak{2}$ (pfeltbanm.

\section{Brattutig: Cronartium.}

Die einzelligen Teleutopporen Diejer heteröcijchen Miojtpilze bleiben vereinigt unb biffent jo einen fänlenförmigen förper, an Dent fie autd) nod) feimtent unt Sporibien bitloen. S(ecibien fehfent; ats Dent Mincel Der Ureboform billoet fich) bie Teleutojporenjäule.

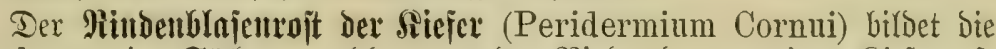

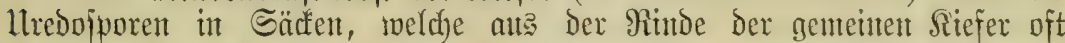
majienthaft herborbred)ent. Die Telentojporenfäutlent (Cronartium asclepia-

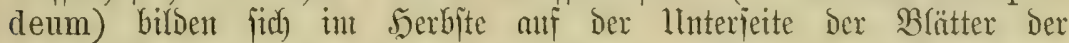

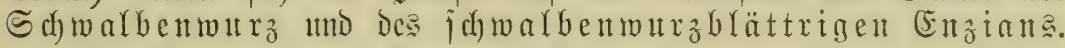

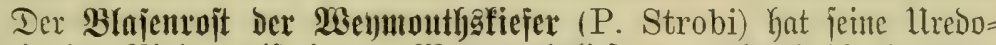

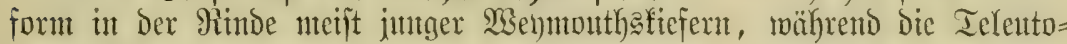
iporen (Cronartium ribicolum) auf ben roten utud $j \mathrm{ch}$ warzen すo hantiaberarten, jomie alf Der Stadgelbeere mb anderen futtis=

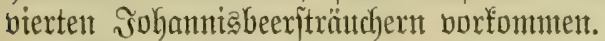

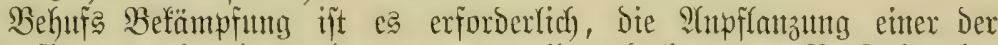

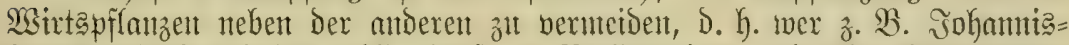

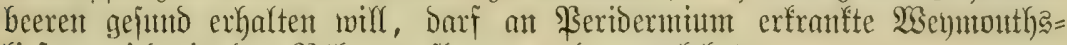

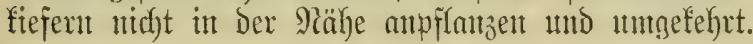

\section{Giattung: Chrysomyxa.}

Die Telentojporenlager finto orangegelb, fleiijdig, polf̈terförming, liegen unter Der Dberhant ber befarlenent Bfflanzen verborgent und

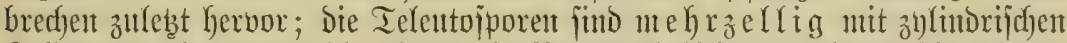

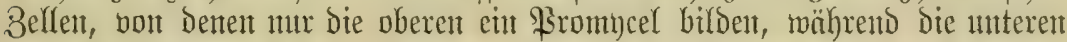

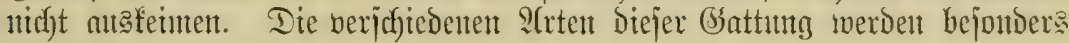
Den Fischten jajäolich.

1. Rur I Ieleutoiporen jind befant.

Der Fidutemuadelroit poer bie Gerbfrectigfeit ber Fidyten=

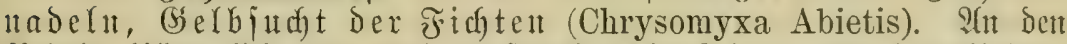
Prabeln bitsen fich boum Julf ab itrohgelbe gituge ober Sulterbinben;

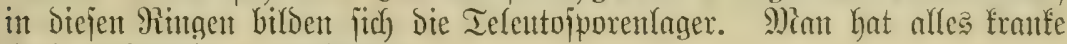

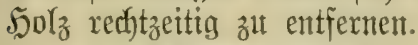

Der Arpenrofenrojt (Chr. Rhododendri). Die ltreso= mo Telento= jporenlager fint gelb unto fonment aufi bett Blätternt Der im Gébirge

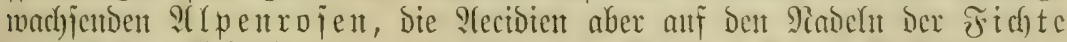

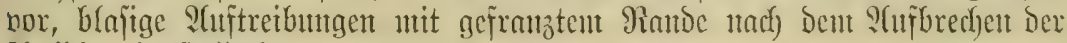
Ylectibien Dariftetlento.

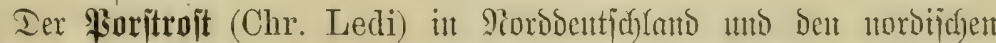

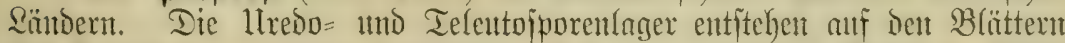

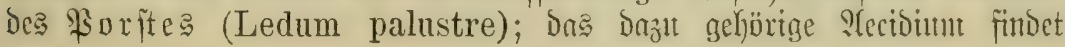




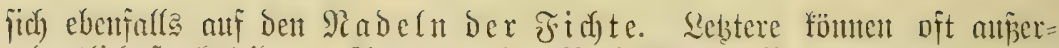

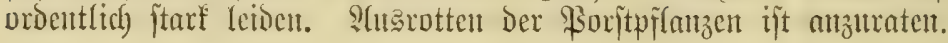

\section{Battung: Coleosporium.}

Die Ielentofporentager fint getb und bleiben bon Der Dberhant Der befallenten Pijtanzen bedect. Die Ielentopporen finto mehrzerrig,

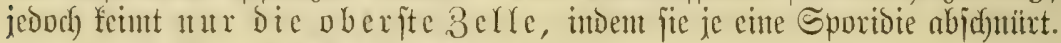

5äutfig ift ber GIodfenblumenroît (Coleosporium Campanulacearum)

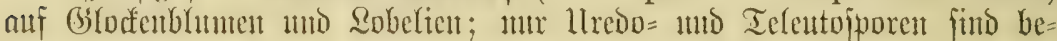
famt.

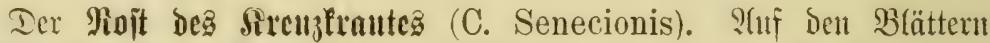

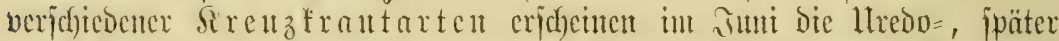

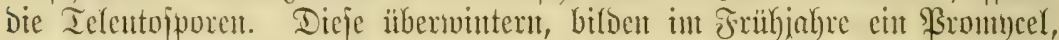
Deffen Eporibien die Miadelu bon Riefern befallen mo dajerbjt Aecibien bildoet.

\section{Binttung: Melampsora.}

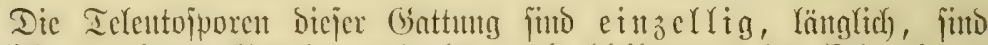

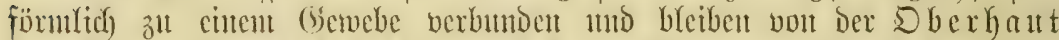

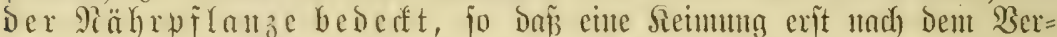

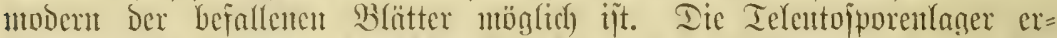

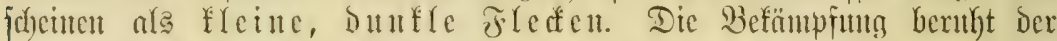

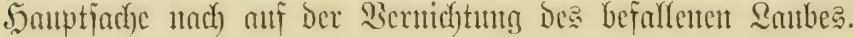

Şieker geljörent:

Der Ffrda) Groit (Melampsora Lini),

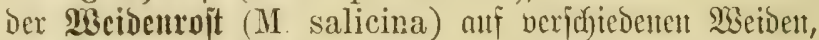

Der Pappefroft (II populina) nuf 'Sappelarten ano

Der (sipenroit (II. Tremulae) auf Der S(jpe pder Ejpe; Der Sicfernorefroit (Caeoma pinitorquum) folt mit ifm in Beziełunt itehett.

\section{Brattung: Calyptospora.}

Die Iefentofporen Gitoen fids in Den Dberhantzerlen der Stengel ber Freiberbere. Iic Sporen fitto vierzellig; fic treiben im

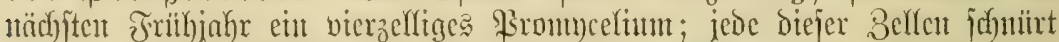

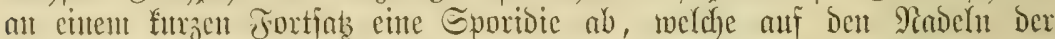

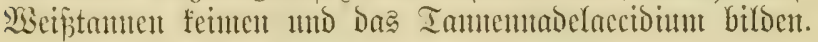

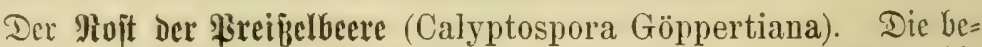

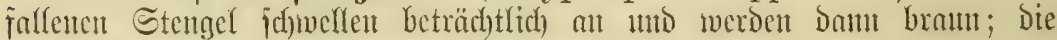
Tecibien auf ben Tammentadeln find länglid).

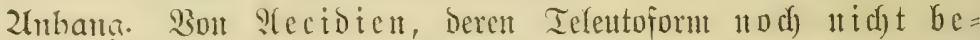
fannt ift, pei Aecidium elatinum criväfnt. Čs vertrjacht Dent

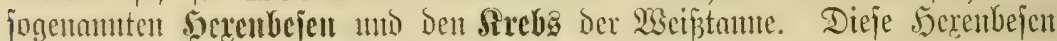

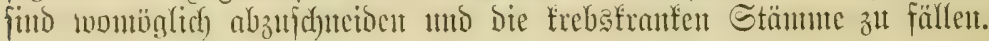


3. Familix.

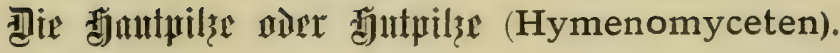

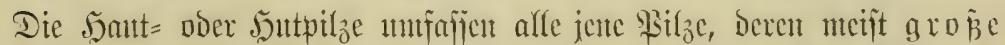

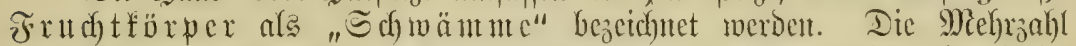

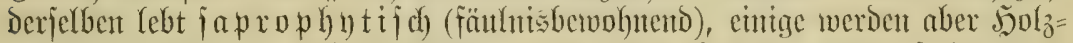

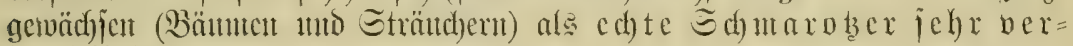
derblich.

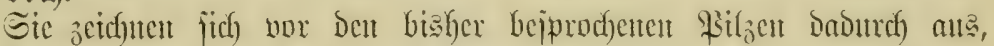
Dañ bie an oder in Den Fruthtförpern entîtehendent Eporenträger (Bajioten) an ihrem Edheitel meijt 4 fleine Jortjübe tragen, auf Deren Spibe ie cine Spore gebildet witro.

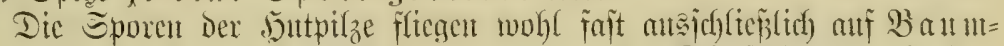

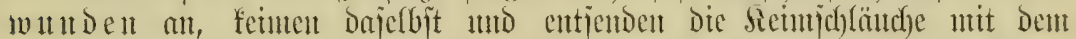

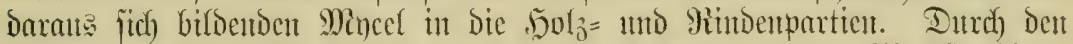

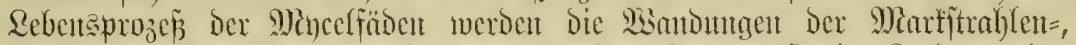

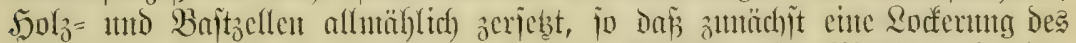
Beflengefïges unD weiterhin cin Berfall Desiclben in ग)intm eintritt;

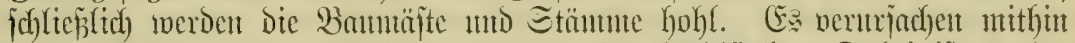

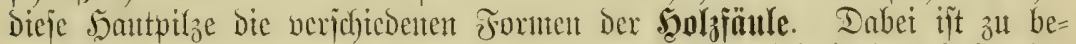
merten, Dañ bie am niddyt mehr lebenden Bellen beftebenden Teile Der

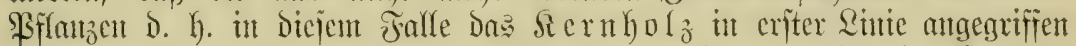
แmb acriebt wiro. Dic Berjebung jofreitet bon inten nach menen fort.

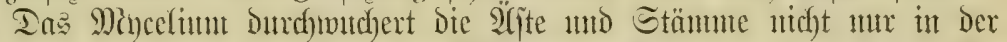

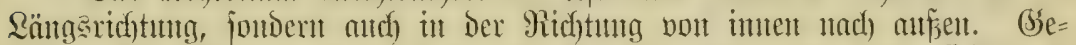

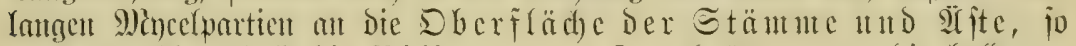

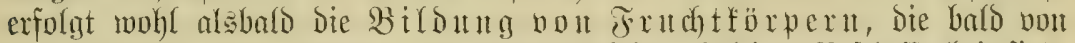
jaftig=weicher, balo leoseriger, oft aber anth fejter, holżiger Beichaffentheit jüto.

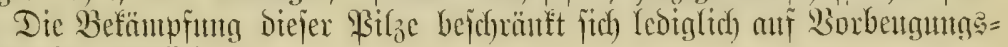
maß̃regelı, ttäntlich):

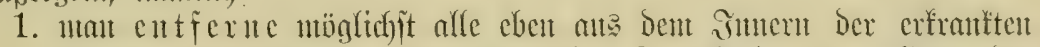

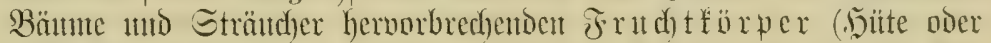

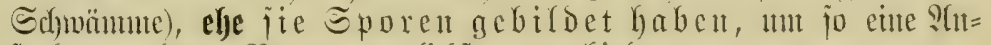

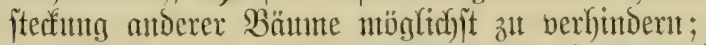

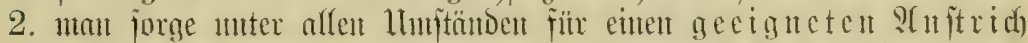

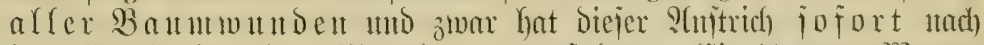

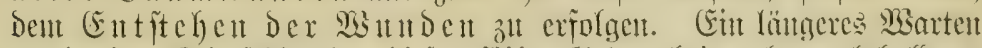

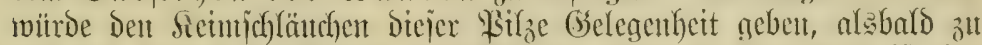

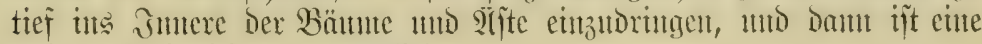
weitere Behandlung unutöglid).

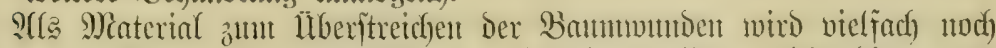
Teex empfohlen. Ieer enthält aber joharfe Etofĩe, weldhe die zarten

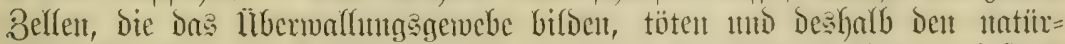

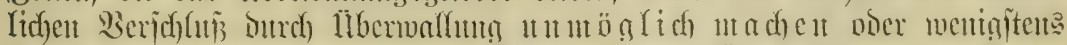

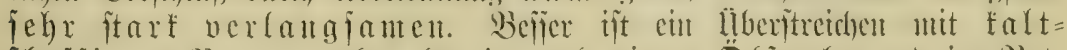

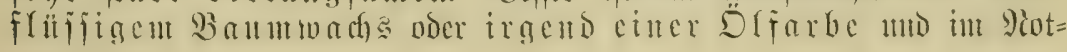




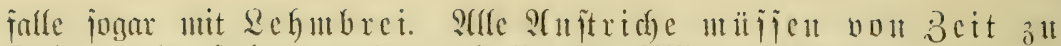

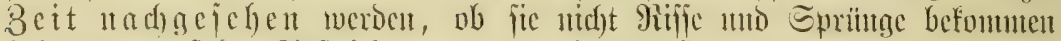

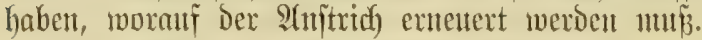

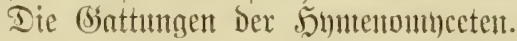

\section{Gattın! : Exobasidium.}

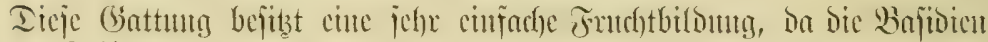

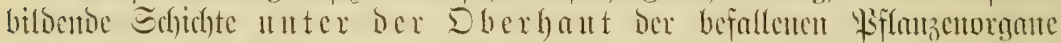

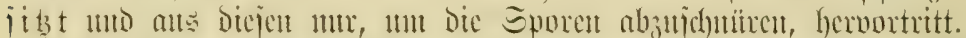

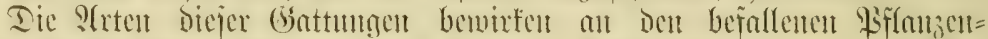

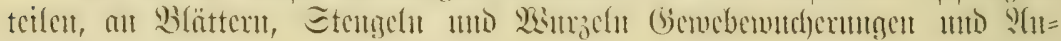
idfinellintgent.

Exobasidium Vaccinii crocugt an ben Etenge

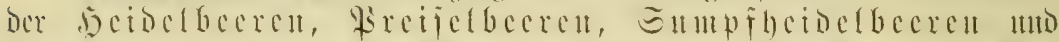

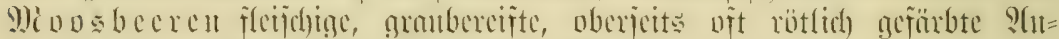

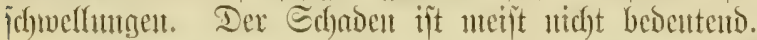

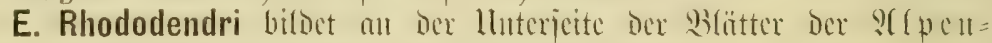
rojen cine ?het Gralläpfel wout miffallentor Form.

\section{Brattumit: Trametes.}

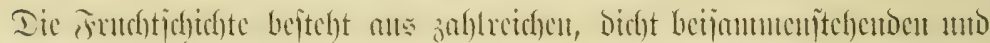

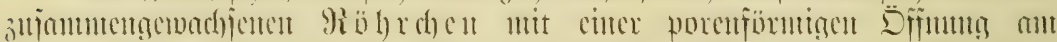

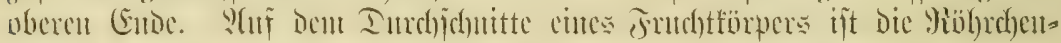

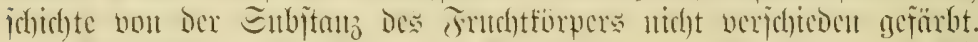

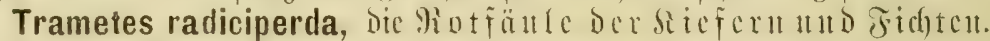

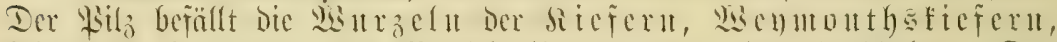

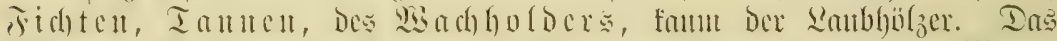

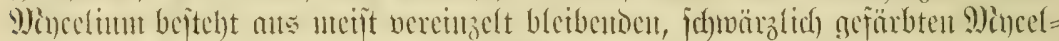

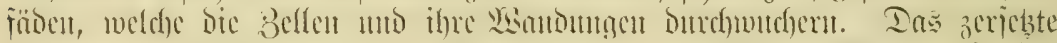
bon affutähliç $a \mathfrak{b}$.

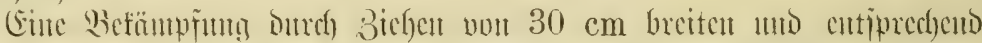

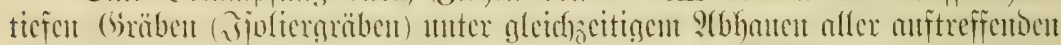

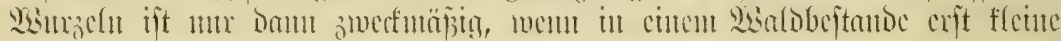
Baumgruppelt crgriffelt füto.

Tr. Pini, die giłng= oder Serufäule der Siefer, auth an

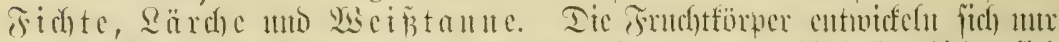

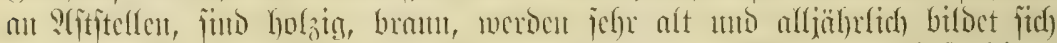

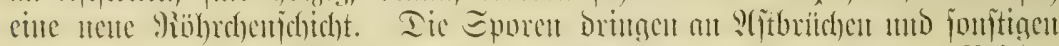

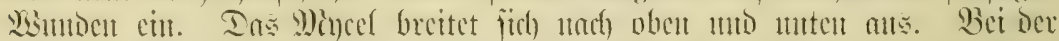

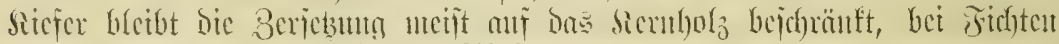

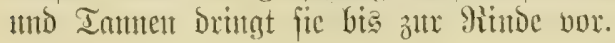

\section{Ginttung: Polyporus, Rölyrenpily.}

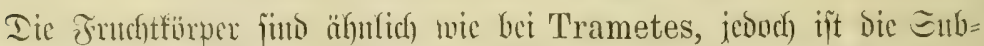

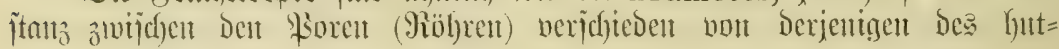


fürntigen Frutchtförpers gefürbt. Die Befäntpintutg bejteht in Der obent

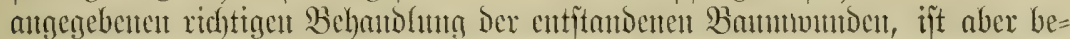

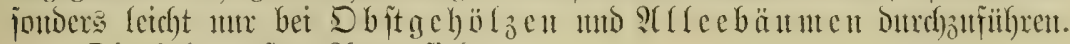

Die befanteiten $\mathfrak{A}$ rten find:

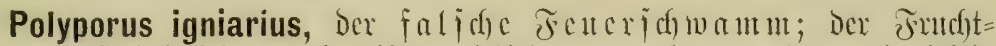

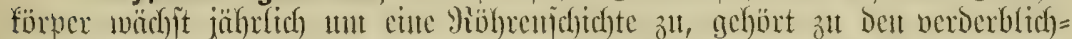

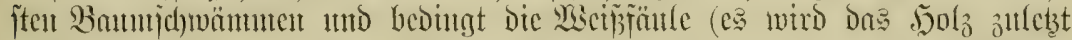

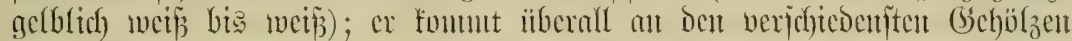

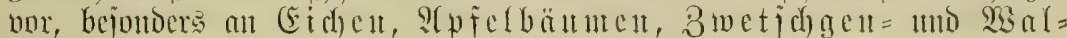

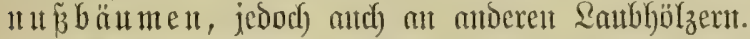

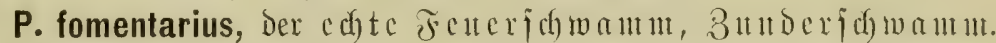

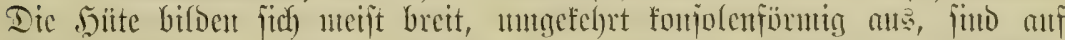

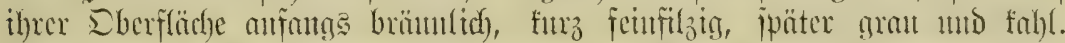

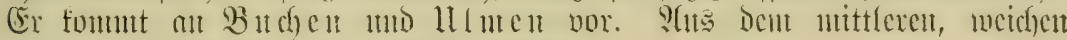

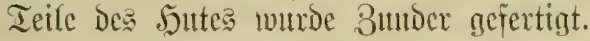

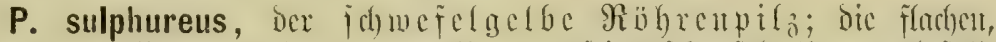

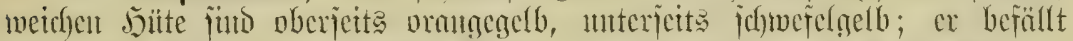

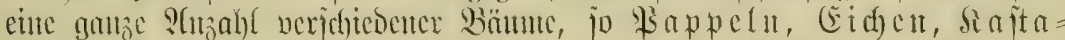

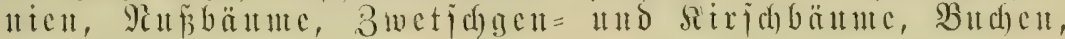
Tantten tuld andere.

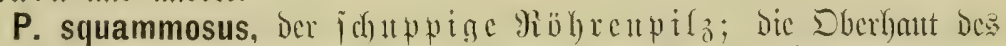

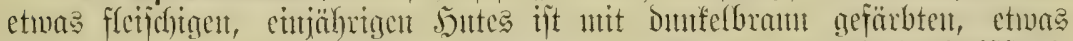

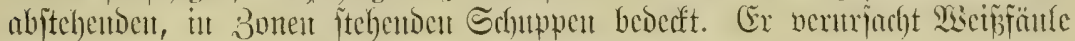

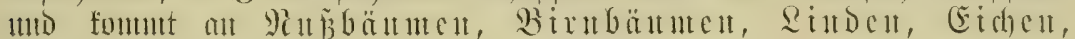

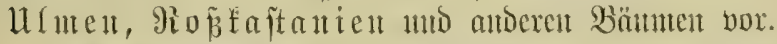

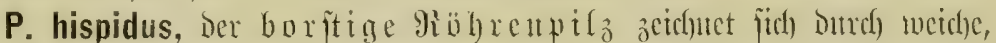

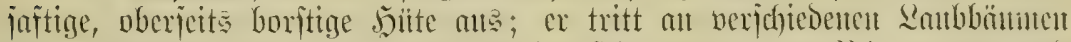

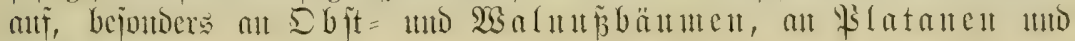
(E) d d ent.

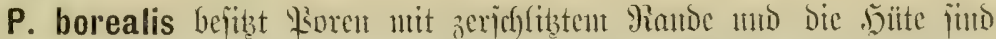

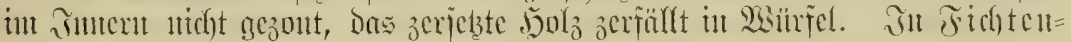
beftändelt.

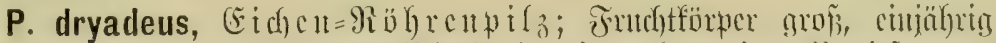

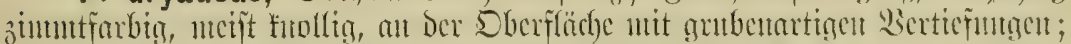

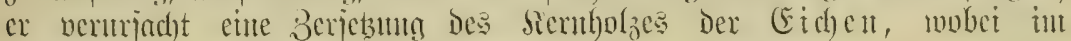

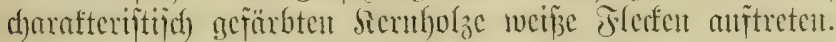

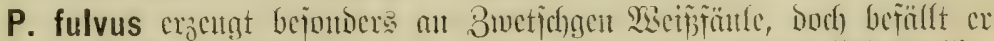

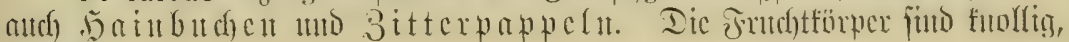
Dreiectig.

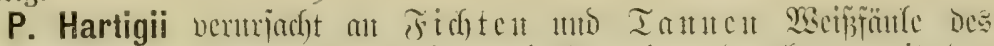

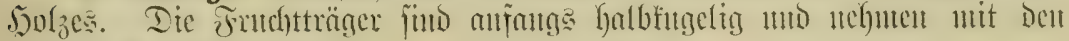
כałyrent Sintiolentornt alt.

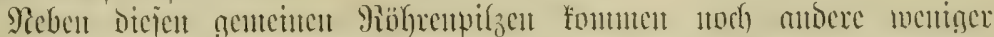

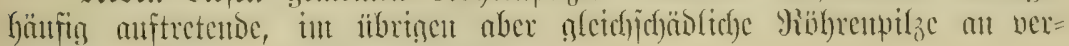

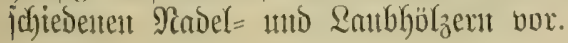




\section{t. Gattıng: Hydnum, Stadjelidjwanm.}

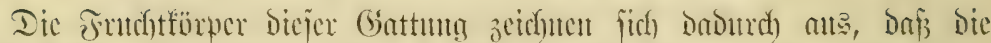
Fruthtidfichte (Hymenium) mit ftad)

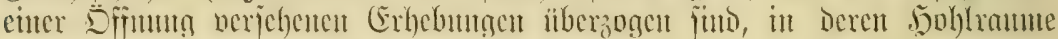

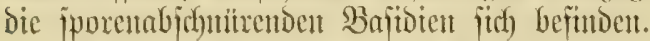

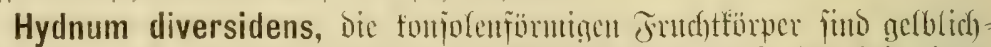

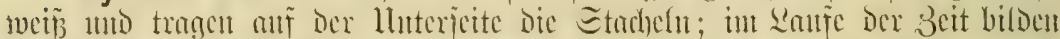

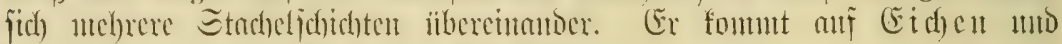

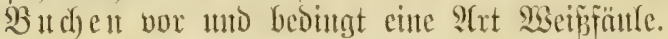

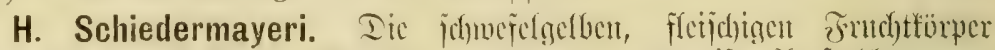

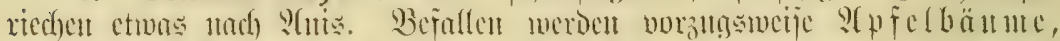

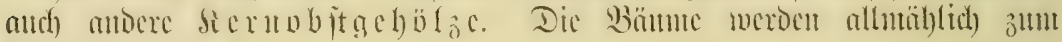
atbiterben gebrach)t.

\section{5. (Sattung: Agaricus, Blätterid)wamut.}

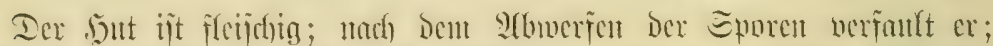

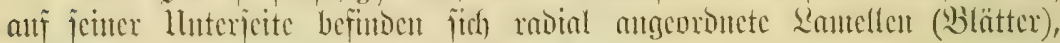
an benen bic jporenbilisenden Bafibient feben.

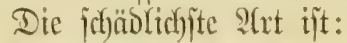

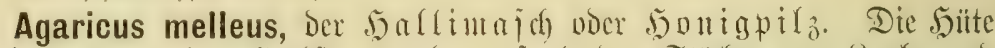

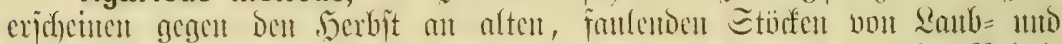

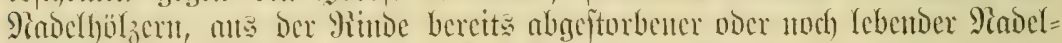

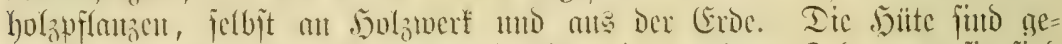

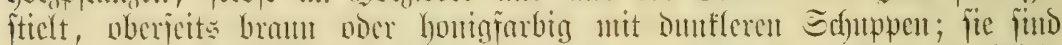

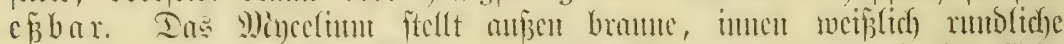

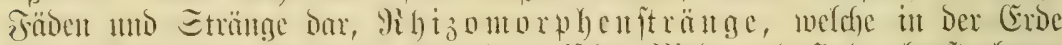

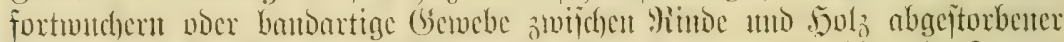

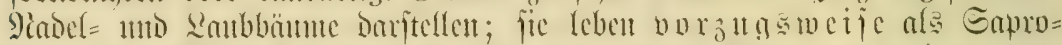

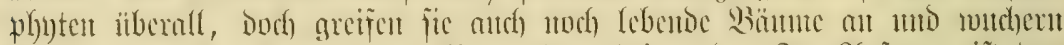

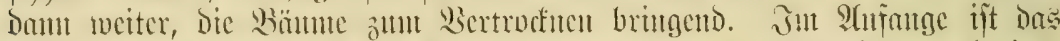

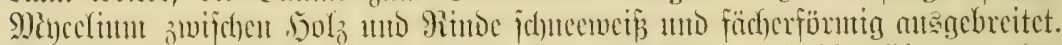

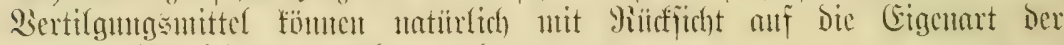
Rebentswetic nicht angewenoet werdent.

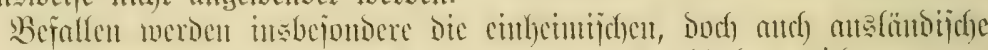

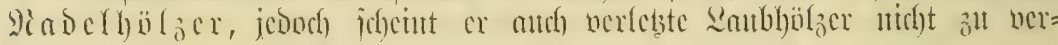
jofinent.

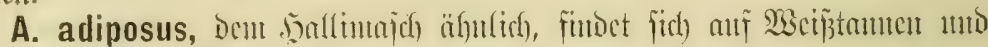

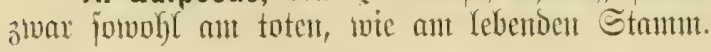

\section{Gattıtı: Merulius, Seatßjidjwamm.}

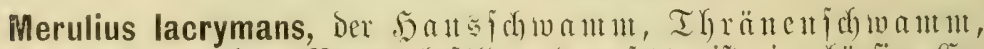

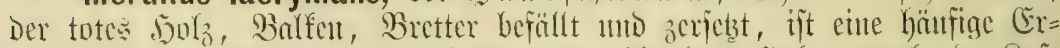

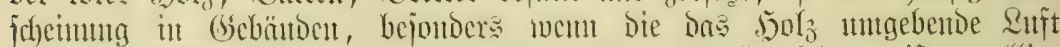

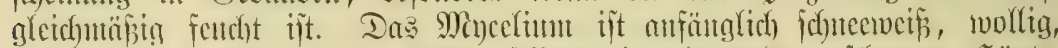

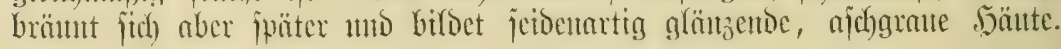




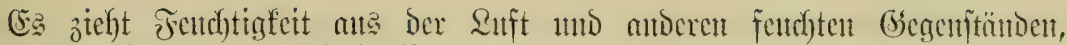

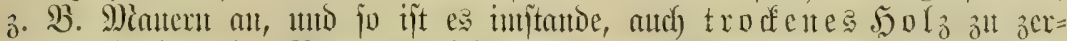

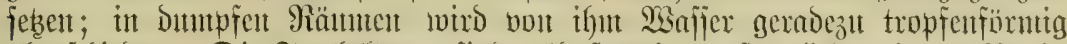
abgejchieden. Die Frutchttörper fünd tellerförntg, anfänglich und ant Fande

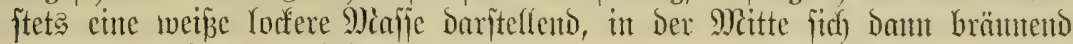
und nit Falten iiberielgent, an Denen bie iporentragenton Syphen gebildet werocn. Die Sporent feinten mur bei Eimuirfing von âffalien.

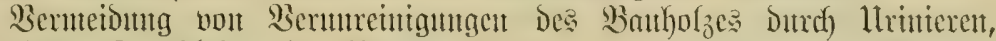

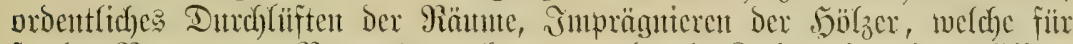

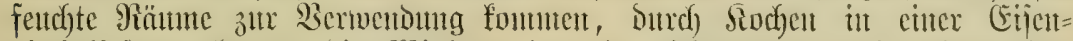

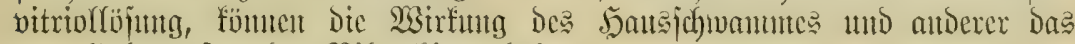
tote $5 \mathfrak{j o l} z$ zerfebender $\mathfrak{P i l} z$ Gintankaltent.

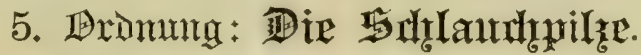 (Ascomyceten.)}

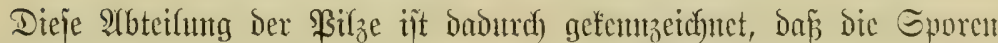
im Jntern ctwas blajig anfgetriebencr Mecelfabencuden an

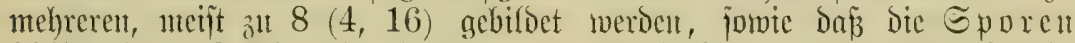

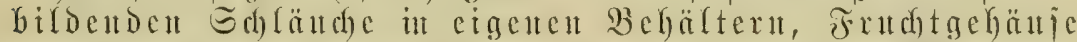

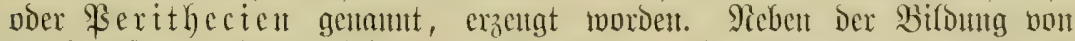

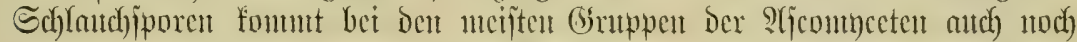

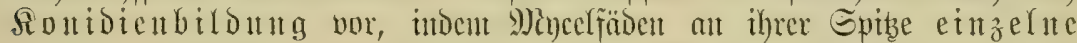

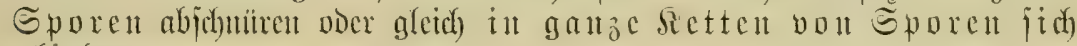
gliedern.

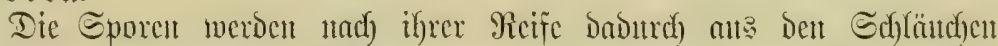

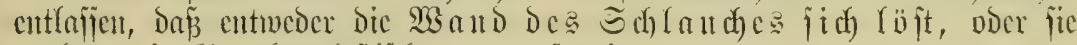
werden mit Getwalt (elaftijd) a a s gefpribt.

\section{1. famtilix.}

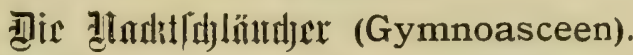

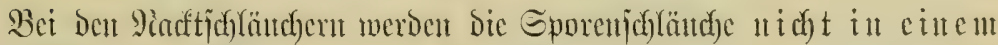

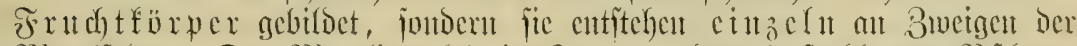

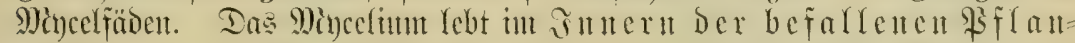

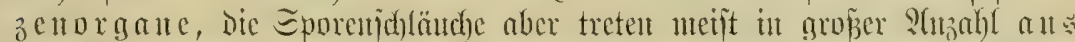

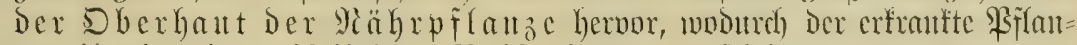

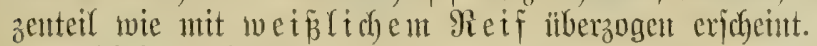

Sjieber gehört mur cute Gánttung:

\section{Taphrina (aud) Exoascus).}

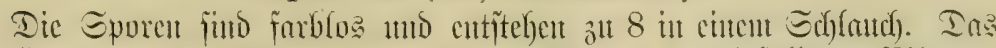

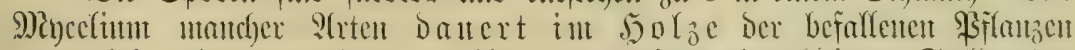

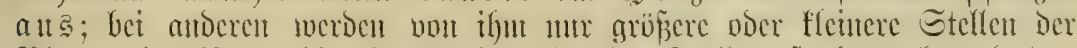

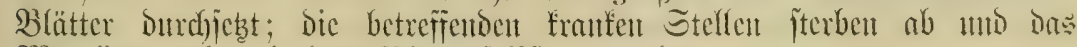
Mucelium geht mit dent Blatte jelbit zugrumbe.

Die wid)tigiten 2(rten fund: 
Taphrina bullata, Blajentraflgcit bex Biruenblätter.

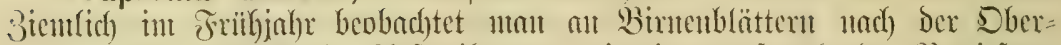

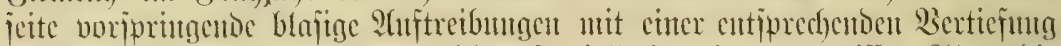

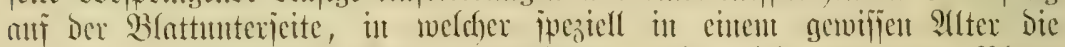

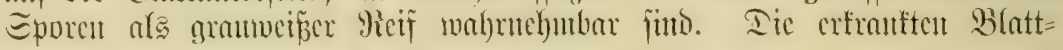

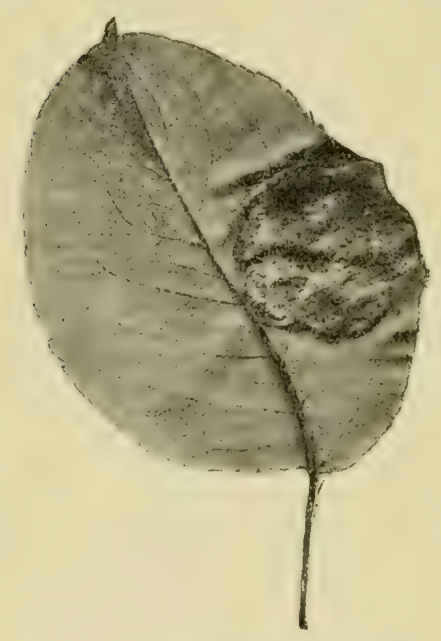

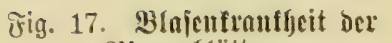
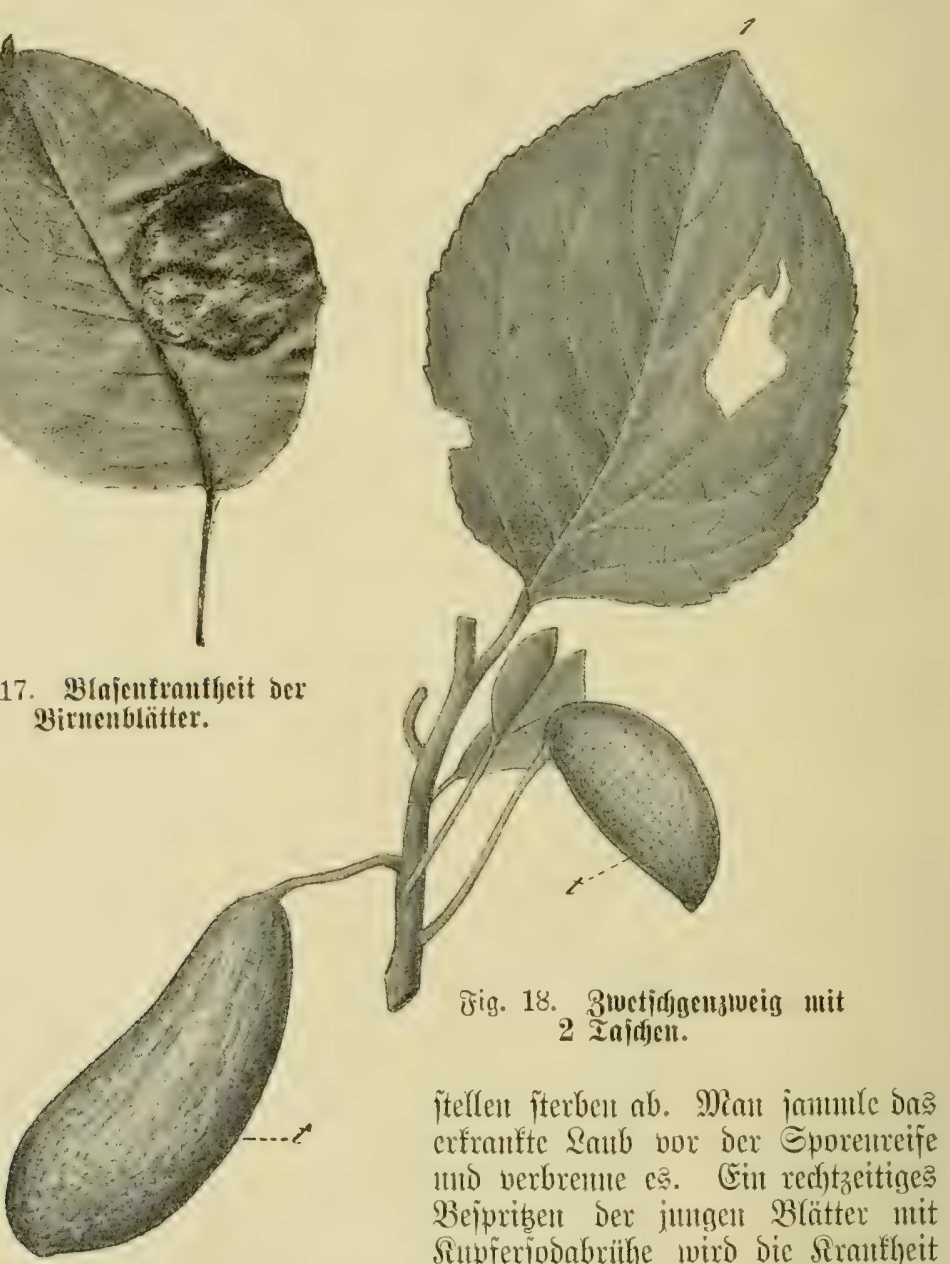


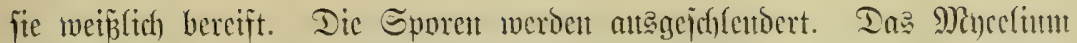
findet fich auth it ben Bwetgen und Dautert

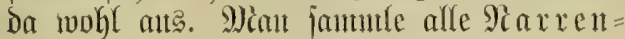

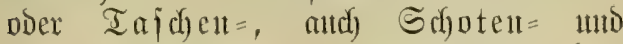
Sungerzuetidfgen genamt, box Der Eporenbildultg แmb verbremte fic; die ntit Iajd)en bejebten Bweige jojuetioe ntan

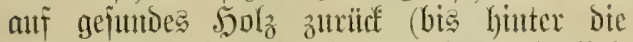

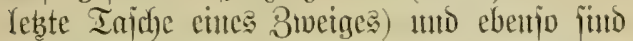

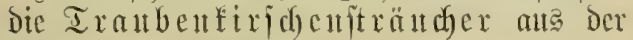

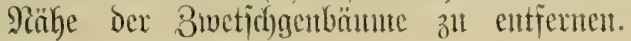
(fig. 18.)

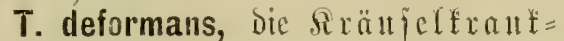

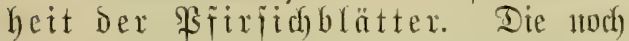

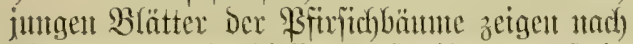
oben bortretente blafige Aniftreibungen oft in Berbintoung mit citer Sitïnunng แnto fräıt= jefung des jungen Blattes. Dic Ututerieite. Der Błajen bedectt fich) unt bent reifartigent llberzıtg

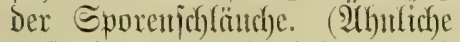
(Exje)einntugent bewirtent atd Blattläuje durdy ilyr Eatgen, Dod) ift iffere Gegentwourt leidft feitzutitfen.) Das M)incclium iiberwintert wohl and in Dell älteren 3weigen unto bringt bou Da it bie Sinoppent cit, jo baf̉ jüntlidue B̉lätter ber jungen Biveige befallent werdent. Start befallene Pffranzen fterben in wenigen ฐalyreu ab. Die Bweige mit fräıffelf́rauten $\mathfrak{B}$ lättern fint baldigit auf gcjunces.5olz zurîd =

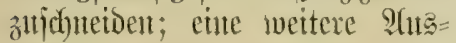
breitung wiro butrch rechtzeitige Bejpribung uit Sutperjoonbribe voer Crntfermm Der Blätter vor: Der Sporenbildung berhindert. (ङ̧ig. 19.)

T. Cerasi, der Syexen= befen dex $\mathfrak{A}$ iridb) älute anf Sit $\tilde{B}=$ tt

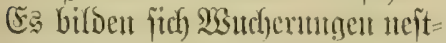
artiger, aljo bidht ftehender, itete unfundutbarer Busige. Dicje

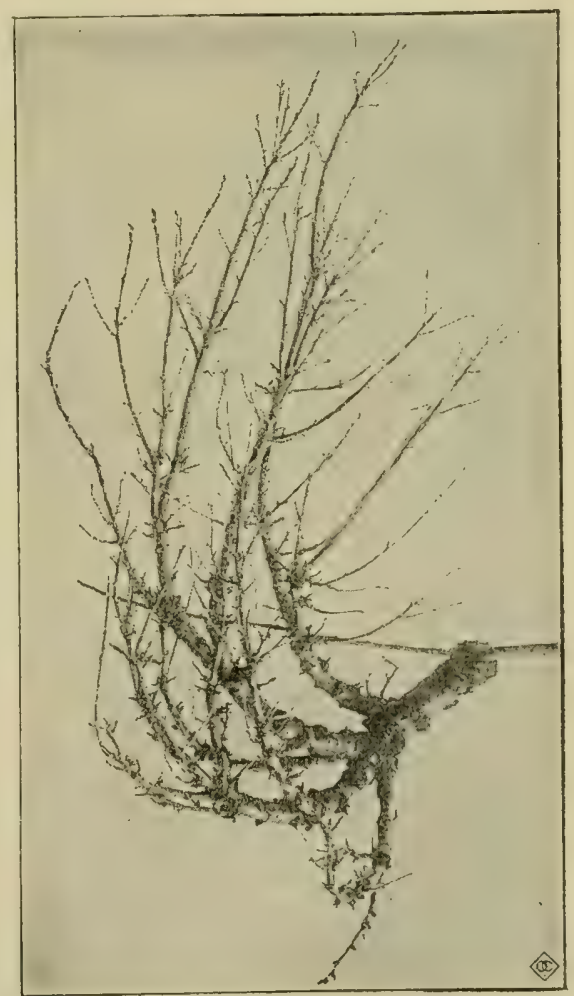

Jig. 20. secrenbejen ocr Siridje. 


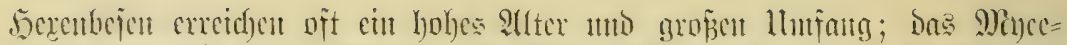

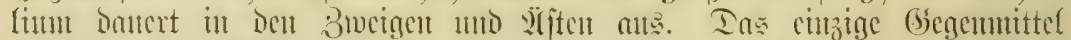

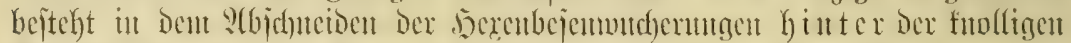

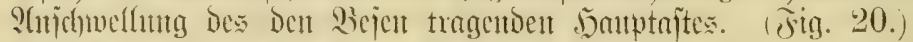

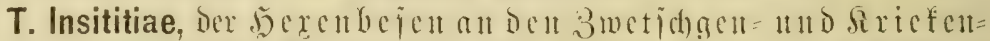

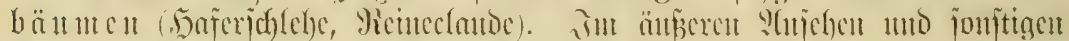

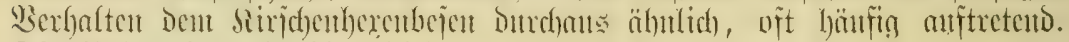
Die Beföntpfung ift bic gletche.

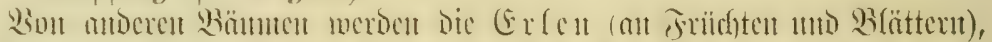

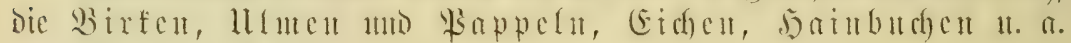

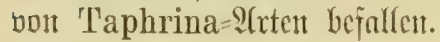

\section{Familic.}

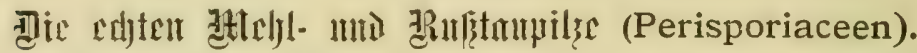

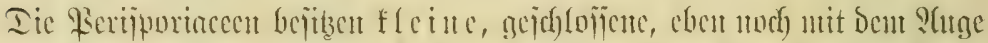

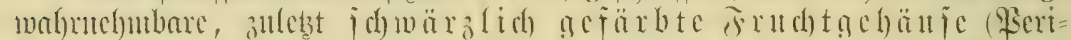

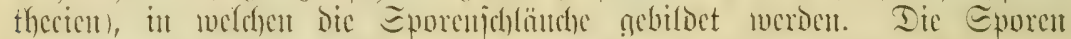

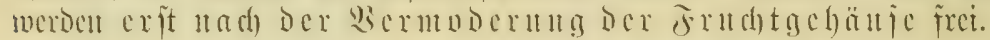

\section{Unterfamilic. Die ednten Mefltaupilłe, Erysipheen.}

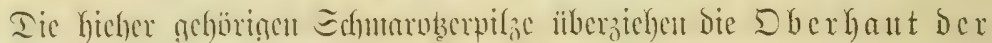

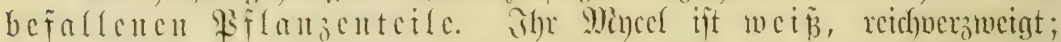

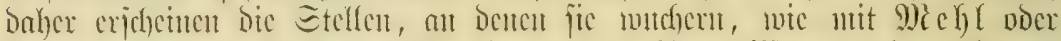

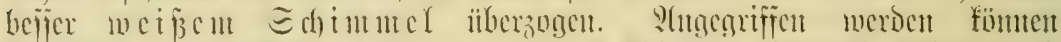

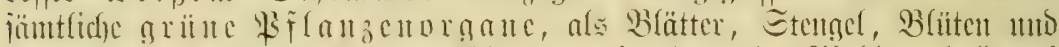

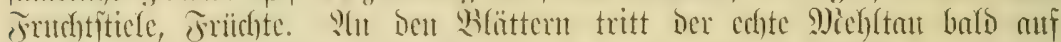
Der Dberjeite, balo atf ber ll uterjete anf, woer ex bedectt bas ganze

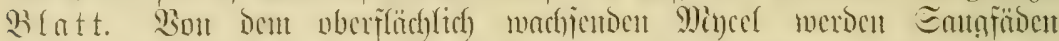

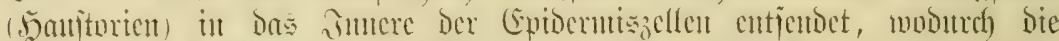

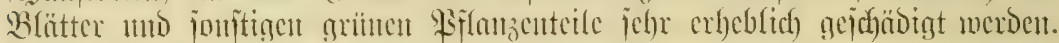

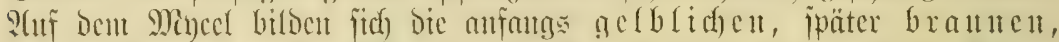

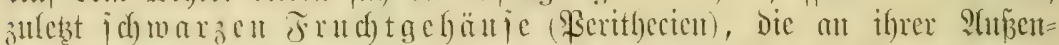

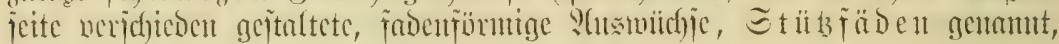
befitzett.

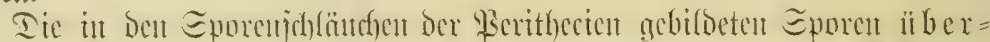

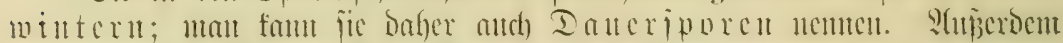

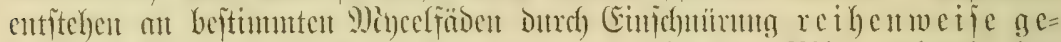

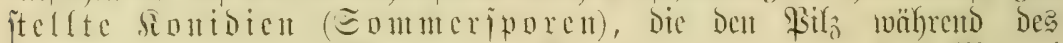

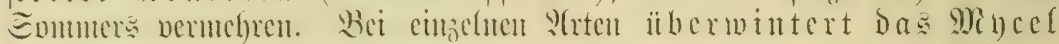

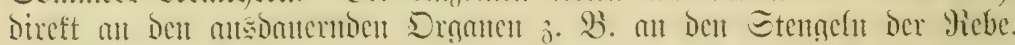

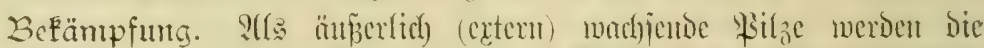

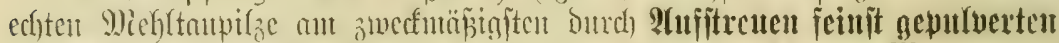

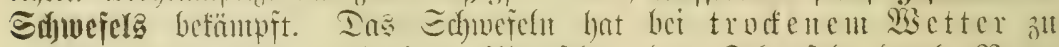

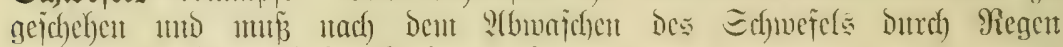
imer wieder wiederfolt werden. 


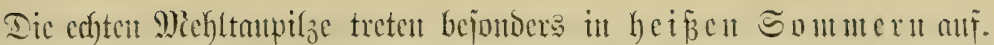
überjidyt ber (s)attugen:

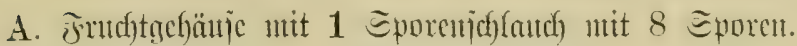

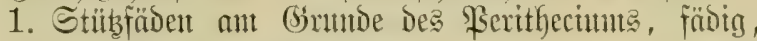
unverżoeigt, geichläıtgelt.

Sphaerotheca.

2. Etiibfädent anf der Eptize Des Peritheciunts, ant Ende gabelig verżucigt.

Podosphaera.

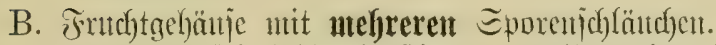

1. SCnbängjel fteif, borftig, ant Ginntibe blajig anfgetrieben.

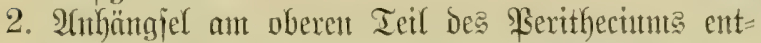
ipringend, oben unerztweigt oder 1 fad gabelig= geipalten und die Enden eingerollt. Uncinula.

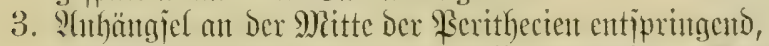
an ber Epthe wicherfolt gabelig verawetgt. Microsphaera.

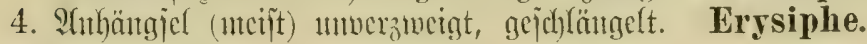

Jait ftets ofine Frudbtgebäuje ijt bei uns bis jeb̧t do Oidium, Der edfte Mehrtalt

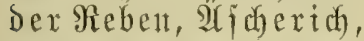
gefumbent worden; er ber= mehrt fich Dutrd) Fontidien แnธ Das Mincel itberivintert

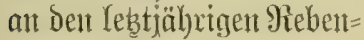
trieben. Ex gebört zur (osattunig Uncinula.

\section{Gattıtig: Sphaero- theca.}

Perithecien mit einent ad)tiporigen Soflaudy; Stilizääben an Orrutude Des \$erithecuunt entipringend, ımberzmeigt, gejchlängelt. Sonioien fettenförmig.

\section{Sphaerotheca pan-} nosa, Der cedite Meghl= talt bex Rojen, Rojen=

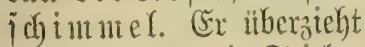
Die Blätter mo Triebe,

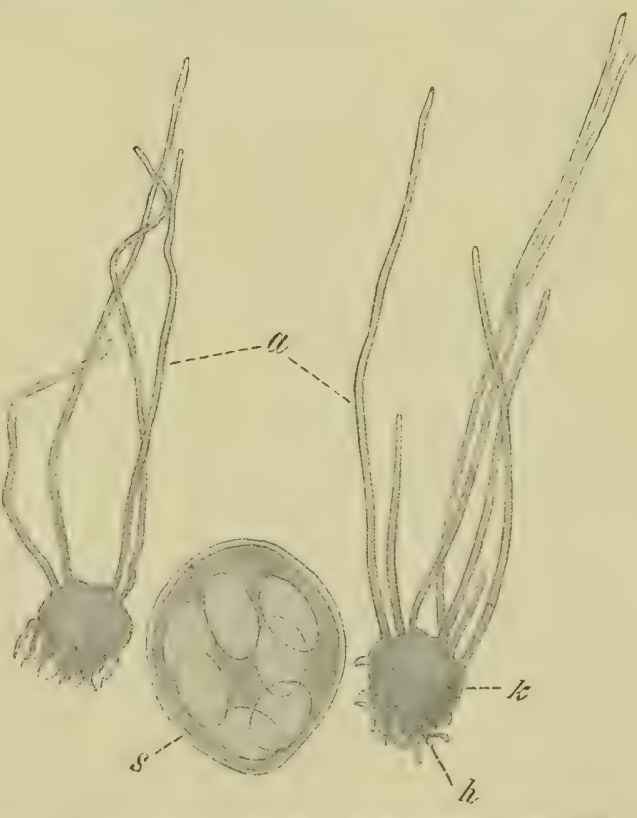

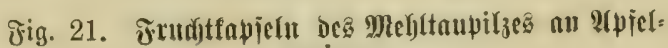
zweigetr.

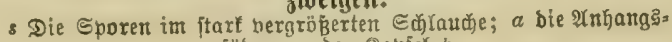
fäbett an Der sapjel $k$.

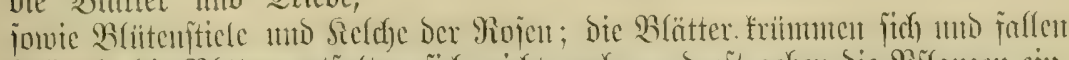

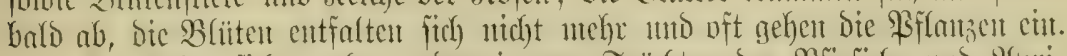

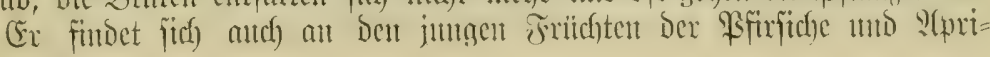




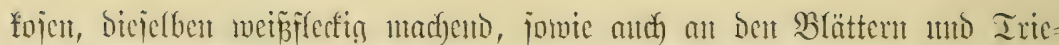
ben Diejer Steindobitgchößze.

Sph. Castagnei, der Mebltau des 5op feus, Der Erdbecten,

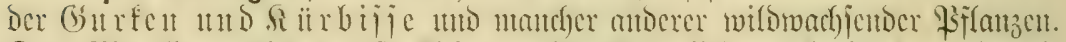

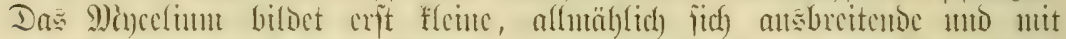

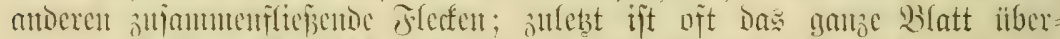

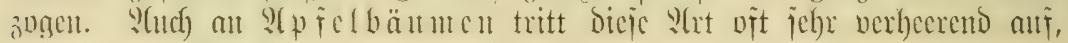

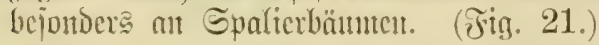

\section{Soltung: Podosphaera.}

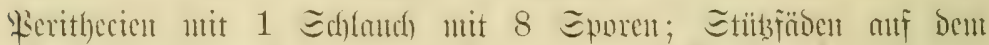

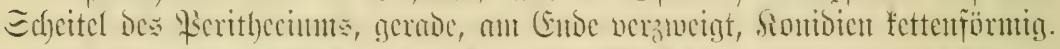

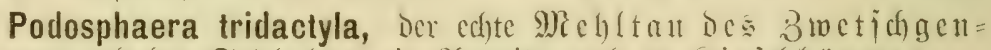

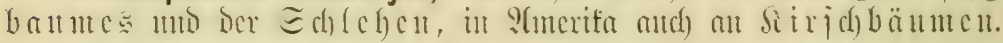

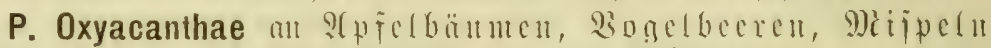

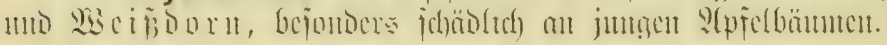

\section{Gattung: Phyllactinia.}

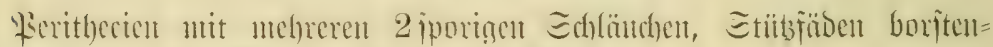
förmig, gerabe, aut Grumbe fugelig aufgeblajent.

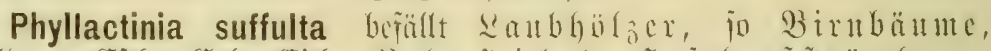

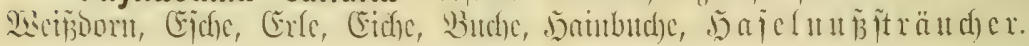

\section{Gattıung: Uncinula.}

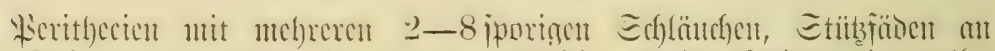

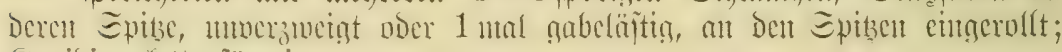
Sontibicn fettenförmig.

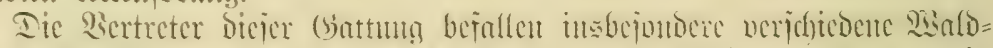

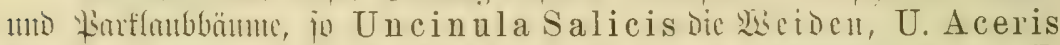
Den Jclbaborn, U. Tulasnei anf Acer platanoides, U. spiralis atr amerifanijocu mo Den ed ten औeben.

\section{Gatttttg: Microsphaera.}

Iic Herithecien enthalten unchrere, 4 bi siporine Echlänche; Dic

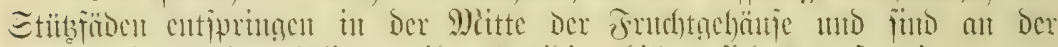

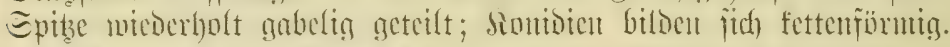

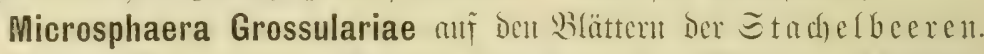

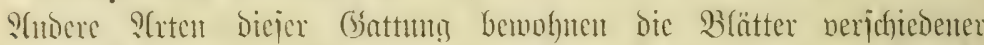

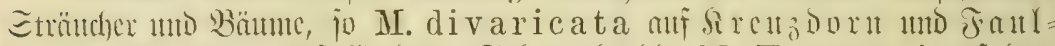

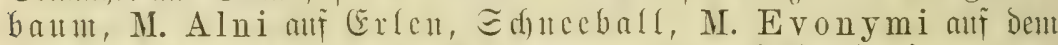

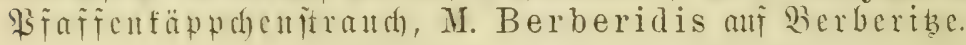

\section{Gattung: Erysiphe.}

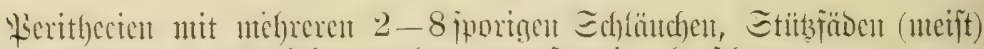

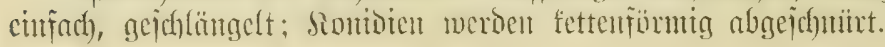




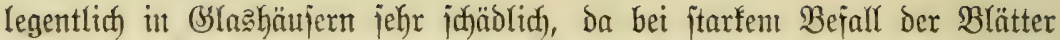
bie Blütenbildung verbindert wird. Man befämpit ifyn in ber gleichen Weije, wie bie borige 2 rt.

\section{Unterfamilic. Muptaupilze, Capnodieen.}

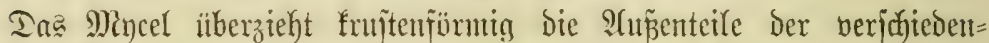

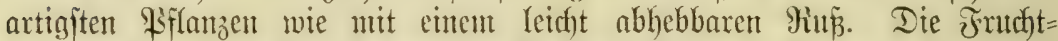

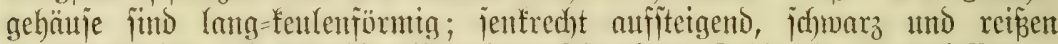

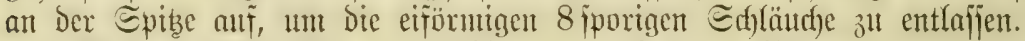

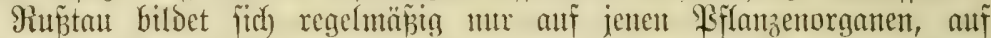

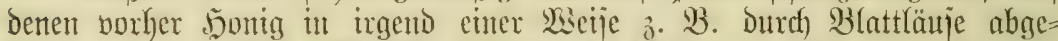

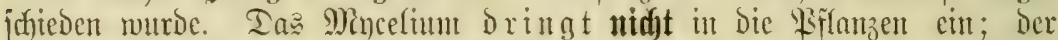

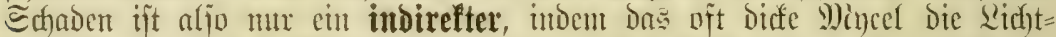

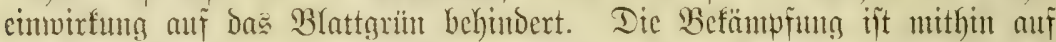

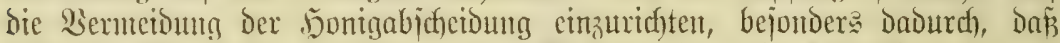
man die Blattläuje vernichtet. Ier Miñ̈tau ijt aljo fein Barajit.

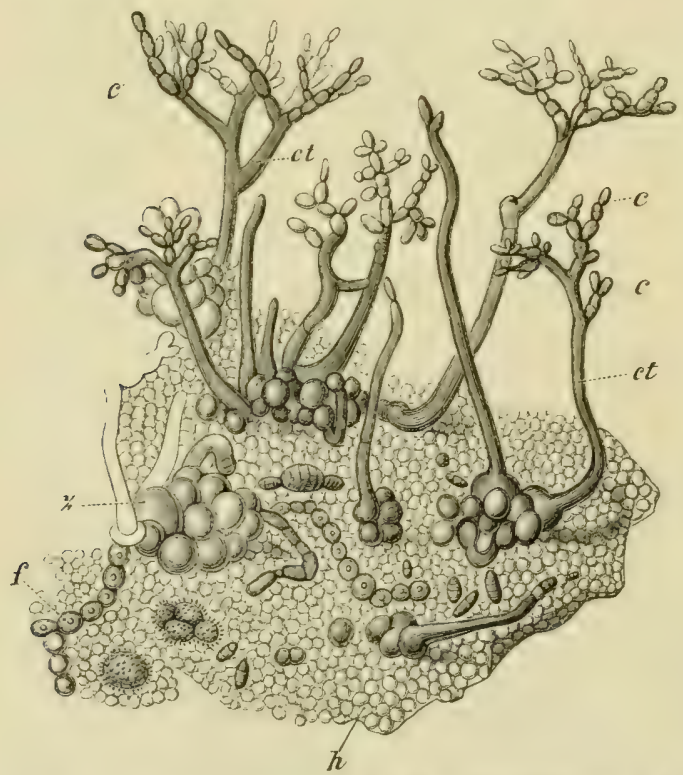

テ̛ig. 24. Snoipenvegetation (Conibienbilbung) Degి Miuptnupilzç.

c Sonibien; et Bafibien, welde bie snofpen abjüntren, aus iftwarzen 3eđkaufen $z$.

\section{Shattung: Ruḅtau, Capnodium.}

Capnodium sali-

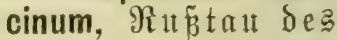
Sopfens, jofwarzer

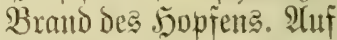
Sopjen tritt Diejer auf lebentoen $\mathfrak{B f f l a n z e n ~ m o h = ~}$ nende Saprophyt oft ichon friifzeitig auf uno fann Dann Durdy Beein= fluțut! Der Ridhteimuix= funt thatiäd) lich jochäolich jeit. Err fintet fich audi) nod atf beridje= denen anderen \$sfanzen, jo Rappelı, Hrmen, Metoen, Eichen, bejon= Ders ftarf an Rinden, ferner an Stein = uno Sennobjtbäument, jo be= jonbers 3rotjdygen= und Lipfetbämuten. Manche Botanifer geben Dem Rubitau nad ben ber= icjiedenen Wirtapflanzen bejondere Tanten. Seben Dex Bildung von Sd) (audfiporen funden fidh nod) andere Bermetrungäformen beim Ruñtau, io z. B. merden an Der Epibe von Mincelfäben einzelne Eporen 


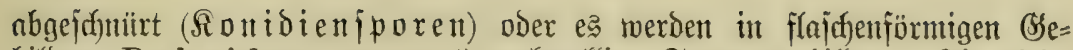

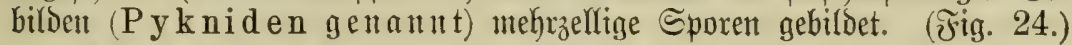

Apiosporium pinophilum, Der $\Re u \tilde{B} t a \mathfrak{d}$ Der $\mathfrak{T} a n t e$, viberżieht in

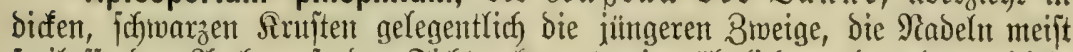

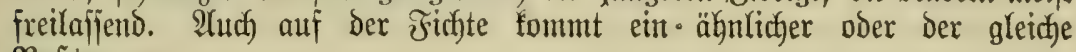
Rū̂tau vor.

\section{Jamilie.}

\section{政}

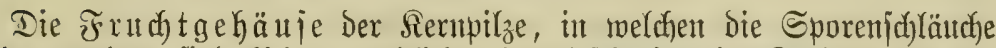
gebildet werben, fimo Hleine, runtoliche voer flajichenfürntige Sapjefn, Die auf

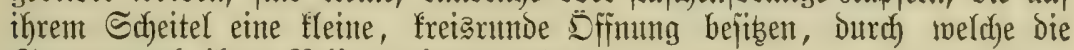
Eporent nach ihrer ßeife entleert werden.

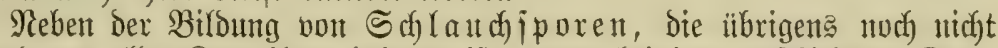
einmal bout allen Sernpilzen befantut ift, treten bei bett veridjedenten Sicrn= pifzen veridiedenartige Ronibienformen anf, jo Dap duth bieje

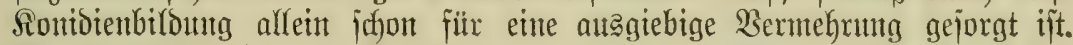

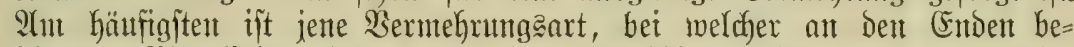

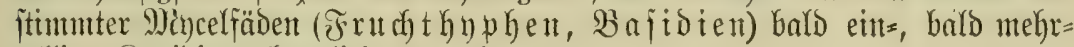
zellige Sionibien abgegliedert iverben.

Befämpfuna. Bahfreidge Bertreter Der Rernpilze merben unferen

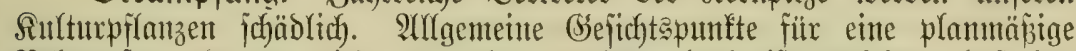

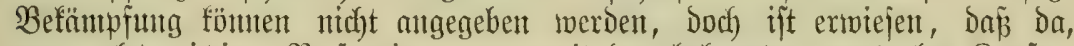
wo redtzeitige bejpribungen mit ben befamtent, neutralen Supfer=

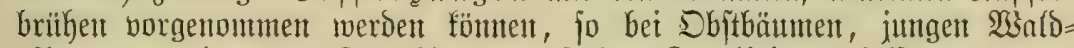

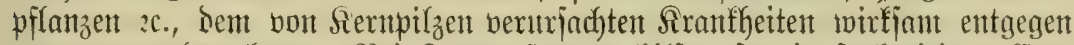

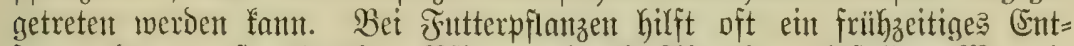

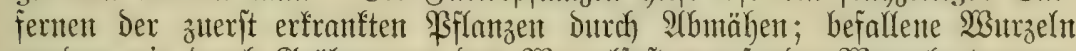

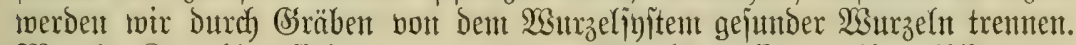

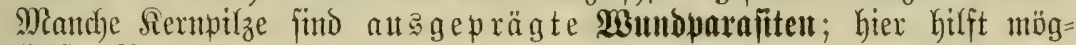

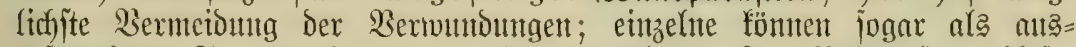
gejprochene Saprophnten angejehen rveroen. Bur Befümprututg biejer

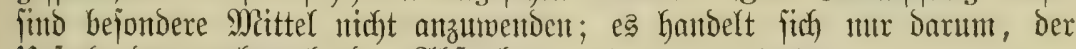
Itrjache des vorkergehenden Mbifterbens entgegen zu tretent.

\section{(E) inteilug Dex Rernpilze.}

1. Hypocreaceen. Fruchtförper (\$erithecient) auf bem Mincelium

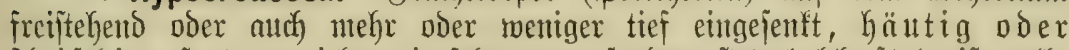

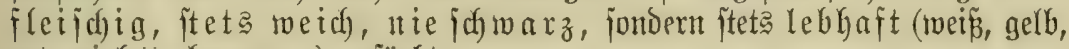
rot, biolett, braun 2c.) gefärbt.

2. Dothideaceen. Frutdffförper ohne Dentlidye eigene Wandung, im

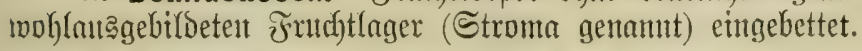

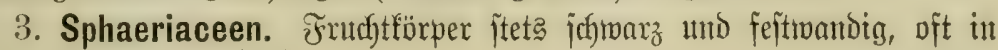
eit శrntudttager eingejentt. 


\section{Unterfamilie. Hypocreaceen.}

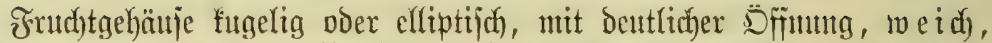

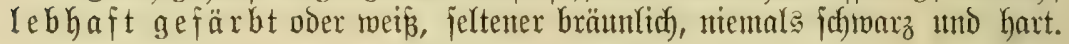

\section{Bsattung: Nectria.}

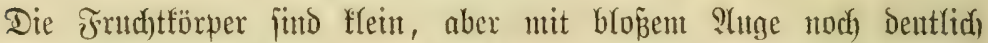
jichtbar, gelb bis lebraft zinnoberrot gefärbt unb entifehent meift

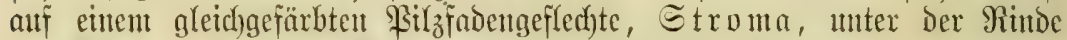
Der äjte unı Brweige. Mian beobadhtet fie fehr häuffig allf abgeftorbenten

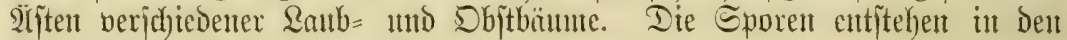

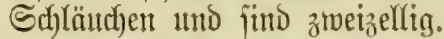

Die Meftria=?laten find höd)itens 2 undoparajiten; fie fömen mu

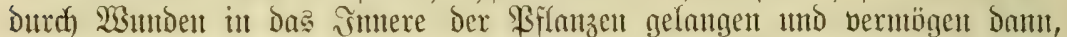

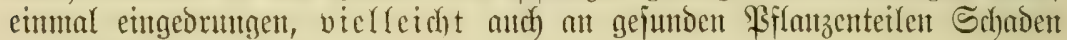
anzuridjten.

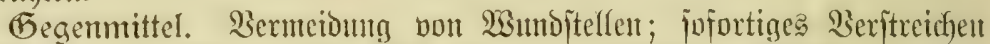

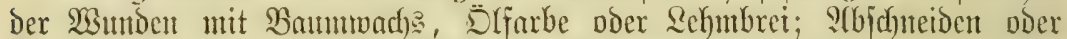

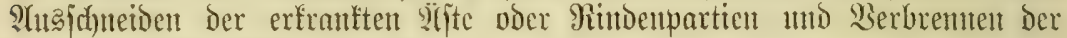
abgeid)nittenen franten Teile.

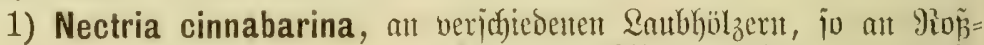
fajtanien, Ahorn, Mlnen, an Dbit=

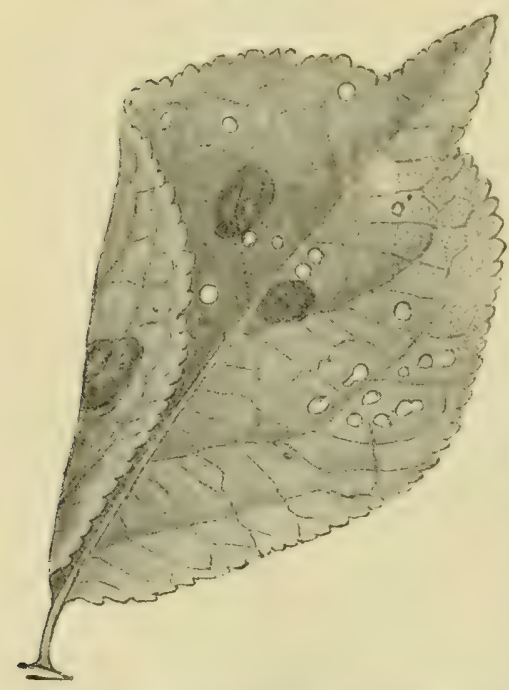

Jig. 25. Polystigma rubrum an Buctidgeu, die gropen Dunflen Flecten. Dic fleinen \&öder rühren bon Corcospora circum. cissa her (fiehe unten).

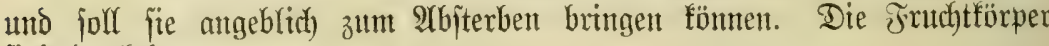
fint bunfe'trot.

bäımen und Beeremĩträudhern, poivie an zahtreich)en Bierbäument unঠ = Sträu= d)ern. Die zimoberroten Fruddftürper jint nut an Den abgeîtorbenen 2ijten unto Bweigen jidytbar.

2) $\mathbf{N}$. ditissima jolf ben joge= nanten firebo der Rnubbüume, jpezielt

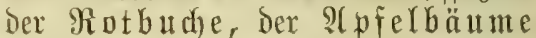
unto anberer verurjachen. Die neutejten Beobadytungen habent ergeben, baj Die erite Ilrjache Des Sirebies Froit bejdjäbigumgen oder Sageljajlag fino; fpäter exjt fiedelt itch an ben voun

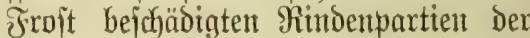
frebspilz als Saprophyt ant. Die Frudytforper biejer Art jinto viel flemer als am vorigen, aud tricht jo hell rot, mebr fitgelig imto finden (iid) oft zahlreich) auf Den toten Rinden= partien bon firebajtellen.

3) N. Cucurbitula befällt Fidd)= ten an irgend weldhen Wunditellen 


\section{Sfattung: Polystigma, \&ohe.}

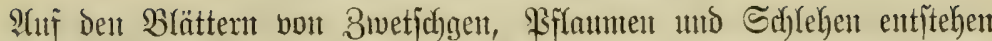

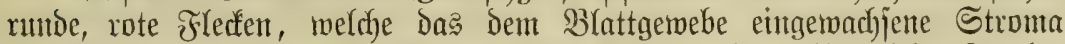

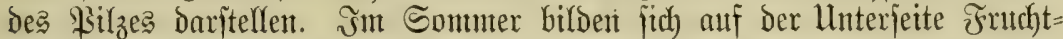
gehäuje (\$infnioen) mit fäbigen, hafenförmig gefrimumten Sporen. Die im nädjten Jriibjahr eine Âftectung verurjachenden einzelligen, hellen

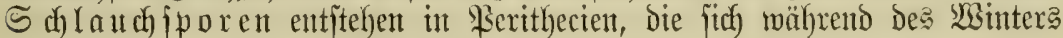
unto Frübjahrs bilben (Fig. 26).

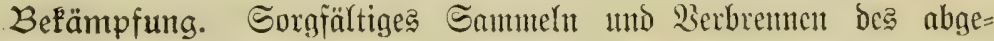
fallenen Rautbes; ein red)t= zeitiges. Befprikett Der 3wetidugenbäınte währeno Doer unmittel(bar nady Der Blattentfaltung wiro jeine Winfing nidyt berfehten. Entipredbende Ditngung wiro Die Bfflanze mider= itanosfälyig macken.

Polystigma rubrum, die Rohefranffeit, bie

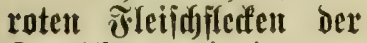
3metidjgen, tritt in man= deen Jahren und in mant= chen Gegendent fo ftarf

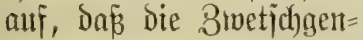
bäume ganz gelbrot exjdyeinen, äbulidy mie mit ben sitterroit be= fallene Bimbäume. $\mathfrak{B} e=$ fallen weroen am ftärfitent die Brwetichgenbäıme

(Prunus domestica mit läıgliç)en Früldyten), เväh= reno die \$fflaumenbäume (Prunus insititia) แmo ebenjo die Shlehen oft mur idyrwad) befallen werden

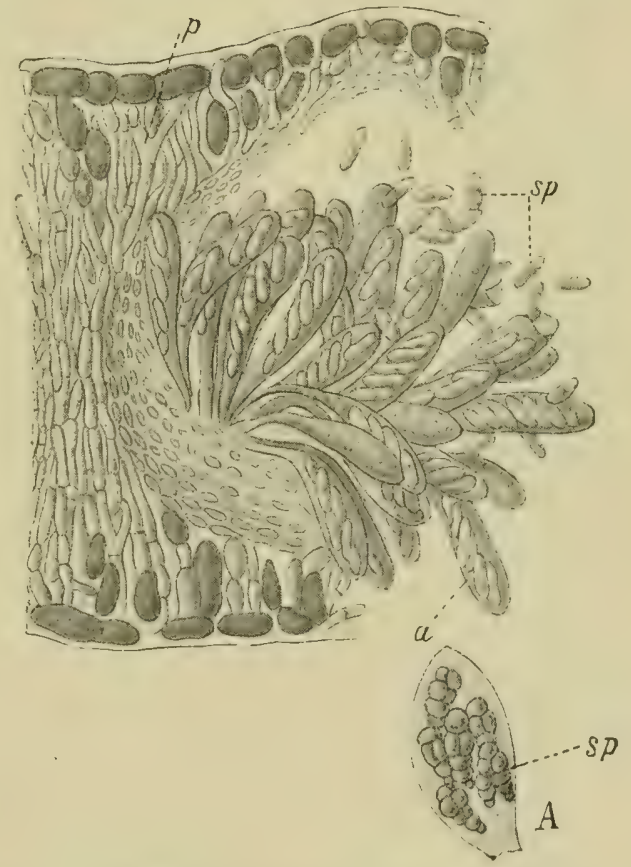

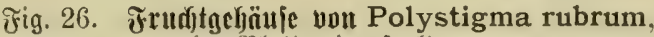
im Blatte eingejentt.

$a$ Sporenjळiäurage, $s p$ Sporen. (ङ)ig. 25).

\section{3. Şattung: Epichloë, folbenjajimmer.}

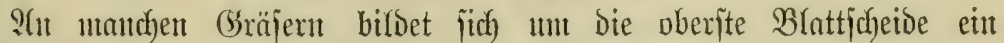

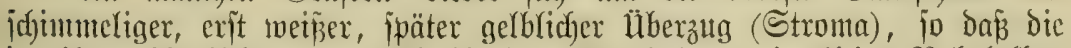

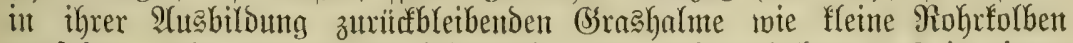
ansjeben. Die Sporen fino fabenartig, lang und entitehen ju 8 in einent Sdhlaudf). Sjieher gehjört 


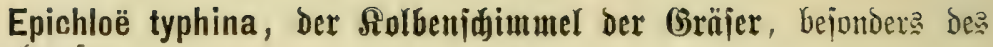
Sinäuelgrajes.

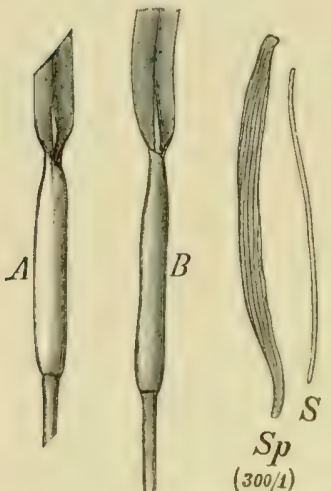

Fig. 27. Epichloë typhina.

$A$ junges, I; älteres Stabium. Sp Eporenjilaud, S Epore.

\section{Gattung: Claviceps, Mutterforn.}

Einzelne Frudyttnoten Der Roggent =, iel = tener Der Mgeizen = und Beritentähren bilden fich in bie befannten violetten, Garten, ftarf giftigen Mutterförner um. Der ganze Entwidflunga = gang des Mittertornpilzes ift folgender: Die im Jrithjahr gebildeten Ed)(aut)jporen infizieren den jungen Frudhtfnoten Der Getreidearten, weldyer rïglich in bas befannte Mutterforn ungebildet

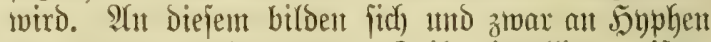
im oberen, mehr engeren Ieile eitzellige, eiför $=$ mige Sionibien, weldye in einer gleidgzeitig fid

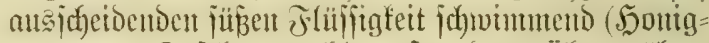
taut) bon Inlfeften tookl auf andere äbren über= tragen werden. Später erhärtet biejes Mitter= forn tnto fällt bei Der Getreioereife oder nit autd) erit in ber Schemte ab. Im Jrilibjahr bilden fidf) auf Diejen Manttertörnem (Sflerotien) $g e=$

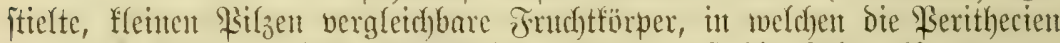

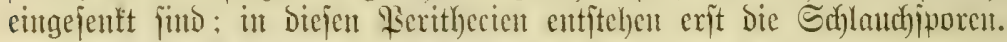

Claviceps purpurea, ذas genteine Mintterforn. In mand)en Jahren ijt Die Mutterformbildung fehr ftarf; 3-5\% Matterfömer Dent Mehle

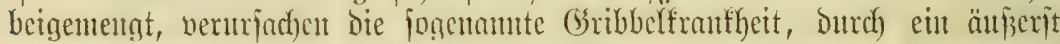

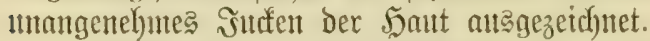

Befämpfung. Iic Mìtterförner miiffen jorgfältig ats dem Satgetreibe entiernt mo verbrant merben. Man bari fie meder

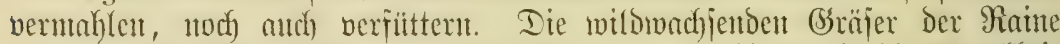

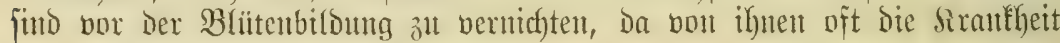
anf bas Gsetreide itbertragen wiro.

\section{Untexfamilie. Dothideaceon.}

Das aus geglieberten Föben beitehento Mancel muchert int Jumern

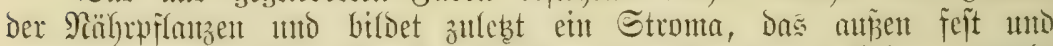

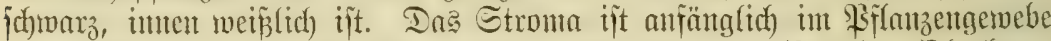
cingejenft uno twiro crit jpäter, nteijt nad) dem Berreipen ber Dberfbaut,

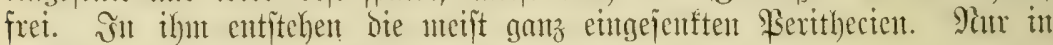
wentgen Gattungen fommen Sdymarober vor.

\section{Gattıng: Diachora.}

Diachora Onobrychidis, Der Doppelidjori Der Cipparjette, erzentgt an

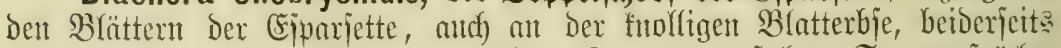

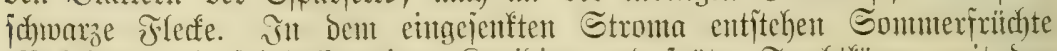

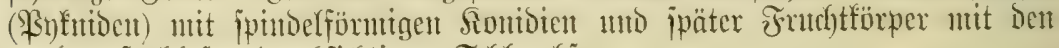
ovalen, farblojen Durdfirdtigen Guflaudjporen. 


\section{Sfattung: Plowrightia.}

Plowrightia morbosa verurjadyt an 3retidggenbäumen uno Steit= objtgehölzen in Ŝmerifa die jehr verderblichen Blak knots, die in Ber= frümnungen unt ftarfen Beroictungen Dex 3meige befteben. Die Srhlaudjporen fino bell uno bejtehen aus einer größeren vberen anto fleineren unteren Belle (J゙tg. 28).

\section{Gattung: Phyllachora.}

Das Stroma, beridjeden gejtaltet, jofmarz ift mit flemen eingejentten ßeri= thecien unto flemten, eiförntigen, hellen eint= zelligen Sporen bedectt.

Phyllachora graminis, $\quad j$ d d toat $z \mathfrak{e}$ Wülf́te auf ben Blättern berjchiedenter Grä̧er billdento.

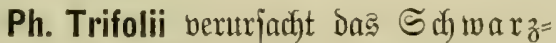
wexden des Rlees in fendiden Jabren und fentodyten Ragen, indem añ Den Blättem, bejonders ber Unterjeite, großje johtwarze Flecten in Mienge entitehen. Dem Miejen= flee jowie anderent Alleearten gelegentlid) ge= fäbrlich.

\section{Sfattung: Dothidella.}

Das Stroma itellt jubrarze Flectent anf Blättern dar; Die Sporen jind zmeizellig.

D. betulina auf Birfen.

D. UImi auf $\mathfrak{H} r \mathrm{men}$.

\section{Unterfamilie. Sphaeriaceen.}

Das Mincel ber edhten \$arajiten ijt fäbig, wädhit alf oder in Den Nährpflanzen unto jtellt häufig einten fejtent Pilzgemebeförper (Stroma) Dar. Die \$erithecient find meirt fugelig mit vorgezogener Meintung, Derb=

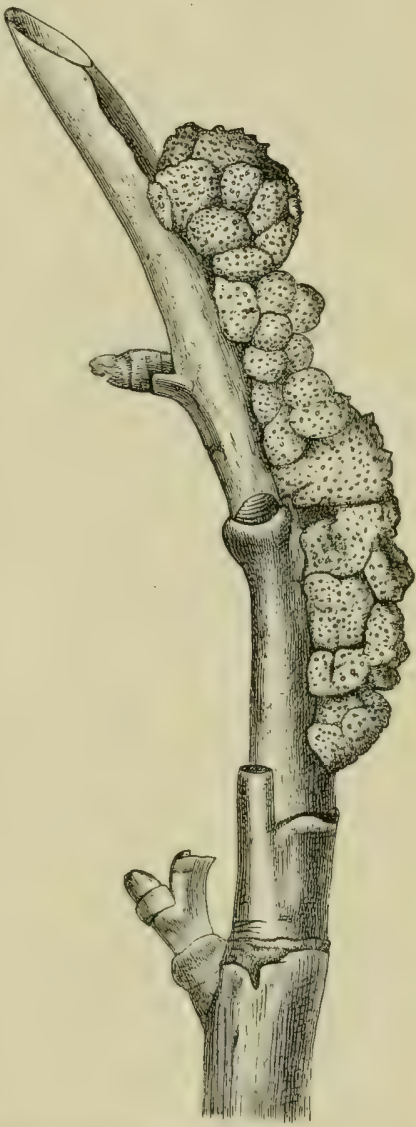

₹̛ig. 28. Plowrightia mor. bosa. mantig, fdumärzlich, oft freifteheno, oft etwa: it Dą Stronta eingejenft. Sporen jehr veridjieden geitaltet, fingelig, eiförmig bis läugliḑ, jelbit fäbig, eint= bis melgrfad) querteilig oder jelbjit

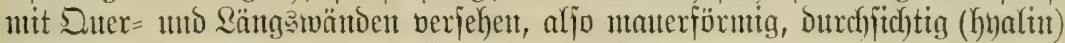
voer grünlich ober gelb oder jchwarz gefärbt.

\section{Battutg: Trichosphaeria.}

Fruchtfürper fugelig, mit aurredtitehenden Borjten verjehen, Sporen

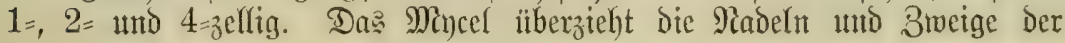


Tannen, jeltent autd) ber Fidsten, bie Padeln und jpäter aud bie Bweige

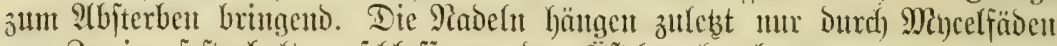

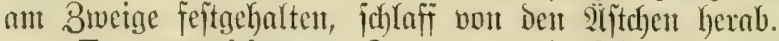

Tr. parasitica an I a $n \mathrm{en}$ แnd (jeltent) an $\widetilde{F}$ idsten, in Tamten= beriüngumgen gełegentfich) Sthadent verurjachento.

\section{Sattung: Herpotrichia.}

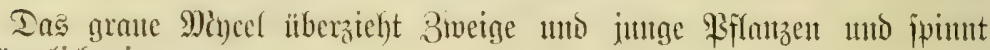
ïe förmlide ein.

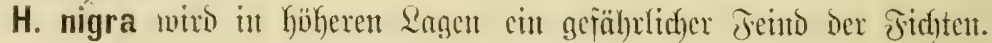

3. Battıng: Rosellinia.

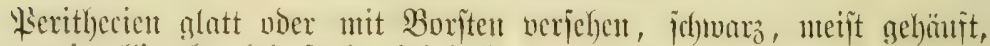
Sporen cinzellig, Duntelgeförbt, fpindelig.

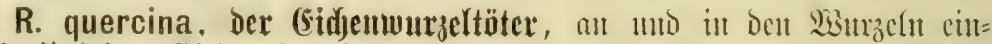

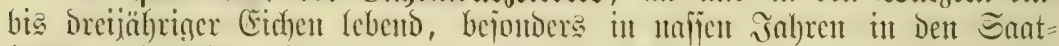
becten verderb(ich) mitretend. Das Mancel bilbet fadeuförnige Stränge,

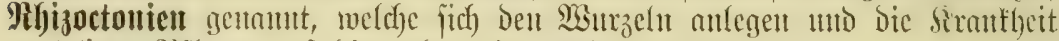
von ener \$iflanze anj bie andere in Boben itbertragen.

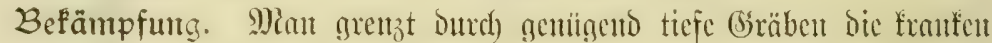
Bfflanzen von den gejunden ab.

$\mathfrak{A} \mathfrak{h} \mathfrak{a} \mathfrak{g}$.

Rhizoctonia violacea, Der Ruzerue ober filectod crhält fitch bejüglich

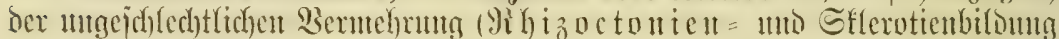

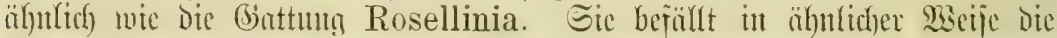

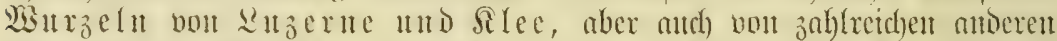

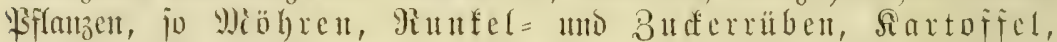

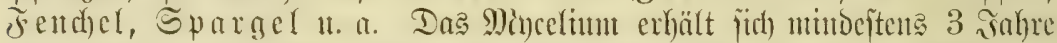

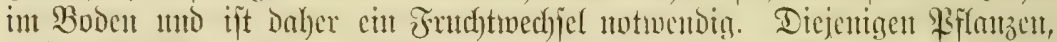

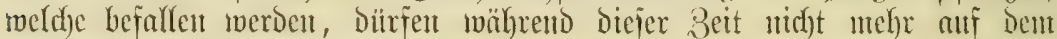
infizierten Jeld gebant werdent.

Altch Dematophora necatrix, ber Murzelpilz ber Mtebe, mag an biejer Eterfe untergebradgt fein. Die von Dicfem Rarajiten befallenen

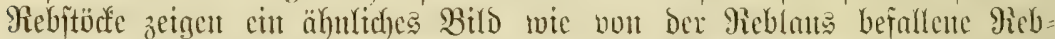

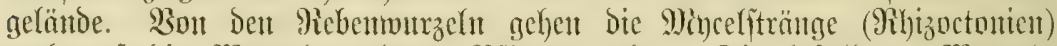

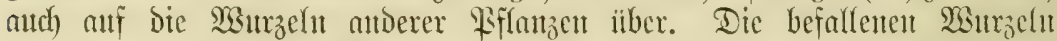
werden getötet und die Pflanzen werden infolge $\mathfrak{W}$ afferntangel gelblich) mo fterbent ganz ab.

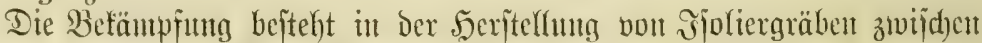
Dent gejunton unto franten Rffanzen.

\section{Gattung: Cucurbitaria.}

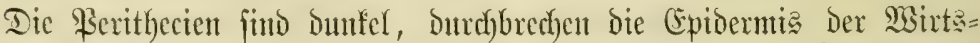

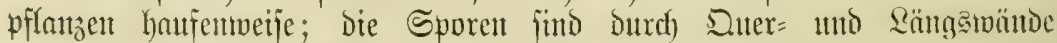
mauterförmig gefärdjert. 
C. Laburni auĩ dem (Goloregenjtraud. Dex Barafit fanu mur

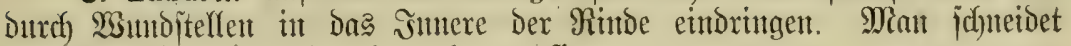
bie erfinutten 2 ijte ab und berbremit fie.

\section{Gattung: Stigmatea.}

Die Herithecien jizen juci ant dent befalfenten \$iflanzenteilent. Die Echlaudjporen beitehen au 2 ungleichen Bellen. Die Sionidien beitehen ats 4, ie mit ciner Borite verichenen Bellen. Die bratnen Berithecien bildent fich erjt rö̈hrenis Des Winters und Frühakre auf den faulenden Blättern.

St. Mespili (Entomosporium maculatum), die BLattbräıne der Birne॥, Quittell uns Miipeln. $B e=$ fallen merden die jungen Birnwildringe it Bamm= jobulen jebr jtart, ebenjo die jungen Dutten = und Mitpelpflanzen, aud iverden mandhe ed le Bir $=$ nenjorten gletdfarfe ex= beblich beiachäbigt. Die Brät= ter Der Binnembildlinge bräıneıt fidd, fallent friigzeitig ab uno auf ifrer Dberjeite jieft man bie kleinen, glän= zent = idywarzen Frud tförper (Jig. 29).

Befpriben mit Supferjodabrübe hilft gegent biejen Rarajiten.

\section{Bsattung: Sphaerella.}

Perithecien zart, Dett bejallenen Drganen Der Wirt: pflanzen eingejentt; dic

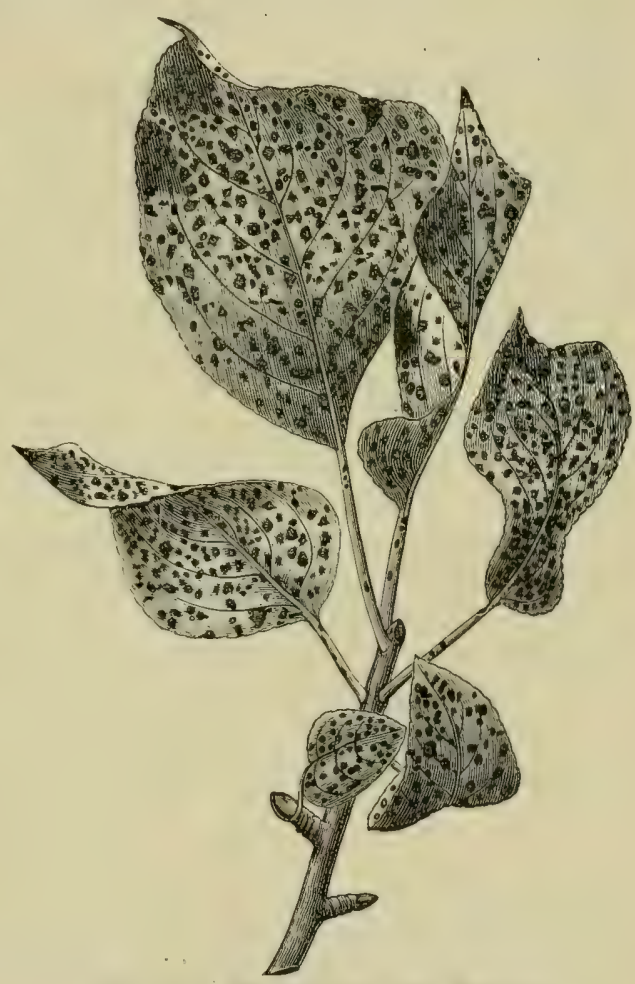

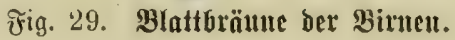

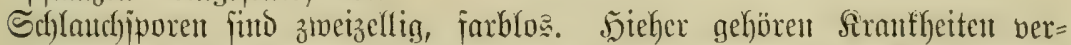
idfiebener Sulturpflanzen, bie unter den Bezeidfunntgen ifrer fiontoien ala Phyllosticta, Septoria zc. bei ben jogentannten untbollítändigen Pilzen, Fungi imperfecti, aufgezählt merdent.

\section{Brattutg: Leptosphaeria.}

Berithecien jofwwarz, in Den befallenen Drganen ber Wirtapflanzent anfangs eingejenft. Sporen ipintelförmig, aber mur burch Dutermände mefrzellig. 


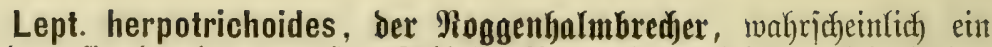

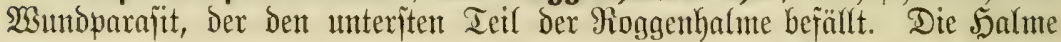

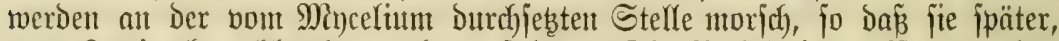

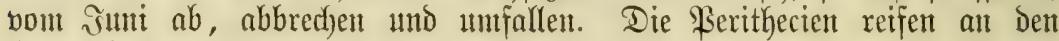
Stoppeln.

Befämpfung. Tiefes Eintffliigen der Stoppeln bald nard der Ernte.

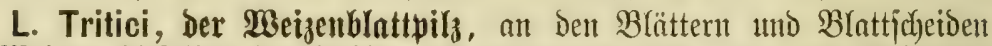

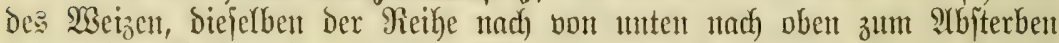

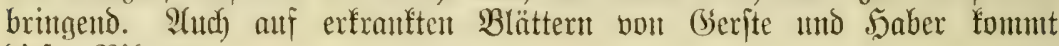
biejer $\mathfrak{P i l}_{\text {z }}$ bor.

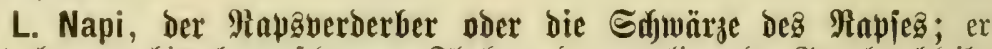

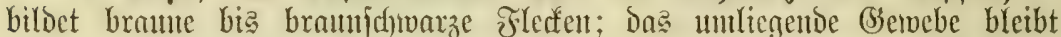

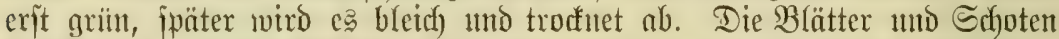

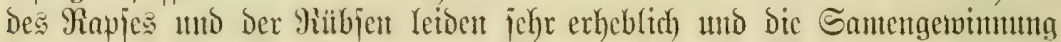
faum bei ftarfent Befall gauz unterbleiben. Die Siranffert breitet fird bei

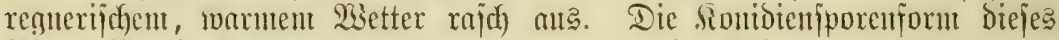

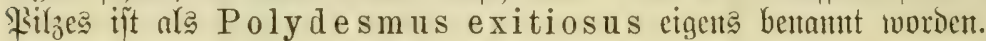

\section{Battuttg: Ophiobolus.}

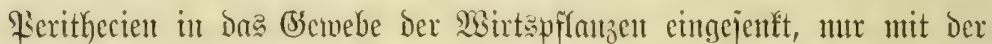

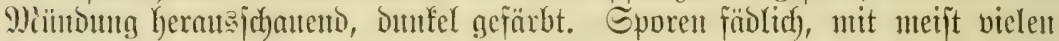

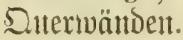

0. herpotrichus, Der $\mathfrak{W e i z e n f a l m t o ̈ t e r . ~ D a g ~ M i n c e l i u m ~ d i e j e s ~}$

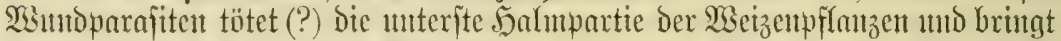

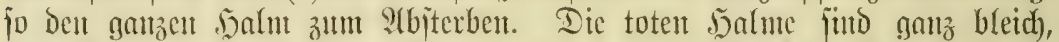

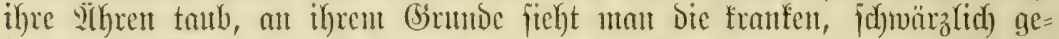
färbten Stellen. Die Weritfecient reifen nuf Den Stoppefit.

Befämpfung. Cin friilzzeitiges, ticfes llntervfliigen der Stoppeln

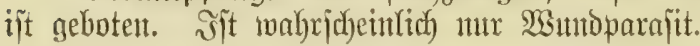

\section{Wattutg: Pleospora.}

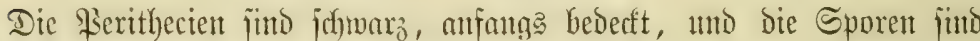

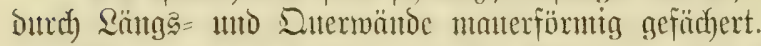

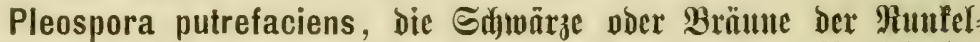

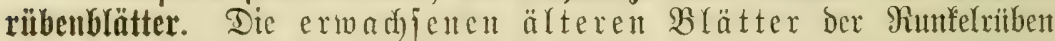

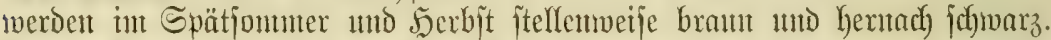

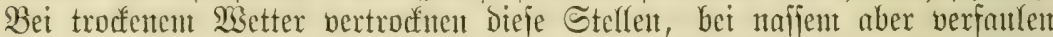

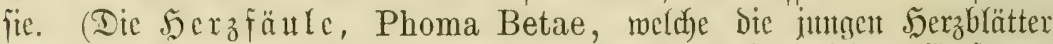

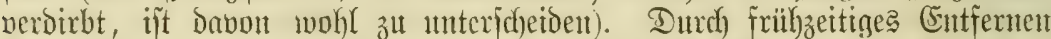

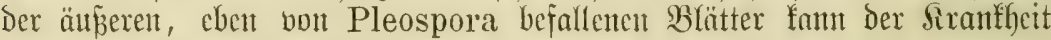
Eintbalt gethant werben.

PI. Hyacinthi befällt die Schuppen der 5y)acinthen.

PI. herbarum, altrf) Cladosporium herbarum, befällt bie Siätter

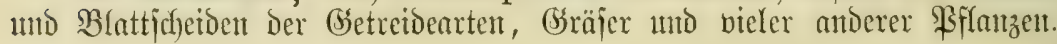




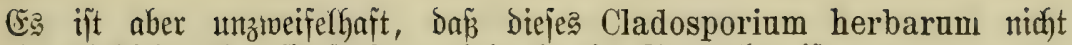
ein twirflider Barajit jondern vielmebr ein Saprophyt ift.

\section{Brattung: Gnomonia.}

Perithecien eingejentt, ntit gejdynäbelter Mündung. Die Schläuche bejiben an ber Spibe eine Berbidunt mit feiner S̈finung. Sporen hell, $1-4=z e l f i g$.

\section{G. erythro- stoma, bie} Blattieudie oder Röte Der Rir = idjen. Die be $=$ fallenen $\mathfrak{B l a ̈ t t e r}$ befomment im Raufe des Som= mers gelbgrüne Flesten bon der (Sröpe eintes Fünfpfentig = ftüife? und blei= ben aud nach) dem Brätterfáll nod) am Baaunte hängen (ร่̌g.30). Die $\mathfrak{B e}=$ fämpfing bejteht Gier am zroedt= mäß̈igiten in der Abnalime der am B̧aume ıีährenı des Winters
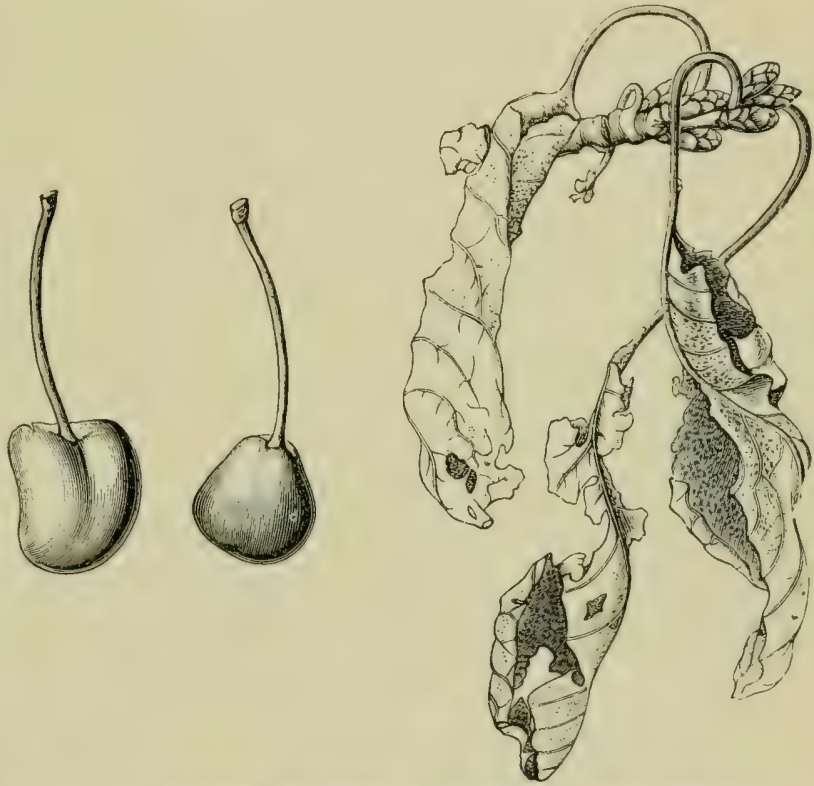

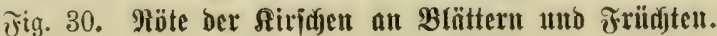

(Gnomonia erythrostoma).

bängen bleiben=

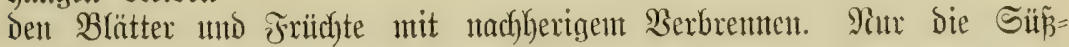
fixichen merden befallen.

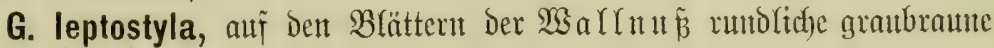
Flectent bildento.

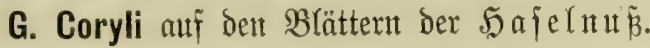

\section{Jamiltx.}

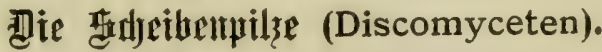

Die Sofjeibentif

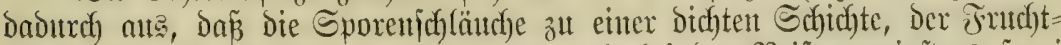

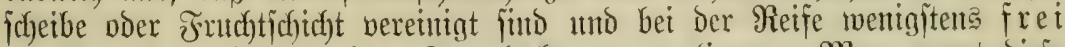

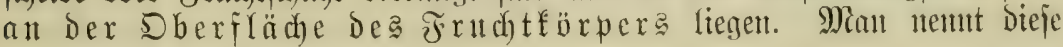




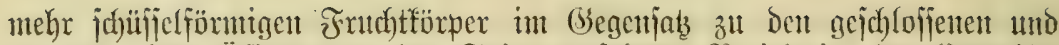

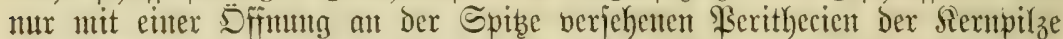
Apothecien. Nicbenbei bilden fid and vielfach norh andere Sporen=

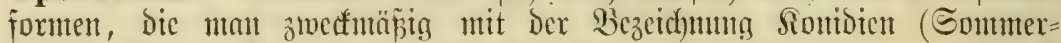
iporen) betegen faun. Bmijhen Den Sporenjd)läudhen liegen, mie aud,

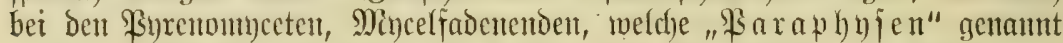
ıerben. Dic Eporent fimb vielfad) mit einer Gallerthiille untgeben.

\section{Softung: Lophodermium, Der Ritzenidorị.}

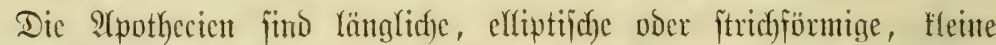
johmarze Gebänje, weldye in bie Dberbant des Pflanzenteifes ganz cinge=

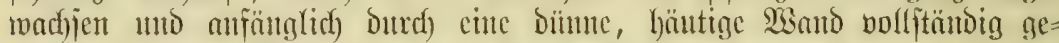

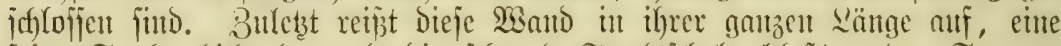

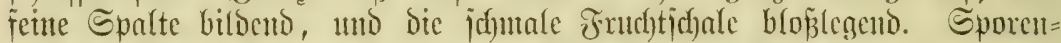

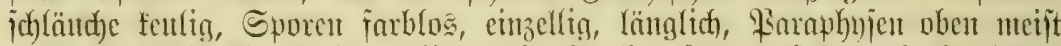

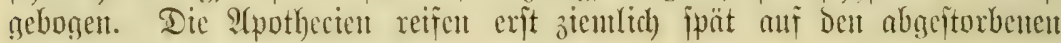
indeln.

L. Pinastri, Ribenjujorf ber fiejer, and fïr bas Sintehold, für bic

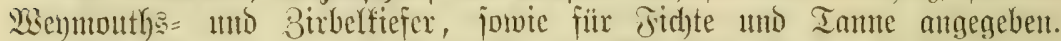

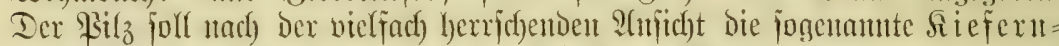

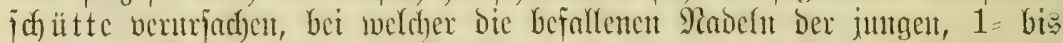

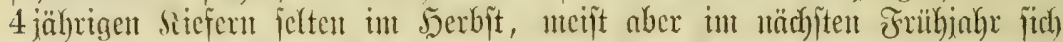
brämuen mo abfallen. (E) unterliegt aber fan einem 3 toeifel,

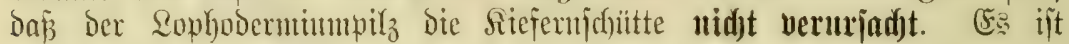

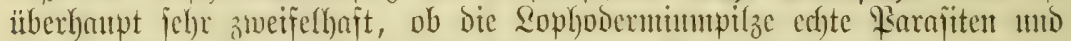

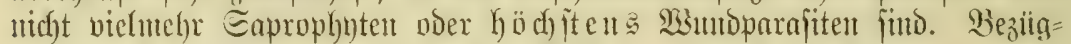

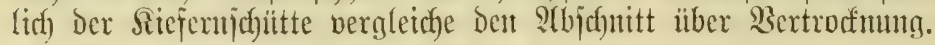

L. macrosporum, ber Ribenjd)orf Dex Fidfte.

L. nervisequium, der Ribenjdorf der $\mathfrak{B e t}$ btanne.

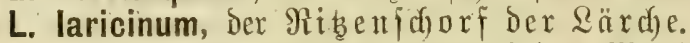

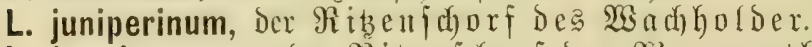

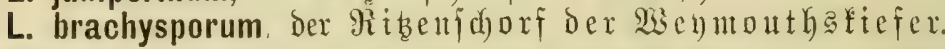

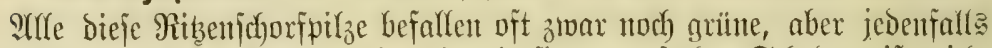

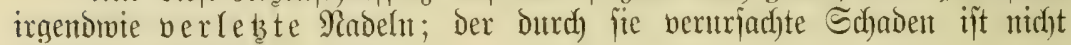
bejonders erbeblick.

\section{Gattung: Rhytisma, ocr Rumzeljourị.}

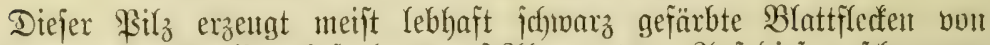

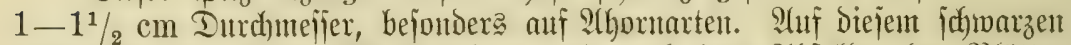

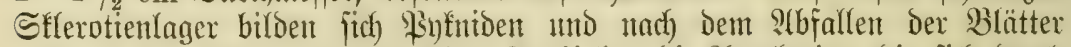

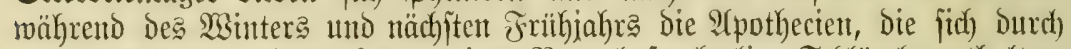
Spalten öfinten, żvijchen fädenartigen Paraphyjen feulige Edyläudhe enthalten, aus Denen zuletst nadelförmige, burch Suterwände gefädberte Eporen ants= gejd)leubert merben.

Befämpfung. Man jamntle möglichjit jorgfältig dą abgejallente 


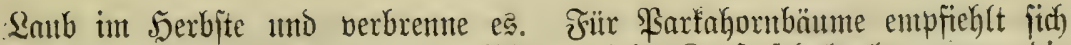

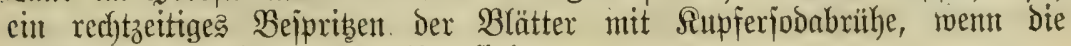
Blätter etwa. balb ausgemadjen fint.

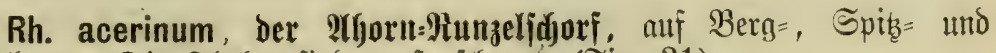

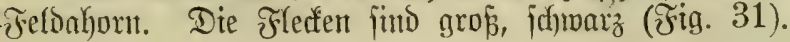

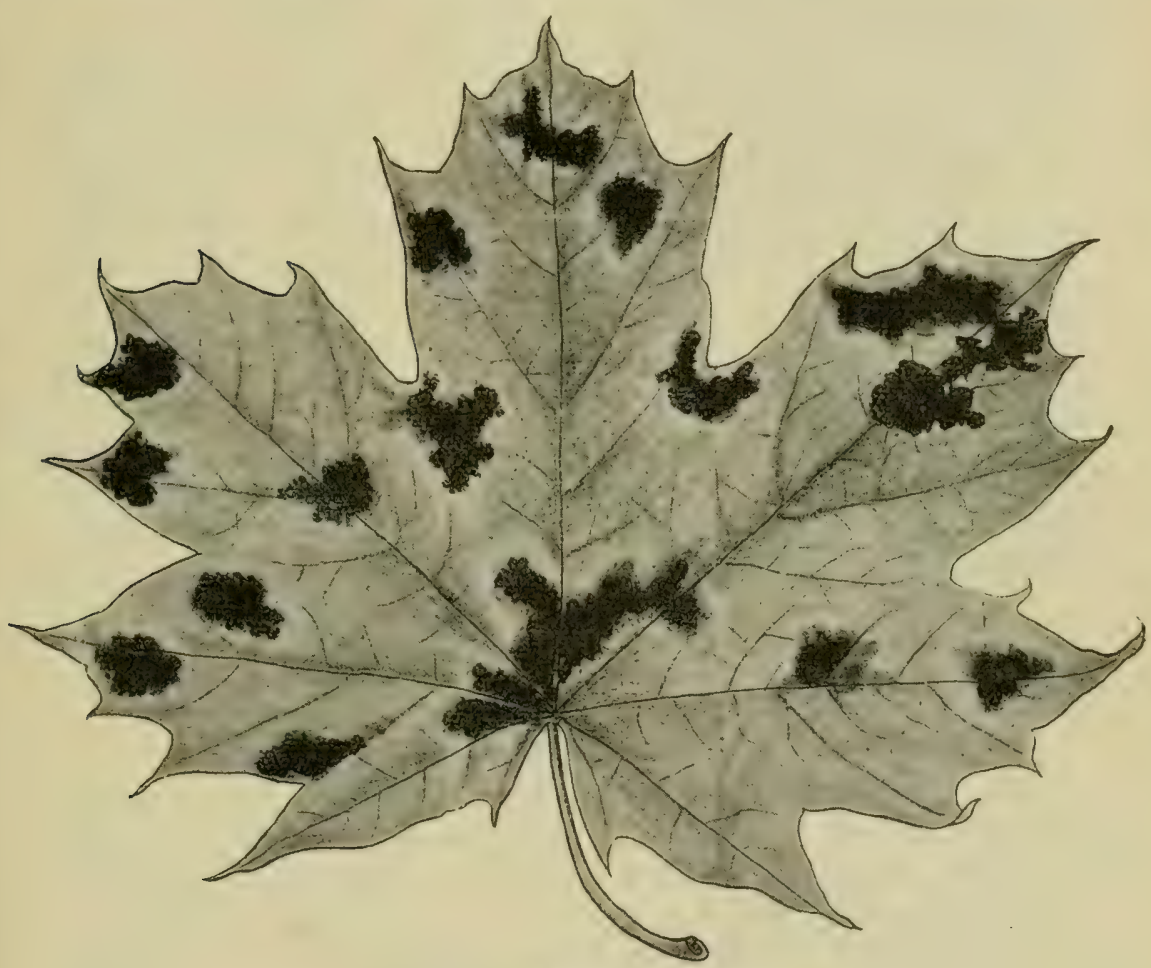

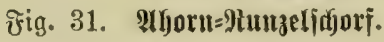

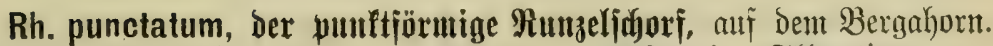

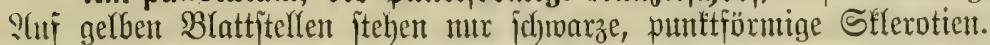

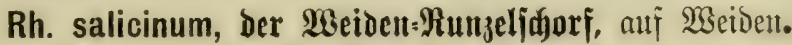

Rh. Andromedae, auf Atroromeden, Rh. Empetri, auf der Raujdbeere.

\section{Grattung: Pseudopeziza.}

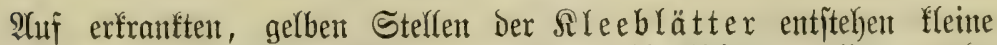

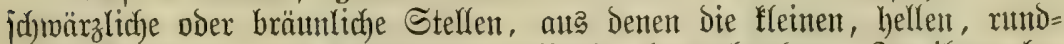

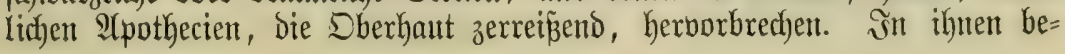




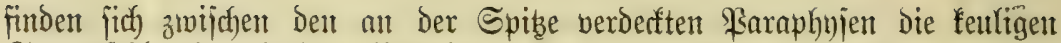
Sporenichläudje mit den eiförntgen, einzelligen, hellen Eporen.

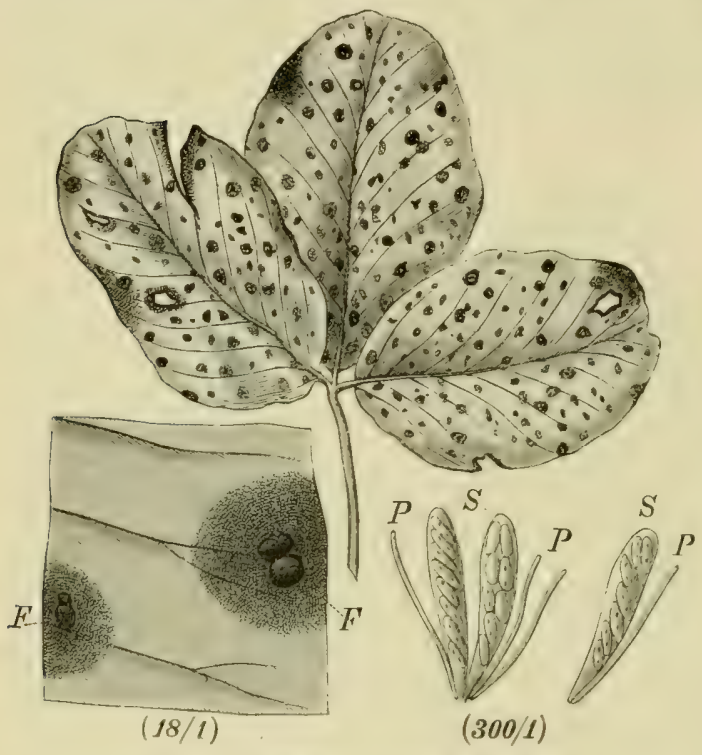

Fig. 32. Pseudopeziza Trifolii.

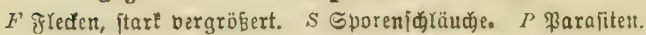

Ps. Trifolii, bie Blattfledentrantheit Des Aleeß, auth auf Dem Wiefen= und frie= d)enden Rlee mo auf $\mathfrak{Q}$ uzerne. $\mathscr{A}$ น⿰ bett noch lebendent Blättern entitebent vom Frithjahr biz Jerbit fleine bis grö́pere, braute oder jưnuärz= liche, jpäter bertrod $=$ nende Stellen, auf denen fidc Die Frutd)t= icheiben bilden. Die Srantheit fant Slee= jeldernt jehr jäbädlich merben. Das ficherite (Gegentmittel beftegt wobl it bemt algbal= bigen গAbmähen de? Silees bcin erjten $\mathfrak{A} u \tilde{f}=$ treten Der Siranffeit.

\section{Góttıng: Dasyscypha, Rärdjentrebö.}

Die ans Den bejallenen Rflanzenteilen ber Qärche Gerborbredjenden

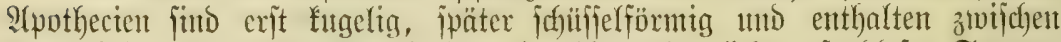
Paraphyjen Die Schläudhe mit Den einzelligen länglidyen, farblojen Sporen.

D. Wilkommii, der Särdentrebs. Das Mincelium tritt nur

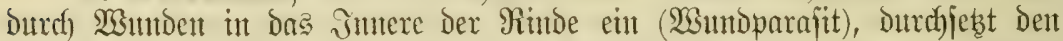

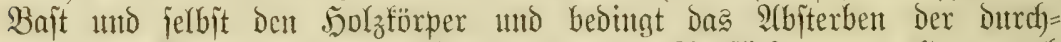

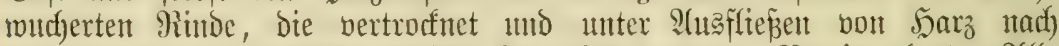

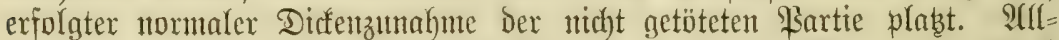

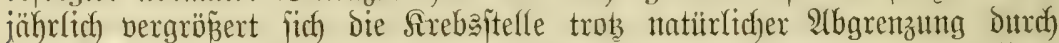

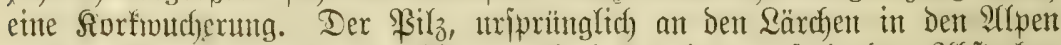
cinfeimijoh, hat fich in Der (Ebene verbreitet uno verurjadyt bas s(biterbent Der Rärchent in ben Niederungen.

\section{Sattuntg: Sclerotinia.}

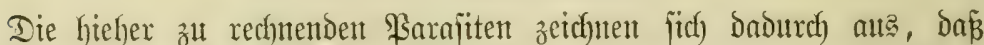

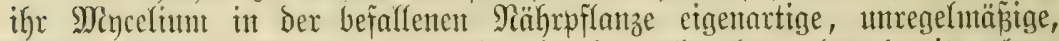
fnolfige Sïrper bildet, bie entweder in der erfrantten oder bereite abge=

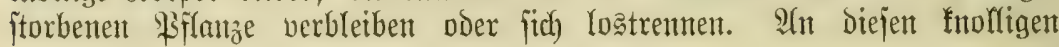




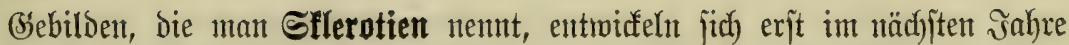
bie Frudhticheiben, bie in ben Schläuthen längliche oder elliptijche, eitrzellige, farbloje Sporen enthalten. Micht jelten fommt bei ben \$ilzen biejer

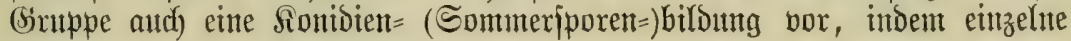

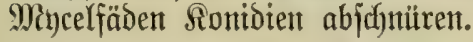

\section{Die befannteften $\mathfrak{A}$ rten jind:}

Scl. Trifoliorum, ber fileefrebs noer bie Sflerntienfrantheit Deßె

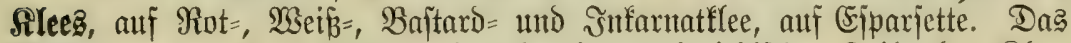

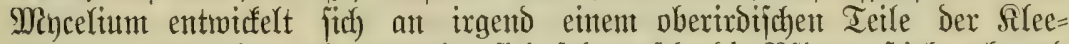

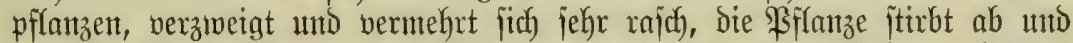
Das Mecelium bildet ganze Maffen berzweigter uno verfloct)tener dïmer

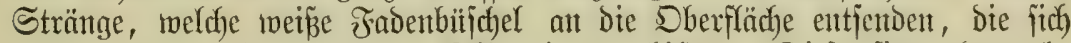
rajich zu den ilberwinternden Sflerotien umbilden. Dieje jiben Den $a b=$

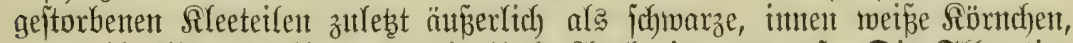

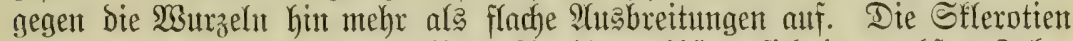
bleiben einige Jahre rebengfähig. Sat ifnen bilden fich im näbhiten Jahre bie Apotheciell.

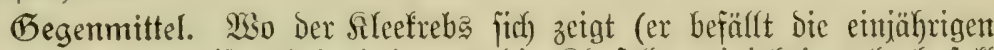
Płflanzen vorzugatweife), behandelt ntan bie Siteefelder emjährig, (Dod) joll Die Siranffeit an Dent zweijährigen Pflanzen nicht jo ftarf auftreten).

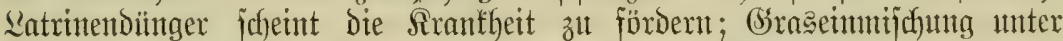

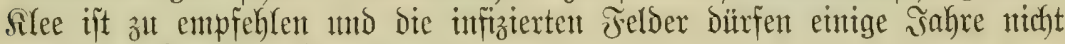
mebr mit Sllee bejtellt werden.

Scl. Libertiana verurjadyt eine ähnlidhe Rranflyeit.

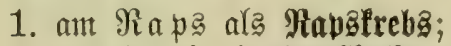

2. am 5 anf als Şanffrebs;

3. an Siartoffelt; int Den Stengeln bilden fich Die Silerotien;

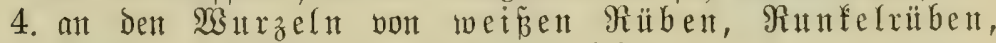
Mëhren, Eidgorien mo an Rettichen;

5. ant Den Rnollen dex Topinambur (Helianthas tuberosus). geförent:

Sel. Fuckeliana tritt an zahlreichen \$Fflamzen auf. Sjieber follen

1. Die Édelfäule der Weinbeeren, unter Botrytis cinerea befannt. Sar ïberreife Beeren merben befallen.

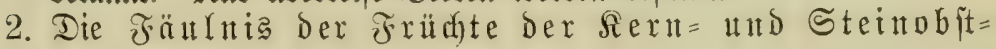
jorten.

3. Das $\mathfrak{B}$ criffimmeln und die Sflerotienfrantheit ber Speijeziniebeln.

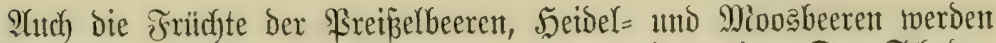

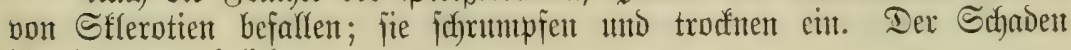
ijt nicht beträchtlich.

Das fidferite Gegenmittel gegen bie verjdjedenen Formen bon Sflerotien=

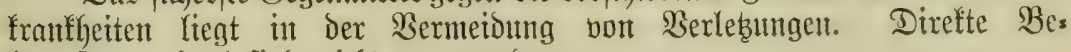
fämpfungsmittel find nicht anzumenden. 


\section{Hamilte.}

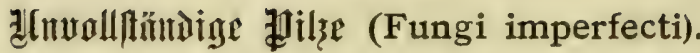

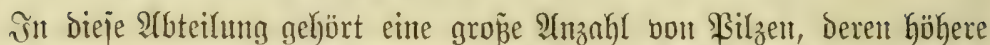
Fruthtforment entweder nicht oder utur matgelhaft befant find. Sie werden

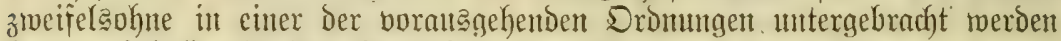
fönten, fobald alle ihre Futdhtformen bollitändig befamut find.

Das gegliederte 9Jincel Der ßarajiten twuchert int Jumern ber be=

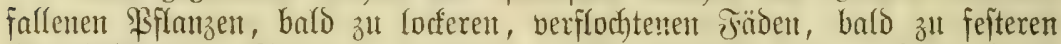
Gemebeförpern (Stronta) vereinigt. Die Fortpflanıuntg expolgt Durd)

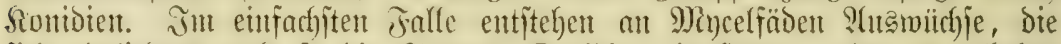
jidf abghliebern mo jo bie Eporen (Sionibien) Darjtellen, oder es erkeben

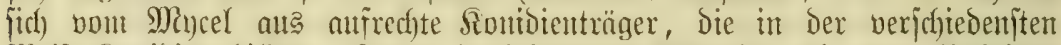

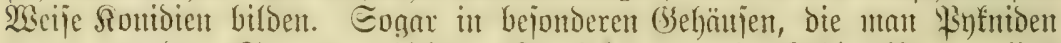

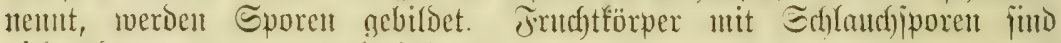
nidyt oder nux ungentiigend befanmt.

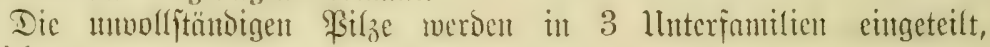
näıเtid):

1. Sphaeropsideen: Die Sontibien merden in Sintution (Gebänjen) gebillot.

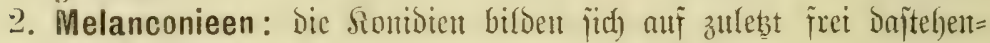
Den Ronitionlagern.

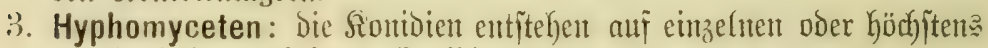
孔 Büntolı veremigten Siontöienträgern.

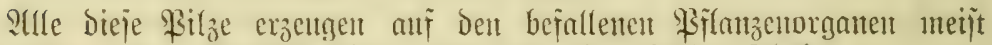
mehr oder wentiger Dentlich abgegrenzte mo oft gefürbte Flectent.

\section{Unterfamilie: Sphaeropsideen.}

Die Sonidien werden in idwarzen, meijt fugeligen Gschälien

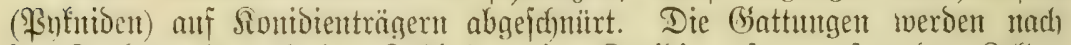
der Farbe und ntad) Der 3nht Der eine Sionidie zujanmenjebenden Bellen unterjichiedent.

\section{Gattung: Phyllosticta.}

Sionibien eillzellig, farblos, fitgelig bis länglich, flein, in meijt

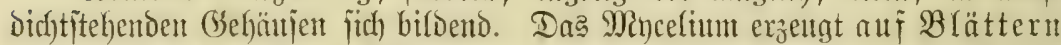

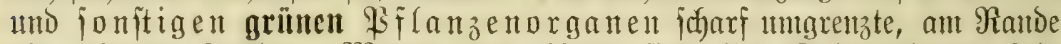
Dit gefürbte Jlecten. Manche bon ihnen jimo ben Sulturpflanzen fehr jchäblict).

Befämpfung. $\mathfrak{B}_{\mathrm{D}}$ e richtig ausgeführte Bejprib̧ungen mit Sinpferjoon = ober Sutpferfalfbriihe vorzunehmen.

Die widftigiten $\mathfrak{A}$ rten jitto:

Ph. Cannabis auf $\mathfrak{5} a \mathfrak{n}$.

$\mathrm{Ph}$. Humuli anf $\mathfrak{H}$ opfen. 
Ph. Brassicae auf bleidhen Frecten Der Rohlblätter utno ber

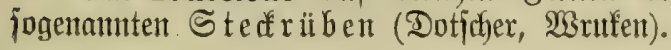

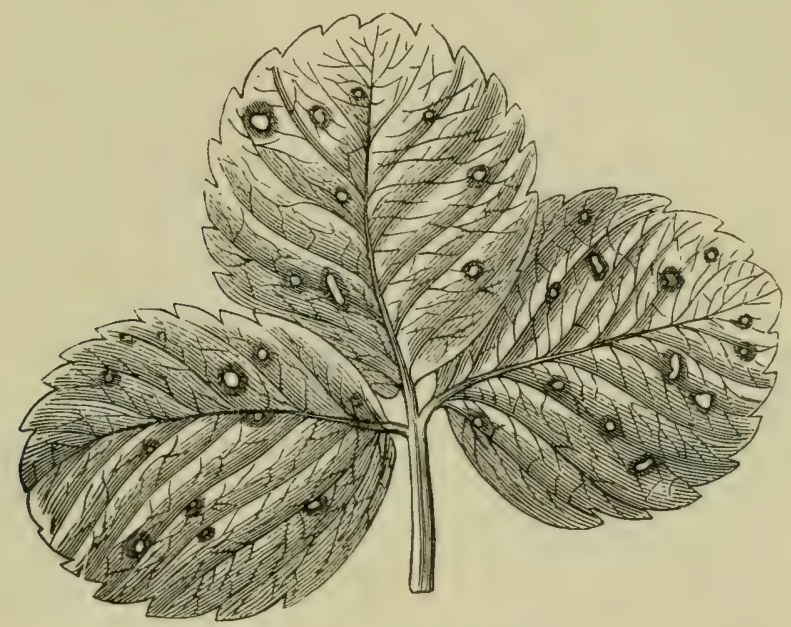

Æig. 33. Phyllosticta fragaricola aư (Erobcerblätteru.

Ph. Tiliae arf den BYättern der \&inde.

$\mathrm{Ph}$. ribicola auf fleineren Blattflecten Der roten iogantiabeeren.

Ph. Grossulariae auf Blattffectent ber Stachelbeere.

Ph. fragaricola auf ftarf́ rotım\}äum = ten Fledfen der Exdbeerblätter, die läjtigite Siranfffeit Der Erobbeere, weldhe aber Durch SBejpribung mit Rupferiobabrithe volf= ftänoig befäntpft werben fant. Man be=

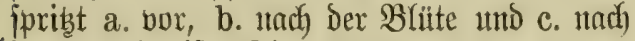

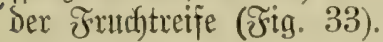

$\mathrm{Ph}$. Rosae aư rot ımịäımten $\mathfrak{B l a t t}=$ flecten Der $\Re$ o jen.

$\mathrm{Ph}$. pirina auf trodenen, braunberan= Deten F̂lecfen der Birntent. Die meip̈lichen Flectent find nicht butrdjidjei= neno, wem mant bas Blatt gegen bą Qidfht hä̈tt (テ̛⿰氵. 34).

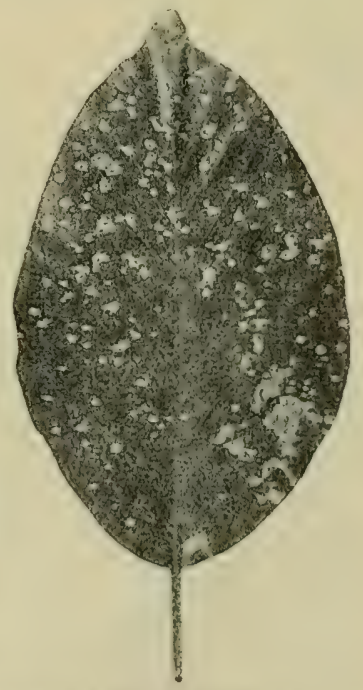

Fig. 34. Phyllosticta pirina auĩ Birueublätteru. 
Ph. Mali auj ebenjoldben Flecten der $\mathfrak{A} p$ felblätter.

Ph. Cerasi auf Rixjhenblättern.

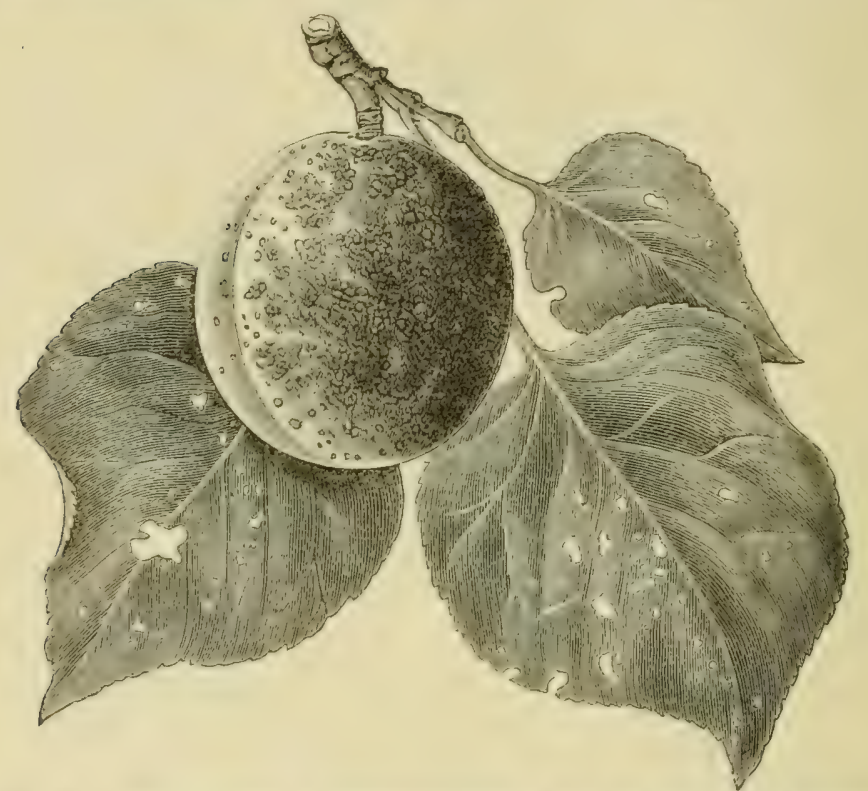

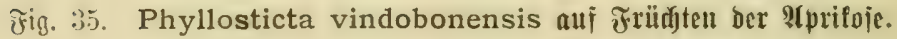

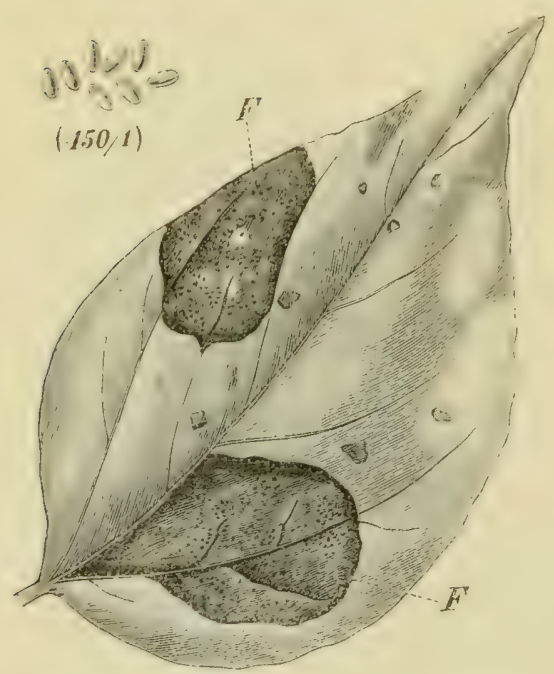

Fig. 36. Phyllosticta phaseolina. F Brattfecten. C conidien.

$\mathrm{Ph}$. prunicola auf den 3wetiog genblättern.

$\mathrm{Ph}$. vindobonensis aut jufjor= figen Stellen Der 2Tprifofen= frïd)te (Fig. 35).

$\mathrm{Ph}$. Persicae anf $\mathfrak{B}_{\text {fix }}$ it $d$ ) $=$ blättern.

$\mathrm{Ph}$. phaseolina, auf $\mathfrak{B}$ ohnen grofie brautue Flecfen bildend (Æig. 36).

Ph. Tabaci auf hellen trodfenent Flecten ber $\mathfrak{I} \mathfrak{a} \mathfrak{b} \mathfrak{a}=$ blätter (Fig. 37).

$214 \mathrm{~m}$. Fait alle in Siultur befindlichen Bflanzen, bejonders auch bie Zierjträucher, find von \$hyllo= itiftaarten befallen.

\section{Gattung: Phoma.}

Sintioien cinzellig, farb $=$ los, fugelig bis zylinorijd); 


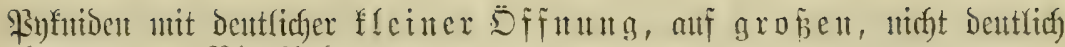
abgegrenzten Blattfledfen cnt= itekento.

Phoma Hennebergii, Die

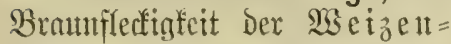
ähren. 2In Dent Spelzen Dex श्रhren des Meizens, auth alf bent Blättent bilben jï̌ch braunte Flecten. Eine jeltente firantheit Dę $\mathfrak{3 e i z e n}$

Ph. Betae, die 5erz $=$ fäule oder Troffenfäule

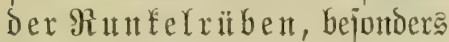
Der 8 uderüubu. Etwa von 2Yugujt an twerden die jungen Serzblätter jodnonz; allmählid werdent autúf bie älteren Blätter ergriffen; ebenjo jebt juch die

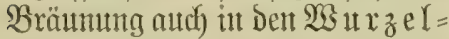
törper fitein fort, jo da ́z die Mauzel von obenther zut faulent beginnt. Trocfenheit begitnitigt

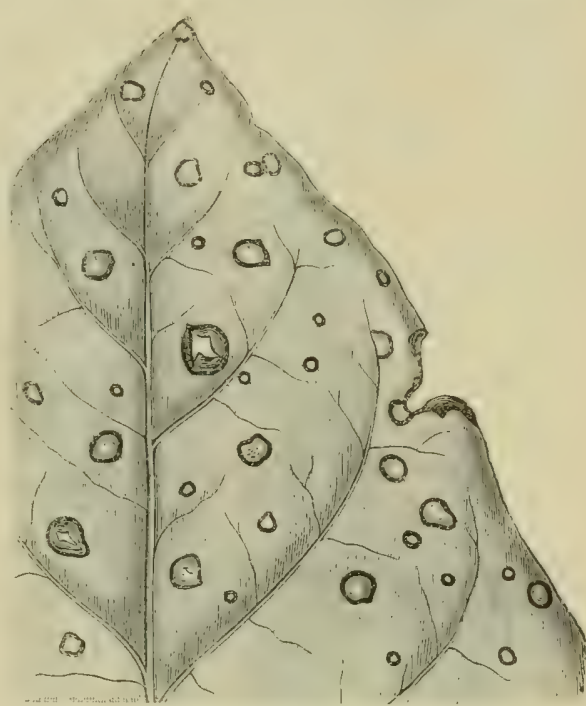

テig. 37. Phyllosticta Tabaci.

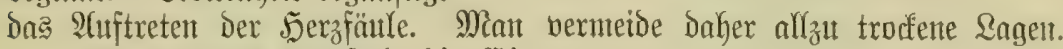

$\mathrm{Ph}$. abietina ventriadyt die (E) $\mathrm{it}=$ ichürungatrantheit ber jungen Innnenzweige Die befallenen îte, an Denent Deutfiche (Einjidnintngen fich berinton, an weldyen Das Rindengemebe abgeftorben ift, fterben ab; die Nadeln fallen aber nicht $a b$.

\section{Brattung: Ascochyta.}

Sontibien zmeizelfig, farblos, ei=

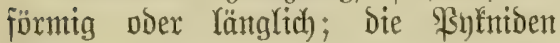
fïzen auf verfärbten Stelfen ber be= faflenen Pffanzenteite.

A. Pisi an Bohtten, Erbjen,

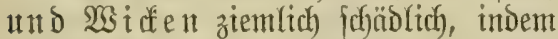
bie Flecten ant Den Suttlent oft bis zu Den Sament bororingen. Mant vermetide e?, flecfige Bohnen, Errbjen แnt Widfen

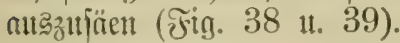

\section{Siattuntg: Actinonema.}

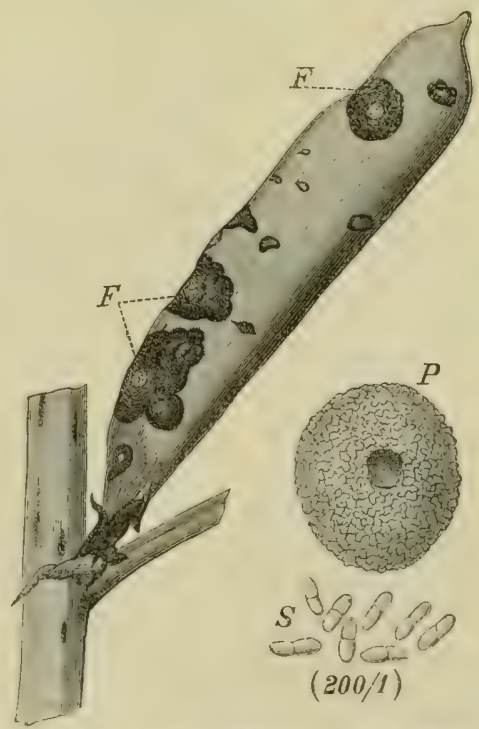

Sontibien zmeizellig, farblos; bie \$infuiden fiben auf dent fajt ober=

¡ig. 38. Ascochyta Pisi auf $\mathfrak{A}$ tere bohnert.

$F$ frecten, $P$ Putriben, $S$ Sontibien. 


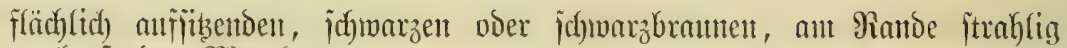
ats(anfentoen Mincel.

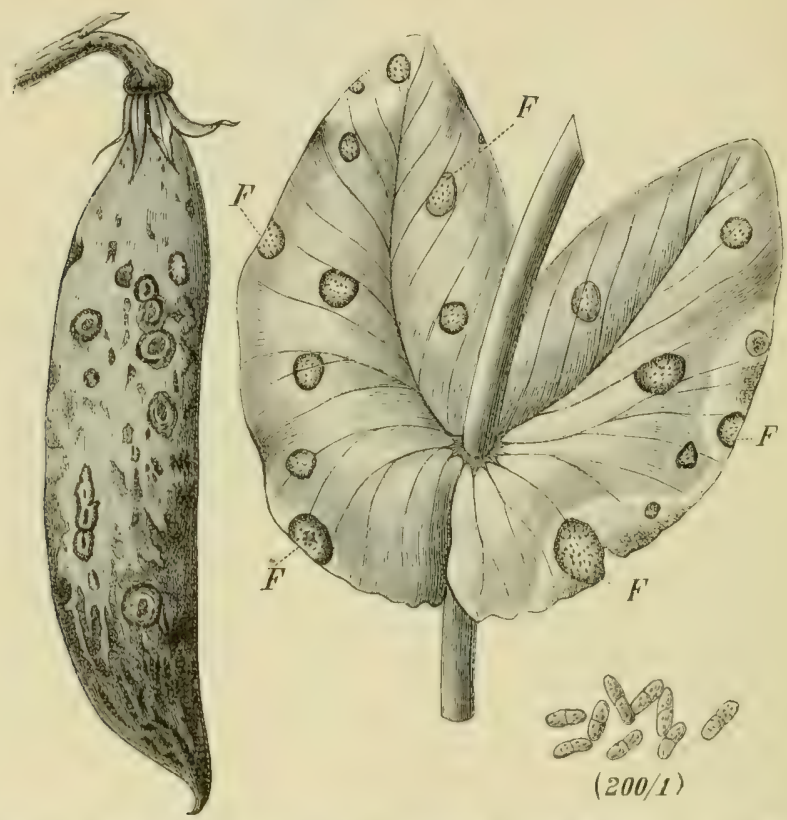

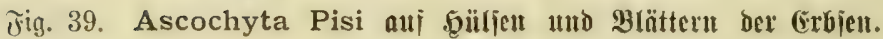
FF Fुtecten, $L$ Rontibien.

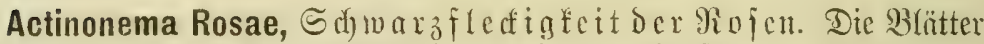

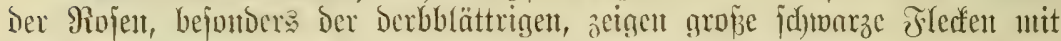
jtrahlitig an

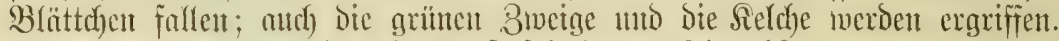

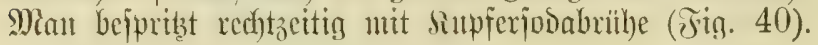

\section{Brattung: Septoria.}

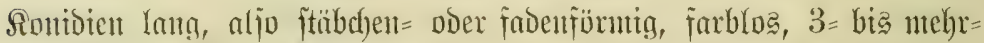

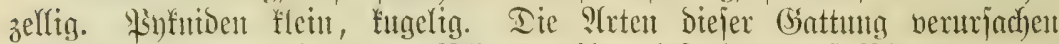

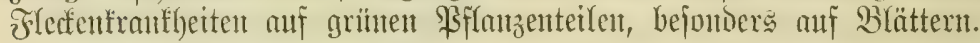

Septoria Tritici auf ben muteren Blätteru und Blattidjeident des

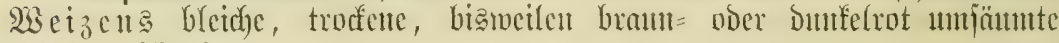
Flectent billbento. mriachento.

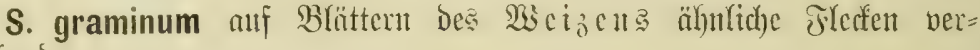


S. glumarum anf Den Spelzen des $\mathfrak{X e i z e n s . ~}$

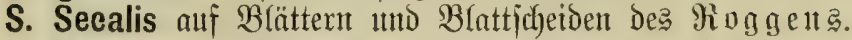

S. Avenae anf Blätterı unt Blatticheiden des 5 afers.

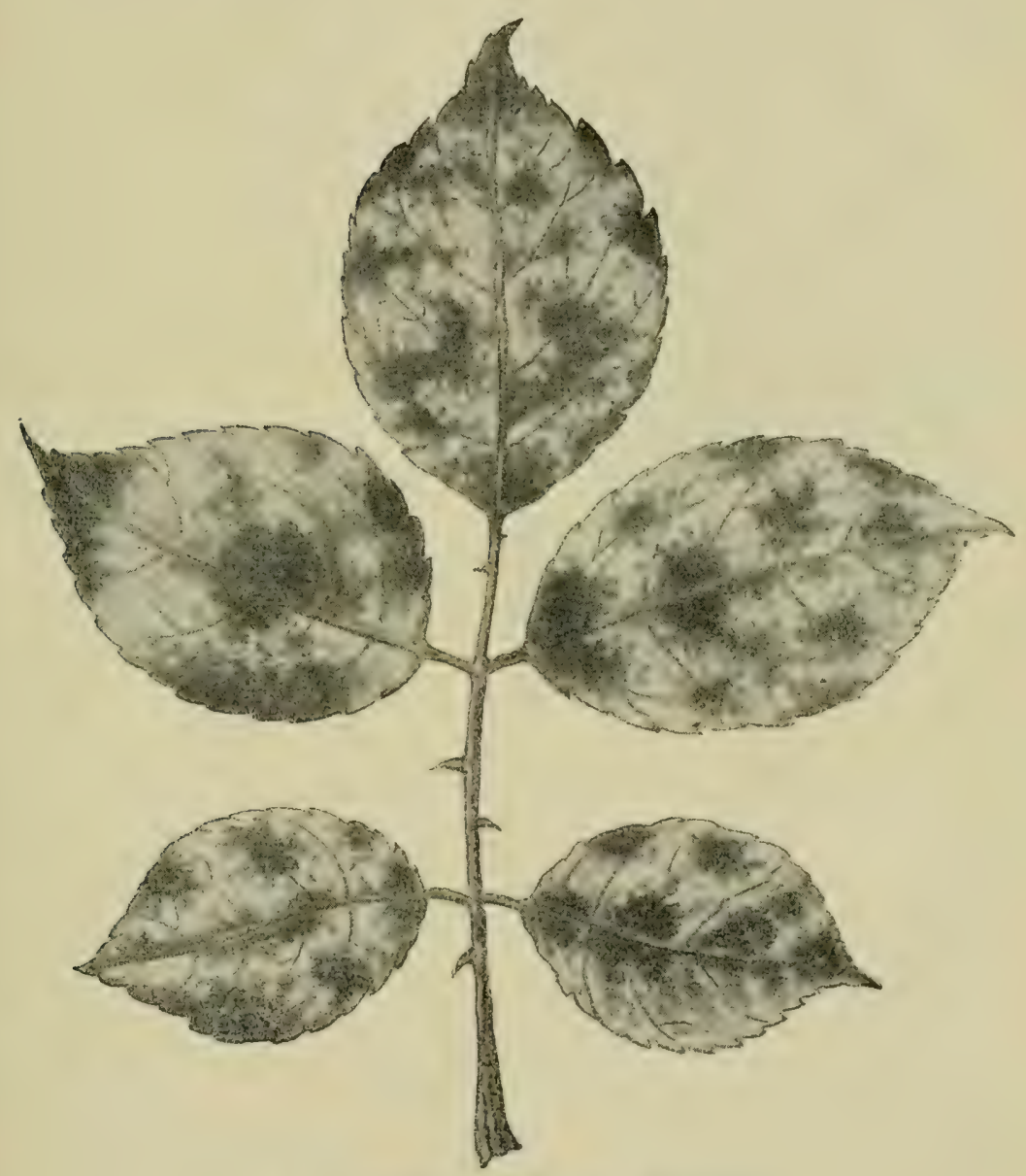

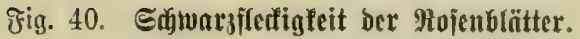

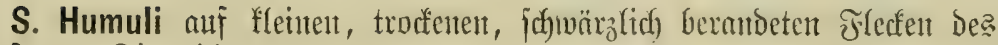
Jूopfeñ (Fig. 41).

S. Cannabis auf brauten, trocfenten Błattf̃ecten des 5 anfez (F̧ig. 42).

S. Armoraciae anf bleidfen oder bräunlichen Fleden ber MReer = rettidbblättex. 


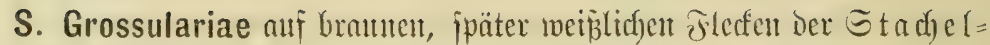
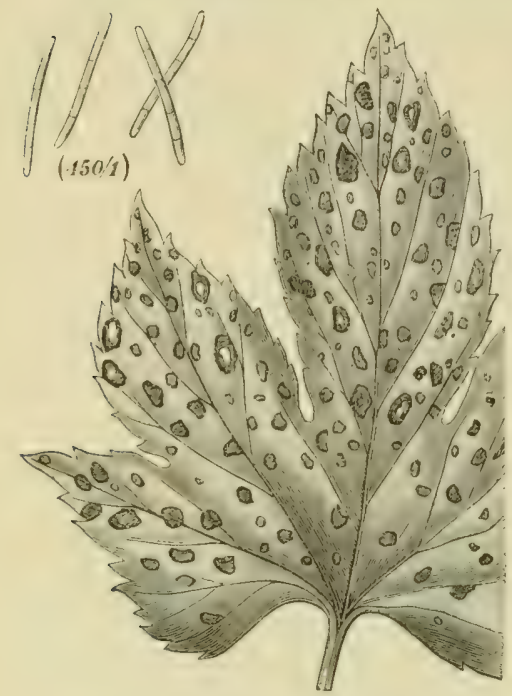

Æig. 41. Septoria Humuli.

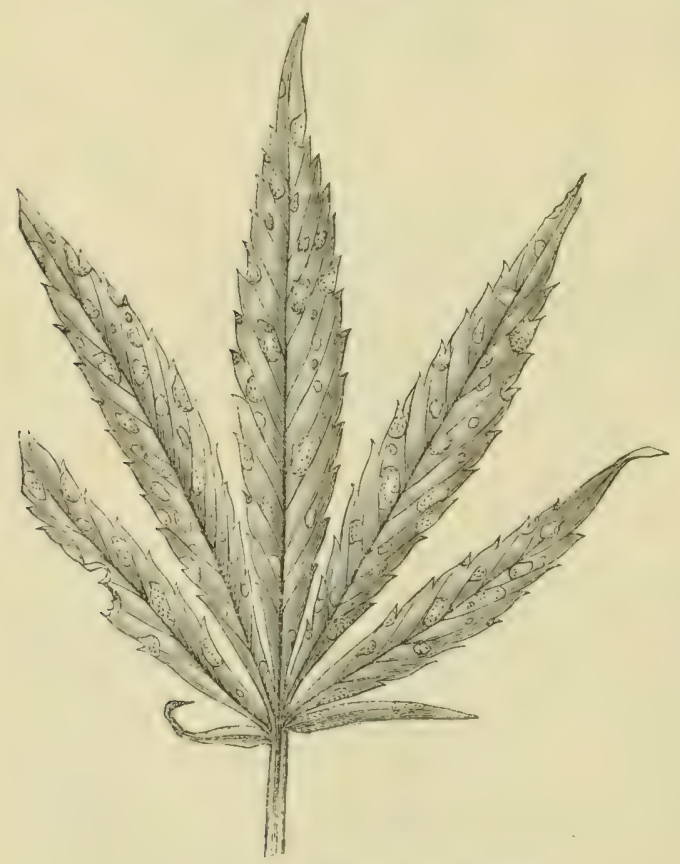

§ig. 42. Septoria Cannabis. allftretento. brätteru. blätterit.

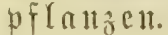

S. Ribis auf fleimen mebre extigen Flectent ber juswarzen Johanuts= beerent, bäufig gegent den Serbit zit

S. pirieola auf weifß̧ichen, bräun= (id) unfäunten, Durchjidyeinenden Flectent ber Bitublätter. Die Sirantfeit tritt fowoht in $\mathfrak{B a m m}$ joulen alకె anch an äYteren Bimbäumen jebr

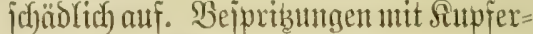
jodabriibe helfent (Jig. 43).

S. Mespili auf MRijper=

S. Cydoniae auf Dutten=

S. Lactucae allf flement, trodfe= nen brautuen Blatffrlecten Der Salat=

S. Endiviae auf ebentioldhent Flerten Der Entivie.

Iufjer biejen widc)= tigeren 2 (rten fint fojt jäntlidge Sittuttrgewäd)je und bie millowachjendent Bffanzett von Septoria= artent befallen.

\section{Brattutig: Pesta- lozzia.}

Die Sontioten fint länglich, $3=$ bis mehr $=$ zellig, braungefärbt uno att Der Epitze mit einer oder mehreren farblojen Saarzerten werjelyen.

\section{Pestalozzia Hartigii} foumt att jungen $\widetilde{F}$ id ten แnd Tannen bor unt besingt das 9lbiterben ber Rinde ummittellbar itber 
Der Eroc. Der Stanm ïber ber befallenen Stefle verdicft fich; ;päter ftirbt bie \$ffanze ab.

\section{Unterfamilie: Melan- conieen.}

Die Sontioien entiteben in Lagern, woldhe anfänglide von der

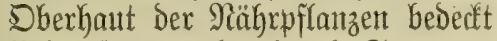
find, jpäter aber burch Sprengent Der Dberhaut fret meroen.

\section{Gattung: Gloeosporium.}

Sionibien einzellig, farblos; eiförnitg oder lünglich auf fonidien= lagern fich bildento.

Die midytigjten $\mathfrak{A}$ rten finto:

Gloeosporium nervisequum auf den SBlättern der $\mathfrak{B}$ latanen bräınliche Streifen längs der Nervent des Blattgrumbes bildend

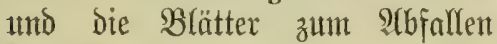
bringeno.

GI. ampelophagum, Der jufwarze Brenner oder bie ŜAnthra= toje der $\Re$ eben, auf allen grinten

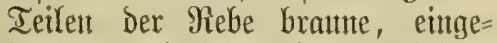
funfene, mit jobnarzent, wurffigen

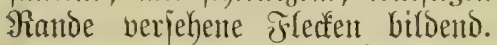

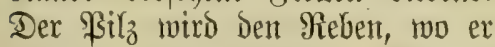

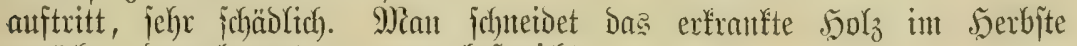
zuribd und berbrent $e^{2}$; man beitreidft

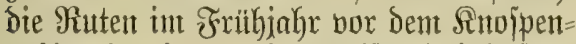
aufbruch mit $5 \%$ iger Eijenbitriollöpuntg (ङ่̧g. 44).

GI. Ribis, die $\mathfrak{B} \mathfrak{L}$ attbräıne Dex roten כohanntabeeren. Die Blätter ber Johanniabeerent werdent vom sult ab in ber Reibenfolge bon unten nad) oben erjt braunflectig, rollent jid zujammen, beroorren uno fallen alsbard ab. Der Schadent ift beträrbtlidy). Ein frillyzeitiges Beppritzen mit Supferjodabrïbe bilft.

GI. curvatum anf Den Blättern ber

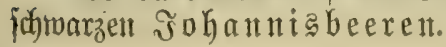

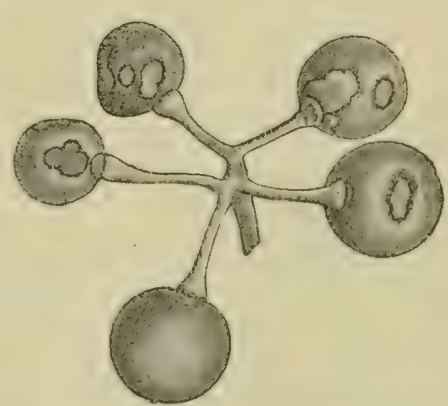

テ̛ig. 44. Gloeosporium ampela. phagum. 


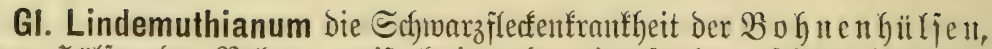
an ben Šilijen Der Bohnen meijt freisumbe, eingejunfene, jofwarzberandete Flecten berurjachend. Man jorge fïr trodfenten Boden und jebe nux pilz̧reie Eanten (F̧ig. 45).

GI. Iagenarium aũ deı Friid)ten Der GS urfen brautu, eingepunfene Flecten bildoend; bie Sporen erjheinen an ber Sber= flärdye als jodletmige Sittgeln ober Wiilite.

\section{Siattung: Marsonia.}

Sonibient einzeln, zweizellig, faft farbloes.

Marsonia Juglandis berur= jaud auf ben SBlättern Des Mal= mipbaumte brautu bis graute Fledfen. Dieje Siranffeit tritt fajt alliäbrlid

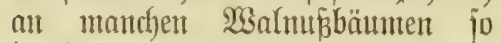
jtarf́ anf, Dẩ die Blätter jodjon von Enve Jult ab abfallen. $\mathfrak{B} e=$ ipriben mit Supjerjodabrilhe hilft vorbentgent (Jig. 46).

3. Unteríamilie: Hyphomyceten.

Tie Sintibien bildent jith ant freien Irägern des Minceliums, indem einzelne oder zu Büijd) ln bercinigte Moncelfadenenden an ihrer Epibe fie abjomintent.

\section{Giattung: Monilia, Jrudtidjimmel.}

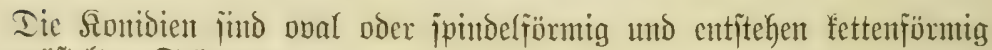
aน⿰ beräjtelten Trägern.

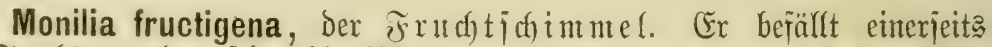

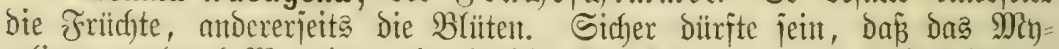

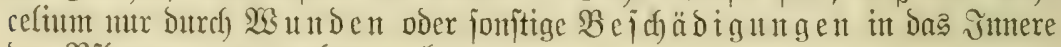

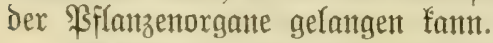

Befallen merden: 1. Die Frühte der Pifanmen (Bwetichgen),

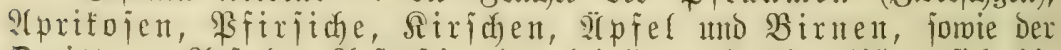
Sutten. ?af Der Alupenjeite der befallenen Früchte bilden fich bie 
gratten Sporentajent in zonenförntiger $\mathfrak{A}$ (noromung. Dit bleiben bie $\mathfrak{a b}=$ geptorbenten Frïchte an ben Bäunen hangen (Fig. 47 ıno 48).

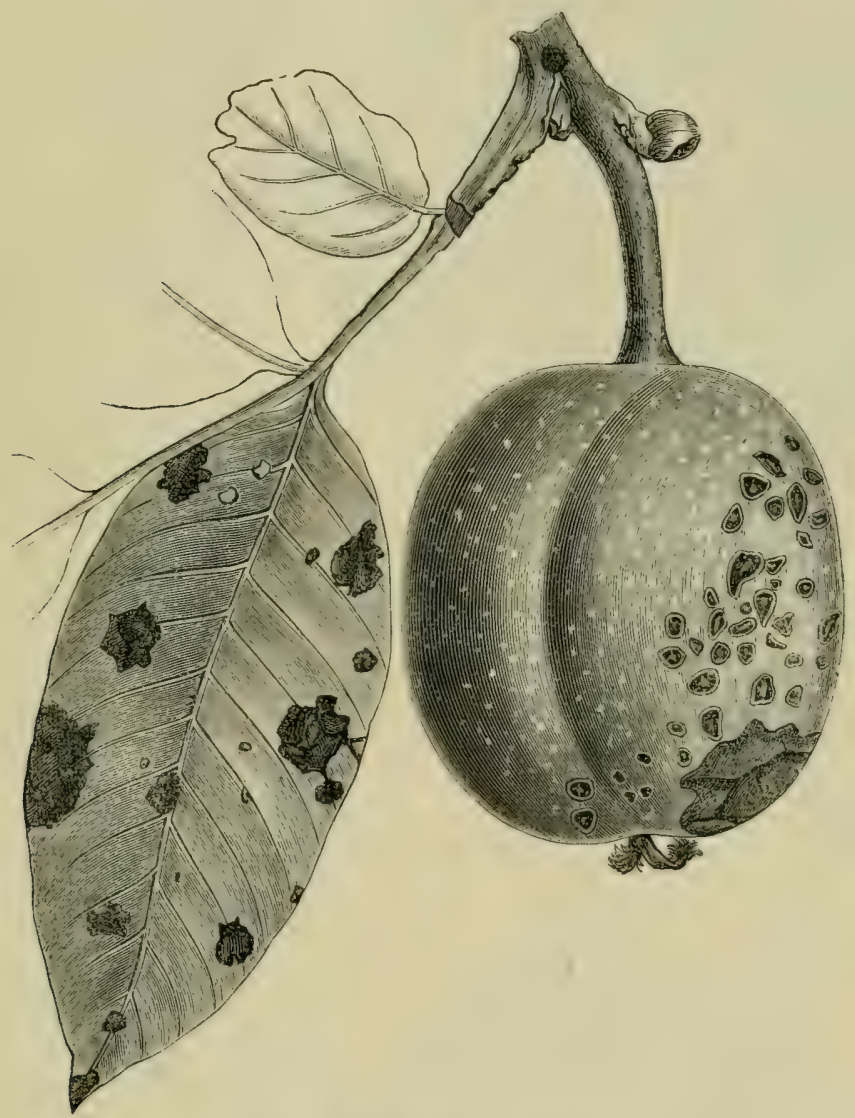

Fig. 46. Marsonia Juglandis.

Ias Blatt nuit Flecten bon Marsonin Juglandis, bie Frudtidjale mit Septoria epicarpii.

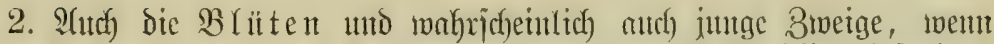
fie durd) Froft gelitten haben, werden angejtedt; jo leiden bejonder: Die Sit

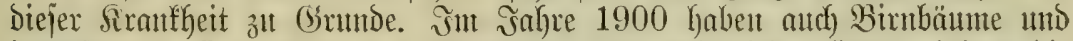

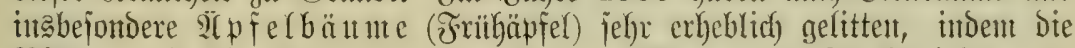

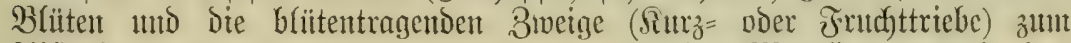

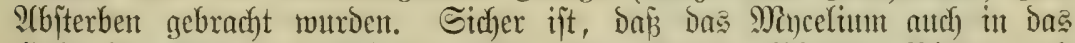

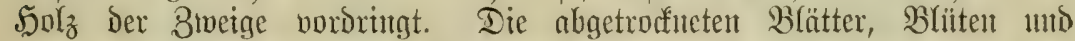
jungen Friud)te bleiben anth) päpäter nod) an ben Broeigen Kängen. 


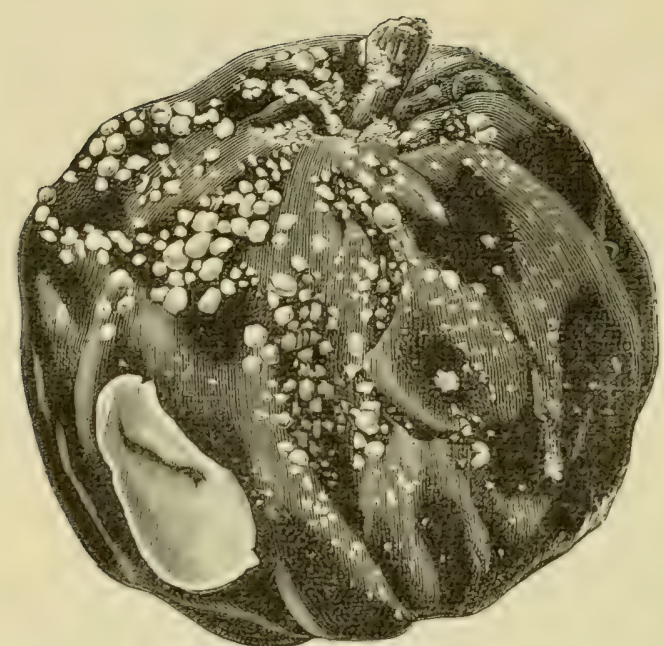

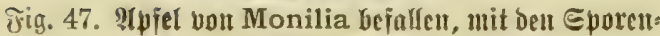
politeru bedectit.

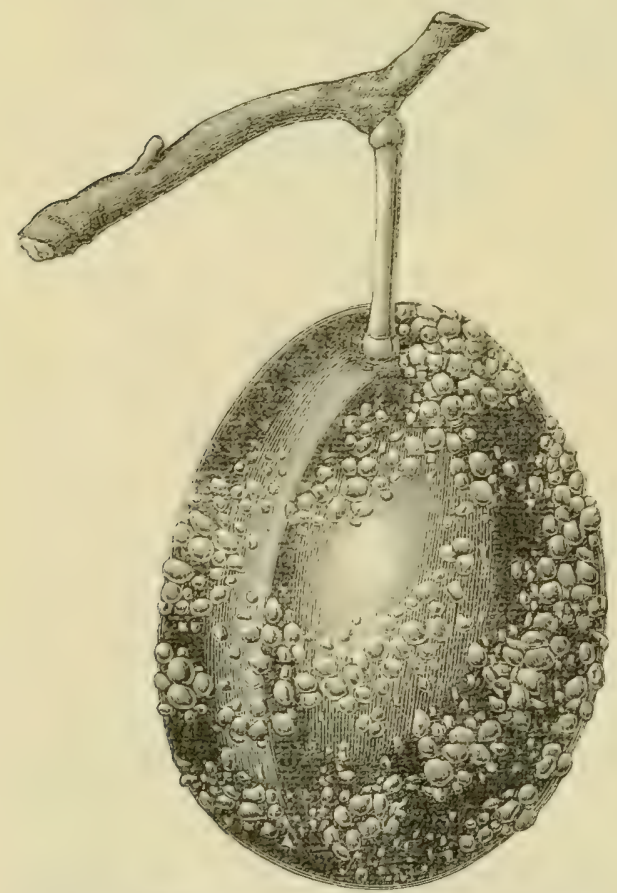

F̌ig. 48. Bf(nume mit Frudotidjimmeliporen: politernt.
Bef̈ämpfuna. 9)laı vernichte alfe mit Monilia beiebten abgefallenen ober nody att Den Bweigen hängenden Frühte, wähle mut miderftandşähige Sortent und jujübe fic bejonteres gegen Fröfte währento Đex Bliitezeit แnti Der Biattentfaltutg. Ŷch) eine Bcfpribung mit Supjerjodabrilhe hat getholfent.

Die anf Steinobit vorfontmento Frorni iviro unter der Bezeirisum M. cinerea and ala eigette $\mathfrak{A}$ rt aufgefajpt.

\section{Gattung: Fusicladium, die Sorjorffrantfyeit.}

Die fontioten fint $\mathrm{ei}=$ förmtig bis flajudenförmig, ein = bis zweizellig; fie ent= itehen auf furzaufrechten Sonidotenträgern. Dą $M(\mathfrak{y})=$ celtum irt grüntich.

Fusicladium dendriticum, bie Sdforftrant= Geit ber îtufer. Der $\mathfrak{B a}=$ rajit befällt fomohl bie Blätter als autd) bie Frühte unto bie grint (einjährigen) Bweige und veruriadyt exit id)roärzl(id)=grïne Fledfen ; ipäter werden die befallenent Etellen auf dent Brättern unl Stengelnt graut oder graubrauts. Die befallenten Friichte entwicfeln fich nidht

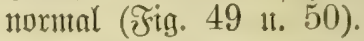

Befämpfung. $\mathfrak{A}(\mathfrak{3})=$ berläifiges Mittel hat jith eit redytzeitiges, wiederholtes 


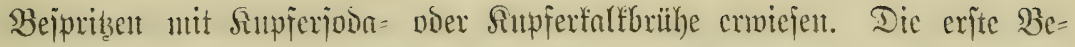
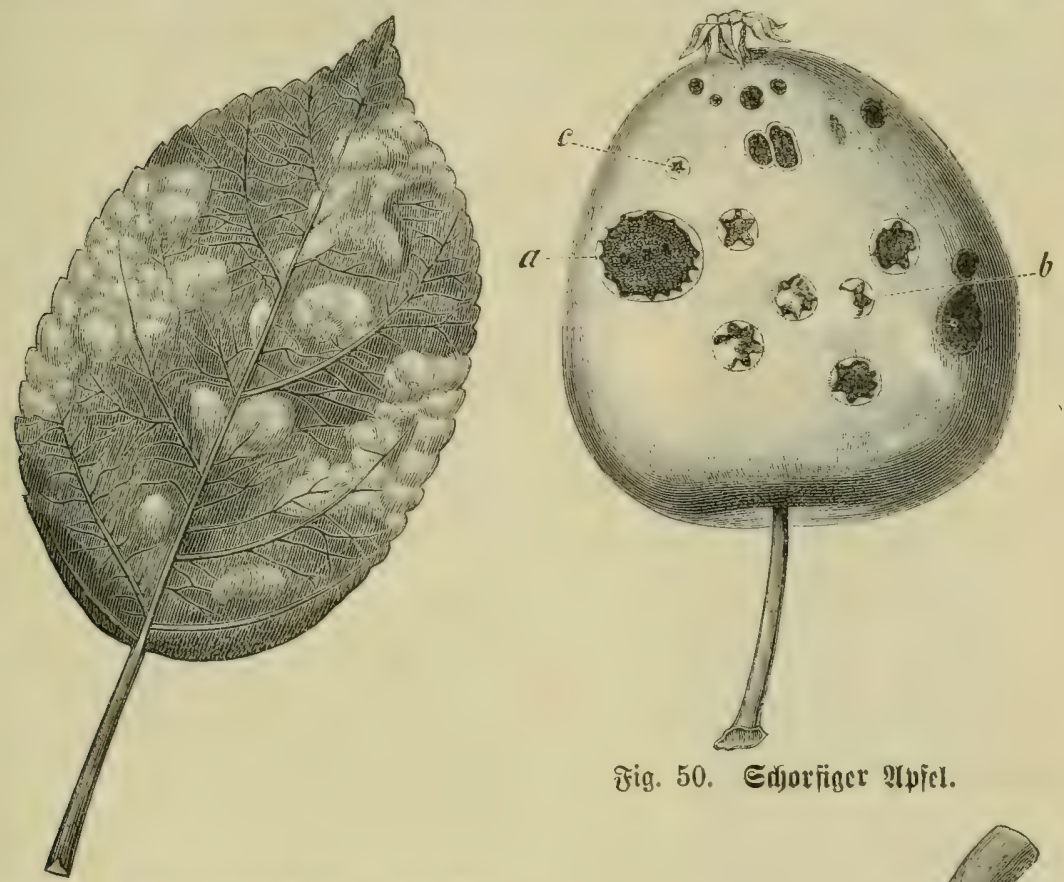

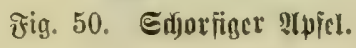

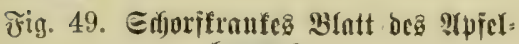
battites.

Die befallenten Etcllem find grau und bertrodnet.

ipribuntg hat ipäteptene ummittelbar nach Dem Berbliihen zu gejchehen. Die unteren Ât ite gróperer Bäunte weroen an itärfiten angegriffen. Bei $\mathfrak{N e n p f l a n z u n g e n t i f t ~ a n f ~}$

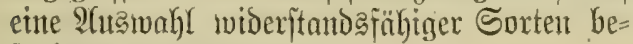
jonders zh adytent.

F. pirinum, Der Birnenjdorf, bex vorbergehenden firantéfeit ganz ähnlich, wer= urjadyt an Den Blättert, grïnent Brweigen und Früdyten mandjer Birnemorten Dent gleidjent Edfaben, wie bie vorige Stet ant 2 preflbäıment. Die bejaflencu Birnent

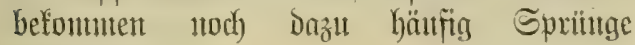
(Fig. 51).

Die Befämpfung ît natiurlid) Die gleid)e.

F. Cerasi fonut ebeño an Sirjöhen bor.

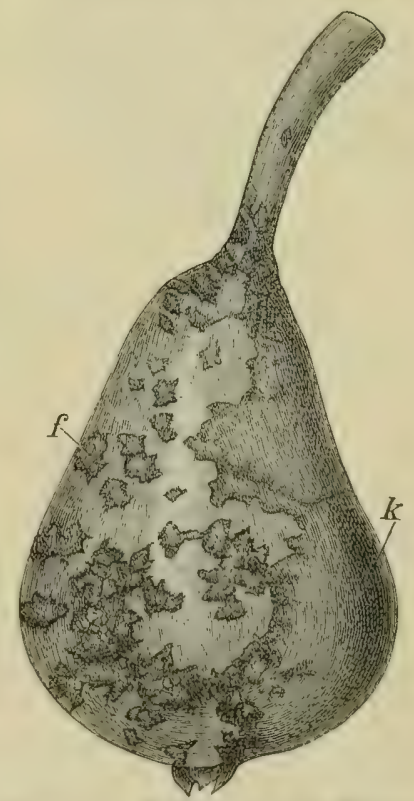

テ̛ig. 51. Єđjolf mu ber Birne. 


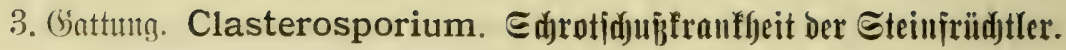

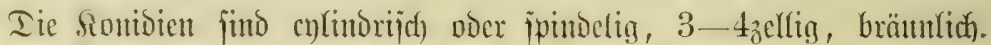

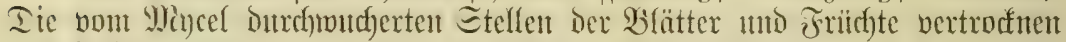

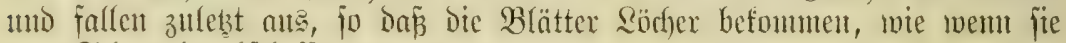
von Safrot Dutrdjichofien wären:

Clasterosporium Amygdalearum, Die $\Xi$ drotichunfunufheit

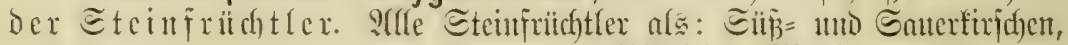

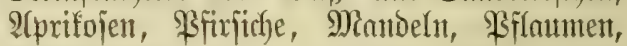

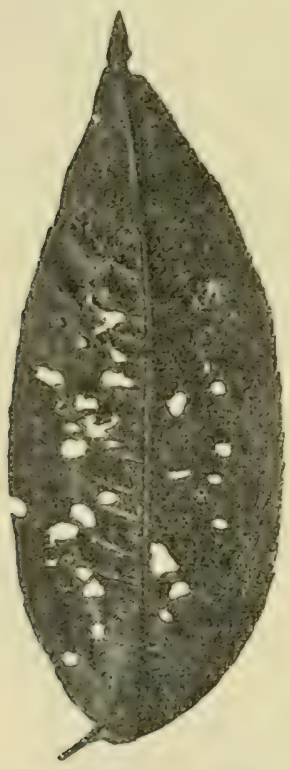

Fig. 52. Clasterosporium

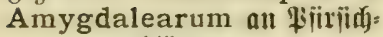
blättern.

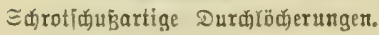
Sirrichlorbeer 4. F. to. merden befallen unto zeigen Die d)arnfteriftijd)en Iöd)er (Jitg. 52 tno 53).

Beß̈äntpfung. Rechtzeitiges Bejpribent bex $\mathfrak{B l a ̈ t t e r ~ j o j o u t ~ t u a ̈ b r e n t o ~ b e r ~} \mathfrak{B}$ lattentfaltung jchintebt bor biejer Siranffeit, Die in mandben Jakrgängent jefre gefälyrlid) twerden fam.

\section{Battutug. Ceratophorum.}

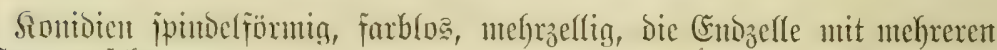
Boriten veriekent.

Ceratophorum selosum berurjacht an den griuten Teilen bon $\mathrm{Cy}$ tisus hirsutus bräunlidbe Flecfen; Die Blätter fallen ipäter $a b$.

C. Weissianum beritrjacht in äbnlidyer $\mathfrak{B e i j e}$ dic $\mathfrak{B}$ Lattfallfrantheit Des (S) oldregen? (Cytisus Laburnum).

\section{Grattung. Helminthosporium.}

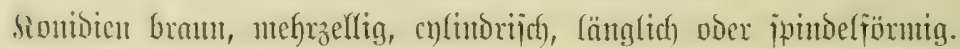


Helminthosporium gramineum verurjact)t exỹt all delt unteriten, jpäter aud an ben oberen Blättern Der (Ǵ) rite antrangs bräunliche, jpäter in Der Mitte verbla inte uno rebbaft brammot umiämmte, längliche Fllecfen. Dic be= fallenten Blätter trodfnen raid) $a b$.

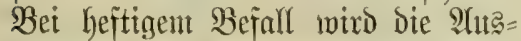
bildung Der fiörner erbeblidy beein= träd)tigt (J̧ig. 54).

\section{Sóntuntg. Cercospora.}

Die Sontioten fint idfmeit= förmig, mehrzelfig, reicht grïnlict) gejärbt.

Cercospora beticola erzetigt bejonters in naijen Jahrgängen an Den Blättern Dex $\Re$ un fel $=$ แt 3 แ⿰㇒⿻土一𧘇 (ick) an ben älteren, päter autch an jüngeren, zahlreid)e, ficharfuntgrenzte, bräunliche Flecten, die bas aflmäh)= liche Afbiterbent der Blätter zur Folge Gaben. Die Befämpfung beifelyt

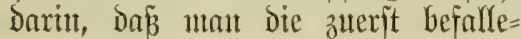
nten $\mathfrak{B l a ̈ t t e r ~ e n t f e r n t ~ I n t o ~ v e r f i i t t e r t ~}$ (Fig. 55).

C. circumcissa verurjadyt an Steinfrifd tlern, bejonders anf den Blättern Dex 3rwetichgenbäunte, der Ûprifojen unto SFirfiche erit bräuntidye Fledfen mit cinem rout = itigent Rande. Das tote Semebe

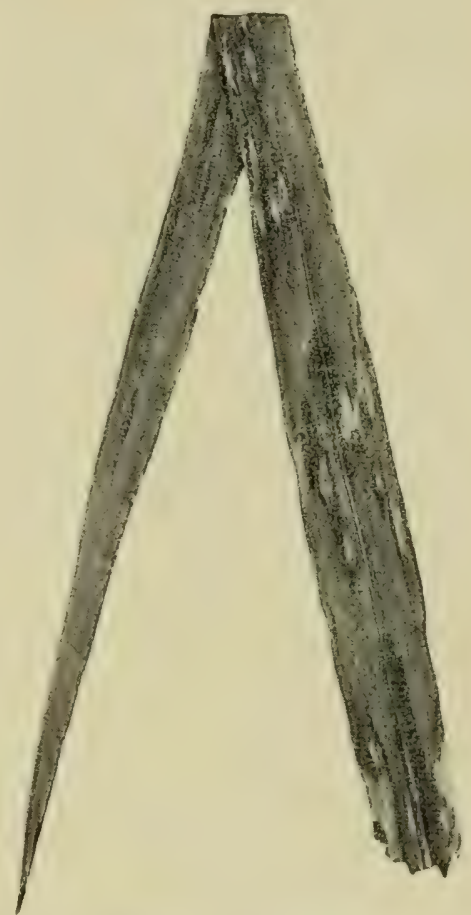

Jig. 54. Helminthosporium gramineum an cinen Geritenblatte. fällt jäter aนte und die Blätter be=

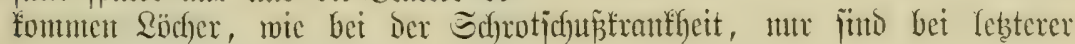
bie 9iänder nicht rutlfitig.

Man bejprizst red)tzeitig uit Den befannten Supferbrïhen.

C. zonata veruriacht auf Den Blättern Der $\mathfrak{A}$ fferboblte zicurlich

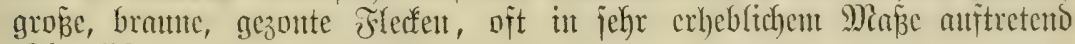
(รึig. 56).

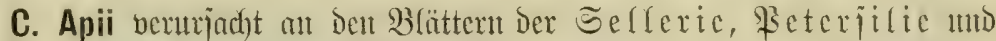

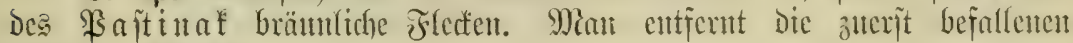
(äuß̧æren) Blätter.

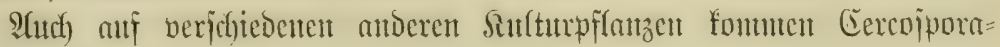
arten bov. 
7. Gattung. Heterosporium.

Dic Sivntibien fint fängficd), $3-5_{3}$ ellig tuto bejitzen eine ftadhelige oder förnige Şatt.

Heterosporium echinulatum erzettgt ant Der (b)artenticlfe erfit fleme, fpäter grë̈zer merdentoe, etwas violett. itmurandete Flectent. Mianthe Mielfen= zitdoter milifient Die Sinttutr gattz alfógchen, wetur dic Sirantffeit in ifyrent Göröten muftritt. (5in redftzeitiges Inno öfteres Bejpriben mit Dent Sitpferbriifhen bilfyt autd) zimeifelsohnte gegen bieje Sirantheit.

H. variabile, die Brattrlede ett frat heit deg Spint. So= mofyl an Der jintgent, af intabejontwere ant bot bliibentoent Spinatpflanzen treten auf Dell Bilättern

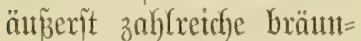
fiche, numblidge, im Эomern bleidhe Flledten aut, weldhe Die Siffamzen mbranddbar ittachent. Eitte Direfte Befämpfung iìt nicht möglich), Da bie B̧ätter gegefien twerbert. Biter= leidyt giebt es Sorten, tweldye nischt befallen iwerben.

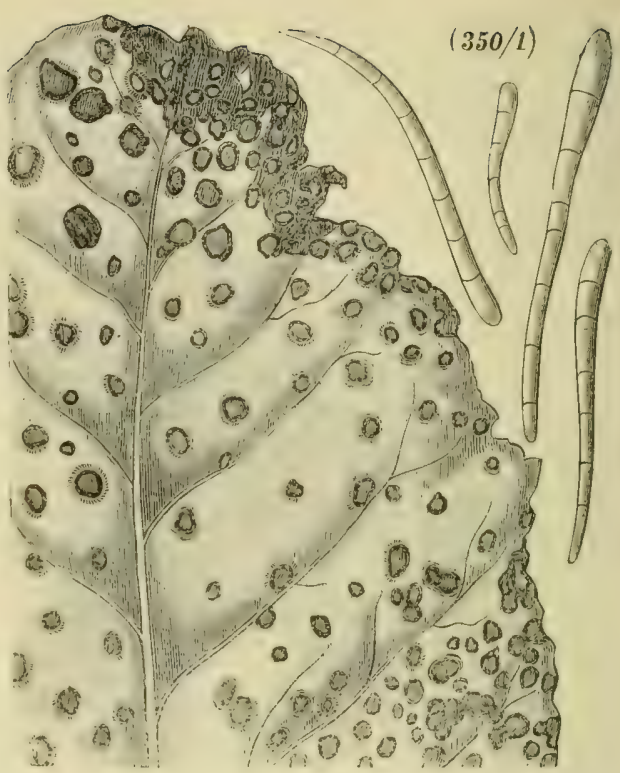

Fig. 5.5. Cercospora beticola auj Mutfetruiben.

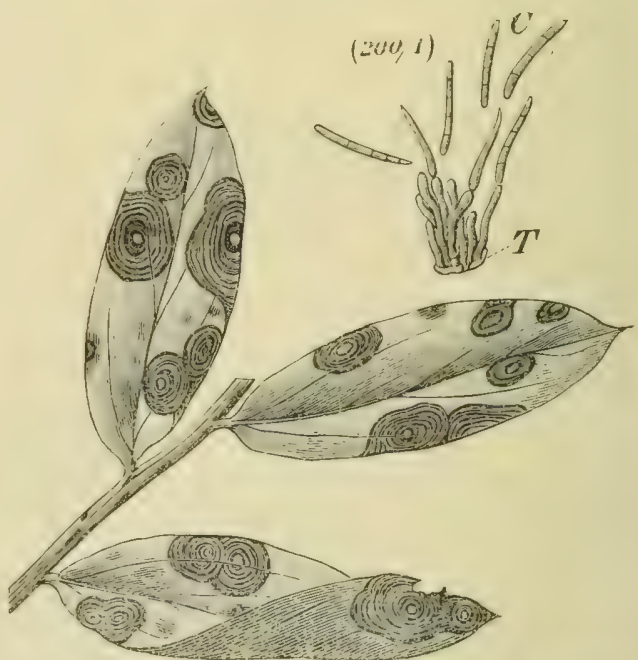

Fig. 56. Treferbolyte mit be॥t gezonten frletfer von Cercospora.

7 ' Sporenträger, C Sontibien. 


\section{$-95-$}

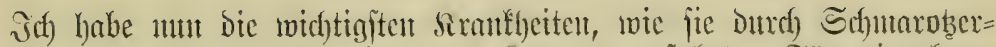

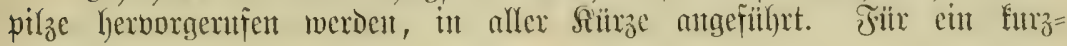

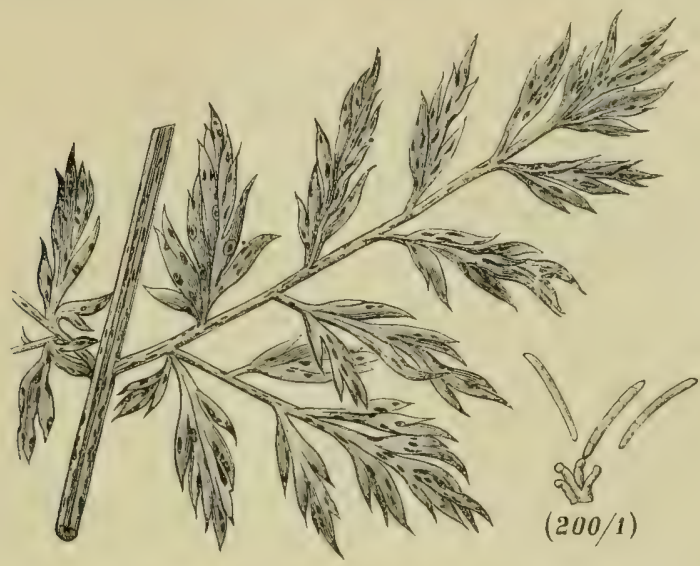

Fig. 57. Cerospora Apii.

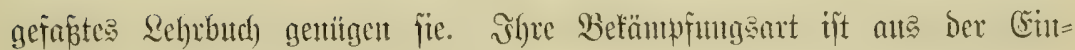
leitung Ginreidfento ffrar oargelegt. 


\section{II. $\mathfrak{U} \mathfrak{b}\{d \boldsymbol{n} i t \mathrm{t}$.}

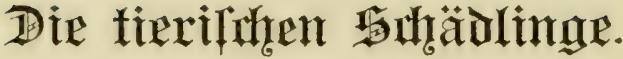

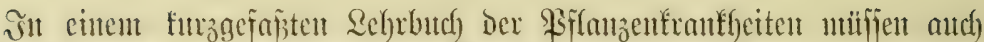

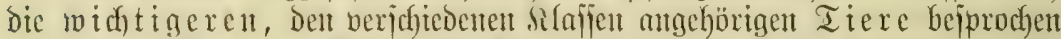

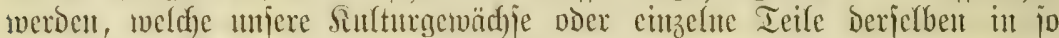

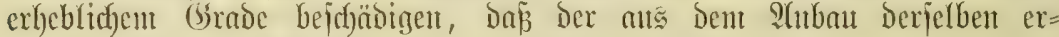
martete (Extrag gäızlid do der teil weife verloren iit.

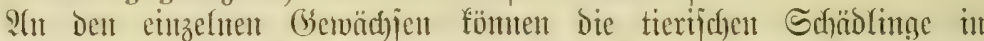

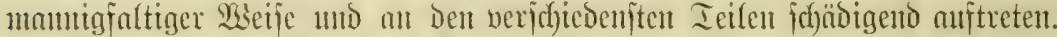

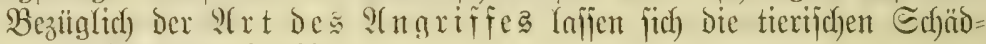
linge in 2 Brmppen einteifen:

1. entweder bie Tiere frejien jeci, oft jogar nut voriibergehend an Biffanzen,

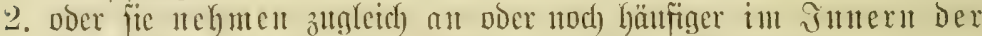

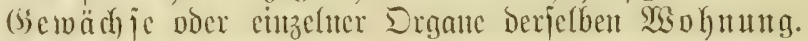

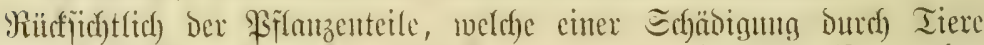

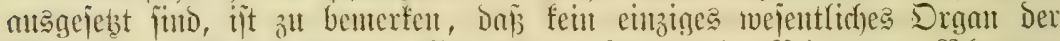

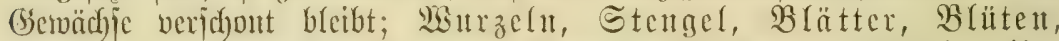

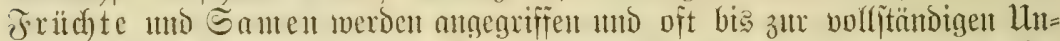

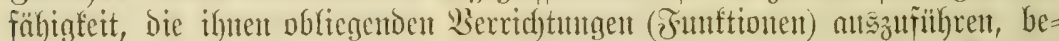

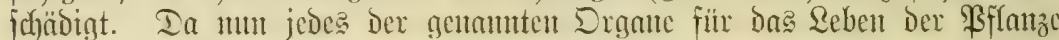

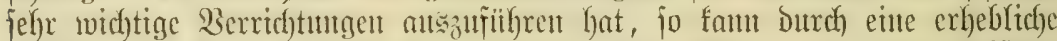

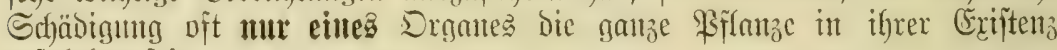
gefähroet jein.

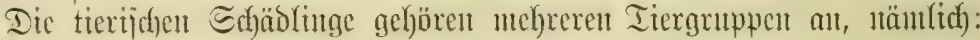

1. Den Mirbeltieren (Sätgetiere unto 2ügel),

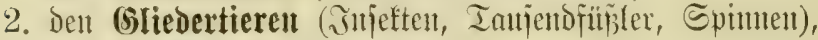

3. Den Meidjtieren (Scl)uecfen),

4. Den Mïrmern.

\section{A. Befämpfung der fhädlichen Tiere im allsemeinen.}

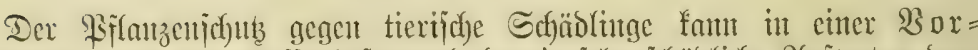

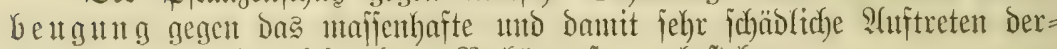

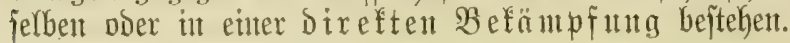




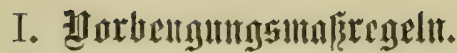

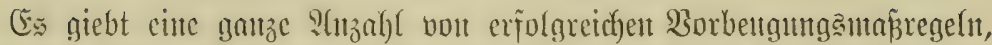

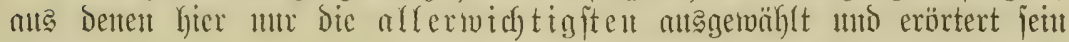
mögett.

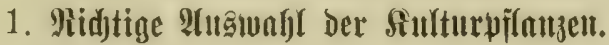

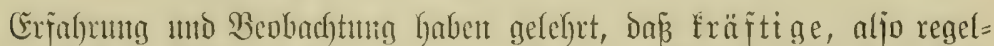

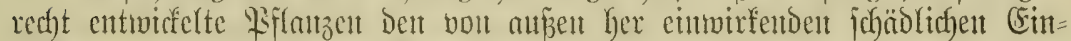

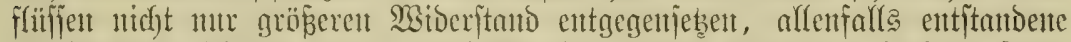

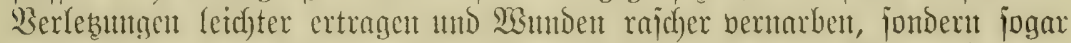

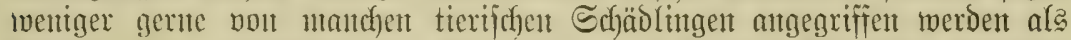

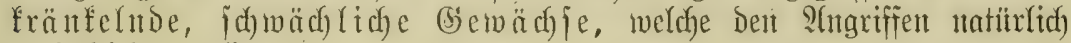
atto) reidhter erliegent.

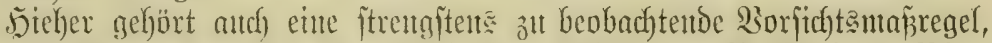

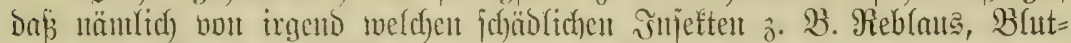

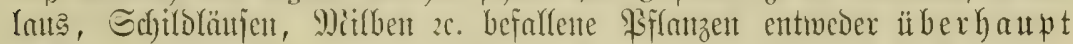
nid th angejchafft ober wentigiten in ungereinigtem und unge=

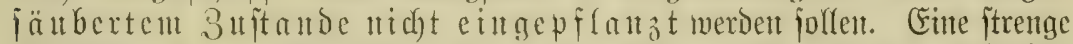

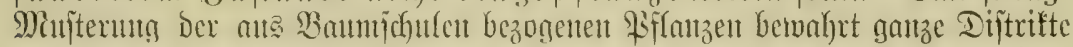

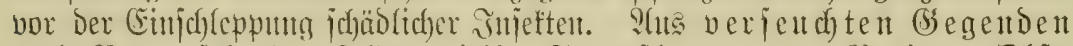
แnd $\mathfrak{B} a \| n j$ d) bäume nid)t bezogen twerbell.

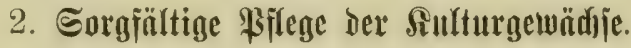

Gad)e ciner jorgföltigen Bfflege ift $e^{3}$, bon futturgemächjen die tierijchen Guäblinge mb̈glidg ft fernzuhalten.

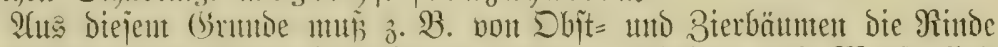

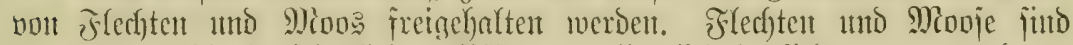

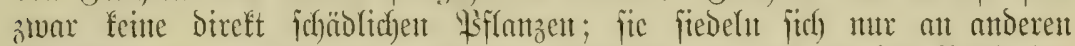
(Begenftänden, jo Matem, Etemen, Brettem und auth an Der Borfe der Bäume, an und fteflen bei mb bie Sippe der Eptphyten, b. h. Der

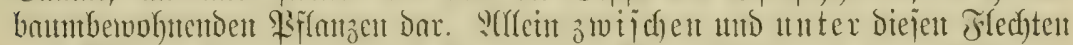

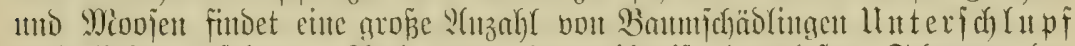

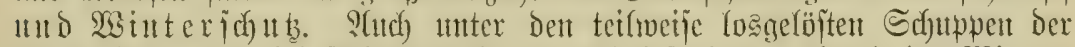

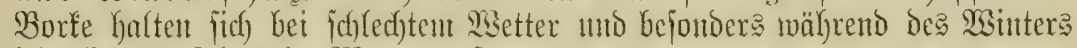
ichäbliche snjetten in Menge nuf.

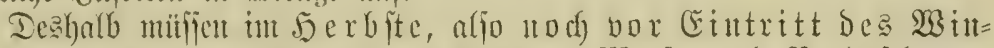
ter

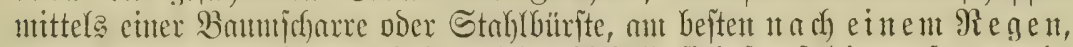

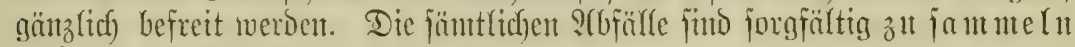
und zu verbrenueu.

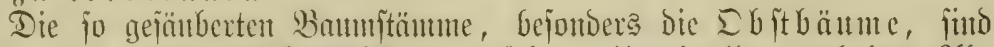

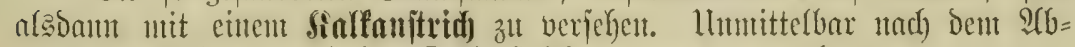

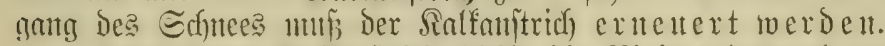

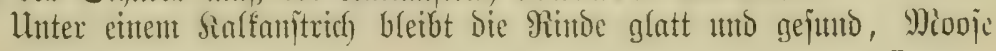
$\mathfrak{B}_{\mathrm{C}} \mathrm{i} \bar{B}, \mathfrak{P}$ flanzenfrantheiten. 


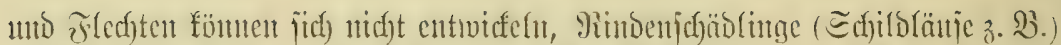

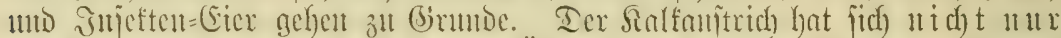

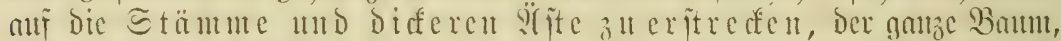

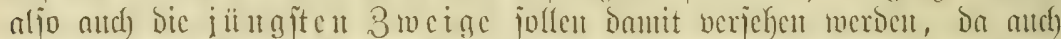

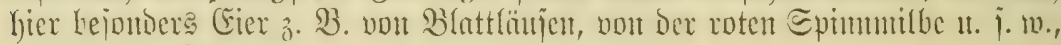
abgelegt toerdent.

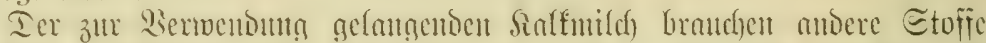

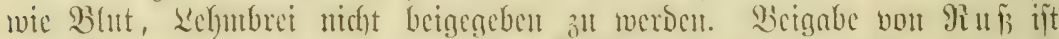

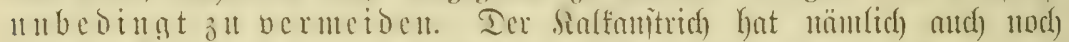

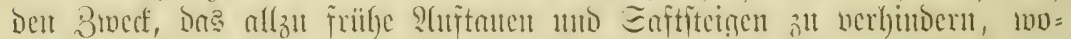

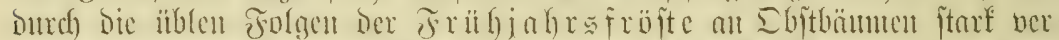

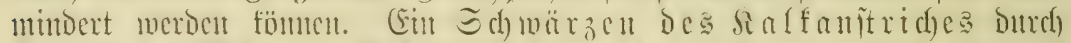

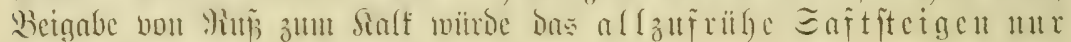
begitnitigen.

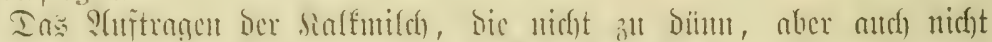

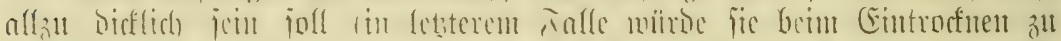

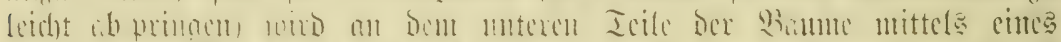

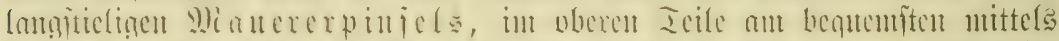

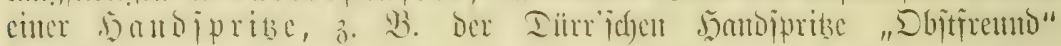
bejorgt.

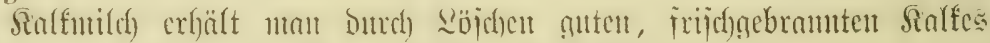
it Sanjer (etwon 8-10 Silo in 100 Riter Waffer).

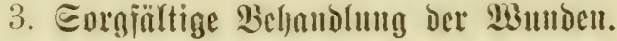

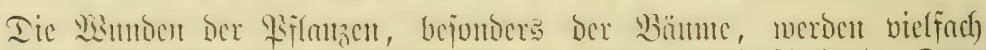

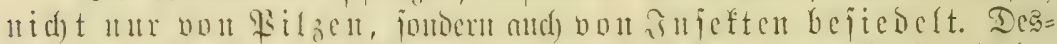

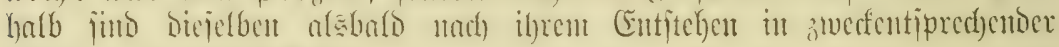
Meije zu verftreiden:

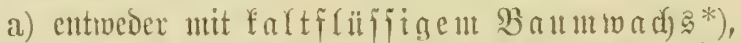

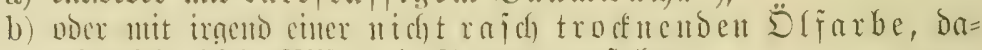

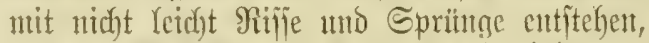

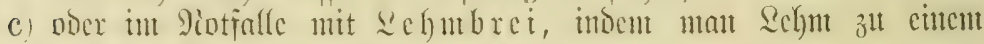
bifflichen Brei mit Waffer verriilyrt.

*) Serftellumg von faltflüffigem Baımuvachs.

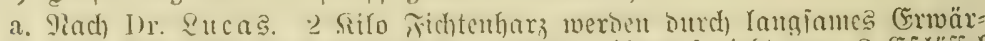

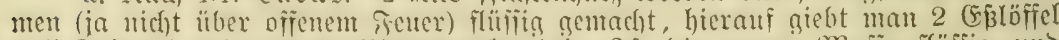

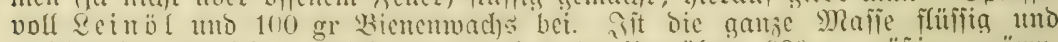

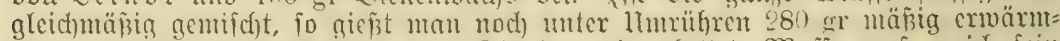
ten etma sograbigen oufohol bei. Die herund erfaltete Mafic mus meich fout

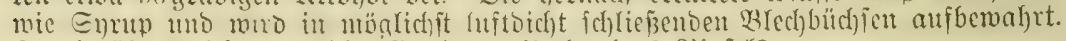
Dantit überfireicht man bic \$Bmben mittels eimes Błinfels.

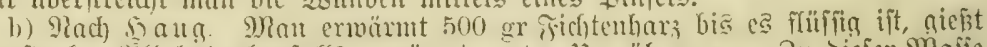

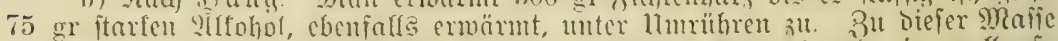

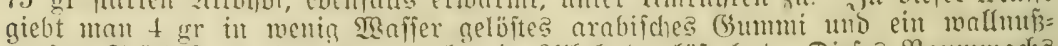
grop̉es Stüd Soda, bas man vorlex in 2(lfohol gelöit hat. Iiefes Bammmad)

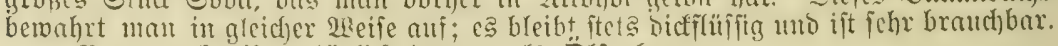
Baummachs ift natürlich teuerer als S̈lfarben. 


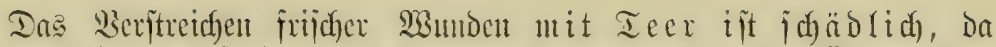

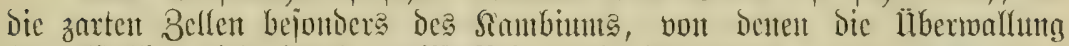

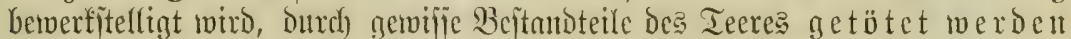

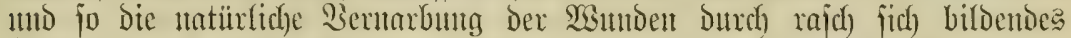

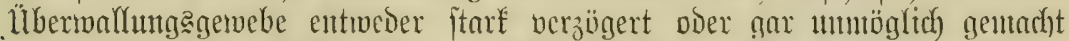

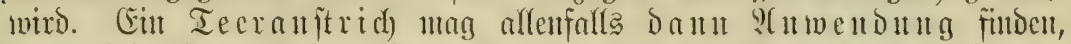

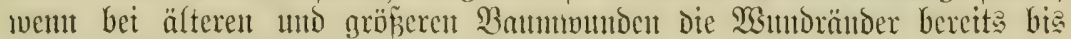

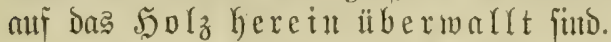

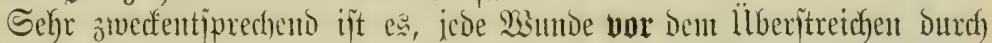
cincs Der eben getrumtent Miaterialien mit einer $6-8 \%$ igent Silnferjoda=

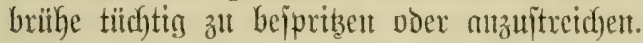

\section{4. (Entjermung Der bürren ?ilite แnd 3weige.}

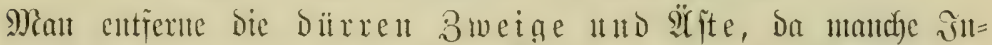

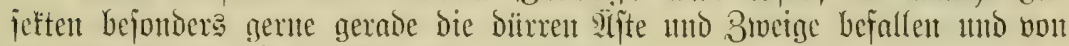
Da gclegentfich) auf gejunde Teile iibergehen.

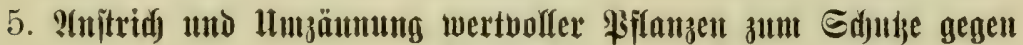 Tierfrņ̃.}

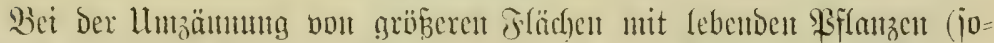

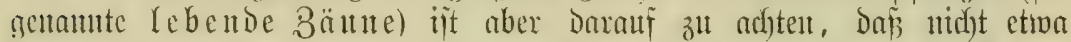

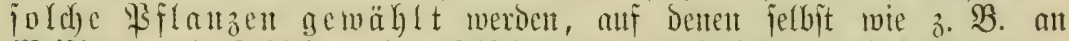

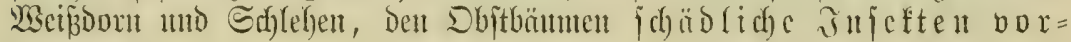
to 1 itmett.

\section{Begen $\mathfrak{M i l d o f r a ̣ ~}$}

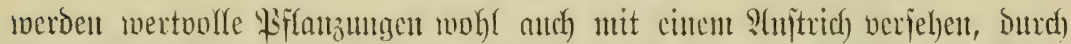

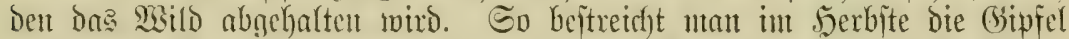

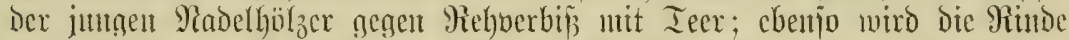

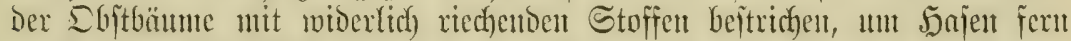

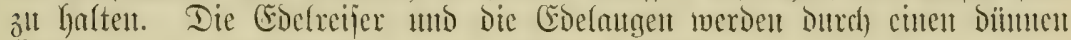
litberzatg boit Baumtwadjs gegen Injeftent gejujükzt.

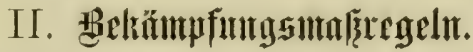

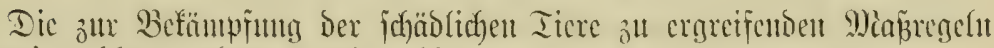
juto mittelbare ober untuttelbare.

\section{a) Mittelbare (indirefte) Bcfänt}

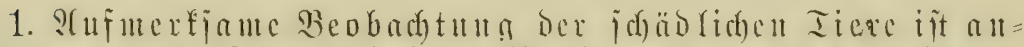

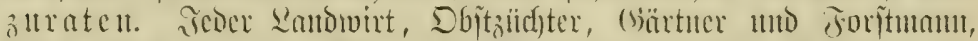

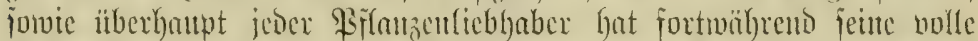

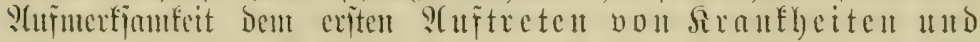

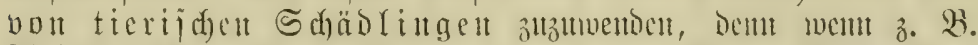

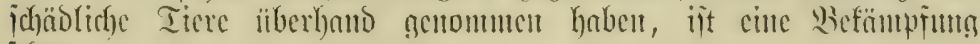
j(d)wer. 


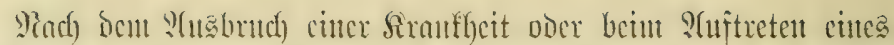

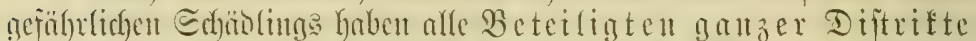

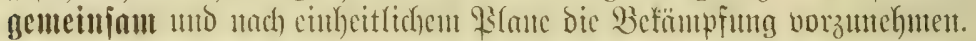

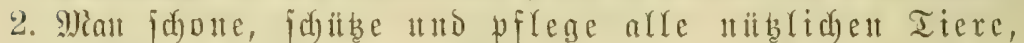

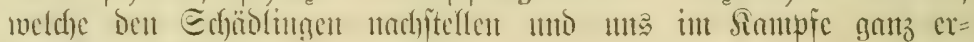
heblicf) mnterititibent.

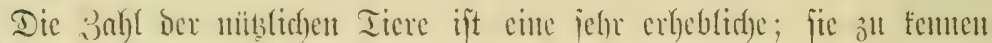
ift von grofer 23 idftigheit.

Bu ifuen gehören:

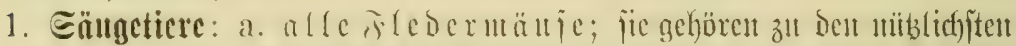

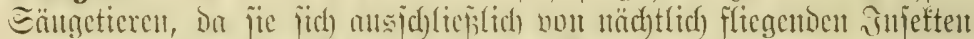

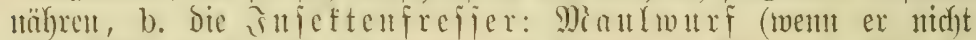

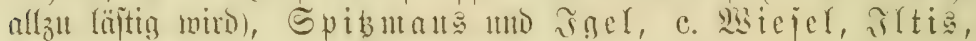
die bejonders föbolidyen Shagetieven nadyjtellen.

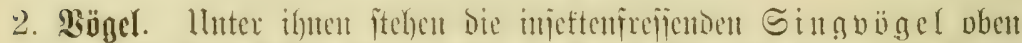

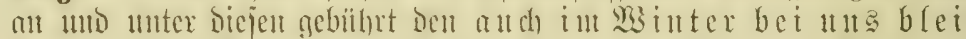
benden Der $30 x x a n g$;

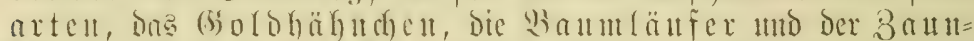

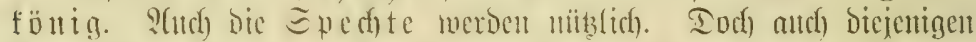

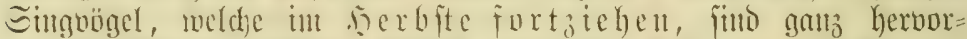

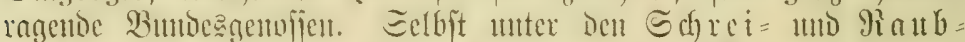

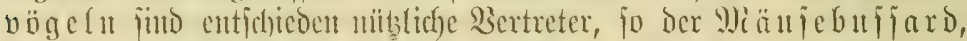

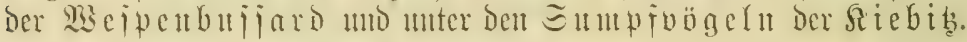

Q⿱⿴囗十介

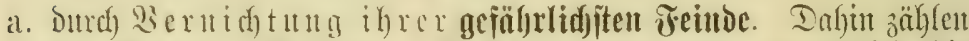

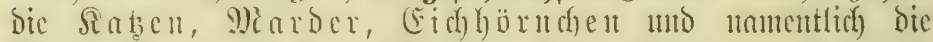

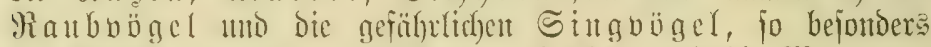

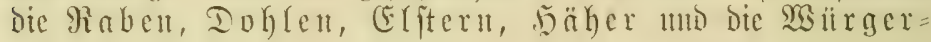
arten.

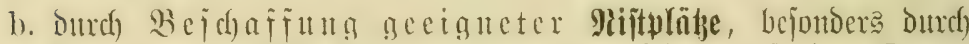

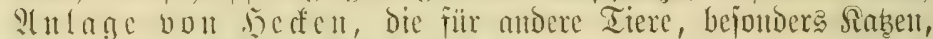

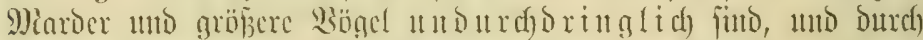

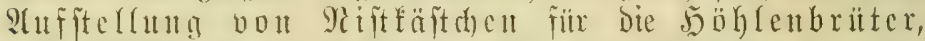

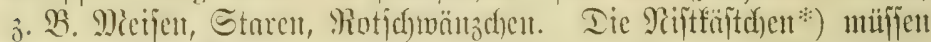

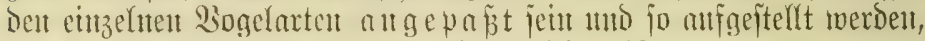

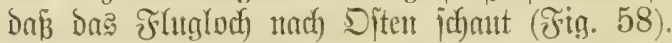

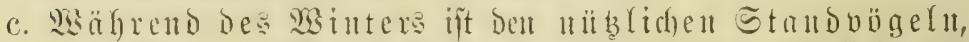

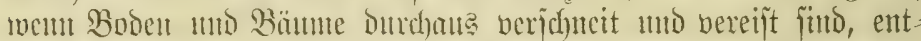
iprediendes jutter zu ftreueu an geetgneten, bor Sdhnee ant

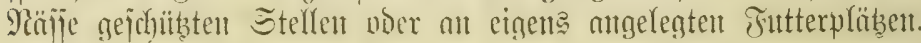

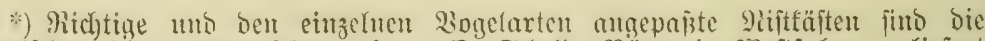

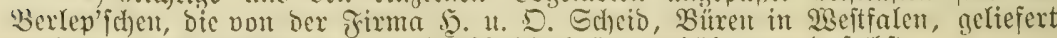
werben. QTuch Niftäftchen für 5albhöblenbrüter crhält man Dajelbit. 


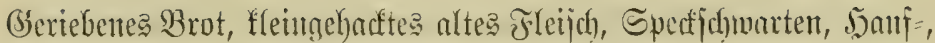

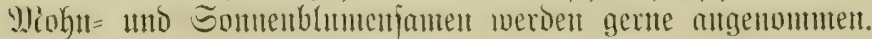

3. Wian forlue bie injeftentütenden

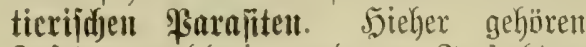
Injetten, welde in anderen כnieften

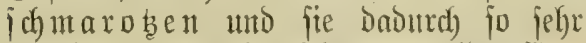

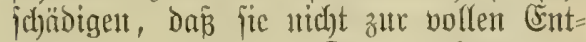
widfelung gełangen. Daz̆l rechutet man bie Raupellfliegen tno ingbejondere Die Sd lupfweipen (Эd)teuntontident). Dic Weibdyelt bohreelt zat= meipt bie Rarven alt= Derer Injeftent an unto legen je nad) llmitün= Dent 1 bis viele Eier in Diejelbent. Die Rar= vent Der Sdylupfiveipen niâlyeen fird bont ibrett Wirtent, wobutrdy bieje jo jel)r geidübtgt mer= Delt, Da ja fie, jet nod) ats Rarbe poex Yianpe oder ale \$appe,

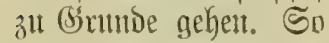
fieht mant nebent Dent toten Siaupent Des Rold $1=$ uveişlings häuftig Die

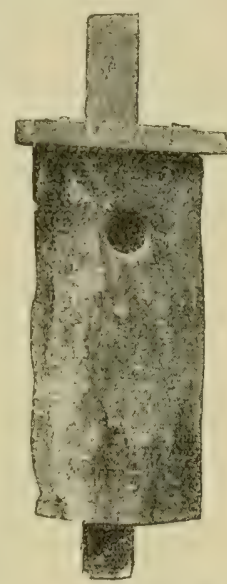

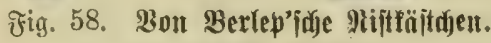

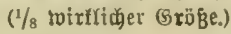

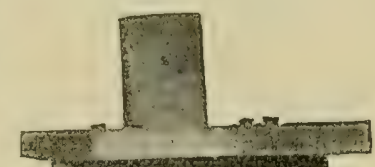

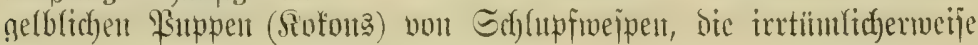
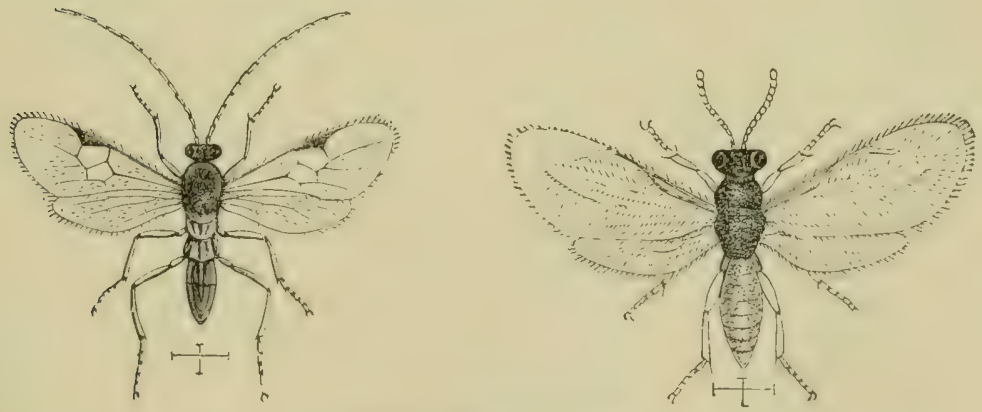

Fig 59. Edfutuiweiper.

Microgaster glomeratus.

Pteroma'us puparum.

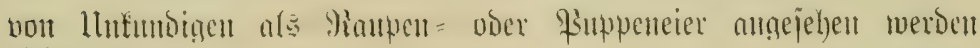
(ङ̧ig. 59). 


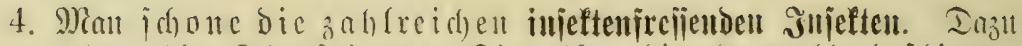
zählen dic storilicgen (sig. 60), die Sianclbalsjliege, Deren Larbe bon Jujetten, bie unter Banmminden berborgen leben,

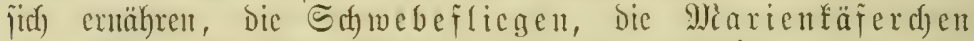

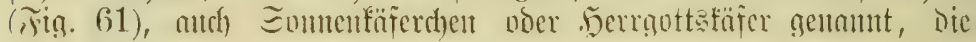
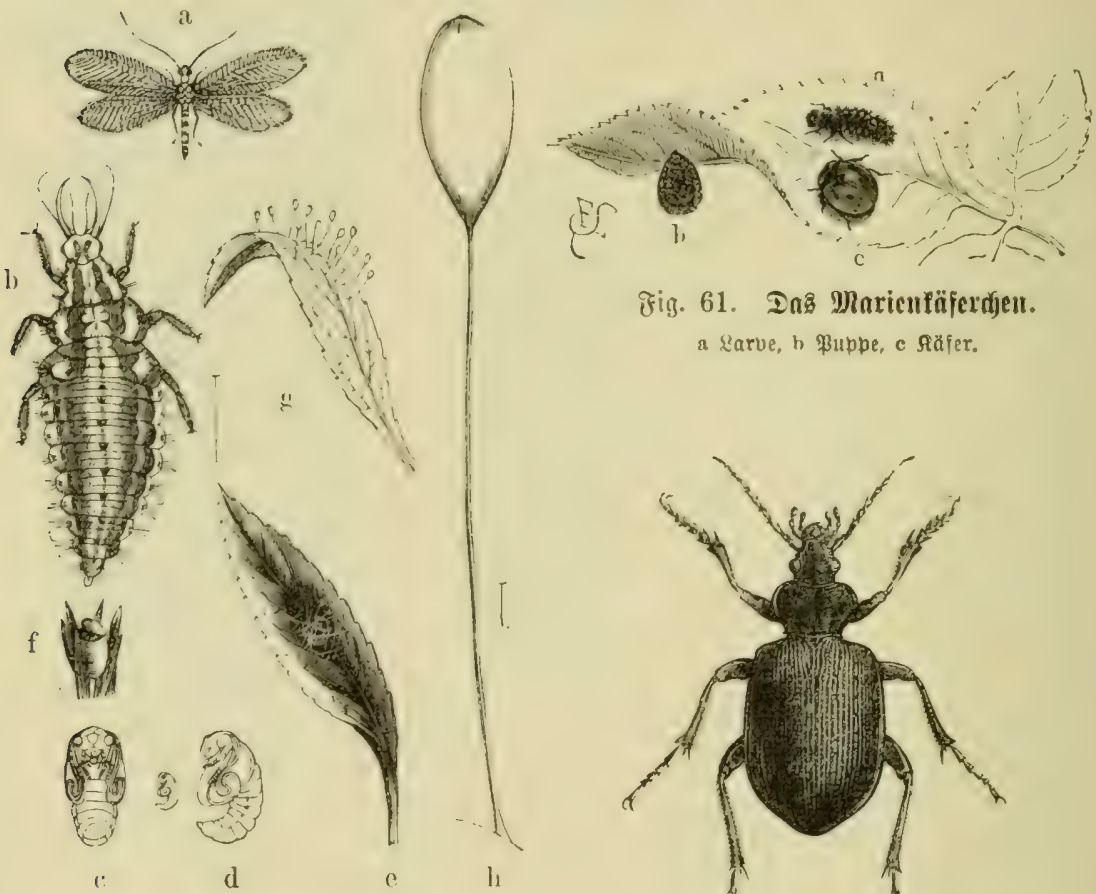

Æ̛̣g. 61. Dกริ Maricufäferdjeu.

a Larue, b łuppe, c Räfer.

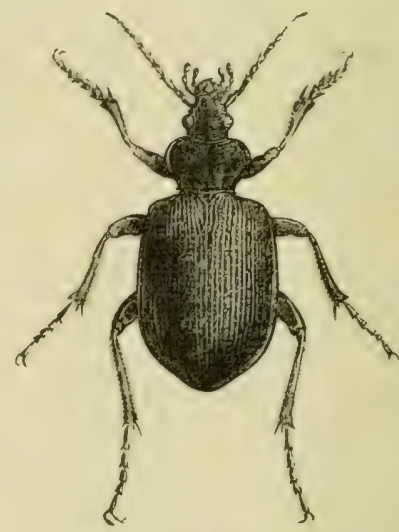

ช̛ig. 62. Ter Pruppentüuber.

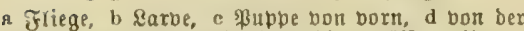
Seite, e bas nod) geidjloffene, $f$ bas geöfinete (5ocon, " tie geiticlten Eier, h ein eimzelnes (Fi. (b, c, d, b bergriogert.)

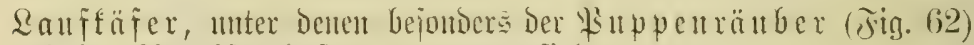
und ber $\mathfrak{A}$ meijentäfer zu nemen fint.

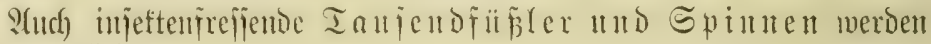
แ⿰กร nübisich).

\section{b) Itnmittelbaxe (Dixefte) Befämp}

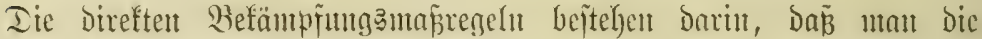

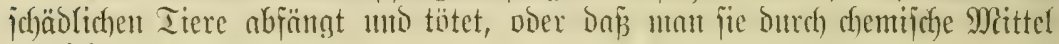
vernit(f)tet. 


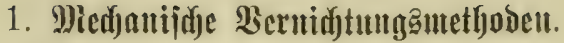

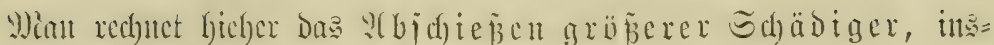

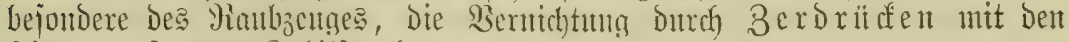
Fingern oft unter Bubilfenahute cintes Sandiduthes ats weichem Seder oder aus raubeut Stofĩ, Daz Bertreten, Berbrentuen.

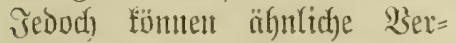
nichtunganittel nicht immer an= getwentet werdent, vhute baj auch die \$flanzen bejchäbigt twerben, jo z. B. betm Serbremtm Der Raupenteftex.

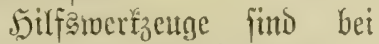
Derartiget Sernidhtutuge= methoden: Raupenjcheeren, bie allf einer Stange bejejtigt werden fömten, গaupen=

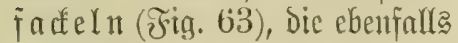

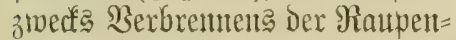
nejter auf höheren Bäumen auf Stangen geitedft uerocn, F $a n \mathrm{~g}=$ trid)ter (Fig. 64), Int bie Jnjeften, Larben ntwo bejonders Siäfer beiu Abjöbütteln Darit

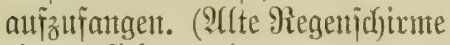
eignen ficf gut $D a z u$.

Das Abjülitteln won

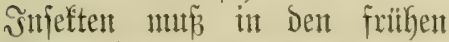

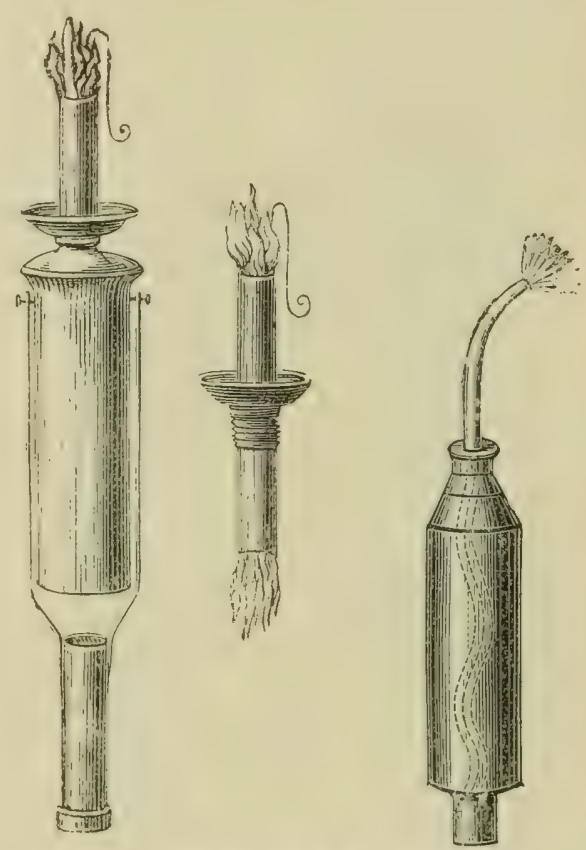

ờig. 63. Mlaber'idje Miaupenfadeftn.

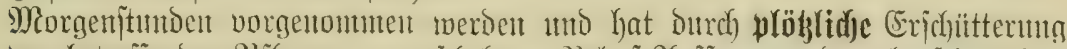

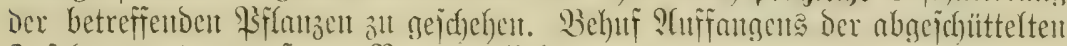
Injettent muter größ̄eren Bäumen finto g $\mathfrak{e}=$ nitgend grofe Tüder ausabreiten, anf welche die Räfer fallent.

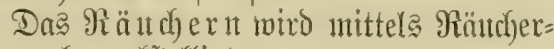
piantent bemerfitelligt.

Fine Bernidutung durdy foüblidbe (5) aje, z. B. Sdjtwefelfohlenitoff, ift mur in

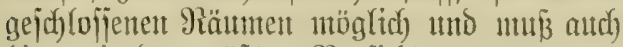
Gier mit Der gröfizten Borficht borgentonmen verden, Dantit enterjeits die Menichen, weldye bie Arbeit autafilfren, andrerjeits bie von Injeften za johitbenden \$Bflanzen nidj)t

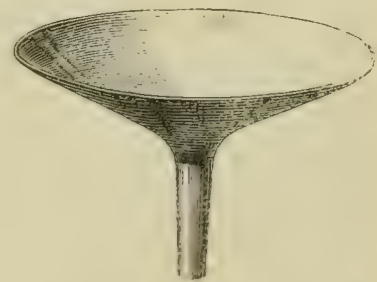

Fig. 64. Bledjtridgter zum (Ein= jantuelı von Injeften. gejuäbigt twerbett.

Seimringe und Silebegürtel, Um Sdjäsinge an bem Emporjteigen 


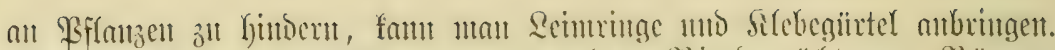

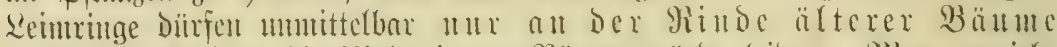

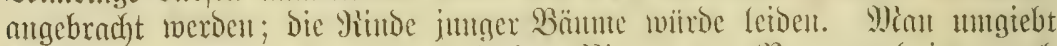

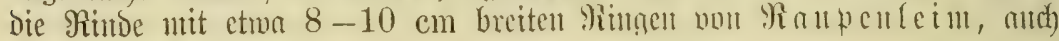
Brumataleim gentamt (Fig. 66).
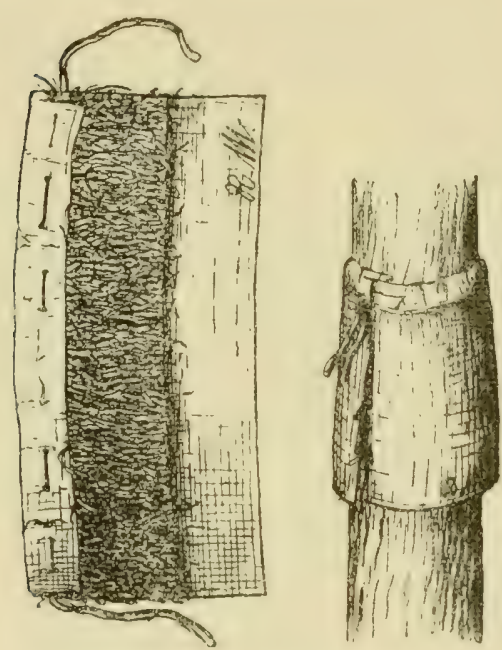

Trig. 65. Doftmnoenfinlle.

Finftijacher und jejöner ijt bic 2nubrumang von Silebegïrteln. Diejelben beitehent als etwa $10 \mathrm{~cm}$ breiten Streifen einte Yyaltbarent,

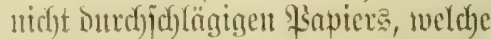
ınt beu Baumitau jo gebuntout Iverion, Danj bie Enton iiberemanter greifen, und Dẩ Das Papter an Der alleufalls Dutrch $\mathcal{A}$ btrabent zu glätten=

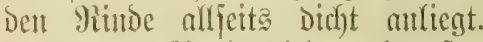
Dex untere Yiand wiro mad) anfen

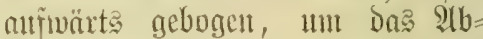

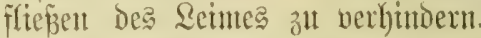
Dieje Bapieriptreifen werden jobann

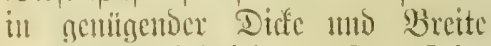
mit Recin beitridfen. Der Reim joll 3 Monate lautg nut flebento bleiben. Die Reimgürtel merben montöglich am bequemiten auf $3 \mathfrak{B r u f}$ t= höhe angebradjt. Epäter ift Der

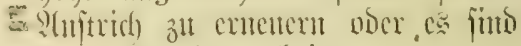
nene Giirtel anzubringen.

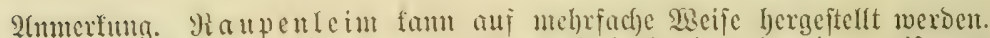

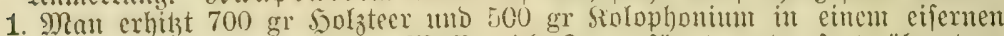
Iopfe vorfichtig (o anit bie Mafie nidgt fouer fängt) unter fortwäbrendem

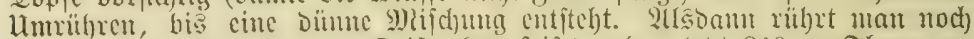

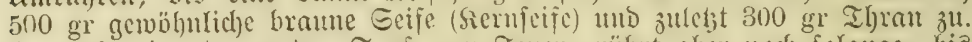
Sernach nimmt mant Den Topf vom Fenter, rïfrt aber nod) folange, bis Der Raupenteim erfaltet ift.

2. Man fdumilzt äbnlid) wie oben $500 \mathrm{gr}$ Siolophonium und $200 \mathrm{gr}$ Sd)meine=

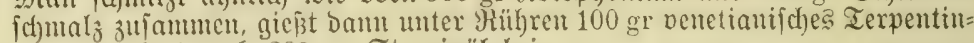
of und zulest nod) $200 \mathrm{gr}$ Stearinöl bei.

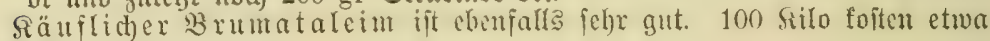
15 Diarf.

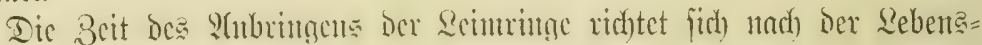
meije Der abzufangenden Injeftent.

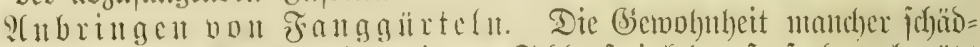

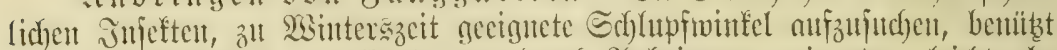

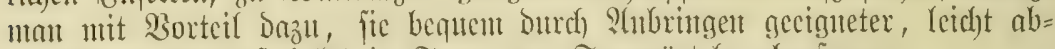
mefmbarer Ehlupfivinfel in Form von Janggürteln absufangen.

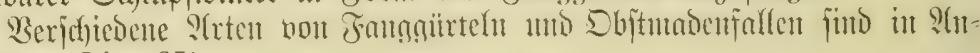
wentumg (テig. 65).

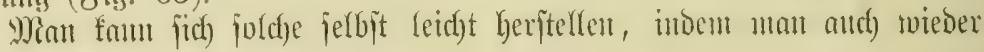




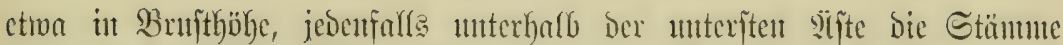

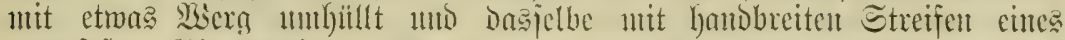

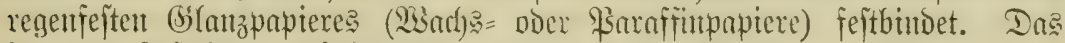
ftrantme Feftbindent erfolgt aber mut an oberen Rantoe.

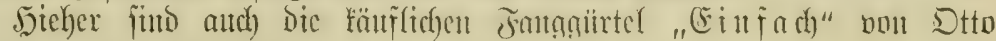
Sinzberg, die J్ ofheiner

Fanggürtel won

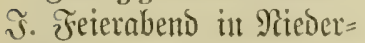
hatient ant Inumes z"t rect)men.

MSidjtig irt bie redjt: geitige Plbualjute diejer Janggürtel, ehe bic Injeftent im Fribjabr fie berlafien. Sulfe Darunter berindlidyen Schäslinge jind zu vernichten.

Ĩn Fanggläjern, bie mit Syrup ober Bier halb zu füllen jimb, fömten Fruchtichäblinge gefangen soeroen; alt mit Qeim be= ftrickenen Stäben Fliegen, Sdhmetterlinge, Erofflobe.

Durch Fanglater= nen werden nädhtliche Injeften angelocit mo burd) geeignete Borrid)= tungen getötet. $\quad 2(1)=$ locfungamittel fino z. 23 .
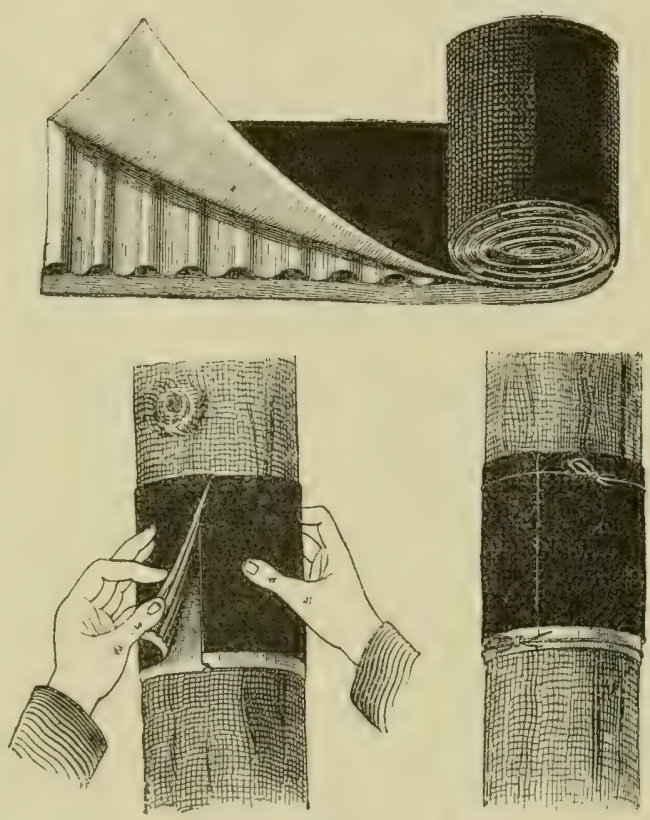

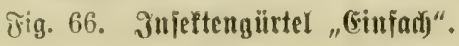

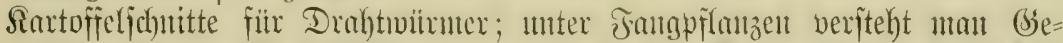

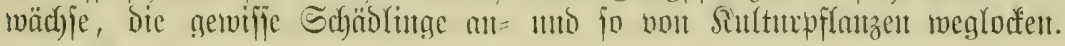

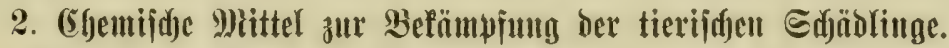

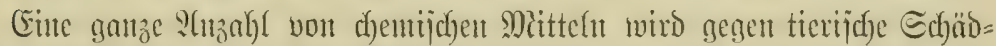

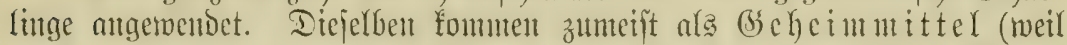

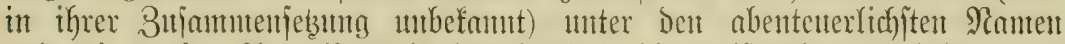

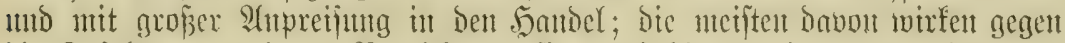

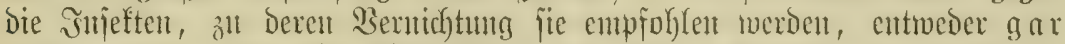

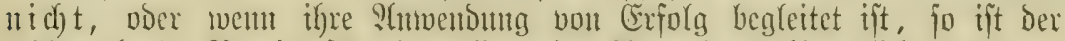

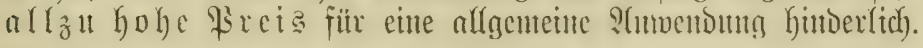

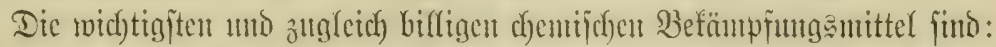

1. Gebraunter finlf́, In fein gepurlvertem Buftande bient $\mathfrak{e r}$ zur $\mathfrak{B} e r=$

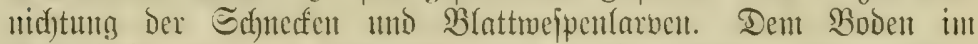
Berhältnie von $1: 4$ beigegeben tötet er bie Mirmer (Nematnden). 


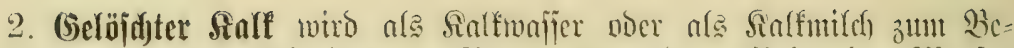

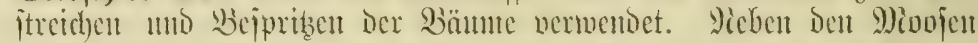

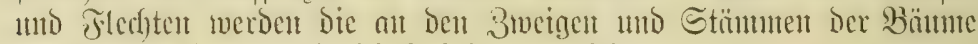
abgelegtent Eier mandjerlè șnjeften vernidgtet.

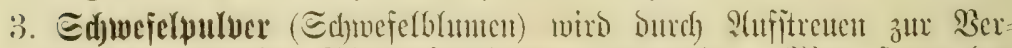

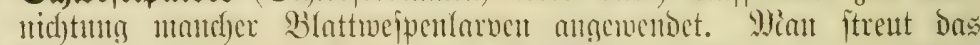

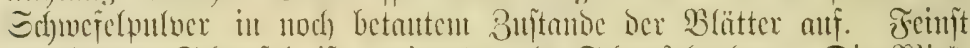

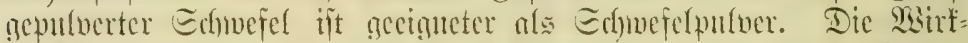

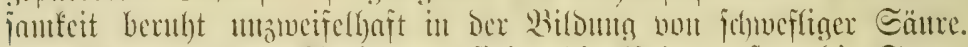

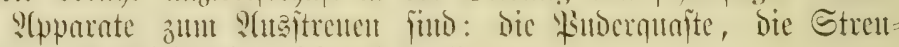

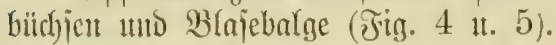

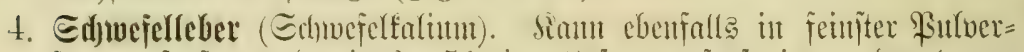

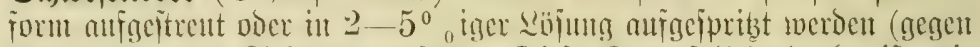

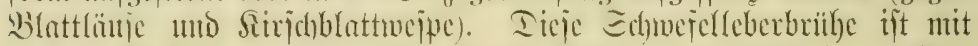

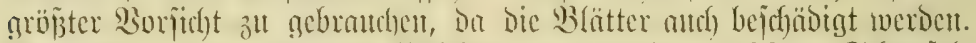

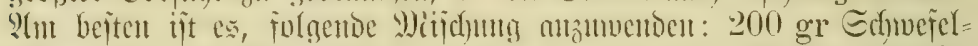

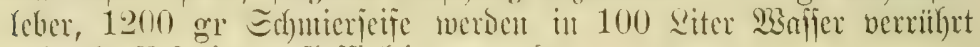
uto als Bejpributgaftiifitgeteit vermentet.

5. Edfuefelcalcium wird cbenjo verwentet wie Edhmejelleber. Mian

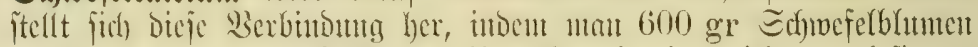

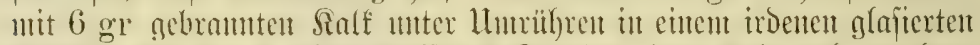

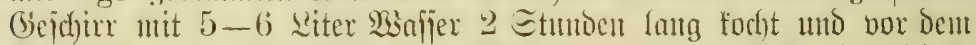
(Bebrauth an 100-120 Siter waijer berbiumt. Echwefelcalcium wiro mit Erfolg gegen dic rote Epime (Tetranychus telarius)

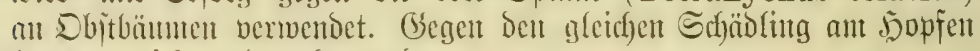
fant es nicht gebraudidt merdent.

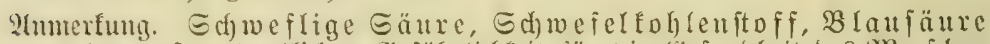

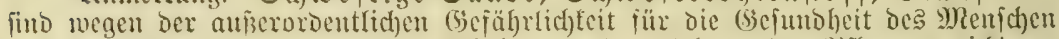

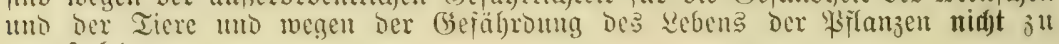
empfeblem.

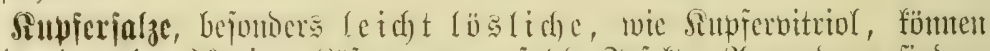

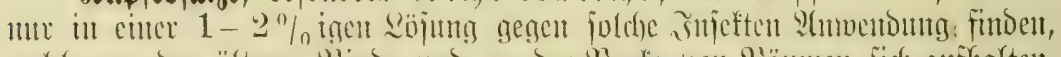

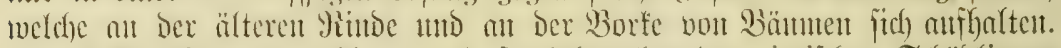

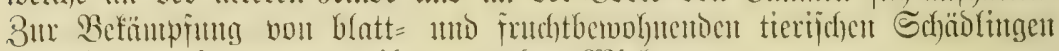

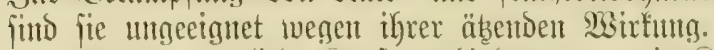

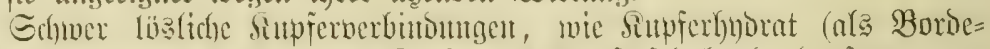

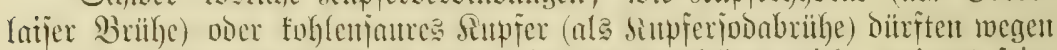

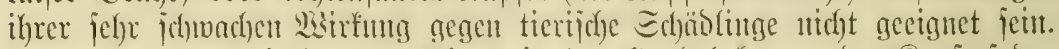

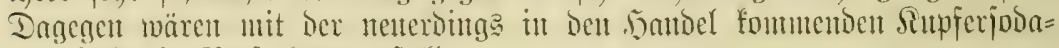

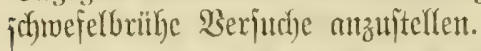

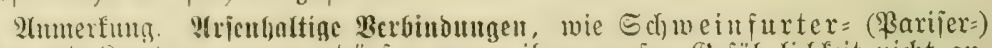

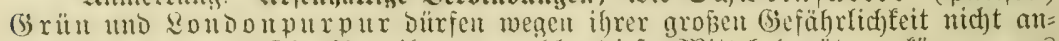
gemendet merben. Die 2lmerifaner, weld)e bieje Mittel bentizen, fömen unt bierin fein $3 o r b i l d$ jein.

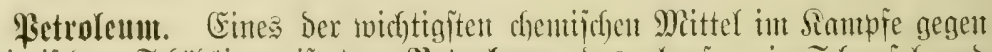

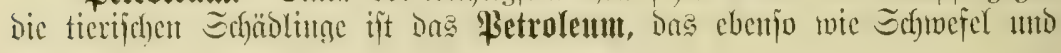




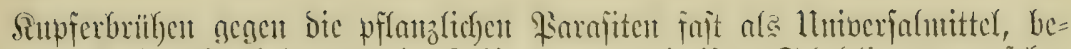

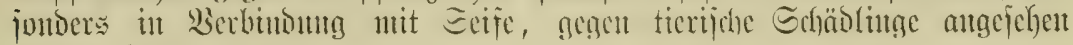
werdelt fantr.

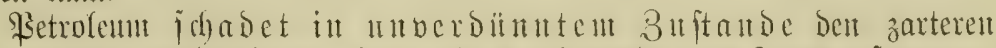
BFfanzenteifon ut $b$ ebingt, famt aljo wnt in verbünnter Form alfgetragen

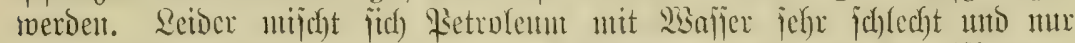

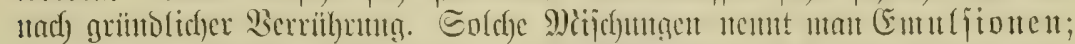

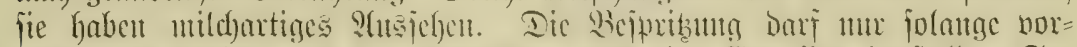

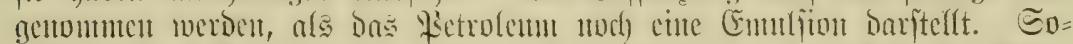

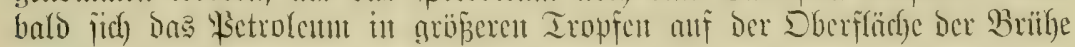

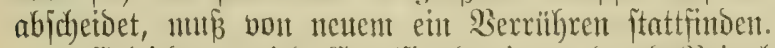

Erleid)tert mird Emutfronbercitung Dutch Beigabe nou Seife.

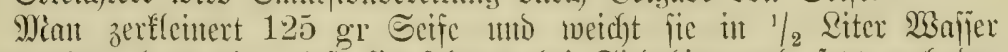

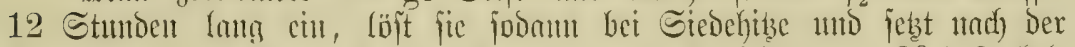

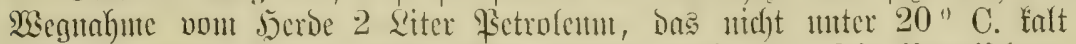

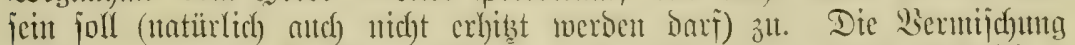

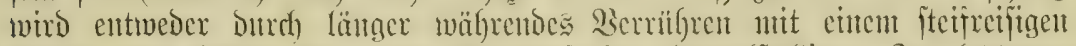
Bejen ober beffer mit enter Bhlumentpribe bemerfitellight. Jll lebterem

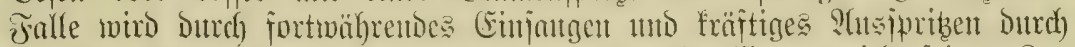

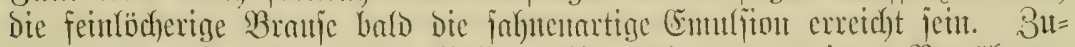

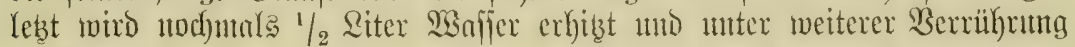
beigentijcht.

Die Stärfe (Sionzentrationt) Der Betrolentutentulfion hängt von der

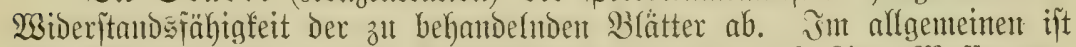

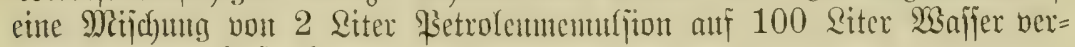
bümnt, genitgent itart.

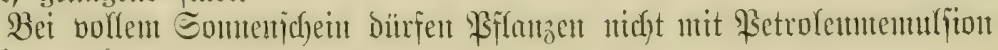
bejpribst werdent.

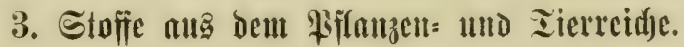

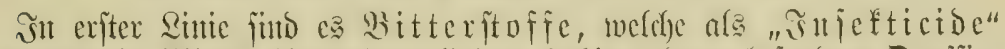

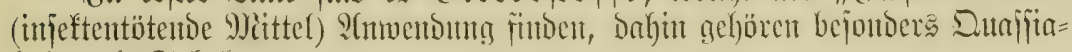
Golz anto Iabat.

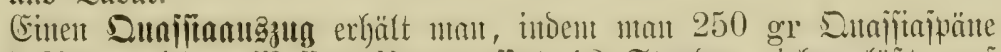

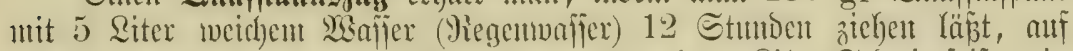

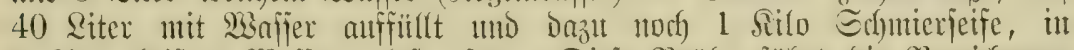

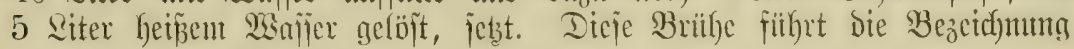

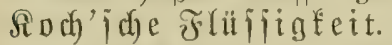

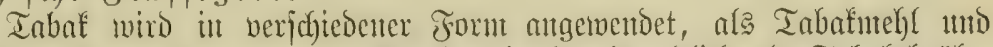

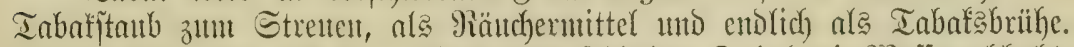

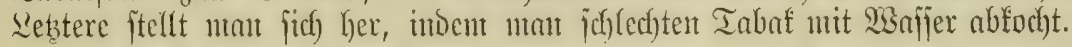

Iabafjajt ober Iabafbrïlye ift neridjeconent Injeftengiften beigejebt,

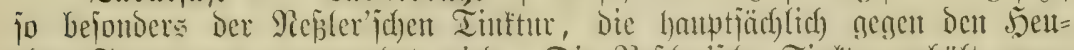

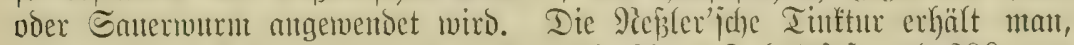

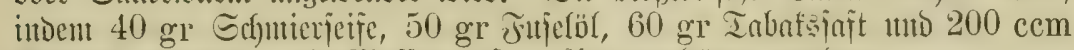

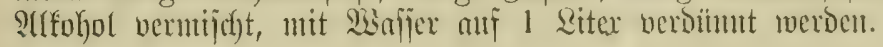




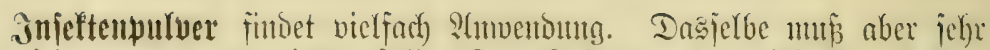

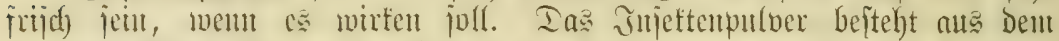

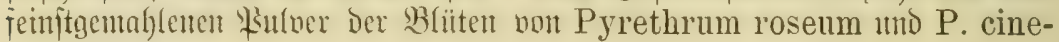
rariifolium.

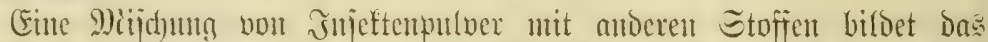

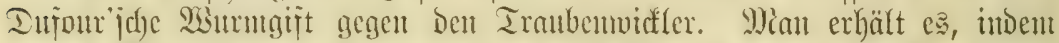

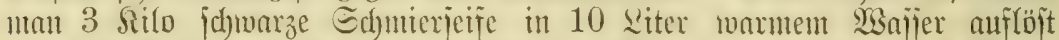

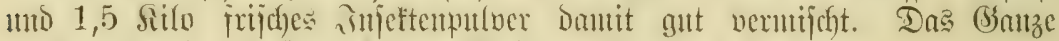

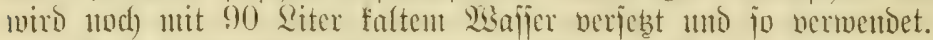

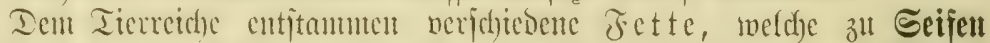

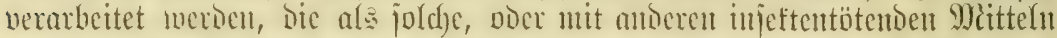

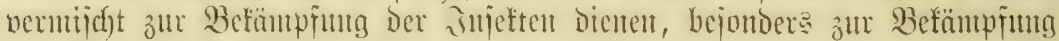
von $\mathfrak{B l a t t}=$ unto Sdhiloläutfen.

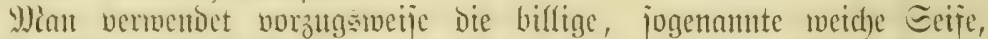

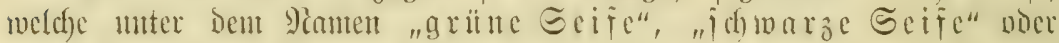
"S (d) mierjeife" allgentein befamnt iit.

\section{B. Spejielle Beiprechung der wichtigiten tierifhen Schädlinge.}

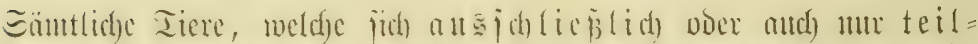

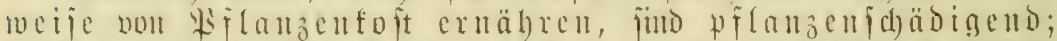

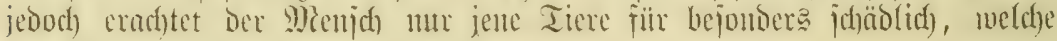

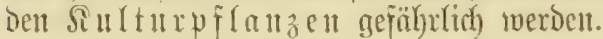

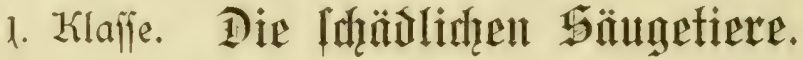

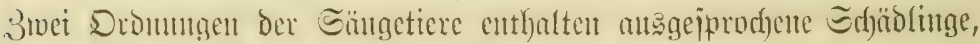
rämlid) bie Wiederfäuer mo die Magetiere.

\section{a. Wiederfäuer.}

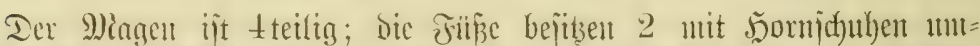

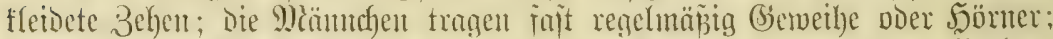

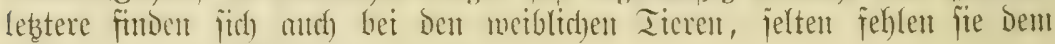

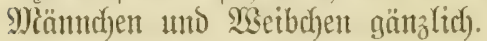

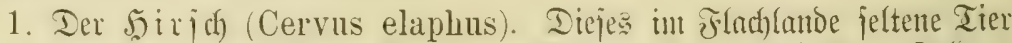

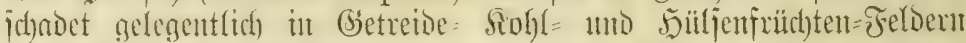

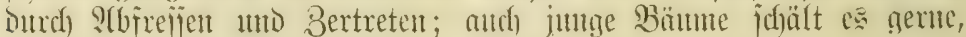
bejonders int idnueereidjen 2 Sintern.

2. Dn Reh (Cervus capreolus). Es gehört in Dent Gíegentoent, 100

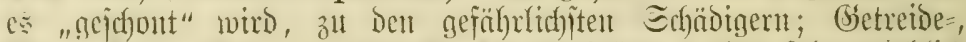

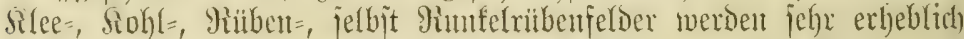

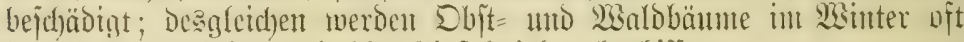
jehr jtarf entrindet and bie Gipjeltriebe abgebiffen. 


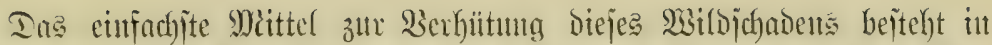

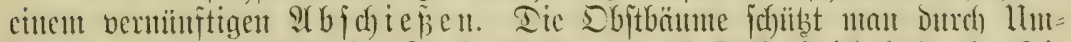

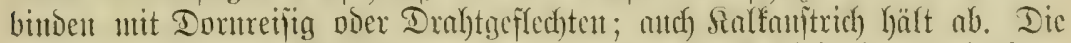

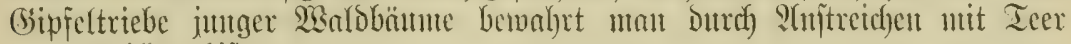
bor "2Biloverbi的".

\section{b. Die Kagetiete.}

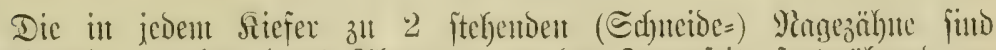

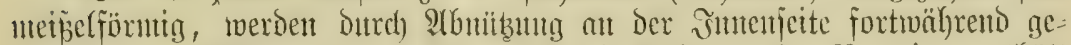

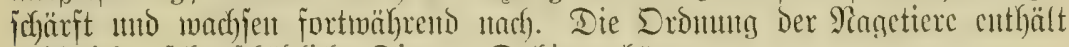
zah)lreiche, jefyr foüsoliche Iiere. Dahin gehörent:

1. Der $\mathfrak{H}$ aje (Lepus timidus). Er wiro it Sohlfeloern läftig umb

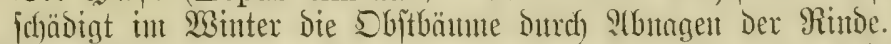

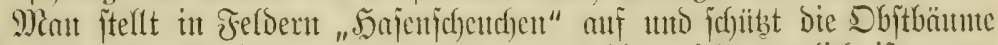

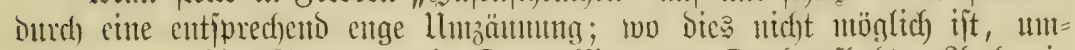

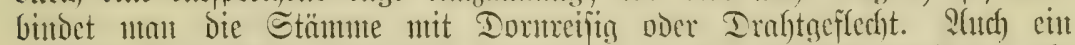

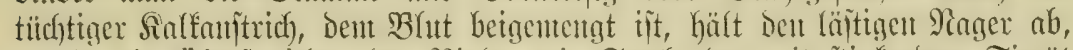

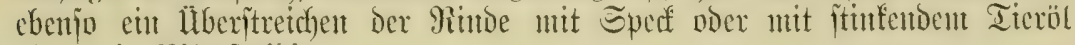
voer mit \$itfrofötiótit.

2. Der நautiter (Cricetus frumentarius). (Er lebt in felbit ge=

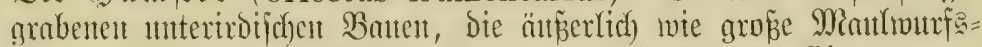

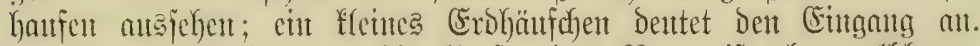

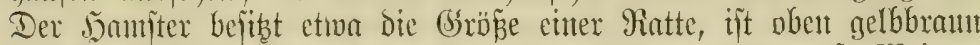

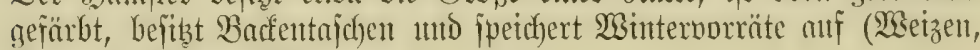
Bohnen, (Erbjen, Rilben zc.).

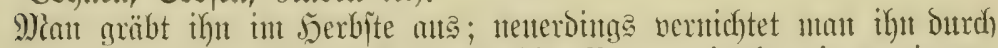

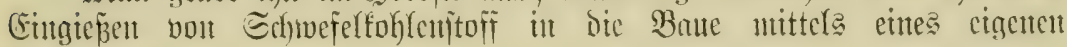
2(pparates.

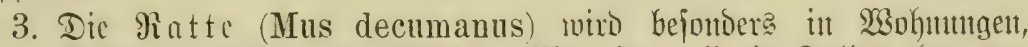

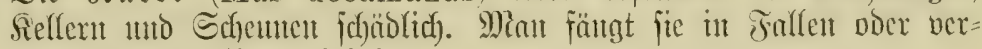
giftet fie mit Mceerziviebel.

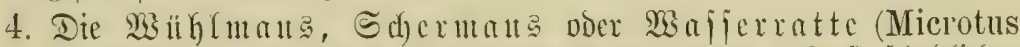

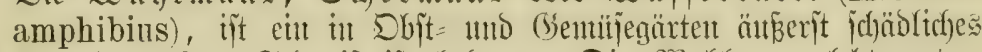

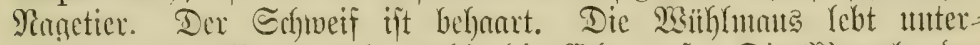

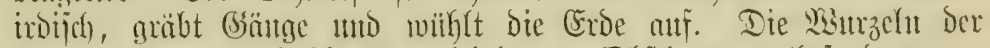

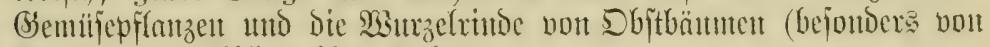

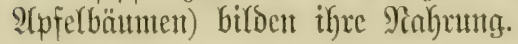

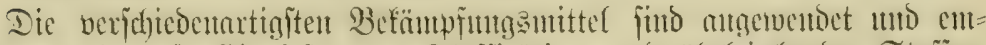

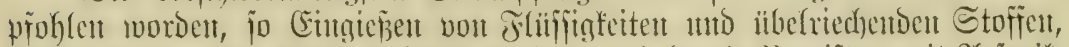

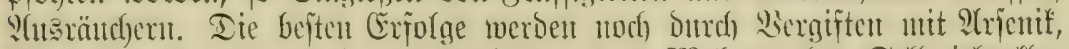

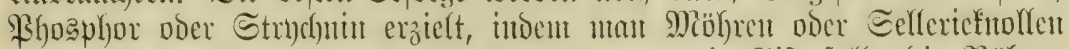

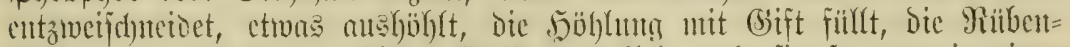

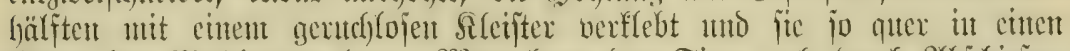

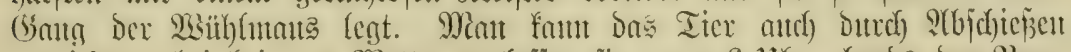

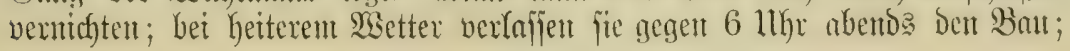




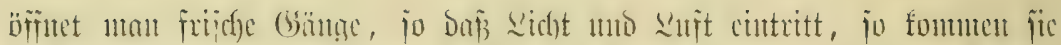

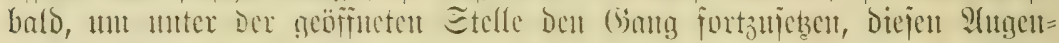
blicf wäh)lt maut zuแ ?(bichicjict.

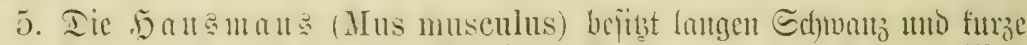

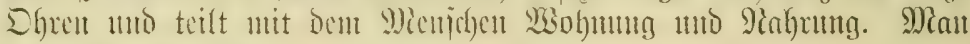
fängt jie in Frallent.

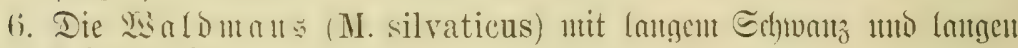
Dhren แmo

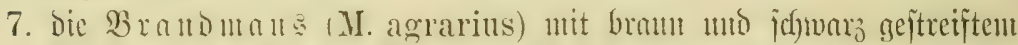

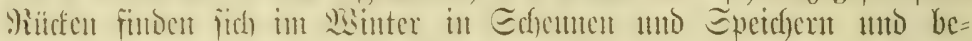

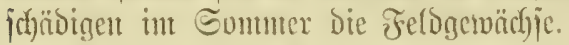

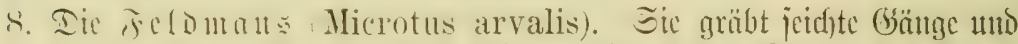

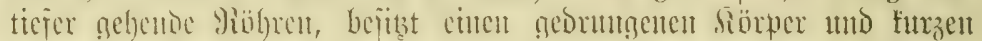

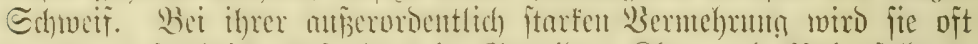

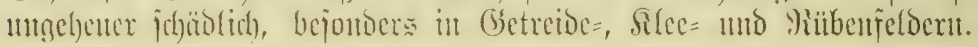
woribent.

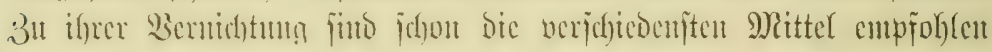

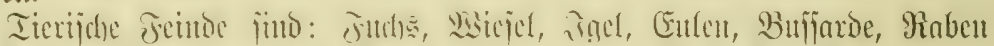

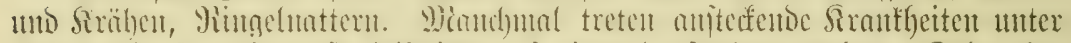

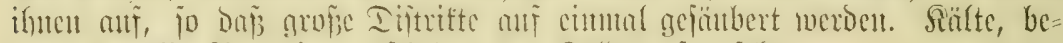

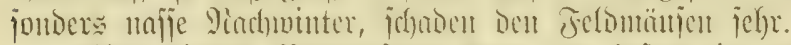

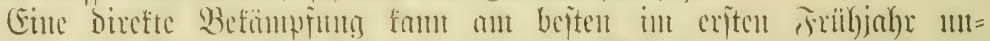

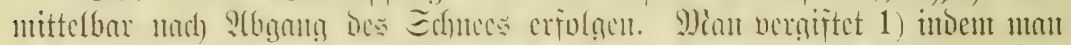

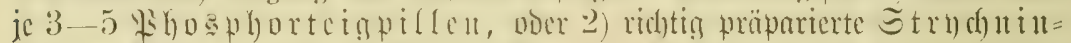

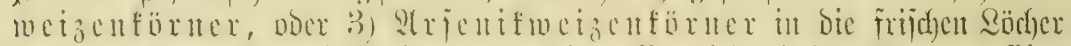

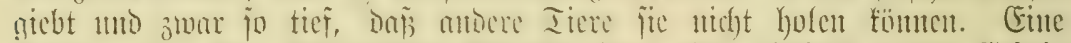

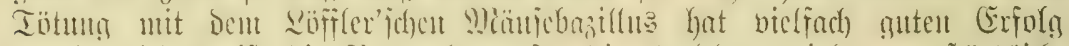

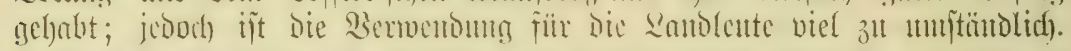

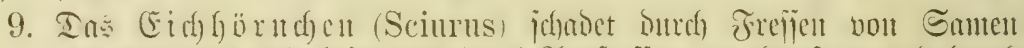

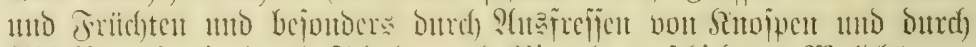

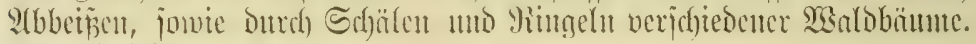
Mian jufieft es ab

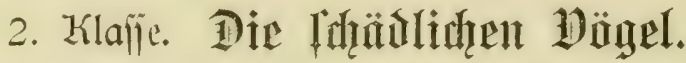

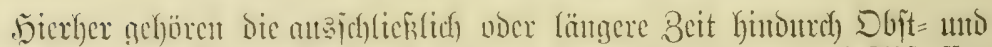

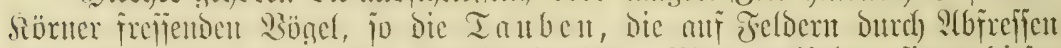

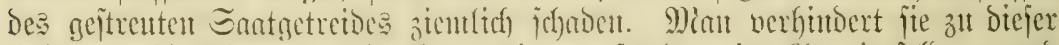

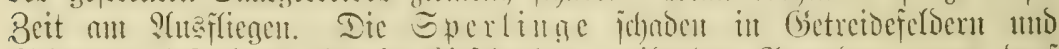

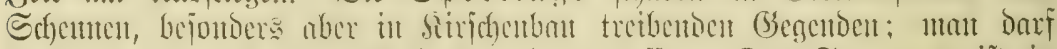

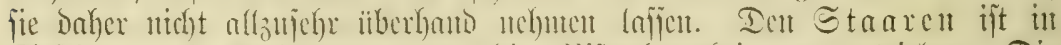

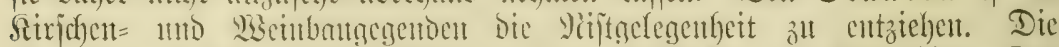

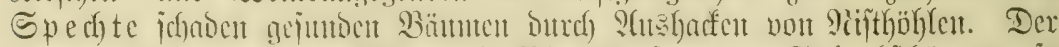

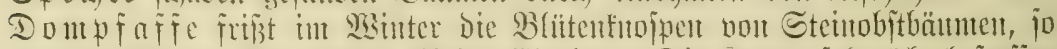

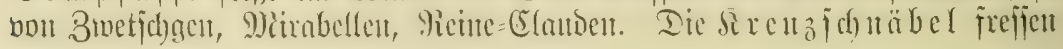




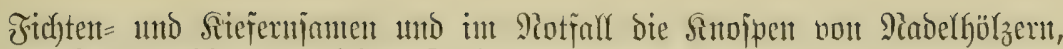
Der Rernbeiner vernichtet Sinojpen.

\section{Klaffe. Die Inlefrtent.}

Der Sïrper ber fertigen Impeften noer Gerftere befteht nus brei $\mathfrak{A}$ (b= id)ntitten, näunlid)

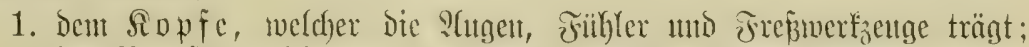

2. Der Bruft, welche aus 3 Yiungen beiteht. Jeoer Brultuing trägt

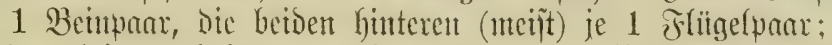

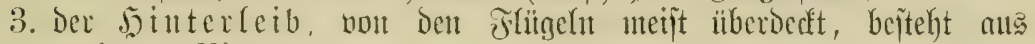
mehrerent Pintugen.

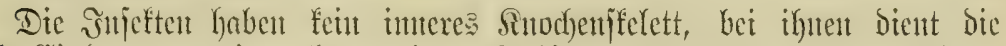

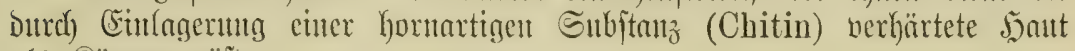
als Rörpergeriifte.

Die Beine der smjeften fimb genliebert.

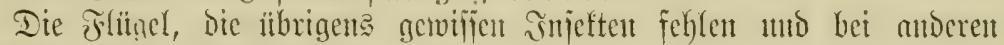
berfiummert fitto, Dienen ihnest zunt Frtegent.

Die jümtlichen Injetten Gabent cine Berwanthunn, "Mietantor=

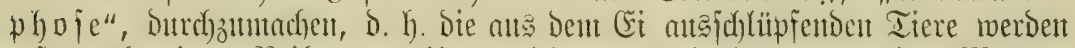

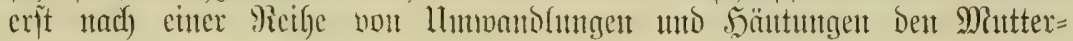
tieren ähnlid).

Die Metamornhoie ijt eine vollfommente, wemt anf Dent

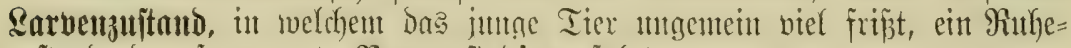
3nftanto, Das jogctumute Pulppenitadium forgt.

Wir haben aljo: E⿺⿻一𠃋

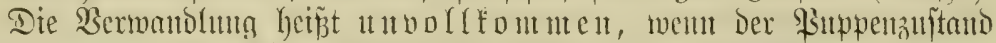

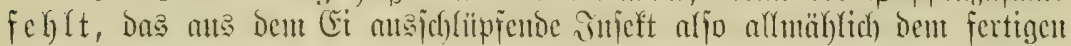

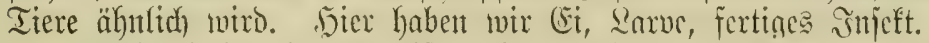

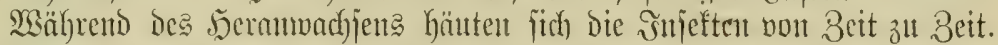

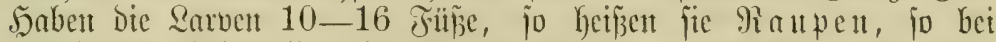
Sdymetterfinget, habent fie 18 -22, jo nemut man fie Sifterraupen, futo jie fun $=$ unto fopflos, jo heipen fie Maden*).

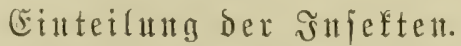

Die smpetten zerfallent in 7 Drommgen, nämlid

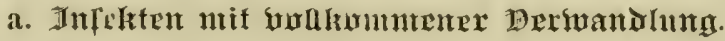

1. Säfer, Coleopteren.

2. Sdumetterlinge, Lepidopteren.

3. Sautflügler, Hymenopteren.

4. 3weiflügler, Dipteren.

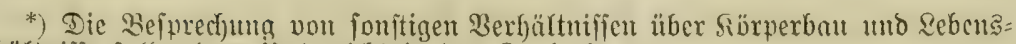
verfältuiffe falfen bem interricht in ber 3oologic zu. 


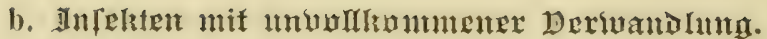

5. Siebiflïgler, Neuropteren.

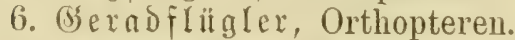

7. Sdyabelferfe Rhynchoten.

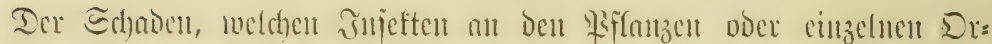

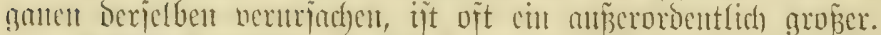

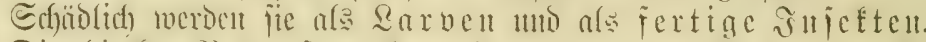

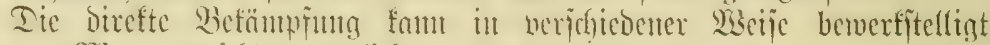
Juerden. Mant vernichtet nännlich):

1. entroder bic Eier,

2. oder bie $\mathfrak{R}$ arben,

3. voer bic \$supen,

4. oder bie fertigen snjeften.

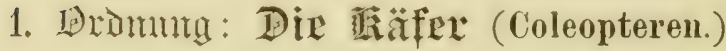

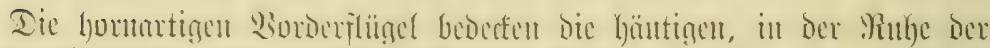

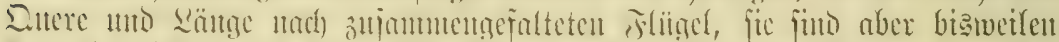

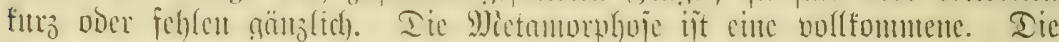

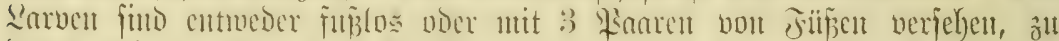

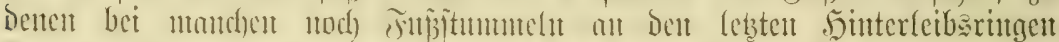

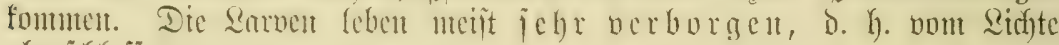
abgejoldofijent.

Iic \$ffanzenjichäblinge gebören fulgenton samilien an.

Die Rnufläfer (Carabiden). Iie jühfer finto boritenföming, elf-

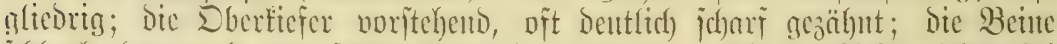

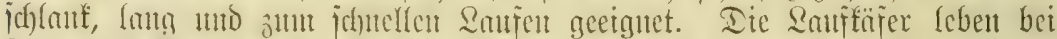

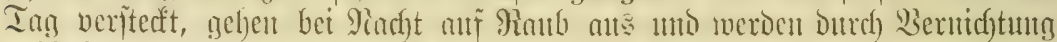
zablreidjer andorer snjeften nilblidid).

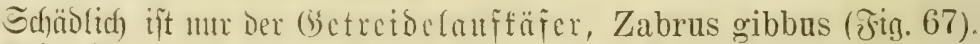

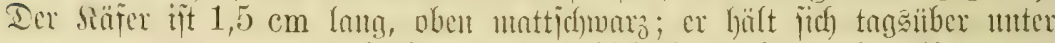
Steinen und Erojicholfen alf, ltad)te flettert ex

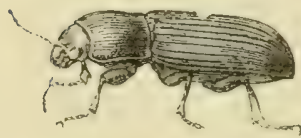

Figig. 67.

Getreidelnujfäjer.

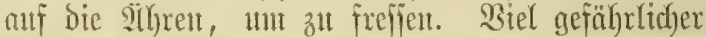
finto bie 3 safure zur Entroiffung benötigenden $2-2,5 \mathrm{~cm}$ langen, oben etruas abgeplatteten, id)twarzföpfigen utto braumrürtigen Rarbent. Die

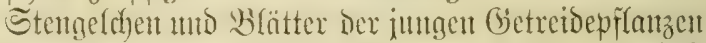

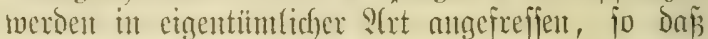
iie wic zerfinttert atsjebent. Ganze Strectent fömmen bernidftet werden. Shtod junge Erobeer=

friidyte werbent befrefjent.

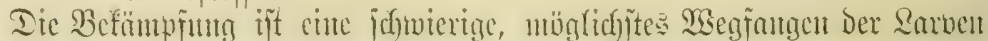

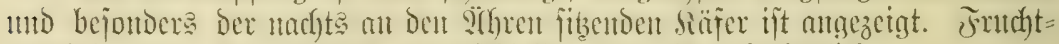

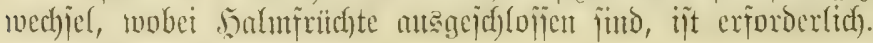




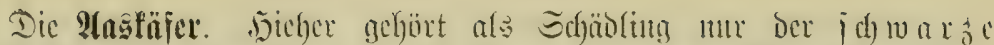

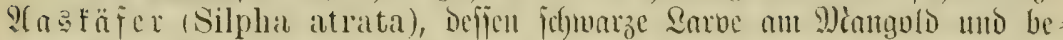

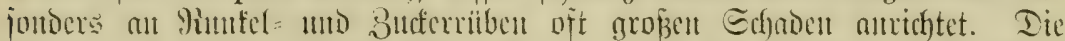

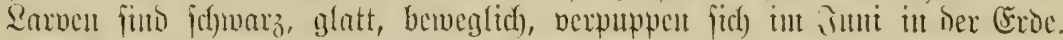

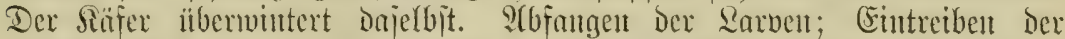

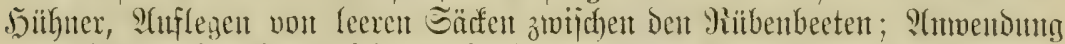
von Irjenbrithen fant nidgt empfohlent werden.

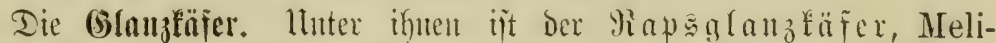

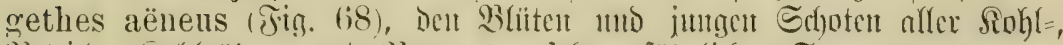

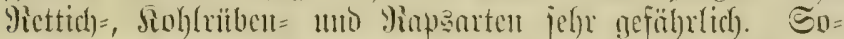

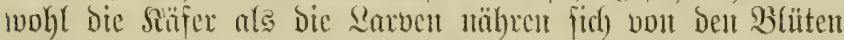
mino jungen Früdyten. Die Berpuppung criolgt in Der Erde. Es folgen ntel)tere Gentrationen in Sonmer; Die grïnlich), erofarbigen, 2 $\mathrm{mm}$ Langen Sïfer ïberwintern

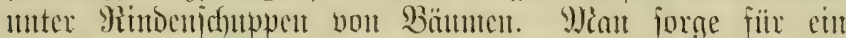

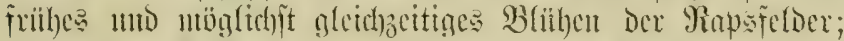

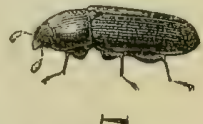

Fig. 68.

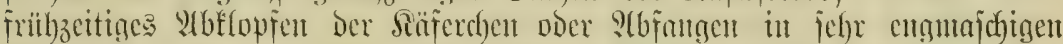

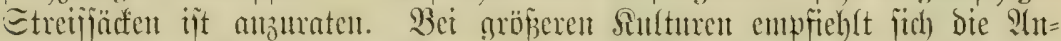

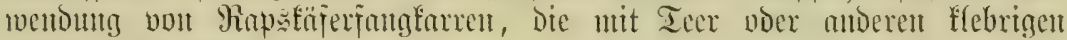
Stoffell bejtrichen finto.

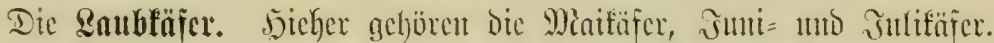

Die Maifäfrarten (Nelolontha vulgaris, hippocastani, villosa)

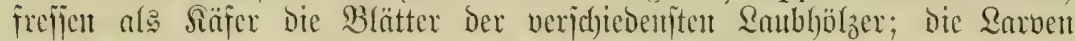

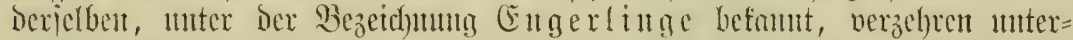

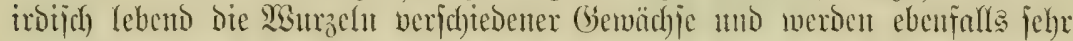

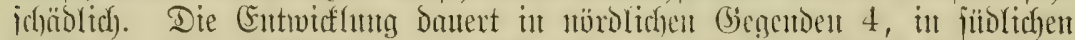

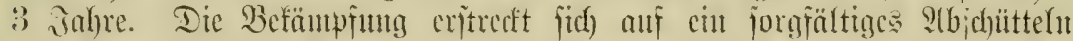

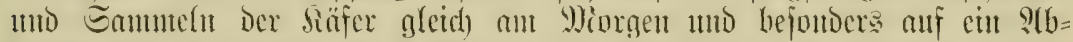
fangen ber Engerlinge Durch Braben nto Bearbeiten Des Bobens. Ilnter=

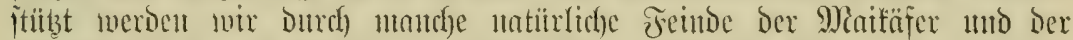

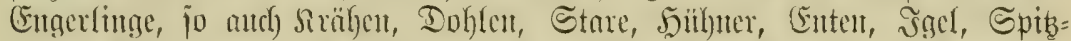

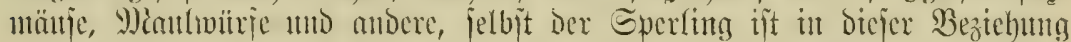
nïb(ic). Die getöteten Whafäfer fömen zแ Dïnger verarbeitet weroen.

Der B̉rach)

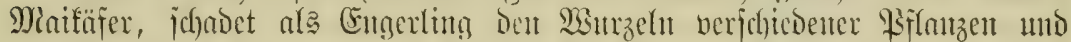
als Stiffer ben Erobeern, Erbjen, Ditfen Sohnen, Den Siohlpflanzen uno neridgiedenen Dbitbäımen. Die Entwidfluttg erforbert Den Beitraum cines Jahres. Die Befämpfing gleicht jenter bes Minifäfers.

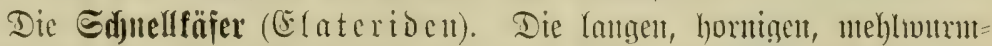

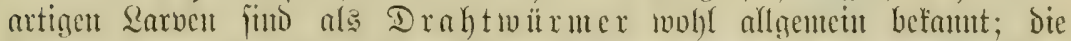

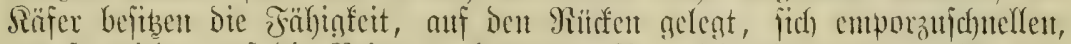

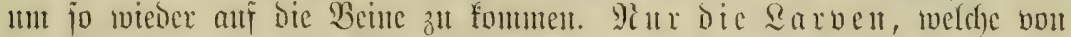

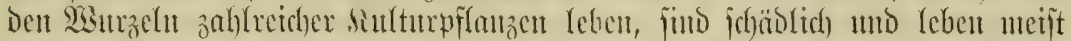
mefyrere sahre in Boden, che fic fith verpuppen (Jitg. 69). Die hänfigiten bei ın vorfommenden $\mathfrak{A}$ (xten finto:

$\mathfrak{M}_{\mathrm{i}}$ i , sflanzentranfheiten. 


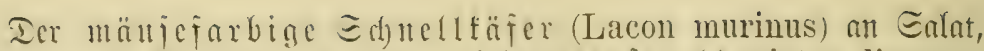
Cidhurien mo Siartoffelı; Der Eantjanelleäfer. (Agriotes lineatus

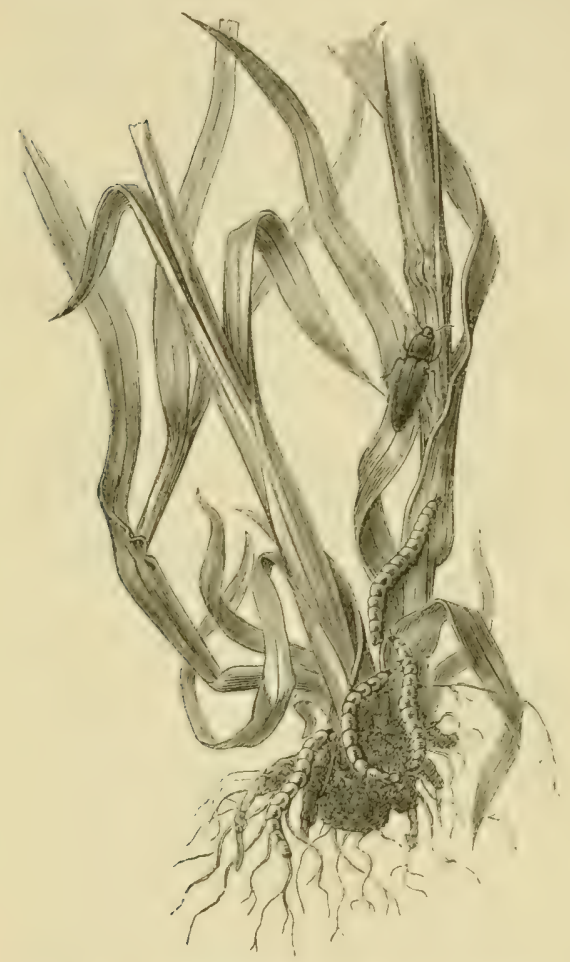

¡ig. 69. Enatidjucllfäjer mit Draljtumm. und obscurus) an zahlietchen Feto = und Gemiliepflanzen; Der Salatjd)nelltäfer (A. sputator) an juttgent Ealatpflatzen, Der Mlöbrenfduelleafer (A. striatus) an siöbren. Dic Betämpfung ît jelyx id)wer; $\mathfrak{A b}=$ judfen Der Drahtwiilmer bei der Bobentbearbeitung, voriutytiges

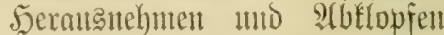
Der Durd) Den Fráp beruidyteten İff(anzen, 3miid)entpflanzung bon Salat zrwijichen andore Gentiije= arten; anf Feldern zieht man jd)unte Gräben Imo fiillt fie mit Dinnger; Dabuein verzichen iidf) Die Draftmintmex während Des Winters eritent Friifjafyr atsgehobent twer= Den. Das ficherite Mittel für Freldex ift das Strenent bout gebranten Sialf́, etwa 40 biz 70 Bentuer anf Den Seftar. Midjtig ift natïrlidy Der Sdjuts aller larbentrefĩenton Bögel.

Die Snmenfäfer. Die hie= her gehörigen flemen Räferdhen jehen Rüfieltäfern ähnlid), funo jebr flem, bewegen jidf lebgaft, legen ifre Eier an die jungen

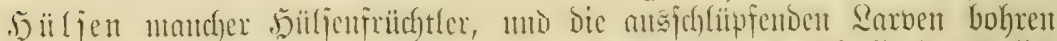

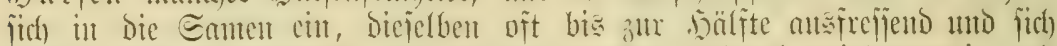

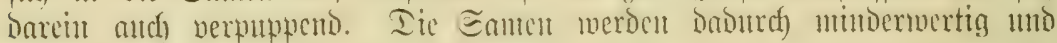
gebent jefre johlechtes Snatgit.

Sieher gefören: Der Erbjentäfer, Bruchus

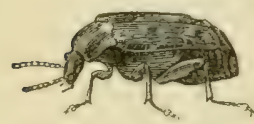

F̌ig. 70. Erojentïfer.

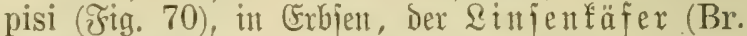
lentis) in Simjen, der gemeine Samentäfer

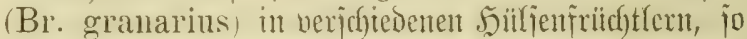
in Ruffbohnten, der Bohnentäfer (Br. rufimanus)

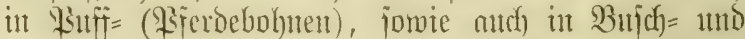

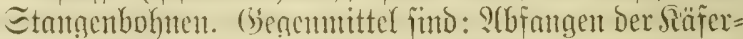

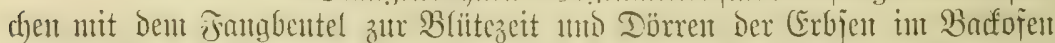
vährenı 1-2 Stumben bei $42-45^{\circ} \mathrm{R}$ (ja nicht böher bei Snatgut),

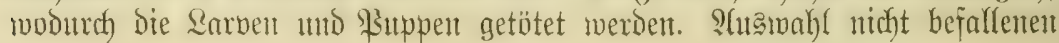




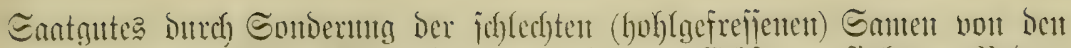

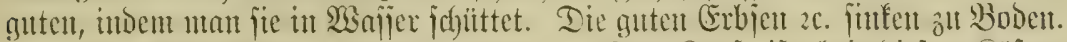

Iic Plïifelfäfer (Curculionidem). Iex Sopp ijt bei biejen Siäfern

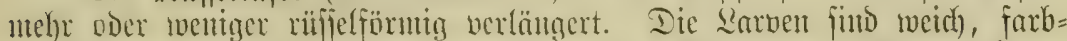

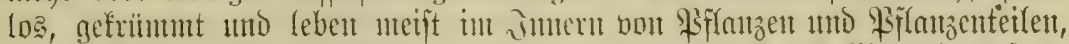

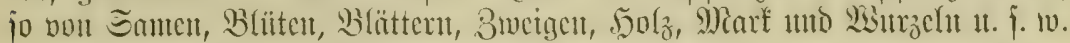

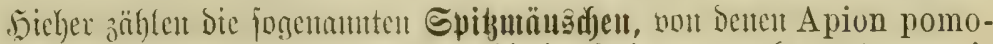

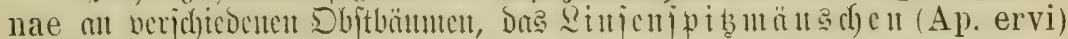

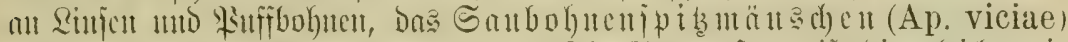

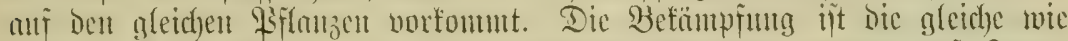

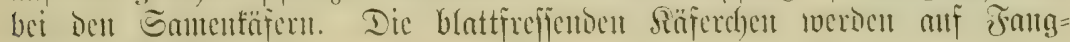
ichirme abgetlopft.

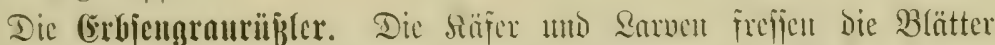

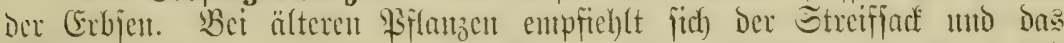

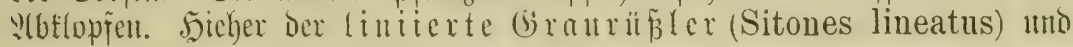
Der rotfditentige (S) $x$. (S. tibialis).

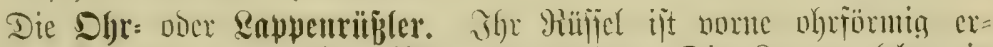

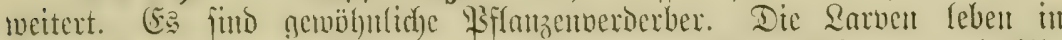

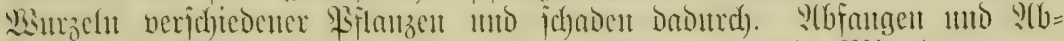
florfen ant friihen 9)iorgen ift woht bas entäig rationelle Mittel.

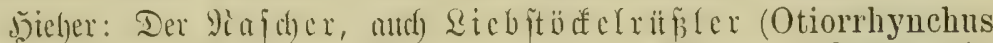

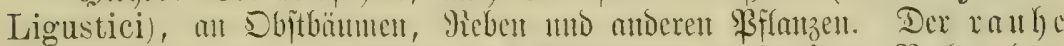
Lappentü Sappentiblex frefjen an gicben uno an Dbitbäument.

Dic Blïtenriijelfäjer (Authonomus). Dic Weibdyen bolyen in Frïh=

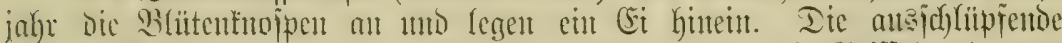

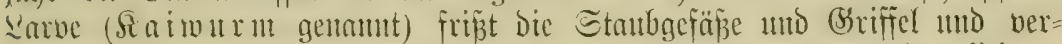

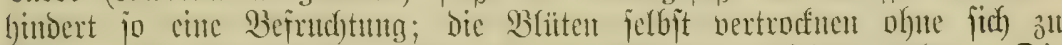

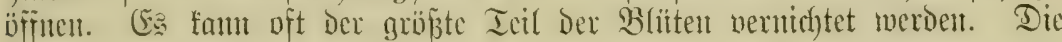
Serpuppung erfolgt in ber Crobe.

Die Räferdyen werden Durdh abjudyen,

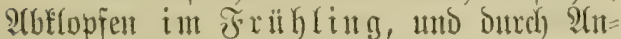
bringung von Janggürtelı abgefangen unto vernichtet. Dahin gehören:

Der atpfelblittenjed)er (Anthonomus pomorum) alt itpfeln.

Der B̉irntuoipeniteder (An. piri) an Bimen (Jig. 71).

Der Steinfrud)titedor (An. druparum) alt Steinobitbüuncu; Dic Rarbe lebt aber in Den Samelt mo dic Sicife der Frutcht uviro nidgt befimbert.

Der Eroberitedier (An. rubi) an ben Bhtiten Dex Erobeeren,

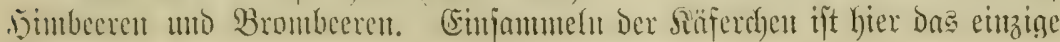
M)ittel zux Befämpfung. 


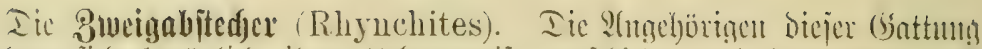

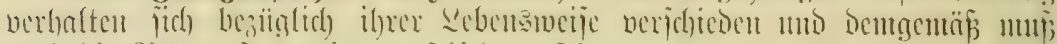
anch) Dic Betämprimg cinc verjefjedene jein.

Ier 3ucigabited)er (Rhynchites conicus) Ins Mectoden bobrt

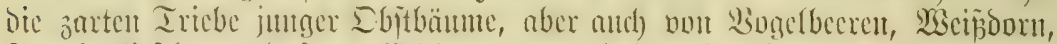

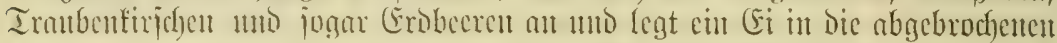

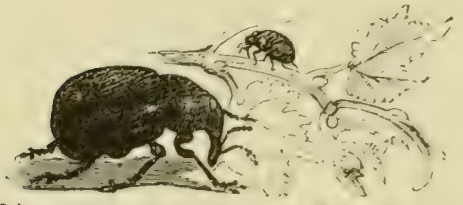

vig. $72 . \quad$ Etmblblaucr Mebcuitedjer

(Rhynclites betuleti L.)

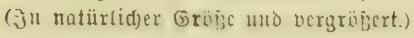
aber nod) häugengebliebenten Stweige. Die Rarben leben im Miarfe der welfent Iricbe, verpulppen fich in Der Eroe uns ber int Jerbite fertige, gläuzend blate oder blangrïte ffectue Siäfer jutd)t itt

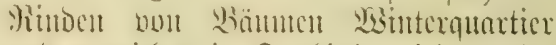

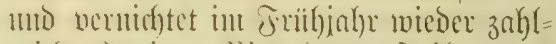

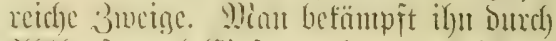

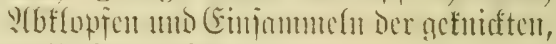
tuelfentolt Iriebe.

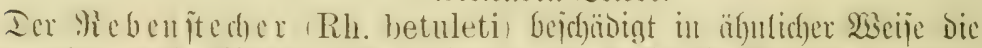

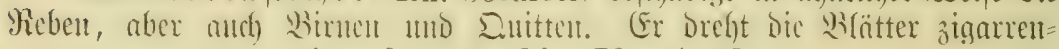
artig 3ujamuten (Fig. 72 แmo 73).

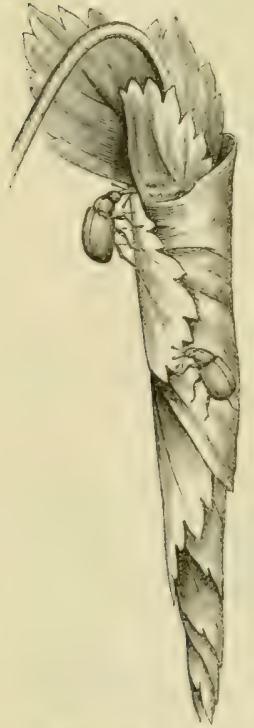

ivig. 73 BHattuniffel Dez 'liebenitedicr: ncbit zwei Rinieru.

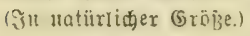

Die $\mathfrak{A} p$ felftedfex (Rh. Bacchus und auratus);

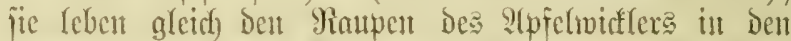

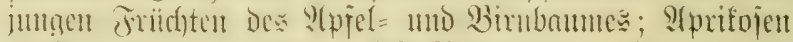
werbent un angefrefien. Die Berpuppung erfolgt in Dex Erobe. Mlan jommle alle alogejallentent Fridd)te uni ber=

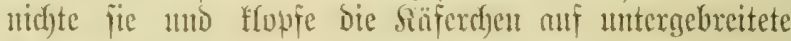
Iilcher ab.

Der Piflaumenbolicer (Rh. cupreus) an 3metichgen 2c. und Sitrjhen. Die Rave lebt in junnen 3netid)gen. Die Berpuppung exfolgt in ber (Erbe. Iis abgefaltenent Früd)te fint alsbalo cinzujammeln zu vernichten tuto die fiâferd)en find int Friibjabr ab= zuflopien.

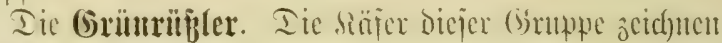

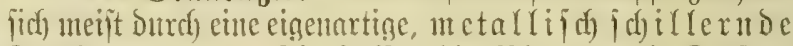
Färbung aแz. Sie frefīen die B̧ätter und Sinoipen bou verichiedenen Dbitbäuncu un sruthtiträudbern. Mo fie in grofer Mlenge auftreten, werden fie jebr jofäblicly. Mlan fanm fie zu jeber Ingeszeit, ant bejten aber aut Morgen, auf untergebaltene Tüber oder Echime ober Tridfer abtopfen. Iabin gchören Polydrusus mollis unı sericeus at Ebjtbäumen, Phyllobius alneti, argentatus, dic an verichicdencu Laub= bäımen แแ⿰ an Dbitbäımen nuftreten, Ph. Viridicollis

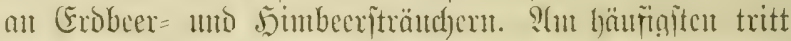

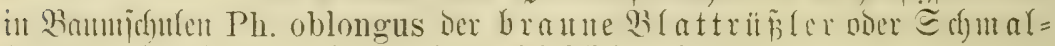

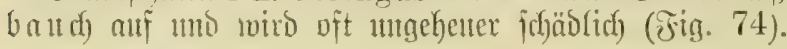




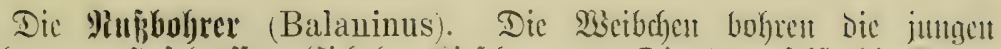

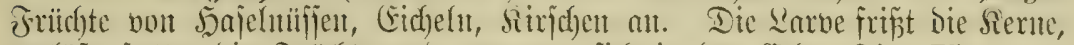

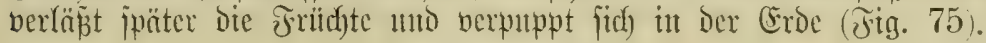

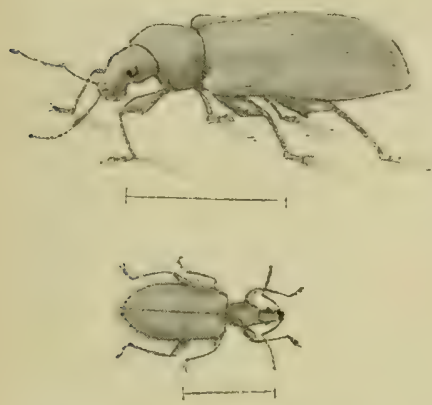

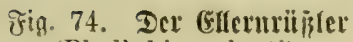

(Phyllobius alneti).

Ier Edjmalbaud) (Phyllobius oblongus).

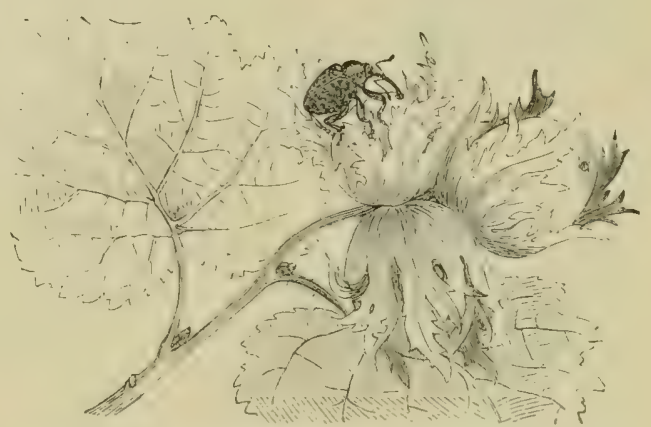

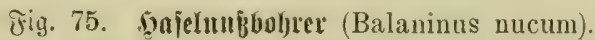
(Dieje Figur iłt Brefm:s iffuftriertem TierYeben entnommen.)

Jjicher gefören: Balaninus nucum mo B. venosus der 9infbofrer,

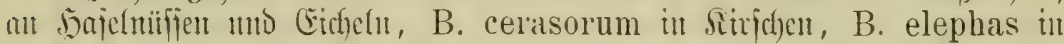

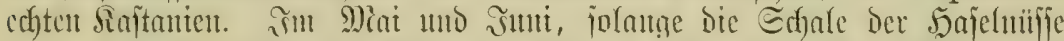

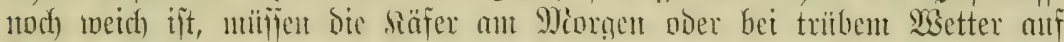

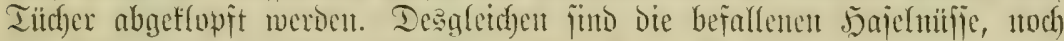

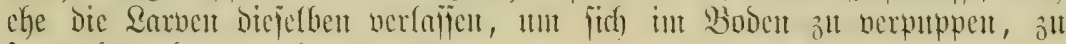
jantutelnt uno 3̆t verbremtent.

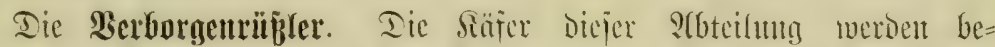

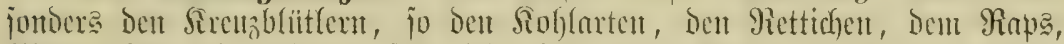

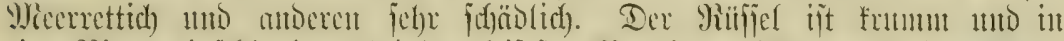

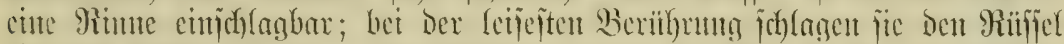

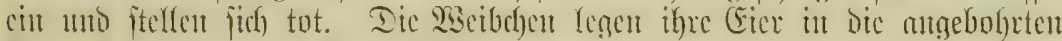

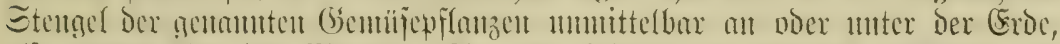

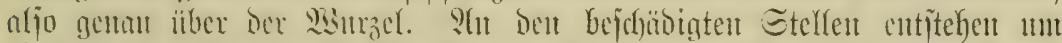

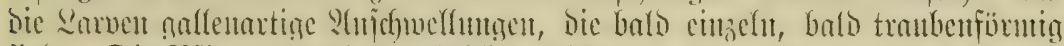

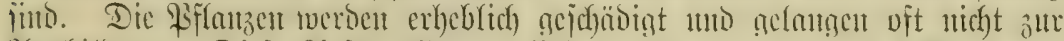

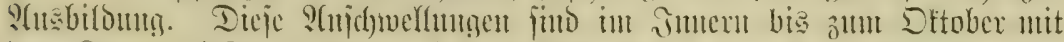

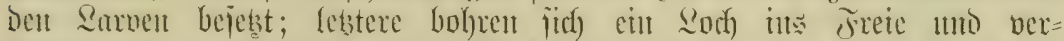

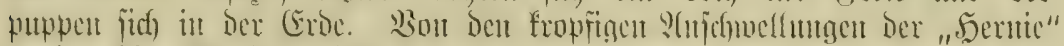

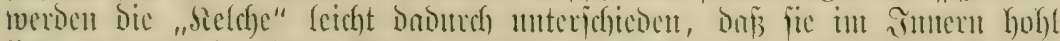

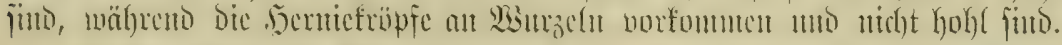

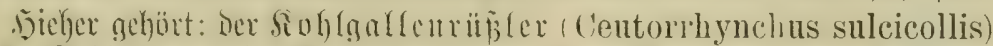

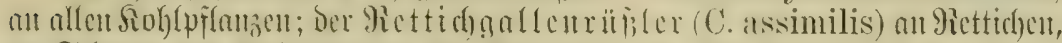

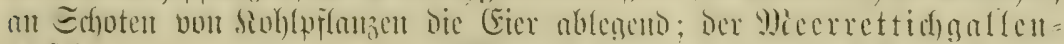

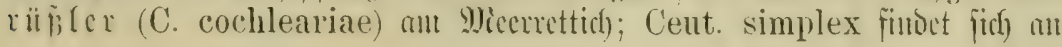




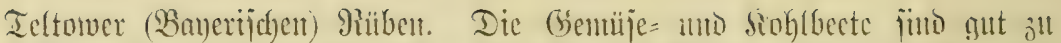

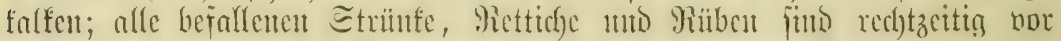
Dem $\mathfrak{A}$ (twandern ber Ratben zu bernichten, ebenjo alle befallenen Sdhoten (Fig. 76).

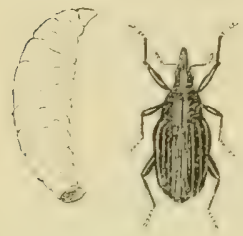

Æig. 76.

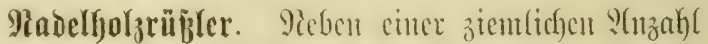

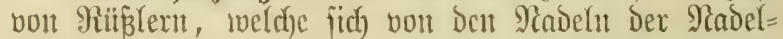

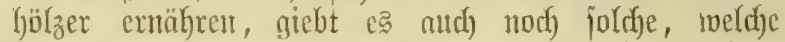
ipeziell Dem 5jolze und der Rinde gef̈ährlich merden. Die Räfer benagent bie Rinbe bejonders jüngerer

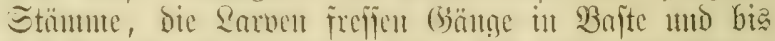

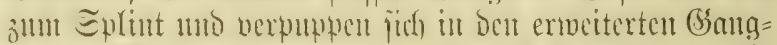

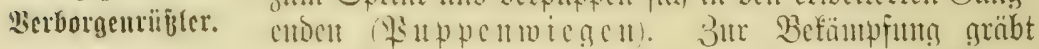
man Brutbäımte cin, an weldhe bie Eter abgelegt

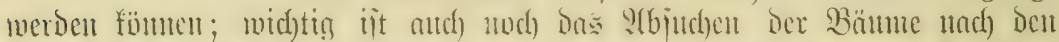

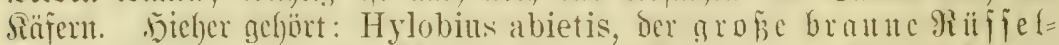

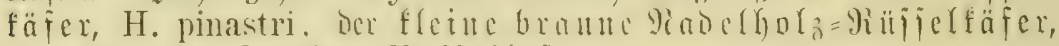

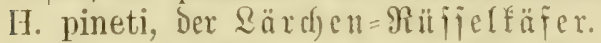

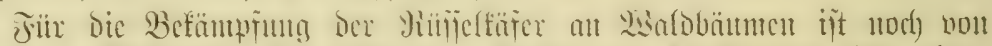

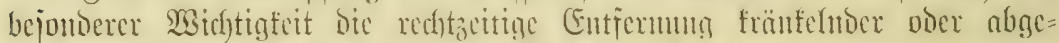

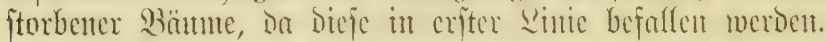

Iic Borfenfäjer Bostrychiden). In siörer bieju Siäferchen ift

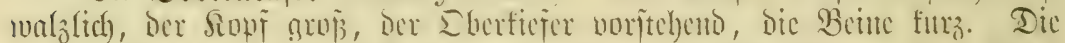

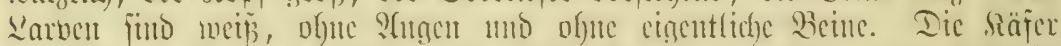

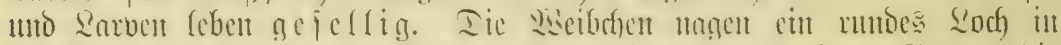

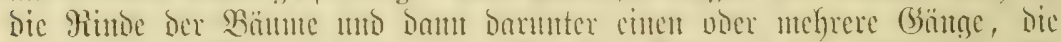

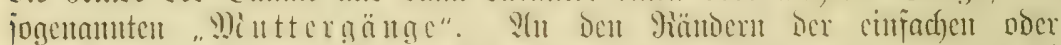

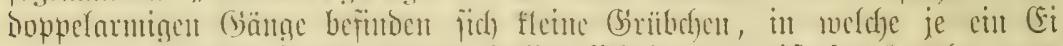

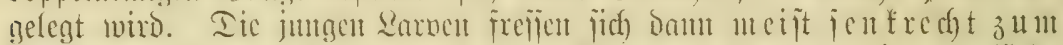

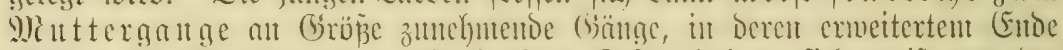
(2Bicge) fic fidf verpuppen; Die fertigen Säfer bohren fich urcift von ber

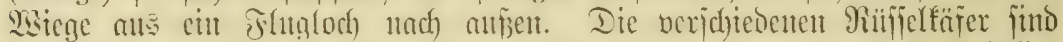

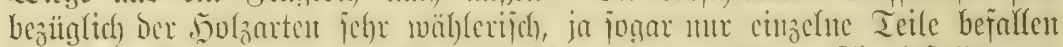

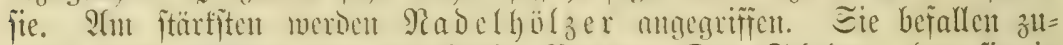

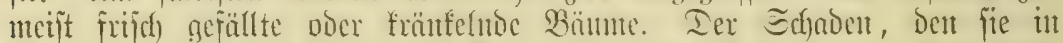

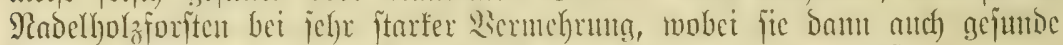

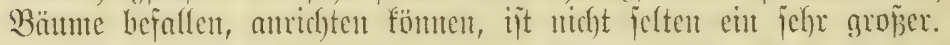

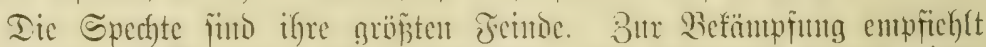

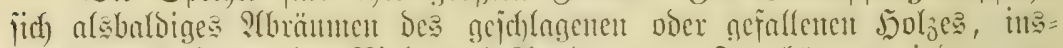

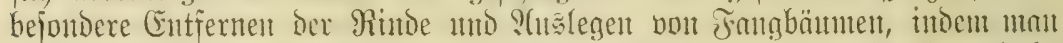

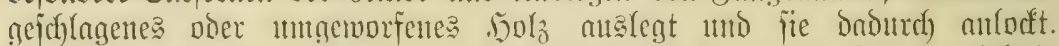

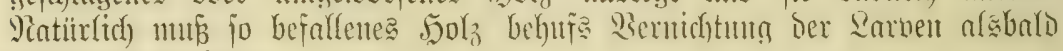
verbramnt werdent.

Die bidhtigften S(rten find:

1. Iex grofic Dbitbau= 


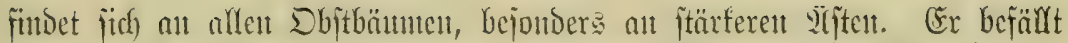

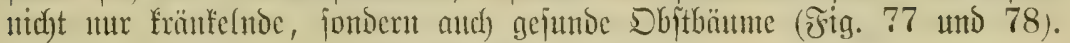

2. Der ungleidye Borfentäfer (Bostrychus dispar) befälft einte grofie $\mathfrak{A} n z a h)($ von Raubłolzbäumen, aber auth) von MandelGölzernt. Bon Dbitbäunten find es Stprel= 4mo Bintrent= bäunte, \$sflanment= (3wetichgent $=$ ) ntno Sirich $=$

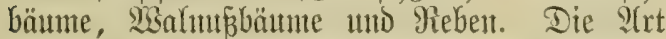
Des Frẩes ijt atts der beigegebenten Beidynung z erjehen. SUffitellen bon Jangbäunten, $\mathfrak{A}=$

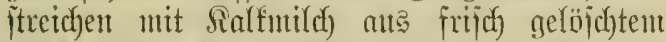
Sialf, Sdunt3 Der Spechte irt bon wejentlidyent Bortcil bei ber Befämpfutg (Jig. 79 แ. 80).

Der gemetue Borfentäfer, Błud = bru de er (Bostrychus typographus); er be= fällt bie Jithte in höherent arter; der vielzähnige 23 . (B. laricis) an

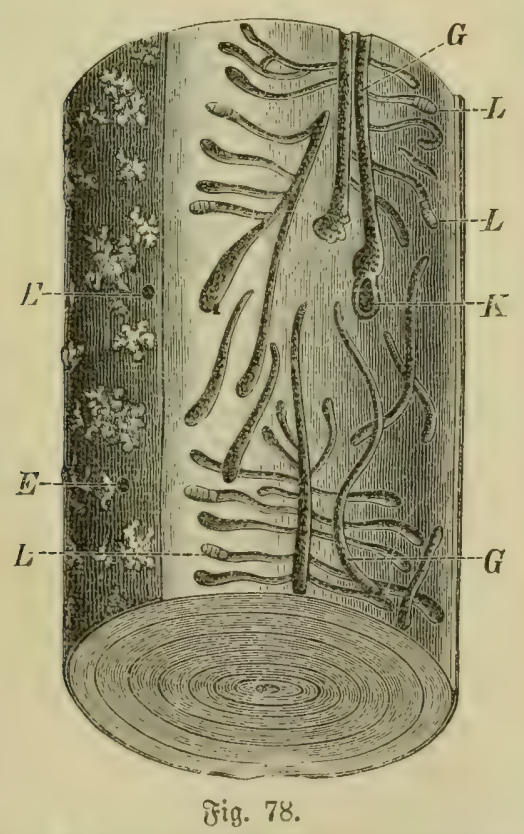

Gliiaf eillę̧ bom großen Splintfăfer (Bostrychus pruni) bejallenen 20pferbaumftamme马, pou bem ein Teil bir Rinde abgeläălt sit, um bie von ben Räferlarben $L L$

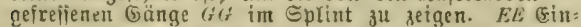
gangsfteflen ber Moutterfäfer, $K^{-}$ein cntwiçitter Säfer in ber Puppentwiege. (Matürlíge (BröBe.)

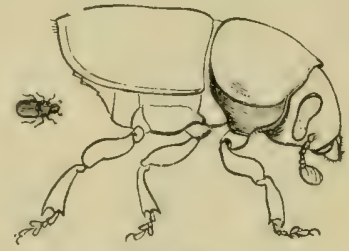

Jig. 77.

Ier arope Dbötbnunt.@pliut: fîfer (Scolytus pruni).

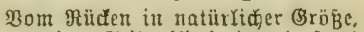
von ber Seite ffizjiert und ftarf vergröBert.

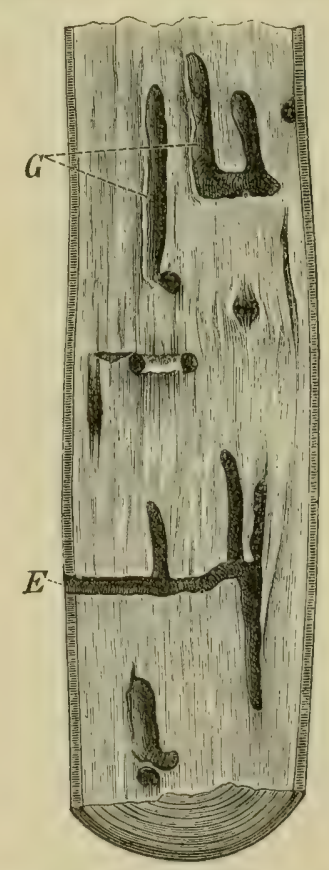

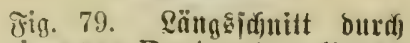
einen vou Bostrychus dispar befallenen 2 Pfelbaumitamut.

G bie శraß̄gänge mit iţren Eingangs. öffmugen $E_{0}$ ( (Ratürtiçe \&röBe.)

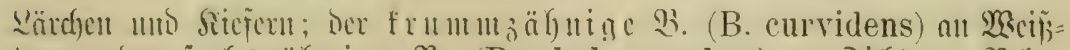
tanne; ber fedfazöhnige B. (B. chalcographus) an Jidften. Reben 


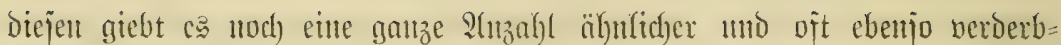
lidłer Borfentäfer.

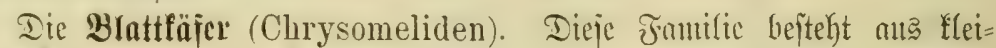

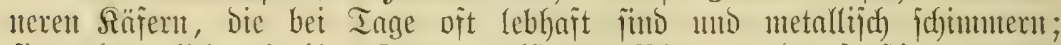
fie nähren jich) wie ihre \&arven meijt von Blättem oder fonfigen grimen

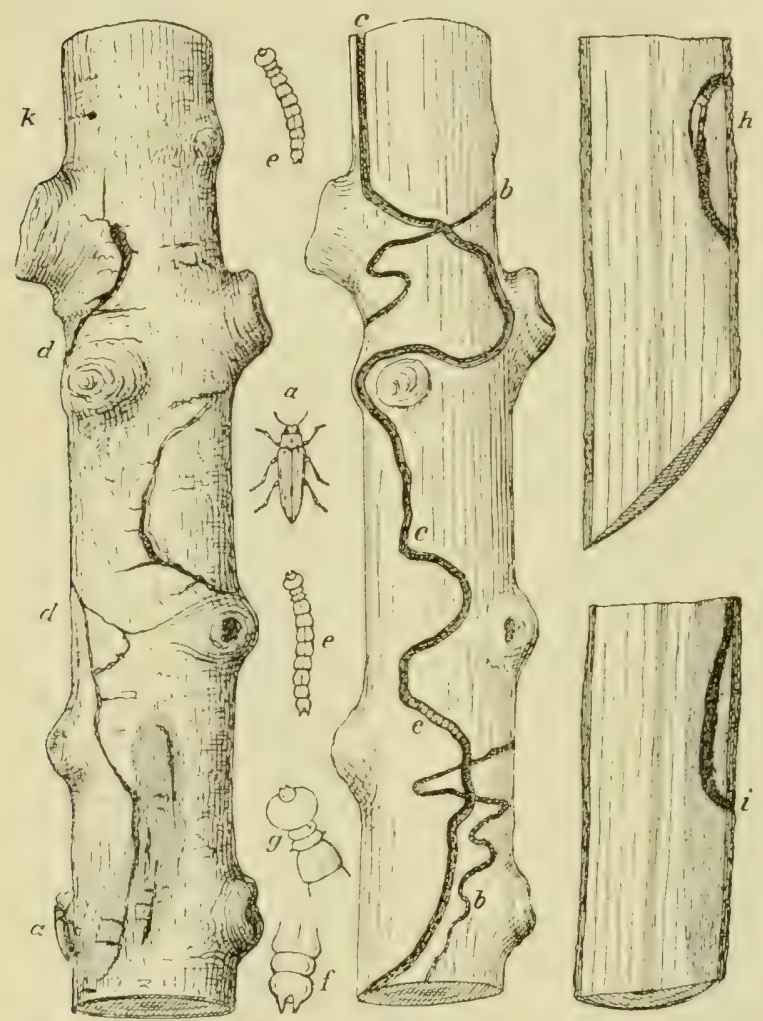

כ̌ig. So. Der gebuditete Pradjtfäier (Agrilus sinuatus) mebit Larue und Frẩ Derielfen im Birnbanut.

" Räier; e Larbe: $f$ beren hincres, y beren norberes (Enbe terg'.); 4 ber anfangg bünte, bet e treitere Rarbengang; a Rifie uno Sprünge ber junnen

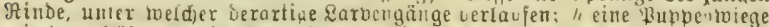
mil bem Säfer; ? eine Yeere Zuppentviege; $k$ ein flltglod in ber Rinne: bei $h$ und $i$ bebentet bie Echattierma bite fonmustg graugrinte färbung ces trorzes in cer 1tmjebun der quppenturge.

Psflanzenteilen; oft minteren und ife $=$ letieren jie die Blätter. Die $\mathfrak{B} e=$ fïmpfung ift je nad) DeIt Giattungen eine verichiedente.

hörett:

Sieber ge=

Der Rettid)= blattfäfer (Chrysomela Raphani); er fript nebít jeiner Sarbe am Barten= ampier; audd juadet Der Siäfer Den Meer= rettichbliiten; ber beildecufarbige Blattfäfer (Chr. violacea) an Brefferminze; Der Soloradofäfer (Chr. decemlineata) jchadet als Siâfer uno Larve Dem fiartoffelfraute in 3 Ssenerationen; die Säfer viberıin= tern itt ber Erbe, cbenjo berputppen fict) Die Larben Ganobreit tief in Der Eroc. Er fommt iil SAnterifa nor.

Die Spargel:

fäfer zerfrefīen als Rarven unb Sïfer die Etengel der Spargelpflanze, über=

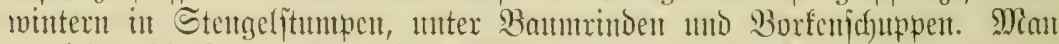

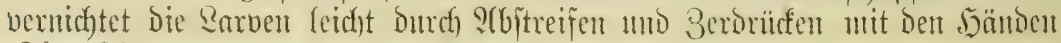
(Fig. 81).

Daber gebürt bas rote Epargethähnden (Crioceris asparagi) 
แmo ber zwölfpunftige Spargerfäfer (Cr. duodecimpunctata), Das Lilienhäbuden (Lema nerdigera) frifit bic Blitter der Lilien.

Die (b)etreidebähnd en (Crioceris granella tulo melanopa) an (Siäjern und Getreide, fint oft jebr juäblid). Beppribungen mit Iabafsertraft und $10 \%$ iger Âtnt) (farbollöjung werdent empfohlen.

\section{Der Mieerrettidblattfäier} (Phaedon armoraciae) ift ein arger Schäbling ber Mieerrettich = pflanzen, indem der Räfer แnd jeine \&arbe bie B̉lüten mo Blätter jebr ftarf befreffen, jo bafi it man= dhen Gegenden Der Meerrettidbou unrentabel miro. Der Siaffer hat im Jahr ztuct Gsenterationen, liberwit= tert in allerlei Schllupfwinteltr. Die Serpuppung exfolgt it ber Eroe. Die Befäntufung jebst in ber $\mathfrak{B}$ eije cin, Doñ man bie eritu Säfer und Derent Earben abjutdyt und bei ftarfen 2 utftreten mit

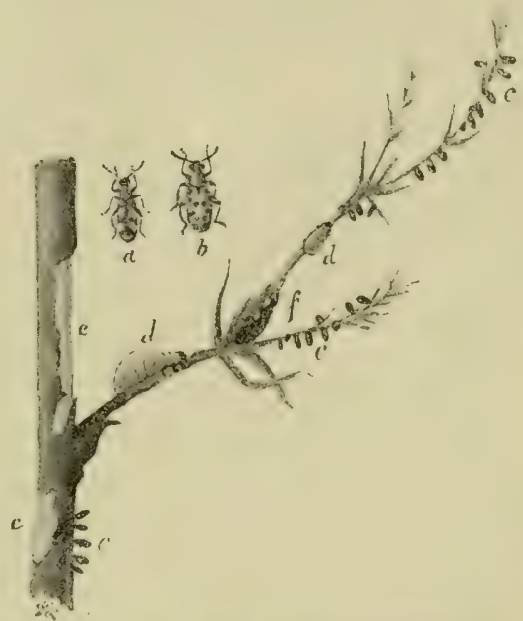

テึig. 81. Tic Epargelyähud̆en.

$a$ Crioceris asparagi, $b \mathrm{Cr}$, duodecimpunctata, c Eier. d Rarbe, $f$ Räfor, e Frabitellen.

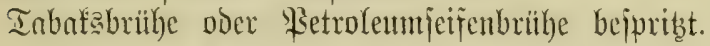

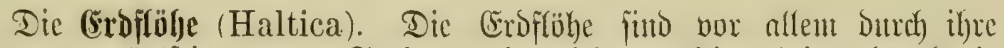

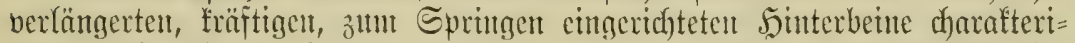
jiert. Die platten Zarven Yeben mintercno int Jimenn Der Blätter; Die

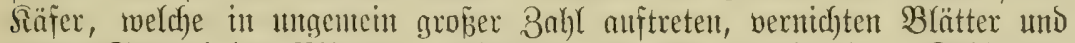

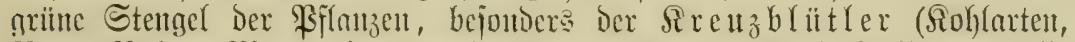

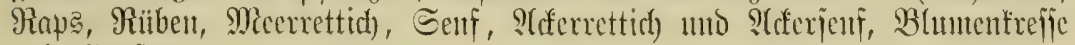
แtกI Sopfen).

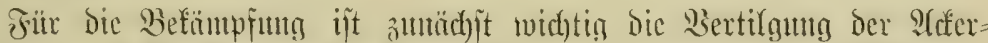

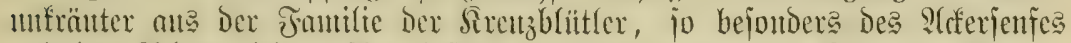

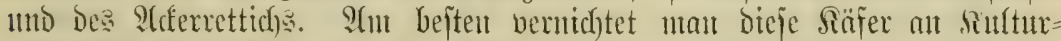

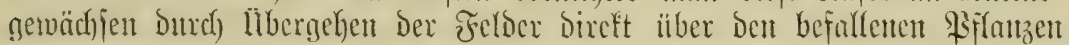
mit cincm unterieits mit Teer ober ciner anderen flebrigen Menje be=

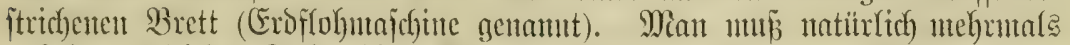

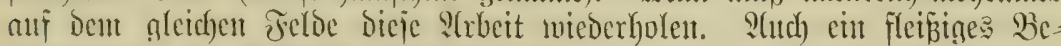

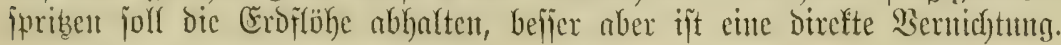

Die bäufigiten $\mathfrak{A}$ rten finto:

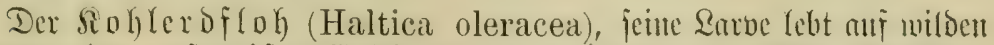
Wifunsen; Dex geftreifte (Erdflok (H. nemorum) an Siohl, Siettichen,

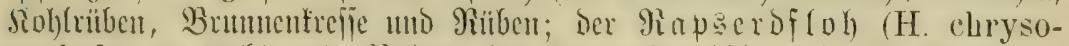
cephala an hoht mo Shiben; dex bogenftecifige (5. (H. flexnosa) 
an Siohlarten; bor Sircijenerdifoh (C. nigriceps) nu Gartentrefie mo

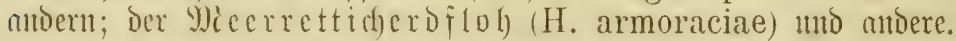

2(nmerfung. Iic Miaricnfäjerdfelt (Coccineliden) uno deren Earven find, ba

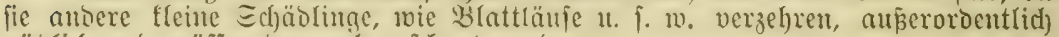
nüblich) tmo müfjen bemnach gefchont verben.

\section{Dromma: Bie Drdţmefferlunge (Lepidopteren).}

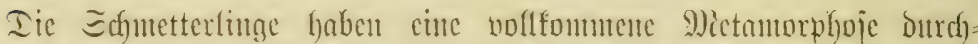

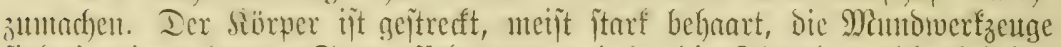

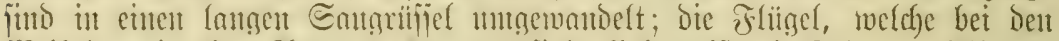

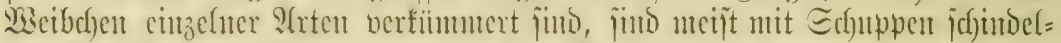

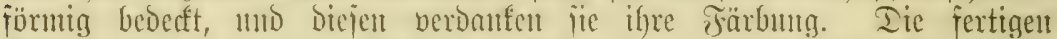

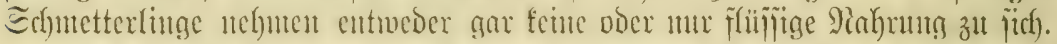

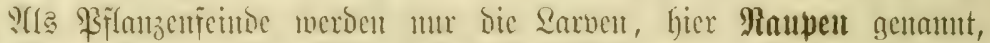

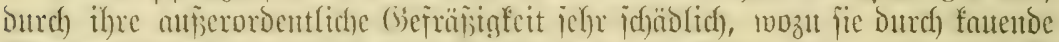

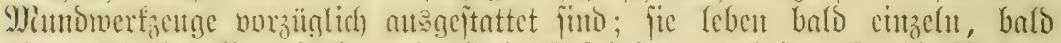

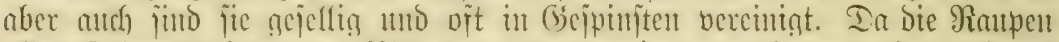

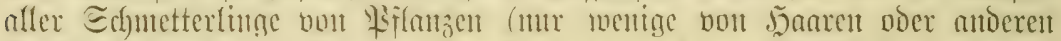

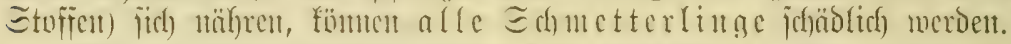

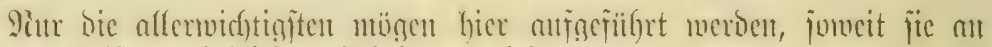

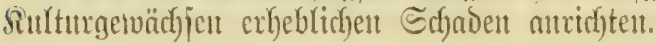

\section{Familie.}

\section{Die Tugfaltrr (Papilioniden).}

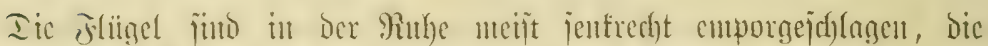

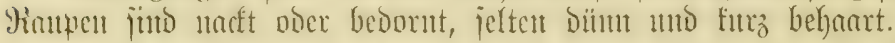

1. In: Ingpfancuange (Vanessa Jo). Tie itarf troboututu

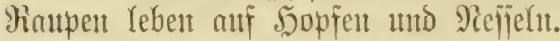

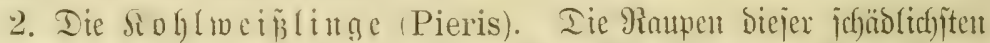

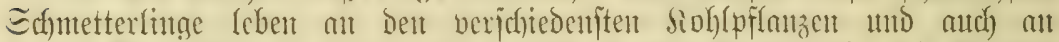

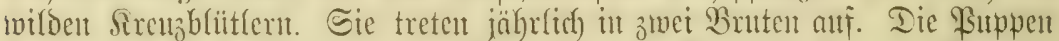

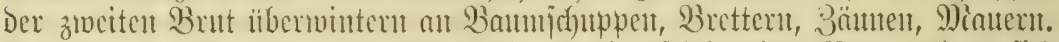

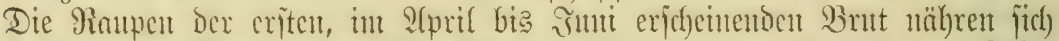

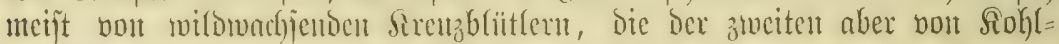
gewädjent. WSir mutericheiben:

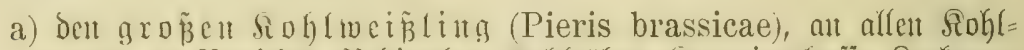

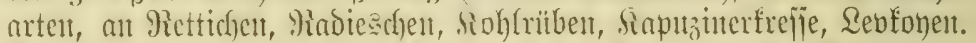

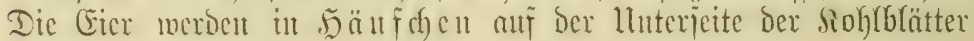
abgelegt (ケig. 82).

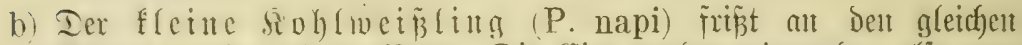

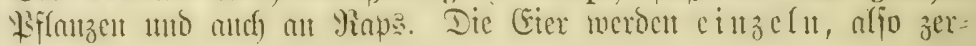
itreut, abgelegt. 
c) Der Mejedafalter (P. Daplidice) frip̃t an Rejeda, mo ebenjo nod) alt Sobl uto Riap.
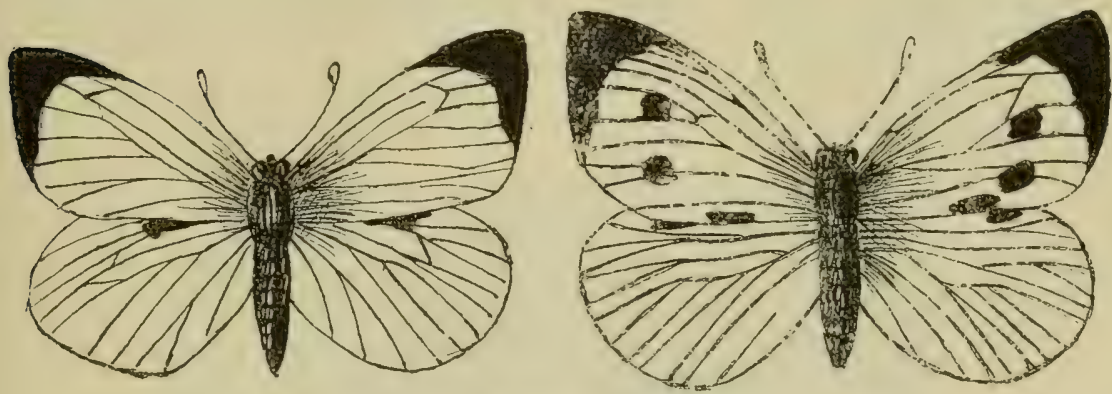

Fig. 82. Grofer folftusipling.

a Mänแสฺก.

b Weibder.

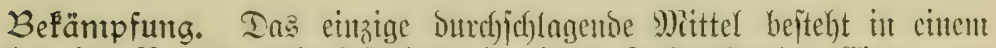

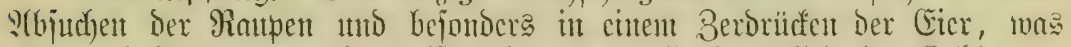

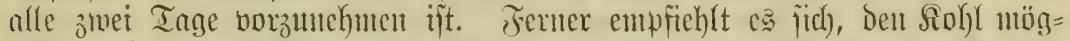

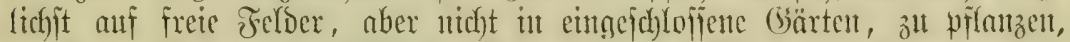

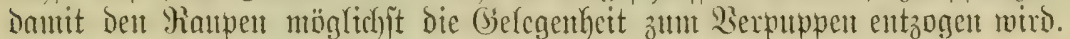
Iie natirrlidyen Fembe, bejonders die Schlupfweipen, find ju jefonen.

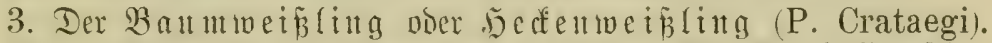

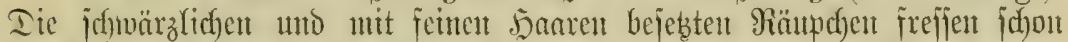

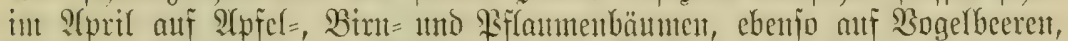

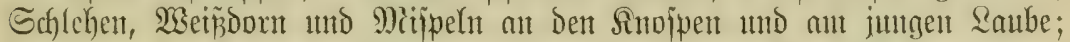
iie Gaben in ffemeren, immerbin aber leicht benterfbaren Nejtern iiber=

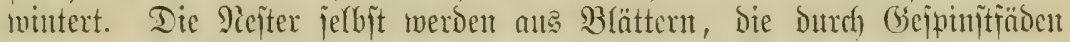
verbunden find, gebilinet; mant nenut fie flletue Raupenuefter jum

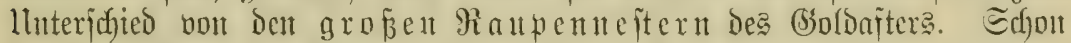
int Junt fliegen bie Echmetterlnge und bie Eier werden bis zu 150 auT

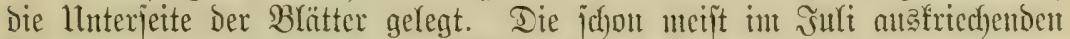

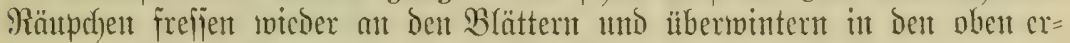
sö̈hnten fleinen Ramenneftern gejellichaftlich.

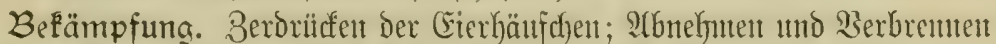

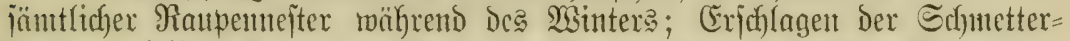

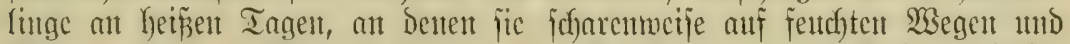

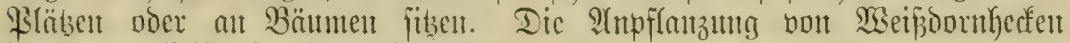
bürfite möglichjt einzujøränfen jein.

\section{Hamilix.}

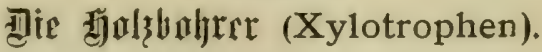

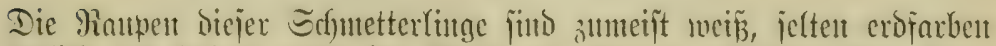

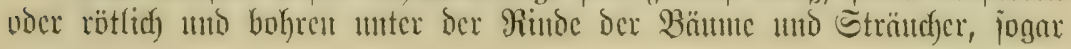




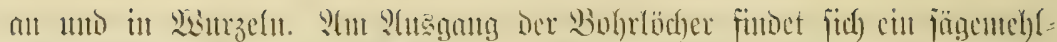

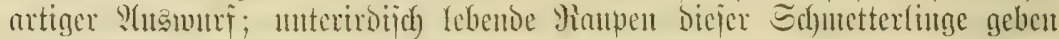

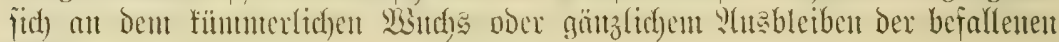
\$flauzen zu erfenmen.

Sieher gehört:

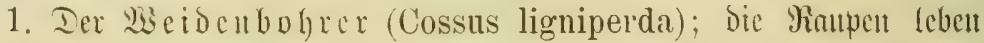

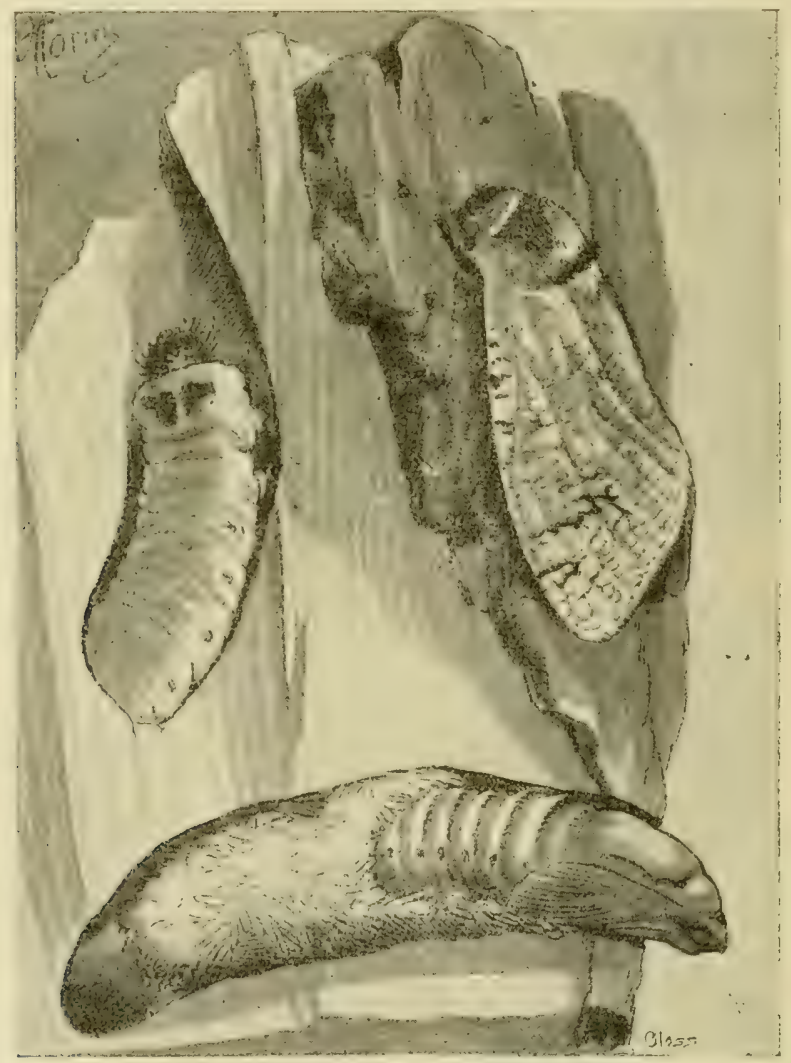

Fig. 83. Mascibentofjer nebjt 9inupe und Puppe.

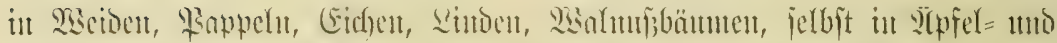

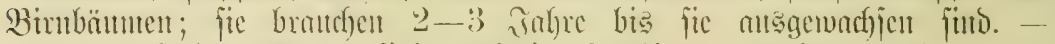

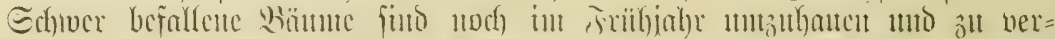

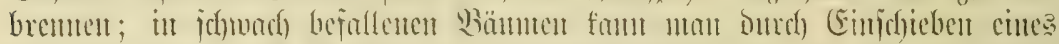

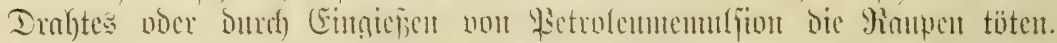

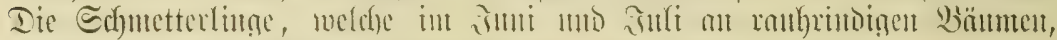

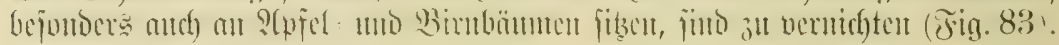




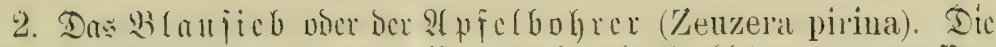

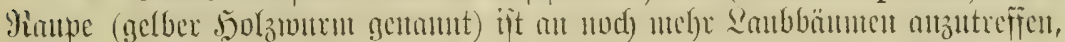

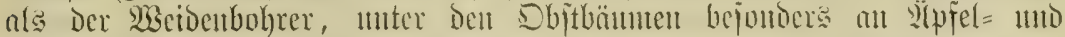

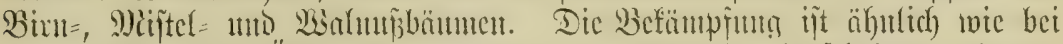

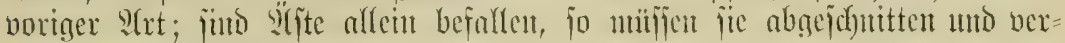
nidhtet werdell (Jig. 84).

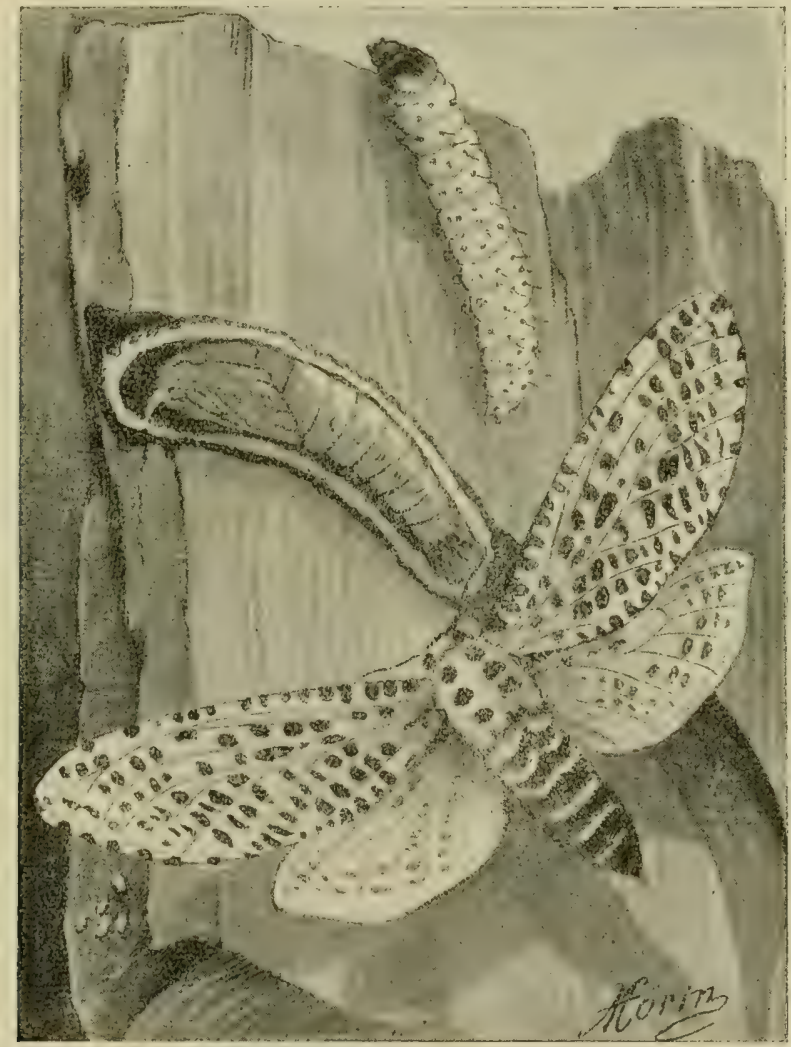

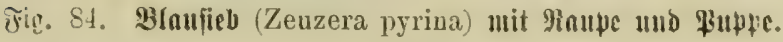

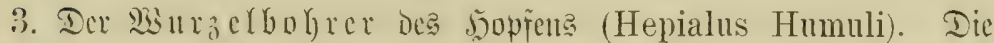

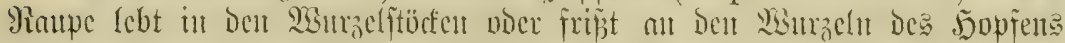

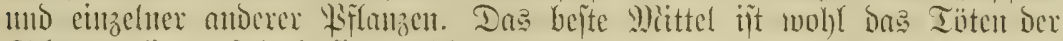
Schntettertinge, fobald fie zit fliegen anfantgent.

4. Der ?hifelbaumglasflügler. (Sesia myopiformis). Dic

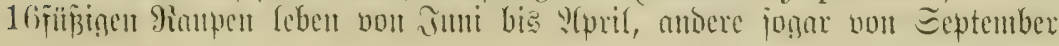




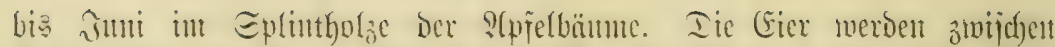

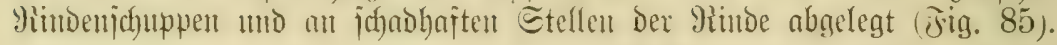

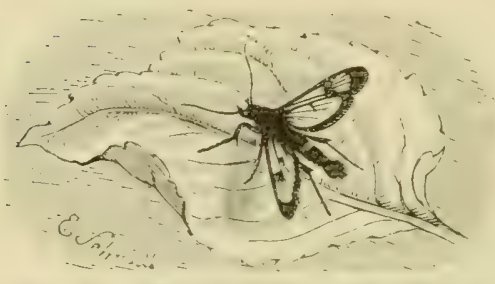

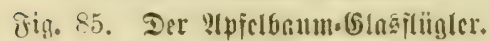

BeF̈ämpfuna. EFinfangen Der Sdymetterlinge, Ritndenpflege uno Sialfantrich) ift anzumenden.

An Johanniabeeren jääbigt ber Jobantizbeerglaģlügler (Sesia tipuliformis) mo an 5int= beeren der bimbecrglasflïglex (Sesia hylaeiformis). Whan judt Dic Shaupes alif und ichnetoet bie

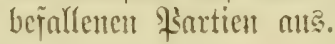

\section{Fantiltr. Dir Fitumer.}

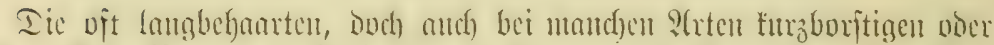

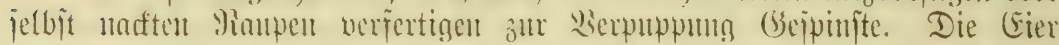

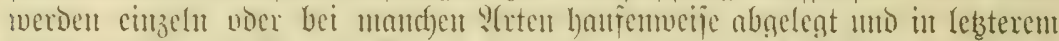

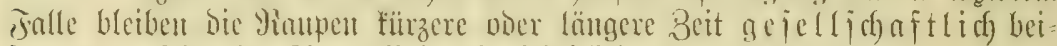

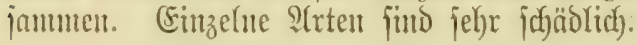

Die suidjtigjten bavon find:

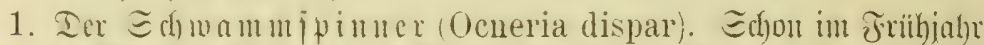

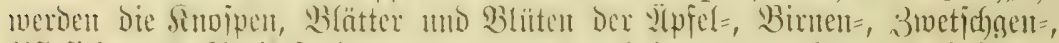

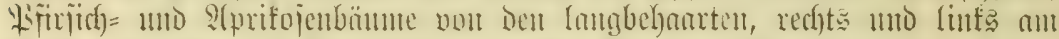

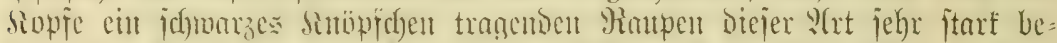

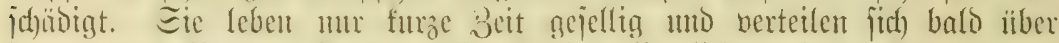

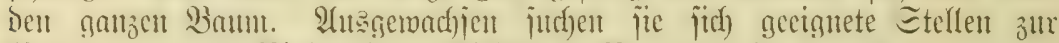

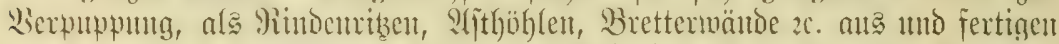

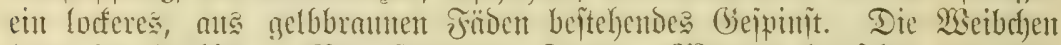

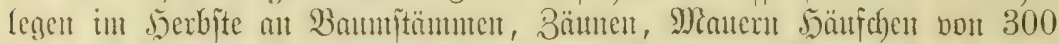
bi: 500 (5iern, weldye jogleich) mit Den gelblichgranten Jjaarent bes Shinter= leibes beflebt werden, jo Daj Der ganze Eierbanfen wie cine Zundermajie,

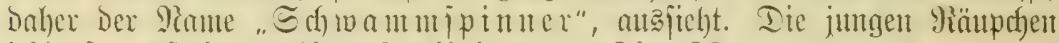

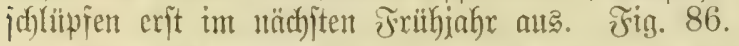

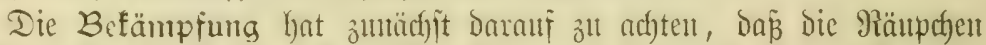

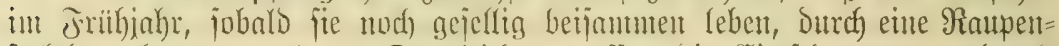

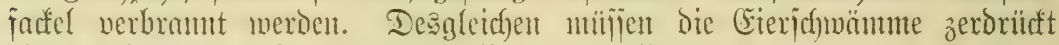
oder verbrant werbent, wo mant fie alth treffen mag.

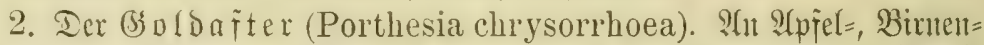

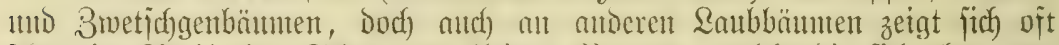

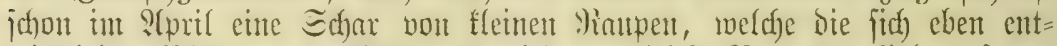

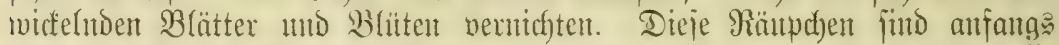

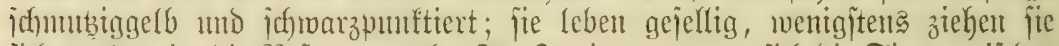

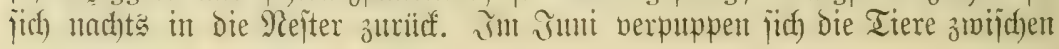


ว̇ı

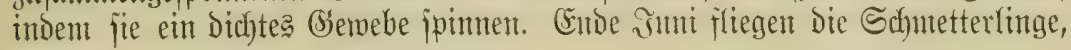
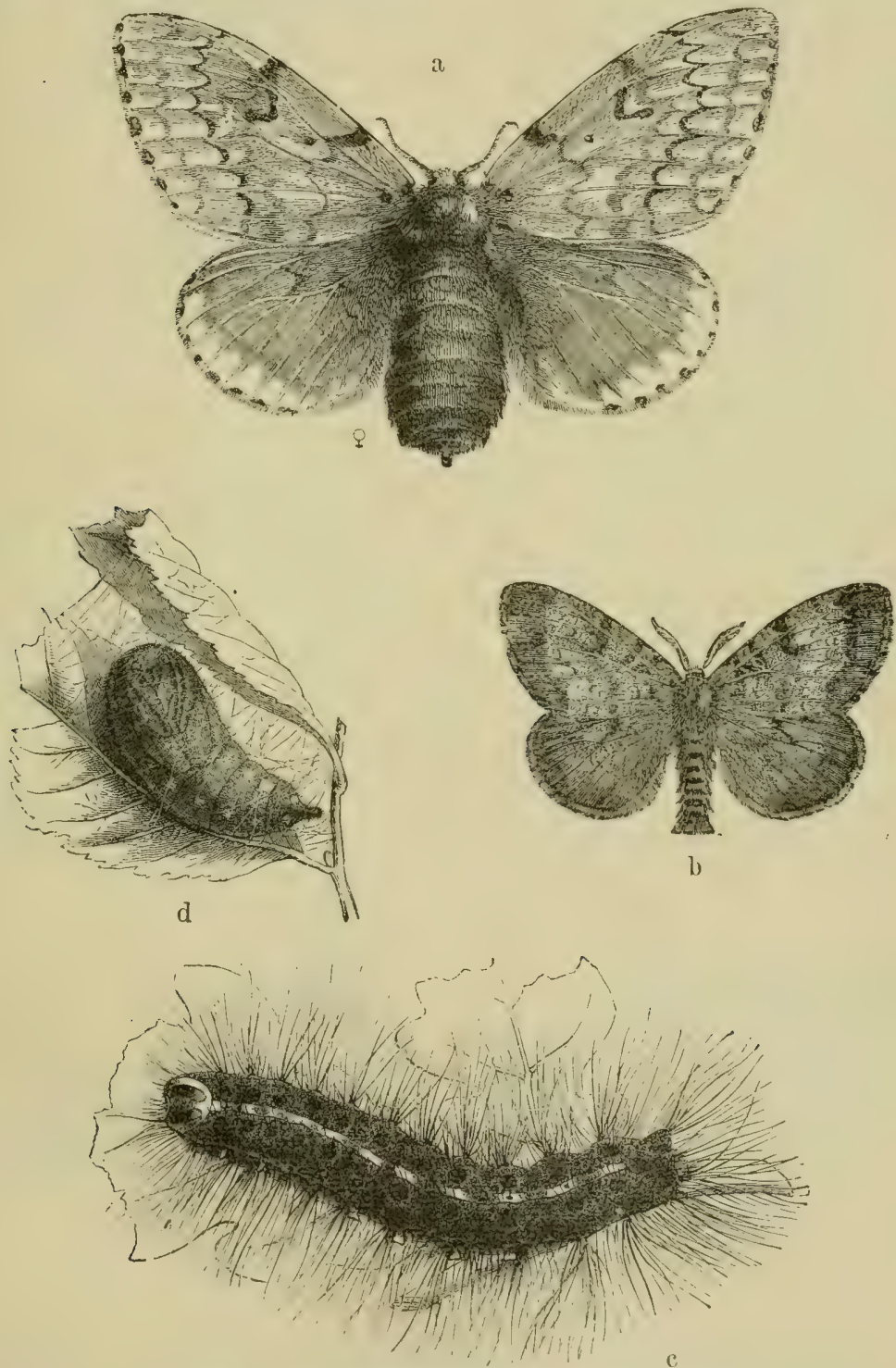

テ̂ig. 86. Der 巨djuammipinnex (Ocneria dispar).

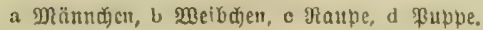

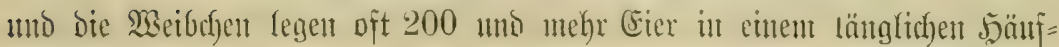




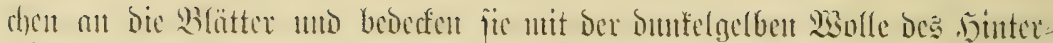

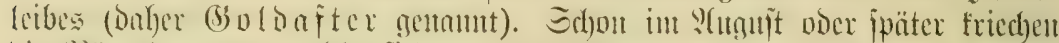

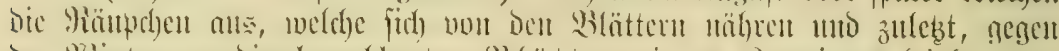

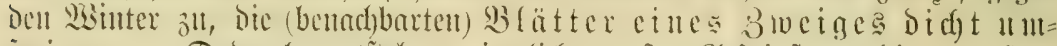

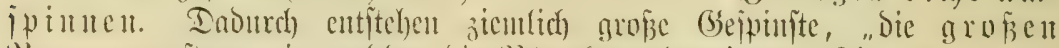

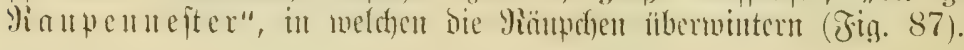

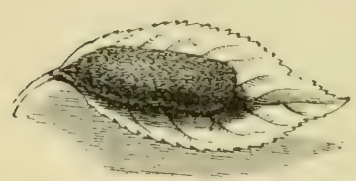

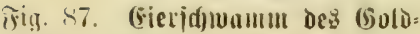
niters (Porthesia chrysorrhoea).

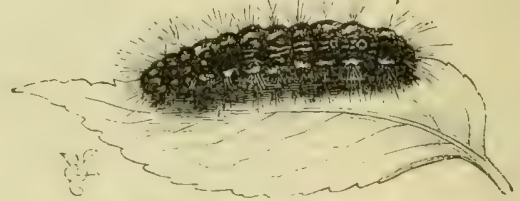

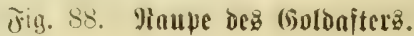

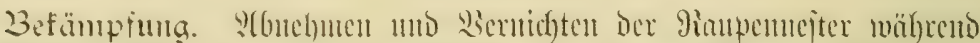

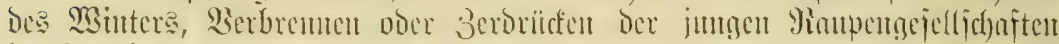
iiti Jrithjabr.

3. Dor gingelipinter (Gastropacha nenstria). Dic Jimuen

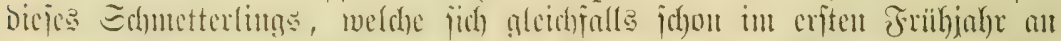

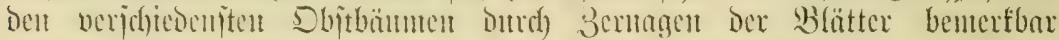

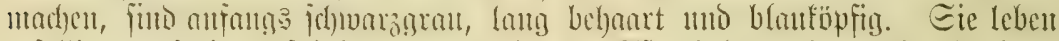

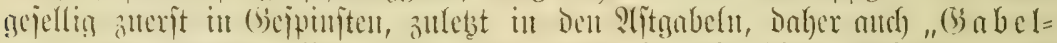

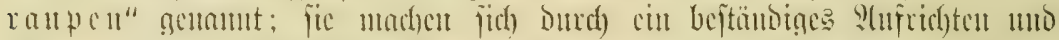

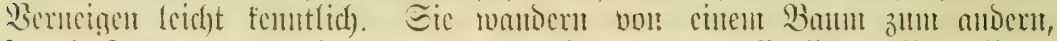

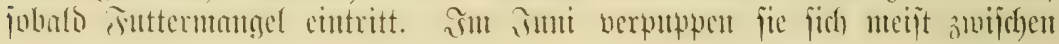

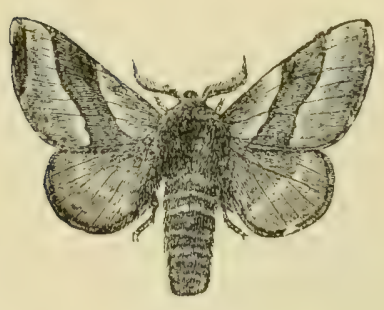

c

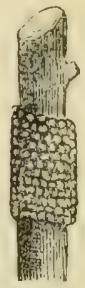

a

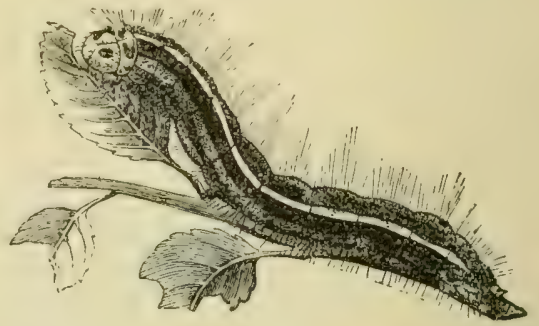

L,

Fig. 89. Miugelipimex (Gastropacha neustria).

a Eier, b Raupe, c tweibridjer Ed)metterling.

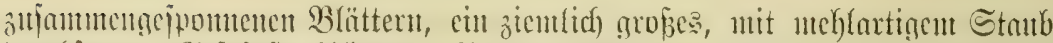

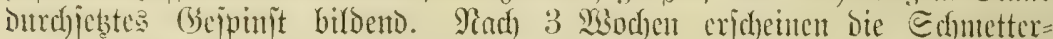
linge, Deren Mseibchen jodann 300-400 Eier nut cincu nidyt allzubicten

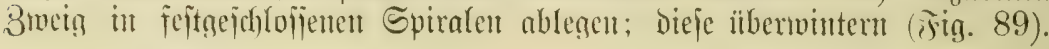


Die Befämpfung Gat barant ôt ad)ten, bañ bie $1 \mathrm{~cm}$ langen (5i=

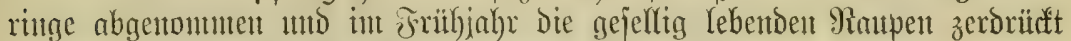
voer mit Ratpenfacfeln berbrant werden.

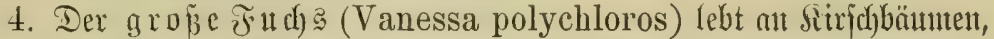

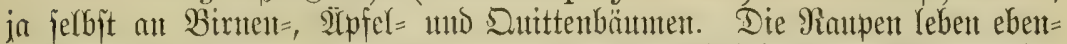

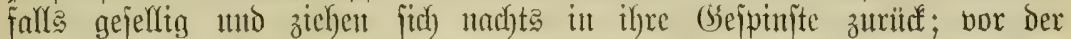

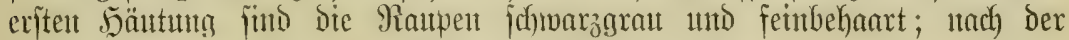

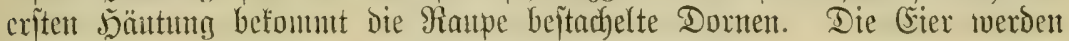
flächenartig an 3weigen abgelegt und itberwintern.

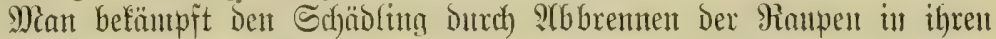
Geipiniten am frilken Miorgen.

5. Die Tionne (Ocneria monacha). Die Ranpen leben ant Fichtent,

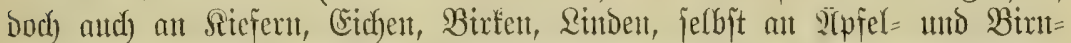

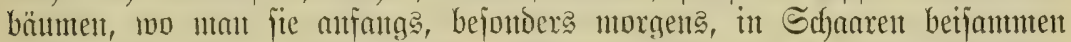

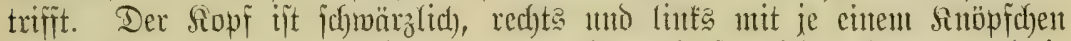

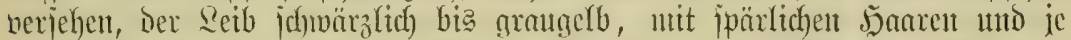

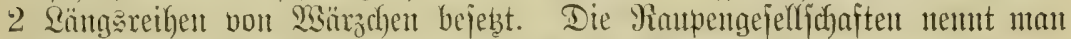
"Epiegel". Jm Julli berpuppt fid) Dic Raupe. Won Ende Juli ab

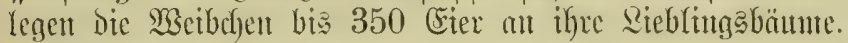

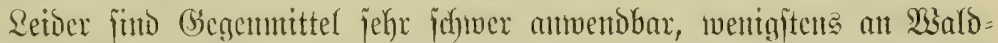

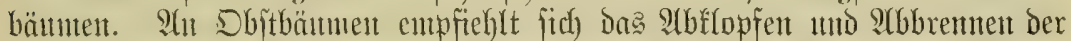

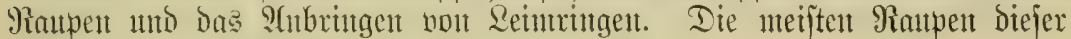
STt gehen Durch Jnfeftionaltanffeiten zu Grumbe.

6. Der Ricfexuipinuer (Gastropacha pini) nälyet fid bou

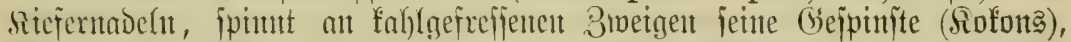

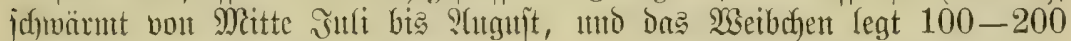
Fier an Sitefern in einer Söble von 1-2 $\mathrm{m}$ in Syäufdben von 20-50 Stür. Die Raupent

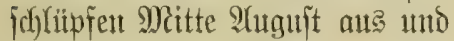
iiberwintern in Mooje, wohit ite fich mittela Fäben Gerablaficn, oder unter Streudecte, jelbjt in Rindentiben uno unter ber Eróe. Daz Ŷtubringen bon Reintringen att Salobeitüntoen uno Dbit= bäument ift loobl das jidcherite Mittel zแx Befömpfuntg.

7. Der $\Xi d)(e \mathfrak{e n}=$ oder Iprifojenfuinuer, aud Znitträger gentanmut (Orgyia antiqua). Die Bïritenraupc Diejes Spinners frifít Die B̉lättex

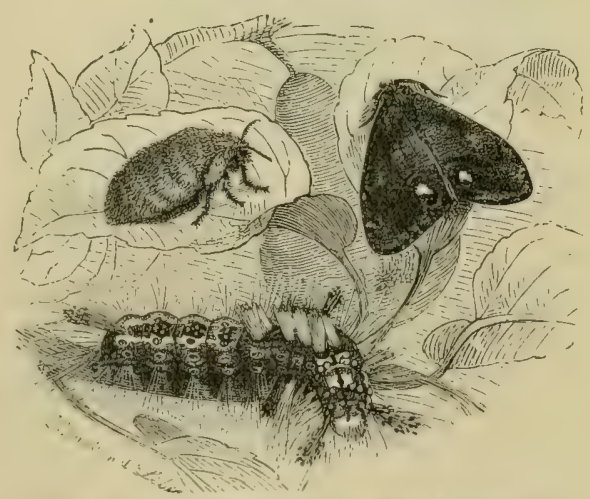

ซig. 90. Raitträger (Orgyia antiqua). Meibđen, Männđen, アaupe. merichiedener Dbitbäume, bejonteres nou Spalterobit uns noiro baburdh

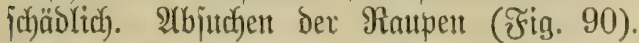




\section{Iamilive.

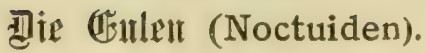

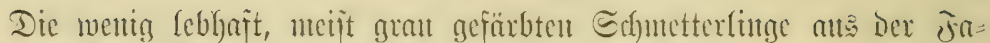

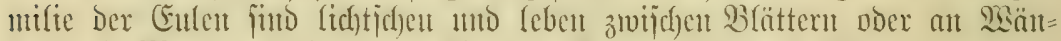

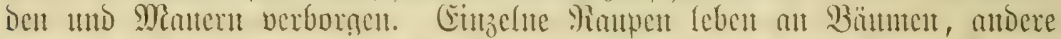

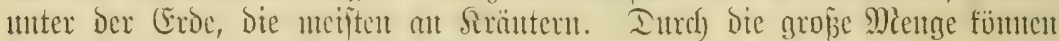
einzelne $\mathfrak{A}$ rten jebr juäblid) meroen.

Die twidytigiten 2 (rten fint :

Dic 23 interinateule (Agrotis segetum), beren Hatpen als

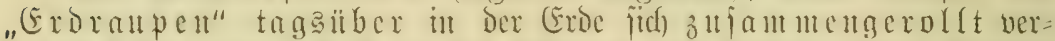

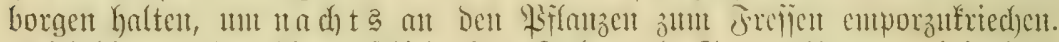

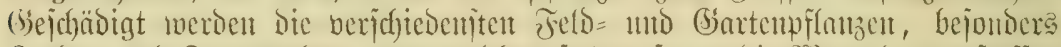

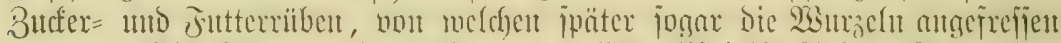

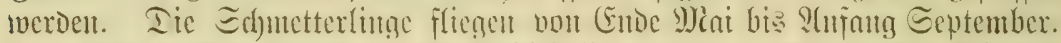
Die Eicr merden cinzelu an Dic Erojichollen gelent; während bes $23 i n t e r$

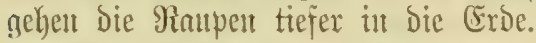

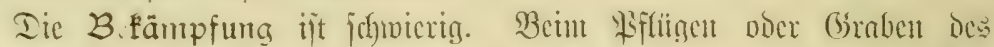

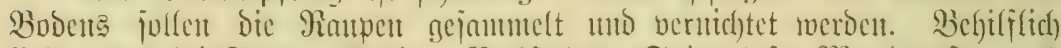

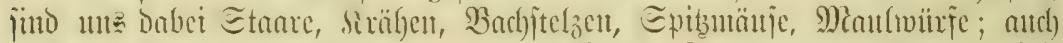

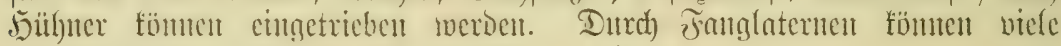
Sdjmetterlinge angeloct und vernitchtet werden.

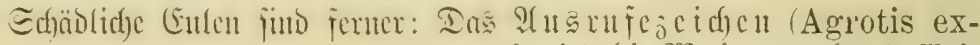
clamationis), die $\mathfrak{W e i z e n t r e ~ ( A ~ T r i - ~}$

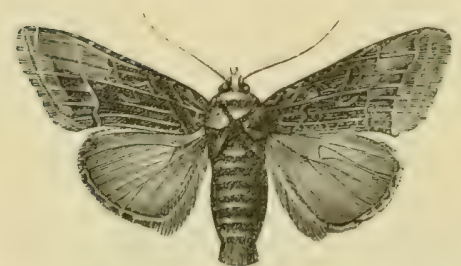

Fig. 91. (iammneule (Plusia gamma). tici 1t. andere). Bejonders hälffig fommen Ententerten an Gemtiifepflanzen bor, fo bie (5) a murculc, Plusia gamma (Fig. 91), Die (semüleett le (Mamestra oleracea),

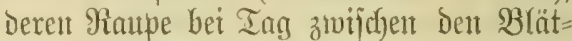
tern beritefft lebt und an Sioblarten, Salat, Spargel, Erbjen, Bobnen u. i. w.

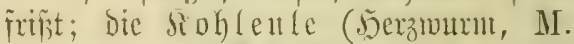

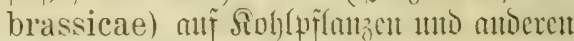

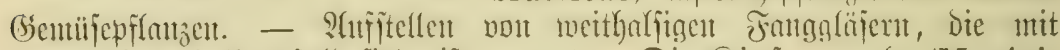
Fruthtiaften halb gefiult finto, ift anzuraten. Die Siefernenle (M. piniperda) frifist an Riefentt.

\section{Tamilite.}

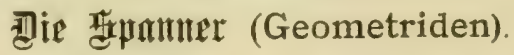

Dieje Edfmetterlinge haben bon ber cigentïnlichen ipantenoen Bangart

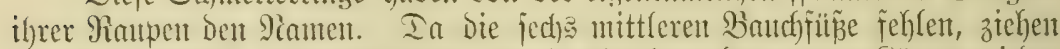

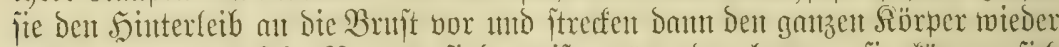

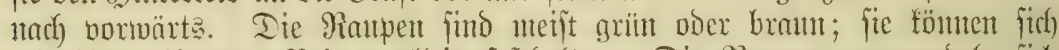
mit ifren binteren Beinen allein jejthalten. Die Faupen verwandeln fid) 


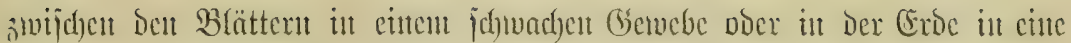

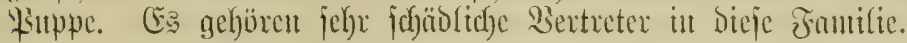

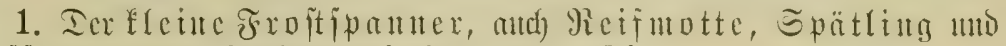
Frejfer gentant (Cheimatobia brumata). Die Schmetterlinge, von Denen bic \$3eibchen mingefliigelt, Die Mämd)en alfein geflitgelt funt, foblitpfent int

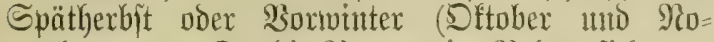
vember) alts. Da bie Fimpent int Boben fidf ver= puppen, io milffen bie atsgejchlitpften Wetbohen, Itm die Sier alf bie Btweige ablegen zlt tömen,

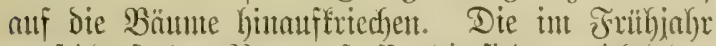

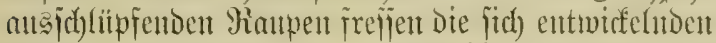
Blätter der Bäume ab, jelbit die Bliitentunopen merden wernichtet. Die befallenten Büutnte jefjen bit fo ans, als wb fie voul froft verbramnt wïrett (J̌tg. 92).

Die Befämpfung iit cinfach. Secben ben

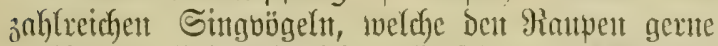
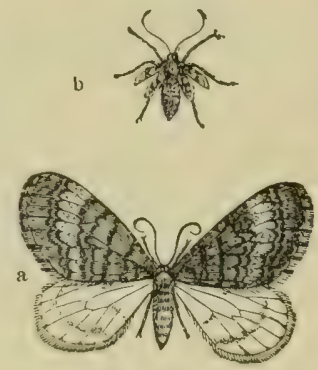

Æig. 92.

Sleiner Frtoftipaunct

(Cheimatobia brunata).

a Miönnden, b $\mathfrak{B}$ cilidjen.

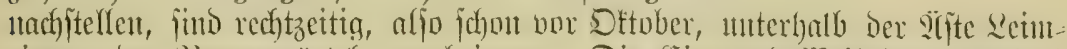

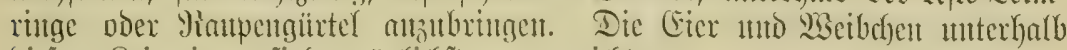
biejer Reuntinge fint möglichjt zal bernidhten. S.tud Ungraben des Bobens im Bereiche der Baumidheiben bon Sีtni bis September ijt ant= 3tratent.

2. Der groje Froftipanner (Hibernia defoliaria). (Ev berbält fich in jeitter

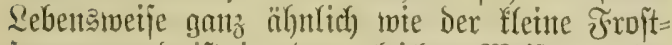
Fpamter und ift it Der gleidfen 2 seije zit be=

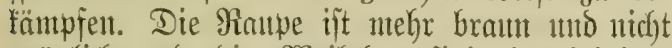
grintlidy tno die. Weibdhen find Iangbeiniger

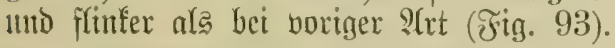

Die Befämpfung ift bie gleiche. Beioe Sarten leben nicht allein an Shitbäumen, jont= berit auth at eiter grofen 2 (nzahl bon 2 aub $=$ bäıเกเeีt.

3. Der Stadjelbeeripantex oder .Darlefit (Abraxas grossulariata). Diejer Schäbling, ber von mnderen Sdjäbigern ant Diejent शähruffanzen an Der cigenartigen jortbemegunt? jebr (cid)t zu untericheiden ift, frifist bic Etachel= beer = mo rohamiebcerftanocu fahl. Ier

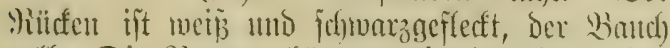
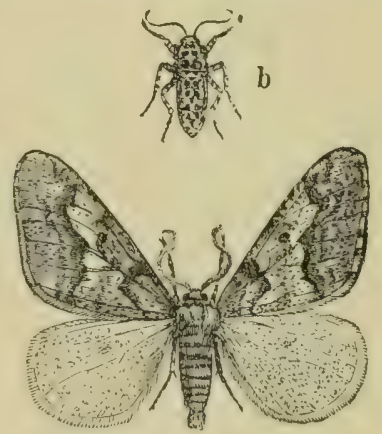

2

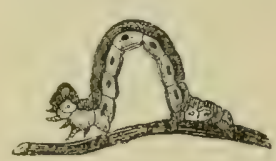

c

テ̃ig. 93.

(5ropiser Froittpanuer

(IHibernia defoliaria).

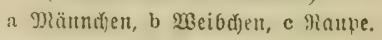

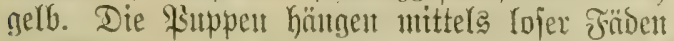

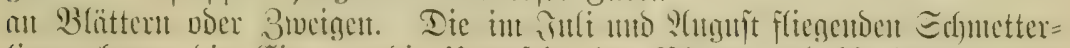

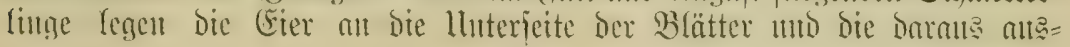




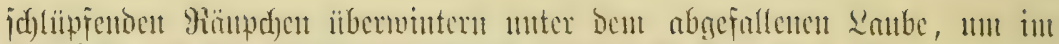

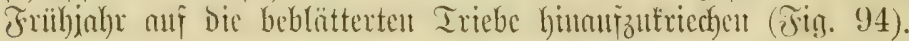

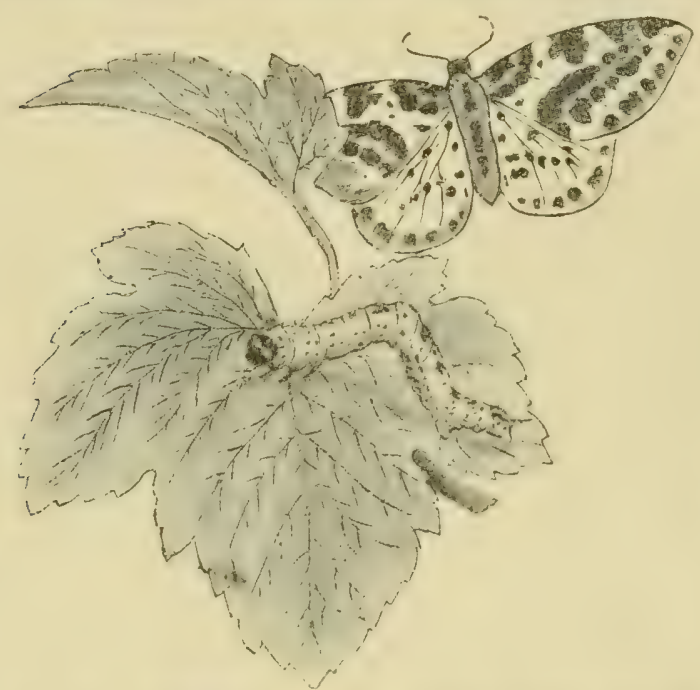

Æig. 94. Etadfelfocripanuer (Abraxas "rossulariata) nebit Raupe.

(Natitry. (Srö̈e.)

\section{Befämpfung:}

9tbelopfen Der Raupen auf Tilicher ill Dell Morgentumben; Sant= meln des abgefallenen Zntbes in Serbite.

4. Dex $\Im_{0}=$ hantizbeeripanter (Fidonia wawaria) fribt int älutlicher Weije att Dett rolyaumisbeer= แnเ Stachelbeerîträı= dhernt. Die Raupen jimo grïn แแ⿰ Ialīeแ auf Dent Yiuidfen weī̄e, aut Baudde gelbe Sinten unto viele idfuwarze Sintte erfenmen. Die Qebenڤmeije ift ähulid), mur iibermointern bei Diejer Atrt bie Eier, die ebellfalls all bie

Blattuntericite abnecent weroen. - Iie Befämpfung ift bie gleidye.

5. Der Sicfermipantex. (Fidonia piniaria) fribt bie Radeln ber

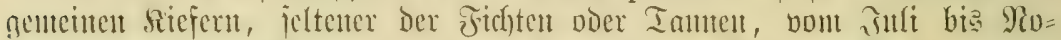

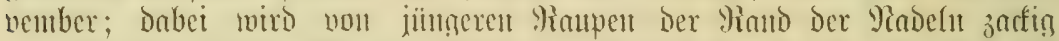

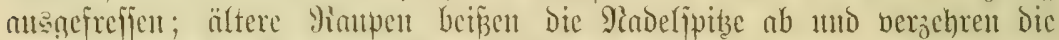

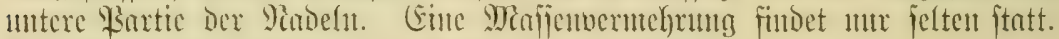
Die Berpuppung erfolgt im Nobember unter Moo?.

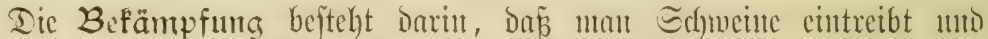

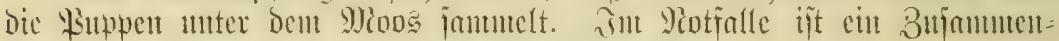
redben ber Stren bei beocutendent Befall anzırtent.

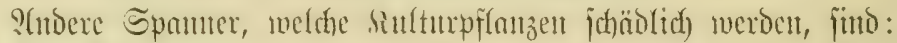

Ier gifabarberipannex (Timandra amataria) nll Rhabarber,

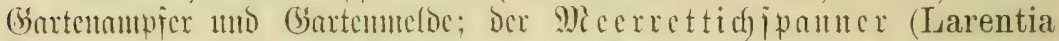
fluctuata) an Meerrettich) uno anoeren firenzbliitleru; Der bratturote Becripaner (L. russata) an Erobceren, and . Dimbeeren, Bronberen und Seidelbecent.

\section{Tramilie.}

\section{Die Bültsiter (Pyraliden).}

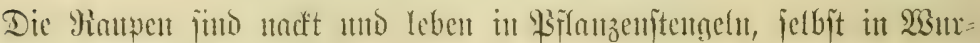
zellt, in Fett anto sarbs. 


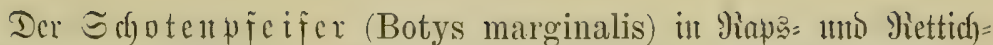

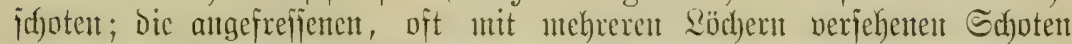
jeben wic Flöten oder Pfeifent ans. Dic Serputpuntug erfolgt in Der Erobe.

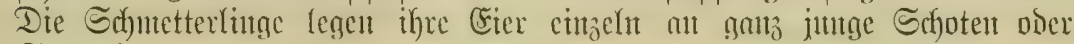
Stentgel.

Der Soht = ober Mecrettidfoit

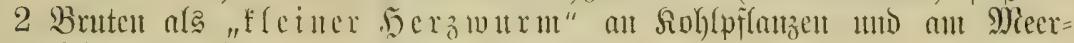
rettid), hier bejonters Die Enment zeritörento.

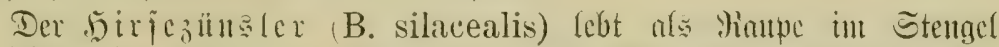

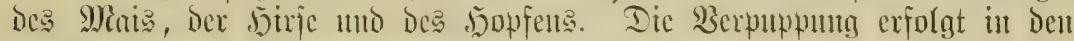
Interen Stengelitiolfen, bis mohin die Ranpe fripist.

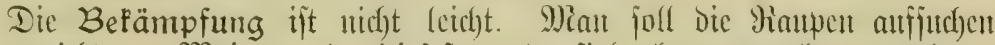

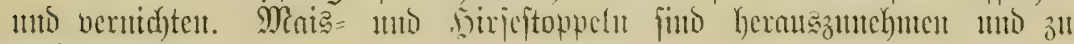
verbrentert.

\section{Yamrilte.}

\section{包ie 势idter (Tortriciden).}

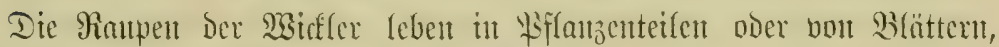
weldye fie zu ihrem Sodhtbe zunumenziehen.

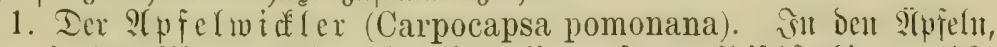

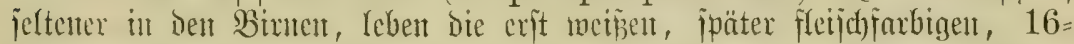

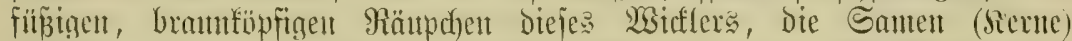

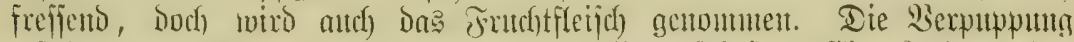

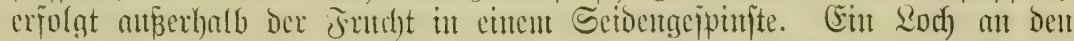

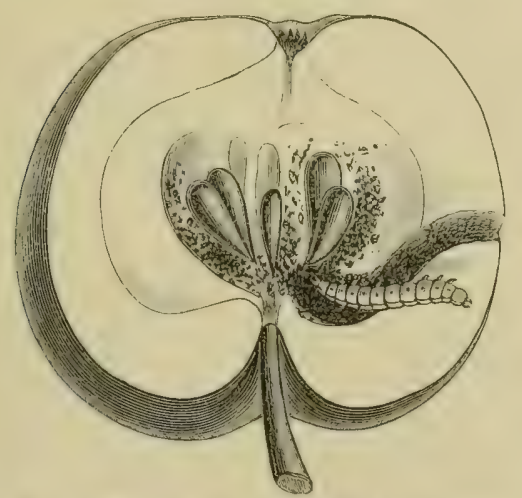

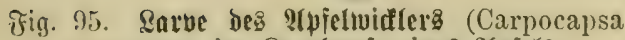
pomonana) im Serubatje cines :Tpiels. (शatïrlicje (Bröge.) Früchten ift inmer ein Betveis Dafïr, Doñ bie Riaupe in ber Jutucht toax und biejelbe bereite berlafien hat. Dft twerdent zwei und mehr nebeneinander hängende, meift zujammengeflebte Friidbte bout ciner Siatpe antgegriffen.

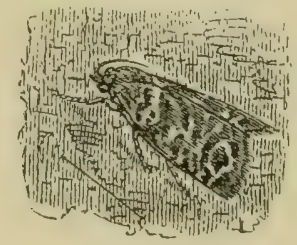

Fig. 96. Der :1pĩelwidfler (Carpocapsa pomonana L.).

Die jo befallenen Fritchte fallen meift norzeitig mo frithreif bont $\mathfrak{B}$ anm.

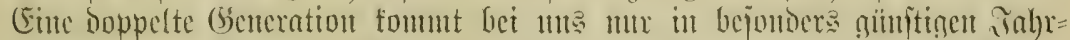

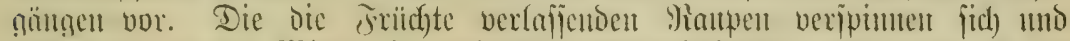

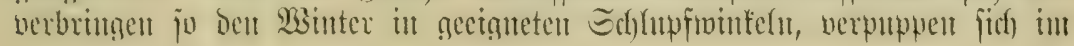




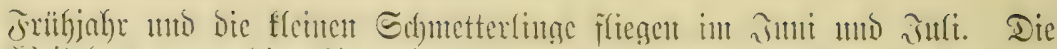

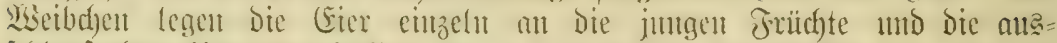

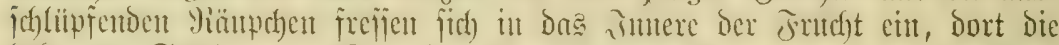

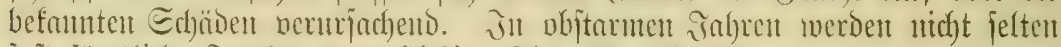

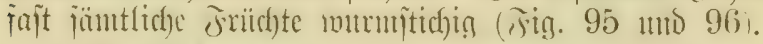

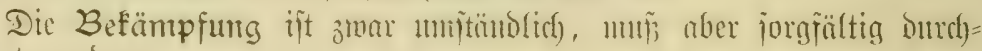
gepiifyrt werdent.

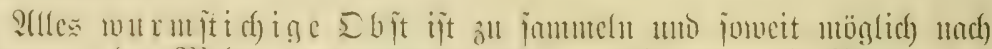

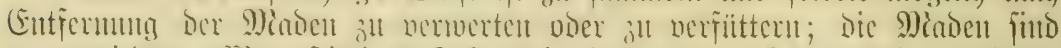

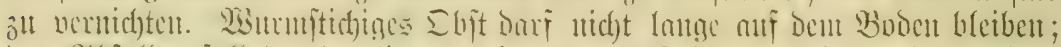

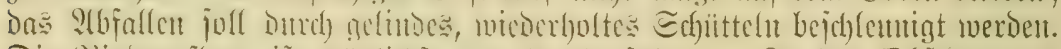

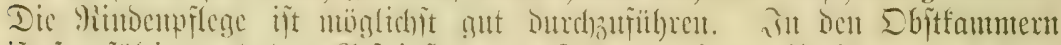

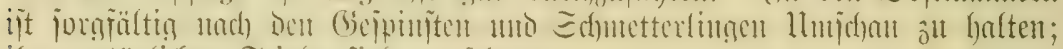

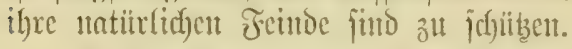

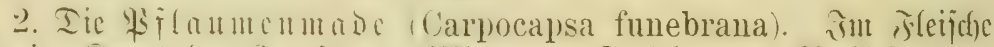

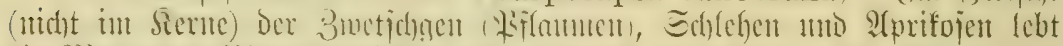

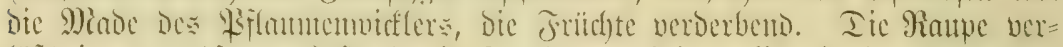

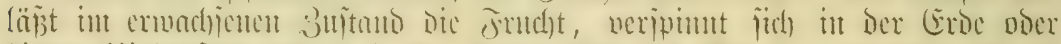

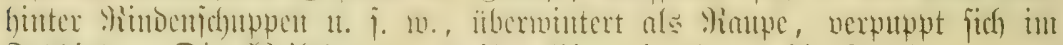

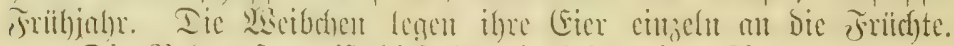

Die Befïmpfuth ît biejelbe toie bei voriger Art.

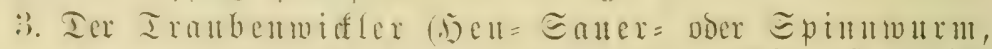

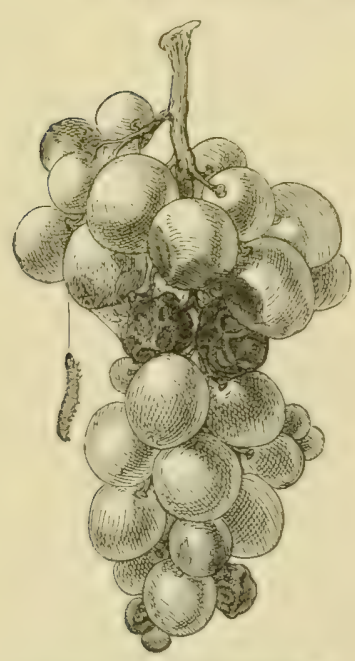

Fึig. 97. "Eauterwurm"

(Manpe) nebit $\mathfrak{B} B$ irfungen de Trajeg it der Irnube.

Conchylis ambiguella). Die erft rötlid)=

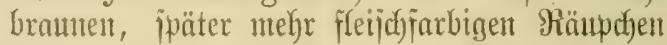

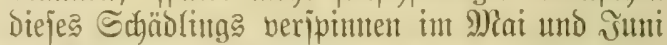
bie fnoipenden $\mathfrak{B}$ (ittentrauben und frefien $3 a \mathrm{~h})=$

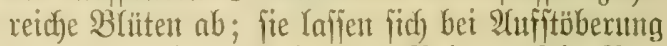
jofort a! cinem Jaden zu Boden. Die Ber= puppung Der Raupe ber eríten Beneration

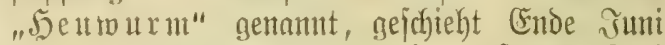
und antiange Ĵtli in ben (Sejojeinent

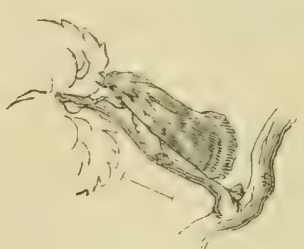

テig. 98.

Eintbindiger Irnubemuiffer (Conchylis ambiguella). (Trauben), zroijcten Seftîtroh, unter Rintonfeben ic. Mitte Suli erjoheint Der Sifmetterling. Die Weibrben legen die Eier nummelyr meiryt an bie Bceren uno bie Räupdjen bicjer zociten Gsente= ration, "Saner=

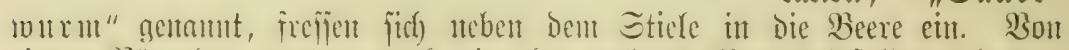

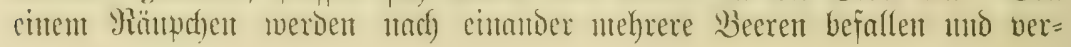




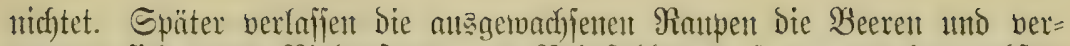

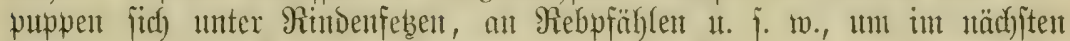

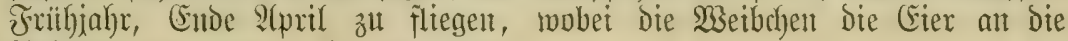
Rebentinopen Yegen (Fig. 97 แ. 98).

Befämpfung. Das bejte Mittel ijt cin jorgfültiges YUjucthen und

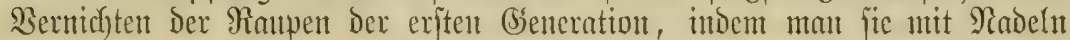

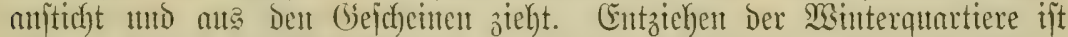

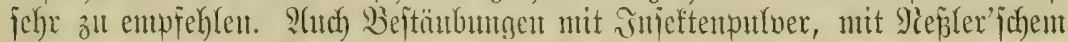

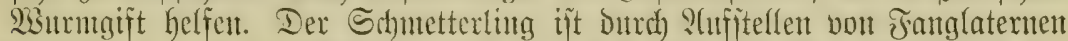

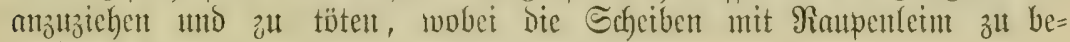
fitreiden fints.

4. Der befrenzte Iraubentotafer oder Die Weinmotte (Conchylis botrana = Grapholitha botrana). Die Räupchen funo grün.

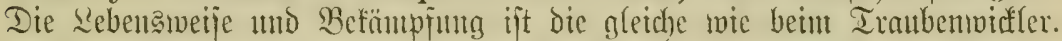

5. Der Springunrut (Tortrix pilleriana). Die Iebentwetie ift

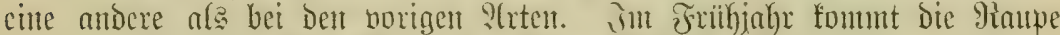

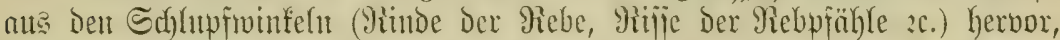

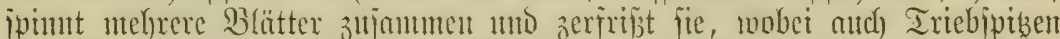

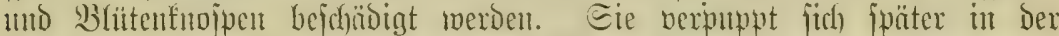

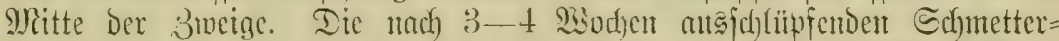
linge legen Die Eicr an bie Dberfeite Der Blätter in Dad)ziegeliger l̈ber=

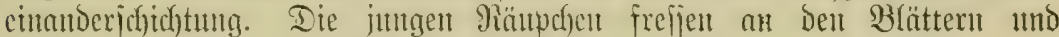
iibermintern jpäter it ben befaunten Echltipfivinfelıt.

Befämpfung. Beroriuden der gelben (Fifäufd)en alif der Blattoberjeite,

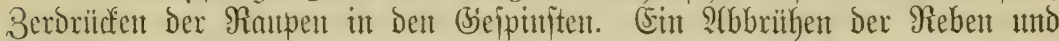

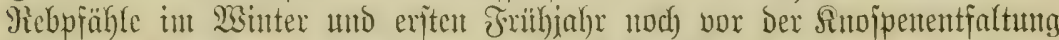
jolf gute Dienjte geleiptet haben, bod) ift Sorjicht nötig, unt bie Reben nicht zut juäbigen.

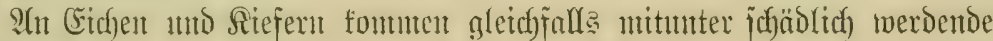
W3ifflerarten vor.

\section{Familie.}

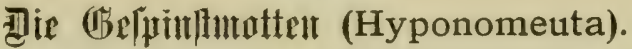

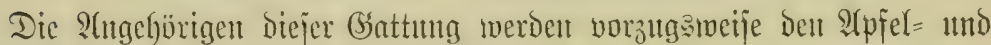

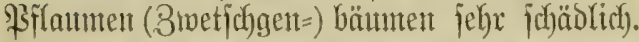

1. Dic $\mathfrak{A}$ pfelbaumgejpinftmotte (Hyponomenta malinella).

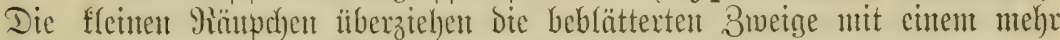

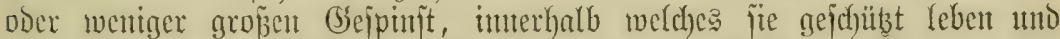

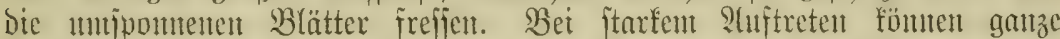

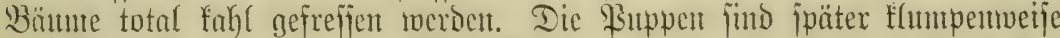

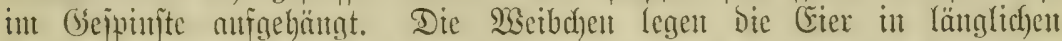

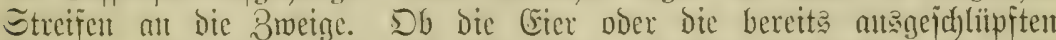

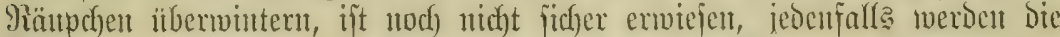

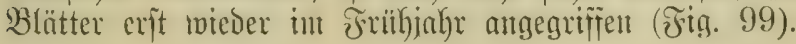




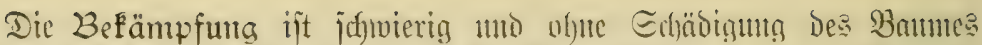

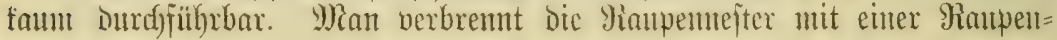

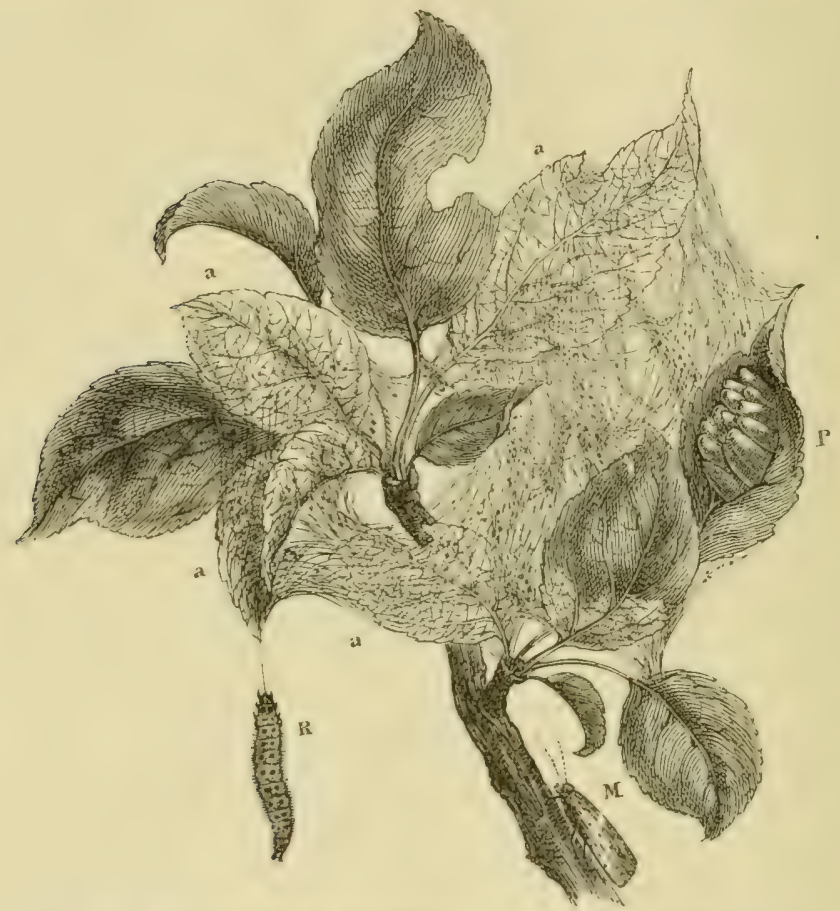

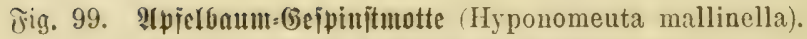

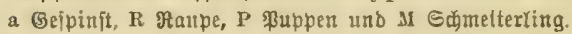

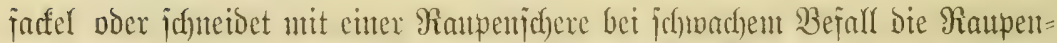
nefter ab. Sorveit erreichbar zeroritct mant Die Ranpen mit der Santo.

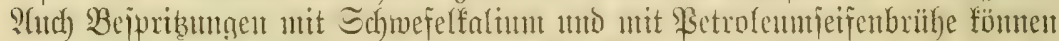

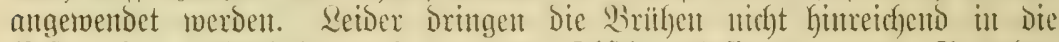
Wejter ein. Jebenfalls mn bon Den Dbjtbaumbejtbern ganzer Segentien gleicf)mäp̈ig vorgegangen twerden.

2. Die Bf la un ugefpinfturote (H. padella) frifst an Bfflaumen=

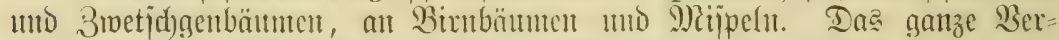
halten unD Die Wietämprung ijt bie gleidye wie bei ber borigen.

3. Dic Bifafenbiltchengcipinjutute (H. cognatella) ant Pfaffenfäppd)en แmo

4. Die Tranbentixidengejpinturte (H. padi) an ber Iraubenfiriche. 


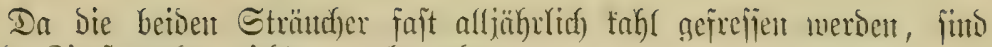

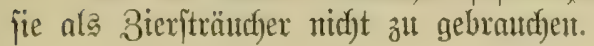

\section{9. 筷amilite.}

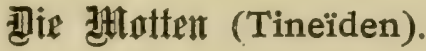

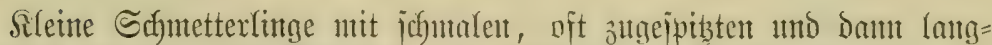

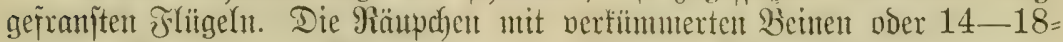

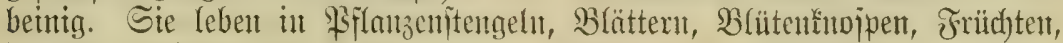

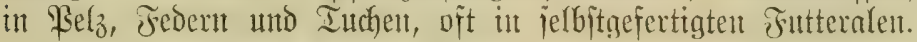

Die widjtigitent 3 ertreter fint :

1. Dic Dbftblattututermotte, aud Fiflaumenlaubidabe

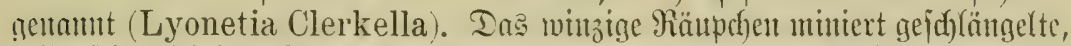

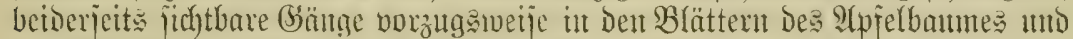

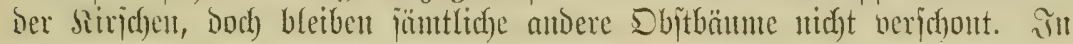

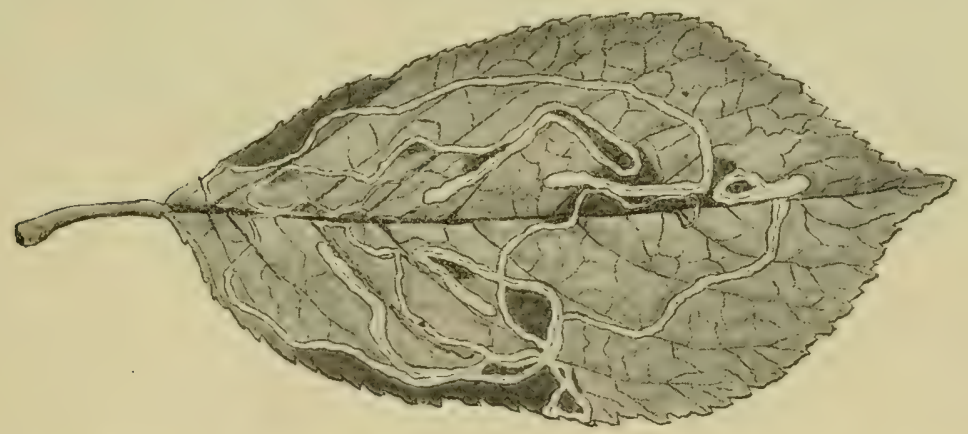

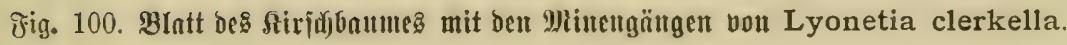

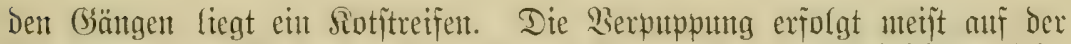

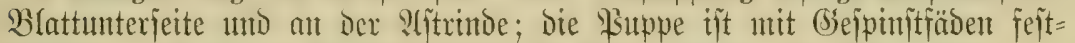

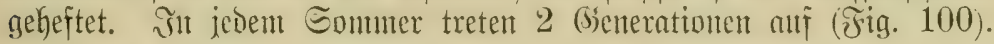

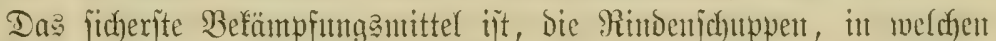

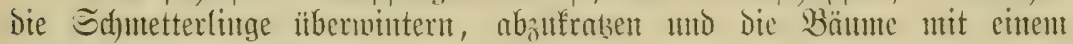
Ralfamitrich zut berfehent.

2. Die Cemiostoma scitella. Dieje Mintte minicrt treisumo

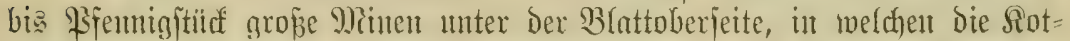

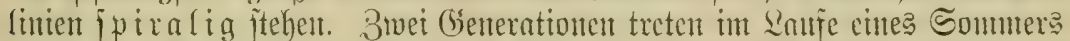
auf. Die Berpuppunn erfolgt ant Stamure. Ithet bie lilberwinterumg ift

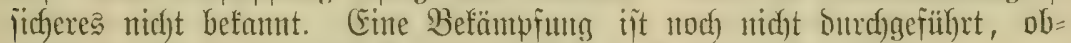

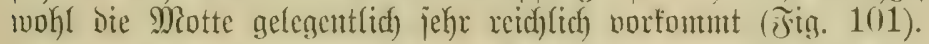

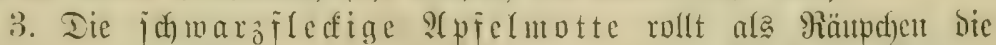

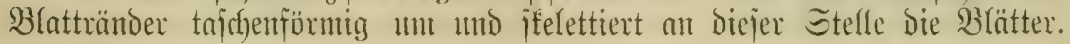




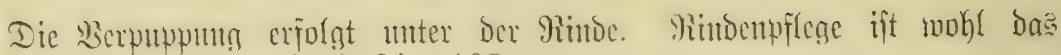
befte Befümpfingemittel (ð̛ig. 102).

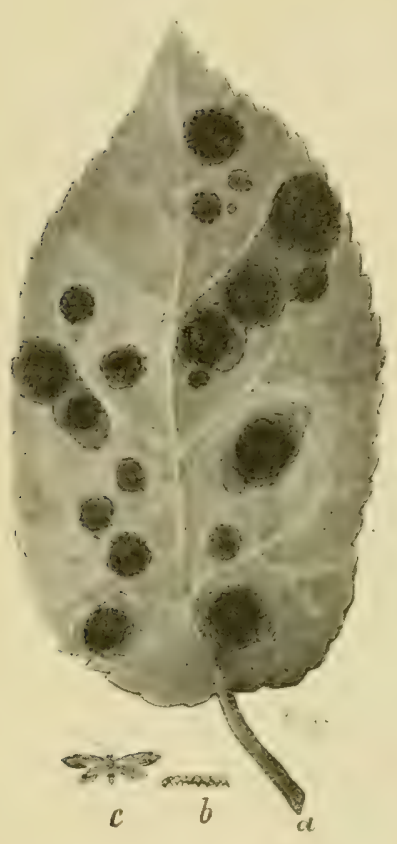

ซึig. 101.

Cemiostoma scitella.

a Bratt mit ben freistunben sytinen,

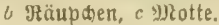

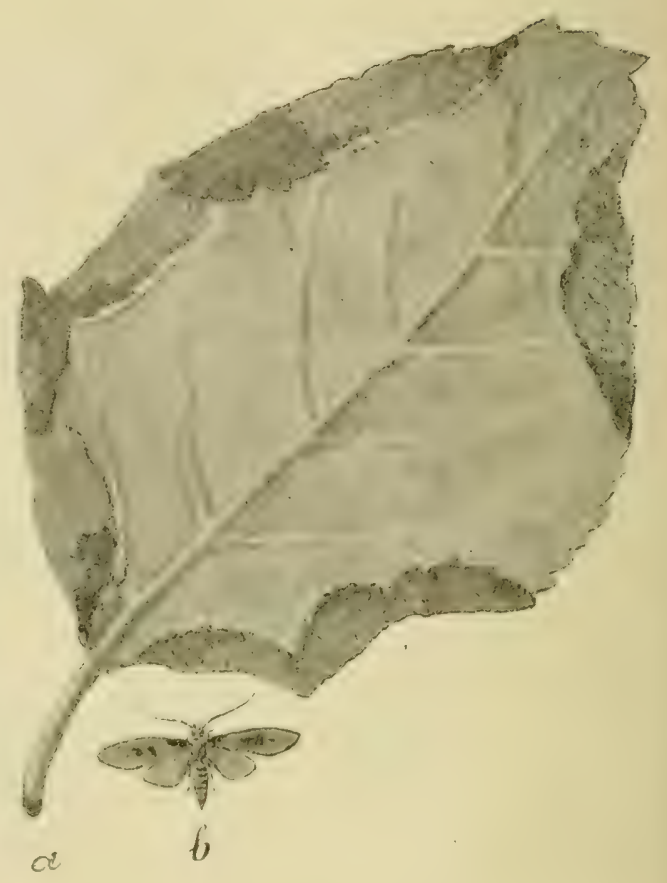

ঔig. 102.

Gelechia rhombella.

4. Tie Zürdenututeruntte (Tinea laricella). Die Rampe

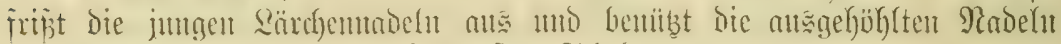

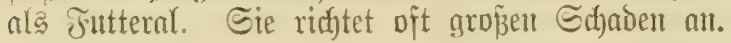

Sduth Der injeftenfrefienden S3ögel ijt bei

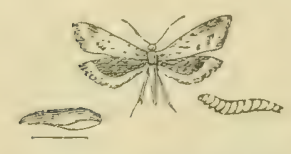

gig. 103. Dic Sormuntte. all biejen 9 Rotten das beite zum Edfube Der gerährdeten \$iflanzen.

4. Die Rormmotte, der weize Sorn= wurm (Tinea granella). Die Zarbe frifít die Getretoetümer Der wberen Gdjichten Der (Setretidehamifell ani Dell Epeidyen all

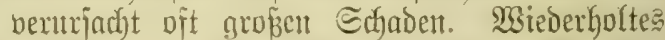

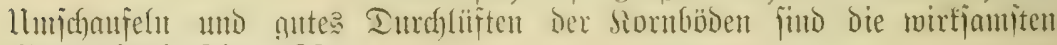

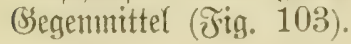




\section{Brommg: Die fauffliulex (Hymenopteren).}

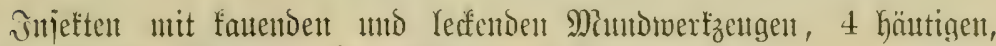
toenig geaderten Frägeln mo bollfonmenex Metamorphoje.

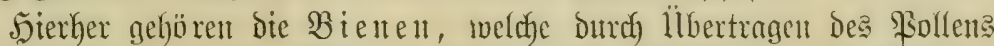
bei Der Befrutchtung Der Rfflanzen, bejonders ber Dbjtbäume, ber Gemilife=

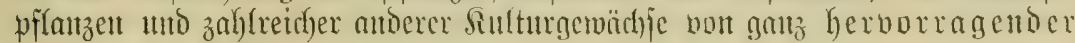
Bebeututg futto.

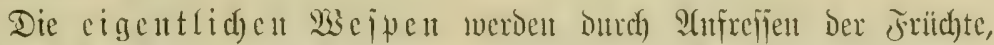
bejonteres Der Wintent mo Weinbeeren, jebr läjtig. Mian Käınt in bie ge=

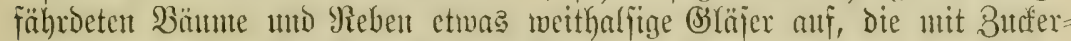

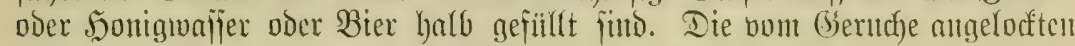
23eipen friechent hittein und ertrinfen.

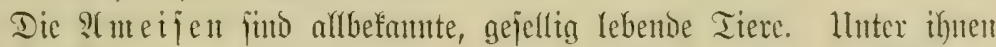

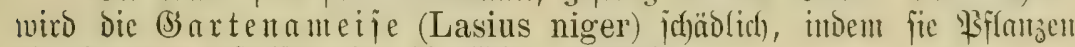
oft rings̆un anfreffen oder bie crobe aufroithlent.

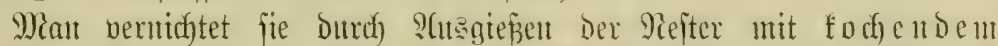

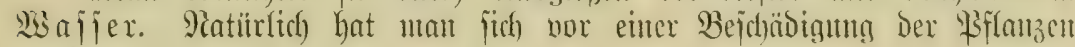
3ll huitell.

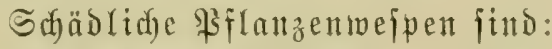

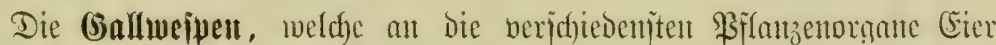

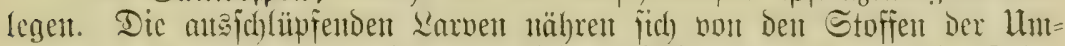
gebung und exzengen Durdh auggejofiedente Säfte, weldye ant bie Bellen

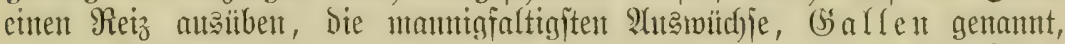
jo die Rojengalfmejpe (Cynips rosae) die jogenanntent Schlafäpfel oder Bedeguare an Rojen.

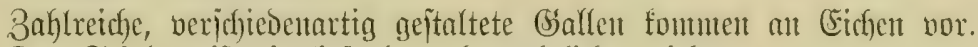

Der Schaden ift ein bejontors beträdhtlidfer nidyt.

Die Blattweipen. Sie enthalten unter allen Familien der $23 e j p e n$ bic

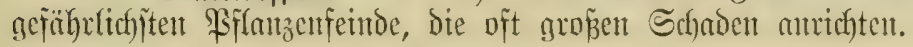

Dahin gehören:

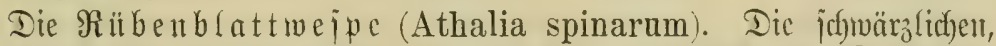
iiff) eimrollenton Rarben tretent in Eommer verheereno an Sohylriben, Etoppelrïben, Meerrettich utno (Sartenampier auf, jäntlid)e Blätter bie

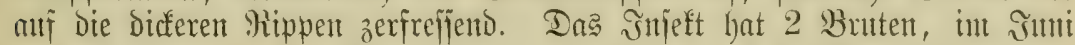

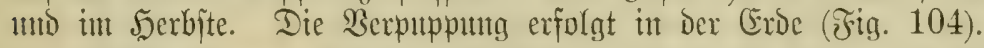

Befämpfunz. Die Rarven füto jorgfältig abzultejen; bie Erobe ijt

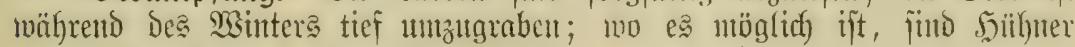

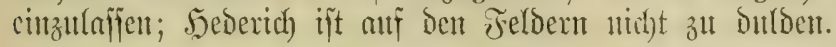

Die gedorute Erobeerblattivejpe (Monophadnus genicula-

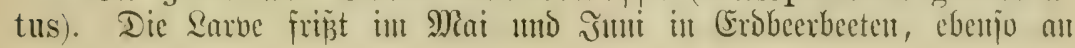




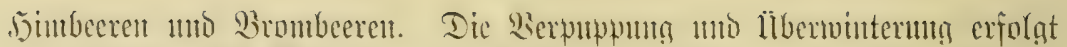

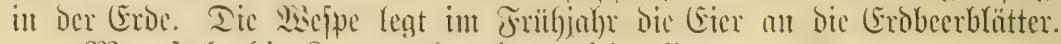
Mian jutche bie garben ab und vernichte fie.

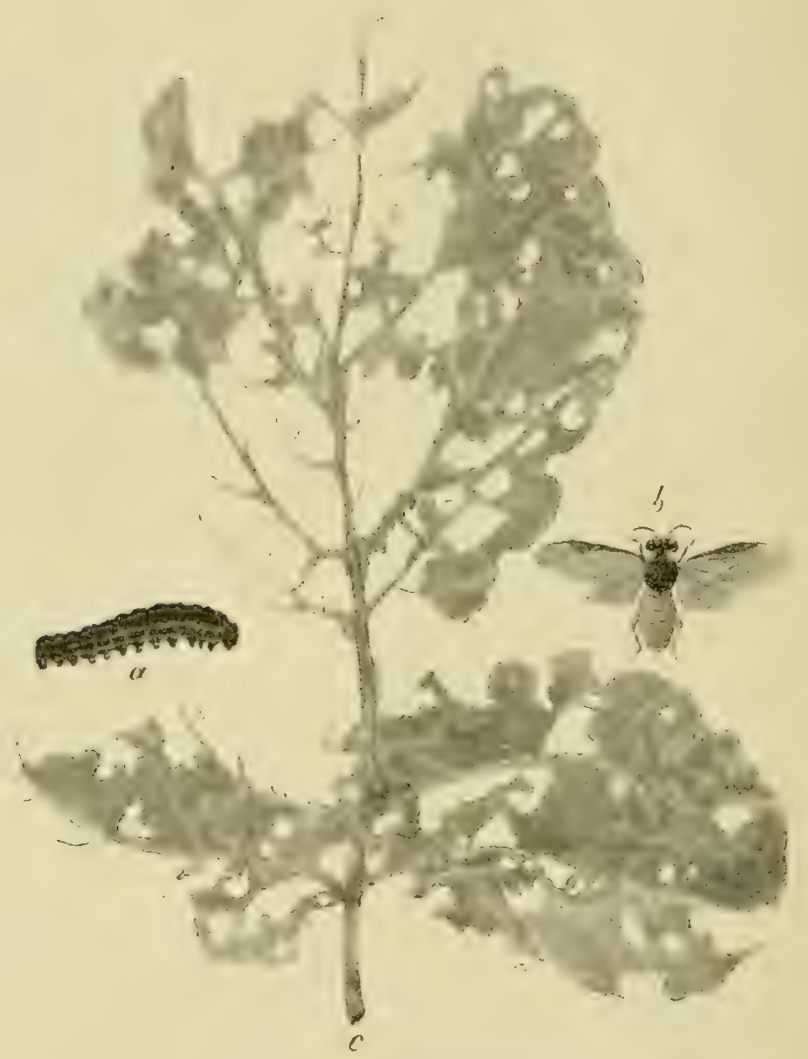

Fig. 104. Milbenblattweipe.

a Rarbe. $b$ Friege. $c$ Berfreffenes gratt.

Die gelbe $\Xi t a d$ clbeerblattwcipe (Nematus ventricosus). Dic

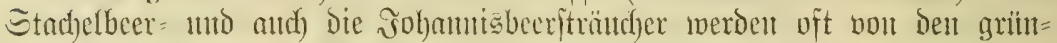

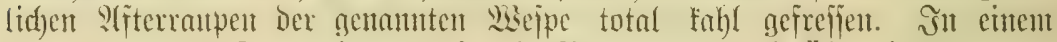

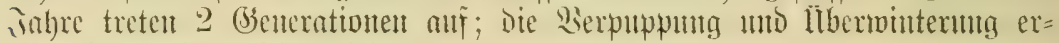
folgt im Bodent (J゙tg. 105).

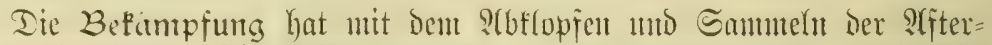

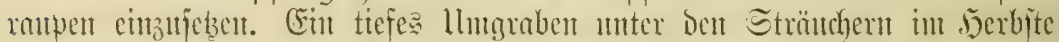
ift gleidffalle etraas won Erfolg.

Dic (betreibehalmmefpe (Cephus pygmaens). Die Larben 


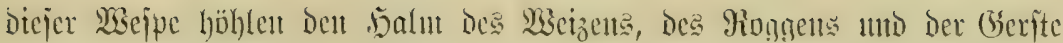

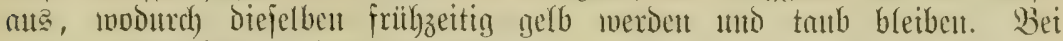

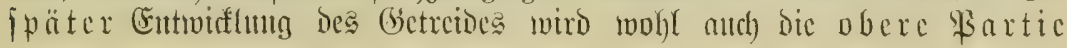

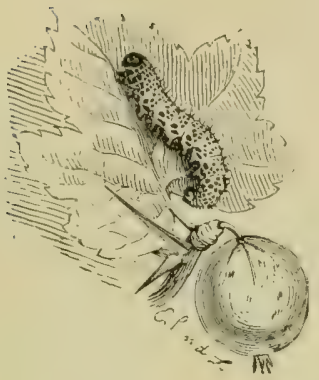

Fig. 105. Gelbc Etndjetbect:\$3lattweipe (Nematus ventricosus). Larve, Wẹpe (Yekztere bergrögert).

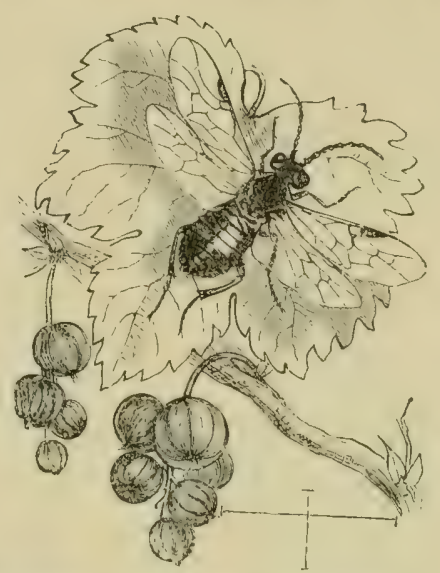

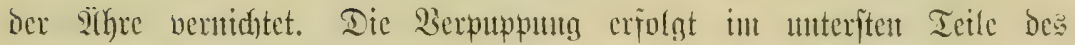
5ralltes, aljo in belt Stoppeltt.

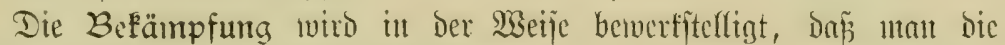
Stoppelut abbremut oder tief unterpfliigt.

Sourtige judäoliche ßejpen find:

Dic gemeine Rieferu=Bufdhorublattucipe (Lophyrus pini)

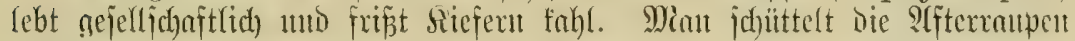

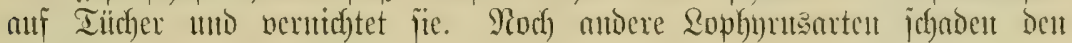
Siefert.

An Den Fidftemmotu fript Nematus abietum, bic bxan

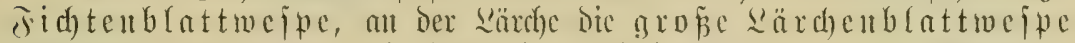
(Nematus Erichsonii) uto bic teitue Sicferublattuefpe (Nematus

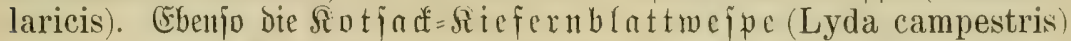
uno bie grof́c Ricferugcjpinftwejpe (Lyda pratensis) an Sitefern.

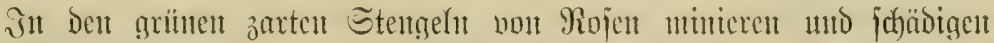

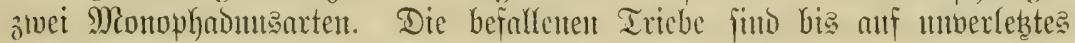

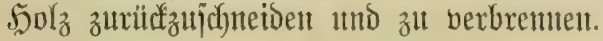

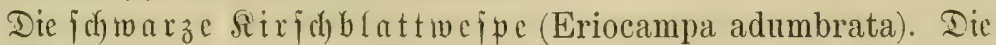

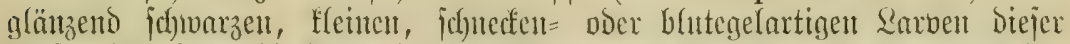

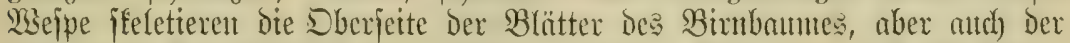

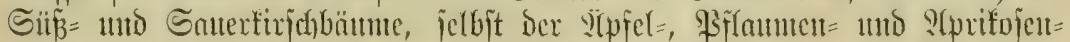

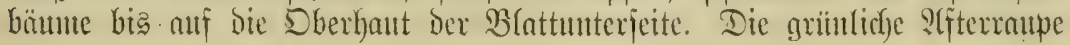




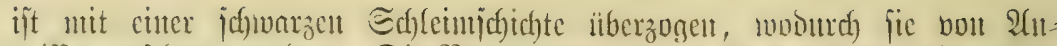

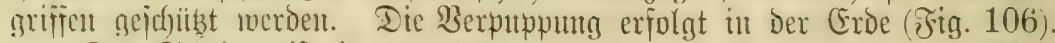

Der Sdjabelt ijt ill ber lebtelt Beit bet ftarfer Butrafume Der Tierc jebre erheblidf) getwordent.

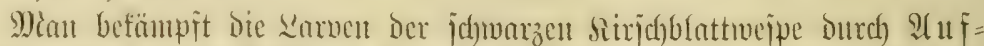

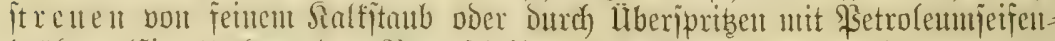

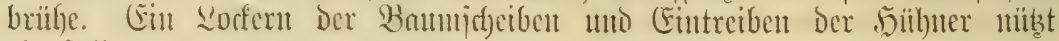
ebenfalle.

Dic Birugcipinjtweipe (Lyda piri) hat beziliglich) be (be-
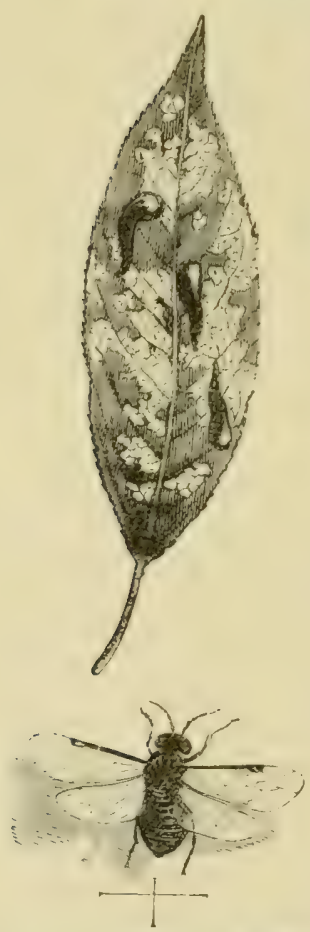

Fig. 106. Edjwarze Sirids: blattweipe (Eriocampa adumbrata). Earve, Weppe.
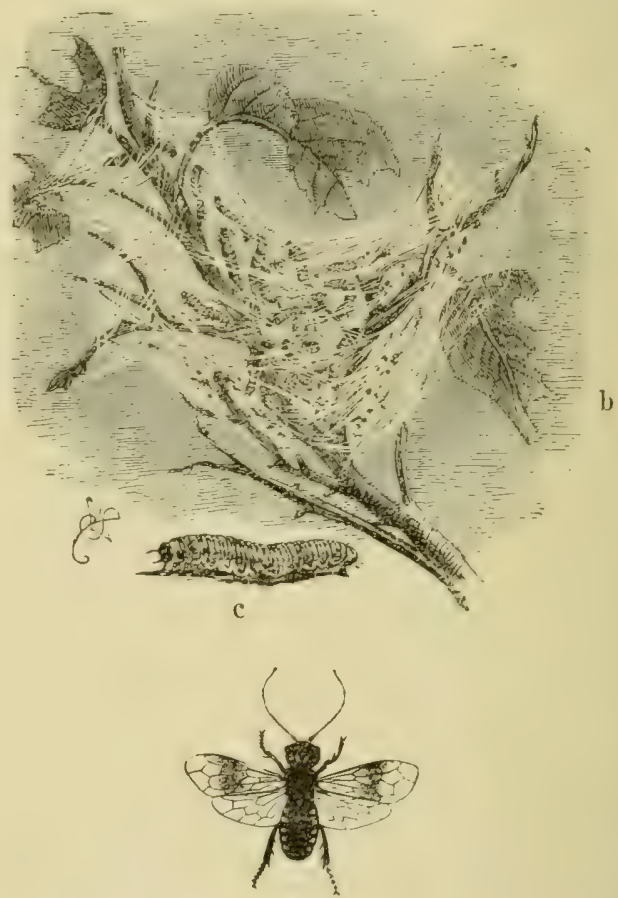

a.

F̛ig. 107. Birn=(Gejpinjtwejpe (Lyda piri). a खeipe, b Beipinit, c Raxbe.

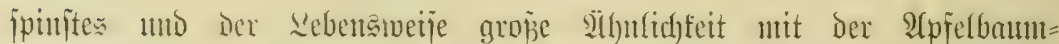

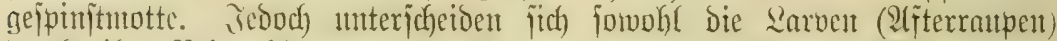

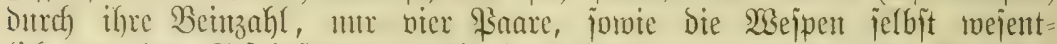

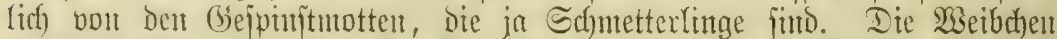

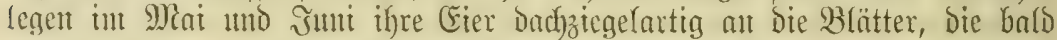

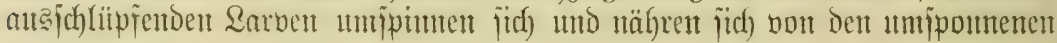




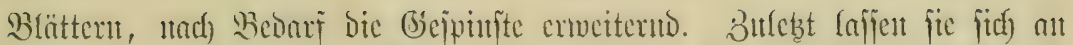

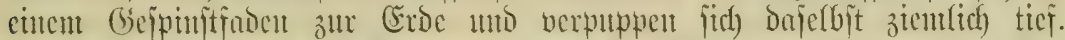

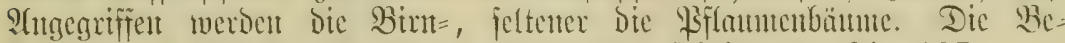

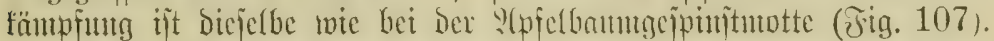

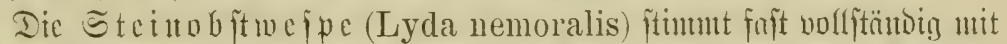

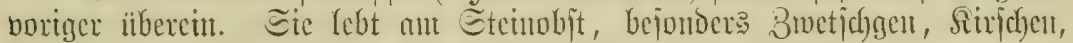

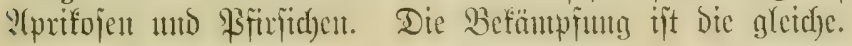

\section{Bromma: Die Bunetfithler miter fliegen. (Dipteren).}

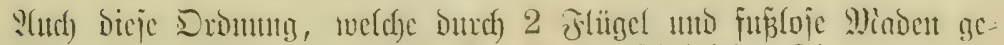

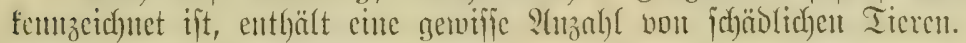

Die ividhtigiten berjelben find:

Dic Ririd)fliege (Spilographa cerasi). Daz

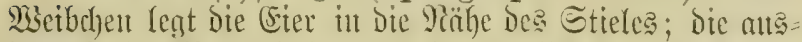

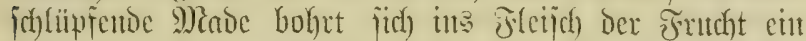

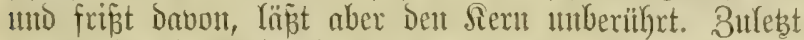

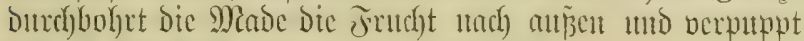
iich) in Der Eroe (Fitg. 108 und 109).

Die Bez̈ämpfuna ijt jobwertị. Mabige Sitrichent bürfent ant Baume nicht hä̈tgent bleibent und muiffen, ment abgefallen, alabald bon bonen aufgelejen ineroen. Die Eroe unter befallenten Sirjobbäument ijt tief un= zugraben, Damit bie \$inppent möglichjt ticf fonmment uns

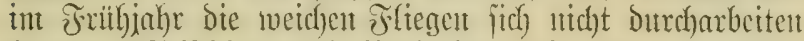
fömtent. Gseip̧blatt unto Berberiben, in Derent Friid)tut die Maden Ieben, finto in Der Nähe der Sirjichbäınte uicht zll Duldoelt.

Die Spargelfliege (Trypeta fulminans). Die

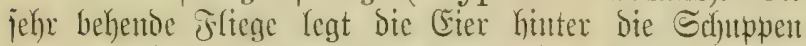
Dex alts bent Boben Kerborfonmenton Triebe. Die

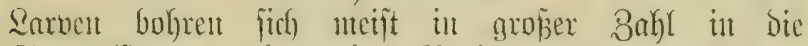
Spargelftangen ein, eine 23erfinmmerung unt $\mathfrak{B e r}=$

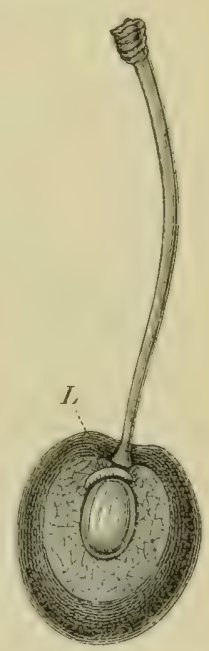

Fig. 108. Siridie mit Der Stivid): fliegenlarue $L$.

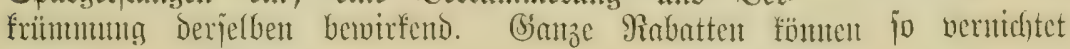
toeroent (J̃ig. 110).

Bepämpfung. Snt Sherbjte noch ober gleid) im erften Frithjahte werben die jtehen gebliebenen Spargel=

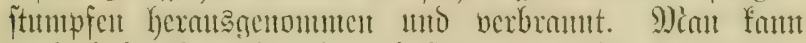

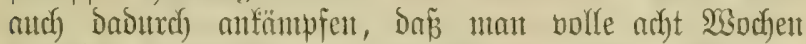

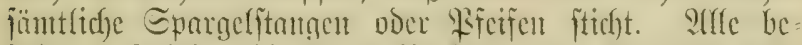

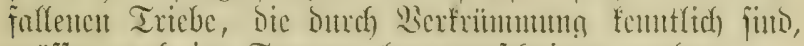

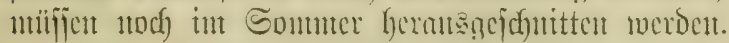

Die Selferieflicge (Piophila apii). Die

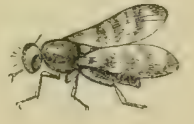

זig. 109. Sitidjpliege. Bergrößert.

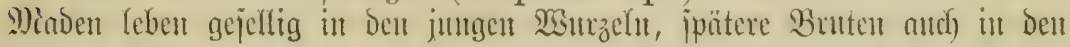




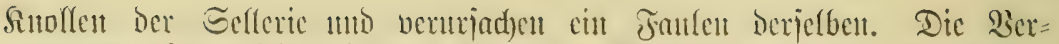

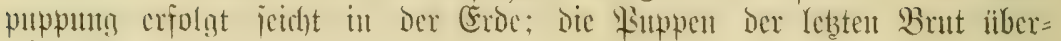
ivinterit.

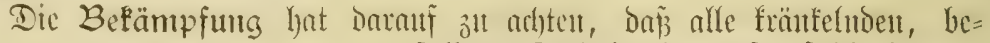
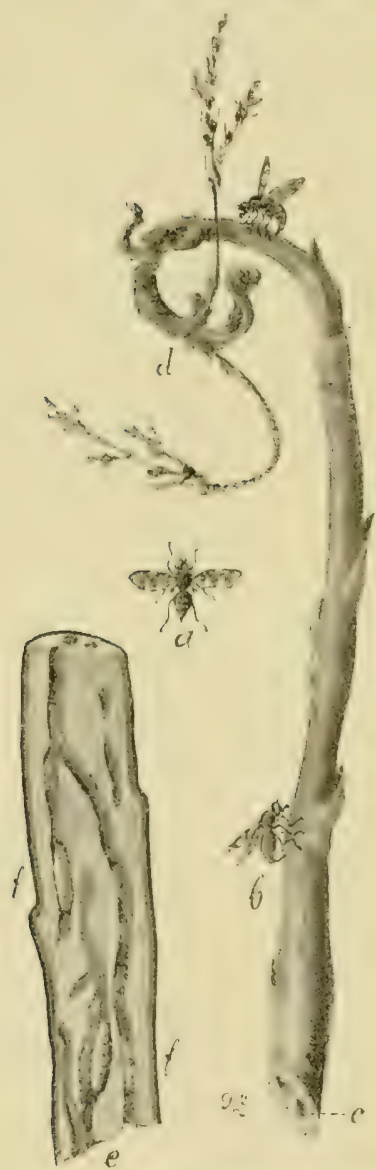

fig. 110. Die Epargelflitege.

a Friege, $b$ Fier regende Friege, $c$ Mabett= gänge, $d$ Verfrimmung ber Stenger, ef łuppert. fallentu Selleriepflanzen jorgföltig hernus= genontmen mo nerbrautht merden. Bil=

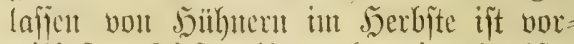
teilhaft. Iiefes llmgraben int Serbite, Wedjel mit Dent Dumetiex und bet ftartent

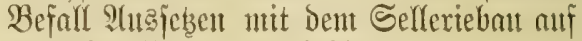
2 Jahre ift anzuempfehlen.

Dic Miöhreufliege (Psila rosae) verurjadyt bie Eifenmadigfeit Der Miöhren (nelben Riben). Die Miöluren= fliege legt im Frillyjahr ant bie Miöhrent Inten bic (Fiex, dic aubgetrodbenten Mia= Dest bohrent fid it bie Wantzel cut, worauf die Pflanzen meift melten mo nidgt jeltent gantz abiterben. Die Mraben ver= puppent fich in ber (Exde oder felbjt Hod) ôun Teil in Der Miobremumrzel fteffent. Edhout und 10-14 Iagen erjodjeint bie z'veite Brut, bet jehr warmem $\mathfrak{B e t t e r}$ jo= gar cite britte, it ber gleidyen Meije icfabento. Dic llberwinterung exfolgt in Der Eroe in \$itppenzuftant.

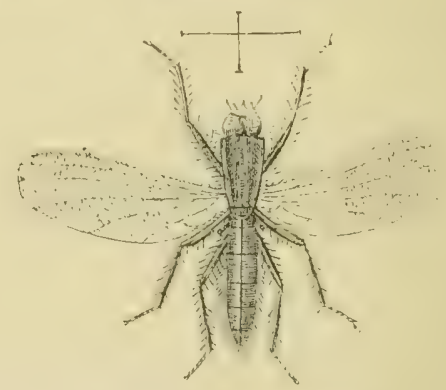

Jitg. 111. Die Rettidjflicge.

Die Befämpfung hat Darañ ăl adhteu, Dañ cijenntadige Mröhreut

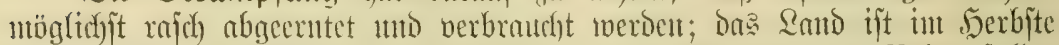

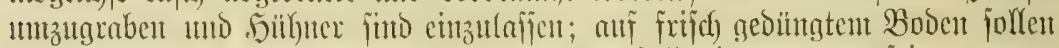
Möbrent nicht gebant meriont and bie Sant foll nitht zal eng jein.

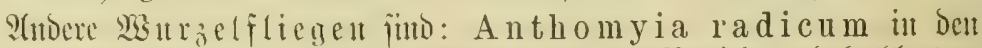

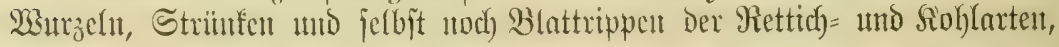


im Siohlnabi, oft hälfig; cbemp bie Siohlfliege (Anth. brassicae) in

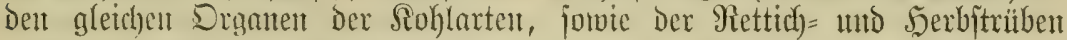

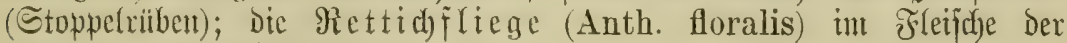
Rettiche utb Rabiesdjen (Fig. 111).

Die Befämpfung ît bic gleiche wie bei bon vorker genannten 2.rten.

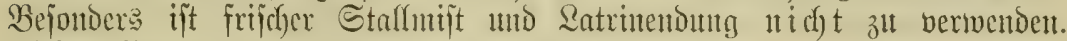

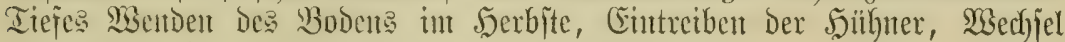
Des. Sodents in jedent Jahre ift von Bebentutng.

Dic (Setreibcfliegen. Sie treten bald als 3eritörer ber jungen Saaten

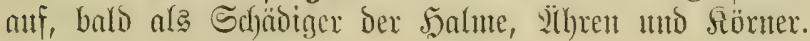

Steher gehörelt:

Die Friffliege (Oscinis frit). Die jungen Saaten melfen im Serbjt oder jterbent gantz ab. llnterjudcht man die Piflänzchen, jo findet man bei dem $\mathfrak{W}$ urzelfnoten hinter den Blatticheidon erjt ein voer einige Maden, jpäter die

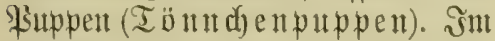
Frühling werben bann bie Sommer= getreidearten unter ben gleichen $\mathrm{E} r=$ fideinumgen angegriffen. Bum britten Mate uniro in Sonmter das Som= mergetreide (nicht das Winter= getreide) Gefallen into zwax, wem 3. B. Der Safer beim (5rjucinten Der britten Gseneration noch junge Iriebe hat, jo weroen bieje wie friifer bejdjäbigt, voer es merden

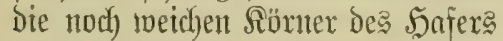
แmb ber Gierite befallen umb ber= nichtet, bie Spelzen entruidfeln fidch jedod) normal, jo Daj man den Silgren uns Ritpent Den Befall nidyt ammerft. Die siffrdyen fint oben taıb (Fig. 112).

Die Belämpfung bejchräntt iid) Daxauf, Das Mintergetretioe io ipät als möglich anzutbauten.

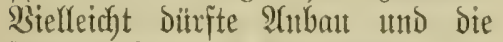
fpäter erfolgenoe Bernicftumg Der befallentell Saat bont Srfolg jein.

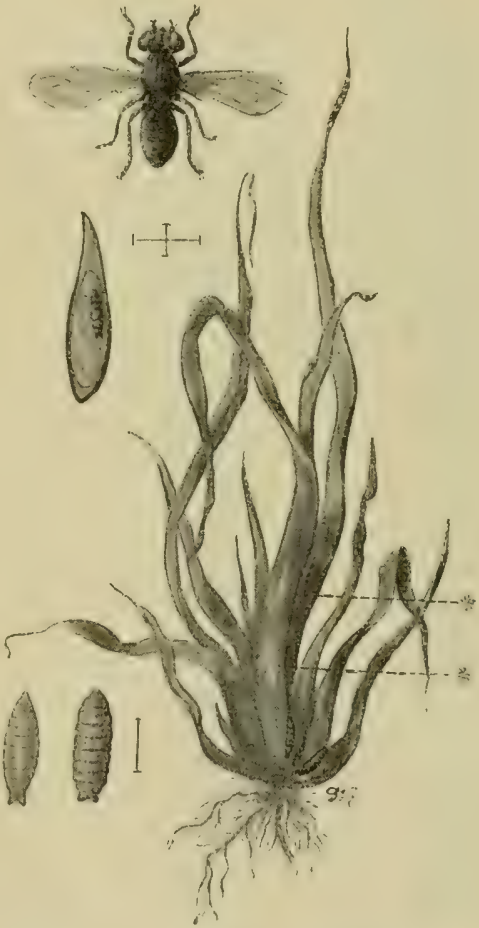

Fig. 112. Fritfilege (Oscinis frit).

Die fletue Jrtfflege (Oscinis pusilla) verbält fưf älunlich).

Die Seffenfliege ober Dex (jetretbeverwiitex (Cecidomyia

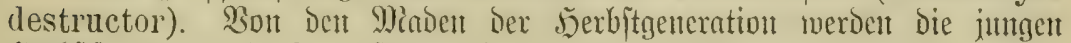

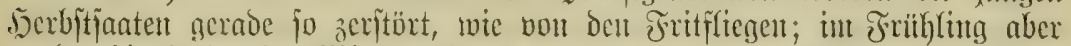
iverden Die Salme Des Winterweizens mit Fiern belegt; Die Mane zernagt den 


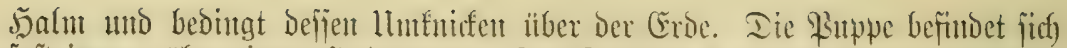

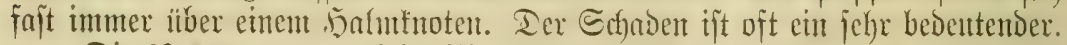
Die Befämpfung. Dic Misinterjaaten find möglichjt jpät zu bejtellen;

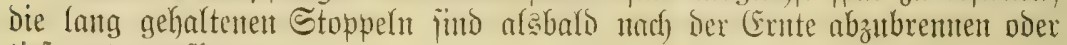
tief unterzupflitgen.

Die Şalmfiliege (Chlorops taeniopus). Dicje Sllicge befällt mux

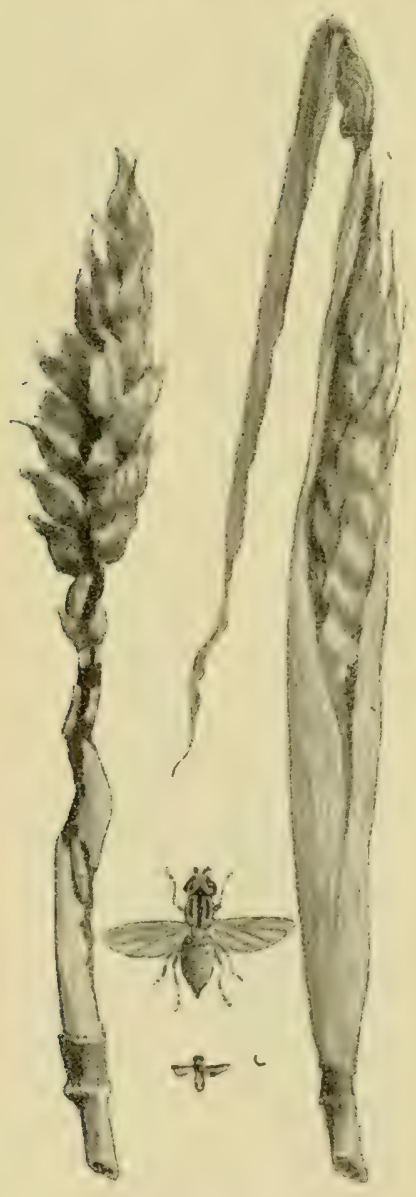

ชิig. 113.

(5etrcibebnamiliege (Chlorops taeniopus). den Meizen unto jeltener audch bie Gerjte. Dic Made Der Serbjt= generation befällt die jungen Meizenpflanzen in ber gleichen Weife, wie bie Fritffiege. Dagegen ijt Der Sidnonen, weldhen Die Sommergenteration anridgtet, jehr charafterifitijh. Die Fliege legt bie Sier ant Den Brumb der ïhre und Die Made fript jich bou da eittent (Soang bis zum oberjtent Sinoten Gitub. Siter exfolgt aud bie $23 e r=$ puppung. Diejer Jrẫ bewirtt cime Berfiluzıng Dę oberiten 5 alm= gliedes unter gleidyzeitiger 3 'er= bidutug; Die Ithre bleibt in ber Blatticheide itecfen. Man nemnt bieje Siranffeit "Sodagra oder (bic) t" Des Wetzents (Into ber (Serfte) (Jig. 113).

Befämpfung. Die Saat ijt im Serbite möglicjit jpät uno in Jruiblitg möglichjt friibzeitig zu bejtellen.

Atud) nod) einige andere, bett Frit = แno Şalnffiegent ähnltidge aber jelten vorfommentoe ârten meroent beobactstet. Figre $\mathfrak{B e}=$ fämtprimng hat nach ben angegebenten (śnundiäben zu exfolgen.

Die Mituicrifiegen. Die Lax= ven Der Betreibeminterfliegen pinx.D.z, frefien im smtmern Der $\mathfrak{B l a ̈ t t e r ~ S u a ̈ n g e ~}$ (anth) Motten aus Der Silafie Der Erfymetterlinge bertriachen ähnliche Bejöjübigumgent) ober aröß̈ete Stelleı aus, bie unit Sot bejekzt fints. Sift findet man nuch die Miadent barit. sift eine größere 3 aht jold)er Minengänge an cintem $\mathfrak{B}$ (atte vorbanden, jo

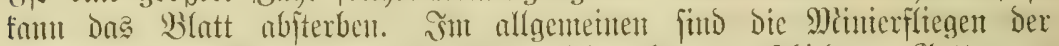
Getreidearten nidat befonders jöholid). Sie gehören verjabiedenent Sattungen 


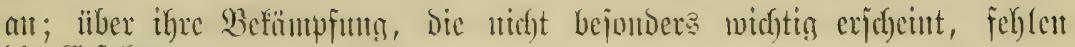
dic Exfahrungen.

Die Runfelfliege (Anthomyia conformis). Cie frižt vom Jumi

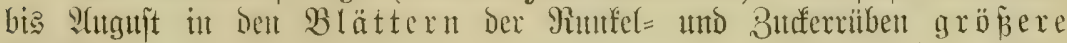
Stellen ans, iiber wedchen bie blafin abgehobente Sberbant liegt. Der Edjadent ijt int Der lebent Beit nidyt unbedeutend.

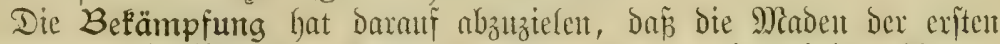

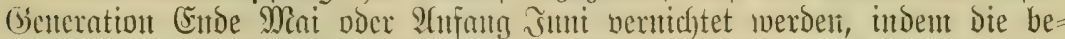
jallenen Blätter jorņ̧ältig abgejudgt, entfernt und berbrantut werbent. Da die Pisppen in ber Erde iibermintern, ift ein tiefes llmpflitgent nad) Den Ubernten anzuraten.

Die Erbjentuierfiege (Phytomyia pisi) mituert it dent Silättern Dex Erbje.

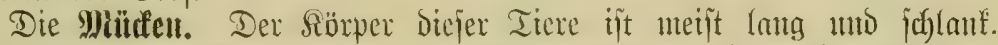
auftreten.

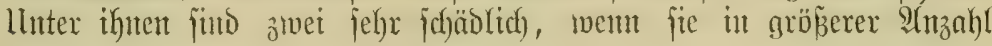

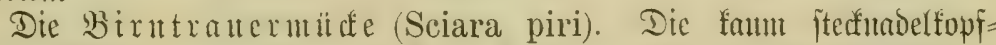

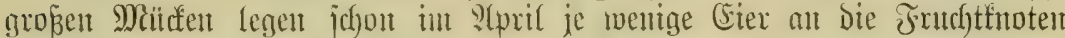

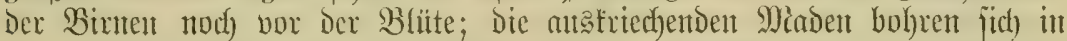

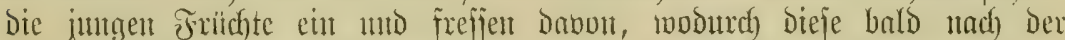

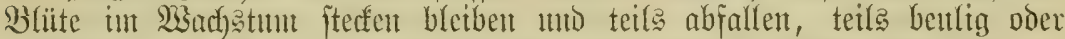
geichwärzt an $\mathfrak{B}$ annte bängen bleiben mo beint Durchichneiden jich als mabig ermeijen.

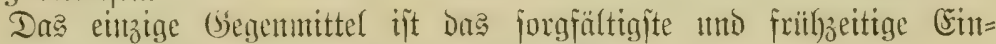
janmeln und Berbremten Der befallenen Jrü̉dte.

Sentger zablreid) tritt cine andere M)iidfe, Cecidomyia nigra, an Bimen anf, welche bie SBinten voute an Sieldye Durd) ihren Fra be

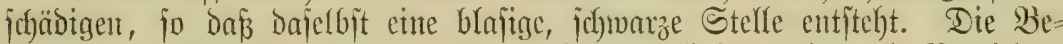

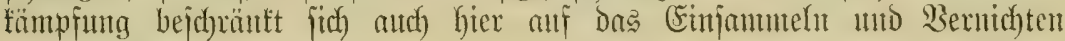
Der befallenten Friad)te.

Die Sadjnafen. Dic bis $20 \mathrm{~cm}$ langen, graten, wummï̈rmigen

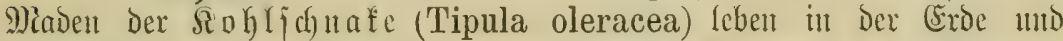

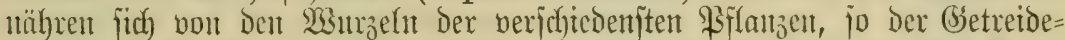

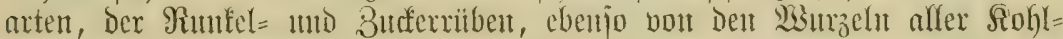

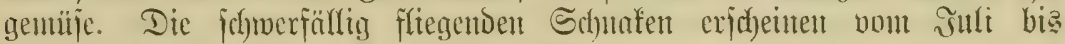
Dftober und regent ifre sier it bie Erde.

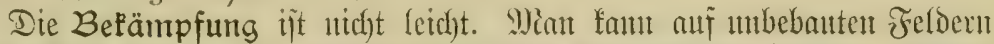

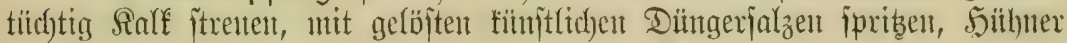
cuntreibent, bejontoers anf das eben gegrabenc Gartentland.

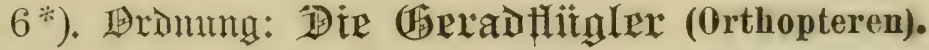

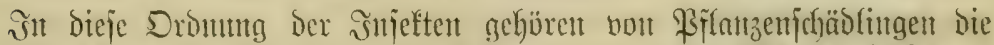

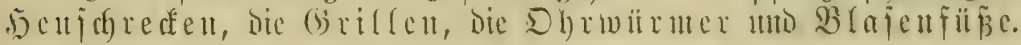

*) Die 5. Sromung: "Dic Slebrlinglex", wixd, Da fie fente Exholinge ent= hält, hiex nicht berïcfitchtigt. 


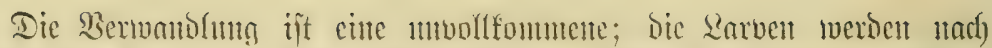

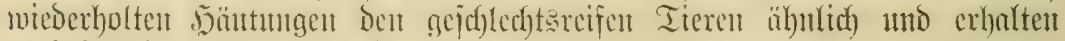

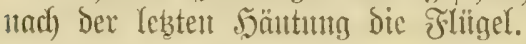

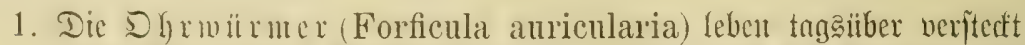

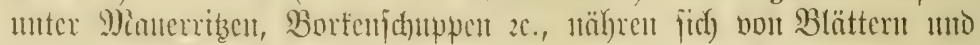
Fritchten, folfen aber and Tiere antgreifen 140 verzelyren.

2. Dic Balajeníḯ (Physopoda).

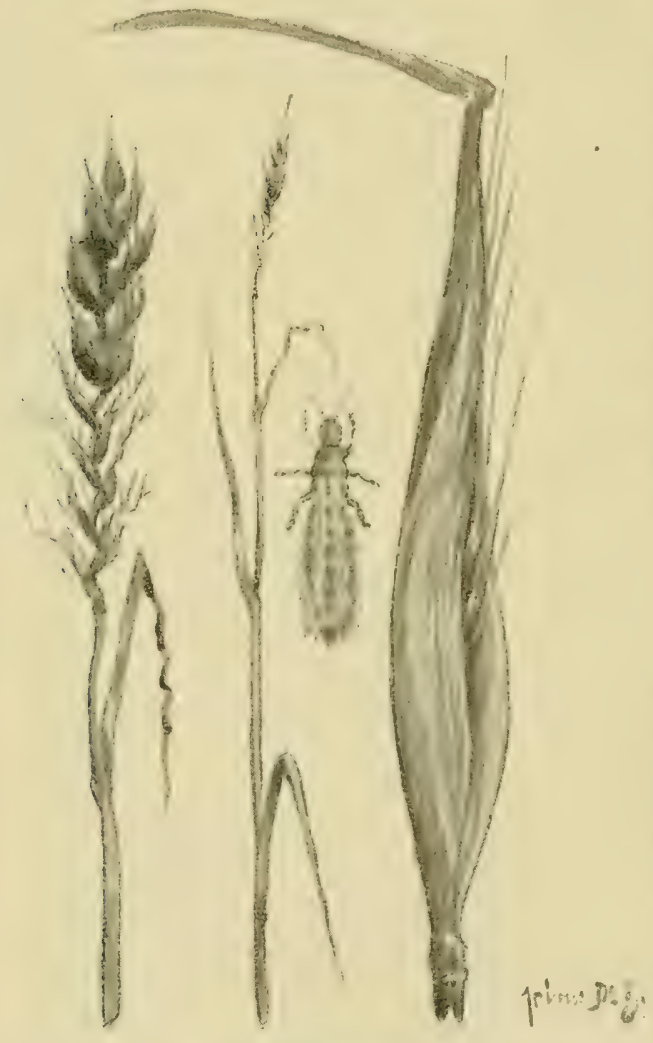

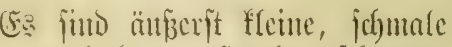
แnto lantg geitrectéte, ichtwärz= (ich) gefärbte Imieften, welche in Treib̧äı jern an B̉lättern, utud bejonderg hinter Den oberiten Brattidyeiden Der betreidearten ber= ftecft leben uno bie uteren Teile Der İlgren bernichten. Die Rarbent finto rotgelf. Wor Der Ernte verlaffen bie Blajenfiine die BFfanzen Into itberwinter" it Dett Stoppeln voer in jonftigen Siflanzenteilen uno unter Erojidjolfert.

Şieber gehört Der

(3) treideblajenfuf (Thrips cerealium).

Ein Begenmittel ift bei Der verborgenen Rebentweife diejes Błafenfubes nicht an= mentbar. Miant hat mur Darauf Kinzumirfen, daß̧ die İibren fidf rajd) entrvidfeln. Sbemp fino Die Stoppeln alsbald tief untexżtpflügen (Fig. 114).

Der Treiblats=

刃ig. 114. Getreibeflnfenjut (Thrips cerealium). morrhoidalis) Yebt ant blajenfup (Thr. hae-
morrhoidalis) Yebt ant
Grlaßhaubpfrnzen. Bejpribent

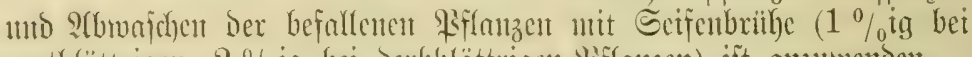

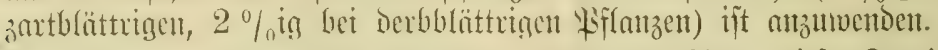

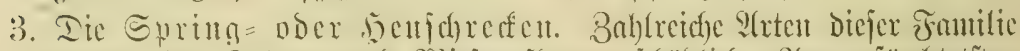

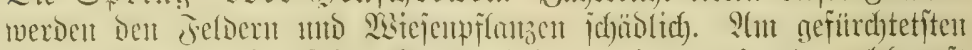

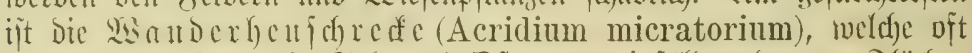

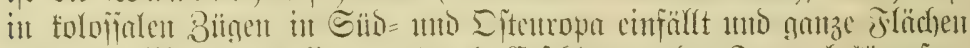

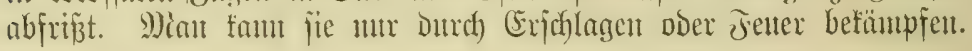




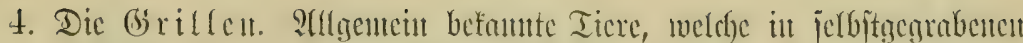

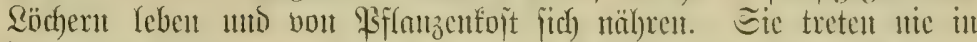

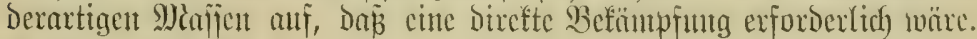
Dafiut gehört bie Jeldgrille (Gryllus campestris).

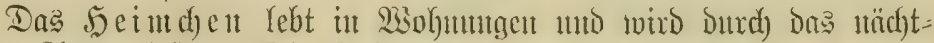

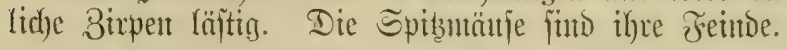

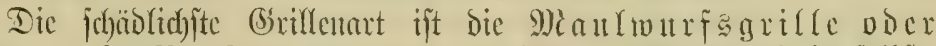
Werre (Gryllotalpa europaea), weld)e anf sitturtoulo it jelbĭt=

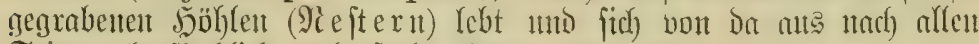
Seiten obcrfläd)lich) barlanfende Siänge bohnt (Fig. 115).

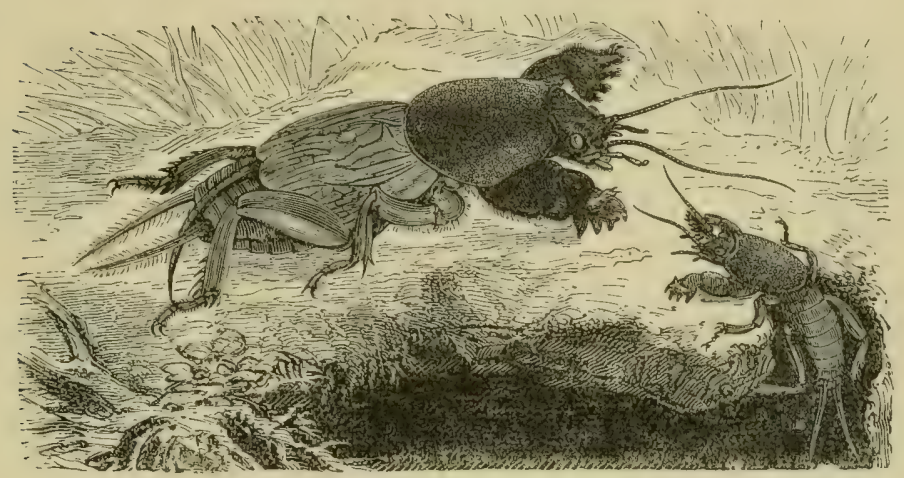

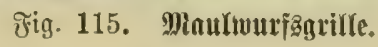

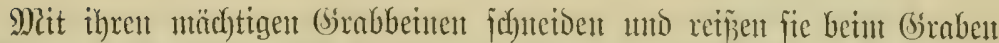

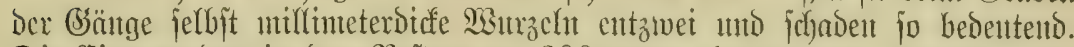

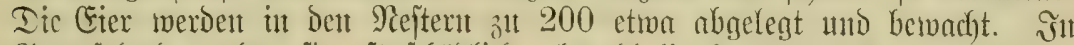

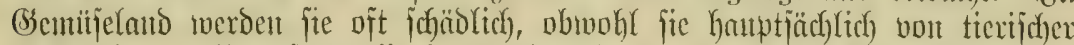

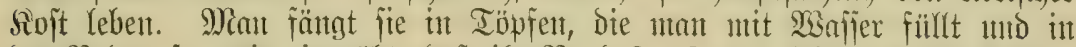

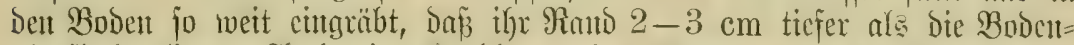
oberfläche liegt. AYtch eine Sialfung Des Bodens ctiva 40 Bentuer auf

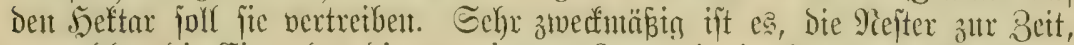

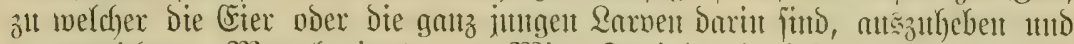

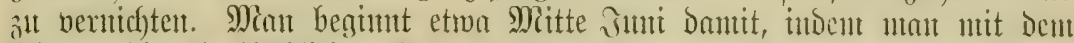

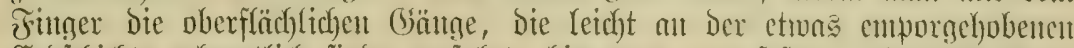

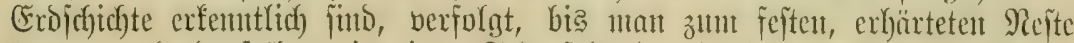

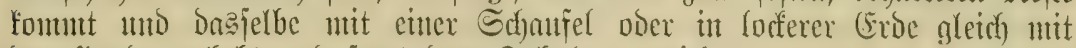

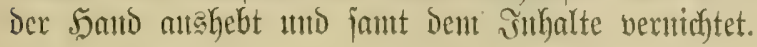

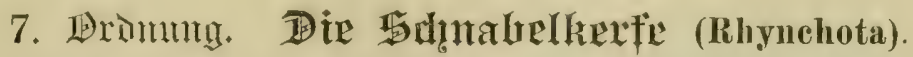

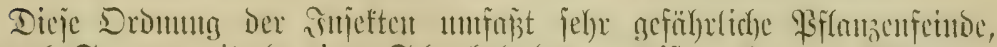

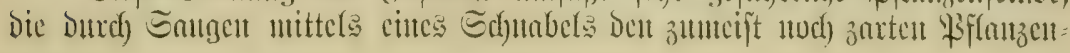




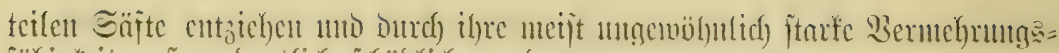

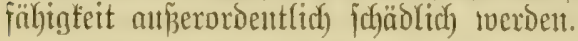

Syieber find zu rechnen:

1. Die Bitaden.

2. Die Manzen.

3. Die Blattflölye.

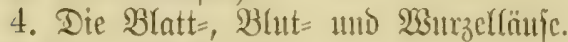

ว. Die Sdjild läuje.

\section{Fantilte.}

\section{게 $\mathfrak{i} \mathfrak{e} \mathfrak{B} \mathfrak{i} \mathfrak{a}$ i $\mathfrak{e} \pi$.}

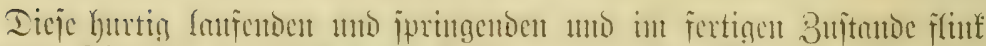

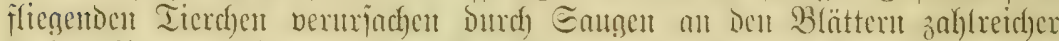

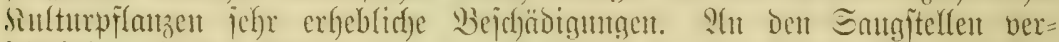

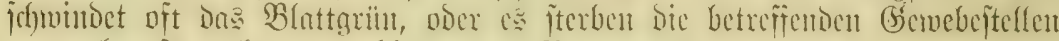
ganz $n \mathfrak{b}$, oft verfiinmern bie ganzen Blätter.

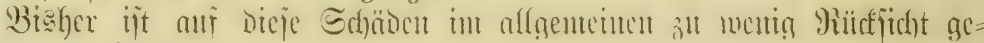
nomment wordent.

Die widftigften $\mathfrak{A}$ rten fino:

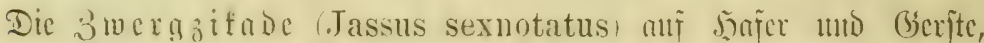

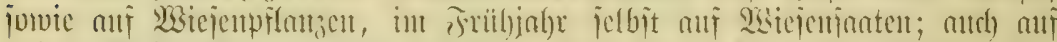

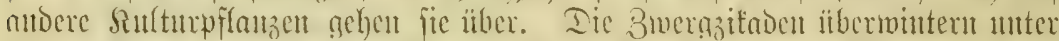

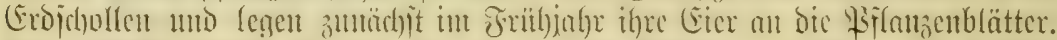

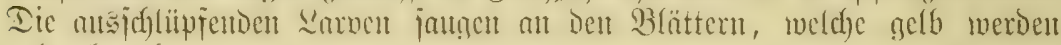
utto abtrocfittett.

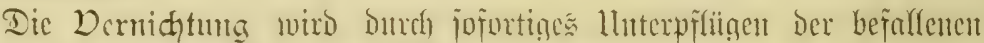
Gtellen Der Bietreidefeldoer betwerfitellight.

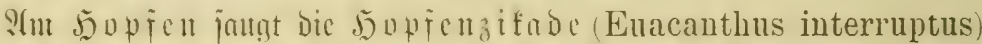

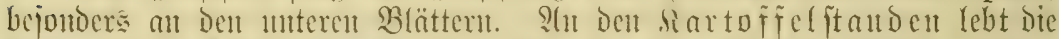
Siartofielzifade (Typhlocyba Solani), Dic Sin̈uelfrantheit herbor=

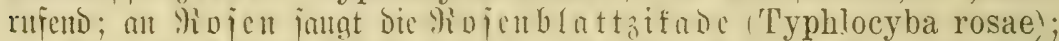

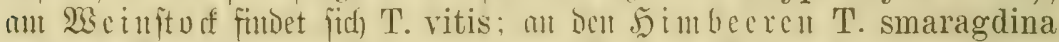

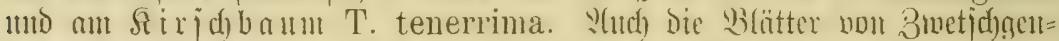

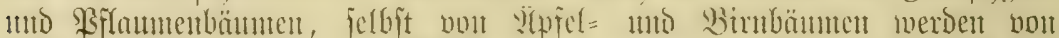

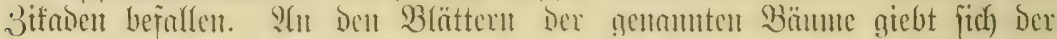

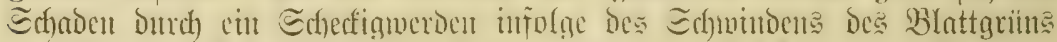

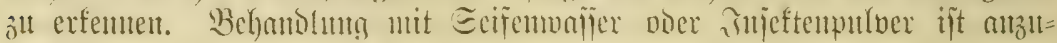
emprehlent.

\section{Iamilix.}

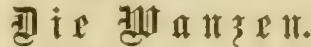

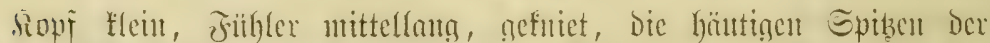

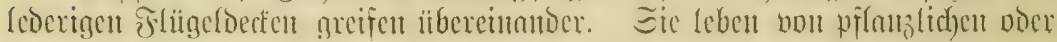
tierijhen Stoffen. 


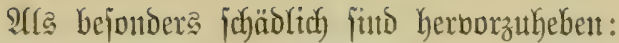

Dic Siolflwaltze (Eurydema oleraceum), Durd) Eaugen an fohl=

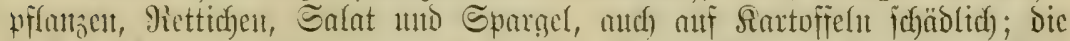

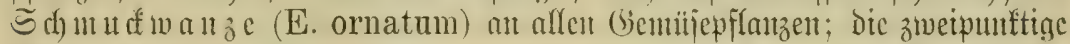
Wiejentwaje (Plyytocoris bipunctatus) an Ropf = แno Blumentohl, cbenio an Sartoffetu; Die Sartoffel manze (Lygaeus solani) an Rar= toffeltr.

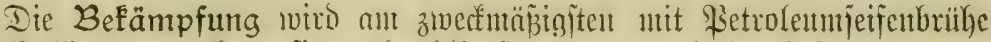

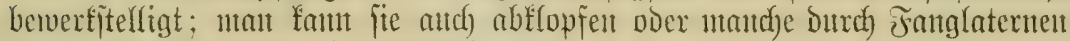
herbeilocten und bann fangen mo töten.

Dic நopfentwanzen werdent gelegentlid) anjerordentlich joüolid); Inter ifnen ift bie gelbliche 5 opfentwa $n \mathfrak{c}$ (Capsus vandalicus) be=

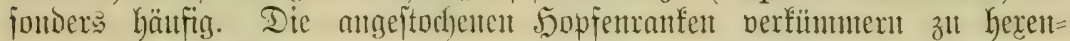
bejenartigen Wudcherungen, woburch bidftitehende Bweigbiijdyel entitehen.

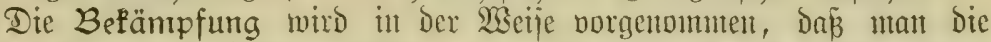
Tiere alf geteerte Bretter abflopft แnto itebejondere bic 5opfenitangen

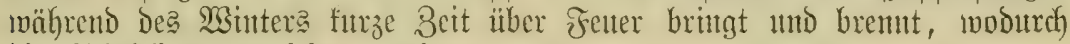
bie Schäblinge vernichtet werden.

\section{Tamilit.}

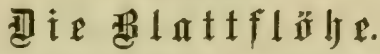

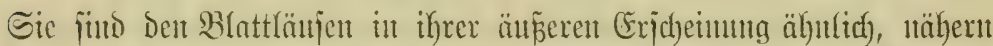

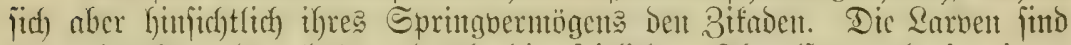

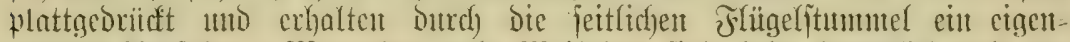

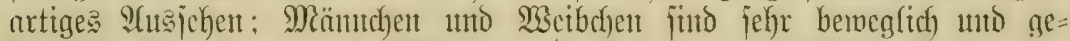

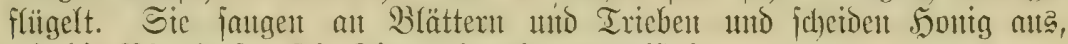
vie die Blattläuje. Die Iiere übermintern meijt in

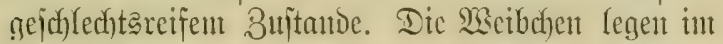

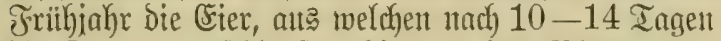
Die Rarbent anteffhlitpfen, bie bon dent Brättent an bie Broeige mandern und fid ba feitjaugent.

Befämpfung. Man bernichtet fie ill Der gleidjen Weije wie die Blattläuje.

Dic befantejten Sitten finto:

Der grof́e Birnfanger (Psylla piri)

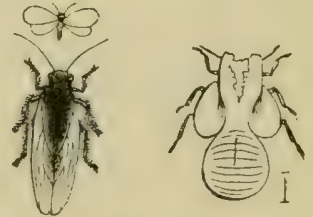

ซig. 116.

(Broper Birmauger.

¿arbe uno fertigę Iier. alt Birnbäument แno ber Âpfeljauger (Ps.

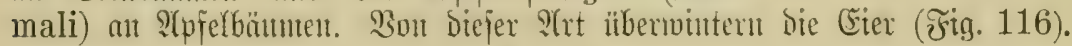

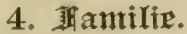

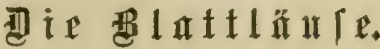

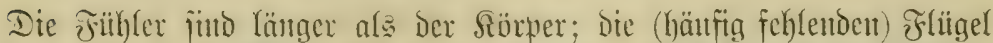

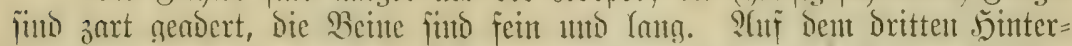

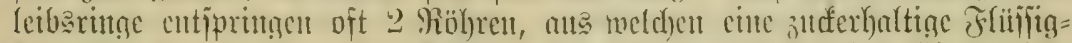

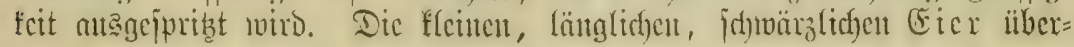




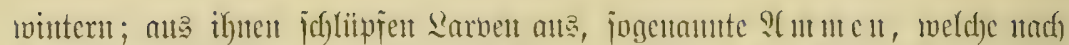

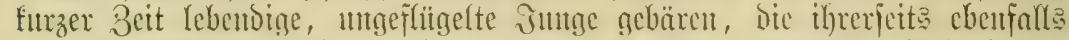

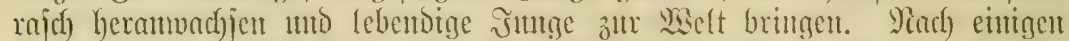

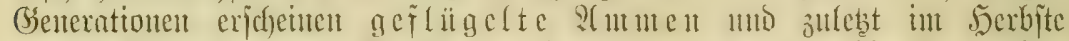

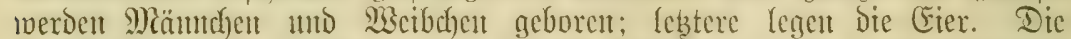

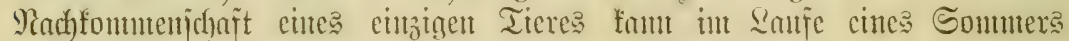

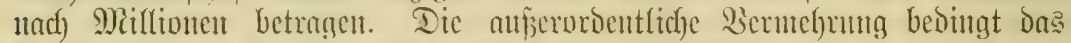
folonienfürntige 3ujanmenfeben der Blatt= แmo Bhttäuje.

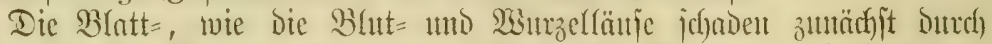

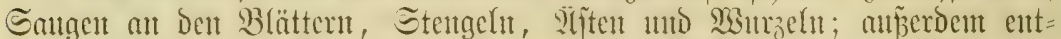

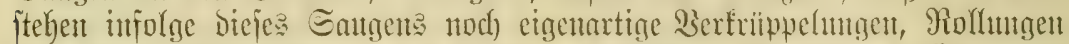

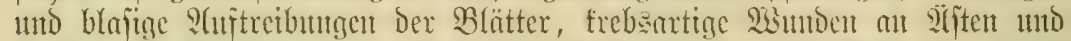

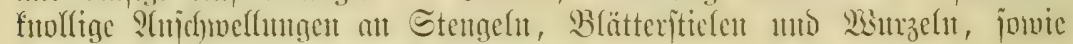
gallenartige Mipbiloungen ant Sinvipen.

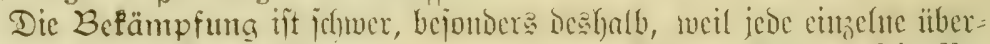

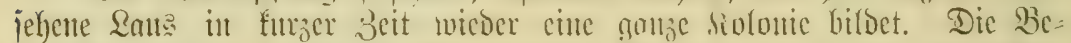

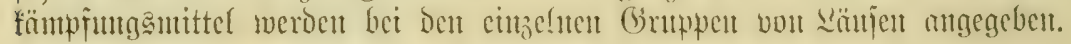

\section{a) Die eigentlichent Slattläuje.}

Die Befümpfungemittel ber eincutlichen Bifattlänc fint folgendo:

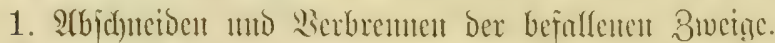

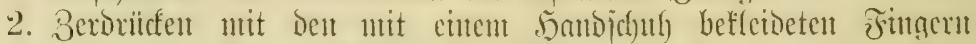
muter möglidyjter Sdyoum Der Piflanzenorgane.

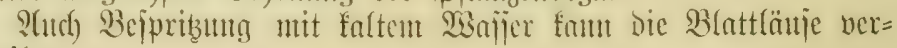
treibett.

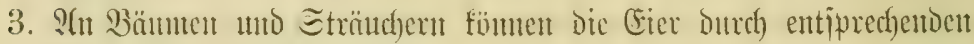
Sialfanitrid) erfitift merden.

4. 2fmvendung von כinjeftempulver.

5. Befpribung mit Sd)mierieifenlöjung, $2{ }_{2}^{1 / \%} \%$ ig.

6. Die Neßjler'jule Iinftur.

7. Iabafbrithett.

8. Betroleumemulfion.

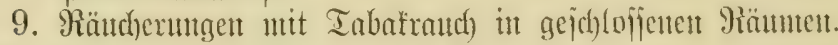

Die roidfigften Brattungen und Arten funt:

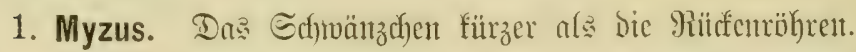

a) Die solyantisbeerblattlaı (M. ribis), ant Dett Blättent ber Sohanniabeere nach Der Dberjette zul blafige, oft rotgefärbte IYutreibungen bildento.

b) Die Sitrid) blattlatz (M. cerasi), die Blätter ber Trieb= ipizent zurülftrollent.

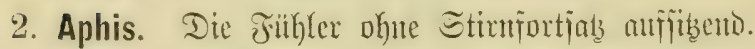

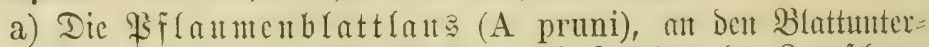

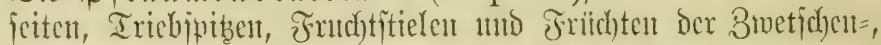
Bffaumen= แก๊ 2rprifojenbäıme lebento. 
b) Dic Bfirficbblattlaแs (A. persicae) ant Bffirfichbuntuc an

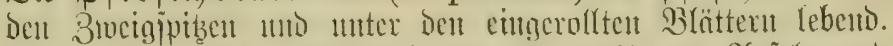

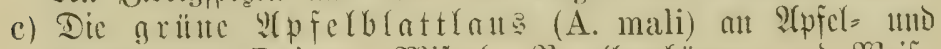

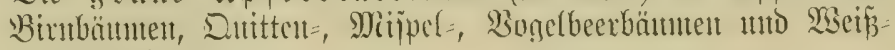
Dormifträududerut.

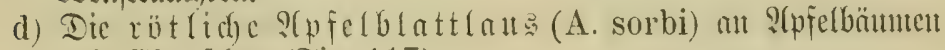
unto E⿹berejhen (Jig. 117).

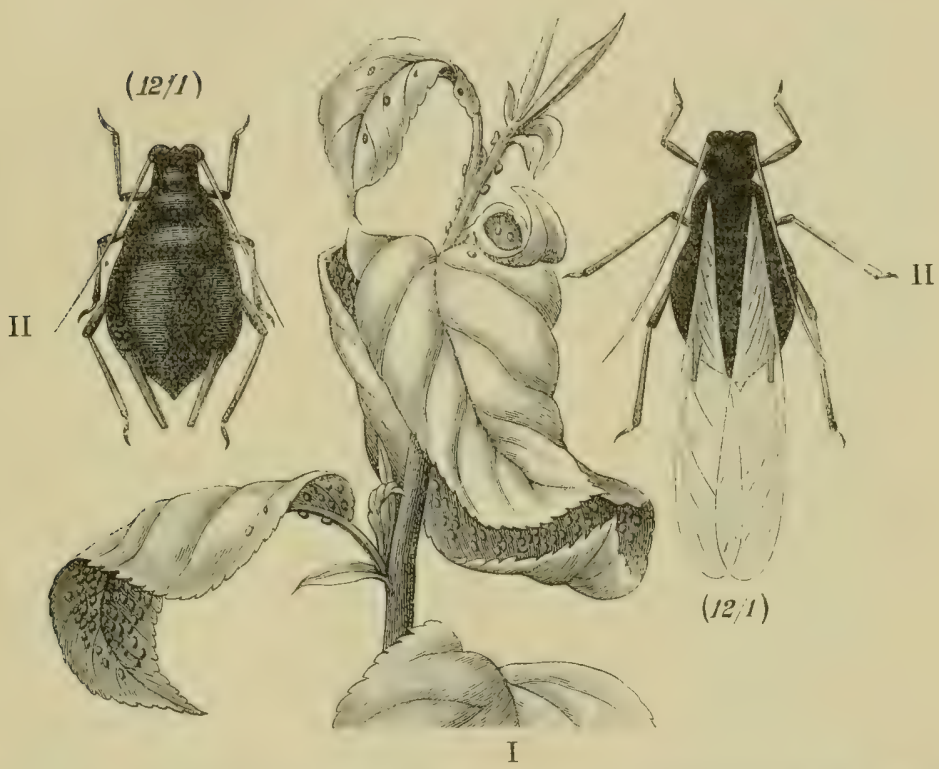

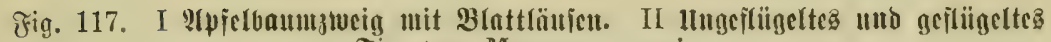
Iicl von Myzus cerasi.

e) Dic Stadbelbeerblattlaus (A. grossulariae) ant dou

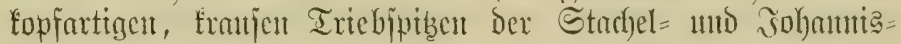
beeriträutcher.

f) Die Rofenblattras (A. rosae) an Rojen, grin.

g) Die łferdebolyenla bohnett ıno zahlreichen anderen Biffanzent.

h) Dic It ruenblatt Der litmenblätter.

i) Die 5aferblattlans (A. avenae) an Şafer, Gerfte แnt Meizen.

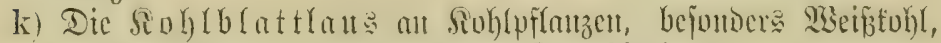

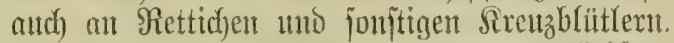

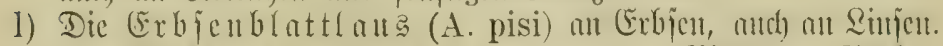

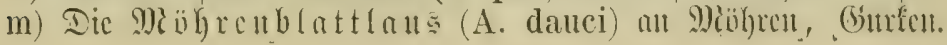


n) Iic 9$) i$ obublattlate (A. papareris), cinc ber gemcinften Ifrten, bie aujer bem Mohn nod) an Den meijten Bemitje= Hffanzen norfonmut, io au Mannolo, Fieterfilic, fierbel, Miöbre,

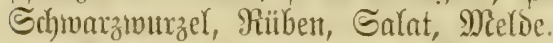

o) Die Sartoficlblattlans (A. solani) an Sartofieltr.

p) Die giclfenblatt (aus (A. dianthi) aut Relfen.

\section{Pharodon.}

Dic 5opfenblattlau (Ph. hmmuli) anj Dent .̧onfen, (joll citten Ietl des iahres aud auf Eteitobjtgehölzent (eben).

4. Siphonophora. Die Jithler aui eintent Stimifortiab.

a) Tic (Getreibeblattaus (S. cerealis), dic Eommeroümc verurjad)end. Iie Iiexe lchen inmerbalb Der Blattïchetoen.

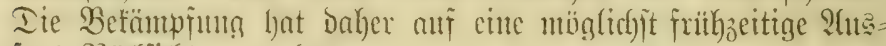

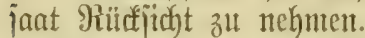

b) Iic vobantisbectuojpenblattans (S. ribicola) an Den Iriebipiben Blätterbiifdjel vernijachento.

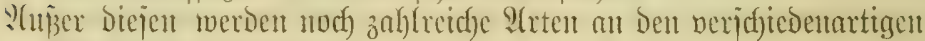
Biffanzen menteridieden.

\section{Chermes.}

Dic Fidftenglllaug (Chermes abietis) nerurjadyt häufig

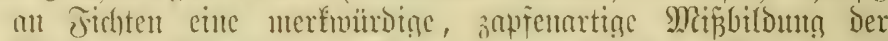

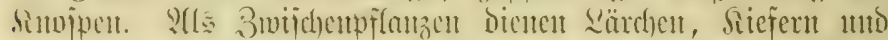
Sirbelficion, Dajelbjt dic molligen Läuje Darjellento. Siod)

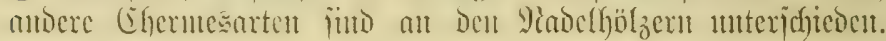

\section{b Die Wollänje.}

Iic 23 olt1a

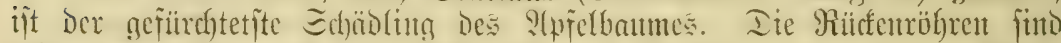

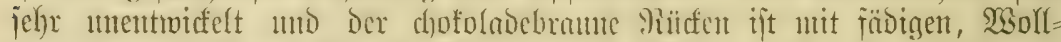

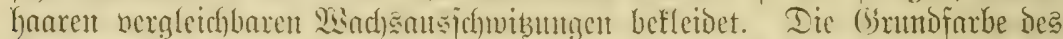

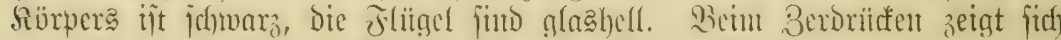

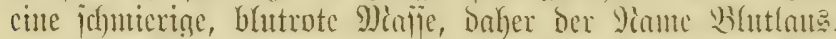

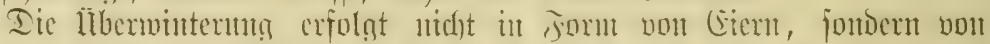

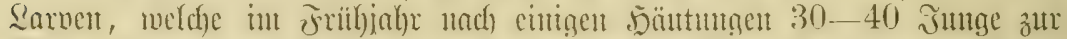
Welt bringen, die jich ihrerjets in ber uferden Weije fortpflanzen. Gegen

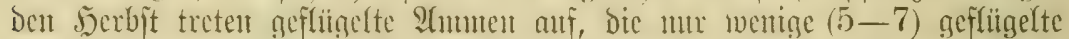

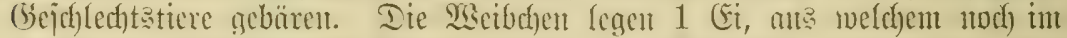

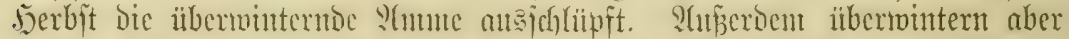

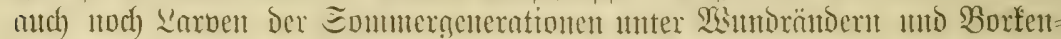
ichuppent.

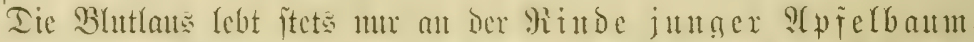

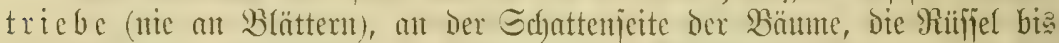

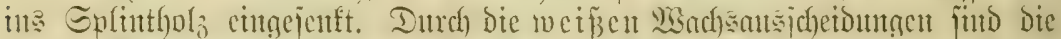

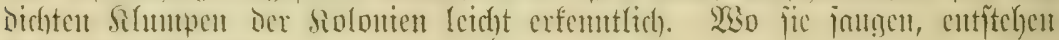
luebartige Wumiett. 
Benterfentsuert ift mux:

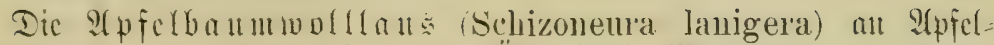

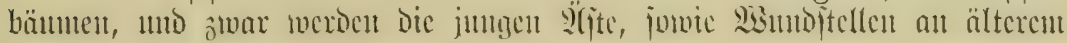
5olze bejallen (Jig. 118 เ. 119).

Die Befämpfuna Der B̉htutanto ijt jebr ichroer. Man wendet ein Berdrürfen Der BGutfausfolonien mit einer iteifboritigen Bürite vder ebenjoldyem Binjel, die man ntoch) in ftärffere Sdymterjeifenlöjung tauchen fann, an. Cin nachbertges überitreichen Der Wumben mit billigent Fette ift auzu= ratent. Spributittel helfen nicht, on man z"ll

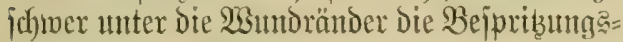
fliipiftgkeiten (Retro= leumentulfion, $\mathfrak{S}$ (ntti= nonit, 2 oplol) ber $=$ bringen fam. Man

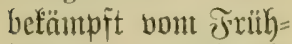
jahre an, jobald die Heinen Siolonient jüt) zcigen itno unterjudst nlle 14 Iage Die Bäıแกเe.

Yus berieuditen B̉mumichulen Ditrfen juttuge $\mathfrak{A}$ prefelbätume niddet bezogen werden.

Bei jebr ftarfer Intabreitung geht dic

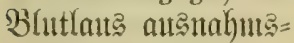
weije andh auf Birm= bäume, Misctiborat

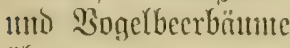
iiber.

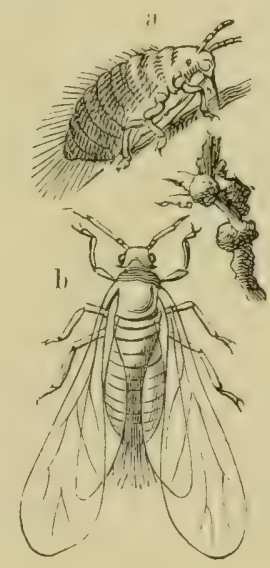

Fig. 118.

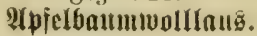
a Ungeftügeltes, b geplïgeltes Tier, "Durch bas Sauqen gebilocte ftebsartige finotent.

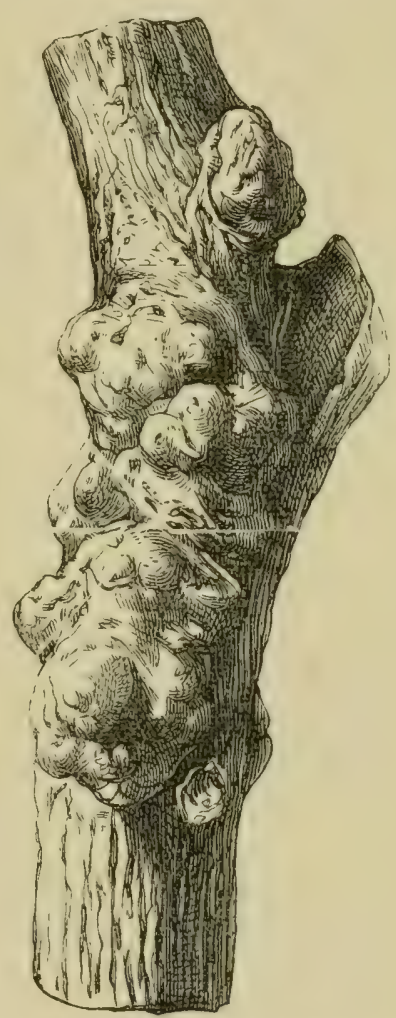

Fig. 119. Sirebafnoten, Durrof bic Błนt!nแ@ betwirft. itbet.

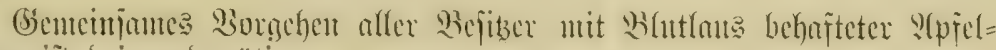

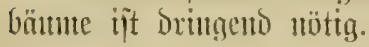

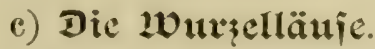

Dex cinzige wid)tige Wertteter ijt Dic Meblau (Phylloxera vastatrix).

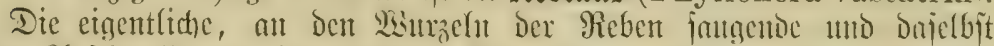

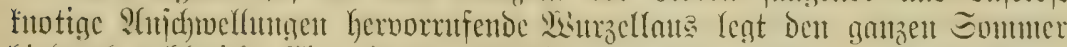

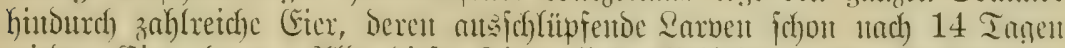

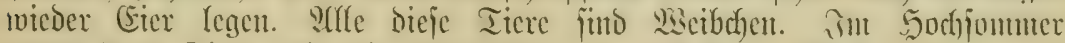

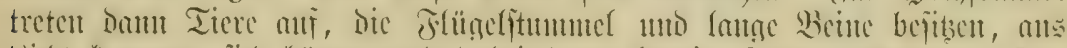

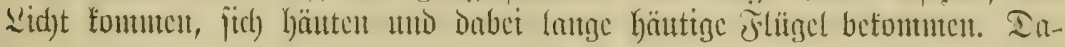




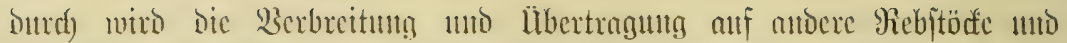

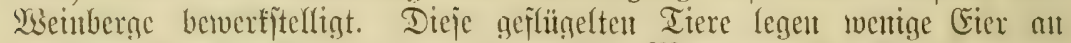

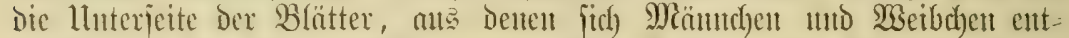
wrifeln. Dieje fund Intgeflitgelt uno ohne Riiffel. Die Weibchen diejer

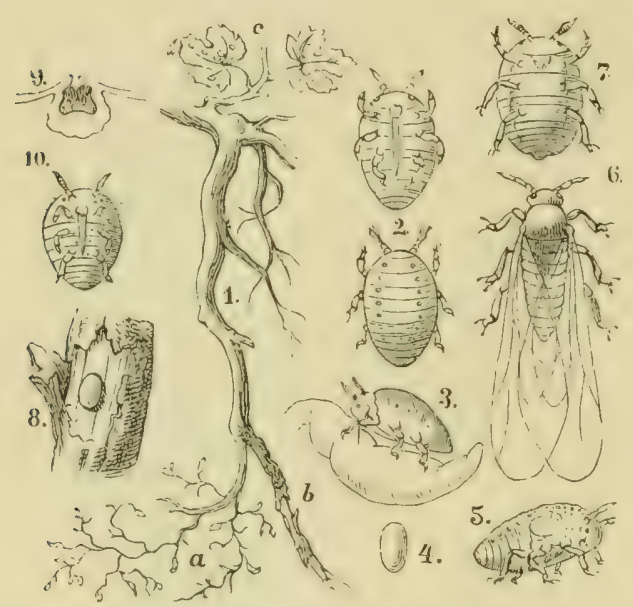

Fig. 120. Reblaแs.

1. Reve uit Ruraus. a Murzelfnoten, " Winterlager bou Rebläuicm, Blattaaffen. 2. \$urzellaus bon ber \&audjeite

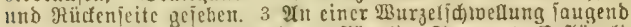
4. Fi berfelbet. 5. Rarbe ber a flitgerten Form. 6. Beflügelte

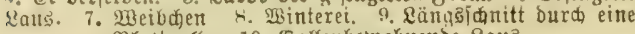
Brattgalle. 10. Ballentetwohnende Raü.

Fig 1 berfleinert, $2-10$ ftarl vergröbert.

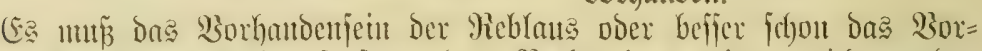

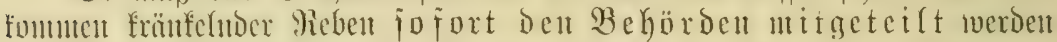

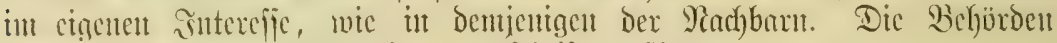

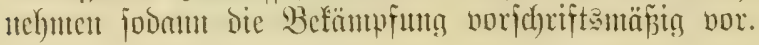

\section{อ. Tamtlte.

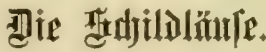

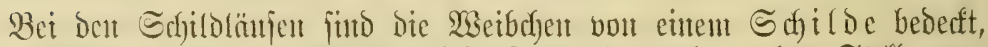
unter welchen jie, an Don PFflanzen feitgejangt, bautent an ber Stelle ver=

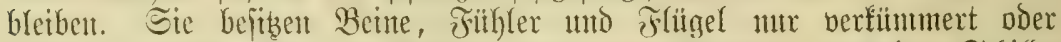

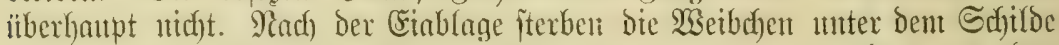
ab, Die ausgejh(iipften Intugen friechen herwor uns wandert an Den

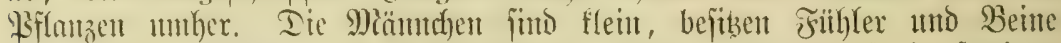

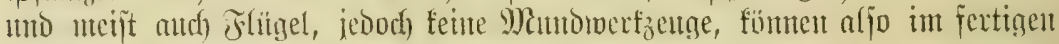

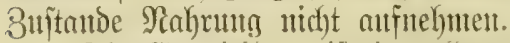

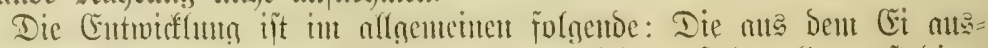

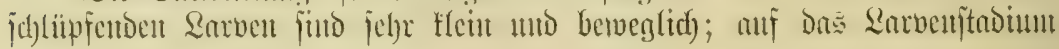




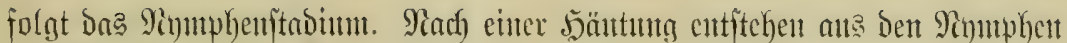

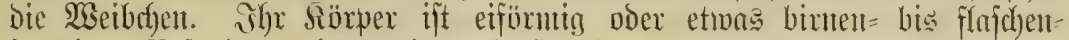
förntig. Befonder eigenartig unto fïr bie Untericheionng Der (5sattungen

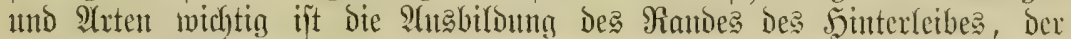

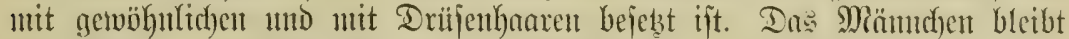

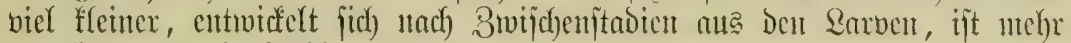

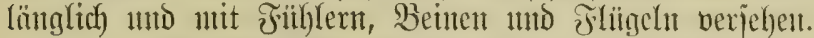

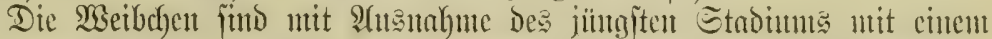

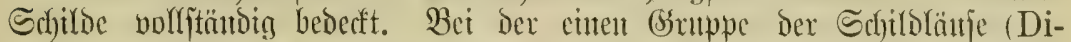

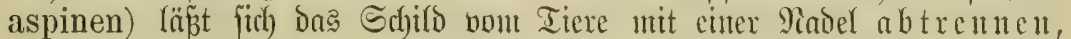
bet Der auberen Sruppe (Lecaniinen) ftellt bie Riuffulhaut jelbit bas Schild

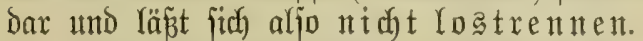

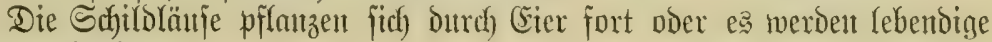
Jitugen abgelegt.

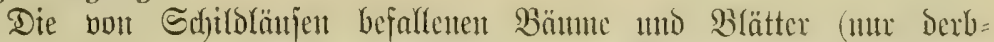

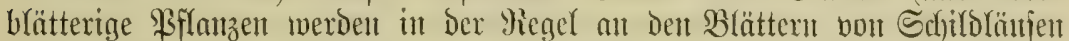

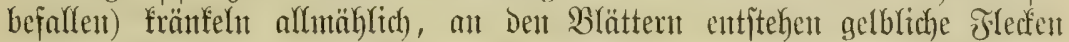

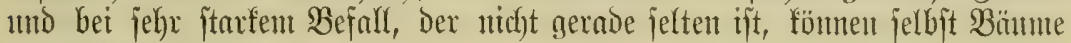
zugrunde gehent. Siäfer.

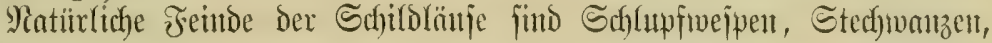

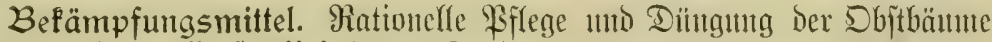

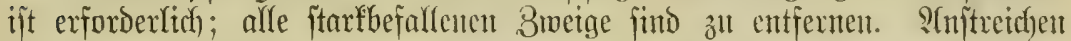
nit Ralfutild), S(bbiinjten mit fteifboritigen Bitrften unter Bermenoung vout Seifentwafjex, Wejpribungen mit Sdfwefelcalcum doer Betroleumemutfionen fino a॥zumenden.

\section{Unterfamilie. Die Diaspinen.}

Das Sabilo ift mehr fladh, abtrembar mo befteht als ber bei

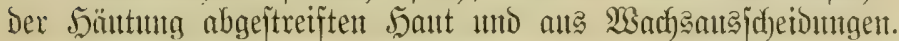

a. Driijenthare gefranft oder ber zoeigt:

b. Drifjent)aare glatt (nid)t gefranit oder nidgt berzweight).

a. Sifild rundich:

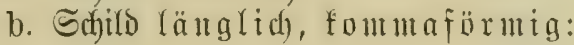

Aspidiotus.

Diaspis.

Mytilaspis.

\section{Sóntung. Aspidiotus.}

Driijenfaare gefranit ober verzmeigt.

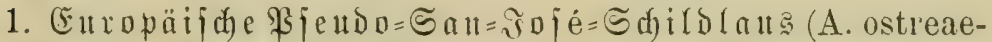

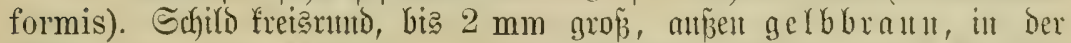

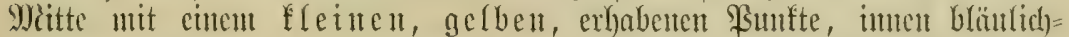
arant. Die Darmuter befindolidhen Tiere helf= bis dunfel gelb. Sie fundet

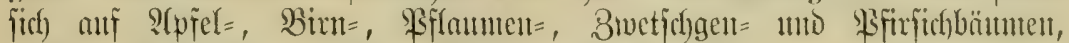
fermer alf Weifjoorn, Rinden, Weiden mo \$appeln.

2. (S) raufdrarze aujeruförmige Sd)ildras (A piri); fie 


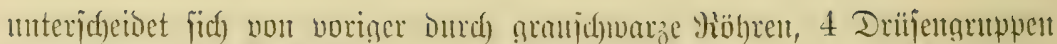

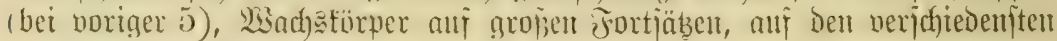
Dbjtbäumen vorfonmtent, oft mit voriger zugleid).

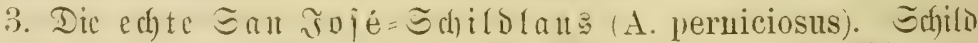

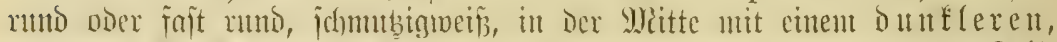
arhabenen \$innte, mterjeits (imnent) mit cinent centralen orangegelben Teil.

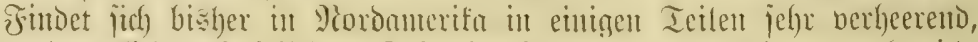

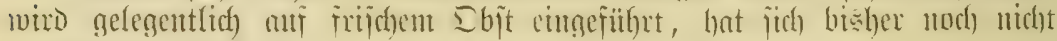
in Furopa angefiediclt.

\section{Sattuntg. Diaspis.}

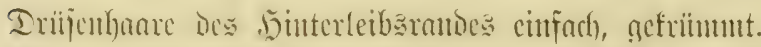

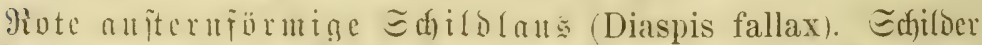
Der weibchen rumblid), hell bis idhmutziggran, in ber y)itte mit einer

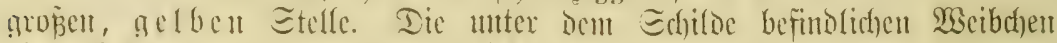

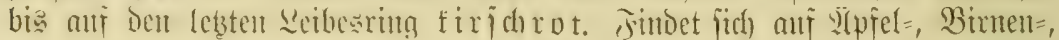

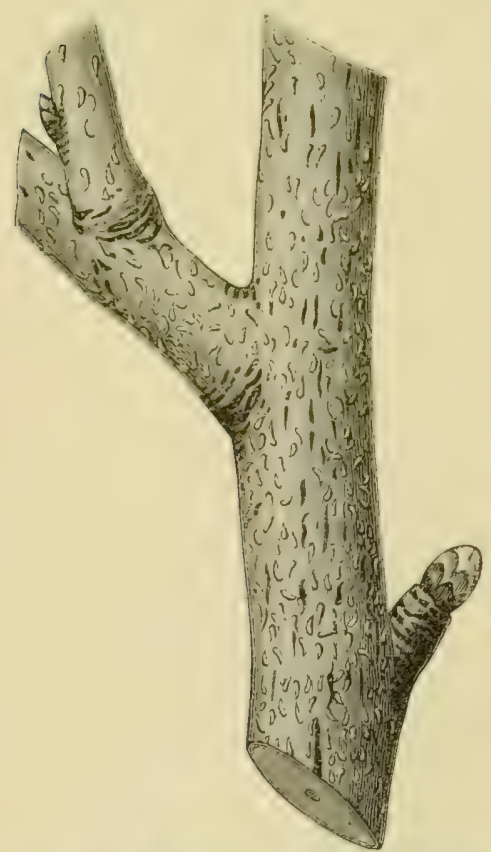

T̃ig. 121. Ifpielstucig mit fommanjaild= lä̉ien (My'tilaspis pomorum) bejeţt.

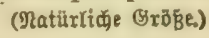

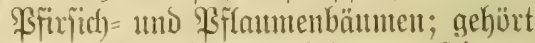
in Deutidslano zu Den jeltenteren Tieren.

\section{Giattutg. Mytilaspis.}

Sommalaug ober fomma= fürmige Sodildidaz (M. pomorum). Sileit, $2-3 \mathrm{~mm}$ lang, fomma fiormig, erbaben, befl= oder Dumlelgrait. Unter Dem ipiken Ende nitst das gelbe Weibchen. Sie findet jich) an $\mathfrak{U}$ pifel=, Bimen=, Piflaumen=, Bfirfichbäumen, an Weip̧oorn, Weiden, Ṡappeln, Johamtisbeeren, Simbeeren, Brombeerent uno an veriffiedenten alloeren (Setwächjen (รig. 121).

Th Rebelifommalans (M. vitis) nit Reben.

Drangentommalaus (M. citricola), ant Citronen $=$ mo Drangen $=$ bäımen und Friichtent.

2. Interfamilie. Lecaninen.

Ier Mitcfen Des Titeres bitset Das Exyilo.

Fiir Dentidiland foumen mur 2 Sattungen in Betradit.

1. Die Eier ober Intugen liegen frei Huter Dent Srfilde Der SGeibchen: 


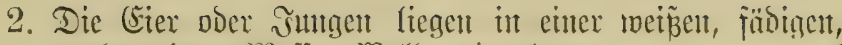
wacheartinen Mafje (Wolle) cintgebettet:

\section{Pulvinaria.}

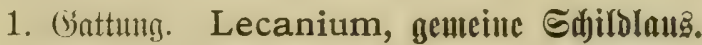

Edhitser mebre oder wentger erhaben, aber länglich ober rumb ober fugelig mit qutabratija gezeidnteter 5aut. Eier oder Jumge frei, b. b. nicht in einer $\mathfrak{B a d}$ anolle ciugebettet.

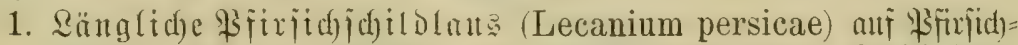
bätnten, aud) anf Johamnis - ıno Stachelbeeriträuchern. Schild läng=

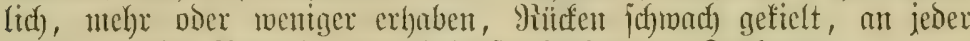
Seite cinzelne Funzeln, von hellfajtanienbranter Färbuntg.

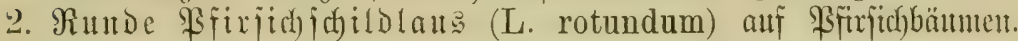
Schild futgelig, fajt glatt, abgerumbet, jchwärzlidu)=bram.

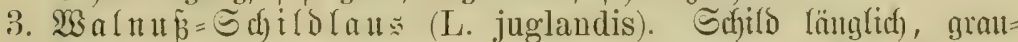

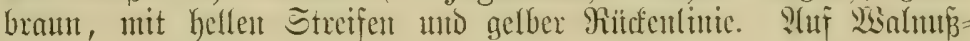
baumarten (Juglans regia und nigra).

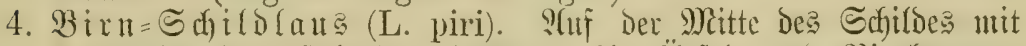

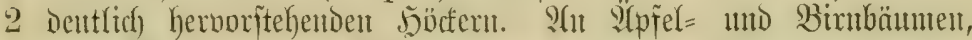

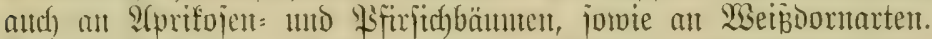

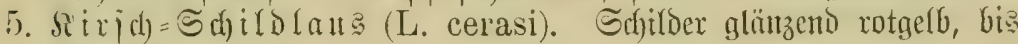

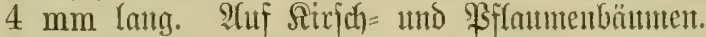

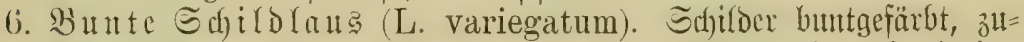

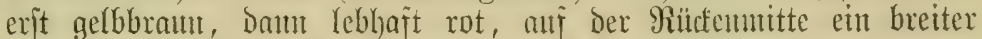

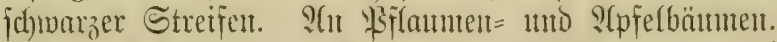

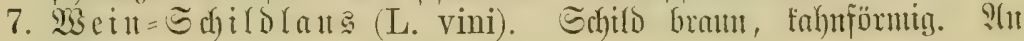
Heben.

\section{Gattung. Pulvinaria.}

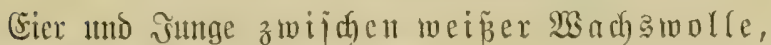
unter bem Schillde das Meibchen.

1. Reben= vitis), Durd obige Merfmale dbarafteriftert, ant Den Yieben (Jig. 122).

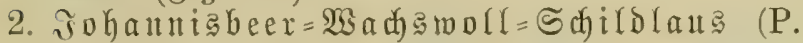
ribesii) an sohannisbeerjtändbert. Daneben fonmut anf Jofjannisbceren now Lecanium ribis wor.

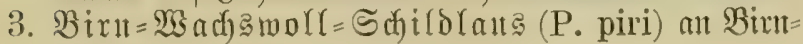
bäımen, Dutittent.

\section{Klaffe. Die Spinnenfiere (Arachniden).}

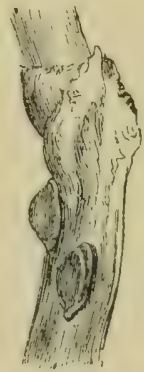

Fig. 122.

Rebenidillo:

lout (Pulvinaria vitis L.) ant Mebitorf.

Unter Den Spinnentieren find $e^{2}$ einzelne Sertreter

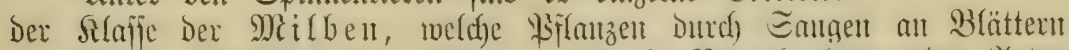

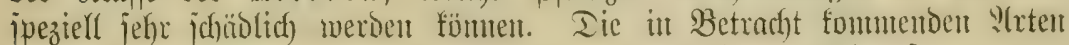

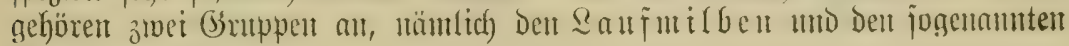
(s)allenmilben. 


\section{Fautilte. \\ Dic danfutilluen.}

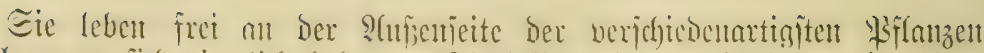

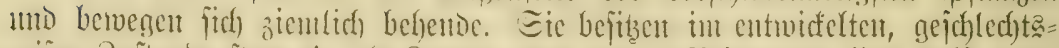

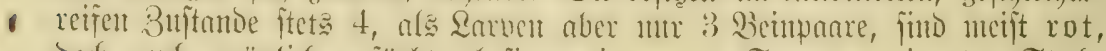

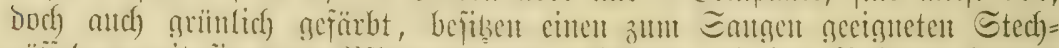

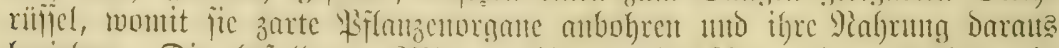
bezichen. Dic befallenen Siflanzcutcile nexblajfen noex erhalten ein

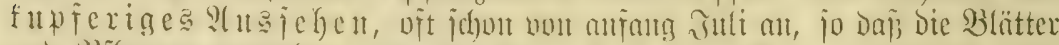

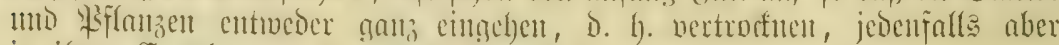

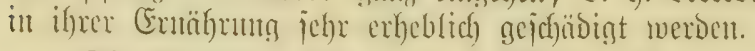

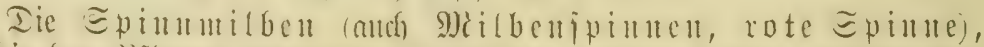

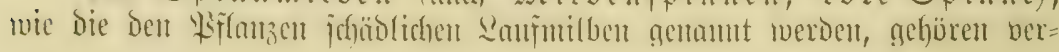
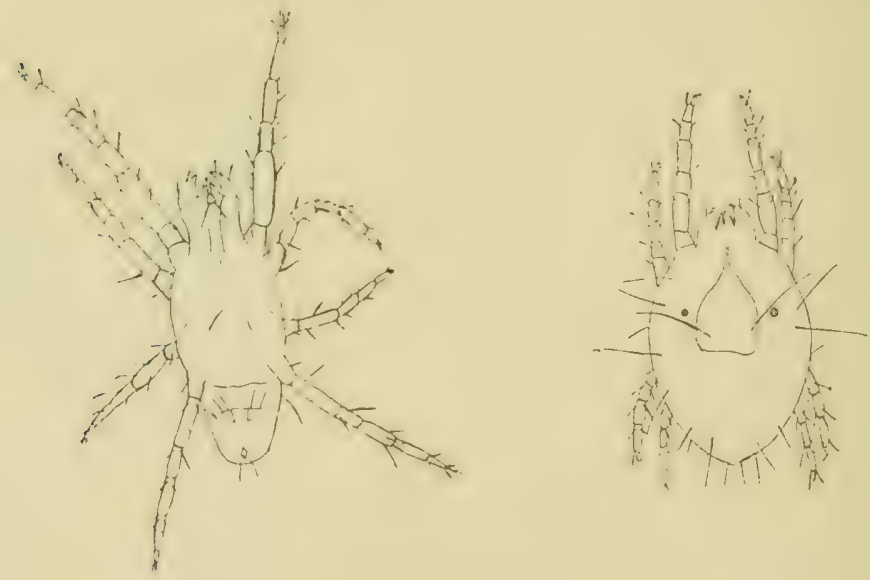

テ̃ig. 123. Epinmutloe॥

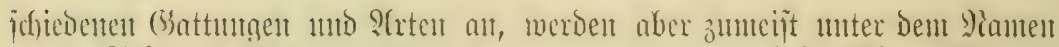
"rote Spiume" "T'etranychus telarius) aujammengefajt (テૅtg. 123).

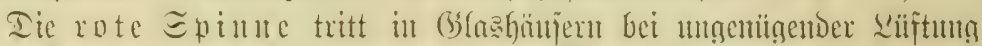

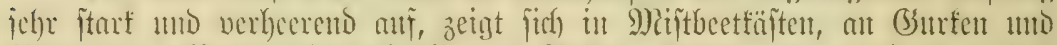

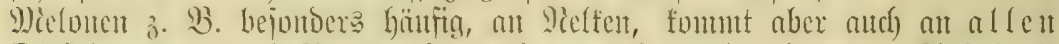

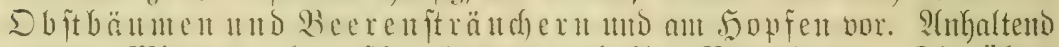

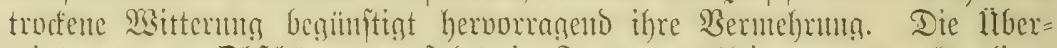
winterma an Dlfítbämmen expolgt in jorm nou flemen, roten, fugeligen

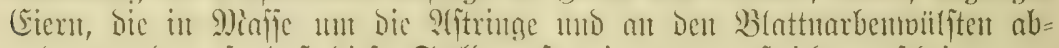

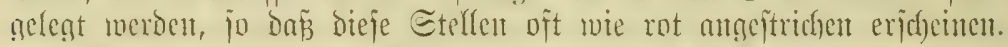

Dic Stad) elbeer= 9) i l be (Bryobia ribis) fonmt an den Blättern Des Stadidelbeeritrautches nor. 


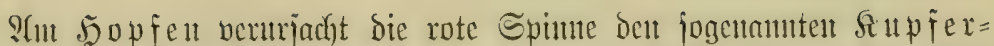

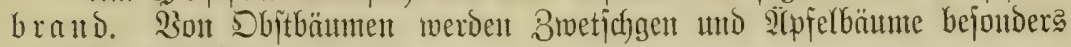
jtart heintgejudt.

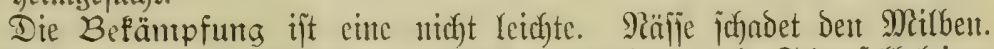
Bepribumgen mit Iabafsertraft, Betroleunemulfion utto Sdyefelfalciun it $1 \%$ iger 20 jiung fino erfolgreicf.

\section{Famtlie.}

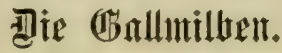

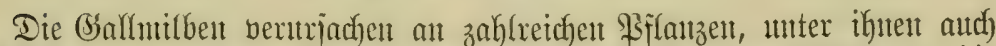
an Dbitbäument tnto am Wein, eigentartige, meît filzartige Bildungen, die

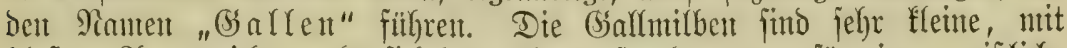

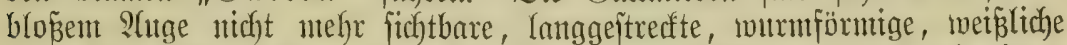

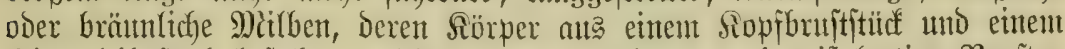
Sinterleibsituid beiteht, weld) lețteres in cinem zwei geipelartige Boriten tragende Edfwanzlappen endigt. Die 2 Beimpare, am Burtitüuf befeftigt,

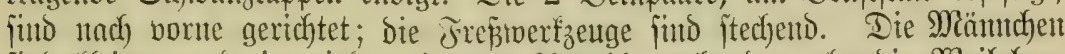

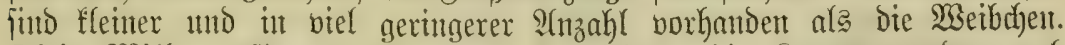
Dieje Mifben pflanzen fidf) Dutrd Eier fort; Die Larben twerben nad)

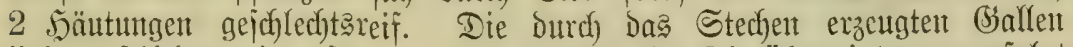

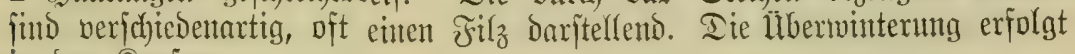
itt Dent Sitopen.

Dieje Ballmillben führten frither verjobiedente Namen, io Phytoptus, Phyllereus, Volvulifex 2c. Sie gefören 2 Sattungen an; die 2 In= gebörigent der Grattuttg Eriophyes fino am jochäolichitent.

Die Befämpfung

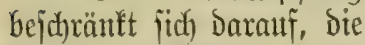
befallenen $\mathfrak{B l a ̈ t t e r ~ f r u ̈ b = ~}$ zeitig zut entfermen und zu verbremtur, allenfalls find Die befallenen Triebe $a b=$ zujuneiden. Bsegen Die nid)t in eittent Fitze lebenten Mitlben twentig= ftenz ijt eitte Bejpribut? mit \$etroleumenulfion erfolgreich.

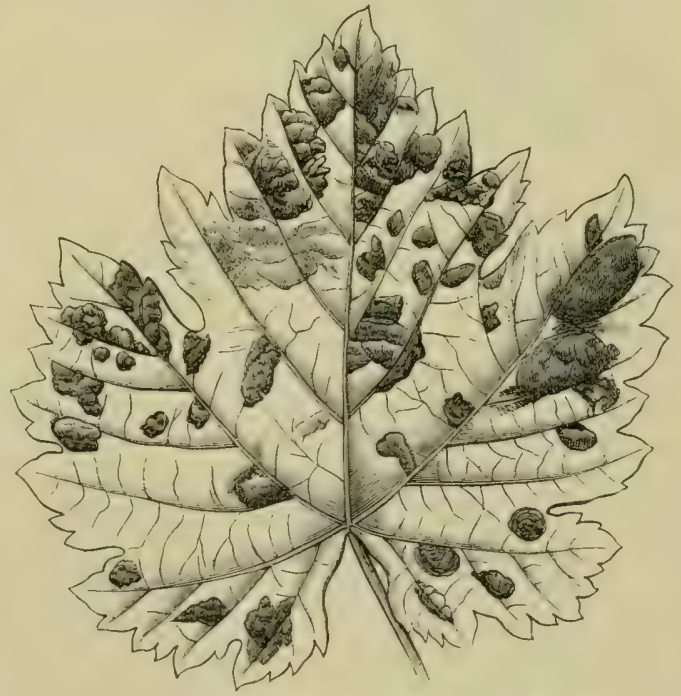

Fig. 124. Weinblatt mit ben Filsporten von Eriophyes vitis.

Die widhtigiten $\mathfrak{2}$ rten füto:

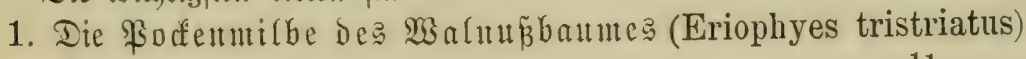
Wei $\bar{B}$, Planzentrantffiten. 


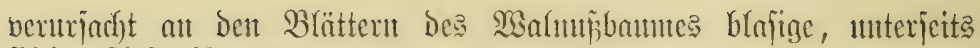
filzige $\mathfrak{A} u$ freibungen.

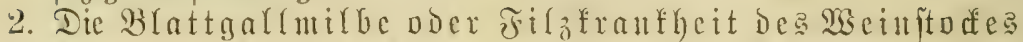
(E. vitis), cbcuf̃alle blafige, muterīits firzige $\mathfrak{A} u f t r e i b u n g e n ~ b e=$

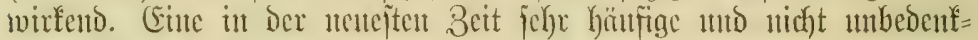
liche Sranffeit (Fig. 124).

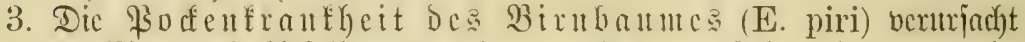

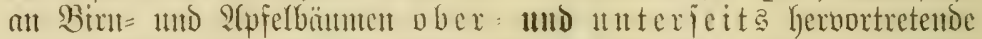

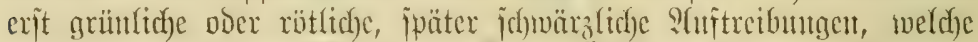
unterjeits auf ifrer Mitte cinc fleme Dffmung befiben. Batro in Bantmidnulen jehr idjäd=

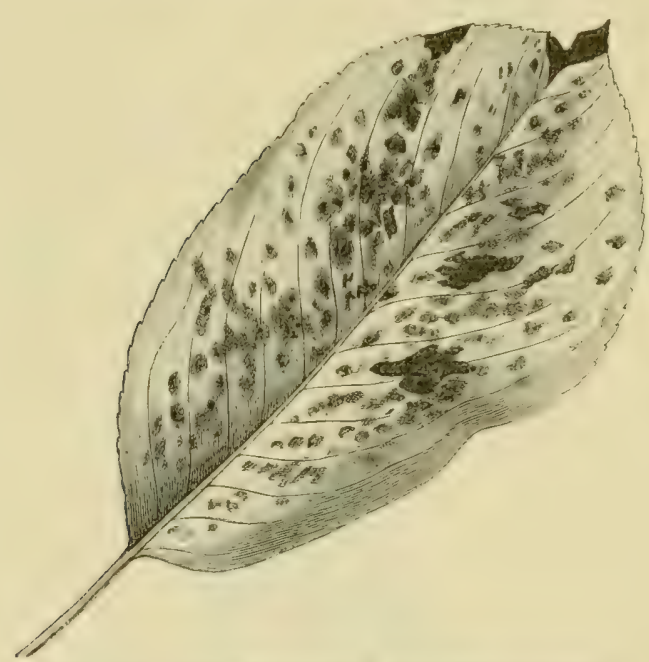

Fig. 125. Focteufrauffecit bcr Birnenblätter.

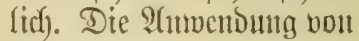
\$etroleumemurfion hat bei jebr ftarfem Befall bor Dent Invipenaufbrud zu crfolgen. Ein Entblütternt ijt mur baun angezeigt, went unt einzelıte Slätter oder Biweige befaffent jinto (Fig. 125).

4. Die Filzgallenmilbe Des Ápfelbaumez (E. mali) erzentgt filzige Steflen auf Der 11uterjeite ber 2 (pfelbaumblätter.

5. Die Rindengallmilbe des $\mathfrak{B f r}$ aumenbaume? (E. phloeocoptes) er= zengt fleme, Dunfelrote, fungeligge Bsallent aut dent Iebtäh̆bigen Zmeigen ber

Bffaumen= und Afprifojenböume und Der Sry)

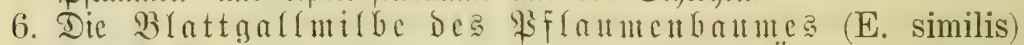

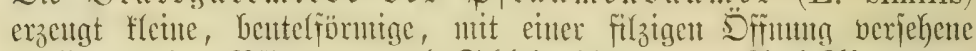

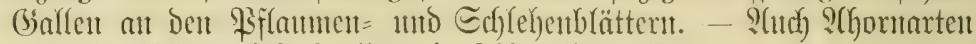
unt bie Rinton find bäıfig mit Fitzanallen bejebst.

7. Die Sindipengaltmirbe des jobaunisbeeritraudes (E. ribis) bentrjacht fintopentgallen ant roten uno jdyarzen Johanuiz=

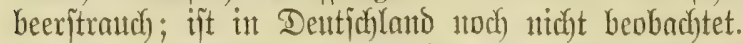

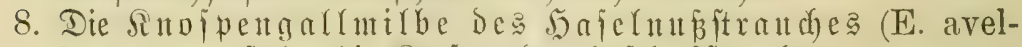

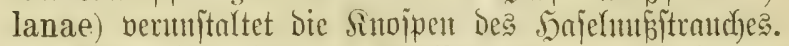

Die 2Urten Der Gattung Phyllocoptes verurjachen unr friifzeitige Bräııntng uno Błeich)untg Der Blätter.

Sieher gehören: Phyllocoptes Schlechtendahlii, att dent

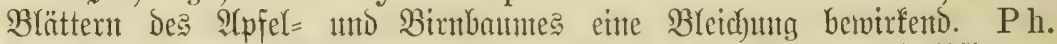

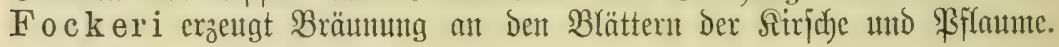




\section{Llaffe. Die Tatlentfiilist (Myriapoden).}

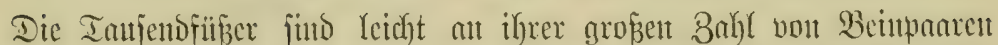

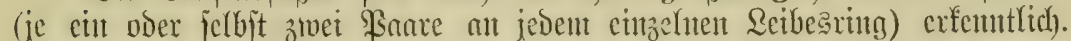

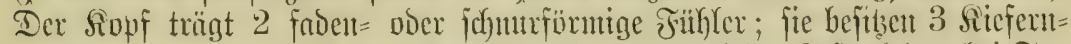

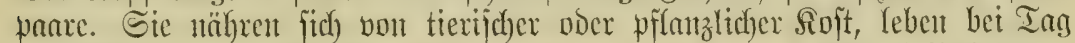

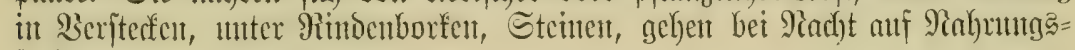
jutche.

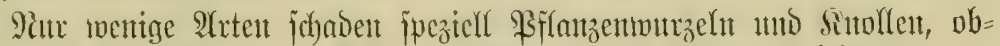

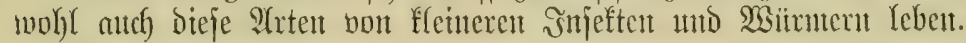

3t crmähntet füto Julus guttuìtus, J. terrestris mu

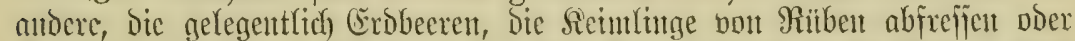
Sinollent aubhöblen. Eie legen Die Eier ffumpentucije in bie Eroc. Eine

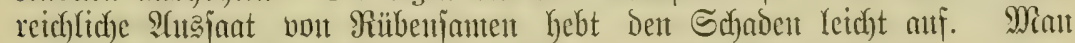

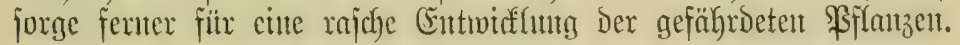

\section{Llaffe. Die 1Hetuthtiere (Mollusken).}

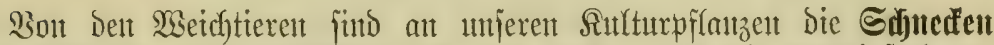

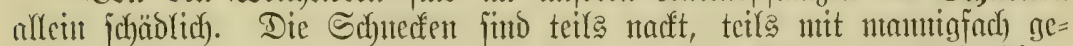

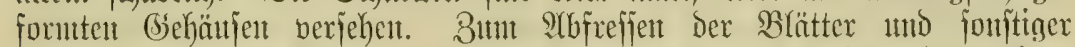
ntiinter oder zarter Bfflanzentorgane bejitzent bie Schnedfen cinten Korttartigen

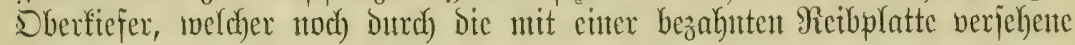
Bunge unterititįt wixo.

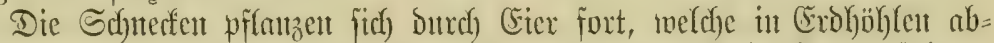

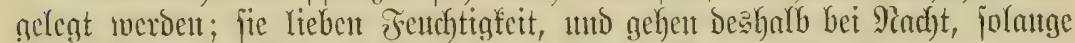

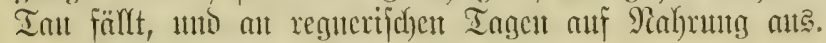

Die Befämpfung iit oft nidht leidht.

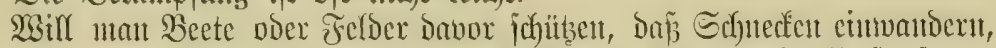

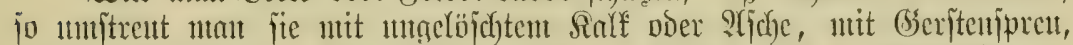

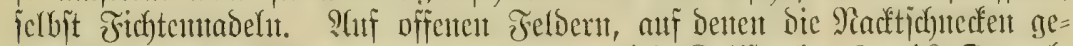

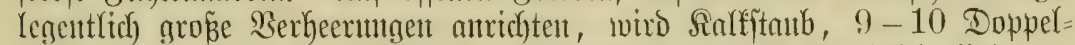

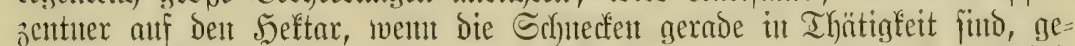

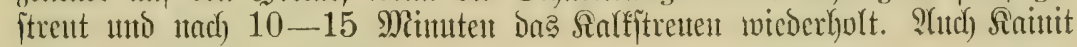
fautu ala Streumittel bienten.

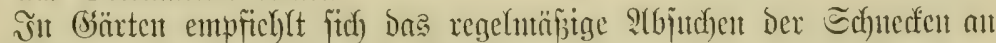
Regentagent unt ant Mcorgen, fo lange Ian liegt.

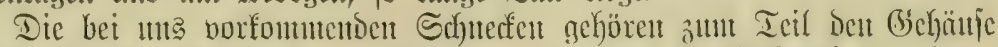

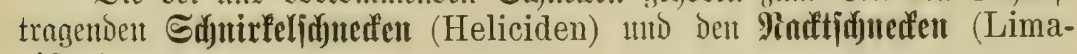
ciden) alt.

Die ridytigften $\mathfrak{A}$ (rten fint:

\section{Madtidjunedfen.}

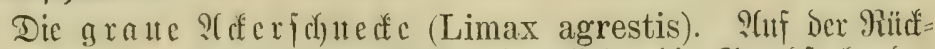

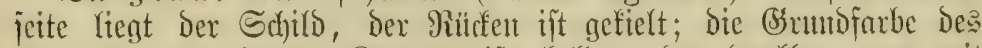
$30-60 \mathrm{~mm}$ langen Siörpers ijt helfer voer butuffer graut mit 


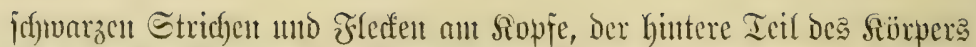

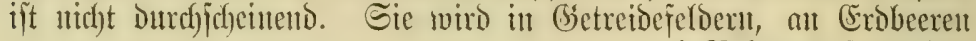

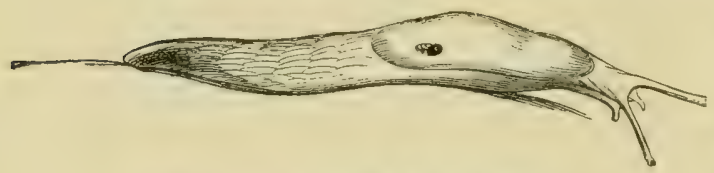

כ̌̃

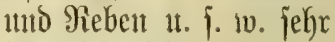
ichäblich (Æign. 126). Die $B a 4 m=$ id) Ite fife (Limax arborum) befibst eitent Durdjidyeituenden fïrper unis ichaset bejonders aก Bäıment.

\section{2. (Bebüแjeiduedent.}

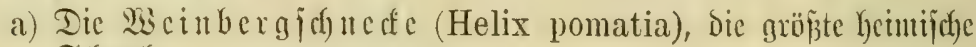
Sifluedfe.

b) Die (Gartenjd) uifeljenede (H. hortensis) mit gerben ober

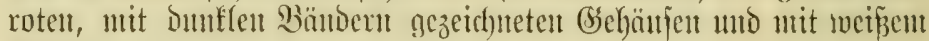
Manojaunte.

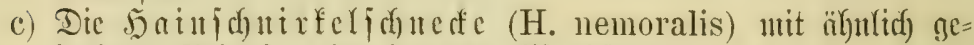
färbten (Şebäuje, aber bramen Mambjamm.

d) Die $B$ an

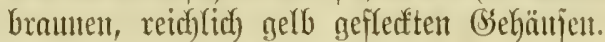

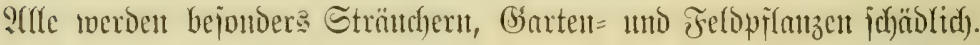

\section{Klafje. Dir Hürumer (Vermes).}

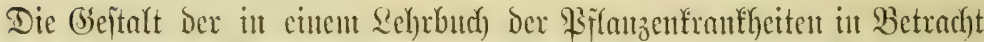

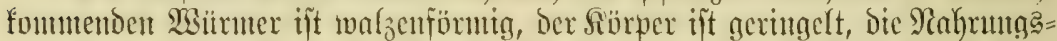
aufuabute erfolgt dutch Den Mamo, die Fortpflauzung geidjiebt durd) Eiter.

\section{Familix.}

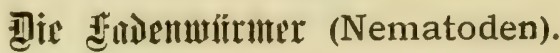

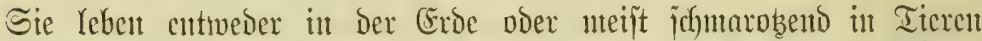

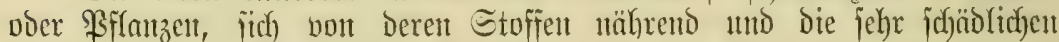

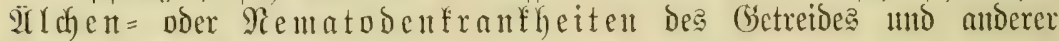
Pflanzen verurjachento.

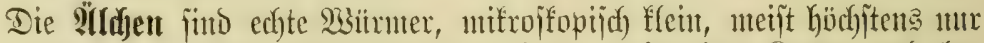
bis $1 \mathrm{~mm}$ lang, befizen cincu walzenförntigen, geringeltent Siörper mo be= wegen jich jod)längelno fort.

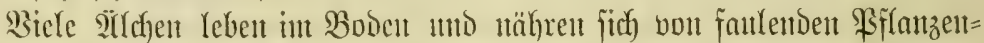

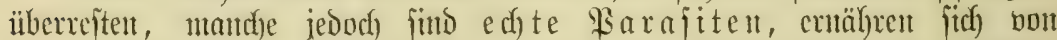

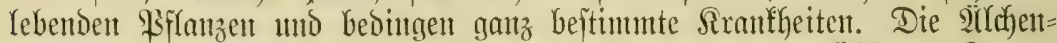

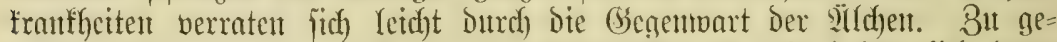
mifijen 3eiten aber verlafien bieje bie Mirtspflanzen แno halten fich bann

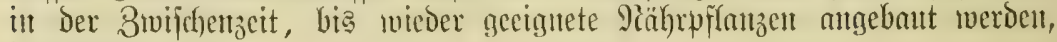
im Bobelt auf. 
Die widhtigften भ̈Idhenfunfleiten fint:

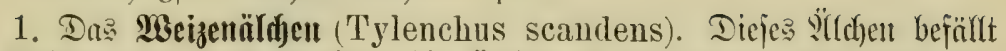
Den 23 cižn

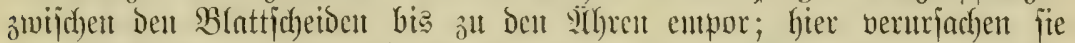

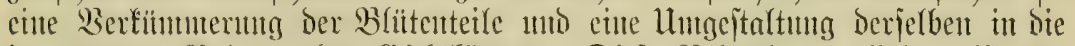

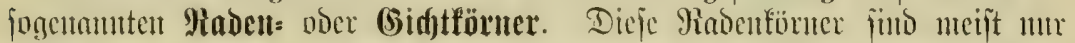

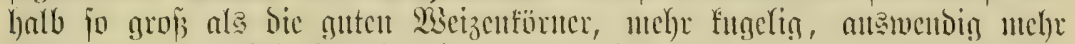

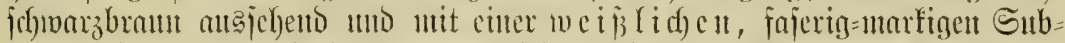

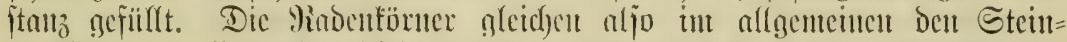

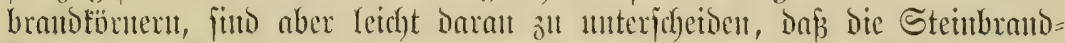

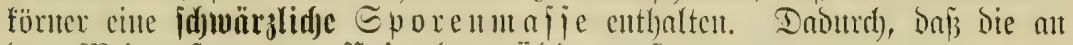

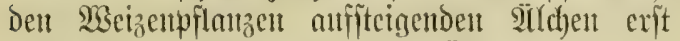

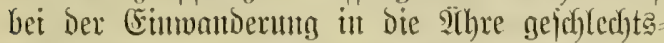

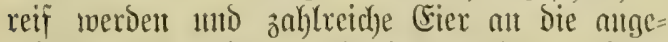
griffenen Frudhtfinten abgelegt iverden, erfolgt Die Bermutaltum meĩt aller $\Re$ örner e t ner

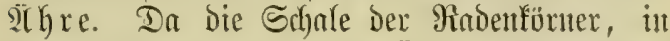
Deren J̃ınerent die jungen sil(d)en fidd) befinden, jebr hart ift, jo werdent bie Miumdyen erít nach) ber Sermejuttg bicjer Schale fret, alfo borzltgêtweije Dant, went Die Rabenförtter mit

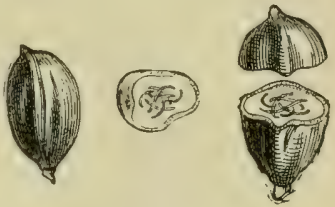

ช̛ig. 127.

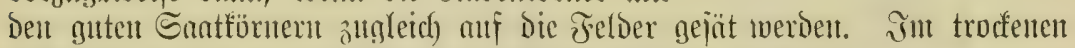
3uftande fömtent fie jobrelnug lebensfähtg bleiben (şig. 127).

Befämpfung. Nian vertwende mur gauz reincs, D. h. von Raden=

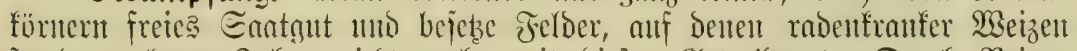

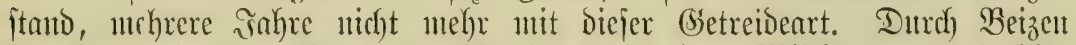

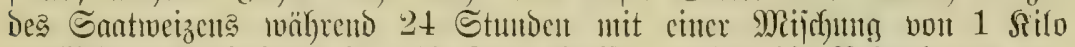

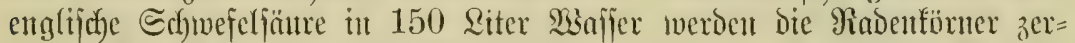

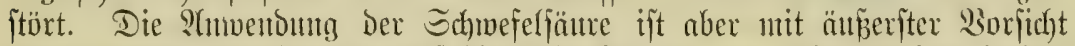

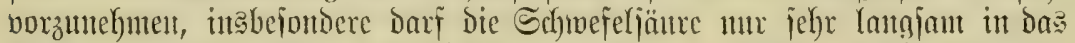

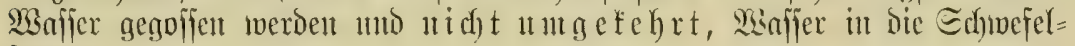
jüute.

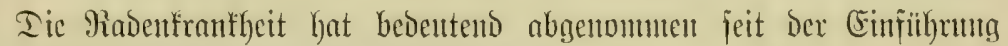
bejierer Samenreitigungmajditten.

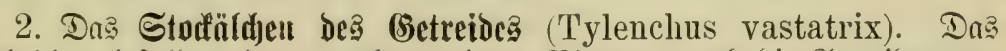

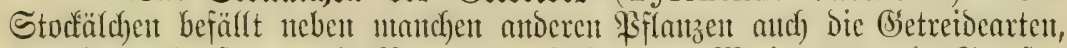

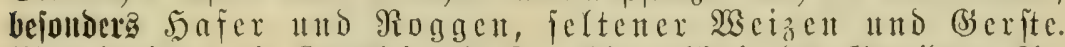
Mian bezeidutet dic Siranfleit als Stodf

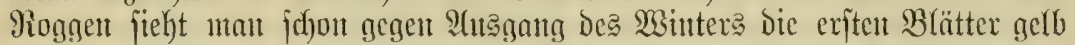

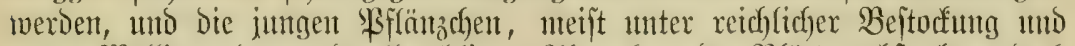

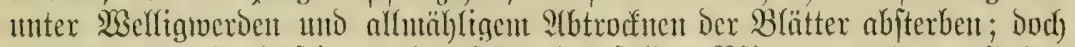

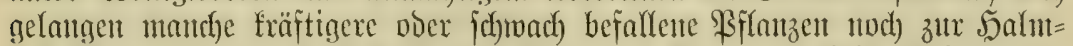
Imo Sïnterbildung; Freilich bleiben bie Salnte fiüzer und beim Safer treten

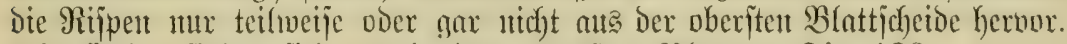

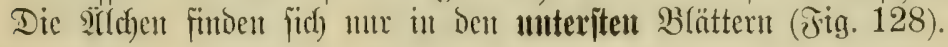




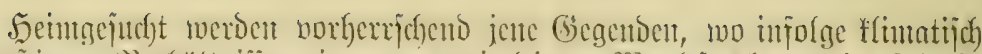

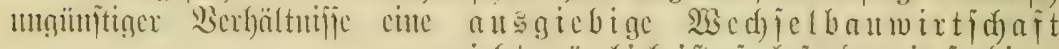

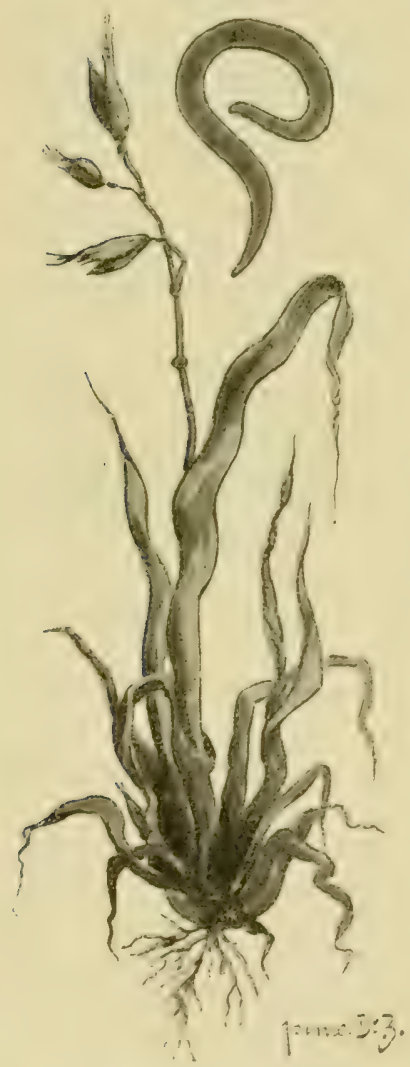

ชิig. 128. Etoffäldf)en (Tylenchus devastatrix). ntid) $t$ mög $(i d)$ i ft, jo bejonders int janbigen Gégenden uno inl Gébirgalagen.

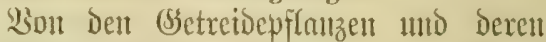

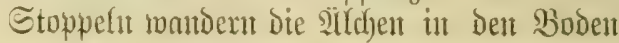

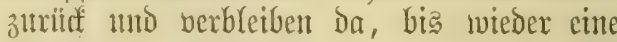

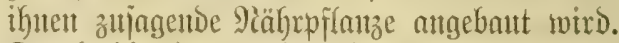
Dutrcl) Die Den Filipen Der Tiere und be

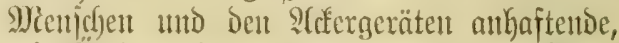
mit 2(ld)en befebte Eroe sviro bie über= tragutitg Der 2̂̉(d)ell auf andere Fetber be= uverfiftelligt. Neben Den Bsetreidepflanzen merden nod zahlreide andere giflan=

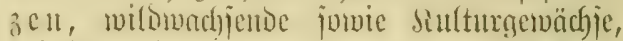

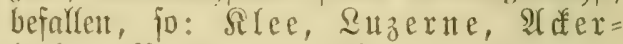
bohne, Budneizen, Rarden, Speije= zwiebeln, 5nazinthen, Serfen uno

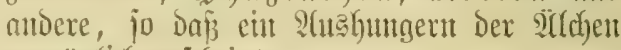
umutöglich ericheint.

Die Befämpfung iit jefre jabwer. $3 \mathfrak{l}=$ nübujt jolfen Bflanzen, weldse bon Dent

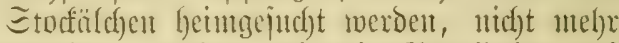
angebaut swerdent umo mit Bsetreideban anf verieuditen Feldern ift einige Beit ausan= jeben. SAbiduürjen Der Stoppetn und Ber= brement Derjelbent ift nuzutraten. Cine itarfe Eirjant fönnte Daz̧ı beitragen, Die Ernte

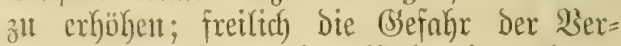
mehrung Der Sematoben ift bamit autd) ge=

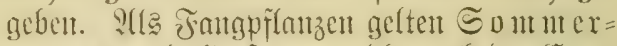
roggen unb $\mathfrak{5} a \mathfrak{f e r}$, weldye nad) Der (Ernte unnuttelbar z̆lt bauten suären, Damit fid́) an ifnen nod)mals bie \$iematodent einiteflen und

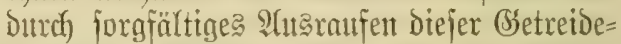

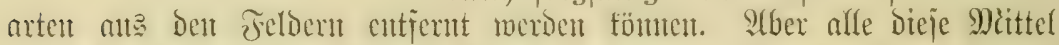

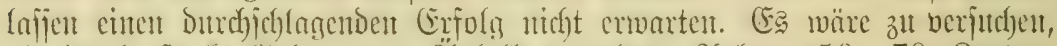

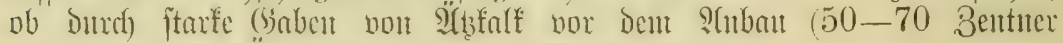

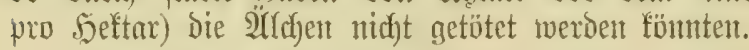

3. Iic Miübentumatoben poer dos Riibenäldden (Heterodera

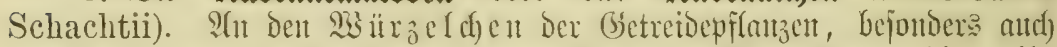

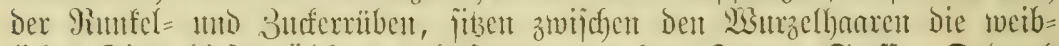

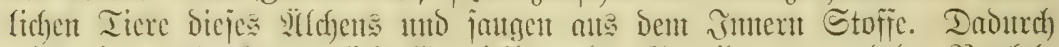

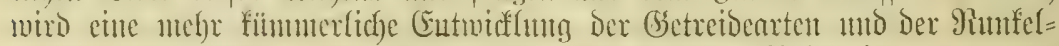

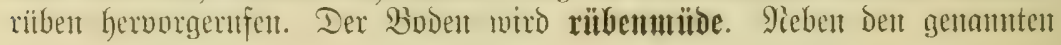




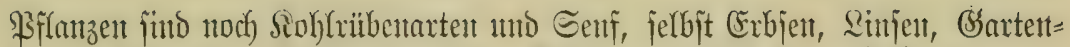

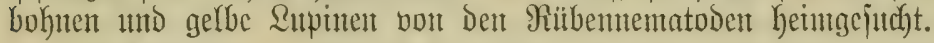

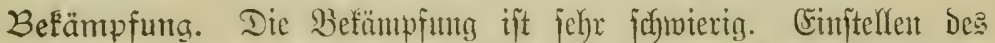

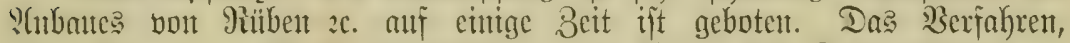

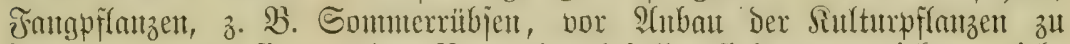

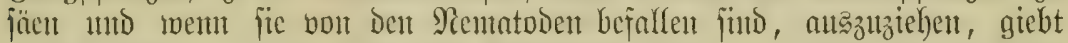

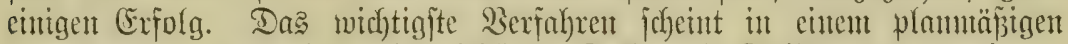

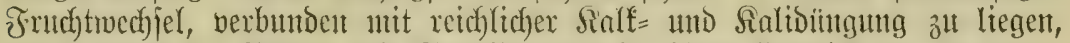

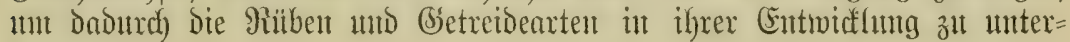
ftüțen.

Inmertung Das Rleeälchen, Sartoffeläldyen ftimmt mit ben

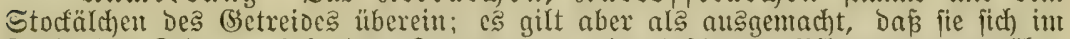
saufe ber Beit an befondere Formen, an eine beftimmte Bflanzenart gemöhnt

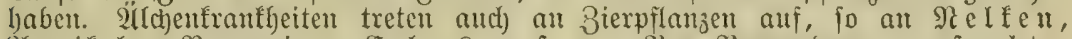

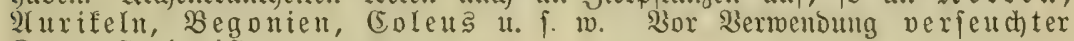
rompoiterde ift zut warnen.

\section{Jamilix.}

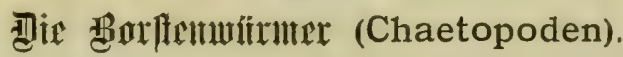

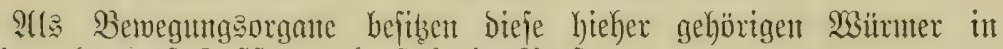

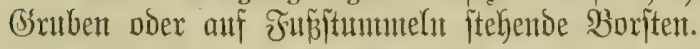

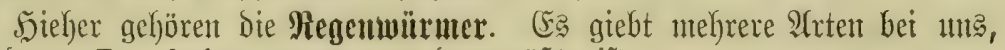
bon Denen Lumbricus terrester ber gröp̈te i itt.

Die Regentwümer reben in feiter, fenchter, berjanterter Froe uno

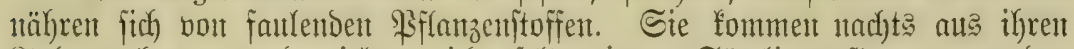

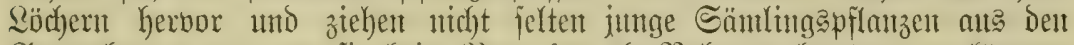

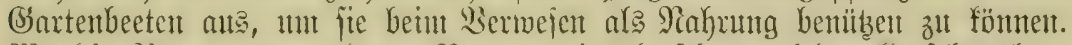

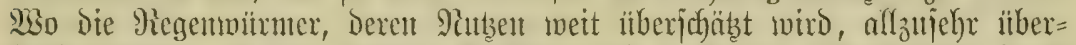

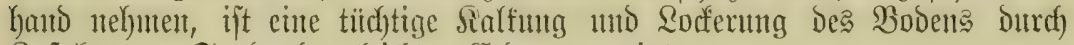
Buffulyr vont Sand ober Yeidgter Eroe angezeigt. 


\section{In hang.}

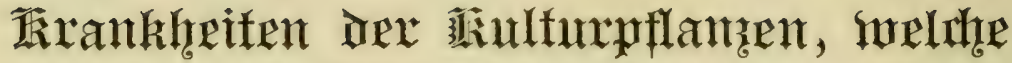

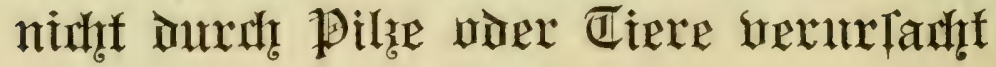 Grexter.}

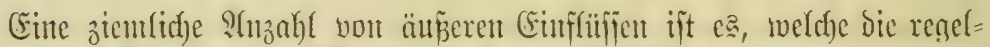

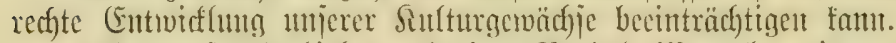

Ehne ali alle hieher gehörigen Serhältnilije näher einzugehen, jei mur auf Die wejentlidjftent aufmerfiam gemardyt.

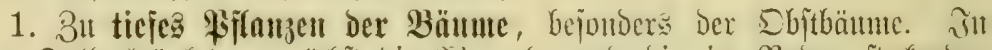

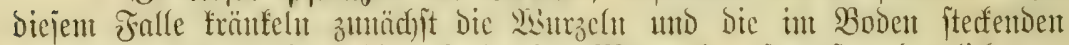

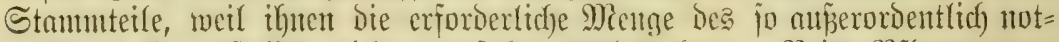

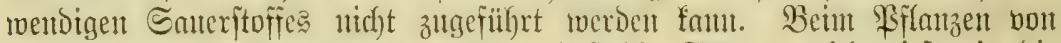

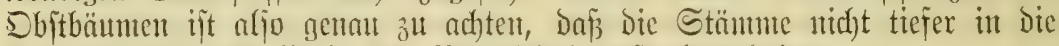
Eroe fonmunen, als fie in Der Baumidnule gejtanden haben.

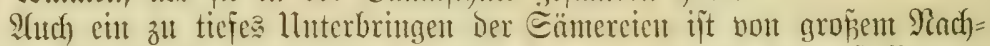
teil, Da Eamen in bedentenderen Tiefen bie erforderlidje Sanerîtofïmenge

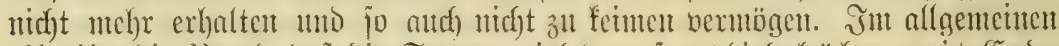

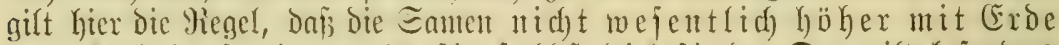

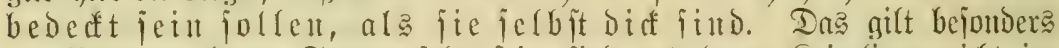

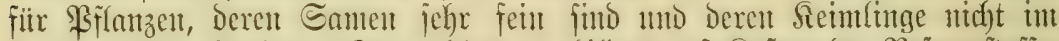

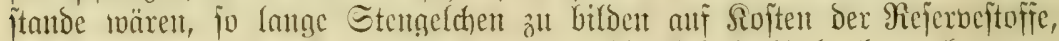

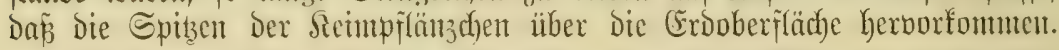

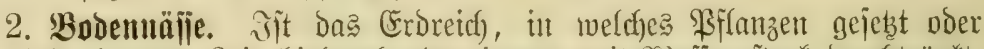

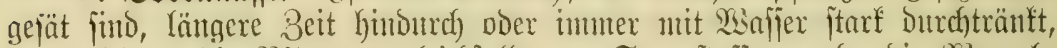

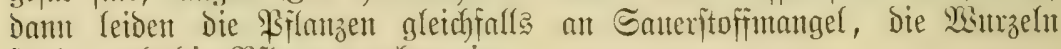
faulen uto bie $\mathfrak{B f l a n z}$ en geten ein.

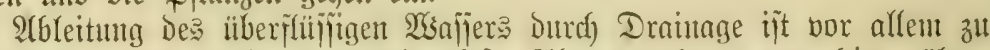

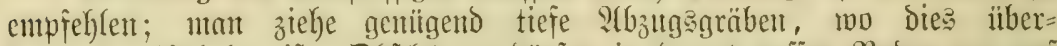

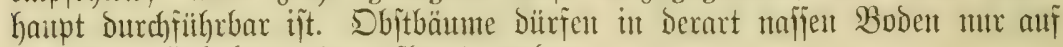
Erobügel (Erthöbutnen) gepflanžt weroen.

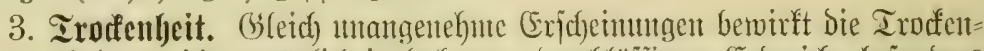

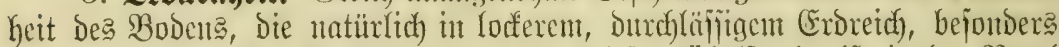

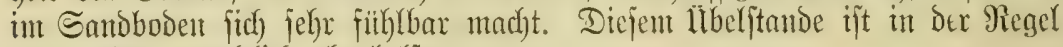
meift nicht griindlidy abathelfen.

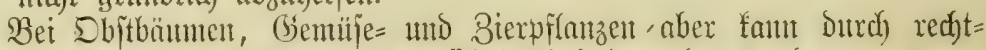

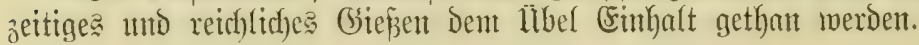




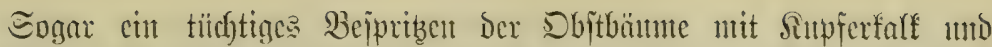

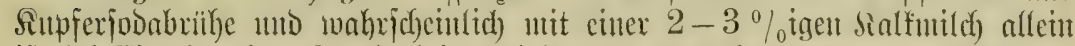

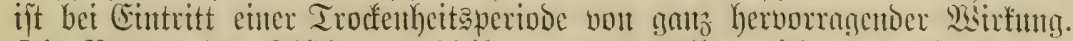

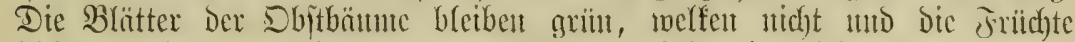
bleiben erfalten. Die genmunten Mittel wirfen in biejent Falle "ver=

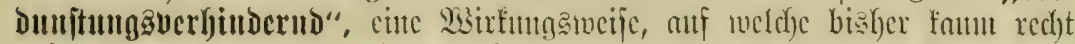

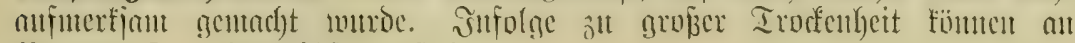
Bämmen Irodéturije entiteben.

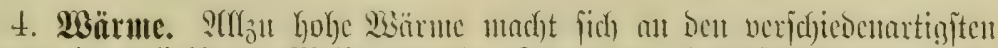

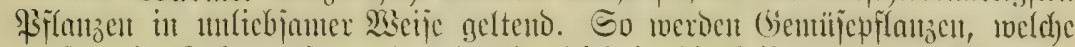

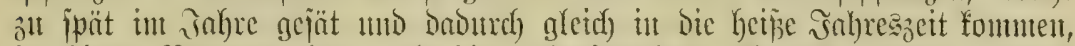

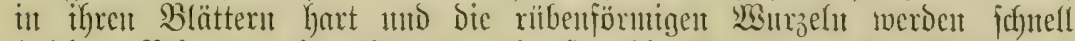

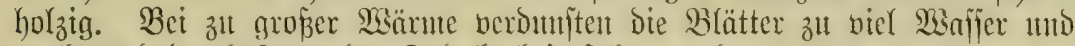
ce fant baburch jogar ber Iod herbeigefiilynt werdent.

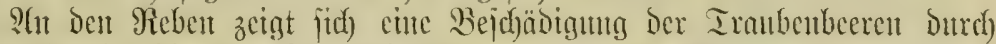

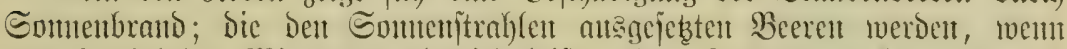

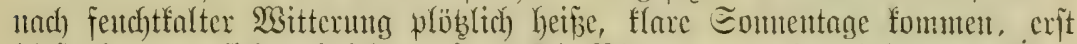

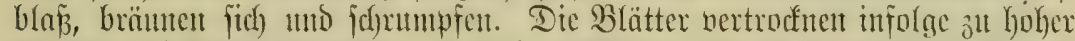

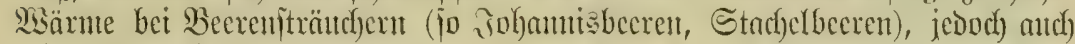
bei Dbjt = mo Ranbbänmen vom Rande her ab, oft unter teilweijer Sin=

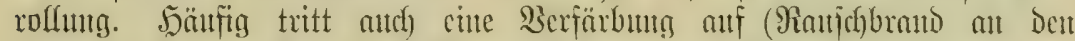

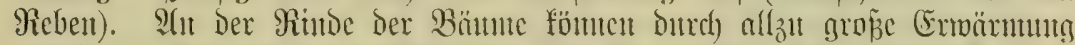

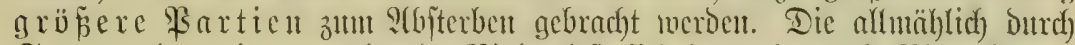

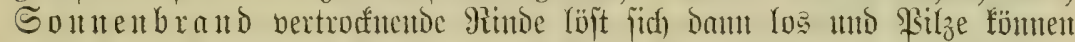

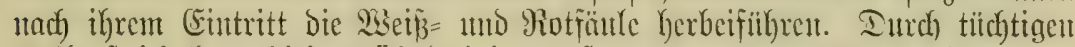

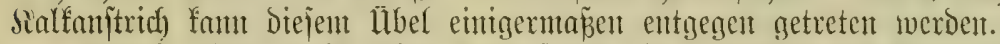

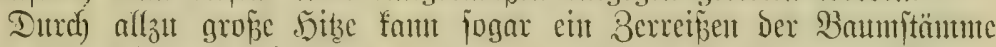

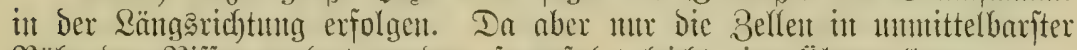

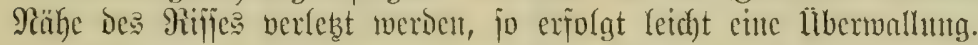

5. Fïlte. Mantgel an Märnte bebingt bei ciner grofenen Mentge bout

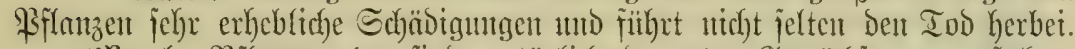

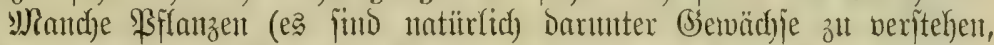

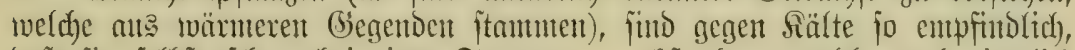

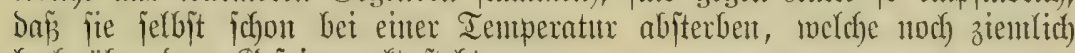
hod) iiber bem Gefrierpunft jteht.

(Gegen Sälte verbalten fich) Die einzelnen Barietäten (Eortent) einer Âtt

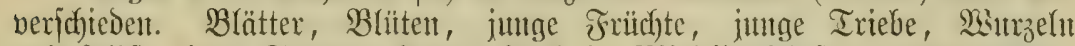
ImD jelbft ältere Stümme föment ftart in Mitteidenjognt gezogen weroen.

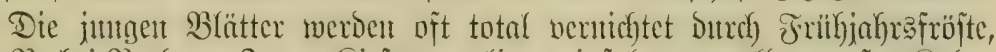
jo 3. 23. Gei Batchen. Jutuge Sitefern verlieren infolge von allzu grö̧er Siälte=

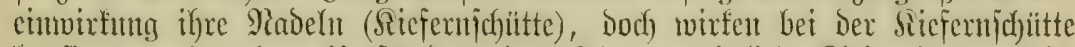

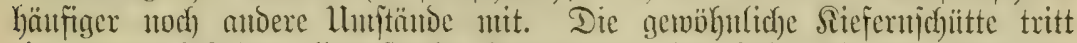

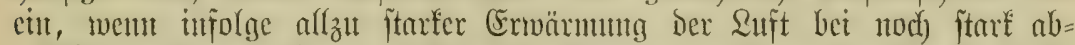

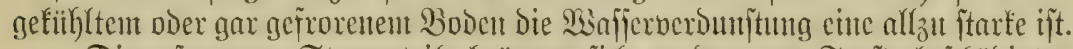
Die exfrorenen Stanmteife brümten fich an ben von Frofte bejchäbigten 


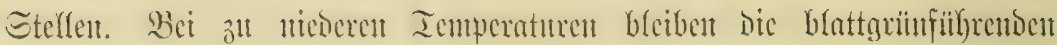
Drgane pit gelblich.

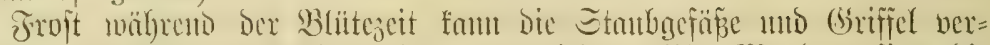

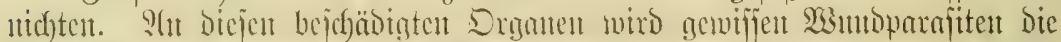

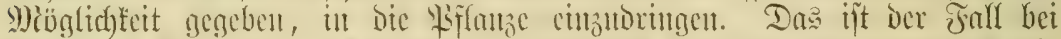

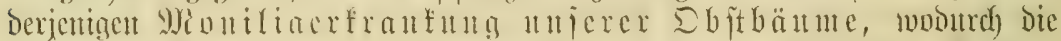

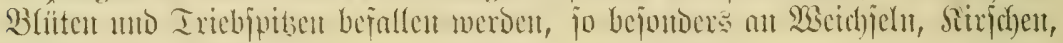
İipfeyt 1tul Binten.

(E⿱

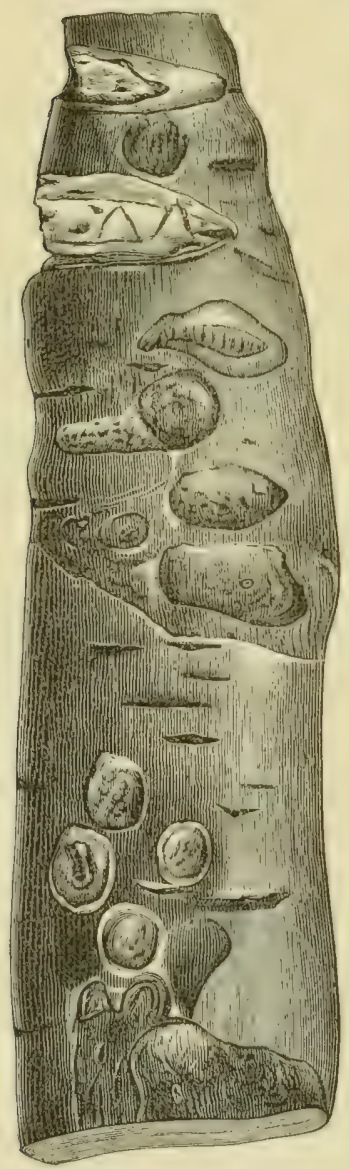

テig. 129. Birnbaumrinoe mit fleiner froitplattent. Der Bantuldyeibent mit Sdytee oder Stroh) Das Afuftauen des Bodens und die Saftitrömung ztt verzb̈geru.

Jntutge Frud)tanlagen, Deren Błïtezeit ge= rabe in eine froftperiode gelangten, vertroffiten

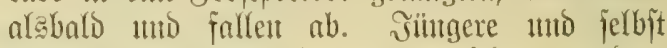
ältere Brweiginizen föntmen bernichtet merden. (5) bleibt Damm nidjts weiter ïbrig, ale bis

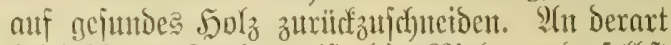

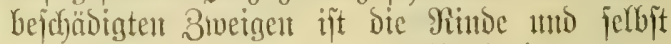
bas Miarf braun ge=

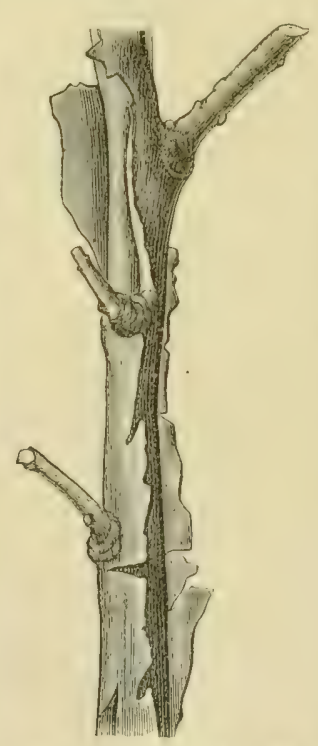

テ̛ig. 130. Durd) Froit getöteter \$ipjelbaumzweig mit gejprengten Sorts idjidjtell (尺roftlappen). färbt. 2Atı biejem litbel (ciden natiitr(id) am fitärf= iten alle jene \$iflanzen= arten Into Sorten bon Sitlturgemädjen, tweldye fïir Dą Slima einte Srtes nirift geeignet find. Untoorfidgtiges (sinfiilyren von Getreidejorten, be= jonders aber bon Gese= minjebarictn̈ten 1 mo $D$ b jit $=$ jorten aut? เvärmerett Gegenden hat oft einen gantz altiferordentlicken Ethadent zur Folge. Dex= artige Sortell bon Sitll= turrpflanzent entwidefelt fidc) oft sabre uno salyr= zehnte lantg, went auñergetwöhnlidye Sälte= cinnirfingen uidfyt ein= treten, ganz regelred)t; eit cinjiger "jefhr ftrenger" Binter faum aber jämtlidfe fïr bas betreffentio Si(inta nticht geetgute Eorten ber= nichtent. 


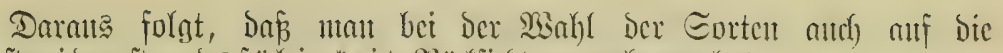

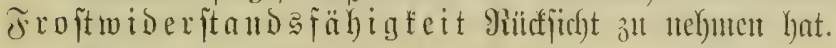

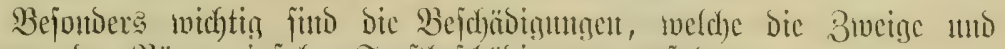

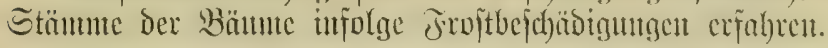

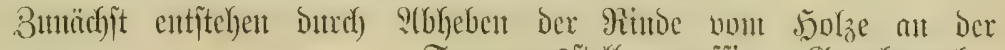

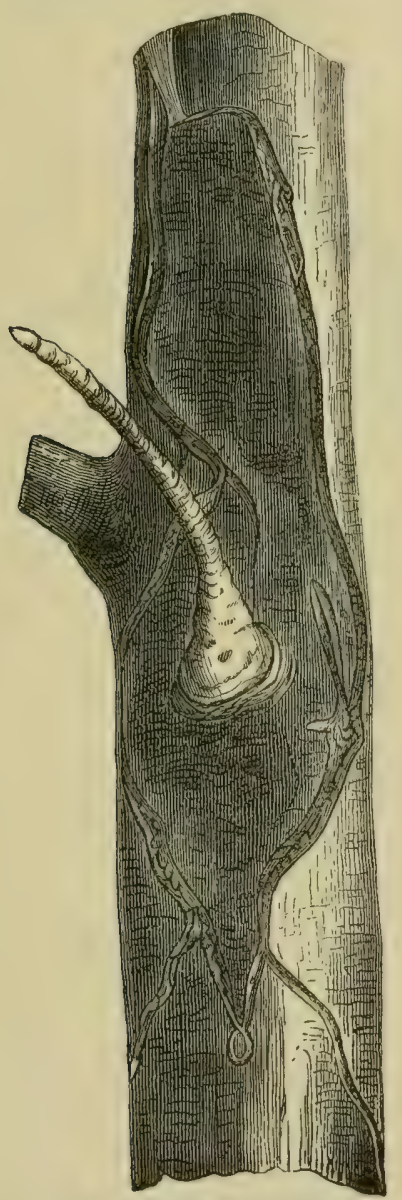

Fig. 131. Brantiger 2fpiel ftanmu.

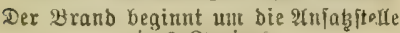
cines 3roeiges.

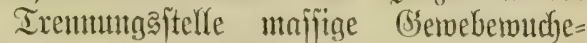
rutngen, weldye zut Bilfoung vout Froit $=$ benlen Serattafijuting gebett.

2(1n glattrinsigen 3meigen entîtehent

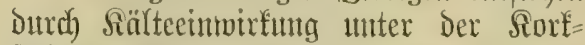
jujidate Rifife; Dą Darunter Yiegente Rintongemebe bräunt fich) und fitirbt ab, Das Borfengewebe hebt fich brajig ab

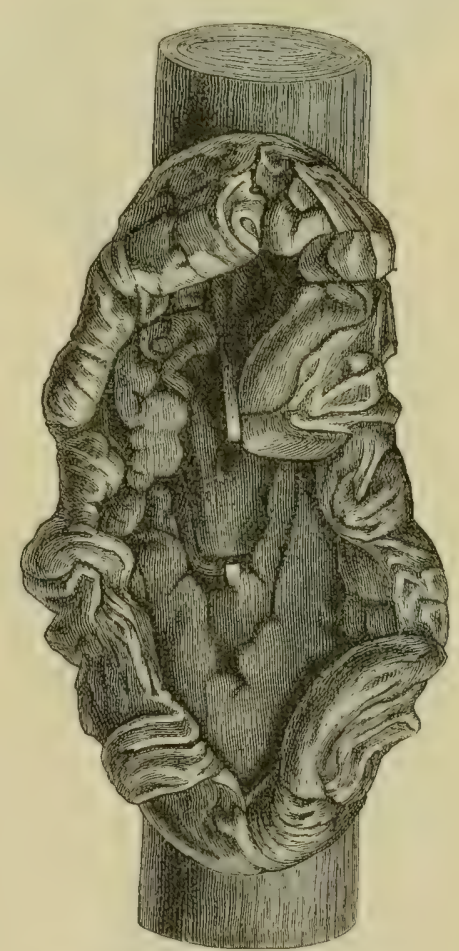

ช̛ig. 132. Der offene Sirebr.

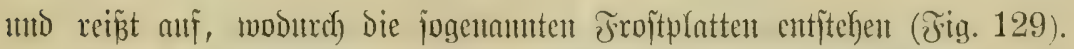

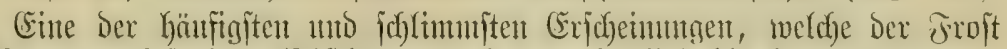

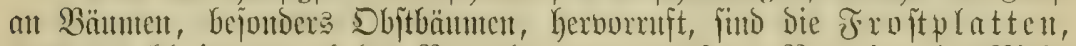

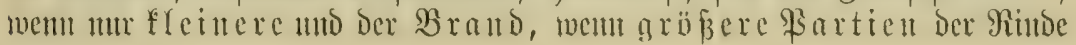




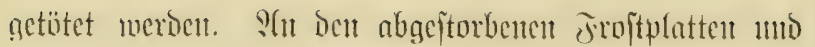

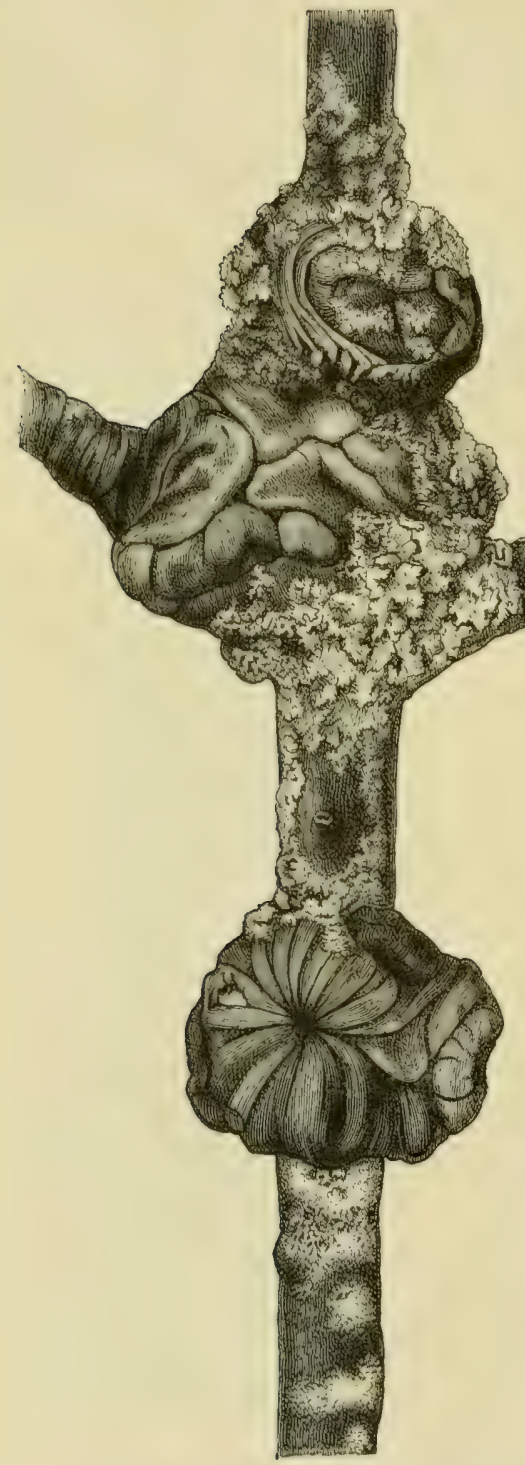

Jig. 133. Del geidjlolienc firebs.

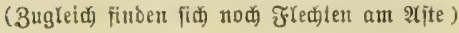

Brantojtellen jültt Die bertrofintete Rinde etruas eit

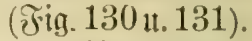
?(tud) bic

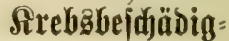
Iแเgen Der Bäıtıนe, bejonders der Dbjtbätmue, fitı anf uripriunglidse Froitbeichäbig= umgen 3 utrild $3 \mathfrak{s}=$ filibrent ttto die Nectria ditissima, iveldye nod)

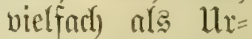
jactie Des Sirebje? Des Stpĩelbantre angejefent toirs, ift mutx eine nadjträg= lictre Erricheimutug. Der Pitz fant erift einoringen, ween bereits eine Beichäbigung vorliegt.

Mian interiderioet zivei

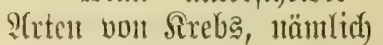

a) Dell offentll Srebs; bei ifym ift imt Góruttoe Der Wumbe eine abgeitor=

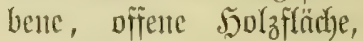
weldse vont einem über= watlumgaranto untgeben wiro (J̧ig. 132);

b) Den gejdlofienent Sireba, bei weldhell bie beicjäbigte Stefle Dutrdy mtafitige î̉berwallungärän= Der fait iiberoecft twiro (รing. 133).

Beim offenten Srebs fterben

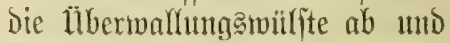
werden jährlidf ivieder ententert;

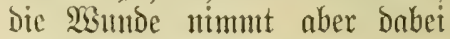
itets att llinfang zut.

Şäufig bitrot fid ber offene Srebs in Der Ildj)el Der

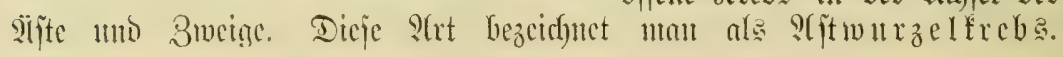




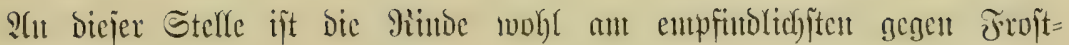
cimbirfintg.

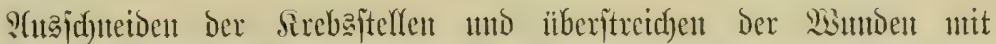

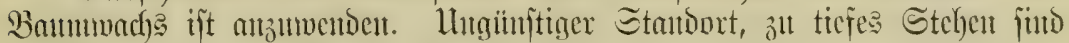

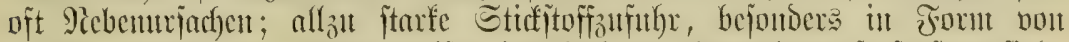

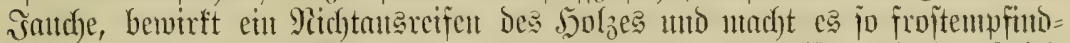

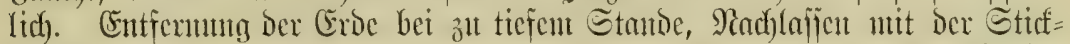

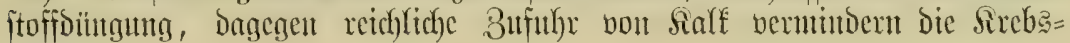
gefalyr.

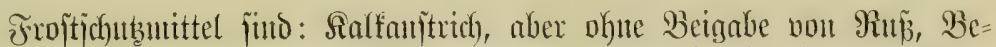

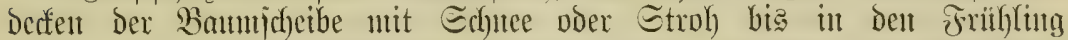

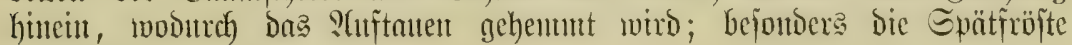
miniffen Gefämnft toerden.

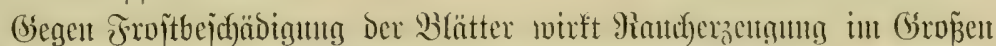

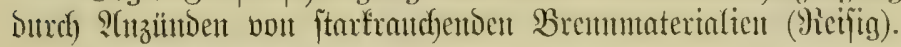

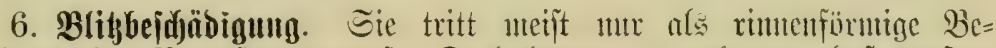

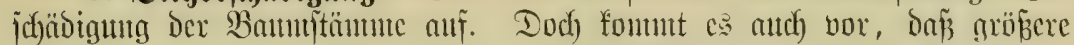

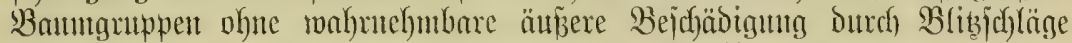
getötet werben. Jal biejent Falle suiro bas Eambitum netötet.

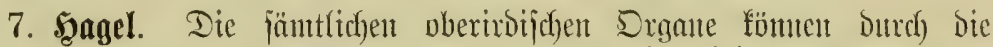
Sagelfürner jelye itarf bejchäsigt werben; io inerben beim

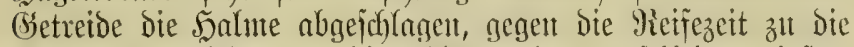

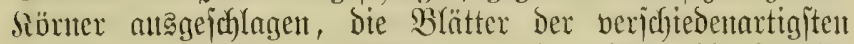

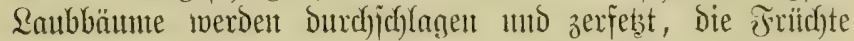

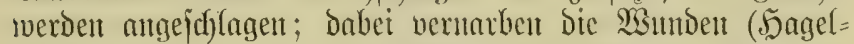

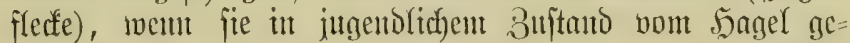

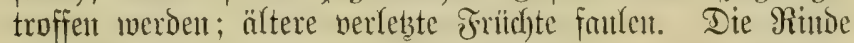

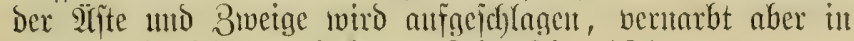

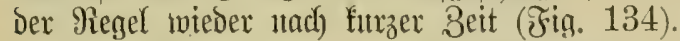

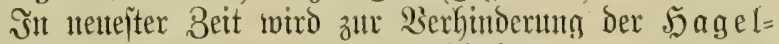
wetter cin jogenamte

8. Eturm. Sheftige Mistnde brechent doer Ftïrzen ganze Bäunte, ja nidf) felten ganze Bauntgruppent. Die einzige

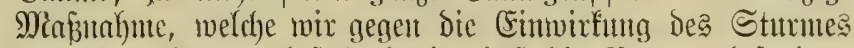

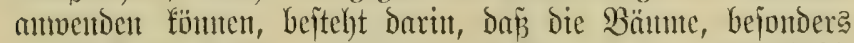

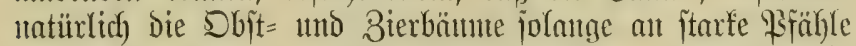

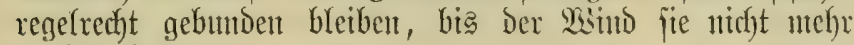
merfent fantt.

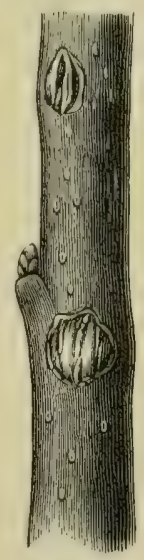

Æig. 134.

5eageltuminde.

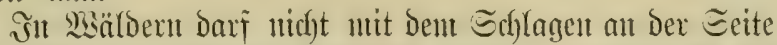

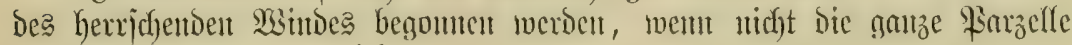
auf einmal geî́d)lagett wiró.

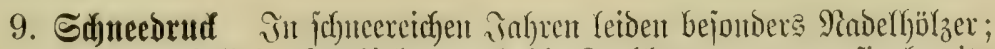

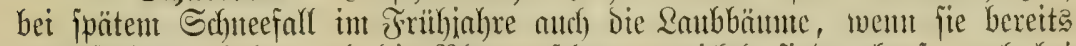

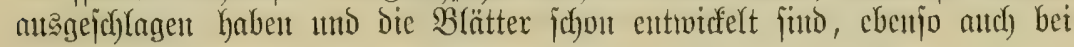




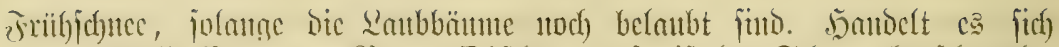

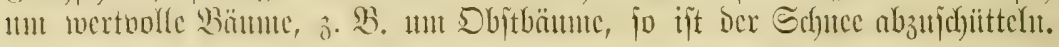

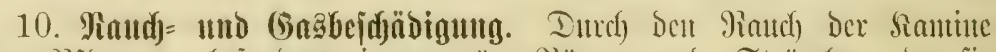

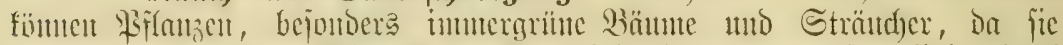

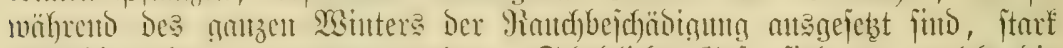

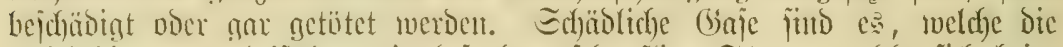

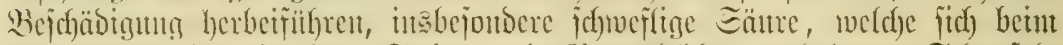

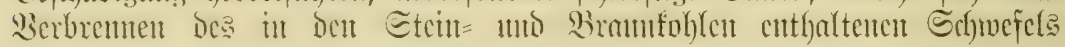
bifbet.

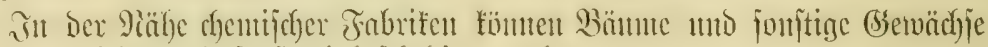
Dutrdy verjodiedene (Gaje ftart bejdäbigt werbent.

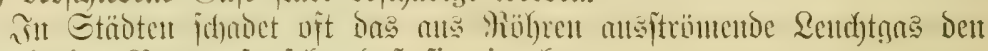

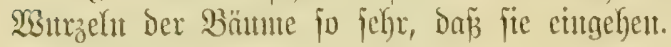




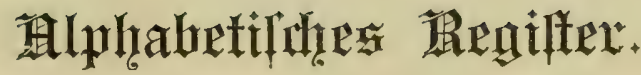

ภำڤäjer 113.

Abraxas 131.

2(äerbohne 47. 93.

Yderfrunmbals 50 .

2diferichneffe 164.

Actinonema 83.

Hecioicniporen 44.

2)garicus 58.

Agrotis 130.

Whorn 64. 77.

Albugineen 30.

Qillden 164.

Alectorolophus 7.

2rlpenroje 56.

2urpenrojenroft 53.

2tmeifen 139.

Andromedae 77.

Intherioien 28.

Anthomyia 144. 145.

Anthonomus 115.

2̈lpfel 82. 88, 90.

2Ypfelfaum 53. 57. 58. 64.

2fpfelbaumgeipinitntotte 135.

X)pfelbaumglaefliagler 125.

Upielblütenfted)ex 115.

Ipjelbohrer 125.

\{rpfelmotte 137.

2Ypfelfauger 151.

2Ypfelitecter 116.

2Ypfelmidéter 133.

Aphis 152.

Apiosporium 67.

Uprifoje 48, 82, 88, 92.

Iprifojenjpinner 129.

खrjenit 110.

乌̈lither 65 .

îficheridy 63.65 .

Ascochyta 83.

थื่comnceten 10, 59 .

Aspidiotus 157.

20itrurzelfrebs 172.

A̛gentroit 7.

அuะrufezeidjen 130.

autöcija) 44 .

23afterioie 26.

Bafioiombeten 10.38.
Baumwad) 98.

Baaumweip̈ling 123.

Bedeguar 139.

beizen 17.

Befämpfungèmetroden 13.

BefämpFungs̄mittel 15.

Berberize 49. 64 .

Bergflad) 7.

Beutenbrano 42.

Birfen 62. 71.

Birnbaum 51. 57, 60, 64 .

Birnen 73. 81. 86, 88. 90.

Birngejpinnitweipe 142.

139. Cercospora 93.

Birnfnojpenitect)er 115.

Birniauger 151.

Sirntrauermüiffe 147.

Blajebalg 16.

Blajenjub 148.

Blajentrantheit der Birne 60.

Blajenroit 53.

Błätterid)twamm 58.

Blattalftranteit ber Reben

Blattflölye 151.

BInttgallmillbe 162.

Blattfäfer 120.

Blattläule 151.

Blattweipen 139.

Błaujieb 125.

Brithbejüäbigung 173.

Blütenrüfifelfäfer 115.

B̊tutlans 154.

Bobennäife 168.

Bohne 47. 82. 83. 88.

Bohnenfäfer 114.

Bobnenroft 47.

Boraginaceen 49 .

Borbelaiferbrübe 18.

Borkentäfer 118. 119.

Boritentmürmer 166.

Brand 171.

Branomaus 110 .

Branopilze 38.

Bremia 32. 38.

Brombeerroit 51

Budbruder 119.

Budje 57. 58. 64.
Butfelidjorf 26.

Burgunoerbrilbe 18.

Burbaun 48.

Calyptospora 46. 54 .

Capnodieen 66.

Capnodium 66.

Carabiden 112.

Carpocapsa 133.

Cecidomyia 145.

Cemiostoma 137.

Cheimatobia 131.

Chermes 154 .

Chlorops 146.

Chrysanthemum 65.

Chrysomyxa 46. 53.

Eichorien 79.

Clasterosporium 92.

Claviceps 70.

Clostridium 25.

Coleosporium 46. 54 .

34. Conchylis 134.

Cronartium 46. 53.

Cucurbitaria 72.

Cuscutaceen 3.

Cuscuta europaea 5.

Cystopus 31.

Cytisus 92.

Dasyscypha 78.

Daueriporen 12. 44.

Dematophora 72.

Diachora 70.

Diaspis 157. 158.

Discomyceten 75.

Doldenblïtler 36. 48. 65 .

Doppelichorf 70 .

Dothideaceen 67. 70.

Dothidella 71.

Drabtruirmer 113.

Ebelfäule der Meinbeeren 79.

(5id)en 57. 62. 64.

(5idjentwurzeltöter 72 .

(Eichbörndyen 110.

Eijporen 10. 28.

Elateriben 113. 
(Ellenrübler 117.

Endivie 86.

Engerfinge 113.

Epichloë 69.

Erbjen 37. 47. 83.

Erbjengraurübiler 115.

Erbjentäfer 114.

Erbienminierfiege 147.

(Erbjenrojt 47.

(Erobeere 64. 81 .

Erobeerblattweipe 139.

(5robeeritedyer 115.

(Froflöhe 121.

Eroraupen 130.

Eriophyes 161.

(Erlen 62. 64.

Erysipheen 62. 64 .

Erysiphe 63.

(Efduen 57. 64.

Eiparjette 47. 70.

(Eipenrojt 54.

Eulen 130.

Euphorbia 47.

Euphrasia 7.

Exoascus 59.

Exobasidium 56.

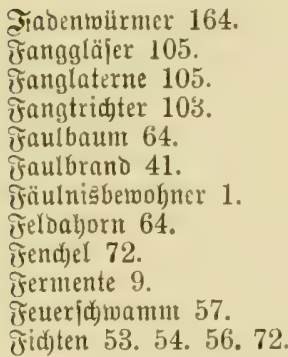

Fidutenblattrueipe 141.

Jidatennabelroit 53.

Fidonia 132.

Filztrantbeit Der Mebe 162.

Fladjidjorf 26.

fflachsroit 54.

Iflad)sileide 5.

F̆(ad)sfeidengemädje 3. 5 .

F̂leijuffledten 69.

Jitiegen 143.

Iflorfliege 102.

Flugbrano 40. 41.

isritfliege 145 .

Froitplatten 171.

Froitipanner 131.

ปันd)ร 129.

Fungi imperfecti 80.

Fusicladium 90.
Gabelraupen 128.

(5)allmillben 161.

(5)alfweipen 139.

Gammaeule 130.

Sartennelfe 74.

(5artenfrefie 31.

(5a)

Gastropacha 129.

Bemiileeule 130.

Geometriden 130.

Gerad flüglex 147.

(Berite 41.49. 93

Gejpinftmotten 135.

Getreidearten 49.

Getreideblajenfús 148.

(Setreideblattroit 49.

Getreidefliegen 145.

(Getreidebähndden 121.

(Setreidebalmroit 49.

Getreidehalmocipe 140.

Betreidelauftäfer 112.

Getreideminierfliege 146.

Gietreibevertwijfter 145.

(5id)tförner 165.

(Sitterroit 51. 53.

Glanżäfer 113.

(3)fiedertiere 96.

Glocosporium 87.

(5)lockenblumten 54.

Gnomonia 75.

(jioloafter 126.

Golblact 31.

Goloregen 47. 73. 92.

Goloregenroft 47.

Gräjer 65.

(5rauribşer 115. 116.

Grillen 149.

(Burfen 6488.

Gymnoasceen 59.

86. Gymnosporangium 46.51.

sagel 173.

5ainbuche 57.62. 64 .

5olbidmarotjer 7.

sualfintajd 58.

5alnifliege 146.

5ुamiter 109.

รัanf 5.41 .49 .50 .80 .85$.

5anffrebs 79.

๖anfruirger 5.

Syarletin 131.

Sale 109.

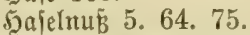

5ajelnub̆bohrer 117.

5)auรmaน 110.

ราausfdwamm 58.

Haustorien 4.

5̧autpilze 55.
Seioelbeerent 56.

Soeimdien 149.

Helminthosporium 92.

Jernie 24.

5efienfliege 145.

heteröcifid) 44 .

Heterosporium 94.

5eufidreden 148.

5̆euturm 134.

nerenbeien 54.61. 62.

Hibernia 131.

5imbeerenglasflïgler 126.

simbeerroit 51.

5iride 108.

Sirie 42.

Sirjebrand 42.

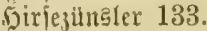

$50 l_{3}$ bobrer 123.

ઝolzfäule 55.

5onigidjwamm 58.

5opien 5.64.66, 80, 85 .

5opfentwanze 151.

Sopfenzifade 150.

5opfenzünకler 133 .

Sungerzwetidge 61 .

5utpilze 55.

Syacinthen 25.74.

Hydnum 58.

Hymenomyceten 55 .

Sinphen 8.

Hyphomyceten 80.88 .

Hypocreaceen 67. 68.

Hyponomeuta 135.

Injetten 111.

Iniettenpulver 108.

Jochjporen 10.

Johannisberen 49 . 81.86.

87.

Johanniąbergląflüglex 126

Johannisbeerroịt 49 .

Johannisbeeripanner 132.

Jjoliergräben 23.

Junifüfer 113.

Julitäfer 113.

Säfer 112.

Ralfanitrich 97.

Sialf, gebrannter 105 .

Salf́, gelöldhter 106.

Rälte 169.

Ramelhalsfliege 102.

Raxbenidimmel 37.

Siartofiel 25. 26. 33. 72. 79.

Rartoffelfrantlyeit 33.

Siartoffeliajorf 26.

Sartoffelzifade 150. 
Saitanien 57.

Sieimlingstöter 30.

Rernfäule 56.

Siernobit 58.

Rernobitfäule 79.

Sernpilze 67.

Riefer 53. 54. 56. 76.

Sitefernblattweipe 141.

Sieferneule 130.

Siefernjpanner 132.

Sitefernjpinner 129.

Rixjden 61.64.82.88.90.92.

Sirịb)bäume 57.

Sixjdblattroejpe 141.

Siridgenroft 49.

Sixpdfliege 143.

Sirichlorbeer 92.

Slapper 7.

Slebegurtel 103.

slee 37. 47. 71. 72. 77.

Rleetrebs 79.

fileero|t 47.

fleeichinmmel 37.

Sleepeide 4. 5.

Sileeteufel 5.

Sileetod 72.

Sinojpengallmilbe 162.

Robl $21.24,81$.

sobleule 130.

Soblfliege 145.

Sohfgallentibjter 117.

Rohlidunedfe 147.

Roblweif̆ling 122.

Robläungler 133.

Rolbenfixje 42.

Solbenjdimtntel Der Bräjer

Roloracotäfer 120.

69.

Sompojiten 31. 65.

Ronibien 27.

fornmotte 138.

forntourm 138.

Sxäufelfrantheit 61 .

Sxautfäule 33.

Лrebe 172.

Rrebs der \&aubböume 68.

Sreuzbliutler 31. 36.

Sireuzoorn 64.

Sireuzlraut 54.

Sriecten 62.

Sironenroft 50.

Sropftrantheit des Sobras 24.

Siupferbrano 161.

Siupferjałze 106.

Rupferjodabribe 18.

Supfervitriol 17.

Rupfervitriolfalffrithe 18. Ruirbis 64.
Särche 56. 76.

\&ärdenblattweipe 141.

Särdenfreb马 78.

\&ärdyenmotte 138.

Sappenrilïler 115.

Lathyrus 37.

Saubtäfer 113.

Raudrojt 49.

Rauffïfer 112.

Lecanium 158. 159.

Seimring 103.

Leptosphaeria 73.

Stebjtödtelrüß̄pler 115.

Silienbäbndyen 121.

Sinden 57. 81.

Sinjen 37. 47.

Qinjentäfer 114.

Sobe 69.

Lophodermium 76.

Loranthaceen 6 .

Subine 46.

Rupinenroft 47.

\&uzerne 5. 37. 48. 72. 77.

Quzernenroit 48.

Suzernenjeide 5.

Suzernentod 72.

Lyonetia 137.

ątaitäfer 113.

刃atis 42. 48.

פlaisbrano 42.

Maisroit 48.

Malvenroft 48.

Mamestra 130.

Mandeln 48. 92.

Marienfäferden 102.

Marsonia 88.

Maultwuxiggrille 149.

Meerrettic 31. 85.

Meerretticjblattfäfer 121.

刃teerrettichgalfenrïßjler 117.

Meerrettichjpanner 132.

Mebltau, edter 62 .

Mehltau, falidger 27. 30. 32.

Melampsora 46. 54.

Melampsoraceen 46 .

Melampyrum 7.

Melanconieen 80, 87.

Meligethes aëneus 113 .

Merulius 58.

Microgaster glomeratus

Microsphaera 63. 64.

101.

Minierfliege 146.

Mípel 73.86 .

Mlijtel 6.

Mitefier 1.

Mobn 37.
Mohnjofimmel 37.

ฏłöhren 72. 79.

Mäbrenfliege 144.

Mohrhirje 42.

Monilia 88.

Mloosbeere 56.

Mopaiffrantheit 27.

Motten 137.

刃luiten 147.

Mutterforn 70.

Mncelium 8.

Mytilaspis 157. 158.

Myxomyceten 24.

Myzus 152.

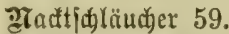

Mactijunecten 163.

Jadelhölzer 58.

Rabelbolzrüß̄er 118.

Nagetiere 109.

Rarrentrantheit 60 .

Ra ffäule 25.

アajduer 115.

Nectria 68.

Relfenropt 48.

Riflfäjten 101.

Rijtpläßse 100.

Ronne 129.

Ruถ̄bäume 57.

(9) Gitbaumplintfäfer 118.

Sbftblattminiermotte 137.

Ocneria 129.

Datjenzunge 49.

Odontites 7.

Dhrmilumer 148.

Oidium 63. 65.

Dogonien 28.

Dojporen 10. 28.

Ophiobolus 74.

Orgyia 129.

Orobanchaceen 5.

Orobanche 5.

Drobus 47.

Orthopteren 147.

Oscinis 145.

¿appeln 57. 62.

Yappelroji 54.

Parafiten 1. 3.

Sarajiten, tierifuse 101.

Baftinat 94.

Perisporiaceen 62.

Peronospora 32. 36.

Peronosporaceen 27. 32.

Peronosporeen 30.

Pestalozzia 86.

Peterjitie 93. 
Betroleum 106.

\$Fa fientäppç)en 64.

łffirfid) 48.61.82, 88, 92.

Bflaumen 88. 92.

şflaumenbohrer 116.

'Bflaumengeipinịtmotte 136.

SFlaumenmade 134.

Pharodon 154.

Phoma 82.

Phragmidium 46. 50.

Phosphorteig 110.

Phyllachora 71.

Phyllactinia 63.

Phyllocoptes 162.

Phyllosticta 80.

Phylloxera 155.

Phytophthora 32, 33. 34.

ßilze, unvollftändige 80.

Piophila 143.

Plasmodiophora 24.

Plasmodium 24.

Plasmopara 32. 24.

Blatanen 57. 87.

Platterbien 37. 47.

Pleospora 74.

Plowrightia 71.

Plusia 130.

Sbotentrantbeit 162.

Boctenmilben 161.

Podosphaera 63. 64.

Polyporus 56. 57.

Polystigma 69.

Borré 49.

Porjtroit 53.

अradttäjer, gebudyteter 120.

Hreipelbeere 54. 56.

Prombcelium 12.

Pseudopezizza 77.

Psila 144.

Psylla 151.

Pteromalus puparum 101.

Puccinia 46. 48.

Pucciniaceen 46 .

Pulvinaria 159.

Buppenräuber 102.

Pyrenomyceten 67.

Pythicen 30.

(Quafiiaaนริวน 107.

Euendeljeide 5.

Quitte 51.73. 86. 88.

Zånentörner 165.

Rape 31.

Rapsglanjtăfer 113.

Rapstrebs 79.

RapsuerDerber 74.

Piatte 109
Raud 173.

Maupenfactel 103.

Maupenleim 104.

Baupennejter 128.

Raupenjdere 103.

Maujdbeere 77.

Mebe 34. 64. 65. 72, 87.

Mebenjteder 116.

Meblaus 155.

Megentwirmter 166.

Эié) 108.

Meifmotte 131.

Reineclauben 48.

Jettic) 31. 79.

Rettidffiege 145

Mettidgatlenriibler 117.

Mbabarberpanner 132.

Mibinanthaceen 3.7 .

Mibizoftonien 72.

Mhizomorphenjtränge 58 .

Rhytisma 76.

Mindenblajenroit 53.

Rindengallmilbe 162.

Pingeljpinner 128.

Ringfäule 56.

Yiemenblumengemädje 6 .

Mttzenjdjorf 76.

Möte Der Siridjenblätter 75 .

Roggen 41. 43. 49. 74. 85 .

Moggentalmbrecter 74 .

Roggenitengelbrano 40.

Rosellinia 72.

Mojen 37. 63. 81. 8t.

Pofenblattjifade 150.

Mojenroft 51.

Rojenidjimntel 37. 63.

Mośtajtanien 57.

Moltpilze 43.

Motbudje 68.

Motiäule 56.

Rog 25. 26. 27.

Miliben 24.31.

Miibenäldjen 166 .

Miibenblattweipe 139.

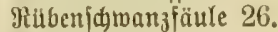

Ribennematoden 166.

Rutbien 24.

Rülfielfäjer 115, 118

ßunfelffiege 147.

Runfelruben 26. 37. 47. 72.

74. 79. 83. 93.

Runfelriłbenbräune 74 .

Runzeljojorf 76.

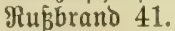

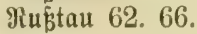

Saateule 130.

ङalat 38. 86.
Samenfäfex 114.

Saprophnten 1.

Sauerborn 51. 134.

Säugetiere 100. 108.

Sdäblinge, tiexijdye 96.

Sd)eibenpilze 75.

Sdermaus 109.

Exdjilbläuje 156.

Schizomyceten 25.

Schizoneura 154.

Sd)laudbilze 10. 59.

Sdhlehen 64.

Ed)lehenipinnex 129.

Edleimpilze 24.

Sdlupfreipen 101.

Edmalbaud 119.

Sdimetterlinge 122.

Edmierbrano 41.

Ednabelferfe 149.

Sanaten 147.

Sdjneeball 64.

Sdjnedfen 163.

Sd) nedfenflee 48.

Sdneedrut 3.

Sdunelltäfer 113. 114.

Edunittlaud 49.

Edjorf 26.

Edyotenpieifer 133.

Edrotidubifrantlyeit 92

Ed)uppentourz 5.

Edwammipinner 126.127.

Sdjwärmiporen 27.

Sdivarzmurzel 31. 32.

Schwebefliegen 102.

Sdumefel 15.

Ed)mefelcalcium 106.

Sdjwefelleber 106.

Sd) wefelpulver 106.

Sclerotinia 78.

Sellerie 48. 93.

Selleriefliege 143.

Selferierolt 48.

Septoria 84.

Silpha atrata 113.

Siphonophora 154.

Eflerotienfrantheit des flee?

79.

Sommeriporen 12.

Sommermurzgetväd je 5 .

Sonnenblumenroit 49.

Sorghumbrano 42.

Spätling 131.

Epaltpilze 25.

Spanner 130.

Spargel 49. 72.

Spargelfliege 143.

Spargelbähnd 120.

Spargelfäfer 120. 
Epargetroit 49.

Epeijeztwiebel 27. 43. 79.

Epermogonien 44.

Sphaerella 73.

Sphaeriaceen 67, 71.

Sphaeropsideen 80 .

Sphaerotheca 63.

Spinat 37. 94.

Epinatianimmel 37.

Epinnentiere 159.

Epinnmilbe 160.

Spinner 126.

Spinte, rote 160.

Epinnwurm 134.

Spitymäuşdyen 115.

Eporen 10. 11.

Springwurm 135.

Eprigen 20.

Etadjelbeeren 49. 64. 86.

Stadjelbeerblattmejpe 140.

Stadtelbeeripanner 131.

Stachelidinamm 58.

Staubbrano 41.

Steafriiben 81.

Steinbrand 40.

Steinfrudutfted)er 115.

Eteinfruditter 92.

Eteinflee 37.

Steinobitbäนme 48.

Steinobitfäule 79.

Steinobitmeipe 143.

Stengelbrand 43.

Stigmatea 73.

Stintbrand 41.

Stoctäldonen 165.

Stoútrofe 48.

Strudinin 110.

Sturm 173.

Suntpibeidelbeere 56.

Tabal 27. 82.

Tabafjaft 107.

Tagfalter 122.

Tagpfauenauge 122.

Tanne 56.57.67.72.83.86.

Taphrina 59.

Tajdenfranfheit 60 .

Iaujendfü̈̄jer 163.
Teer 99.

Teleutojporen 44.

Tetranychus 160.

Thesium 7.

Thrips 148.

Tiefichori 26.

Tierfrā̄ 99.

Tilletia 40.

Iopinambur 49. 79.

Tortriciden 133.

Trametes 56.

Traubentixidye 60 .

Iraubentrantheit 65 .

Iraubentwiffler 134135.

Trichosphaeria 71 .

Iroctenkeit 168.

Trypeta 143.

Tylenchus 165.

בlme 57. 62. 71.

Uncinula 63. 64.

Uredineen 43.

Uredosporen 45.

Urocystis 43.

Uromyces 46.47.

Ustilagineen 38 .

Ustilago 40, 41.

Vauessa 129.

Beildjenroft 49.

23erborgentïj̆er 117.

Viscum 6.

Bögel 100. 110.

Bogelbeeren 64.

Bulfan 16.

จฺุaholder 56. 76 .

Wadbtelweizen 7.

Walontaus 110 .

खalnuв 57. 75. 88.

Banzen 156.

Bafferratte 109.

Meberfarbe 37.

Meidtiere 96. 163.

Weiden 64. 77.

Meidenbohrer 124.

Beidenrojt 54 .
Weinntotte 135.

Beinito 34.

Meif́orn 51. 64.

Beifroit 20.

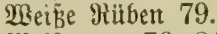

W3eistanne 76. 84.

Weizen 41.49.65.74.83.84.

Weiżenäldden 165.

Beizeneule 130.

Beizenhalmtöter 74 .

Beizentörner, rojenrote 27.

Berre 149.

खejpen 139.

ßenmoutbatiefer 53. 6.76 .

Miffe 5. 37. 47. 83.

Midenroft 47.

खitữ

Widfler 133.

Wiederfüuer 109.

Binteriporen 12.

Mirbeltiere 96.

खुolflaน 154 .

Wüblmaus 109.

Würmer 96.

Wundenbehandlung 98.

Munoparajiten 67.

Bürmer 164. 169.

Murgelbohrer 125.

Burzelfliegen 144.

Burzellaue 155.

Murzelpilz Der Rebe 72.

Zabrus gibbus 112 .

3ifaden 150.

3 itterpappel 57.

3udferriben 37.47 .72 .83$.

Bungler 132.

3underidgroamm 57.

31weigabited)er 116.

3wetidgen 48.60. 62. 64 .

69. 82.

3metjøggenbäume 57.

3 wiebel 49.

3roiebelbrand 43.

3rwiebelroft 49.

3 miebelficinmel 36.

3ygoiporen 10. 


\section{Schutz der Obstbäume gegen}

\section{feindlicbe Ciere und gegen Krankbeiten.}

Don

Profeffor Dr. Eafchenberg u. Profeffor Dr. Soraner.

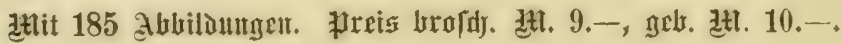

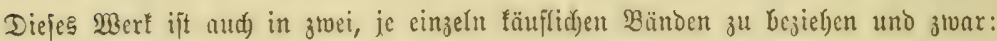

\section{Band:}

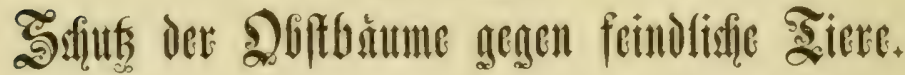

Don Drofefior Dr. E. E. Eajchenberg.

Dxiffe gänzliff ungearbeifete Ruflage von

Dr. (I). Eajchenbera.

Profeffor at ber uniberfitat zu Sarre.

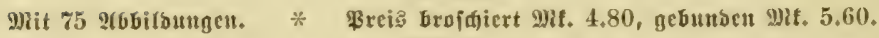

Huszug aus fühlings landwirtlchaftl. Zeitung 1900, Nr. 24:

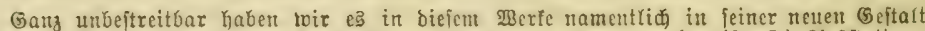

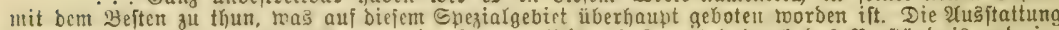

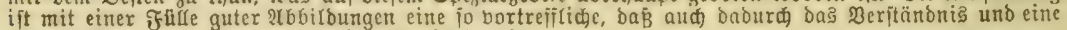
fänelle Drientierung gang erfeblid geföroert fint.

\section{Band:

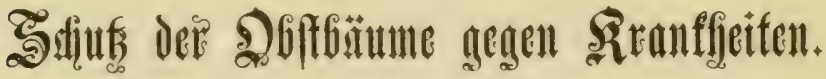

Ein praftifher Ratgeber

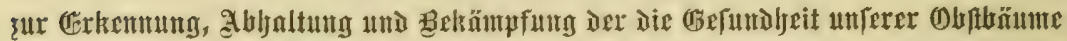

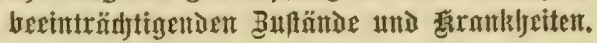
Don Profeffor Dr. $\mathfrak{p} \mathfrak{a} \mathfrak{u} \mathfrak{l} \leq \circ \mathfrak{r} \mathfrak{a} \mathfrak{u} \mathfrak{e}$.

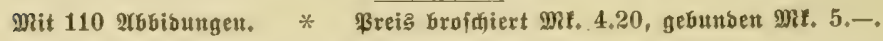

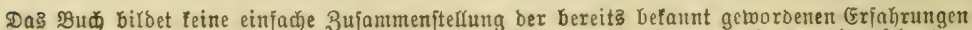
nuf Dem Gebiete ber Softbaumfranffeiten, fortbern bebeutet einen ltmidwumg iu beu herridjenten

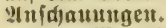

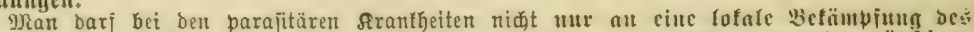

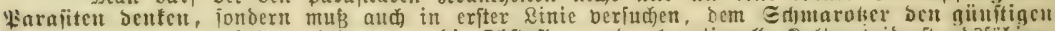

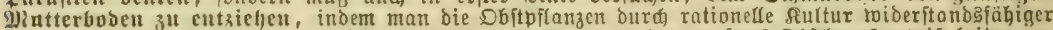

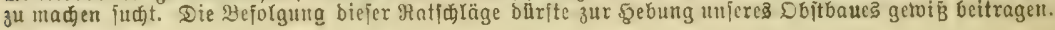




\section{Atlas \\ der Krankheiten und Beschädigungen landwirtschaftlichen Kulturpflanzen.}

Herausgegeben von
Dr. O. Kirchner
und
H. Boltshauser
Professor a. d. landw. Akademie in Hohenheim.
Sekundarlehrer in Amriswell.

Serie I: Getreidearten. (20 kolorierte Tafeln mit Text in MIappe M. 10.-). Wandtafelausgabe: die Tafeln auf 2 Blatt auf Leinwand aufgezogen. In Mappe M. 13.-.

" II: Huilsenfrüchte, Futtergräser u. Futterkräuter. (22 kolorierte Tafeln mit Text in Mappe M. 12.-).

Wandtafelausgabe: die Tafeln auf 2 Blatt auf Leinwand aufgezogen. In Mappe M. 15.-.

„ III: Wurzelgewächse u. Handelsgewächse. (22 kolorierte Tafeln mit Text in Mappe M. 12.-).

Wandtafelausgabe: die Tafeln auf 2 Blatt auf Leinwand aufgezogen. In Mappe M. 15.-.

„IV: Gemüsepflanzen und Küchenpflanzen. (12 kolorierte I'afeln mit Text in Mappe M. 7.-).

Wandtafelausgabe: Auf Lcinwand aufgezogen in Mappe M. 9.-

, V: Obstbäume. (30 kolorierte Tafeln mit Text in Mappe M. 15 -). Wandtafelausgabe: die Tafeln auf 2 Blatt auf Leinwand aufgezogen. In Mappe M. 18.-

In Vorbereitung ist:

Serie VI: Weinstock und Beerenobst. (ca. 20 Tafeln mit Text.) P. (Gelangt im Jahre 1902 zur Ansgabe.)

Die gleiche Einteilung des Stoffes, wie diesem „Atlas der Pflanzen* krankheiten" liegt dom früher erschienenen Kirch n er" schen Werk zu Grunde:

\section{Die Krankheiten und Beschädigungen}

\section{landwirtschaftlichen Kulturpflanzen.}

Eine Anleitung zu ihrer Erkennung und Bekämpfung

für Landwirte, Gärtner etc.

Von Dr. Oskar Kirchner,

Professor cler Botanik an der Kgl, württ. landw. Akademie Hohenheim.

647 Seiten in gr. $8^{\circ}$. - Brosch. Mk. 9.- In IIalbfr, gebd. Mk. 10.20.

Izurze Inkaltsỉbersicht:

Hrstor Teil: Die landwirtschaftlichen Kulturpflanzen mit ihren Krankheiten und l’’schädigungen. I. Getreide. II. Hülsenfríchte. III. Futtergräser. IV. Futterkräuter. \. Wurzelgewächse. VI. Handelsgewächse. VII. Gemüse- und Kïchenpflanzen. VIII. Obstbäume. IX. Beerenobstgewächse. X. Weinstock.

Zweiter Teil: Systematische Beschreibung der Pflanzen und niederen Tiere, welche Krankheiten und Beschädigungen an Iandwirtschaftlichen Kulturpflanzen verursachen: I. Pilze. II. Blütenpflanzen, III. Tiere. 


\section{Dow Tantomamn Honferabente.}

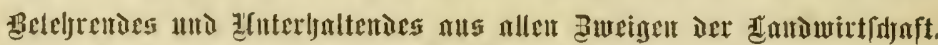

Die Bänoden futo insbejondere zur Reftïre für die jüngere länoliche Bevölferung geeignt, indem fie diejelbe in bie verfhiebenjten Zmeige Der Rand= wirtid)aft belehrent und anregeno einführen, Die Frende an ibrem Beruf erböben tmo zu ulülicber $\mathfrak{I}$ hätigfeit anjporten follen.

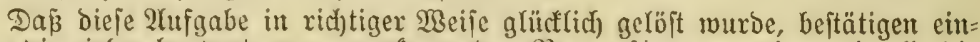
ftumig bie vielen hunderte von anerfentenden Rezcnfionen, wie aud alle die (5mp iehlungen, die dem ourd)weg volf'stïmlich gefdriebenen Samntelwerf pon allen Seiten, darunter von höchiten Steflen, zu teil wurben.

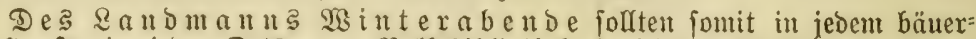

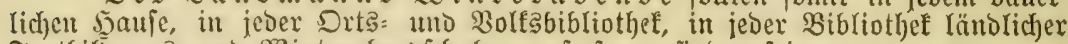

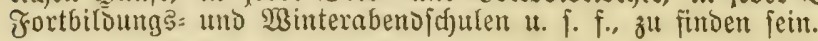

\section{5 Serite.}

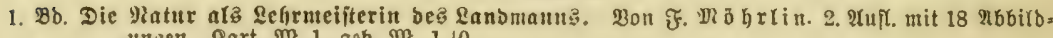
unuer. Rart. M. 1, geb. M. 1.10 .

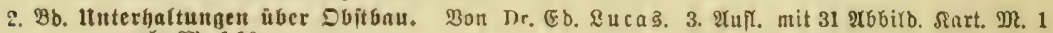
geb. Đr. 1.10 .

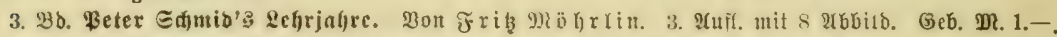

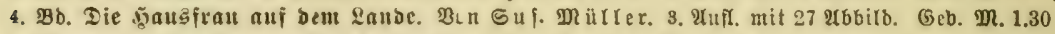

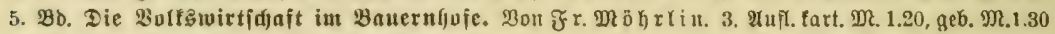

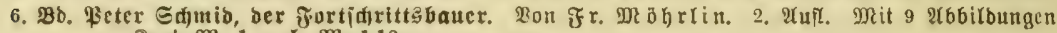
fart. MR. 1, geb. MR. 1.10 .

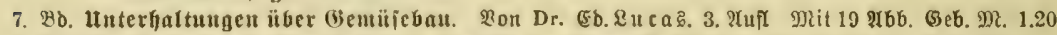

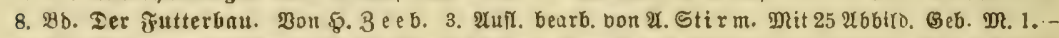

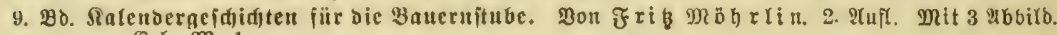
(5)b. MR. 1 -

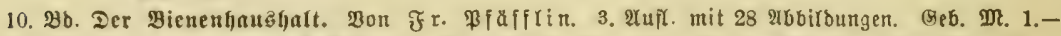

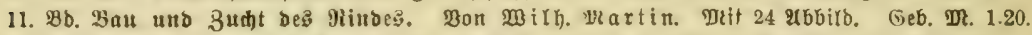

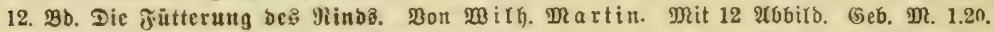

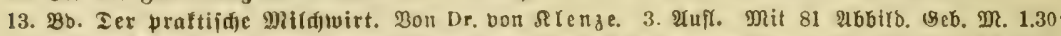

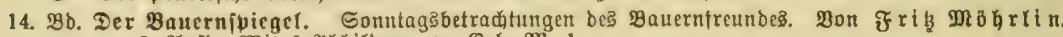
2. 2uft. Mit 6 2ubilbungen. Beb. Mr. 1.-.

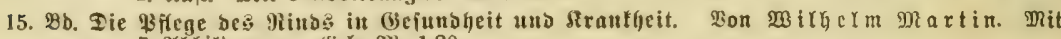
7 צabilbungen.

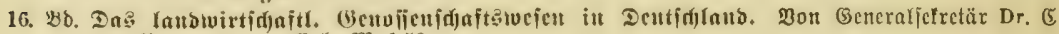
Reumant. (ङеb. Mr. 1.50.

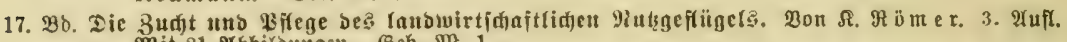
Mit 21 ঐbbiloutgen. (Beb M2. 1.-

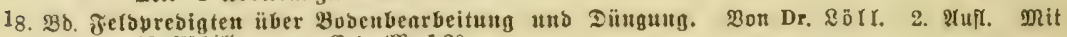
18 2ubbilbungen. (Geb. 'MR. 1.20 .

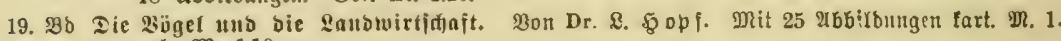
geb. $\mathfrak{M}$. 1.10.

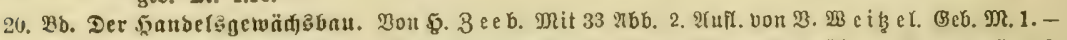

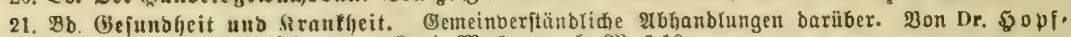

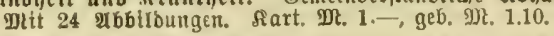

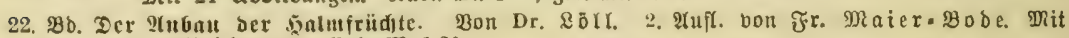
52 शbbirbutgen. (5eb. DR. 1.20 .

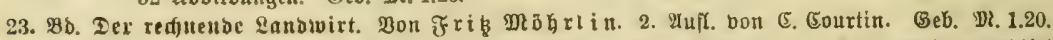

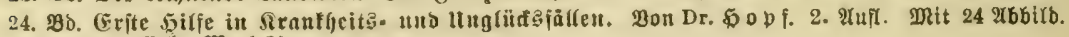
Geb. M. 1.20 .

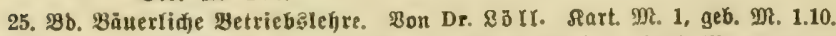

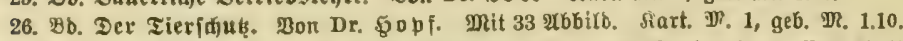

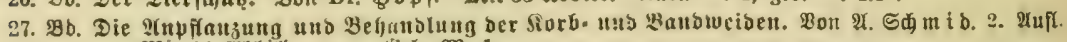
Mit 28 थbbiltungen. Geb. M. 1.-

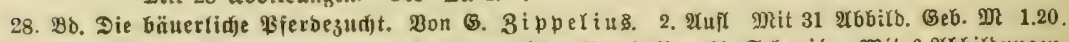

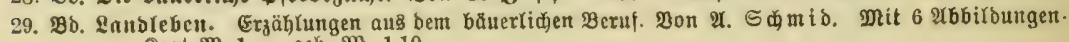
Rart. DR. 1., geb. M. 1.10. 


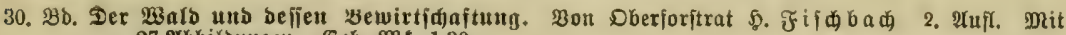
27 थbbildunget. (

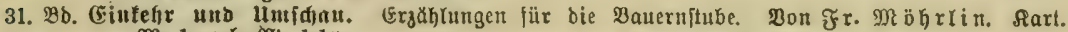
DR. 1 , geb. Di. 110 .

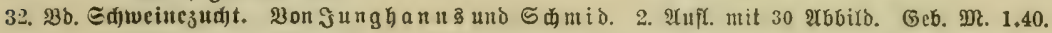

33. 2B. Dic Fijdjudt. Won Dr, (E. Wiebershein. Mit 25 थbbild. Jaat. M. 1, geb. DR. 1.10.

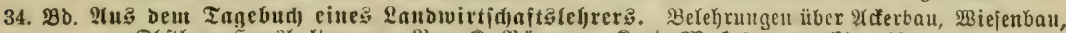

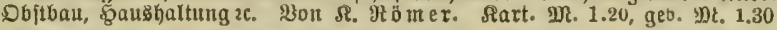

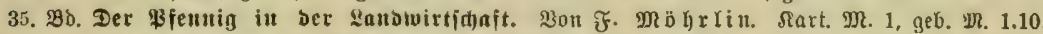

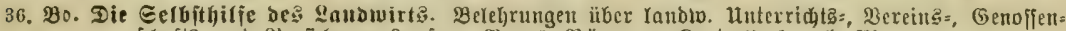

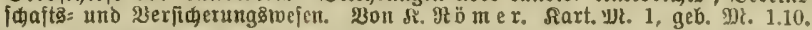

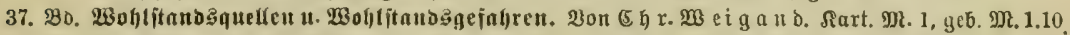

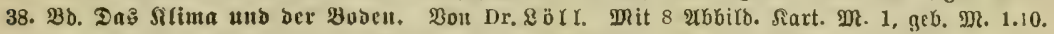

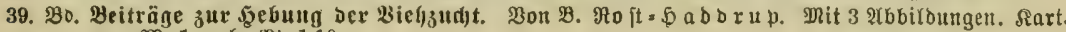
MR. 1, geb. $\mathfrak{D}$. 1.10 .

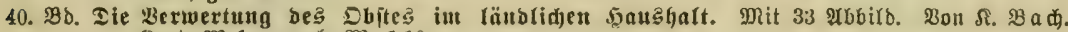
Slart. M?.1.-, geb. M. 1.10 .

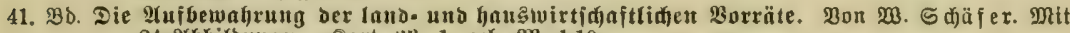
24 2rbbiloungen. Sart. 파. 1, geb. MR. 1.10 .

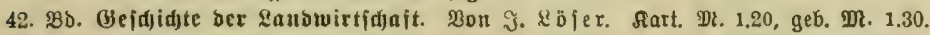

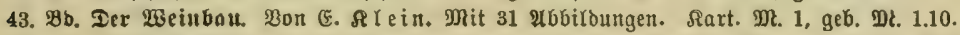

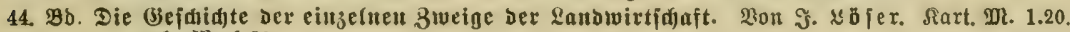
geb. 2 ll. 1.30 .

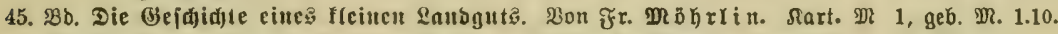

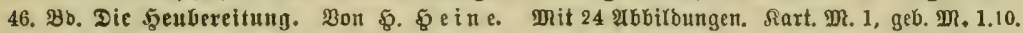

47. $\mathfrak{B D}$. Der Stalloiuger. Don 0 t to Ge

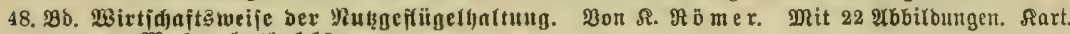

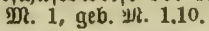

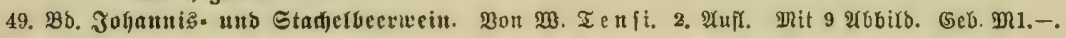

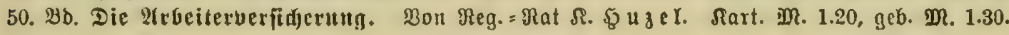

\section{1. \$exte.}

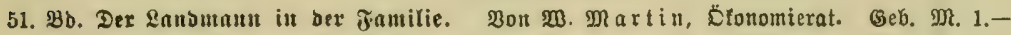

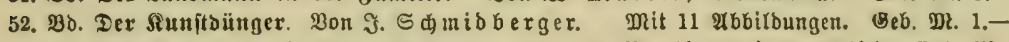

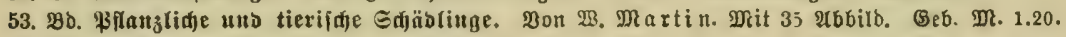

54.

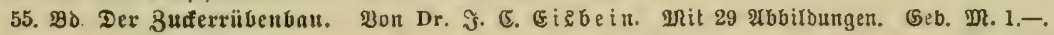

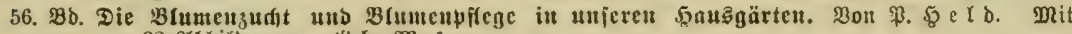
32 थbbiloungent. ॐеb. MR. 1.-

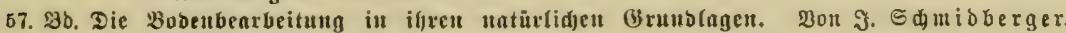
Mtit 9 \{abbildungett. $\mathfrak{D t}$. 1.-.

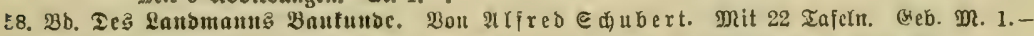

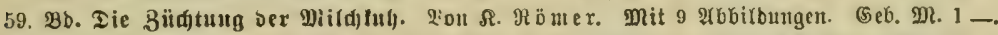

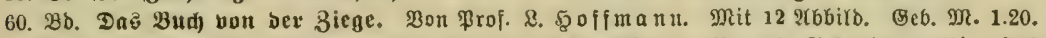

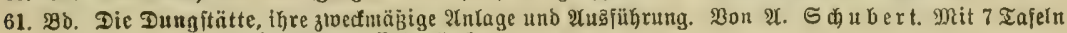
und 12 2tbbiloungen. Beb. עl. 1.-

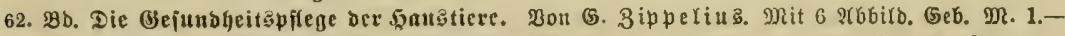

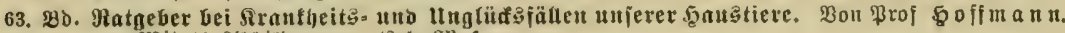
Mit 11 2bbildungen. (5eb. 2Nt, 1.-.

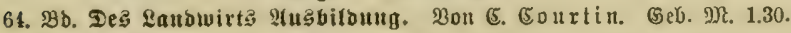

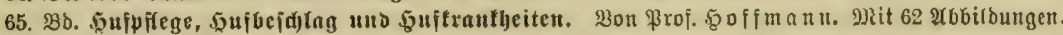
(Beb. M. 1. -

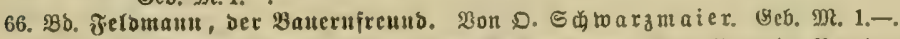

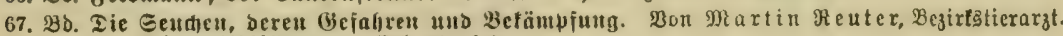

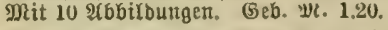

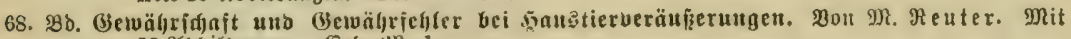

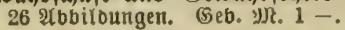

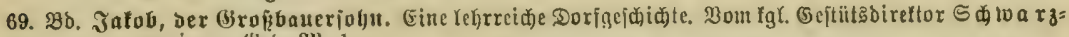
maier. (yeb. Mjt. 1.-

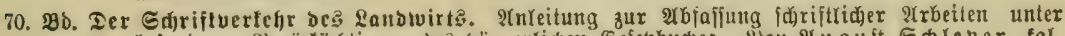

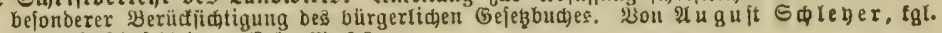

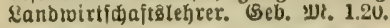

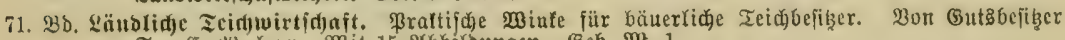

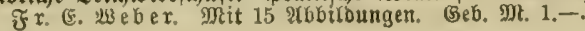




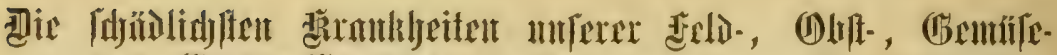

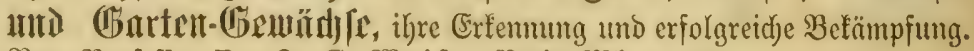

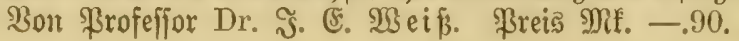

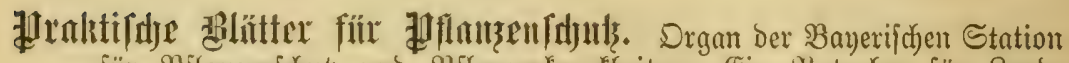
für \$flanzertfduth und \$fflanzenfrantheiten. Ein Matgeber für Ranb=

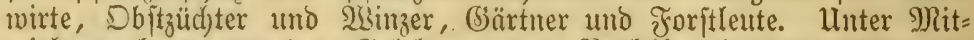
wirfung hervorragender (3̈elehrter unt \$raftifer herausgegeben von

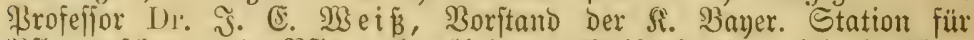

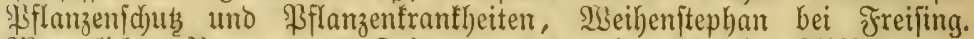
M(onatlid) 1 Jiummer. 8 Seiten gr. $8^{\circ}$, mit zahtreid)en I(bbiloungen.

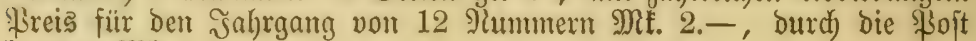

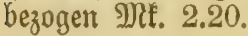

\section{Zeitschrift für Pflanzenkrankheiten. Organ für die Gesamt-} interessen des Pflanzenschutzes. Herausgegeben von Professor Dr. Paul Sorauer. Jährlich erscheinen sechs Hefte, je vier Druckbogen stark, mit lithographierten ' $\mathrm{T}$ afeln und in den 'lext gedruckton A b bild ungen. Preis des Jahrgangs Mk. 15.-. एङ Empfohlen vom K. preuss. Ministerium für Landwirtschaft, Domänen und Forsten und rom K. und K. österreichischen Ackerbauministerium.

Die "Zeitsohrift für Pflanzenkrankbeiten" pllegt die Lohre von den

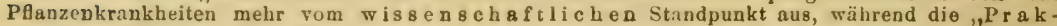
tischen Blätter für Pflanzenschutz" sich bemühen, die Ergebnisse wissenschaftlicher Forschung dem praktischen P flanzenzüchter zum Gemeingutzu machen.

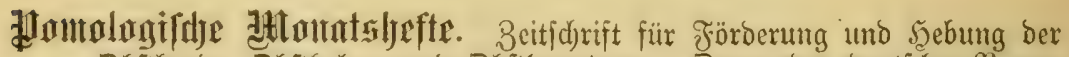
Dbitfunbe, Dbiffultur uno Dbitbenubung. Drgan Des Deutiden \$omo= logenvereins. Sherausgegeben von Dfontonterat $\widetilde{F}$. Rucas, Direfttor

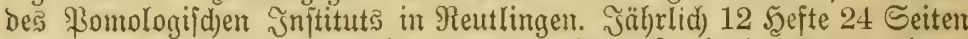

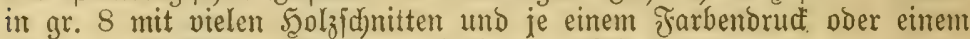
¡d)warzen Sollbillo. Fisets pro J̃ahrgang Mif. 4.50.

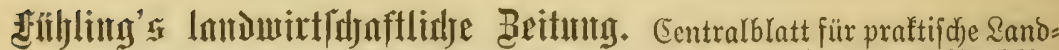

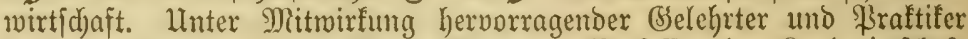

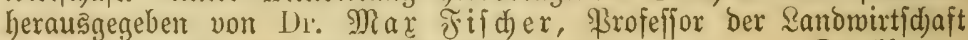
ant Der liniverfität Reipzig. S) (onatlid) 2 Sgefte it $2-2^{2} / 2$ Druffbogent. 2(bonnementspreis pro Duartal Mi. 3.-.

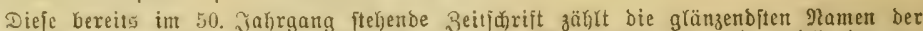

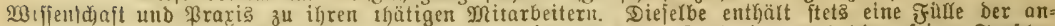

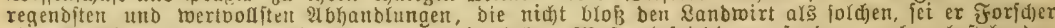

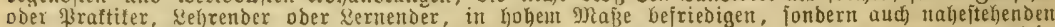

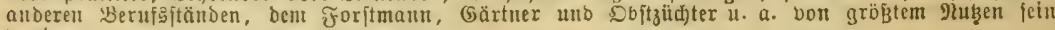
toerben. 
Ohsthall schutz der Obstbänme gegen feindliche Tiere und gegen KrankObstball, heiten. Von Prof. Dr. Taschenberg und Prof. Dr. Sorauer. Mit 185 Abbildungen. Brosch. Mk. 9.-; geb. Mk. 10.-.

Daraus ist einzeln käuflich:

I. Bd.: Schutz der Obstbäume gegen feindl. Tiere. 3. Aufl. Von Prof. Dr. T aschenberg Mit 75 Abbild. Mk. 4.80; geb. Mk. 5.60.

II. Bd.: Schutz der Obstbäume gegen Krankheiten. Von Prof. Dr. P. S o r a u er. Mit 110 Abbildungen. Mk. 4.20; geb. Mk. 5.-.

Pomologische Monatshefte. Organ des Deutschen Pomol. Vereins. Heransgegeb. von Ökonomierat Fr. Luc as, Direktor des Pomol. Instituts in Reutlingen. Jährlich 12 Hefte mit vielen Holzschn. und je einem Farbendr. oder schwarz. Vollbild. Preis pro Jahrg. Mk. 4.50.

Wandtafel der wichtigsten Veredlungsarten nnserer Obstbäume. Mit Text. 3, Aufl, neu bearb. von Direktor Fr. Lu cas. 1 kol. Taf. in Mappe. Preis Mk 2.80; auf Leinw. aufgez. mit Stäben Mk. 4.40.

Obstbautafeln für Schnle nnd Hans. 2 Taf. in Mappe (I. Veredelung und Erziehung. II. Baumsatz, Baumschutz und Baumpflege) mit Text Mk. 1.60. Partiepreis bei 25 Exempl. ohne Mappe aber mit Text je Mk. 1.20, bei 50 Exempl, je Mk. 1.10, bei 100 Expl. je Mk. 1.-.

Anleitung zum Ernten, Sortieren, Anfbewahren u. Verpacken des Obstes. Von E. Lesser. Mit 24 Abbildungen. Steif brosch. 90 \&

Obsthenutzuno Die obst- und Gemüseverwertung für HaushaltungsUluling, und Handelszwecke. Mit kurzen, jeder Obst- und Gemüseart vorangehenden Anweisungen zur Kultur der betr. Nutzpflanzen von H. Timm. Mit $45 \mathrm{Abb}$. Preis kart. Mk. 3.60.

Das Obst und seine Verwertung. Von Fr. Lu c as, Direktor des Pomol. Instituts in Reutlingen. Mit 165 Abbild. 372 Seiten. Gebd. Mk.6.-.

Die Verwertnng und Konservierung des Obstes und der Gemüse. Von Landw.-Insp. B a ch. 2. Aufl. Mit 87 Holzschn. Geb. Mk. 2.80.

Der Johannisbeerwein und die übrigen Obst- n. Beerenweine. Nebst Angaben über die Kultur des Johannisbeerstrauches. Von H. Timm. 3. Aufl. Mit $71 \mathrm{Abb}$. Geb. Mk. 3.-.

Der Johannis- n. Stachelbeerwein und die Bereitung der tibrigen Beerenweine. Von W. Tensi, Pfarrer. 2. Aufl. Mit 9 Abb. Geb. 1 Mk.

Die Fruchtliköre. Anleitung zur Herstell. sämtl. Fruchtliköre, des Maitranks, sowie der Fruchtbowlen. Von H.Ti mm. Mit21 Abb. Geb. Mk.1.20.

Die Obstweinbereitung mit Berücksichtig. der Beerenobstweine und Obstschaumwein-Fabrik. V. Prof. Dr.M.B arth. Mit 28 Abb. 5.Aufl.Mk. 1.30.

DiA Apfelweinbereitung. Ein leichtfassl. Leitfaden für die Praxis sowie für den Unterricht an landwirtschaftlichen Lehranstalten. Von Dr. $\mathrm{Ad}$. Cluss, Vorsteher der gärungsphys. Abteilung der agrikulturchemischen Versuchsstation zu Halle a./S. Mit 37 Abbild. Preis brosch. Mk. 1.50 .

Die Verwertung des Obstes im ländlichen Haushalt von Karl Bach. Mit $33 \mathrm{Abb}$. Preis kart. Mk. 1.-.

Pferdezucht Das Pferd in seinen Rassen, Gangarten und Farben von

Pferdezucht, Prof. L. Ho f fmann, 32 in feinstem Farbendruck ausgeführte Abbild. mit Text. In Leinwandmappe Mk. 14.-. In Halbfranz geb. Mk. 16.-. (Als „Wandtafelausgabe" Mk. 10.-.)

Das Aenssere des Pferdes und seine Fehler. Acht lithogr. Tafeln mit erläuternd. Textvon Dr. A.v.R u eff. In Mappe. Preis 4 Mk. - Dieselben Tafeln auf Leinwand aufgez. (als W andtafel) mit Text Mk. 5.60. 
Pflanzenhaul, landw, Die wichtigsten Futter- und Wiesenkränter. Mit Zenodu, IallW. 53 kolor. Abb. Von Ed. S c h midlin. 4. Aufl. Umgearbeitet von W. S c hüle jun. Karton. Mk. 6.-. D i e Wand t fela u's a b e. (2 Taf. auf Leinw. aufgez.) mit Text Mk. 9-.

Die wichtigsten Futtergräser. Mitkolor. Abbild. Von Ed.Schmidlin. 4. Aufl, umgearb. von W. S c h üle jun. Preis kart. Mk. 6.-. Die Wandtafelausgabe (2 Tafeln auf Leinw. aufgez.) mit Text Mk. 9.-.

Pflanzenkpankheiten, Die Krankheiten und Beschädigungen unserer Pflanzenkpankheiten. ihrer Erkennung u. B ekämp fung für Landwirte, Gärtner etc. Von Prof. Dr. O. Kir chner. Preis Mk.9.-. In Halbfrz. geb. Mk.10.20.

Atlas der Krankheiten und Beschädignngen unserer landwirtsch. Kulturpflanzen. Herausgegeben von Dr. O. Kirchner, Prof. an der landw. Akademie Hohenheim und H. B olt s h a us er, Sekundarlehrer in Amrisweil. In feinstem Farbendruck ausgeführte Tafeln mit Text.

Serie I: Getreidearten. 20 Tafeln. Mk, 10.-.

II: Hülsenfrüchte, Futtergräser und Futterkränter. 22 Tafeln. Mk, 12.-.

IIT: Wurzelgewäichse und Handelsgewächse. 22 Tafeln. Mk. 12.-.

", IV: Gemüse und Küchenpflanzen. 12 Tafeln, ca, Mk. 7.-

V: Obstbäume. 30 Tafeln. Mk. 15 -.

Die letzte VI. Serie wird enthalten:

Weinstock und Beerenobst. (ca. 20 Tafeln).

Zeitschrift für Pflanzenkrankheiten. Organ für die Gesamtinteressen des Pflanzenschutzes. Herausgegeben von Prof. Dr. P a ul S o r a u er. Jährl. 6 Hefte mit Illustr. Mk. 15.-.

Praktische Blätter für Pflanzenschutz. Herausgegeben von Prof. Dr. J. E. W e is s. Preis Mk. 2.- pro Jahrgang (12 Nummern).

pflangenlunde Leitfaden für den Unterricht in der landwirtschaftl. Pflanzenklunde. Pflanzenkunde an mittleren, bezw. niederen landw. Lehranstalten v. Dr. C. W eb er. 3. Aufl. Mit 127 Abbild. Kart. Mk.2.50.

Kurzer Abriss der Pflanzenkunde. Von Dr. C. Weber. 2. Aufl. Steif brosch. $50 \mathrm{Pf}$.

Pflanzennhysiolocie Populäre Pflanzenphysiologie für Gärtner. Von Pllanzenphysiologie. Prof. Dr. Paul Sor a uer. Mit 33 Abbildungen. Preis Mk. 4.50. - In $1 / 2$ Leinwand Mk. 4.85.

Physik Leitfaden für den Unterricht in der Physik an Ackerbauschulen PhySik, und landwirtschaftl. Winterschulen von Dr. C. Weber. 2. Aufl. Mit 177 Abbildungen. Preis kart. Mk. 2.40.

Grundriss der Physik. Für den Unterricht an landwirtschaftl. Winterschulen. Von Dr. C. Weber. Mit $109 \mathrm{Abb.} \mathrm{Preis} \mathrm{kart.} \mathrm{Mk.} \mathrm{1.30.}$

$\overline{\text { Rechtskunde Rechtskunde(Recht des bürgerl. Gesetzbuchs) des dentschen }}$ Rechtskunde, Landwirts. Bearb. v. Dr. jur. H a i d len. Geb. Mk. 3.-.

A B C des bürgerlichen Gesetzbuchs für den deutschen Bauer. Steif brosch. 50 \&. 50 Ex. 20 Mk. 100 Ex. Mk. 35..-

Das Gewäbrschaftsbüchlein. Die für d. Deutsche Reich geltend. Bestimmungen über Viehgewährschaft volksverst. erörtert. 5. Aufl. Mit Klageformular. Steif brosch. 50 s. $50 \mathrm{Ex} .20 \mathrm{Mk}, 100 \mathrm{Ex} .35 \mathrm{Mk}$.

Gewährschaft und Gewährfehler bei Haustierveräusserungen. Von Bez.-Tierarzt R euter. Mit 26 Abb. Kart. Mk. 1.-.

S. auch "Tierseuchen".

Rindviehrucht Die Arten und Rassen des Rindes. Von Prof. Dr. Rindviehzucht, Ramm. Zwei Teile. Mk. 20.-; geb. Mk. 21. -

Wandtafeln farbiger Abbildungen der Rinderrassen mit kurzem Text von Prof. Dr. R a m m. In Mappe Mk. 12 -; auf Leinw. aufgez. Mk. 14.50.

Das Rind, dessen Ban, Zucht, Fütterung und Pflege. Von Wilhelm Martin, Oek.-R. Mit $45 \mathrm{Abb}$. Geb. Mk. 3.60. 
Mit 11 Abbildungen und 19 Tafelbildern. 2. Aufl. Geb. Mk. 1.40.

Teichwirtschaft Ländliche Teichwirtschaft. Profktische Winke für Ieichwirtschalt, bäuerliche Teichbesitzer. Von Fr. Ernst W eber. Mit 15 Originalabbildungen. Geb. Mk. 1.-.

Tiepäprtlicher Inteppicht für Landwirte über Bau, Gesundheitspflege, lieparztlicher Unterpicht Geburtshilfe, Gewährsleistung und erste Behandlung der häufigsten Krankheiten unserer landw. Haustiere. Von P. u. C. Kohlhepp. 8. Aufl. Mit 64 Abbild. Kart. Mk. 1.75.

Merk's vollständiges Handbuch der praktischen IIaustierheilkunde 8. Aufl. Neti bearb, für Landwirte von Prof. L. Ho f fmann. Mit $128 \mathrm{Abb}$. Preis gebd. Mk. 4,20.

Wandtafel fïr erste Hilfe bei landwirtsch. Haustieren. Mit Text. Von Prof. L. Ho f fmann. Mk. 2.50. Auf Leinw. aufgez. Mk. 480.

Die Gesundheitspflege der Hanstiere. Von G e org Zippelius, Kreistierarzt. Mit 6 Abbild. Geb. Mk. 1-.

Ratgeber bei Krankheits- und Unglücksfällen unserer Hanstiere. Von Prof. L. Hoffmann. Mit $11 \mathrm{Abb}$. Gebd. Mk. 1.-.

Tierseluchen. Die Senchen, deren Gefahren und Bekämpfung. Von Bez.Ilerselchen. Tierarzt Re uter. Mit $110 \mathrm{Abb}$. Kart. Mk. 1.20.

Tienzucht Allgemeine Tierzucht. Ein Lehrbuch für Studierende u. Praktik. 11erzucht. Von Prof. H of $\mathrm{m}$ ann - Mit 25 Abb. Mk. 10.-, geb. Mk. 11.20.

Spezielle Tierzucht. Ein Leitfaden zum Unterricht an niederen landw. Lehranstalten. Von Cl. Müller. Kart. Mk. 2.50.

Der Formalismus in der landw. Tierzucht, Von Prof. Dr. Emil Pott. Brosch. Mk. 5.-; geb. Mk. 6.-.

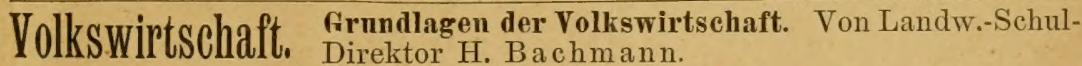

I. Teil: Allgemeine Wirtschaftslehre, Kart. Mk. 1.20.

II. Teil: Agrarwesen und Agrarpolitik. Kart. Mk. 1.20.

Waldhall, Der Wald und dessen Bewirtschaftung. Von Kol. Oberforstrat Waldbal. H. Fischbach. 2. Aufl. Mit 27 Holzschn. Geb. Mk. 1.30.

Weinhereitung Die Bereitung, Pflege und Untersuchung des Weines. Von Geh. Hofrat Prof. Dr. J. N essler in Karlsruhe. 7. Aufl. Mit 52 Abb. Preis 6 Mk. Geb. Mk. 7.30.

Zeichenunterricht Vorlagen für gärtnerisches Planzeichnen. Von A. Zeichenunterricht, L i l i e $\mathrm{n}$ e i n. 17 Taf. mit Text. In Mappe Mk. 5.-.

Vorlagen für landwirtschaftliches Zeichnen, für Lehranstalten etc. Von G. Heid, C. Heinrich, M. Rumpel, H. Zeeb. 33 Tafeln in Mappe, mit erläuterndem Text. Preis Mk. 7.50.

Daraus apart:

I. Elementares Linearzeichnen und geometrische Aufnahmen. 14 Blatt. 3 Mk,

II. Vorlagen für landw. Meliorationen, Plan und Kulturzeichnen, 9 Blatt, 3 Mk,

III. Land ivirtschaftliches Bau- und Gerätezeichnen. 10 Blatt Mk. 2.50.

Vorlagen zum Zeichnen vou Gartenplänen. 3. Aufl. 24 lithogr, Tafeln, darunter 12 kolorierte. Mit Text. Preis gebd. Mk. 3.-

Die Anwendung der Perspektive im gärtner. Planzeichnen. Von $H$. Glinde mann, Kgl. Obergärtner in Geisenheim. Mit Text Mk. 3.50.

Tijoenzucht Das Bnch von der Ziege. Bearbeitet von Prof. L. HoffLlegenZuCht, mann. Mit 12 Abbildungen. Geb. Mk. 1.20 


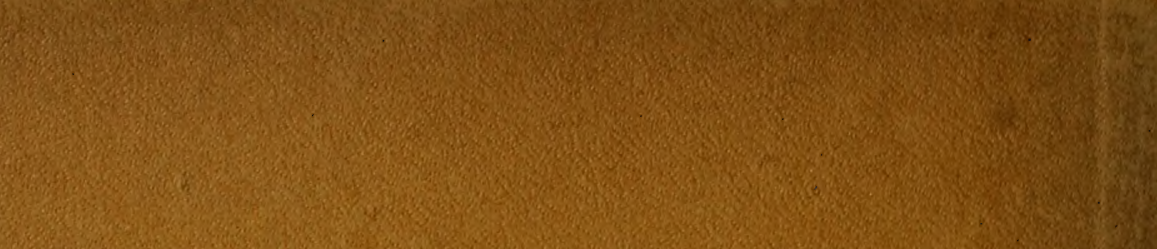

